\title{
DISEÑO DE TABLAS DE REGISTRO UNIFICADAS PARA EL DIAGNÓSTICO Y ESTIMACIÓN DEL INDICADOR DE RIESGO DEL PATRIMONIO CULTURAL
}

TANJA MASTROIACOVO

MAYO 2021

DIRECTORES

$M^{a}$ PILAR SORIANO SANCHO JOSÉ LUIS REGIDOR ROS

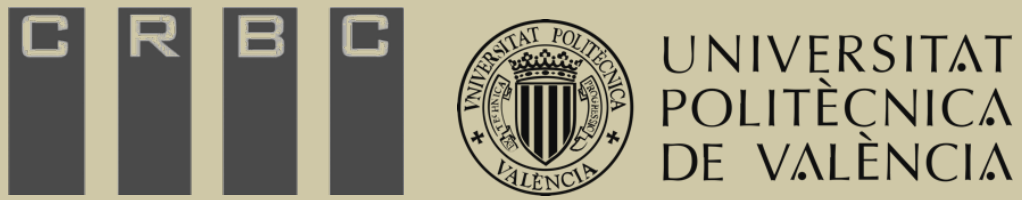



A tutti coloro

che avrebbero desiderato andare a scuola e non hanno potuto.

A México, y sus enseñanzas. 



\section{AGRADECIMIENTOS}

Mi más profundo gracias a todos los seres que han hecho posible mi crecimiento como persona y como profesional en el campo de lo que más amo: las artes, la cultura, la memoria, la identidad. Esto se traduce en un recorrido, el de la conservación del patrimonio, que ha sido y será, rico de experiencias y aprendizajes.

Gracias a mis maestros: familia, amigos, compañeros, profesores y conocidos. Todos los que cruzando mi camino me han enseñado matices de valor inconmesurable, de los que hago tesoro.

Gracias a la Universidad Autónoma de San Luis Potosí por apoyar el desarrollo de mis investigaciones, por medio de los Fondos de Apoyo a la Investigación 2015, otorgados por la Secretaría de Investigación y Posgrado. Gracias a la Facultad del Hábitat por permitirme explorar el mundo de la enseñanza y del aprendizaje, regalándome la oportunidad de reflexionar sobre el valor de la instrucción.

Gracias a la Universidad Politécnica de Valéncia y sus docentes. El tiempo transcurrido en esta casa de estudios ha sido para mí de gran inspiración y me ha permitido crecer a nivel personal y profesional.

Gracias a la Accademia di Belle Arti G.B.Cignaroli de Verona (Italia), en donde he podido aprender de profesores excelentes y de una formación que ha sido de gran valor durante mis años de estudio.

Gracias a las oportunidades de intercambio internacional, como la beca Erasmus en la Escuela de Arte y Superior de Conservación y Restauración de Pintura de Caballete de León, que me han dado la oportunidad de ampliar mis horizontes, aprendiendo a ver lo que me rodea con una perspectiva diferente.

Gracias a la formación ICCROM-LATAM en el sitio arqueológico de Chicanná (Campeche, México) por inspirarme a observar los fenómenos de forma alternativa y enriquecedora.

Gracias a España por permitirme desarrollar mis estudios de Máster en la Universidad Politécnica de València y hacerme sentir como en mi tierra, regalándome mucha vida. 
Nuevamente gracias a mis profesores, por transmitirme sus enseñanzas.

Gracias a las personas que me han apoyado, querido, inspirado, iluminado, aconsejado. Son mis pilares en mis aventuras, Ría y Maria Lucia que aunque sean parte del viento siguen acompañándome. A mi madre Karin, mi hermano Andrea, mi padre Mario. Mis amigos Stefania, Eva, Katharina, Ivonne, Mara, Daniel, Oswaldo, Antonia, Manuel, Claudio, Alberto, Paquito, Juri, Diego, Curzia, Alessia, Juanes y muchísimos más que aquí no figuran y que me hacen anhelar el tiempo compartido. Para Amira una mención especial, un gracias infinito por haber invertido en mis estudios con ánimos y horas de trabajo, por donarme un poco de su verano para que pudiera seguir haciendo lo que amo: aprender.

Gracias a Steph por confíar y seguirme en mis proyectos, a Irene por hallar el tiempo de experimentar con las fichas de registro, a Eleonora por su presencia y gran generosidad en compartir los deleites del oficio de la conservación del patrimonio cultural.

Gracias a Karla por su amistad y por apoyar todas mis ideas y propósitos, en cualquier circunstancia y condición.

Gracias a Carlos, por ser tan buen maestro.

Un gracias "dal profondo del cuore" a las personas que han entrado con risas, amor incondicional, hermandad, tiempo y experiencias inenarrables por tan extraordinarias. Mi gratitud para siempre a Valle, Alejandra, Álvaro, Manolo por el tan bello regalo de vuestra amistad. Nada habría sido posible sin vosotros.

Gracias con profunda estima a mis directores Pilar y Josele, quienes me han iluminado y apoyado en este recorrido.

Gracias a Queta, de todo corazón y con mi profundo aprecio y cariño. Gracias por permitirme cambiar, crecer, aprender, descubrir y cuestionarme.

Hay muchos y mucho más que agradecer.

Con amor, un gracias especial lo dedico a México y sus enseñanzas. 


Resumen

La presente investigación expone los resultados obtenidos en el diseño e implementación de unas tablas de registro para el análisis, gestión y manejo de las fases preliminares de diagnóstico del patrimonio cultural. Este proyecto nace de la necesidad de encontrar un método operativo capaz de brindar un enfoque objetivo para la toma de decisiones inherentes a las evaluaciones diagnósticas y estudios específicos a realizarse sobre los bienes culturales en condiciones de recursos limitados y elevado número de obras o elementos. Debido a la abundancia de variables, factores y materiales que influyen en la conservación del patrimonio cultural, el diseño de una matriz de datos y de una metodología de muestreo unificados representan el primer paso para la comprensión de sus exigencias, además de poner las bases para el futuro desarrollo de estudios de tipo estadístico. Éstos representan un recurso óptimo siendo una rama de las matemáticas que estudia las correlaciones y dependencias entre los fenómenos físicos y naturales y han sido empleados en varias áreas del conocimiento entre las cuales destacan las ciencias sociales, la ecología, la medicina y el control de calidad en los procesos industriales. Entre las herramientas ofrecidas por las ciencias estadísticas, que se ocupan de estudiar una determinada población por medio de recolección, recopilación e interpretación de datos, el análisis exploratorio de datos (EDA) representa un medio de comprensión y formulación de hipótesis a partir de unas tablas definidas de contingencia. En este trabajo se exponen los resultados derivados del diseño e implementación de las fichas de registro y análisis de datos adaptadas para las exigencias del sector de la conservación, ofreciendo un acercamiento a sus posibilidades aplicativas, ventajas y limitaciones en relación a la resolución de casos de estudio reales tratados a lo largo de la experiencia de formación, investigación y docencia en diferentes realidades y contextos. 



\section{Resum}

La present investigació exposa els resultats obtinguts en el disseny i implementació d'unes taules de registre per a l'anàlisi, gestió i maneig de les fases preliminars de diagnòstic del patrimoni cultural. Aquest projecte naix de la necessitat de trobar un mètode operatiu capaç de brindar un enfocament objectiu per a la presa de decisions inherents les avaluacions diagnòstiques $i$ estudis específics a realitzar-se sobre els béns culturals en condicions de recursos limitats i elevat nombre d'obres o elements. A causa de l'abundància de variables, factors i materials que influeixen en la conservació del patrimoni cultural, el disseny d'una matriu de dades i d'una metodologia de mostreig unificats representen el primer pas per a la comprensió de les seues exigències, a més de posar les bases per al futur desenvolupament d'estudis de tipus estadístic. Aquests representen un recurs òptim sent una branca de les matemàtiques que estudia les correlacions i dependències entre els fenòmens físics i naturals i han sigut emprats en diverses àrees del coneixement entre les quals destaquen les ciències socials, l'ecologia, la medicina i el control de qualitat en els processos industrials. Entre les eines oferides per les ciències estadístiques, que s'ocupen d'estudiar una determinada població per mitjà de recol-lecció, recopilació i interpretació de dades, l'anàlisi exploratòria de dades (*EDA) representa un mitjà de comprensió i formulació d'hipòtesi a partir d'unes taules definides de contingència. En aquest treball s'exposen els resultats derivats del disseny $i$ implementació de les fitxes de registre $i$ anàlisi de dades adaptades per a les exigències del sector de la conservació, oferint un acostament a les seues possibilitats aplicatives, avantatges i limitacions en relació a la resolució de casos d'estudi reals tractats al llarg de l'experiència de formació, investigació i docència en diferents realitats i contextos. 



\section{Abstract}

This research presents the results obtained in the design and implementation of registration tables for the analysis, management and handling of the preliminary diagnostic phases of cultural heritage. This project arises from the need to find an operational method capable of providing an objective approach for making decisions inherent in diagnostic evaluations and specific studies to be carried out on cultural assets in conditions of limited resources and a high number of works or elements. Due to the abundance of variables, factors and materials that influence the conservation of cultural heritage, the design of a data matrix and a unified sampling methodology represent the first step towards understanding its requirements, in addition to laying the foundations for the future development of statistical studies. These represent an optimal resource, being a branch of mathematics that studies the correlations and dependencies between physical and natural phenomena and has been used in several areas of knowledge, among which the social sciences, ecology, medicine and quality control stand out. in industrial processes. Among the tools offered by statistical sciences, which deal with studying a certain population by means of data collection, compilation and interpretation, exploratory data analysis (EDA) represents a means of understanding and formulating hypotheses from tables defined contingency. This work presents the results derived from the design and implementation of the data registration and analysis sheets adapted to the demands of the conservation sector, offering an approach to its applicative possibilities, advantages and limitations in relation to the resolution of cases of real studies treated throughout the experience of training, research and teaching in different realities and contexts. 



\section{Sintesi}

La presente ricerca espone i risultati ottenuti nella progettazione e uso di tabelle di registro a criteri unificati utili allo svolgimento delle fasi di analisi, gestione e risoluzione delle problematiche operative proprie delle fasi preliminari di diagnosi dei beni culturali. Questo progetto nasce dall'esigenza di trovare un método d'attuazione in grado di fornire un approccio oggettivo al processo decisionale inerente alle valutazioni diagnostiche e agli studi specifici a realizzarsi su beni a carattere culturale caratterizzati da contesti operativi con risorse limitate ed un elevato numero di opere o elementi. $A$ causa dell'abbondanza di variabili, fattori e materiali che partecipano ed interferiscono nella conservazione dei beni culturali, la progettazione di una matrice di raccolta dati e di una metodologia di campionamento a criteri unificati rappresentano il primo passo verso una comprensione obiettiva delle sue esigenze, oltre a gettare le basi per il futuro sviluppo di studi di tipo statistico. Questi ultimi rappresentano una risorsa tecnica ottimale per l'elaborazione delle informazioni, essendo una branca della matematica che studia le correlazioni e le dipendenze tra fenomeni fisici e naturali, utilizzata in diversi ambiti della conoscenza, tra cui le scienze sociali, l'ecologia e l'analisi dei processi industriali. Tra gli strumenti offerti dalle scienze statistiche, che si occupano di studiare una determinata popolazione mediante raccolta, compilazione e interpretazione dei dati, l'analisi esplorativa dei dati (EDA) rappresenta un mezzo di comprensione e formulazione di ipotesi a partire da tabelle di contingenza. Questa ricerca presenta i risultati derivati dalla progettazione e implementazione di sistemi di registro e analisi dei dati adattati alle esigenze del settore della conservazione, offrendo un approccio alle sue possibilità applicative, vantaggi e limiti attraverso la risoluzione di casi di studio reali trattati nel corso delle esperienze di formazione, ricerca e insegnamento in diverse realtà e contesti. 



\section{Índice}

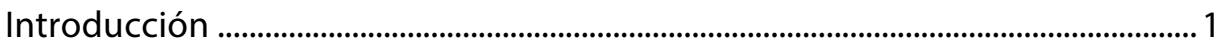

Objetivos .................................................................................................................

1.1. Objetivo general ..................................................................................................10

1.2. Objetivos específicos .............................................................................11

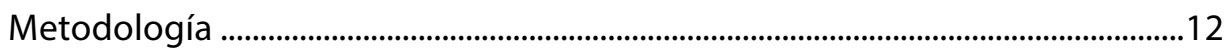

Justificación.............................................................................................................19

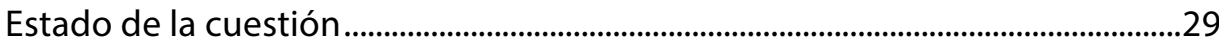

Capítulo 1 - EL PATRIMONIO CULTURAL MEXICANO ………………………......69

1.1 Características generales ..............................................................................69

1.2 Declaratorias, tutela y estado actual ............................................................81

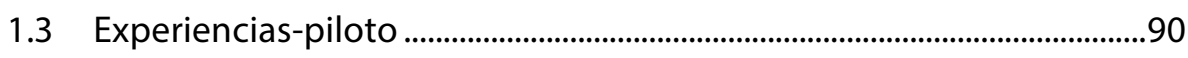

1.3.1 Murales del siglo XX (San Luis Potosí y Ciudad del Maíz) ...............93

1.3.2 Panteón Municipal del Saucito (San Luis Potosí, S.L.P.)...................99

1.3.3 Museo de Arte Sacro (Real de Guadalcázar, S.L.P.) ..........................102 
2.1 Generalidades sobre análisis estadístico ……………………………....... 114

2.2 Diseño de matrices de datos ..................................................................... 126

2.3 Aplicación del método y análisis de datos............................................ 140

2.3.1 Murales del siglo XX en San Luis Potosí ........................................... 147

2.3.2 Panteón municipal del Saucito, San Luis Potosí............................. 161

2.3.3 Museo de Arte Sacro de Guadalcázar, San Luis Potosí .................. 179

2.4 Análisis de ventajas y limitaciones............................................................ 206

2.5 Implementación de las mejoras operativas.............................................. 222

Capítulo 3 - IMPLEMENTACIÓN DEL MÉTODO ……......................................... 228

3.1 Ex hacienda de Peotillos ................................................................................... 228

3.2 Templo de San Martín de Tours (Huaquechula, Puebla) ...................... 246

3.2.1 Retablo de la Virgen de la Luz............................................................ 252

3.2.2 Conjunto de pinturas y esculturas ...................................................... 286

3.3 Templos del centro histórico de San Luis Potosí (S.L.P.) ........................ 307

3.3.1 Capilla de Nuestra Señora de Loreto.................................................. 312

3.3.2 Catedral Metropolitana ........................................................................... 320

3.3.3 Templo de Nuestra Señora del Carmen ............................................. 332

3.3.4 Templo de San Francisco....................................................................... 346

3.3.5 Templo de San Miguelito .................................................................. 354

Capítulo 4 - RESULTADOS Y DISCUSIÓN ........................................................... 369

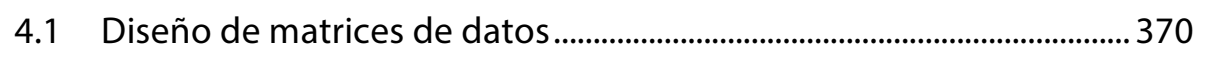

4.2 Aplicación del método y análisis de datos................................................. 375

4.3 Análisis de ventajas y limitaciones ................................................................377

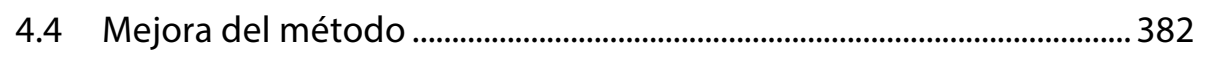

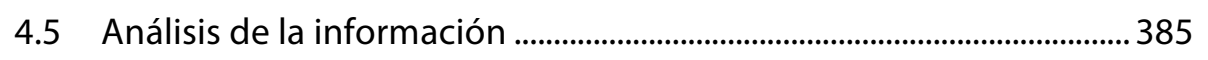


4.6 Generación de los indicadores de riesgo

396

4.7 Representación gráfica de los resultados.

CONCLUSIONES

Bibliografía general. 



\section{Introducción}

La presente investigación expone los resultados derivados del diseño e implementación de un sistema de gestión y recolección de datos útil y beneficioso para los agentes dedicados a la conservación del Patrimonio Cultural, centrándose en la profundización de sus posibilidades aplicativas en las fases preliminares de diagnóstico. El eje de este estudio se desarrolló alrededor de las problemáticas encontradas a lo largo de diferentes experiencias profesionales, de las cuales, las maduradas en México han sido las más representativas. En este contexto se presentó la oportunidad de entrar en contacto con una realidad nueva cuyas peculiaridades se han vuelto una ocasión para la ideación de este método.

Una de las dificultades más difusas en el desarrollo de las tareas de conservación del patrimonio cultural, deriva de las fases de recolección, gestión, análisis y ordenamiento de la información, sobre todo cuando ésta se compone por grandes cantidades de variables. Esto se debe a la existencia de una pluralidad de criterios bajo los cuales poder ejecutar las acciones de registro y elaboración de los datos.

El patrimonio cultural mexicano destaca por las múltiples áreas, factores, obras, variables, etc. que caracterizan el sistema de sus materiales constitutivos, y por ende, los posibles efectos de alteración y deterioro producidos tras su interacción con el entorno. Esta peculiaridad puede considerarse altamente representativa de los desafíos a los cuales los profesionales del sector de la conservación se enfrentan a diario.

La etapa inicial de estudio y comprensión de un conjunto de obras de arte supone la realización de acciones dirigidas al entendimiento de las problemáticas que están afectando sus materiales. La determinación de las necesidades 
conservativas de un bien cultural puede ser lograda por medio de un diagnóstico, que profundiza en las relaciones causa-efecto de las alteraciones y deterioros de los materiales, a partir de la observación, registro y comprensión de las fenomenologías de alteración y deterioro de los mismos, indicando las pautas a seguir para encontrar soluciones exitosas dirigidas a su conservación. Uno de los aspectos más importantes en estas fases se constituye por la observación y reconocimiento de las fenomenologías de alteración y deterioro presentes. Debido a los múltiples factores que participan en las interacciones entre el sistema y su entorno, llevar a cabo las tareas de inspección y registro, sobre todo en circunstancias que prevén el análisis de un número elevado de obras de arte, puede representar un verdadero reto.

Una correcta comprensión de las exigencias conservativas de los bienes culturales influye en la implementación exitosa de medidas, acciones y materiales a aplicarse en las intervenciones de conservación y restauración. Esta delicada operación requiere de recursos específicos: profesionales, temporales y técnicos. En el desarrollo de las tareas de salvaguarda de los bienes culturales pueden presentarse situaciones extraordinarias, en donde los medios disponibles no logran abarcar un diagnóstico pormenorizado de cada elemento.

Gracias a la toma de contacto con estas circunstancias, ha sido posible reflexionar sobre el valor representado por la ideación de un medio de recolección global de datos inherentes al estado conservativo que permitiera una primera selección de la información, identificando prioridades de estudios diagnósticos específicos, a partir de la observación de las alteraciones y la generación de unos indicadores de riesgo.

De acuerdo a estas premisas generales, en esta investigación se plantea el diseño y uso de un medio de recolección, análisis y gestión de datos del Patrimonio Cultural capaz de ofrecer una selección objetiva y representativa de la información, proporcionando una herramienta que pueda mejorar las fases de acercamiento y comprensión de las necesidades de un conjunto de elementos, a partir del análisis visual de cada obra. Esto, pensado para realizarse con una mínima inversión de recursos humanos, económicos y temporales, se dirige a delimitar las exigencias de la colección ofreciendo pautas para la posterior profundización de estudios $y / 0-y$ análisis diagnósticos específicos.

Entre los factores que participan en la generación de una escala de prioridades, representativa del estado conservativo en el que se encuentran las colecciones de obras de arte, la estructuración de los medios de recolección de los datos y los conceptos en ella reunidos constituyen un apartado metodológico fundamental. A partir de estas dos vertientes es posible generar una información específica, definida indicador de riesgo, a través de la cual estructurar los datos y establecer preferencias de actuación. Por ello, es necesario diseñar la metodología de construcción y 
ordenamiento de los criterios de los cuales dependerán los resultados que se asumirán como representativos de los indicadores de riesgo.

Un primer impulso para reflexionar sobre el diseño de un método capaz de abarcar una elevada cantidad de información técnico-material y conservativa de la cual poder estructurar acciones de estudio y conservación miradas, surgió en ocasión del avance en el tema de investigación "Las pinturas murales del siglo XX en San Luis Potosí (S.L.P., México): estudio, análisis e índice de riesgo". Este conjunto de obras, compuesto por murales de variada naturaleza material y técnica, se ubica en diferentes edificios y es expuesto a condiciones conservativas distintas. Este proyecto, implementado gracias a los apoyos otorgados por la Secretaría de Investigación y Posgrado de la Universidad Autónoma de San Luis Potosí, se dirigió a la actualización del registro de las obras existentes en el estado a partir del "Inventario del muralismo mexicano", complementando las informaciones con datos relativos a su estado de conservación y buscando establecer una escala de riesgo a través de un enfoque objetivo.

El orden de registro de los datos, cuya dinámica está estrictamente vinculada con las modalidades de observación del contexto y con la terminología y criterios a emplearse, constituye uno de los atributos útiles para alcanzar un enfoque global y objetivo de las exigencias del patrimonio cultural. Por lo tanto, el uso de unos criterios unificados oportunamente estructurados, puede revelarse una herramienta útil para guiar las acciones de registro de la información en las fases preliminares de estudio.

El propósito de unificar los criterios de registro responde a la voluntad de hacer que cosas diferentes o separadas formen una organización, produzcan un determinado efecto, tengan una misma finalidad, haciendo confluir la pluralidad de conceptos en una única estructura. Varias instituciones dedicadas a la investigación del patrimonio cultural han dirigido sus esfuerzos hacia la formulación de una terminología de referencia uniformada. Ésta se enfoca en proponer unos vocablos unificados, con la finalidad de impulsar la puesta en común de la información inherente las diferentes clases de patrimonio cultural y representa un valioso apoyo metodológico para los profesionales de la conservación.

Estas herramientas, que adquieren la forma de glosarios ilustrados con definiciones estandarizadas, brindan apoyo y claridad para las descripciones semánticas de los procesos y efectos de alteración de los materiales. Un ejemplo destacado de esta labor, que ha sido empleado a lo largo de este estudio, ha sido "European Illustrated Glossary for Conservation Terms of Wall Painting and

\footnotetext{
${ }^{1}$ SUÁREZ, S.O. (1972). Inventario del Muralismo Mexicano. México: UNAM.
} 
Architectonic Surfaces" 2e "Illustrated glossary on stone deterioration patterns" ${ }^{3}$ de ICOMOS-ISCS. Gracias a los términos reunidos en estos glosarios fue posible dirigir las fases de registro y análisis de los efectos de alteración y deterioro presentes en las obras, arrojando datos representativos de las problemáticas existentes en los contextos estudiados.

Sin embargo, las categorías de obras muebles compuestas por pintura de caballete, sobre lienzo y/o tabla, y esculturas en madera policromada, aun no están provistas de glosarios de referencia de características análogas a los mencionados anteriormente. Esto influye en aportar cierto grado de complejidad al enfrentar las fases preliminares de estudio, en particular cuando este esté enfocado a la generación de una escala de prioridades. En estos casos, la observación y registro de las fenomenologías de alteración y deterioro presentes alcanza una mayor dificultad debido a la falta de una clasificación unificada de referencia. Este aspecto deriva de la variedad de investigaciones, a su vez formuladas en diferentes idiomas, a las que un profesional puede hacer referencia.

Otro aspecto que adquiere valor e importancia en relación al diagnóstico del patrimonio cultural es el representado por la educación visual. En las fases de recolección de datos sobre el estado de conservación de las obras de arte, un ojo necesita ser educado para poder observar los fenómenos, y en un contexto que carece de medios de enseñanza experiencial en estos términos es necesario pensar y crear nuevas rutas de aprendizaje.

La falta de estrategias de observación unificadas a las cuales recurrir, multiplica la variedad de interpretaciones a las que se puede llegar en las fases preliminares de diagnóstico. Este aspecto ha sido puesto en evidencia en la experiencia formativa realizada en el marco de las actividades de ICCROM para el área de Latinoamérica y Caribe en 2016. En este contexto ha posible conocer la metodología de Observación Visual Organizada $\mathrm{OVO}^{4}$, una herramienta alternativa para el análisis del estado de conservación de los monumentos histórico-artísticos. Esta propone un acercamiento estructurado a partir de una descomposición lógica del conjunto monumental en unidades simples, yendo desde lo global hacia los materiales constitutivos. A este procedimiento se le asocia un registro visual de los fenómenos

${ }^{2}$ HORNEMANN INSTITUT (2015). European Illustrated Glossary for Conservation Terms of Wall Painting and Architectonic Surfaces. <https://www.hornemann-institut.de/doi/2016ewa2.pdf> [Consulta: 19 de mayo 2017].

${ }^{3}$ ICOMOS-ISCS (2008). Illustrated Glossary on Stone Deterioration Patterns. $<$ https://www.icomos.org/publications/monuments_and_sites/15/pdf/Monuments_and_Sites_15_ISCS_Gl ossary_Stone.pdf> [Consulta: 3 de marzo de 2016].

${ }^{4}$ Experiencia madurada gracias a la formación LATAM-ICCROM en 2016, en el área arqueológica de Chicanná (Campeche, México). Para una aproximación al método véase los apartados Justificación y Estado de la Cuestión. 
de alteración y deterioro que sucesivamente serán relacionados con los componentes del sistema. El método OVO es una "Observación Visual Organizada" que propone reestructurar la forma de enfrentarse al diagnóstico del patrimonio cultural y ha sido relevante para generar reflexiones en torno a la rutina empleada hasta entonces en los delicados procesos preliminares de estudio y diagnóstico conservativo de una obra de arte.

Las consideraciones en torno a las dinámicas de comunicación visual, junto a la voluntad de comprender y analizar los efectos de las dinámicas de alteración en los materiales, brindaron nuevos puntos de reflexión sobre las modalidades de reconocimiento de los fenómenos y sobre como establecer un medio de registro útil a una posterior análisis que tomara en cuenta la información a nivel general y específico.

Dichos aspectos han puesto en evidencia la necesidad de construir una estrategia de ordenación de la terminología para las tablas de registro. El uso de recursos estandarizados, como los glosarios ilustrados, favoreció la estructuración de los conceptos a reunir en las matrices de datos. Mientras para el estudio pintura de caballete y escultura policromada, los criterios se ordenaron a partir de la consulta de textos específicos de habla hispana del sector.

Las experiencias maduradas a contacto con otras realidades internacionales, como España, Italia, México y otras áreas de Latinoamérica, han puesto en evidencia el valor de las imágenes como medio de comunicación universal, por su capacidad de mostrar de forma accesible y fácilmente comparable las morfologías de los efectos de alteración y deterioro en los materiales. Éstas, insertadas en los glosarios ilustrados como medio de apoyo dirigido a la comprensión de los conceptos, representan una herramienta fundamental para la comprensión del estado de los materiales constitutivos de las obras de arte.

No obstante, permanece cierta limitación en el uso de la terminología unificada durante las fase prácticas, en particular cuando se llevan a cabo trabajos grupales. Debido a los diferentes enfoques o niveles de preparación de los agentes involucrados en los proyectos de carácter interdisciplinar, se puede asistir a la generación de resultados y profundizaciones dispares. Estas circunstancias han sido útiles para llevar a cabo un cuestionamiento sobre el tipo de metodología más adecuada para generar informaciones unificadas en términos de profundización y detalle. La propuesta de emplear una matriz de datos única para el registro y análisis de las informaciones, representó una oportunidad aplicativa interesante.

La estructura de recolección y estudio de datos adoptada en esta experiencia derivó de las empleadas en el campo de la Ecología para la medición de la Biodiversidad. El acercamiento a estas herramientas metodológicas se dio gracias a la participación en el diplomado en "Técnicas estadísticas para la medición de la biodiversidad" llevado a cabo en el Instituto Potosino de Investigación en Ciencia y 
Tecnología. La relación entre la conservación del entorno natural y el patrimonio cultural nació a raíz de la exigencia de analizar un amplio abanico de datos para el proyecto "Biotecnologías para la conservación del patrimonio mural arqueológico mexicano"s. A fin de determinar el planteamiento experimental de dicho proyecto fue necesario analizar un amplio espectro de informaciones técnicas y materiales ${ }^{6}$, relacionándolas con los parámetros de efectividad de los agentes biológicos a ensayar. La profundización de las funcionalidades brindadas por las técnicas estadísticas representó el camino hacia la definición de un método de ordenación de toda la información, con particular atención hacia la fase de recolección de las mismas. La planeación de las fases de análisis y registro de las informaciones ofrece la oportunidad de comparar datos que, por su estructura unificada, permiten valorar la situación entre diferentes contextos, o sistemas. Este aspecto produce un avance en la calidad del análisis, evaluación y monitoreo del estado de conservación global del patrimonio cultural.

El método propuesto en este estudio expone dos diferentes modelos de recolección de datos, que han sido explorados a través de la fase de diseño y sucesivamente de implementación del método.

En la fase de diseño del método, entre las tipologías de matrices existentes se escogió la de presencia-ausencia (1-0), así definida porqué se centra en registrar la existencia o falta de una determinada especie y, en nuestro caso, de un determinado fenómeno o producto de alteración. Esta decisión encontró su sustento en la voluntad de focalizar la atención sobre las dinámicas que están afectando al bien cultural sin incurrir en la cuantificación, cuya estimación involucraría procesos y medios más desarrollados y es contemplada para una fase sucesiva de investigación a la presentada en este estudio.

En la fase de implementación del método, tras un análisis pormenorizado de las ventajas y limitaciones encontradas en la etapa de diseño, se introdujo la matriz de abundancia. Ésta, estructurada con valores en el rango 1-4, posee la peculiaridad de permitir una evaluación de la extensión superficial de las alteraciones y deterioros en la misma fase de registro de los datos. La mejora mencionada, tras el análisis de los datos recolectados, ofrece una estimación cualitativa y cuantitativa de las fenomenologías de alteraciones y deterioros presentes en los materiales a las cuales

5 El proyecto “Biotecnología aplicadas a la conservación del Patrimonio Mural Arqueológico Mexicano" fue gestionado y presentado en 2017 al Instituto Nacional de Antropología e Historia, Consejo de Arqueología (Oficio 401.1S.3-2017/645), con el objetivo de profundizar y explorar el posible uso de herramientas de naturaleza biológica a fines conservativos sobre el sustrato pictórico de las pinturas murales.

${ }^{6}$ Los resultados parciales derivados de la primera aproximación al planteamiento experimental se publicaron en MASTROIACOVO, T., SORIANO SANCHO, M.P. Y REGIDOR ROS, J.L., (2017). "Muestreo microbiológico de superficie aplicado al control de biodiversidad funcional al desarrollo de biotecnologias aplicadas al patrimonio mural arqueológico mexicano" en Archè, Revista del Instituto de Restauración del Patrimonio, núm. 11 у 12, 2016-2017, pp. 151-156. 
el profesional del sector puede hacer referencia para entablar prioridades de estudio y diagnóstico.

El diseño de un sistema de recolección de informaciones que pudiera brindar un apoyo para el desglose y desarrollo de las actividades preliminares de estudio en situaciones ordinarias, ha sido el resultado de la participación a experiencias extraordinarias cuales los eventos sísmicos de Italia (2009) y México (2017). Estas prácticas, junto a la actividad de estudio, formación e investigación en el ámbito académico de la conservación y restauración del patrimonio cultural han impulsado la ideación del método de análisis y diagnóstico propuesto en esta investigación.

Debido al contexto extraordinario por el que se caracterizan las situaciones de emergencia, las actividades deben de realizarse con extrema agilidad. Los tiempos de actuación pueden llegar a contrastar con las fichas a disposición de los operadores, debido a que el nivel de análisis e información requeridos para su cumplimentación pueden ser muy puntuales. Aunado a esto, el proceso de almacenamiento e interpretación de los datos, a causa de la variedad de criterios en uso, puede acarrear limitaciones de tipo práctico. Una de estas puede consistir en los tiempos necesarios al traslado de la información del soporte físico al digital, seguida por la pluralidad de informaciones recaudadas y como consecuencia, la complicación en poder consultar e interpretar los datos, determinando las prioridades de actuación.

Las actividades de rescate del patrimonio en ocasión del seísmo de 2009 en L'Aquila (Italia), contemplaron el resguardo del acervo bibliográfico del Arzobispado en el centro histórico de la ciudad. En el terremoto de 2017 que sacudió el centro de México, se realizaron acciones de puesta en seguridad de varias tipologías de obras pertenecientes a recintos religiosos y museísticos del estado de Puebla. Durante el resguardo de los elementos afectados por el deterioro de las estructuras que los albergaban, se puso de manifiesto la necesidad de hallar un método que se prestara a solucionar las posibles limitaciones en términos de recursos humanos, económicos y temporales útiles para agilizar las fases preliminares de acercamiento al contexto de estudio. Esto permite una selección general de las informaciones, logrando establecer prioridades para las actividades de estudio y diagnóstico sucesivos.

Un aspecto importante a valorar para el diseño de esta investigación se constituye por el desarrollo de las actividades didácticas. En la formación del alumnado se vuelve fundamental lograr transmitir de forma sistemática los conceptos, ideas y conocimientos propios del sector objeto de profundización. Las acciones de transmisión del conocimiento representan una fuente de aprendizaje bidireccional, en cuanto el maestro, al compartir informaciones, recibe una retroalimentación continua a través de las inquietudes del estudiante. Esta curiosidad y voluntad de entendimiento permite generar nuevas perspectivas y aprendizajes. La posibilidad de enfrentarse a las tareas prácticas de educación en el 
campo de la conservación del patrimonio cultural ha implicado reflexionar sobre los factores y dinámicas que limitan el fluir de la actividad de registro, con mayor inversión de tiempo y detrimento en la calidad de la información. La influencia ejercida por la educación visual en los procesos de registro ha sido remarcada en ocasión de los estudios sobre los materiales pétreos y sus alteraciones realizados en el cementerio Municipal del Saucito, en la homónima colonia de la ciudad de San Luis Potosí. En este contexto, el uso y conocimiento del glosario "Illustrated glossary on stone deterioration patterns" de ICOMOS-ISCS ha favorecido una reflexión sobre las ventajas y las limitaciones ofrecidas por el diseño de las fichas propuestas inicialmente en la fase de diseño del método representando una oportunidad para reestructurar la metodología.

Los recursos necesarios e invertidos en ocasión de investigaciones y proyectos de intervención dirigidos a la conservación del patrimonio cultural están estrictamente vinculados a una pluralidad de aspectos complementarios. Éstos suelen incidir en la disponibilidad de medios, humanos, técnicos y económicos. El prestigio de una obra o su valoración social, los aspectos políticos, y otros factores determinan en la mayoría de los casos hacia donde dirigir el foco de atención en términos de tutela e intervención.

Los aspectos económicos intervienen notablemente en el desarrollo de políticas de salvaguarda del patrimonio cultural efectivas, siendo factores de los cuales dependen la inversión de recursos humanos, técnicos y temporales a realizarse. Esto puede favorecer la conservación de obras de mayor importancia histórico-artística a detrimento de las expresiones locales o periféricas. Tales circunstancias adquieren mayor relevancia en correspondencia de eventos extraordinarios, como pueden ser las catástrofes naturales, en dónde es necesario tomar decisiones de forma inmediata y en concomitancia con medios operativos limitados.

Estas consideraciones han puesto de manifiesto la necesidad de disponer de herramientas de actuación altamente efectivas y rápidas, cuya implementación contemple un uso de recursos limitado, aplicable a la mayoría de contextos y circunstancias. Estos factores, a la luz de las reflexiones reunidas, podrían representar una respuesta metodológica útil para abarcar un amplio espectro de patrimonio, fomentando la comprensión de su estado de salud, con el valor añadido por la posibilidad de generar indicadores de riesgo a nivel local y global.

La generación de un sistema unificado que permita agilizar las dinámicas de recolección de informaciones que, una vez almacenadas en un medio digital, podría constituir una herramienta de control sistematizado de las condiciones

${ }^{7}$ ICOMOS-ISCS (2008). Illustrated Glossary on Stone Deterioration Patterns.

<https://www.icomos.org/publications/monuments_and_sites/15/pdf/Monuments_and_Sites_15_ISCS_GI ossary_Stone.pdf> [Consulta: 3 de marzo de 2016]. 
conservativas para un amplio espectro de casos. Esto facilitaría las tareas de gestión y organización de las acciones a tomar. En contextos de emergencia, a partir de un análisis global del estado de conservación de las obras antes de su resguardo, se podrían establecer las prioridades de actuación y gestionar el direccionamiento de fondos necesarios a una planeación de estudios e intervención exitosa.

Este conjunto de prácticas y reflexiones en torno a la conservación del patrimonio ha permitido diseñar una metodología sustentada en las experiencias del sector aunada a las potencialidades ofrecidas por el análisis de las informaciones inspirado en las experiencias de estudio estadístico. Las aportaciones derivadas de las problemáticas y metas evidenciadas en el diseño de esta investigación, abren camino hacia una posible sistematización e integración digital de los datos, dejando abiertas futuras líneas de investigación dirigidas a su implementación y desarrollo en otros contextos y materiales. 


\section{Objetivos}

La presente investigación tiene la finalidad de ofrecer una herramienta complementaria a las acciones de conservación del patrimonio cultural, profundizando en las fases preliminares de análisis y determinación del estado conservativo de las obras. En el caso de conjuntos o colecciones compuestos por un elevado número de elementos y/o materiales, las tareas de diagnóstico pueden volverse complejas, poniendo de manifiesto la necesidad de hallar un método de acercamiento rápido y útil a la priorización de los elementos a tratar por medio de un diagnóstico específico. Con la finalidad de ofrecer un método adecuado para la resolución de las problemáticas mencionadas se propone diseñar un procedimiento de registro y análisis de los datos del Patrimonio Cultural capaz de ofrecer una selección objetiva y representativa de las informaciones en función de una estimación de riesgos y prioridades.

\subsection{Objetivo general}

El objetivo principal que se plantea, consiste en diseñar un método de recolección y análisis de datos que sirva para la gestión y resolución de problemáticas inherentes a las fases preliminares de estudio y diagnóstico del Patrimonio Cultural, apto para ser aplicado por profesionales del sector. 


\subsection{Objetivos específicos}

Para cumplir con este objetivo general, se plantea una serie de objetivos específicos:

- Implementar un modelo de matriz a terminología unificada para el registro de las informaciones específicas del Patrimonio Cultural que permita una recolección clara, rápida y representativa de los datos.

- Organizar la toma de datos según las características del sistema constitutivo de las obras de arte examinadas de acuerdo a las definiciones oficiales en uso para favorecer la comparación de los datos obtenidos.

- Aplicar el método diseñado a casos y problemáticas reales para determinar su viabilidad, ventajas y limitaciones.

- Explicar las informaciones cualitativas y cuantitativas arrojadas por el método y su utilidad de acuerdo a las operaciones de registro y análisis de las fenomenologías de alteración y deterioro presentes en los casos de estudio analizados.

- Interpretar las informaciones arrojadas por el método identificando las áreas con mayor indicador de riesgo conservativo. 


\section{Metodología}

Con la finalidad de diseñar un método de recolección y análisis de datos adecuado para la gestión y resolución de problemáticas inherentes a las fases preliminares de diagnóstico del Patrimonio Cultural, idóneo para ser aplicado por profesionales del sector, se ha diseñado una metodología operativa por etapas dirigida a establecer los criterios, materiales y métodos aptos para lograr este objetivo (diagrama 1). 


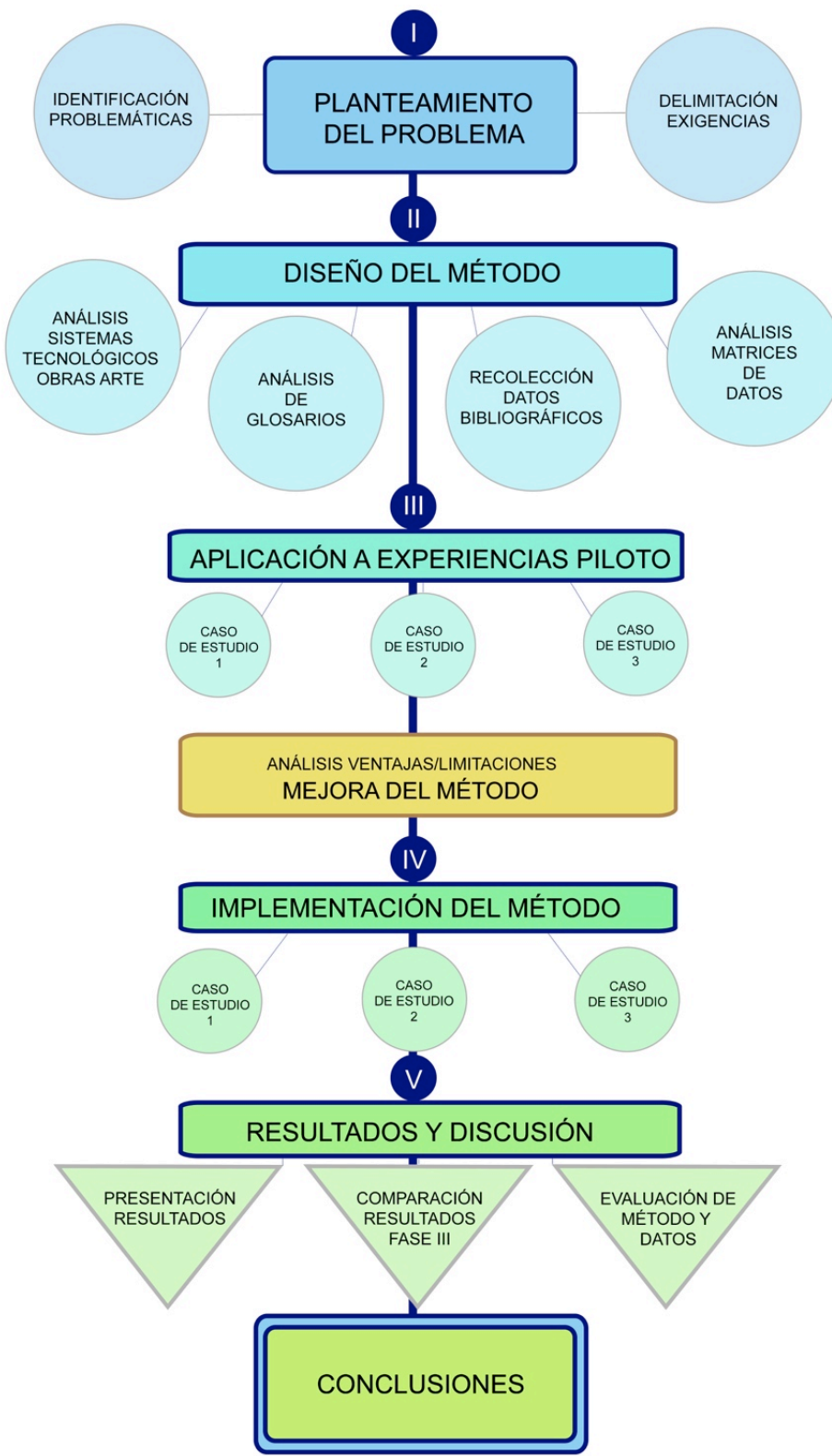

Diagrama 1 - Fases metodológicas para el desarrollo de la investigación. 
En las etapas que se proponen a continuación, se desglosa la metodología seguida para la realización de la presente investigación.

\section{Primera etapa - Planteamiento del problema}

Objetivo: identificar las dificultades y delimitar las exigencias encontradas en el desarrollo de tareas de diagnóstico e identificación de las problemáticas conservativas del patrimonio cultural.

Metodología

a. Recolección de problemáticas derivadas de experiencias profesionales en diferentes contextos.

b. Estructuración de las exigencias derivadas de las diferentes tipologías de contextos, obras y materiales.

c. Selección de casos de estudio que responden a las características de amplitud de materiales, obras, ubicación geográfica y condiciones conservativas para corroborar las posibilidades aplicativas del método.

En la primera etapa de estudio se ha puesto de manifiesto la problemática derivada del registro, análisis e interpretación de las informaciones inherentes a los contextos conservativos caracterizados por pluralidad de elementos y disponibilidad de recursos temporales, técnicos y profesionales mínimos. Parte de la problemática identificada deriva de la extensa cantidad de información a recolectar y los diversos fenómenos a analizar e interpretar.

\section{Segunda etapa-Diseño del método}

Objetivo: implementar un modelo de matriz para el registro de la información específica del Patrimonio Cultural que permita una recolección clara, rápida y representativa de los datos.

Metodología:

a. Recolección de terminología estandarizada de los glosarios y publicaciones del sector para proveer al método de terminología técnica reconocida y empleada a nivel internacional.

b. Análisis de las matrices de datos empleadas en las técnicas estadísticas para la estructuración del método de recolección y estudio de la información.

c. Exploración de los potenciales de cumplimentación de las fichas de registro en campo estadístico y correlación con las exigencias del método propuesto en el estudio. 
d. Análisis de las características de los sistemas a analizar y desglose de las informaciones contenidas en las fichas de registro de acuerdo a sus propiedades.

En la segunda etapa, se ha buscado cumplir la meta de diseñar un método fácil de aplicar, que pudiera arrojar informaciones en tiempos mínimos y con una buena representatividad del estado conservativo de los bienes culturales. Para perseguir esta finalidad, se optó por una recolección de términos a partir de los glosarios oficiales ICOMOS-ISCS (2008), EwaGlos (2015), para crear las fichas de registro de bienes culturales compuestos por materiales pétreos, recubrimientos arquitectónicos y pinturas murales. Para las categorías de bienes constituidas por pintura de caballete sobre lienzo o tabla y escultura policromada se llevó a cabo una selección de conceptos específicos de las fenomenologías de alteración y deterioro a partir de una revisión de las publicaciones del sector de habla hispana. La importancia derivada de esta etapa reside en la voluntad de generar datos unificados, comparables entre diferentes contextos y realidades, cuyo valor semántico puede ser en todo momento consultado, junto a su representación gráfica.

El análisis de la estructura de las matrices de datos empleadas en el campo de la Ecología y en el análisis exploratorio de datos ha sido llevado a cabo con la finalidad de comprender los potenciales aplicativos derivados de las ciencias estadísticas, buscando su adaptación a las exigencias y resolución de las problemáticas identificadas en las fases preliminares de diagnóstico del patrimonio cultural.

La exploración de las diferentes modalidades de cumplimentación de las fichas permite profundizar entre varias tipologías de información a obtener tras el análisis. En esta etapa, se generó una ficha de registro estructurada alrededor de criterios cualitativos (fenomenologías de alteración y deterioro) y cuantitativos. Para estos últimos, se exploraron los potenciales operativos de la matriz de presencia/ausencia (1/0) contemplando la sola recolección de los fenómenos presentes, en vista de una rápida evaluación de los criterios desglosados en las tablas.

Para favorecer una mínima inversión de recursos temporales en la aplicación del método, ha sido tomada en cuenta la morfología estructural de las obras pertenecientes a la categoría de pintura de caballete y escultura en madera policromada. Lo anterior, debido a que la estructuración de las fichas de registro se ordenó a partir del abanico de términos recolectados y buscando favorecer el proceso de observación de las fenomenologías de alteración y deterioro. Por ello, ha sido necesario reunir las variables más difusas en los sistemas de obras muebles mencionados, adaptando los criterios de la ficha de registro a su conformación estratigráfica. 


\section{Tercera etapa - Aplicación del método a experiencias piloto}

Objetivo: Aplicar los modelos de ficha para la recolección de datos a casos de estudio seleccionados como experiencias piloto para evaluar ventajas, limitaciones y mejoras del método propuesto.

Metodología:

a. Selección de casos de estudio pertenecientes a la clase de: pinturas murales, materiales pétreos, pinturas de caballete y escultura policromada.

b. Aplicación del método a las casos de estudio seleccionados por medio del registro de las fenomenologías de alteración y deterioro en las matrices de datos diseñadas en la fase II.

c. Análisis de los datos recolectados con generación de indicadores de riesgo conservativo.

d. Interpretación de las informaciones arrojadas por el método por medio de la bibliografía de referencia empleada en la estructuración de las tablas de registro unificadas.

e. Identificación de las áreas con mayor indicador de riesgo conservativo.

f. Delimitación de ventajas y limitaciones encontrados de acuerdo a los criterios de viabilidad, practicidad, efectividad de uso y representatividad de la información obtenida.

g. Implementación de mejoras al método, por medio de modificaciones al sistema de registro, cumplimentación de las fichas y presentación de los datos tras el análisis.

En la tercera etapa de la investigación se han aplicado las fichas de registro generadas en la fase II a casos de estudio representativos de las problemáticas de acercamiento y comprensión de las exigencias conservativas de los bienes culturales compuestos por las categorías de pintura mural, materiales pétreos, pintura de caballete y escultura en madera policromada, con la finalidad de identificar ventajas y limitaciones en el diseño de las fichas de registro, en las fases de análisis de los datos y en la calidad de las informaciones arrojadas.

En esta fase se han analizado los datos recolectados por medio del procesamiento matemático de los valores reunidos en cada muestra, llegando a generar unos indicadores del riesgo conservativo. Éstos, obtenidos a partir de la elaboración de las informaciones recolectadas en la matriz de presencia/ausencia, han sido contemplados para arrojar una información de tipo cualitativo y cuantitativo en búsqueda de la identificación de las fenomenologías de alteración y deterioro presentes en el contexto de estudio y en función de la determinación de las áreas o elementos con mayor inestabilidad conservativa. Estas informaciones han sido sucesivamente interpretadas a través de la consulta de la bibliografía oficial de 
referencia, empleada para el desglose de los criterios unificados en las tablas de registro, en búsqueda de una correlación de causa-efecto.

Con el objetivo de identificar ventajas y limitaciones en la fase de aplicación de las fichas de registro y análisis de los datos y evaluar la calidad de las informaciones cualitativas y cuantitativas obtenidas, ha sido realizada una revisión crítica de tiempos, medios, modalidades y problemáticas encontrados en la aplicación del método.

Buscando mejorar el diseño inicial del método, han sido explorados otros medios de cumplimentación de las fichas de registro, incorporando la modalidad de matriz de abundancia. Ésta, con la finalidad de proveer el sistema de un medio de estimación de la extensión superficial (\%) de las fenomenologías de alteración y deterioro recolectadas.

\section{Cuarta etapa-Evaluación del método}

Objetivo: aplicar el método diseñado a casos y problemáticas reales para determinar su viabilidad, ventajas, limitaciones y posibilidades aplicativas.

Metodología

a. Implementación del método a los casos de estudio de forma directa y con ayuda de profesionales del sector.

b. Registro de las condiciones, recursos y tiempos empleados y relación con el tamaño de muestra abarcado.

En la cuarta etapa se ha implementado el método sobre varios casos de estudio, buscando involucrar a otros profesionales del sector de la conservación y restauración del patrimonio cultural, con la finalidad de explorar sus potenciales operativos y generar una retroalimentación útil para la evaluación y mejora del mismo.

Con la finalidad de estimar las ventajas y limitaciones de la metodología propuesta, junto a la difusión de las fichas de registro, se ha solicitado una evaluación del método por parte de los colaboradores externos. Ésta, se ha realizado por medio de una ficha de valoración de criterios inherentes a los tiempos, recursos, medios empleados y la calidad de la información arrojada.

\section{Quinta etapa-Resultados y discusión}

Objetivo: identificar ventajas, límites, características y posibilidades de uso del método propuesto.

Metodología:

a. Presentación de los resultados obtenidos a lo largo de la estructuración y aplicación del método diseñado. 
b. Comparación de los resultados obtenidos en la fase II y III analizando funcionalidad, posibilidades aplicativas y limitaciones.

c. Delimitación de ventajas y limitaciones encontrados de acuerdo a los criterios de viabilidad, practicidad, efectividad de uso y representatividad de las informaciones obtenidas.

d. Explicación de las informaciones arrojadas por el método y su utilidad de acuerdo a las operaciones de registro y análisis de las fenomenologías de alteración y deterioro presentes en los casos de estudio analizados.

En la quinta etapa, se han reunido las experiencias y resultados obtenidos a lo largo de la investigación, con la finalidad de cotejar ventajas, limitaciones, potenciales operativos y posibles márgenes de mejora. La valoración del método y la discusión de los resultados se generó gracias a la presentación y comparación de informaciones como: datos obtenidos, recursos empleados, calidad de las informaciones, interpretación de resultados, utilidad y nivel de profundización logrado tras la elaboración de la información. 


\section{Justificación}

Este estudio encuentra su justificación al detectar la dificultad encontrada en la gestión, análisis y ordenación de grandes cantidades de datos, áreas, factores, obras, variables, etc. que pertenecen al sistema de los materiales constitutivos, productos de alteración y deterioro del patrimonio cultural con los cuales los profesionales del sector se enfrentan a diario.

El propósito de este trabajo es brindar una herramienta para recolectar, gestionar y analizar las informaciones relacionadas con el estado de conservación de conjuntos de tipo histórico-artísticos, focalizándose en los métodos de análisis de las informaciones inspirado en las técnicas estadísticas. El desarrollo de esta investigación nace tras la exigencia de encontrar un sistema operativo capaz de estructurar las actividades de gestión y monitoreo de las condiciones conservativas del patrimonio cultural, que pueda aplicarse a conjuntos de obras delimitadas por características comunes tales como ubicación geográfica, tipología de material o técnica, régimen de propiedad, historicidad, etc. en dónde el tiempo necesario para la recolección de informaciones relacionadas con su historial y estado conservativo puede representar un límite en términos de recursos económicos o humanos.

Dicha inquietud surgió de la experiencia en el estudio del patrimonio cultural de la República Mexicana, en dónde fue necesario encontrar un método capaz de ordenar de forma representativa las características materiales, técnicas y temporales constituidas por un amplio espectro de datos y casuísticas. La necesidad de diseñar un sistema eficiente para establecer pautas de actuación y selección de datos para los estudios experimentales encontró en las técnicas estadísticas una herramienta eficaz para lograr un enfoque metodológico altamente representativo y objetivo 
para la resolución de las fases de análisis y gestión de datos y la sucesiva toma de decisiones.

El manejo no sistemático de datos específicos de la conservación de conjuntos monumentales se revela poco eficaz en el caso de número o extensión elevada de obras, y variables tales como técnicas, materiales, factores de alteración y deterioro. El contexto patrimonial de la República Mexicana se caracteriza por una grande extensión territorial, técnica y material en dónde el control y gestión de las problemáticas conservativas se ha vuelto un reto debido a las numerosas obras presentes en el territorio y a la falta de acciones estandarizadas que permitan un correcto planteamiento y ordenación de las acciones a seguir para su estabilización e intervención.

Dicho aspecto ha sido fuertemente puesto en relevancia tras el evento sísmico del 2017 que ha afectado a diferentes áreas de la República Mexicana y que ha puesto la atención sobre las complicaciones derivadas del abarcar una amplia recolección de datos en estrictos márgenes de tiempo y en el apoyo derivado de la actividad de voluntarios y comunidad en las tareas de conservación y resguardo de los objetos que constituyen parte de su identidad.

Para tal caso, se ofrece el ejemplo de las actividades de análisis de riesgos llevadas a cabo para la estructuración de unas acciones de salvaguarda de obras pertenecientes al muralismo mexicano ubicadas en diferentes puntos de la ciudad de San Luis Potosí (México) realizadas en el marco del proyecto de investigación Las pinturas murales del siglo XX en San Luis Potosí (S.L.P., México): investigación, estudio y análisis de riesgo (2015), realizado durante la etapa como profesor-investigador de la Universidad Autónoma de San Luis Potosí (UASLP). El difícil acceso, la cantidad de variables a tener en cuenta, las limitaciones en términos de tiempo y personal capacitado, aunado a la necesidad de estructurar los datos obtenidos de forma objetiva y representativa han focalizado la atención sobre las posibilidades ofrecidas por los métodos estadísticos.

En función de las limitaciones citadas, como primera implementación, se ha generado una solución operativa a través de la creación de una matriz de datos basada en las fenomenologías de alteración y deterioro específicas de las pinturas murales. A partir de la publicación European Illustrated Glossary for Conservation Terms of Wall Painting and Architectonic Surfaces $(2015)^{8}$ se diseñó un modelo de recolección de datos basado en muestras y especies a aplicarse a una población, representada por el conjunto de pinturas murales en estudio. Dicho modelo, definido matriz de deterioro, se ha estructurado de acuerdo a la terminología técnica

${ }^{8}$ HORNEMANN INSTITUT (2015). European Illustrated Glossary for Conservation Terms of Wall Painting and Architectonic Surfaces. <https://www.hornemann-institut.de/doi/2016ewa2.pdf> [Consulta: 19 de mayo de 2017]. 
propuesta en el glosario ilustrado con la finalidad de ofrecer un medio de registro de información normalizado.

A partir de métodos de estudio estadísticos derivados de la rama de la ecología ha sido posible desarrollar un sistema para el análisis de problemas en el campo de la conservación. Lo anterior ha sido posible gracias a la capacitación recibida en el Instituto Potosino de Investigación Científica y Tecnológica (IPICYT) sobre Técnicas estadísticas para el control de la biodiversidad ${ }^{9}$. La posibilidad de complementar las técnicas de recolección y estudio de datos que sirvan para las tomas de decisiones en el campo de las ciencias naturales con los requerimientos del sector de la conservación y tutela del patrimonio cultural ha brindado la base de apoyo para el desarrollo y sustento de esta investigación.

Para esta finalidad, el presente estudio intenta presentar un conjunto de experiencias dirigidas al diseño de unas matrices de datos útiles a la estructuración y unificación de las informaciones en las fases preliminares de diagnóstico. Éstas, inspiradas en las propuestas en los estudios en el ámbito de la ecología, tienen afinidad con las definidas tablas de contingencia que permiten un Análisis Exploratorio de Datos (EDA). Este método ofrece la ventaja de brindar informaciones útiles a la formulación de hipótesis por medio de las cuales poder organizar sucesivas fases de investigación o, en alternativa, desarrollar análisis de tipo estadístico más desarrollado.

Para corroborar la utilidad en la implementación de las fichas de recolección de datos a las exigencias conservativas del patrimonio cultural, estas se han aplicado en algunas experiencias-piloto. Para los materiales pétreos se ha escogido el conjunto escultórico monumental del Panteón del Saucito en la ciudad de San Luis Potosí (México). El conjunto se compone por un amplio abanico de tumbas monumentales compuestas por materiales pétreos de diferente naturaleza. Para esta clase de obras la matriz de datos implementada ha sido la de ICOMOS-ISCS: Illustrated glossary on

\footnotetext{
${ }^{9}$ El Instituto Potosino de Investigación Científica y Tecnológica, que forma parte del Sistema de Centros Públicos de Investigación del Consejo Nacional de Ciencia y Tecnología de México (CONACYT) brinda programas de formación abiertos a participantes externos interesados en desarrollar sus conocimientos en el campo de la ciencia y tecnología. En 2017 se proporcionó el Diplomado en Técnicas Estadísticas para el Control de la Biodiversidad con el objetivo de ofrecer herramientas de tipo teórico-práctico en temáticas sensibles, cuales el medio ambiente y la toma de decisiones, capaces de influir positivamente en las políticas públicas para la conservación del entorno natural. Lo anterior se logra gracias a la aplicación de técnicas de análisis estadístico que generan informaciones y estimaciones sobre el impacto de los proyectos en ambientes específicos tras correlacionar variables y factores específicas que intervienen en el sistema. IPICYT, CIENCIAS AMBIENTALES (2017). Diplomado en técnicas estadísticas para el análisis de biodiversidad. <https://ipicyt.edu.mx/storage-sipicyt/difusion/04-TecEstAnalisisbiodiversidad.pdf> [Consulta: 7 de marzo de 2020].
} 
stone deterioration patterns $(2008)^{10}$ con la finalidad de generar un instrumento basado en la terminología unificada propuesta por los profesionales del sector.

Ambos glosarios aportan ilustraciones e imágenes a representar las fenomenologías de deterioro clasificadas proponiendo un medio de identificación visual como primer acercamiento al registro de las alteraciones presentes en las obras. Tras la primera implementación se han identificado algunos aspectos que podrían ser sujetos a mejorías con la finalidad de hacer más efectiva la fase de registro.

Las experiencias registradas en ocasión del curso de Observación, documentación y diagnóstico organizado por el Centro Internacional de Estudios para la Conservación y la Restauración de los Bienes Culturales (ICCROM) y la Coordinación Nacional de Conservación del Patrimonio Cultural del Instituto Nacional de Antropología e Historia (CNCPC-INAH) de México en el marco del programa LATAM en la zona arqueológica de Chicanná, Campeche (2016) han sido significativas. A cadencia anual el ICCROM organiza, junto a las instituciones encargadas de la conservación del patrimonio cultural del país correspondiente, un programa de formación y fortalecimiento para profesionales con temáticas centradas en las problemáticas de América Latina y del Caribe (LATAM) ${ }^{11}$. Este área comprende una gran riqueza de expresiones culturales de tipo material e inmaterial, compuestas por un variado abanico de materiales, técnicas y soportes que representan una parte significativa del patrimonio cultural mundial. La misión del ICCROM en estas zonas es la de proporcionar nuevos enfoques y perspectivas en el campo de la conservación del patrimonio cultural, alimentando la cohesión social y el desarrollo de la región, atendiendo a sus peculiaridades culturales y sociales.

El curso Observación, documentación y diagnóstico (2016), ha respondido a las exigencias de fortalecimiento de la formación de profesionales dedicados a la conservación del material pétreo, el elemento constitutivo de los grandes conjuntos monumentales presentes en el área Latinoamericana y parte fundamental de los recintos arqueológicos del área en dónde tuvo lugar la experiencia. La meta propuesta en el proyecto formativo mencionado ha sido la de ofrecer nuevos métodos para el análisis visual y la documentación del patrimonio ${ }^{12}$.

\footnotetext{
${ }^{10}$ ICOMOS-ISCS (2008). Illustrated Glossary on Stone Deterioration Patterns. <https://www.icomos.org/publications/monuments_and_sites/15/pdf/Monuments_and_Sites_15_ISCS_Gl ossary_Stone.pdf> [Consulta: 3 de marzo de 2016].

${ }^{11}$ Las actividades desarrolladas por el ICCROM en el área LATAM incluyen cursos de formación, acciones de tutela, salvaguarda y difusión de resultados por medio de la publicación de Boletines periódicos. <https://www.iccrom.org/es/regions/america-latina-y-el-caribe> [Consulta: 15 abril 2020].

12 ICCROM, INAH-CNCPC. Programa del Curso de observación, documentación y diagnóstico LATAM. Zona Arqueológica de Chicanná, Campeche, México. <https://www.iccrom.org/wp-content/uploads/Curso-PiedraLATAM.pdf> [Consulta: 8 marzo 2020].
} 
La relevancia de esta experiencia para el desarrollo del presente estudio reside en la posibilidad de entrar en contacto con la aplicación del método de Observación Visual Organizada OVO diseñado por el restaurador Corrado Pedelíi', como propuesta operativa para las fases de recolección de datos y registro de la información sobre el estado de conservación de los monumentos y extraer un diagnóstico basado en la metodología de la observación cognitiva del contexto. La fortaleza de esta metodología reside en la modalidad de comprensión de las dinámicas de alteración y deterioro que están afectando un bien cultural, que pueden ser desvirtuadas en su comprensión por parte de la influencia ejercida por la experiencia en los profesionales del sector. Su implementación y desarrollo ha sido un desafío frente a los procesos comúnmente empleados en las fases de observación y diagnóstico de un monumento, debido a que la aplicación del método consta de fases simplificadas de asimilación de las características del contexto, alejando al profesional de la visión condicionada por la memoria y conocimiento especializado que podría acarrear una interpretación de los datos poco objetiva. A través de OVO se busca una nueva organización en la observación visual (Rivera Pérez 2015) ${ }^{14}$ con la finalidad de obtener una mirada complementaria a las empleadas por los profesionales, que sea objetiva y completa, de los fenómenos que están ocurriendo en el bien cultural.

Conocer una nueva visión de las fases de observación y examen visual del estado de conservación del patrimonio cultural fomentó el surgir de nuevos puntos de reflexión. Esta investigación propone explorar y solucionar la inquietud derivada de la puesta en práctica de los procesos de recolección y análisis de datos, juntando métodos científicos con análisis matemáticos e informaciones derivadas de la simple observación sin interpretación de los fenómenos, con el objetivo de facilitar dichas tareas y ofrecer soluciones operativas representativas y sencillas.

Cabe señalar que en ocasión de experiencias profesionales en diferentes ámbitos de la conservación del patrimonio cultural, entre las cuales destacan las llevadas a cabo en contextos de emergencia como las ocurridas en ocasión de los sismos de 2009 en la ciudad de L'Aquila (Italia), o en la República Mexicana de 2017, las inquietudes derivadas de los métodos de organización de los recursos y tareas

\footnotetext{
${ }^{13}$ Corrado Pedelí, docente del curso LATAM, es restaurador y conservador responsable del Departamento de Conservación y Restauración del Patrimonio Cultural de la Valle de Aosta (Aosta, Italia). Supervisor de los proyectos de conservación e intervención del área megalítica de Saint-Martin-de-Corléans (Aosta, Italia) y de su museo de sitio. Consultor de ICCROM, profesor y asesor, ha impartido diferentes cursos de formación específicos de las temáticas de análisis y documentación del patrimonio, entre otros.

${ }^{14}$ Corrado Pedelí entrevistado para el Boletín CR conservación y restauración en diciembre 2015. RIVERA PÉREZ, M.E. (2015). "OVO un mortero fluido" en Conservación y Restauración, Boletín de la CNCPC, No 7, diciembre, pp. 84-89.
} 
de conservación ha ido creciendo, junto a la preocupación hacia la identificación y estructuración de las informaciones relevantes que pueden ejercer un peso en la toma de decisiones.

El interés hacia el diseño de un método de observación, registro y análisis de los datos conservativos del patrimonio cultural ha sido fomentado por la extensión territorial de México, aunada a la presencia de colecciones y acervos de obras artísticas de elevado valor social, cultural y artístico que, de acuerdo a otros contextos geopolíticos, sufren la incidencia de la gestión de fondos y toma de decisiones necesarios a su salvaguarda y conservación. En el caso de conjuntos numéricamente grandes y compuestos por diferentes sistemas técnico-materiales, la salvaguarda de una pieza es en parte influenciada por otros factores, tales como su representatividad en la comunidad o el posible retorno de imagen derivado de su intervención. Debido a estas premisas, resalta la necesidad de ofrecer un método de monitoreo general que puede brindar datos conservativos de toda la colección, ofreciendo una estimación del índice de riesgo de las obras para así delimitar las acciones necesarias y urgentes, a la víspera de actuaciones más concretas.

Entre las tipologías de obras de arte que componen el patrimonio, un amplio porcentaje es representado por las colecciones compuestas por pinturas de caballete, sobre lienzo o tabla, y esculturas de madera policromadas cuyo valor reside en el sincretismo técnico y cultural derivado del encuentro entre la cultura europea y la mexicana. La fuerte presencia de dichas obras en los acervos religiosos y privados ha dirigido el interés hacia una ampliación de los materiales involucrados en las matrices de registro propuestas en el estudio, con la intención de aportar una herramienta útil para la resolución de problemáticas encontradas a lo largo de mi trayectoria como profesional conservador. La colección del Museo de Arte Sacro del municipio de Guadalcázar (San Luis Potosí) ha representado la ocasión para el diseño del método de análisis estadístico a aplicarse sobre pinturas de caballete y esculturas, a partir de una recolección de términos propios de esta clase de obras en diferentes publicaciones del tema. Esto representó un reto en términos de estructura y selección de terminología e imágenes, desatando ulteriores reflexiones y aportando nuevas consideraciones en función de una mejora del método inicial.

En el ámbito de la conservación y restauración del patrimonio cultural estas funciones ofrecen una comprensión de las fenomenologías de alteración y deterioro observados, que podrá ser analizada, según las exigencias, por diferentes niveles transversales, brindando informaciones objetivas a través de las cuales se podrán gestionar acciones de conservación altamente efectivas gracias a la posibilidad de obtener perfiles de datos altamente representativos del estado de conservación de los conjuntos monumentales, estructurándolos de forma cualitativa y cuantitativa, permitiendo planear respuestas específicas a las problemáticas encontradas alcanzando una mejora en la gestión de los recursos. 
Este estudio propone una asociación, derivada de las experiencias antecedentes, entre la observación y el registro de los fenómenos visuales y el análisis matemático de su incidencia, aunado a la estimación cuantitativa de las dinámicas de causa-efecto que afectan al patrimonio cultural que permitirá cuantificar, interpretar, gestionar y finalmente focalizar las acciones conservativas necesarias de forma provechosa, integrando la necesidad de un método operativo específico y funcional para el monitoreo, con el fin de facilitar dichas tareas y mejorar las dinámicas de registro de las condiciones conservativas de conjuntos de obras.

Este modelo operativo ofrece una novedad en términos de sistema de recolección y elaboración de datos, gracias a la posibilidad de obtener informaciones a diferentes niveles, según las exigencias del caso. Será por lo tanto posible, tras la recolección de los datos, derivar conclusiones sobre las causas, efectos y riesgos del conjunto de obras en cuestión y formular hipótesis sobre el estado y exigencias conservativas de las mismas.

En el año 2018 el centro histórico de San Luis Potosí fue certificado por parte de la UNESCO como Patrimonio de la Humanidad, siendo parte del itinerario cultural del Camino Real Tierra Adentro y por los valiosos testigos histórico-artísticos presentes en el territorio (Boletín INAH, 2018). Este reconocimiento aporta nueva luz sobre las exigencias y responsabilidades por parte de los profesionales del sector hacia la conservación de la memoria colectiva a través del emprendimiento de políticas y estrategias eficaces que garanticen la permanencia de este importante legado cultural. La relevancia social derivada de la aplicación del método formulado en esta investigación reside en la posible mejoría en las tareas de gestión de las acciones de tutela e inversión de los fondos necesarios para el resguardo del patrimonio cultural, gracias a la posibilidad brindada por la formulación de un plan económico basado en necesidades reales derivadas del análisis de los datos recolectados.

De acuerdo a los indicadores UNESCO de cultura para el desarrollo, el patrimonio es un producto y a su vez un proceso capaz de proporcionar a la sociedad un conjunto de recursos heredados del pasado a emplearse en el presente para su trasmisión a las futuras generaciones ${ }^{15}$. Para lograr esta finalidad es indispensable crear políticas y modelos de desarrollo dirigidos a protegerlos y difundirlos por su valor como medio de promoción de la paz, y del desarrollo social, ambiental y económico. La conservación del patrimonio incide en la formación de la identidad y cultura, siendo una herramienta de trasmisión del conocimiento entre pasado, presente y futuro. Esta relación temporal aporta una mayor cohesión social

${ }^{15}$ UNESCO. Indicadores UNESCO de cultura para el desarrollo. Manual metodológico.

$<$ https://es.unesco.org/creativity/sites/creativity/files/iucd_manual_metodologico_1.pdf> [Consulta: 14 de marzo de 2019]. 
y territorial, sentido de pertenencia entre grupos comunitarios, impulsando la cooperación, desarrollo y fomentando la creatividad y la innovación. Paralelamente, el impacto económico generado por el turismo cultural, representa solo una parte de los beneficios a generar para la colectividad tras la implementación de métodos dirigidos a mejorar las tareas de monitoreo y gestión de los productos culturales localizados en el territorio.

Esto podrá representar un beneficio hacia la sociedad en términos de sostenibilidad, un aspecto fundamental entre los destacados por los indicadores culturales de la UNESCO. El impacto social derivado del análisis entre coste y beneficios, en dónde la inversión económica ha sido fruto de un plan programado, atestigua el valor añadido de las acciones de conservación del patrimonio cultural que además de generar beneficios a la comunidad en términos de conservación de la identidad de un grupo socio-cultural, ayuda a formular políticas, proyectos, planes y actividades dirigidas a la resolución de problemas.

Gracias a la implementación de este método será posible focalizar y considerar con base en las informaciones elaboradas a partir de tablas unificadas los recursos económicos, técnicos y humanos necesarios, favoreciendo un uso sostenible de los mismos que garanticen el atender a las necesidades presentes sin comprometer las necesidades de futuras generaciones. Organización, sistematización, gestión de los medios disponibles con relación a las problemáticas delimitadas cualitativa y cuantitativamente por medio de la asociación entre ciencia y arte.

Las posibles mejoras derivadas de la implementación de métodos sistematizados al patrimonio cultural en las fases preliminares de diagnóstico podrán beneficiar a los responsables del sector y a los usuarios. Complementando las bases teóricas derivadas de la investigación histórico-artística con el análisis objetivo de sus exigencias conservativas, será posible impulsar las actividades dirigidas al conocimiento y valoración de nuestro legado cultural. La comprensión de sus necesidades y prioridades, complementada por el estudio de su relevancia cultural y por los avances técnicos logrados en el área de la ciencia de materiales, podrán favorecer la planeación de recursos y acciones de protección. El método propuesto mira a generar una herramienta unificada para la gestión de las tareas de conservación y tutela, participando en mejorar su sostenibilidad económica y social. 


\section{Referencias bibliográficas}

DONDIS, D.A. (2008). La sintaxis de la imagen, introducción al alfabeto visual. Barcelona: Gustavo Gili.

HORNEMANN INSTITUT (2015). European Illustrated Glossary for Conservation Terms of Wall Painting and Architectonic Surfaces. <https://www.hornemanninstitut.de/doi/2016ewa2.pdf> [Consulta: 19 de mayo 2017].

ICCROM. Enfoque regional América Latina y Caribe.

<https://www.iccrom.org/es/regions/america-latina-y-el-caribe> [Consulta: 15 abril 2020].

ICCROM, INAH-CNCPC. Programa del Curso de observación, documentación y diagnóstico LATAM. Zona Arqueológica de Chicanná, Campeche, México. <https://www.iccrom.org/wp-content/uploads/Curso-Piedra-LATAM.pdf> [Consulta: 8 marzo 2020].

ICOMOS-ISCS (2008). Illustrated Glossary on Stone Deterioration Patterns. $<$ https://www.icomos.org/publications/monuments_and_sites/15/pdf/Monume nts_and_Sites_15_ISCS_Glossary_Stone.pdf> [Consulta: 3 de marzo de 2016].

INAH. "Centro Histórico de San Luis Potosí recibe certificación de Patrimonio Mundial por parte del INAH y de la UNESCO" en Boletines, 7 de marzo de 2018. $<$ https://www.inah.gob.mx/boletines/7003-centro-historico-de-san-luis-potosirecibe-certificacion-de-patrimonio-mundial-por-parte-del-inah-y-de-la-unesco > [Consulta: 15 de abril de 2018].

IPICYT, CIENCIAS AMBIENTALES (2017). Diplomado en técnicas estadísticas para el análisis de biodiversidad. <https://ipicyt.edu.mx/storage-sipicyt/difusion/04TecEstAnalisisbiodiversidad.pdf> [Consulta: 7 de marzo de 2020].

PÉREZ GALINDO, Raúl (2013). Estadística aplicada para ciencias económicas, administrativas y sociales. México, D.F.: Trillas.

RIVERA PÉREZ, M.E. (2015). "OVO un mortero fluido" en Conservación y Restauración, Boletín de la CNCPC, № 7, diciembre, p. 84-89.

RUDOLF, A. (2006). Arte y percepción visual. Madrid: Alianza Forma.

UNESCO (2014). Indicadores UNESCO de cultura para el desarrollo. Manual metodológico.

$<$ https://es.unesco.org/creativity/sites/creativity/files/iucd_manual_metodologic o_1.pdf> [Consulta: 14 de marzo de 2019].

UNESCO (2014). Indicadores UNESCO de cultura para el desarrollo. Indicadores centrales de sostenibilidad. 
$<$ https://es.unesco.org/creativity/sites/creativity/files/digital-

library/cdis/Patrimonio.pdf> [Consulta: 14 de marzo de 2019]. 


\section{Estado de la cuestión}

Para comprender parte del contexto en el que surge esta investigación es necesario destacar algunos de los aspectos que influenciaron la creación del método que se propone implementar. Un bien cultural se compone por un sistema interdependiente $\mathrm{y}$ en constante equilibrio con el entorno conservativo. La durabilidad de los materiales depende de la naturaleza compositiva de los mismos y de las interacciones a nivel físico-químico que se establecen con el medio ambiental que las rodea. Gracias a las experiencias maduradas en el ámbito formativo y académico ha sido posible reconsiderar la importancia de las fases de observación y comprensión de estos fenómenos en donde el diseño de unas fichas de recolección de datos estratégicas, formuladas a partir de las empleadas para el análisis estadístico, podría representar un apoyo metodológico valioso para el registro, gestión y análisis exitoso de las informaciones.

El método propuesto es fruto de un trabajo de investigación de tipo interdisciplinario ya que para su ideación, creación y diseño, cooperaron herramientas, terminologías y métodos derivados de diferentes disciplinas.

Las temáticas y áreas del conocimiento que han representado un medio de reflexión útil para la creación del las tablas de registro a criterios unificados y su metodología de aplicación, se desglosan a continuación:

I. Niveles de registro del patrimonio cultural, precisión y costos.

II. Antecedentes en monitoreo, diagnóstico y gestión centralizada de los datos.

III. Enfoques metodológicos de otras disciplinas. 
IV. Técnicas estadísticas para el estudio del patrimonio cultural y la clasificación de la cultura.

V. Estimaciones de riesgo, recursos y economía del sector cultural.

VI. Metodologías de medición: matrices de registro de datos.

VII. Antecedentes metodológicos en observación y diagnóstico organizados.

VIII. Limitaciones operativas en la comprensión del contexto y de la terminología técnica.

IX. Antecedentes en terminología normalizada.

X. Alfabetidad visual y teoría sistémica de la comunicación.

\section{Niveles de registro del patrimonio cultural, precisión y costos}

El foco de atención y profundización de los exámenes preliminares puede alcanzar diferentes niveles de inspección visual, que están influenciados por las finalidades y exigencias del estudio y por los medios y recursos disponibles. En la publicación "Principios guías: registro, documentación y gestión de la información para la conservación de los lugares patrimoniales" $(2007)^{16}$ se ofrecen interesantes aportaciones al respecto (tabla 1).

${ }^{16}$ GETTY CONSERVATION INSTITUTE (2007). Guiding Principles - Recording, Documentation and Information Management for Conservation of Heritage Places.

$<$ https://www.getty.edu/conservation/publications_resources/pdf_publications/recordim.html> [Consulta: 15 de mayo de 2020]. 
Tabla 1 - Niveles de registro del Patrimonio Cultural. Traducido de GETTY CONSERVATION INSTITUTE (2007). Guiding Principles - Recording, Documentation and Information Management for Conservation of Heritage Places.

\begin{tabular}{|c|c|c|c|}
\hline & $\begin{array}{c}\text { A } \\
\text { REGISTROS DE } \\
\text { RECONOCIMIENTO }\end{array}$ & $\begin{array}{c}\text { B } \\
\text { REGISTROS } \\
\text { PRELIMINARES }\end{array}$ & $\begin{array}{c}\text { C } \\
\text { REGISTROS } \\
\text { DETALLADOS }\end{array}$ \\
\hline PRECISIÓN & BAIA & MEDIANA & ELEVADA \\
\hline $\begin{array}{l}\text { OBJETIVO } \\
\text { DEL } \\
\text { REGISTRO }\end{array}$ & $\begin{array}{l}1 \text { - RECONOCIMIENTO } \\
2 \text { - INVENTARIO INICIAL } \\
3 \text { - PLANEACIÓN INICIAL } \\
4 \text { - DATOS DE REFERENCIA }\end{array}$ & $\begin{array}{l}1 \text { - PLANEACIÓN } \\
2 \text { - CONDICIONES INICIALES } \\
3 \text { - INVESTIGACIÓN } \\
4 \text { - ESTABILIZACIÓN } \\
5 \text { - DISEÑO PRELIMINAR } \\
6 \text { - DATOS DE REFERENCIA }\end{array}$ & $\begin{array}{l}1 \text { - CONDICIÓN INICIAL } \\
2 \text { - DISEÑO } \\
3 \text { - CONSTRUCCIÓN } \\
4 \text { - REGISTROS DE CONSTRUCCIÓN } \\
5 \text { - MONITOREO/MANTENIMIENTO } \\
6 \text { - POSTERIDAD }\end{array}$ \\
\hline $\begin{array}{l}\text { PRECISIÓN } \\
\text { DE LOS } \\
\text { DIBUJOS }\end{array}$ & NO A ESCALA & $\begin{array}{l}\text { PLANOS Y ALZADOS } \\
\pm 5.0 \text { in. }( \pm 10 \mathrm{~cm}) \\
\text { DETALLES } \\
\pm 1.0 \text { in. }( \pm 2 \mathrm{~cm})\end{array}$ & $\begin{array}{l}\text { PLANOS Y ALZADOS } \\
\pm 0.5 \mathrm{in} .( \pm 1 \mathrm{~cm}) \\
\text { DETALLES } \\
\pm 0.1 \mathrm{in.}( \pm 2 \mathrm{~mm})\end{array}$ \\
\hline RESULTADOS & $\begin{array}{l}1 \text { - Documentación fotográfica } \\
2 \text { - Planeación fotográfica } \\
3 \text { - Condiciones iniciales } \\
4 \text { - Dibujos descriptivos }\end{array}$ & $\begin{array}{l}1 \text { - Dibujos a escala } \\
2 \text { - Descripción/Condición del BC } \\
3 \text { - Observaciones } \\
4 \text { - Reporte fotográfico }\end{array}$ & $\begin{array}{l}1 \text { - Dibujos a escala } \\
2 \text { - Descripción/Condición del BC } \\
3 \text { - Observaciones } \\
4 \text { - Reporte fotográfico }\end{array}$ \\
\hline $\begin{array}{c}\text { COSTOS } \\
\text { (TIEMPOS, RECURSOS } \\
\text { HUMANOS) }\end{array}$ & $\begin{array}{c}\text { BAJO } \\
\text { (pocos dias en el sitio } \\
\text { con el grupo de registro) }\end{array}$ & $\begin{array}{c}\text { MODERADO } \\
\text { (varias semanas o más en el sitio } \\
\text { con el equipo de registro y } \\
\text { participación de los conservadores } \\
\text { profesionales) }\end{array}$ & $\begin{array}{c}\text { MODERADO/ELEVADO } \\
\text { (tiempos extensos y actividades } \\
\text { prolongadas en el sitio con el } \\
\text { equipo de registro e incremento en la } \\
\text { participación de los conservadores } \\
\text { profesionales) }\end{array}$ \\
\hline
\end{tabular}

En el texto éstos se estructuran de acuerdo a tres niveles de inspección, bajo, mediano y elevado, especificando cómo el alcance esperado tendrá que estar relacionado con la relevancia del bien cultural, de las necesidades del proyecto y los recursos disponibles. El nivel de precisión de la información requerida, responde a la tipología de herramienta a emplear, la cual se relaciona con los recursos en términos temporales y humanos disponibles.

El Getty Conservation Institute publicó "Registro, documentación y gestión de la información para la conservación de lugares patrimoniales. Ejemplos ilustrados" 
(2007) ${ }^{17}$ en donde se hace hincapié en los métodos, dinámicas y herramientas empleadas en las fases preliminares de estudio de una obra en diferentes contextos, ofreciendo una panorámica de las diferentes herramientas disponibles para la resolución de las fases de diagnóstico. Dichos casos representan conjuntos de obras de un elevado valor histórico artístico para cuya profundización se disponía de recursos importantes. En este estudio propone cumplir con una investigación del estado de conservación del patrimonio acorde a un registro de reconocimiento y preliminar, alcanzando como meta el registro y análisis de las condiciones generales con una inversión de medios temporales, humanos y técnicos bajo: uno o pocos días en el sitio con el personal encargado del registro dotado de herramientas básicas.

El método de análisis propuesto en esta investigación contempla la recolección y registro de informaciones específicas de las fenomenologías de alteración y deterioro en una matriz de datos por medio de una inversión mínima de recursos. Este proceso se basa en la observación y reconocimiento de los efectos producidos por las dinámicas de interacción entre los materiales constitutivos de las obras de arte y el entorno en los que se conservan. Para los fines de la salvaguarda del patrimonio esto se traduce en la comprensión del posible historial conservativo de una obra. A partir del registro de sus efectos visibles, es posible conocer las variaciones y los cambios acontecidos en los materiales como resultado de su interacción con el entorno. Dichos efectos, manifestados a través de fenómenos específicos (diagrama 2), permiten entender las dinámicas conservativas que han afectado a la obra a través del tiempo.

${ }^{17}$ GETTY CONSERVATION INSTITUTE (2007). Recording, Documentation, and Information Management for the Conservation of Heritage Places. Illustrated Examples.

<https://www.getty.edu/conservation/publications_resources/pdf_publications/recordim_vol2.html> [Consulta: 15 de mayo de 2020]. 


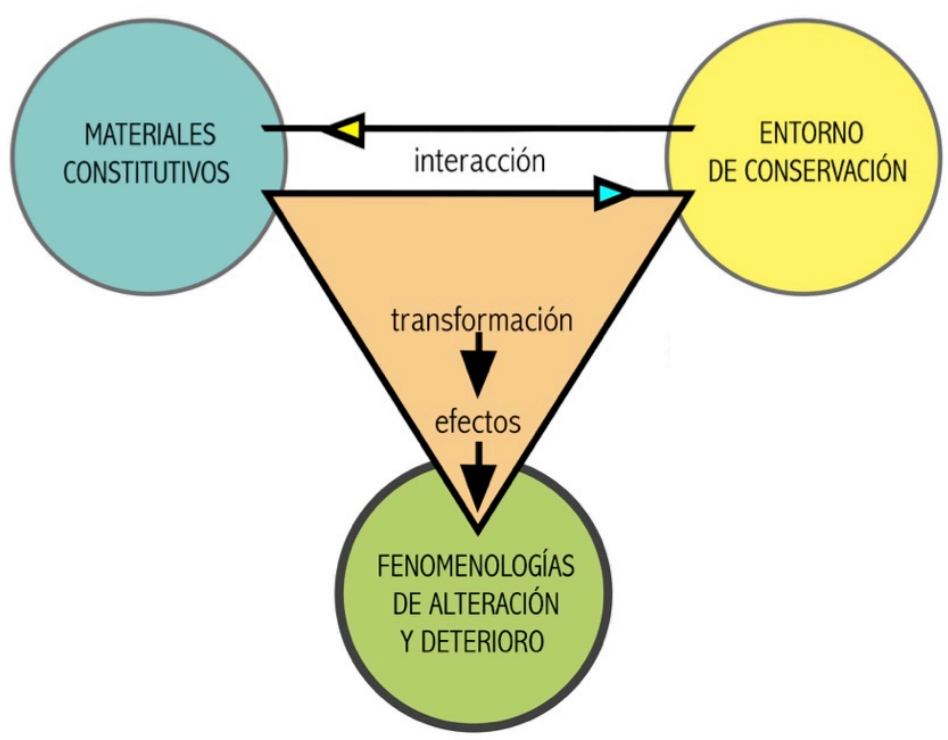

Diagrama 2-Relaciones entre materia y entorno.

Estos procesos son ocasionados por diferentes factores, además de ser fruto de reacciones e interacciones simultáneas, complementarias y complejas. Han sido numerosas las aportaciones y estudios sobre las alteraciones y deterioros de las obras de arte, que han generado publicaciones y fomentado el hallazgo y comprensión de los procesos degenerativos que pueden afectar a la conservación del patrimonio cultural. Estos estudios permiten recolectar un amplio abanico de causas, factores, dinámicas y agentes implicados en la degradación paulatina del patrimonio cultural, ofreciendo una estructura de análisis a aplicarse a los datos obtenidos tras la recolección de informaciones en un modelo unificado de matriz para el registro preliminar. Será posible, a partir de la identificación y clasificación de las fenomenologías de deterioros presentes, abarcar unas hipótesis sobre los mecanismos y causas responsables, además de generar una estimación de las obras en mayor riesgo. Estos datos globales podrán brindar un apoyo al direccionamiento de las acciones de gestión y conservación de los conjuntos patrimoniales en examen para determinar políticas de actuación específicas y funcionales.

\section{Antecedentes en monitoreo, diagnóstico y gestión centralizada de los datos}

El manejo, análisis y gestión de datos sobre problemáticas de conservación de conjuntos monumentales se revela muy complejo en el caso de número o extensión elevada de obras y variables, como lo pueden ser las técnicas y materiales 
constitutivos o los factores de alteración y deterioro. El contexto patrimonial de la República Mexicana se caracteriza por una gran extensión territorial, técnica y material donde el control y manejo de las problemáticas conservativas representa un verdadero reto, debido a las numerosas obras presentes en el territorio.

En México, la Administración Pública Federal ${ }^{18}$ establece cada cuadrienio un plan de desarrollo nacional en el cual se establecen los objetivos a alcanzar en el periodo ${ }^{19}$. Las metas, estrategias y líneas de acción del Programa Institucional de Mediano Plazo 2014-2018 del Instituto Nacional de Antropología e Historia ${ }^{20}$ se revisan al cierre de cada ciclo, de acuerdo con el compromiso del Plan de Trasparencia del Gobierno Federal. Los resultados de este examen se pueden consultar en el documento "Diagnóstico sobre las competencias y alcances logrados en el Plan de Trabajo 2014-2018", difundido por la misma institución en el comunicado del Programa de Transparencia ${ }^{21}$. En este informe se ponen de manifiesto la falta de centralidad en el manejo de los datos inherentes a las obras localizadas en el territorio ${ }^{22}$, y la carencia de medios y procesos unificados para el análisis de la considerable cantidad de patrimonio cultural bajo su jurisdicción ${ }^{23}$. En el mismo documento se aprecia el análisis crítico de los medios, problemáticas y programas disponibles hasta la fecha (2018) para la gestión y la toma de decisiones relacionadas con la conservación de este importante acervo socio-cultural.

\footnotetext{
${ }^{18}$ Artículo 25 de la Constitución Política de los Estados Unidos Mexicanos. <http://www.diputados.gob.mx/LeyesBiblio/pdf/1_060320.pdf> [Consulta: 20 de abril de 2020].

${ }^{19}$ Artículo 26 de la Constitución Política de los Estados Unidos Mexicanos. <http://www.diputados.gob.mx/LeyesBiblio/pdf/1_060320.pdf> [Consulta: 20 de abril de 2020].

20 "La definición de los objetivos, estrategias y líneas de acción del Programa Institucional de Mediano Plazo 20142018 del Instituto Nacional de Antropología e Historia tiene como referente la Ley Orgánica del Instituto Nacional de Antropología e Historia y la Ley Federal Sobre Monumentos y Zonas Arqueológicos Históricos y Artísticos, documentos normativos sobre los que se cimientan las atribuciones conferidas al Instituto en la investigación, conservación y difusión del patrimonio arqueológico, antropológico, histórico y paleontológico de la nación". Ley Orgánica del Instituto Nacional de Antropología e Historia (2015). <http://www.diputados.gob.mx/LeyesBiblio/pdf/170_171215.pdf> [Consulta: 20 de abril de 2020].

${ }^{21}$ CONACULTA, GOBIERNO DE MÉXICO, INAH. Programa institucional de mediano plazo 2014-2018 del Instituto Nacional de Antropología e Historia. <https://www.inah.gob.mx/images/stories/Transparencia/2014/pimp_2014_2018_institucional.pdf> [Consulta: 7 de marzo de 2019].

22 Haciendo énfasis en la dispersión y distancia existentes entre los conjuntos monumentales, artísticos e históricos, y los centros INAH derivados de la gran extensión territorial del país.

${ }^{23}$ CÁMARA DE DIPUTADOS. Nota N ${ }^{\circ} 1510$ (2019). INAH, INBA y Secretaría de Cultura, sin diagnósticos sobre estado del patrimonio cultural material e inmaterial que determinen necesidades de conservación y protección: ASF. <http://www5.diputados.gob.mx/index.php/esl/Comunicacion/Agencia-deNoticias/2019/Febrero/23/1510-INAH-INBA-y-Secretaria-de-Cultura-sin-diagnosticos-sobre-estado-delpatrimonio-cultural-material-e-inmaterial-que-determinen-necesidades-de-conservacion-y-proteccionASF> [Consulta: 20 de abril de 2020]
} 
A partir de 2011 el INAH y el Consejo Nacional para la Cultura y las Artes CONACULTA ${ }^{24}$, han implementado, junto con la Dirección General de Cómputo de la Universidad Nacional Autónoma de México UNAM, una estrategia común dirigida a registrar, consultar y organizar el Patrimonio Cultural de México al que se puede acceder desde toda la república. Esta herramienta se conoce como "Sistema Único de Registro Público de Monumentos y Zonas Arqueológicas, Paleontológicas e Históricas" 25 y tiene la finalidad de facilitar el registro y gestión de las obras de arte presentes en el país. Para los fines propuestos en esta investigación, este proyecto posee el gran interés de presentar, aunque con finalidades de documentación, un esfuerzo dirigido a la recolección, gestión y centralización de las informaciones en un único sistema. En el plan de desarrollo (2014-2018) dentro de las estrategias propuestas se hace hincapié en la necesidad de facilitar el diagnóstico del Patrimonio Cultural y capacitar a las áreas INAH para la resolución de problemáticas derivadas del monitoreo y gestión de las exigencias de los sitios.

En el diagnóstico citado se analizan los aspectos técnicos de catalogación, registro e inventario, evidenciando el uso de diferentes formatos y medios para el procesamiento y registro de las informaciones, una tarea en la que cabe especificar, puede tomar parte personal no especializado ${ }^{26}$. Esta situación fomentó la generación de diferentes tipologías de bases de datos, muchas veces incompletas, sin verificación o pendientes de actualización (Diagnóstico Programa de trabajo

\footnotetext{
${ }^{24}$ El Consejo Nacional para la Cultura y las Artes CONACULTA se creó en 1988 con el propósito de fomentar las actividades de creación, formación y desarrollo en el campo de la cultura y de las artes, preservando el patrimonio cultural de la nación mexicana. En este año se desligó de la Secretaría de Educación Pública (SEP), de la que formaba parte como Subsecretaría de Cultura. Desde 2015 CONACULTA ha evolucionado en la Secretaría de Cultura Federal, con la función de coordinar las políticas públicas en materia de artes y cultura. GOBIERNO DE MÉXICO, "Secretaría de Educación Pública" en Diario Oficial de la Federación, TOMO CDXXIII (4), 7 de diciembre de 1988, pp. 11- 14.

<http://dof.gob.mx/nota_to_imagen_fs.php?cod_diario=206408\&pagina=11\&seccion=0> [Consulta: 10 de diciembre de 2020]; GOBIERNO DE MÉXICO, "Secretaría de Educación Pública" en Diario Oficial de la Federación, 17 de diciembre de 2015.

<http://www.dof.gob.mx/nota_detalle.php?codigo=5420363\&fecha=17/12/2015> [Consulta: 10 de diciembre de 2020]; GOBIERNO DE MÉXICO, "Manual de Organización General de la Secretaría de Cultura" en Diario Oficial de la Federación, 12 de diciembre de 2017.

<https://www.dof.gob.mx/nota_detalle.php?codigo=5501065\&fecha=12/10/2017> [Consulta: 10 de diciembre de 2020].

25 Acceso al Sistema Único de Registro Público de Monumentos y Zonas Arqueológicas, Paleontológicas e Históricas <https://registropublico.inah.gob.mx/index.php/autenticacion/autenticacion> [Consulta: 07 de septiembre de 2019].

${ }^{26}$ Existen diferentes modelos de fichas de registro, que sin embargo no responden a sistemas estandarizados y unificados que puedan ser gestionados, analizados y comparados a gran escala. La necesidad de abarcar el control de un territorio muy extenso, como es el caso de la República Mexicana, desencadena la posibilidad de idear un método que pueda ser delegado a operadores sin formación especializada que representan una realidad en el control, manejo y mantenimiento del patrimonio. Estas figuras suelen ser representantes de las comunidades, voluntarios, custodios, privados, etc.
} 
2014-2018). Esta dispersión y falta de criterios comunes en el momento de recibir e integrar la información, constituyen las principales limitaciones para la creación de un sistema común de datos, aunándose a la manifiesta imposibilidad expresada por parte de la institución de abarcar el procesado y almacenaje de toda la información del gran número de obras estimado. A estos aspectos se suma la debilidad en la organización del personal y en la gestión del sistema, agravado por la falta de implementación en las mejorías técnicas y tecnológicas necesarias para satisfacer las necesidades de registro, gestión, inventariado y monitoreo.

La situación representa una llamada a la creación de infraestructuras, redes y servicios con recursos tecnológicos adecuados para las características de este contexto sociocultural tan complejo y único. El diseño de un método de registro y análisis de datos estructurado sobre la base de las experiencias brindadas por otras instituciones y profesionales podría mejorar la gestión de las problemáticas mencionadas. En total acuerdo con las exigencias operativas expuestas, es posible generar un impacto positivo en la construcción de datos, específicos y generales, representativos del estado y exigencias del patrimonio cultural, apoyando en las tomas de decisiones, orientación de recursos económicos y humanos, y en el planteamiento de las actividades de investigación, conservación y restauración. Una posible herramienta para mejorar la gestión y ordenamiento de las tareas dependientes de las fases preliminares de estudio, como las de diagnóstico y estimación de riesgos dirigidos al direccionamiento de fondos y planeación de futuras acciones de conservación y restauración.

El método planteado en este estudio brindaría la oportunidad de construir indicadores eficaces, ya que las características del sistema propuesto en este estudio permitirían una centralización y estandarización de las informaciones. Estos aspectos representarían la ocasión de poder llevar a cabo una comparación del estado del patrimonio mexicano a nivel nacional y también con otras realidades.

Otro ejemplo de monitoreo sistematizado y centralizado del patrimonio cultural de diferentes países es el brindado por el "State of Conservation System (SOC)" del UNESCO ${ }^{27}$. Este es un sistema de información que comparte una gran cantidad de datos fiables sobre el estado de conservación de las propiedades del Patrimonio Mundial desde 1979, y constituye uno de los medios de monitoreo más completos de cualquier convención internacional. Este interfaz se compone por informes realizados por los países miembros y permite el acceso a relaciones y decisiones adoptadas al respecto por el Comité del Patrimonio Mundial.

${ }^{27}$ UNESCO. State of Conservation System (SOC). < https://whc.unesco.org/en/soc/> [Consulta: 10 de mayo de 2020]. 
El Instituto de Estadística de la UNESCO (UNESCO Institute for Statistics UIS) desde $2009^{28}$ brinda herramientas útiles para la estimación y seguimiento de datos inherentes al estado de las prácticas culturales de sus estados miembros. Proporciona metodologías de tipo estadístico en vista de un análisis comparativo de la participación cultural en y entre los países. Consta con una serie de publicaciones cuya relevancia para la presente investigación reside en las ventajas otorgadas por la unificación de los métodos de recolección de datos que pueden ayudar a generar informaciones estadísticas de cada nación y a compararla con las de otras. El ámbito de aplicación de dicha herramienta se centra en la temática de las expresiones culturales. Para los fines de la presente investigación, su conocimiento es útil para una evaluación de las posibilidades aplicativas y de los posibles alcances brindados por una sistematización en los criterios y métodos de recolección y análisis de los datos a aplicarse en el ámbito de la conservación del patrimonio cultural.

Rand y García Grinda en su artículo "Management documentation indicators \& good practice at cultural heritage places" $(2015)^{29}$ destacan cierta falta de coordinación entre las documentaciones presentadas a escala general, como las brindadas en las plataformas UNESCO, y las llevadas a cabo en contextos específicos, como las generadas en las realidades locales. En la investigación se evidencia el valor de los indicadores, cuales parámetros de análisis y comparativa del estado de salud del patrimonio cultural y herramientas funcionales a su gestión ${ }^{30}$. El programa UNESCO para "La diversidad de las expresiones culturales"31 desarrollado gracias a los apoyos financieros del Gobierno de España, es un ejemplo metodológico de análisis basado en indicadores ${ }^{32}$ dirigido al estudio de las contribuciones de la cultura en el desarrollo de la sociedad. Esto se logra gracias al uso de tablas de datos estructurados para facilitar la elaboración de los indicadores a nivel nacional. Uno de sus aspectos relevantes es el tratamiento de las informaciones, implementado alrededor de una metodología común que contempla el uso de cálculos

${ }^{28}$ UNESCO (2009). Framework For Cultural Statistics.

$<$ http://uis.unesco.org/sites/default/files/documents/unesco-framework-for-cultural-statistics-2009en_0.pdf> [Consulta: 15 de marzo de 2019].

${ }^{29}$ RAND, E. y GARCíA GRINDA, J.L. (2015). "Management documentation indicators \& good practice at cultural heritage places" en The International Archives of the Photogrammetry, Remote Sensing and Spatial Information Sciences, Volume XL-5/W7, 25th International CIPA Symposium. Taiwan: Taipei.

${ }^{30}$ En estos proyectos, dirigidos a la gestión sostenible del patrimonio cultural, destaca la importancia de establecer indicadores adecuados, establecidos y diseñados previamente para impulsar una mejora efectiva de la práctica conservativa.

${ }^{31}$ UNESCO. Diversidad de las expresiones culturales. <https://es. unesco.org/creativity/indicadores-dedesarrollo/caja-de-herramientas> [Consulta: 10 de junio de 2020].

${ }^{32}$ Los indicadores analizados para establecer el impacto de la cultura en el desarrollo de un determinado país: económico, educativo, gubernamental, participación social, equidad de género, comunicación y patrimonio. 
automáticos. Esto favorece la interpretación y la comparación de resultados a nivel particular e internacional.

El uso sistemático de parámetros unificados facilita la estandarización en la recolección y estudio de los datos ofreciendo al mismo tiempo un cuadro general y detallado de las informaciones. Los indicadores cumplen la función de comparar, informar, señalar y medir el estado actual de áreas específicas ${ }^{33}$. En el sector cultural estos aspectos son dirigidos a proporcionar pruebas sólidas y elementos para la toma de decisiones, además de brindar un válido apoyo en las tareas de monitoreo y generación de informes, evidenciando las fortalezas y debilidades de un determinado entorno, ofreciendo un medio de evaluación de las acciones de mantenimiento, priorización, planificación, identificación de riesgo. De las características ideales de los indicadores ${ }^{34}$, en vista de una sistematización de los procesos de monitoreo y actualización del estado de conservación de las obras, se vuelven fundamentales aspectos, como la compatibilidad, que permite una comparativa entre diferentes instituciones y/o contextos, la claridad, para que sean fáciles de identificar y entender, la viabilidad, para que sean fáciles de medir y el uso de un número limitado de parámetros para que la información arrojada sea representativa y eficaz. La selección e implementación de unos indicadores de acuerdo a estas directrices podrá favorecer una adecuada toma de decisiones, priorizando acciones y asignación de recursos sustentados en diferentes grados o niveles de profundización de la información.

La implementación de dichos indicadores permite optimizar recursos, ofrecer diagnósticos e informaciones básicas que aportan datos valiosos ${ }^{35}$ para integrar los informes periódicos de la UNESCO, favoreciendo la gestión sostenible del patrimonio y su conservación. Cuidar los aspectos metodológicos relacionados con su protección, salvaguarda y gestión (diagrama 3 ) a través de unos medios de diagnóstico estandarizados que contemplen el fortalecimiento de capacidades y la participación activa de la comunidad, representa una herramienta complementaria de interés.

\footnotetext{
${ }^{33}$ KUKA, J. (2012) Monitoring cultural indicators, ICCPR, Barcelona, pp. 2-5.

${ }^{34}$ POOLE, N. (2015) Collections Management Performance Indicators. UK: The Collections Trust.

${ }^{35}$ Los indicadores constituyen datos sensibles a nivel político, por ello es posible encontrar casos en donde no se comparte dicha información. La generación de datos representativos sobre el estado de un determinado frangente de la sociedad o, en nuestro caso, del patrimonio cultural, comporta una responsabilidad administrativa. Conocer las exigencias y problemáticas del patrimonio cultural por ejemplo, debería de generar una mejora en las prácticas de gestión del mismo, sustentada en la planificación de medidas concretas para su salvaguarda y conservación. RAND, E. y GARCÍA GRINDA, J.L. (2015). "Management documentation indicators \& good practice at cultural heritage places" en The International Archives of the Photogrammetry, Remote Sensing and Spatial Information Sciences, Volume XL-5/W7, 25th International CIPA Symposium. Taiwan: Taipei.
} 


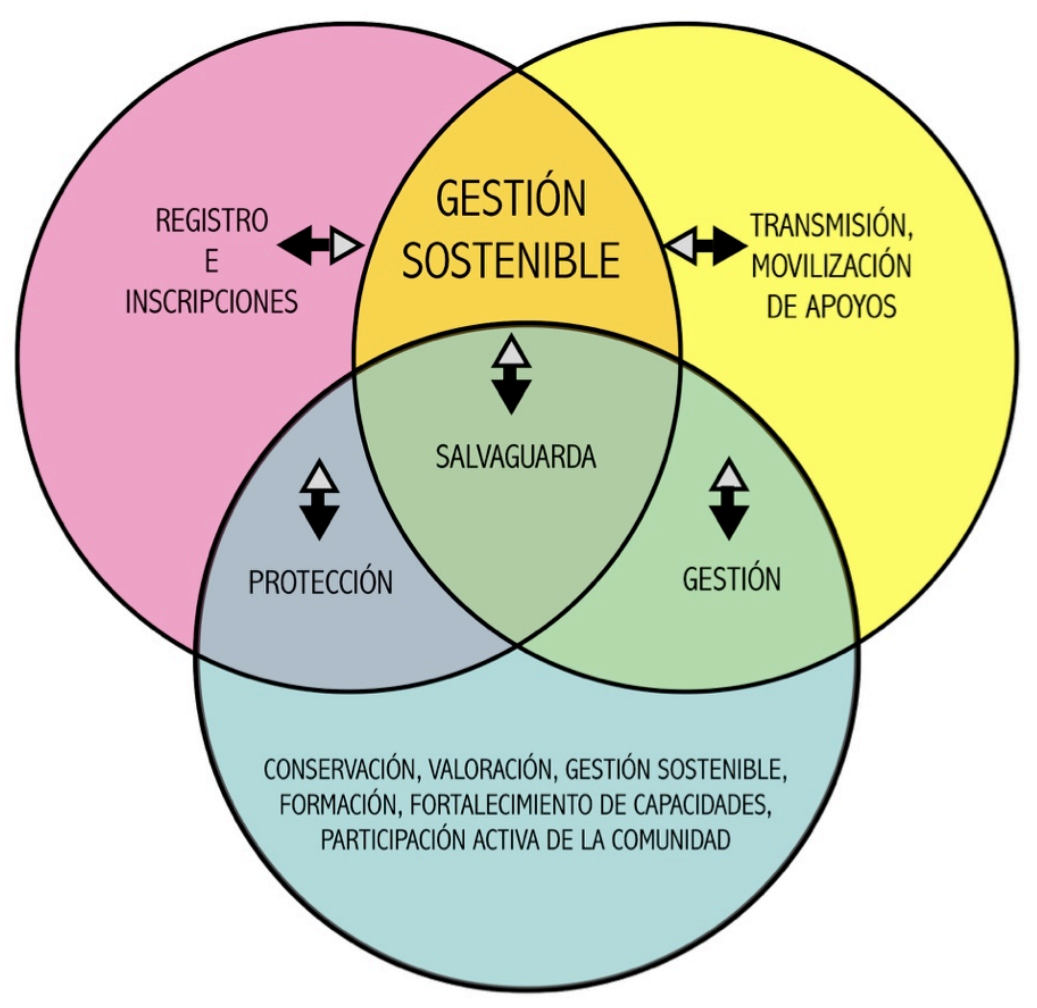

Diagrama 3 - Factores que concurren en la gestión sostenible del patrimonio (UNESCO, 2014) ${ }^{36}$.

Las reflexiones generadas en torno a una necesaria actualización en el manejo de los sitios UNESCO pusieron de manifiesto otras exigencias en las tareas de gestión del patrimonio, como la importancia de proveer dichas actividades de una perspectiva empresarial. Estas aportaciones derivan del análisis de la crisis económica que ha afectado a diferentes realidades a partir del comienzo del siglo $\mathrm{XX}^{37}$. Por lo tanto, en relación a las tareas de gestión de los sitios de interés y relevancia cultural, se hace necesario hallar respuestas a las problemáticas presentes

${ }^{36}$ UNESCO (2014). Indicadores UNESCO para la Cultura y el Desarrollo. Manual Metodológico.

$<$ https://es.unesco.org/creativity/sites/creativity/files/iucd_manual_metodologico_1.pdf> [Consulta: 14 de marzo de 2019].

${ }^{37}$ Esto ha afectado en mayor medida a los países europeos con un perfil económico débil, como Portugal, España, Grecia, Irlanda e Italia. BADIA, F. (2012). "Monitoraggio e controllo della gestione dei siti UNESCO. II piano di gestione come opportunità mancata?" en Tafter Journal, Esperienze e strumenti per cultura e territorio, núm. 52. <http://www.tafterjournal.it/2012/10/01/monitoraggio-e-controllo-della-gestione-deisiti-unesco-il-piano-di-gestione-come-opportunita-mancata/> [Consulta: 10 de junio de 2020]. 
de acuerdo a los recursos y medios existentes, mejorando las estrategias de desarrollo económico, social y cultural de las áreas involucradas ${ }^{38}$. La gestión de los sitios de carácter histórico-artístico involucra, en muchos casos, a diferentes instituciones, aportando una mayor complejidad de gestión. Ésta, deriva de los diferentes sistemas de análisis adoptados por cada ente, y pone en evidencia el valor añadido representado por el uso de unos métodos de evaluación unificado que permita estructurar los resultados en varios niveles y la integración de datos recolectados por diferentes figuras profesionales. En los indicadores de resultado, se vuelve necesario evitar agregar mayores elementos de complejidad, indicando los requisitos de selectividad, tempestividad, medición efectiva como los deseables para estructurar los parámetros de estudio ${ }^{39}$.

\section{Enfoques metodológicos de otras disciplinas}

Los antecedentes presentados en los apartados anteriores han alimentado la inquietud de explorar y realizar un método de registro y análisis de la información alternativo y complementario a los existentes ${ }^{40}$. El desarrollo potencial se centró en las posibilidades ofrecidas por las técnicas estadísticas, empleadas en diferentes áreas del conocimiento para lograr enfoques metodológicos altamente representativos y objetivos dirigidos a establecer pautas de acción específicas y efectivas. Los planteamientos usados en la rama de la ecología previos a las decisiones, se estudian gracias a diferentes técnicas de estudio estadístico, y permiten conservar el medio natural basándose en datos cualitativos y cuantitativos.

La diversidad biológica o biodiversidad define un amplio concepto para cuyo control han sido creadas varias herramientas que reducen sus componentes a supuestos medibles matemáticamente ${ }^{41}$. Entre éstas destacan las técnicas estadísticas, con sus diferentes modalidades de análisis y aplicación. El área de la Ecología representa un campo fértil para el desarrollo de una metodología de monitoreo y estudio de las peculiaridades presentes en el Patrimonio Cultural, gracias a las analogías detectadas entre las exigencias y finalidades de conservación que las acomunan. En función de la protección de áreas naturales ha sido necesario desarrollar técnicas capaces de abarcar numerosos datos diseminados por amplias

38 SIBILIO PARRI, B. (2011), "Uno strumento di gestione del patrimonio culturale: il caso dei siti UNESCO" en Economia e diritto del terziario, Vol. 23, núm. 2, pp. 307-333.

${ }^{39}$ BADIA, F. (2012), op. cit.

${ }^{40}$ Por métodos existentes se entienden las fichas y modalidades de registro de datos utilizados por los profesionales del sector en las fases de análisis del estado de conservación de una obra. Éstas se caracterizan por emplearse con estructuras y metodologías independientes y no unificadas.

${ }^{41}$ MAGURRAN, A. E. (1988). Ecological diversity and its measurement. New Jersey: Princeton University Press. 
escalas espaciales, coordinando diferentes autoridades dedicadas a su tutela, considerando tiempos de acción muy cortos. Esto ha favorecido el estudio y creación de métodos para la medición de diferentes parámetros, indicativos del estado de un determinado sistema ecológico, con la finalidad de lograr su conservación, manejo y monitoreo ${ }^{42}$. Lo anterior encuentra su justificación en la presión temporal ejercida por las dinámicas de gestión y disposición de fondos de naturaleza económica y de los recursos humanos administrados por entidades públicas y sujetos a ciclos determinados, como pueden ser los relacionados con las realidades sociopolíticas responsables de su tutela. Esta realidad puede llegar a entorpecer y atrasar las acciones de protección, agravando el estado de conservación de los materiales. Disponer de un método de registro y análisis de las dinámicas que están afectando al patrimonio cultural, ofrece una herramienta útil para focalizar las acciones necesarias, disminuyendo notablemente los implementos económicos, humanos y técnicos necesarios brindando datos representativos a exponer a los organismos responsables de su protección.

\section{Técnicas estadísticas para el estudio del patrimonio cultural y la clasificación de la cultura}

Numerosas han sido las aportaciones en el uso de técnicas estadísticas en áreas específicas del Patrimonio Cultural. Es relevante mencionar que en el campo de la arqueología $a^{43}$ ha sido desarrollado uno de los medios informáticos de estudio y análisis estadístico que actualmente es utilizado en otras disciplinas. Es el programa PAST "PAleontological STatistics", equivalente a estadísticas paleontológicas, desarrollado en 2001 por Øyvind Hammer del Museo de Historia Natural de Oslo (Noruega) y David A.T. Harper del Museo Geológico de Copenhague (Dinamarca) y basado sobre un programa anterior diseñado por Paul D.Ryan de la Universidad de Galway (Irlanda) ${ }^{44}$. Este software gratuito funciona como una hoja de cálculo y, tras insertar los datos, ofrece la posibilidad de obtener diferentes tipologías de análisis y gráficos. Este programa, creado para estudiar informaciones relativas al contexto

\footnotetext{
${ }^{42}$ SPELLERBERG, I. F. (1991). Monitoring ecological change. Cambridge: University Press.

${ }^{43}$ Una de las primeras áreas de aplicación de las técnicas de estudio estadístico en este campo ha sido dirigido al análisis espacial y a la arqueología del paisaje. El Dr. Víctor M. Fernández Martínez de la Universidad Complutense de Madrid, en su "Arqueoestadística: métodos cualitativos cuantitativos en arqueología" (2015) cita, para un acercamiento al tema, los siguientes manuales en castellano: HODDER, I. y ORTON, C. (1990). Análisis espacial en arqueología. Barcelona: Crítica; GARCÍA SANJUÁN, L. (2005). Introducción al reconocimiento y análisis arqueológico del territorio. Barcelona: Ariel.

${ }^{44}$ HAMMER, Ø., HARPER, D. A. T., RYAN, P. D. (2001). "PAST: Paleontological Statistics Software Package for Education and Data Analysis" en Paleontología Electrónica, №4, 1., p. 9.
} 
arqueológico ${ }^{45}$, ha sido empleado en muchas otras áreas del conocimiento entre las cuales se cita el de la ecología y del análisis de la biodiversidad ${ }^{46}$.

Para un acercamiento y comprensión de las ventajas brindadas por la aplicación de las ciencias estadísticas a la arqueología, destaca el texto "Arqueoestadística, métodos cuantitativos en arqueología" ${ }^{\prime 7}$, en donde se halla una panorámica de estas técnicas de análisis y sus ejemplos de aplicación práctica. En él se menciona la importancia de los números en relación a las actividades de contar, medir y comparar determinadas características de una excavación, además de una buena definición de lo que es la estadística "la ciencia matemática que trata de la recolección, análisis, presentación e interpretación de todo tipo de datos, sobre todo los susceptibles de adoptar, directa o indirectamente, una forma numérica, con el fin de ayudar en la toma de decisiones o explicar la regularidad o irregularidad de algún fenómeno". El texto citado pone en evidencia que uno de los puntos fundamentales a tener en cuenta a la hora de analizar un conjunto de informaciones es la calidad original de los datos de partida. Éste se determina en la fase inicial, a través de lo que se define como matriz de datos y muestra. Otro aspecto relevante para los fines de esta investigación, es el que se refiere a cómo los datos seleccionados constituyen un producto de la interpretación del profesional en acción y podían variar según las condiciones y formación del mismo.

Entre otras aportaciones en el campo del análisis de datos en ámbito cultural se citan las desarrolladas con la finalidad de analizar los aspectos socio-económicos de la cultura, generando indicadores basados en datos objetivos que permiten llevar a cabo una comparación de los estudios a nivel internacional ${ }^{48}$, y las implementadas para gestionar los riesgos derivados de situaciones de emergencias ${ }^{49}$. Entre las instituciones y grupos de trabajo es digno de nota recordar las labores de UNESCO, ICCROM, World Heritage Centre, Canadian Conservation Institute, y los proyectos fomentados por la Comisión Europea en el marco de colaboraciones entre instituciones educativas de nivel superior.

\footnotetext{
${ }^{45}$ De acuerdo a Fernández Martínez "este programa ha sido creado para una tipología de datos muy próximos a la arqueología, como lo son los geológicos y paleontológicos". FERNÁNDEZ MARTíNEZ, V.M. (2015). Arqueo estadística, métodos cuantitativos en arqueología. Madrid: Alianza, p. 23.

${ }^{46}$ El primer contacto con el software PAST ha sido en ocasión del Diplomado en "Técnicas Estadísticas para el Control de la Biodiversidad" en el departamento de Ciencias Ambientales del Instituto Potosino de Investigación Científica y Tecnológica en 2017.

${ }^{47}$ FERNÁNDEZ MARTÍNEZ, V.M. (2015), op. cit.

${ }^{48}$ UNESCO (2009). Framework For Cultural Statistics.

$<$ http://uis.unesco.org/sites/default/files/documents/unesco-framework-for-cultural-statistics-2009en_0.pdf> [Consulta: 15 de marzo de 2019].

${ }^{49}$ ICCROM, ICOMOS, IUCN, UNESCO, (2010). Managing disaster risks for World Heritage. $<$ https://whc.unesco.org/en/documents/115730> [Consulta: 15 de febrero 2019].
} 
La UNESCO, a través de la cooperación entre su Instituto de Estadística (UNESCO Institute for Statistics, UIS) y su Sector Cultural, propone una aplicación de estas técnicas de análisis a la gestión de datos referentes a las actividades culturales en el marco del programa UNESCO Framework for Cultural Statistics (2009) ${ }^{50}$. El proyecto destaca el valor e influencia política ejercida en cada contexto social por los testigos culturales, tangibles e intangibles, empleando el análisis estadístico como base de elaboración y análisis de los datos objetivos útiles para la toma de decisiones. Poniendo en evidencia el valor de la cultura en el desarrollo de la economía y la sociedad, ha sido posible generar datos estandarizados eficaces para la comparación nacional e internacional de las realidades sociales, económicas y educativas de los países, analizando las actividades y dinámicas de diferentes industrias culturales. Un trabajo en constante desarrollo en donde el análisis matemático se pone a disposición de las posibilidades comparativas entre diferentes contextos gracias a la generación de datos objetivos y altamente representativos.

En ocasión de este proyecto se ha considerado una posible extensión adicional de la matriz de indicadores seleccionada, con el objetivo de probar la viabilidad de dicho esquema de acuerdo a la naturaleza del objeto de estudio. La propuesta de entonces, aun siendo directamente implementable y medible, también desveló el potencial de desarrollo futuro en la recopilación de los datos, destacando la existencia de datos que no se pudieron medir porque simplemente aun eran inexistentes ${ }^{51}$. Desde un análisis crítico, uno de los aspectos esperados fue que el modelo pudiera hacer posible la evaluación comparativa internacional a partir de una serie de diferentes enfoques propios de la cultura estadística ${ }^{52}$.

Por ello, se han diseñado y empleado unas matrices de recolección de datos basadas en las exigencias de estudio del proyecto (tabla 2).

50 Este programa de 2009 ha impulsado el uso de definiciones estandarizadas dirigidas a la clasificación económica y social de la cultura, con el objetivo de fomentar una mejor comprensión de su estado y una comparativa entre los países participantes. Entre los parámetros evaluados: medición de la dimensión económica de la cultura, identificación de actividades culturales productivas y de los productos culturales, análisis del comercio cultural internacional y del empleo cultural, medición de la dimensión social, de la participación cultural, y del patrimonio material e inmaterial.

51 Para profundizar este aspecto es fundamental recordar la característica "flexibilidad" del mercado cultural. Éste se compone de elementos y dinámicas en constante evolución, de ahí la consideración de la constante evolución y actualización en la matriz de datos propuesta en el estudio presentado en 2009.

52 UNESCO-FCS (2009), op. cit. 
Tabla 2 - Matriz de los ocho dominios del FCS (traducida de: UNESCO-FCS, 200953).

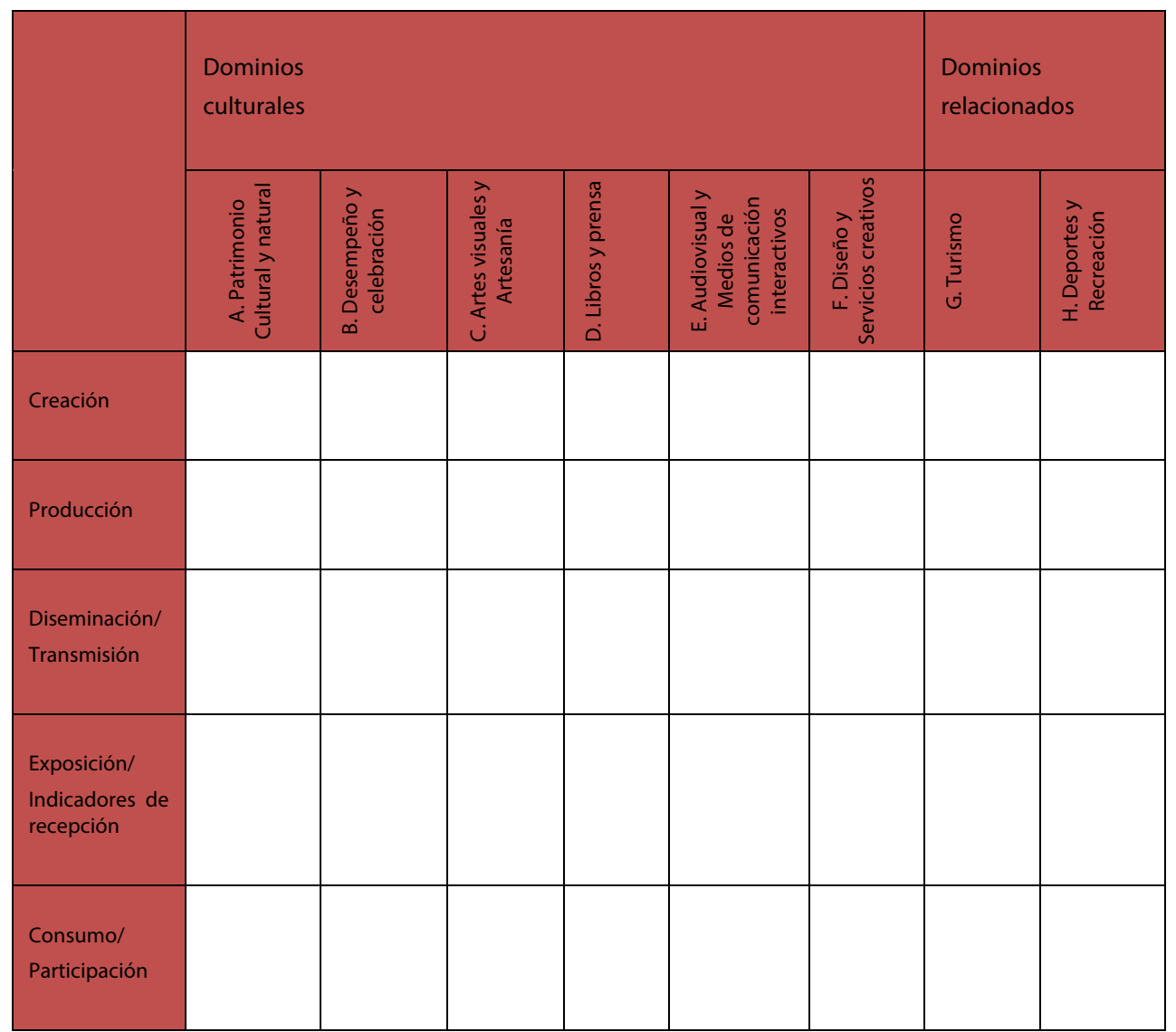

Un amplio porcentaje de las metodologías que se apoyan en estimaciones matemáticas se proponen hacer frente a casos de tipo excepcional, como desastres

${ }^{53}$ Este modelo de ficha para la recolección de datos ha sido generada a partir de las experiencias del grupo de trabajo EU LEG Eurostat (2000) y del anterior FCS-UNESCO (1986). Dicha matriz ha sido creada mediante la tabulación cruzada de los ocho dominios del FCS, ordenados en las columnas A-H de la tabla. Estos corresponden a dominios culturales (A-F) y dominios relacionados $(G-H)$ siendo: patrimonio cultural y natural (A), desempeño y celebración (B), artes visuales y artesanía (C), libros y prensa (D), audiovisual y medios de comunicación interactivos $(\mathrm{E})$, diseño y servicios creativos $(\mathrm{F})$, turismo $(\mathrm{G})$ y deportes y recreación (H). Su estructura ha sido pensada para ser un medio práctico y pragmático de recopilación de datos. Para mayores referencias, de acuerdo a lo citado en UNESCO-FCS 2009: LEG Eurostat (2000). "Cultural statistics in the EU" en Eurostat Working Paper, Population and Social Conditions Series, 3/2000/E/No1. Final report of the LEG. Luxembourg: Eurostat; UNESCO (1986). "The UNESCO Framework for Cultural Statistics. Statistical Commission and Economic Commission for Europe" en UNESCO, Conference of European Statisticians. Third Joint meeting on Cultural Statistics, 17-20 Marzo 1986. CES/AC/44/11-13 Febrero 1986. 
naturales $\mathrm{u}$ obras artísticas reconocidas de forma universal por ser representativos de una nación o época. La formulación de una metodología operativa que permita ser aplicada a gran escala y a todos los niveles de obras que componen el Patrimonio Cultural representa una herramienta capaz de simplificar las tareas de gestión y manejo cotidianas.

\section{Estimaciones de riesgo, recursos y economía del sector cultural}

En el ámbito del análisis y generación de estimaciones de riesgo destacan las aportaciones producidas para la determinación de índices de deterioros en materiales pétreos ${ }^{54}$ cuya aplicación requiere de recursos temporales, técnicos y profesionales específicos. En los casos propuestos, las actividades de monitoreo se organizan en segmentos compuestos por anamnesis, diagnóstico y fase terapéutica en dónde el diagnóstico es llevado a cabo a través de etapas a desarrollarse in situ, en laboratorio y en simulaciones experimentales ${ }^{55}$. Estas valiosas contribuciones representan una herramienta de análisis y estudio de las problemáticas presentes en los materiales cuyo nivel de profundidad es directamente proporcional a la inversión de los recursos profesionales, humanos, técnicos y económicos necesarios. Los resultados brindados ofrecen una panorámica exhaustiva del estado de los materiales, aportando conocimientos específicos de su naturaleza mineralógica, textural, y sobre el estado de los procesos de alteración y deterioro presentes, llegando a una cuantificación micrométrica de las informaciones citadas. Como resultado final se obtiene una determinación de litotipos y formas de deterioro, estableciendo clases de daño y escalas de prioridades ${ }^{56}$. Esta metodología ha sido aplicada a importantes casos de estudio entre los cuales se cita la Tumba No.770 en Petra (Jordania), el Templo de Karnak en Luxor (Egipto), la Mezquita El-Merdani en El Cairo (Egipto), la Iglesia de Sao Francisco de Asís en Ouro Preto (Brasil) y la Iglesia de San Quirín en Neuss (Alemania). Como parte de los resultados de investigación se generan unos medios visuales representativos con mapeos de las áreas afectadas por los fenómenos presentados ${ }^{57}$. Dichas investigaciones encabezan una amplia serie de estudios dirigidos a presentar y estructurar los índices de riesgo ofreciéndolos de forma puntual, analítica y científica para cada obra.

\footnotetext{
${ }^{54}$ FITZNER, B. \& HEINRICHS, K. (2002). "Damage diagnosis on stone monuments - weathering forms, damage categories and damage indices" en Natural stones and weathering, Geological Institute. Aachen: University of Technology. <http://citeseerx.ist.psu.edu/viewdoc/download?doi=10.1.1.610.6890\&rep=rep1\&type=pdf > [Consulta: 13 de mayo de 2019].

${ }^{55}$ Ibídem.

${ }^{56} \mathrm{lbli}$ dem.

${ }^{57}$ Iblidem.
} 
Los aspectos económicos relacionados con el sector cultural, en concreto con el área encargada de la conservación y restauración del patrimonio, representan un sector cuyo nivel de gestión y análisis resulta complicado, debido a la dificultad en la aplicación de indicadores específicos capaces de brindar un medio de comparación entre realidades locales e internacionales. La gestión de fondos dedicados a la cultura, representa una parte importante en la economía y desarrollo de los países, por su estrecha relación con la sociedad y por las dinámicas que se generan entre ella y la inversión de recursos derivados de los ciudadanos que con ella establecen relaciones e intercambios a varios niveles. Según el análisis estadístico de los indicadores culturales de la UNESCO-FCS de 2009, ${ }^{58}$ las fuentes de financiación cultural se clasifican en públicas y privadas $^{59}$. Las primeras son de origen gubernamental o institucional y pueden ser aplicadas de formas directas por medio de subvenciones o indirectas bajo forma de exenciones fiscales. A estas se suman las iniciativas privadas, derivadas del mercado, y las generadas por organizaciones sin ánimo de lucro y donaciones ${ }^{60}$. La realidad presenta muchas zonas de sombra en dónde los esfuerzos comunes por parte de las instituciones y de la sociedad comprometidas con la conservación del patrimonio cultural no logran implementar políticas efectivas debido a que las acciones de tutela se ven influenciadas por criterios dictados por retorno de imagen e inversión. Este fenómeno establece escalas de prioridades basadas en el valor monetario del patrimonio cultural, dejando excluidos testigos considerados secundarios a favor de otros.

\section{Metodologías de medición: matrices de registro de datos}

En el marco del análisis estadístico estudiado en el campo de la ecología, se puede escoger entre diferentes métodos de medición, según las exigencias del caso. Las

\footnotetext{
${ }^{58}$ UNESCO (2009). Framework For Cultural Statistics, op. cit.

59 Entre los esfuerzos dirigidos a la conservación del legado cultural de la República Mexicana, destacan las iniciativas propiciadas por los Patronatos, asociaciones civiles sin ánimos de lucro, cuya finalidad es la de recaudar fondos a través de campañas y donaciones. EN 2019, el Instituto Nacional de Antropología e Historia anunció la creación de su proprio patronato: INAH A.C.. Éste, tiene el objetivo de establecer una conexión entre sociedad civil y patrimonio cultural, impulsando la protección y conservación del patrimonio cultural de México. Para la ciudad de San Luis Potosí, el Consejo del Centro Histórico ha constituido, con las mismas finalidades de protección del legado histórico artístico de la ciudad, el Patronato de Restauración y Conservación del Patrimonio Artístico del Centro Histórico, integrado por empresarios, especialistas en conservación y representantes de la sociedad civil. INAH-GOBIERNO DE MÉXICO. "Surge el Patronato del INAH A.C., puente entre la sociedad civil y el cuidado del patrimonio cultural de México" en Boletín de Noticias, 25 de octubre 2019. <https://www.inah.gob.mx/boletines/8613-surge-el-patronato-del-inah-a-cpuente-entre-la-sociedad-civil-y-el-cuidado-del-patrimonio-cultural-de-mexico> [Consulta: 10 de diciembre de 2020]; "Patronato de Restauración y Conservación del Patrimonio Artístico del Centro Histórico". <https://centrohistoricoslp.com/patronato-restauracion-conservacion/> [Consulta: 10 de diciembre de 2020].

${ }^{60}$ UNESCO (2009). Framework For Cultural Statistics, op. cit.
} 
ventajas ofrecidas por el sistema basado en la medición por número de especies ${ }^{61}$ es de los más empleados, debido a que ofrece informaciones representativas de la diversidad de especies ${ }^{62}$ presente, brindando datos cuantitativos y cualitativos altamente entendibles (tabla 3 y 4). La detección y registro de las informaciones es sencilla porque se estructura según la cumplimentación de unas fichas de registro, definidas como matrices de datos, que tras su análisis permiten cuantificar y elaborar las informaciones a través de procesos matemáticos ${ }^{63}$. Encontrando un paralelismo con las posibilidades derivadas de los sistemas de análisis de la biodiversidad, de donde procede parte de la inspiración para este proyecto, se puede considerar complementar dichas técnicas con las necesidades del conservador, llegando a introducir una herramienta de monitoreo y estudio complementaria a las existentes.

Tabla 3 - Ejemplo de matriz de presencia-ausencia (1/0) de especies aplicada a la ecología.

\begin{tabular}{|c|c|c|c|c|}
\hline Tipo & Área 1 & Área 2 & Área 3 & Total \\
\hline Especie 1 & 1 & 0 & 1 & 2 \\
\hline Especie 2 & 1 & 0 & 1 & 2 \\
\hline Especie 3 & 0 & 0 & 1 & 1 \\
\hline Especie 4 & 0 & 0 & 1 & 1 \\
\hline Total & 2 & 0 & 4 & 6 \\
\hline
\end{tabular}

Tabla 4 - Ejemplo matriz de abundancia de especies aplicada a la ecología.

\begin{tabular}{|c|c|c|c|c|}
\hline Tipo & Área 1 & Área 2 & Área 3 & Total \\
\hline Especie 1 & 5 & 0 & 2 & 7 \\
\hline Especie 2 & 1 & 0 & 9 & 10 \\
\hline Especie 3 & 0 & 0 & 0 & 0 \\
\hline Especie 4 & 0 & 0 & 7 & 7 \\
\hline Total & 6 & 0 & 18 & 24 \\
\hline
\end{tabular}

${ }^{61}$ La medición por número de especies se estructura alrededor del registro de todas las especies presentes en un área determinada. Para la conservación del patrimonio esto se traduce en el registro de la cantidad de especies-deterioro observadas en la obra de arte.

62 La diversidad de especies representa la riqueza o variedad de especies diferentes presentes en un determinado ecosistema. Este concepto, trasladado a las necesidades de conservación del patrimonio corresponde a la variedad de especies-deterioro diferentes que están afectando a la obra en estudio.

63 CLAUDIA E. MORENO, (2001). Métodos para medir la biodiversidad. M\&T-Manuales y Tesis SEA, vol. 1. Zaragoza: CYTED, ORCYT/UNESCO \& SEA. 
Un ejemplo de aplicación de dichos modelos de fichas al estudio y comprensión del patrimonio cultural se encuentra en las llamadas tablas de frecuencia de contingencia. Éstas se componen por una matriz estructurada alrededor de dos ejes, correspondientes a filas y columnas, en donde se estructuran las frecuencias o abundancia de determinadas características. Éstas permiten la comparación entre diferentes variables, de tipo cualitativo, para encontrar relaciones significativas por medio de las cuales poder extraer hipótesis y/o conclusiones. Pueden ser de tipo dicotómico, es decir que solo pueden adoptar un estado u otro ${ }^{64}$. Ejemplo de ello (tabla 5) son las matrices de presencia/ausencia (1/0) de un determinado rasgo (en el ámbito arqueológico) o de una determinada especie (ecología). $O$, en alternativa, pueden ser de abundancia, en donde se expresa la cantidad de cada característica reportada en la tabla (tabla 6).

Tabla 5 - Ejemplo de tabla de contingencia de tipo dicotómico (presencia-ausencia 1/0) aplicada al estudio arqueológico de restos óseos.

\begin{tabular}{|l|c|c|c|c|}
\hline \multicolumn{1}{|l}{ Tipo } & \multicolumn{1}{c}{ Área 1 } & \multicolumn{2}{c|}{ Área 2 } & Total \\
\hline Varón & 1 & 0 & 0 & 1 \\
\hline Mujer & 1 & 0 & 0 & 1 \\
\hline Infantil & 0 & 1 & 0 & 1 \\
\hline Indeterminado & 0 & 0 & 1 & 1 \\
\hline Total & 2 & 1 & 1 & 4 \\
\hline
\end{tabular}

Tabla 6 - Ejemplo de tabla de contingencia con matriz de abundancia aplicada al estudio arqueológico de restos óseos.

\begin{tabular}{|l|c|c|c|c|}
\hline \multicolumn{1}{|l}{ Tipo } & \multicolumn{1}{c}{ Área 1 } & Área 2 & Área 3 & Total \\
\hline Varón & 5 & 0 & 0 & 5 \\
\hline Mujer & 1 & 0 & 0 & 1 \\
\hline Infantil & 0 & 4 & 0 & 4 \\
\hline Indeterminado & 0 & 0 & 7 & 7 \\
\hline Total & 6 & 4 & 7 & 17 \\
\hline
\end{tabular}

Gracias a las vertientes de investigación, definición e identificación de las fenomenologías de alteración y deterioro del patrimonio cultural emprendidas por los centros de investigación y organismos internacionales (ICOMOS, UNESCO,

\footnotetext{
${ }^{64}$ FERNÁNDEZ MARTíNEZ, V.M. (2015). op. cit., p. 32.
} 
universidades, grupos de trabajo) se dispone de todo lo necesario para una correcta implementación de estas técnicas al análisis y gestión del patrimonio. Fundamentando el método de medición en el número de especies presentes en un determinado conjunto se logrará determinar su diversidad, ofreciendo informaciones claras derivadas de estimaciones numéricas basadas en datos visuales y cualitativos. La detección de las tipologías de alteración y deterioro existentes será facilitada por el apoyo derivado de los glosarios ilustrados y definiciones normalizadas que ofrecen un recurso muy amplio en cuanto a terminología y dinámicas de causas, efectos, mecanismos de cada uno de los fenómenos.

\section{Antecedentes metodológicos en observación y diagnóstico organizados}

En la experiencia madurada gracias a la formación LATAM-ICCROM en 2016, en el área arqueológica de Chicanná (Campeche, México) ${ }^{65}$ ha sido posible conocer y aplicar de forma práctica el método de Observación Visual Organizada OVO ideado por el restaurador Corrado Pedelí. El propósito de su implementación residió en la creación de una táctica de acercamiento a las problemáticas conservativas fundamentada en la lógica de la percepción y de la psicología cognitiva con la finalidad de establecer un acercamiento objetivo ${ }^{66}$ al examen visual. El método explora una nueva perspectiva para enfrentar las fases preliminares de estudio.

El procedimiento ofrecido por OVO se basa en una reorganización de las dinámicas de observación y análisis de las obras de arte estructurándose como un medio de análisis organizado, constituido por diferentes fases:

- abstracción del sistema;

- descomposición lógica;

- determinación de conexiones;

- descripción de atributos;

- identificación de las formas de deterioro;

- establecimiento de relaciones entre elementos y deterioros;

\footnotetext{
${ }^{65}$ En el marco del programa de conservación de los materiales pétreos de la región de Latinoamérica y Caribe donde varios profesionales del sector, procedentes de diferentes países del área latina y de Europa, llevaron a cabo el proceso de observación, estudio y diagnóstico de los monumentos presentes en el sitio arqueológico maya.

${ }^{66}$ Cabe destacar que, por la presencia de la actividad de interpretación que el conservador ejerce en la fase de observación, puede presentarse un margen de error asumible relacionado con el entendimiento, interpretación y conocimiento de las dinámicas que se están observando. Esto ha proporcionado la oportunidad de buscar métodos nuevos capaces de facilitar la interacción objetiva del operador con el entorno.
} 
- construcción de las secuencias cronológicas del desarrollo de las alteraciones;

- búsqueda de las causas por medio del diagrama causa-efecto ${ }^{67}$.

La Observación Visual Organizada nace de la combinación de varias metodologías derivadas de las ciencias $\operatorname{cognitivas}^{68}$ y la Tecnología de la Información (TI) ${ }^{69}$. El enfoque OVO ha sido desarrollado con el objetivo de brindar una capacitación práctica capaz de proporcionar un enfoque del sistema (sitio en examen) para la evaluación de su condición conservativa. Parte de las inquietudes que se originaron de este método surgieron de la necesidad de trabajar en equipos interdisciplinarios, donde diferentes orientaciones o niveles de conocimiento podrían complicar el análisis del $\mathbf{s i t i o}^{70}$. Un ejemplo de la dinámica citada está constituido por los diferentes enfoques de observación derivados de la formación o bagaje cultural específicos de cada persona. Un conservador podría dirigir su análisis visual hacia el registro de los efectos de alteración en los materiales, incluyendo interpretaciones de los fenómenos en acto; un arquitecto podría analizar el sistema en términos preferentemente estructurales, mientras un geólogo podría centrarse en los detalles de tipo químico y estructural del material pétreo. Todos los acercamientos al problema son válidos, sin embargo responden a dinámicas de visualización diferentes. Para suplir a esta posible limitación, OVO propone estructurar lógicamente el conjunto, concibiendo un contexto arqueológico, un monumento o un objeto como un sistema dinámico que puede ser descompuesto en subsistemas y entidades más simples. Cada unidad puede a su vez aislarse y

${ }^{67}$ RIVERA PÉREZ, M.E. (2015). “OVO un mortero fluido" en Conservación y Restauración, Boletín de la CNCPC, № 7, diciembre, pp. 84-89.

68 "Actualmente la ciencia cognitiva se define como el estudio interdisciplinar de la mente, en la que participan las siguientes disciplinas: Ciencia de la computación e Inteligencia artificial, Linguïstica, Neurociencia, Filosofía y Psicología, entre otras". NICOLAS MEDINA, C. (2008). "La ciencia cognitiva y el estudio de la mente" en Revista IIPSI, Facultad de Psicología, UNMSM, Vol. 11, núm. 1, pp. 183 - 198.

${ }^{69}$ La Tecnología de la Información (TI) se constituye por el uso de ordenadores y equipos de telecomunicación para la manipulación, gestión y trasmisión de datos.

${ }^{70}$ La metodología OVO desde su creación en 2005 ha sido objeto de experimentación y actualización continua en los cursos ICCROM y en países de Asia, Europa y Oriente-Medio. MAGAR, V. y PEDELl, C. (2008). "Training on Archaeological Conservation in Southeast Europe: an Approach to the Preliminary Condition Assessment" en ICCROM Newsletter Diciembre 2008, n³4, pp. 10-11. <https://www.iccrom.org/sites/default/files/2018-02/iccrom_newsl34-2008_en.pdf> [Consulta: 11 de mayo de 2020]. Cabe resaltar que la metodología OVO se propone como una herramienta en constante evolución, constituyéndose como un proceso activo más que como un punto de llegada, gracias a la constante aplicación e intercambio de experiencias con los profesionales del sector y de acuerdo a las inquietudes generadas en el afán de refinar las posibilidades operativas de las delicadas fases de recolección de informaciones conservativas. 
caracterizarse con atributos y comportamientos, dibujarse y finalmente vincularse con las demás para formar un nuevo modelo conceptual ${ }^{71}$.

En línea general, el examen visual suele ser fruto de una combinación de lógica y acciones técnicas compuestas por observación a simple vista, registro de las informaciones, elaboración mental de los datos observados, registro gráfico y fotográfico, deducción de las dinámicas en acto y creación de un diagnóstico. El método OVO propone estructurar el proceso operativo en tres fases principales: observación y descripción de la información visible y objetiva, elaboración de datos, investigación de causas. Cada fase se divide en pasos específicos, que involucran la implementación y desarrollo de un sistema de diagramas ${ }^{72}$ dirigidos a la representación objetiva de los fenómenos registrados, seguida por el proceso deductivo con el cual se logra formular hipótesis sobre las alteraciones vigentes. El proceso se lleva a cabo por medio de una secuencia preordenada ${ }^{73}$ (diagrama 4).

${ }^{71}$ PEDELÍ, C. (2013). "An interdisciplinary conservation module for condition survey on cultural heritages with a $3 \mathrm{~d}$ information system" en International Archives of the Photogrammetry, Remote Sensing and Spatial Information Sciences, Volume XL-5/W2, XXIV International CIPA Symposium. Strasbourg: P. Grussenmeyer, p. 483-487. <https://doi.org/10.5194/isprsarchives-XL-5-W2-483-2013> [Consulta: 11 de mayo 2020].

${ }^{72}$ En la metodología OVO los diagramas constituyen el eje metodológico para lograr la descomposición lógica y objetiva de las informaciones. Para su análisis y estructuración se emplean diagramas sinópticos, asociativos y de Ishikawa. Esto permite llevar a cabo una jerarquización de los datos, la asociación entre factores $y$ finalmente permite el paso de la fase objetiva a la fase deductiva.

73 PEDELI, C. (2014). "A methodology for an organised visual examination on condition assessment of cultural heritage" en e-dialogos, Annual digital journal on research in Conservation and Cultural Heritage, no 4, december, pp. 22-29<http://www.diadrasis.org/public/files/edialogos_004-PEDELI.pdf> [Consulta: 11 de mayo de 2020]. 


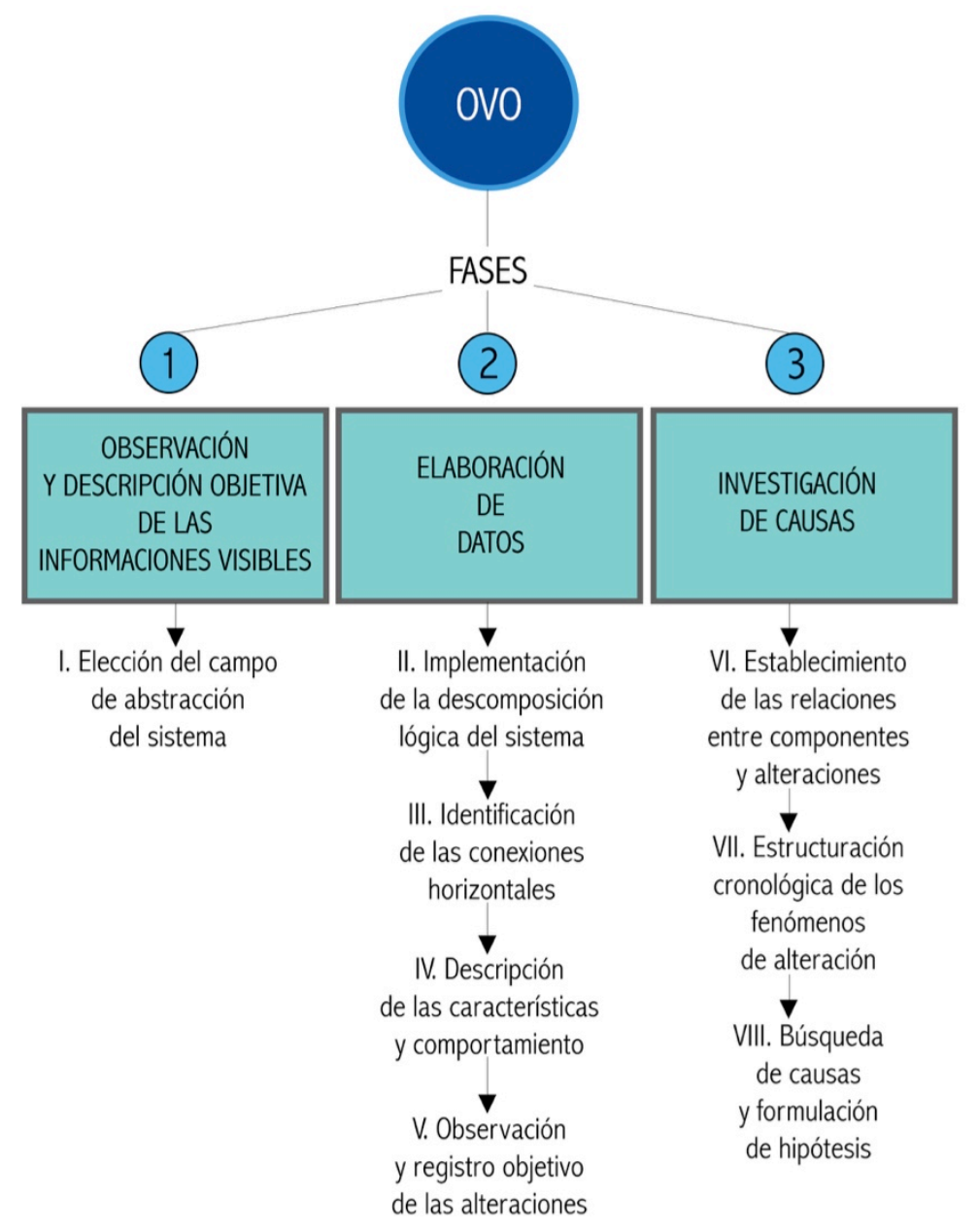

Diagrama 4 - Fases principales y secuencias de la metodología OVO ${ }^{74}$.

La primera fase contempla la observación y descripción objetiva de las informaciones visibles. En este momento se decide el sistema de abstracción que se utilizará para estructurar el sistema (paso I). La fase dos está dedicada a la elaboración de los datos. En ella se implementa la descomposición lógica del sistema (paso II) dirigida a propiciar un acercamiento neutral al conjunto. Esto se logra descomponiéndolo en grupos, como por ejemplo los materiales constitutivos

\footnotetext{
${ }^{74}$ Elaborado a partir de las informaciones en RIVERA PÉREZ, M.E. (2015). op. cit., pp. 84-89.
} 
o los elementos funcionales. Dicha información se tendrá que estructurar de forma jerárquica ${ }^{75}$ por medio de una representación sinóptica ${ }^{76}$ (diagrama 5).

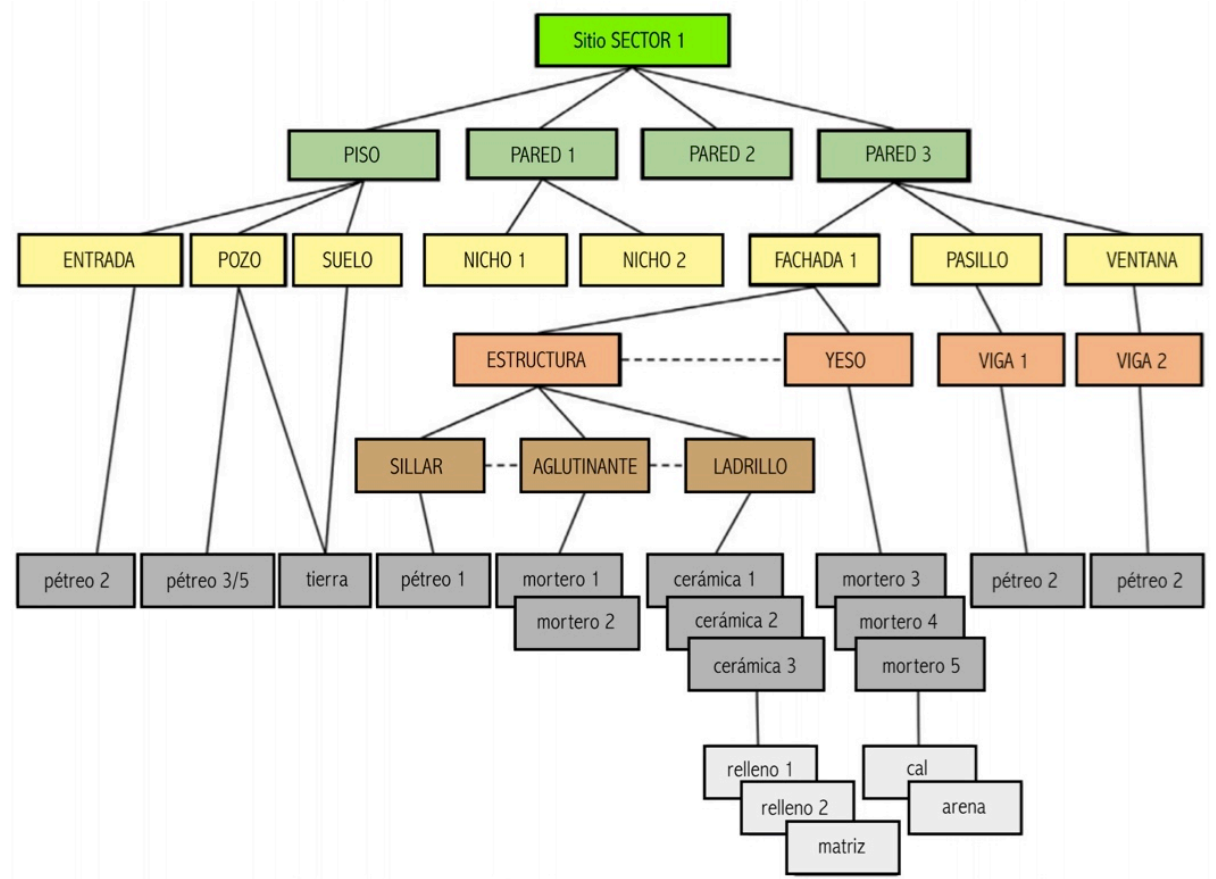

Diagrama 5 - Metodología OVO: ejemplo de modelo de representación sinóptica (diagrama jerárquico). Traducido de: Pedelí, C. 2014.

Acto seguido se establecen las relaciones horizontales por medio de conexiones (paso III) y se describen atributos ("qué es") y comportamientos ("qué hace") de cada elemento (paso IV) ${ }^{77}$. Esta fase se concluye con el registro de las fenomenologías de alteración y deterioro (paso V). En este momento se emplean

75 Cabe destacar que en las directrices del método un enfoque no excluye otro; las relaciones se pueden expresar de otra manera siempre y cuando se respete el mismo orden en todo el proceso. Pedelí, C. (2014), op. cit., pp. 22-29.

${ }^{76}$ Representación que logra presentar a primera vista las informaciones principales con claridad.

77 Para lograr identificar las características necesarias (fase 2, paso IV) de manera sencilla y objetiva el autor recurrió a la metodología del Análisis Orientado a Objetos (Oriented Object Analysis OOA) y al Lenguaje de Modelo Unificado (Unifi and Modeling Language UML). Éstos conciben estructurar los sistemas en fracciones más pequeñas que a su vez se clasifican según características lógicas logrando simplificar su gestión y análisis. PEDELİ, C. (2014), op. cit., pp. 22-29. 
unas herramientas de soporte. Gracias al apoyo de los glosarios estandarizados ${ }^{78}$ y sus imágenes consiguiendo una visualización comparada de los efectos de las dinámicas presentes. Éstos se observan y registran de acuerdo al mismo método de abstracción lógica seguido para el análisis inicial del sistema ${ }^{79}$.

La tercera fase contempla el establecimiento de relaciones (paso VI) entre componentes originales y formas de alteración, por medio de un diagrama asociativo (diagrama 6).
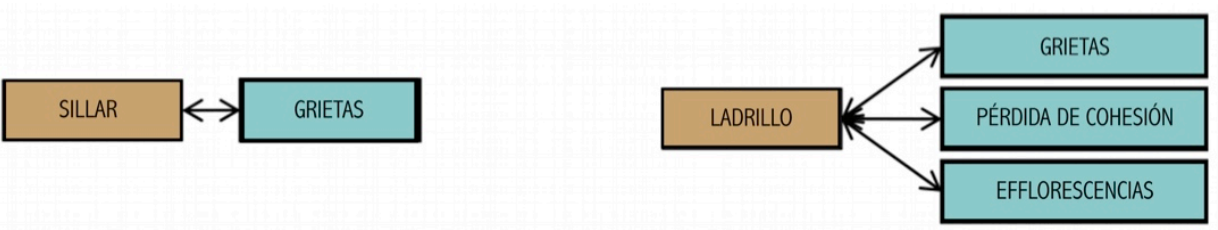

Diagrama 6 - Metodología OVO: asociación entre componentes funcionales (izq.) y materiales (der.) y formas de alteración. Traducido de Pedeli, C. 2014.

Sucesivamente se pasa de la fase objetiva a la fase deductiva (paso VII), con el objetivo de reconstruir la cronología de las formas de alteración ${ }^{80}$ (diagrama 7), hasta llegar a la búsqueda de las causas (fase VIII) por medio de la formulación de hipótesis. Para lograr esto se propone el uso del diagrama de resolución de problemas ${ }^{81}$, también conocido como de "causa-efecto". El problema es constituido por el efecto de alteración y deterioro visible en el sistema (diagrama 8).

\footnotetext{
${ }^{78}$ Se puede elegir el glosario más idóneo según el caso.

${ }^{79}$ Las alteraciones aun siendo fruto de las modificaciones de los materiales constitutivos del sistema, siguen siendo parte del mismo. Por ello, son tratadas como parte de la estructura y analizadas de la misma forma lógica, respetando el orden jerárquico y de abstracción.

${ }^{80}$ El proceso deductivo de esta fase contempla un backtracking mental, PEDELl, C. (2014) dirigido a componer las fases cronológicas de manifestación de las alteraciones. Esto no incluye la interpretación del proceso de deterioro.

${ }^{81}$ También conocido como Diagrama Espina de Pescado o Diagrama Ishikawa "es un método de estructuración de las informaciones que contempla la representación de varios elementos (causas) de un sistema que pueden contribuir a un problema (efecto). Es una herramienta efectiva para estudiar procesos y situaciones, y para desarrollar un plan de recolección de datos". CIENCIA Y TÉCNICA ADMINISTRATIVA CYTA. Herramientas para el Análisis, Cuantitativo y Cualitativo, Aplicables a sistemas de gestión de la calidad $<$ http://www.cyta.com.ar/biblioteca/bddoc/bdlibros/herramientas_calidad/causaefecto.htm> [Consulta: 20 de abril de 2020].
} 


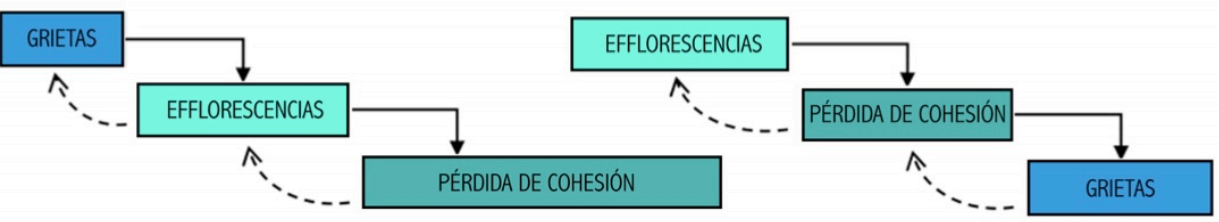

Diagrama 7 - Metodología OVO: ejemplo de reconstrucción cronológica de las fenomenologías de alteración. Traducido de Pedeli, C. 2014.

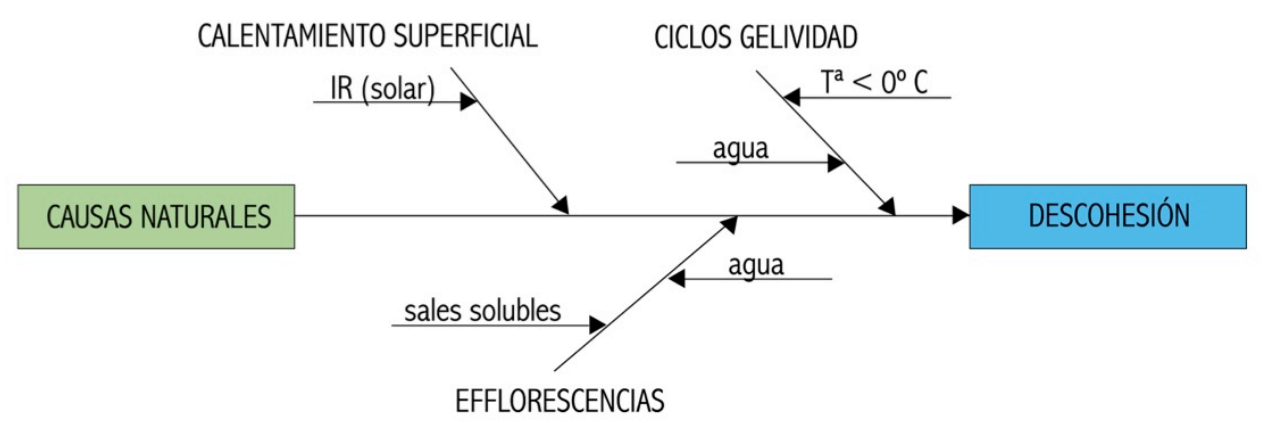

Diagrama 8 - Metodología OVO: ejemplo de Diagrama de Causa-Efecto aplicado a la formulación de hipótesis para identificar las posibles causas y dinámicas a raíz del deterioro del sistema. Traducido de Pedelì, C. 2014.

Para la aplicación de esta metodología al estudio del patrimonio es contemplado el uso de los glosarios sobre alteraciones y deterioros, concebidos como soporte visual para la fase de identificación por medio de comparación de las imágenes y conceptos ejemplificados ${ }^{82}$. Lo anterior constituye tan solo una de las vertientes de utilidad de estos documentos.

La metodología OVO abre el camino al desarrollo de una nueva perspectiva en las fases de inspección preliminar ${ }^{83}$ derivada de una puesta en discusión de los procesos generalizados en las rutinas de los operadores del sector. Estos puntos ponen de manifiesto las posibles fortalezas derivadas del complementar terminologías e imágenes estandarizadas con la implementación de rutas de observación sustentadas en la lógica cognitiva.

\footnotetext{
${ }^{82}$ En el proceso de observación OVO el apoyo metodológico de los glosarios ilustrados es contemplado para la fase 2, paso 5 de la metodología OVO. Véase diagrama 3 de este capítulo.

${ }^{83}$ Cabe destacar que esta herramienta no se propone como medio de mapeo o documentación, más bien ofrece un camino complementario a dichas tareas.
} 
Para los fines de esta investigación, el conocimiento de la metodología OVO ha puesto el foco de atención sobre el valor de las fases de observación del bien cultural, destacando el potencial de profundización y comprensión del contexto conservativo a partir de la observación y registro de las fenomenologías de alteración y deterioro. Paralelamente, al abrir una ruta de reflexión crítica hacia las metodologías de interpretación in situ de los fenómenos de alteración y deterioro presentes en los materiales comúnmente adoptadas en las rutinas de aproximación al bien cultural, ha favorecido la meditación entorno a la posibilidad de crear un nuevo método de registro y análisis de los deterioros.

\section{Limitaciones operativas en la comprensión del contexto y de la terminología técnica}

La experiencia con las actividades de registro de las condiciones conservativas de la estructura $\|{ }^{84}$ del sitio arqueológico de Chicanná (Campeche) en el curso LATAM Observación, análisis y diagnóstico ha sido útil para tomar consciencia de las posibles limitaciones que aun coexisten en el momento de enfrentarse a trabajos interdisciplinarios. Figuras cuales conservadores, restauradores, investigadores, geólogos, arqueólogos, arquitectos e historiadores presentes en el curso han sido partícipes de una revisión crítica sobre la importancia del uso, manejo y conocimiento de la terminología oficial, llevando a cabo un acercamiento a las problemáticas existentes en la realidad.

Gracias a la interdisciplinaridad presente entre el grupo de integrantes del curso, ha sido posible generar unas observaciones críticas sobre la terminología oficial y posturas propia de las diferentes figuras profesionales. El uso del glosario de ICOMOS-ISCS "Illustrated glossary on Stone deterioration patterns" (2008) durante las sesiones de observación y análisis visual de los fenómenos de alteración y deterioro fomentó el intercambio de reflexiones sobre el valor semántico de las definiciones, poniendo de manifiesto cómo la disciplina de pertenencia de los participantes puede llegar a influir en el foco de atención y proceso de su examen visual.

La diferente interpretación y postura por parte de los componentes del grupo se veía influenciada por su formación y por el nivel de conocimiento del material pétreo, ocasionando confusión por parte de los diferentes observadores en relación a la terminología más adecuada a emplearse, según fuese la interpretación

84 La estructura II del sitio arqueológico de Chicanná (Campeche, México) es uno de los edificios más representativos del área debido a la presencia de la representación del Monstruo de la Tierra en su lado oeste. "Chicanná significa en maya yucateco "en la casa de la boca de la serpiente" (Chi: boca, Can: serpiente, Ná: casa), nombrado así por su descubridor, el ingeniero Jack Eaton". INAH, GOBIERNO DE MÉXICO. Zona Arqueológica Chicanná. <https://www.inah.gob.mx/zonas/63-zona-arqueologica-chicanna> [Consulta: 22 de abril de 2020]. 
semántica de los detalles proporcionados en el glosario en examen. Otro aspecto controvertido derivado de esta experiencia práctica se refiere a la identificación de fenómenos muy específicos, cuya clasificación requeriría de análisis de tipo físicoquímico que no siempre están al alcance del observador en el momento de dictaminar el diagnóstico in situ. El uso de esta terminología podría determinar una interpretación de los fenómenos observados basada en la experiencia, sin sustento objetivo ${ }^{85}$. Se citan a ejemplo de esto palabras cuales pátina, pátina de oxalato, pátina ferruginosa, enmugrecimiento, mancha de humedad, tinción, algas, hongos. Todos los términos indicados corresponden a alteraciones del aspecto visual en términos de color y brillo, cuya percepción podría llegar a ser subjetiva, derivándose de la experiencia del profesional, de su acervo de informaciones relacionadas con los fenómenos, y del nivel de conocimiento adquirido en el tiempo.

\section{Antecedentes en terminología normalizada}

En función del diseño de una matriz de datos funcional y objetiva, se vuelve necesaria la implementación de un método de selección y estructuración de la terminología oficial basada en las limitaciones observadas durante el trabajo in situ con la participación de profesionales de diferentes sectores y nacionalidades que pueda suplir a las posibles carencias generadas por diferencias en la formación y experiencias, favoreciendo la observación y registro neutral, ajeno a posibles interpretaciones subjetivas.

Desde principios del siglo XXI ha ido incrementando el interés hacia una formalización de las palabras empleadas en las sesiones técnicas específicas de la investigación y estudio de los materiales. Esto ha canalizado diferentes esfuerzos por parte de los profesionales del sector, reunidos en grupos de trabajo interdisciplinario, hacia la generación de palabras cuyo entendimiento y valor semántico fuera "normalizado", es decir sujeto a normas reconocidas y empleadas de forma universal. Esta inquietud ha fomentado diferentes iniciativas, dentro de las cuales se citan las de ICOMOS e ISCS ${ }^{86}$, para los materiales pétreos, y el grupo de

${ }^{85}$ El sustento objetivo se refiere a los resultados cualitativos o cuantitativos arrojados por la realización de análisis diagnósticos de tipo instrumental.

${ }^{86}$ El Comité Científico Internacional para el estudio de los materiales pétreos (International Scientific Committee for Stone ISCS) de ICOMOS ha proporcionando un foro internacional para el intercambio de experiencias, ideas y conocimientos en el campo de este material. Entre sus objetivos destacan la simplificación y la desmitificación de la información científica necesaria a los profesionales del sector para la comprensión de los fenómenos de alteración y deterioro. Este esfuerzo quiere fomentar una mejor comunicación entre las figuras encargadas de la conservación de esta clase de patrimonio, supliendo a las problemáticas derivadas de una falta de lenguaje común. Bajo estas inquietudes ICOMOS e ISCS han desarrollado el glosario ilustrado de los patrones de deterioro de materiales pétreos, en donde exponen las dinámicas y efectos de los fenómenos de alteración en estos sustratos. En este trabajo se pueden consultar definiciones e imágenes de los procesos recolectados tras una minuciosa investigación y examen de los glosarios preexistentes. Entre las finalidades del proyecto destacan la de complementar las aportaciones 
trabajo europeo que ha producido el Glosario $\mathrm{EwaGlos}^{87}$, para las pinturas murales y superficies arquitectónicas. Gracias a estos proyectos se han generado documentos con definiciones traducidas a los idiomas en uso en las realidades de pertenencia ${ }^{88}$, acompañadas por representaciones enfocadas a esclarecer el valor semántico del sujeto, poniendo el foco de atención en una unidad en el uso y manejo de la terminología técnica. Para las obras muebles, cuales esculturas policromadas y pinturas sobre lienzo o tabla, las publicaciones y proyectos llevados a cabo por los investigadores de la Universitat Politècnica de València y de la Universidad Complutense de Madrid han representado un recurso efectivo para reunir terminología y conceptos a insertar en la matriz de datos ${ }^{89}$.

previas brindando traducciones y definiciones unificadas en diferentes idiomas (inglés y francés), favorecer la comprensión de los fenómenos (imágenes fotográficas), apoyar la difusión de un lenguaje unificado a través de la definición de los conceptos. ICOMOS-ISCS (2008). Illustrated Glossary on Stone Deterioration Patterns.

<https://www.icomos.org/publications/monuments_and_sites/15/pdf/Monuments_and_Sites_15_ISCS_GI ossary_Stone.pdf> [Consulta: 3 de marzo de 2016].

87 El "Glosario europeo ilustrado para la terminología de conservación de las pinturas murales y de las superficies arquitectónicas" ha sido desarrollado gracias al esfuerzo conjunto de diferentes instituciones europeas dedicadas a la conservación del patrimonio y en parte financiado por el programa de Cultura (2007-2013) de la UE. Bajo la coordinación del Instituto Hornemann de la Universidad de Ciencias Aplicadas y Artes HaWK Hildesheim-Holzminden-Göttingen, y coorganizado por Universitat Politècnica de València (España), la Universidad de Arte y Diseño, Cluj-napoca (Rumania), la Universidad de Malta, Karabük Üniversitesi (Turquía), el Centro Interdisciplinar de Conservation et Restauration du Patrimoine (Francia) y el Instituto de Conservación de Croacia. Estos profesionales se han acompañado por los participantes de diferentes países europeos generando un proyecto enfocado a la comunicación y dirigido a diferentes figuras: conservadores, investigadores, gestores culturales, estudiantes, trabajadores y público en general. Uno de los objetivos ha sido el de fomentar el intercambio interdisciplinar entre las personas relacionadas con esta clase de patrimonio, brindando una herramienta con definiciones, conceptos, traducciones e imágenes, capaces de mejorar la comunicación, la comprensión y la cooperación a nivel internacional entre los encargados de la preservación del patrimonio. Las informaciones están traducidas en los idiomas principales de la UE (inglés, francés, alemán) y otros (búlgaro, croata, español, húngaro, italiano, polaco, rumano, y turco). HORNEMANN INSTITUT (2015). European Illustrated Glossary for Conservation Terms of Wall Painting and Architectonic Surfaces. <https://www.hornemann-institut.de/doi/2016ewa2.pdf> [Consulta: 19 de mayo 2017].

88 La necesidad de proporcionar un sistema de comunicación interdisciplinaria e internacional entre los diferentes profesionales de sectores afines y específicos a la conservación del patrimonio cultural ha generado varias publicaciones entre las cuales destacan: MARTíNEZ CABETAS, C. y RICO MARTíNEZ, L. et al. (2003). Diccionario técnico Akal de conservación y restauración de bienes culturales. Español-Alemán-InglésItaliano-Francés. Madrid: Akal; XARRIÉ, M. (2007). Diccionario de conservación y restauración de obras de arte 1 (A-Z). Barcelona: Balaam.

${ }^{89}$ CALVO, A. (2002). Conservación y restauración de pintura sobre lienzo. Barcelona: El Serbal; CALVO, A., GARCÍA FERNÁNDEZ-VILLA, S., BAILÃO, A. (2018). Terminología básica de conservación y restauración del patrimonio cultural. Madrid: Universidad Complutense de Madrid.

<https://www.researchgate.net/publication/323613615_Terminologia_basica_de_conservacion_y_restaura cion_del_Patrimonio_Cultural> [Consulta: 12 marzo de 2019]; VIVANCOS RAMÓN, V. (2007). La conservación y restauración de la pintura de caballete. Pintura sobre tabla. Madrid: Tecnos; VIVANCOS RAMÓN, V. y CASTELL AGUSTÍ, M. (2010). Problemas y tratamientos del soporte de pintura de caballete. Valencia: Universidad Politécnica de Valencia. 
La terminología elegida para las matrices de datos se ha seleccionado y estructurado a partir de los glosarios generados en las últimas décadas con la finalidad de ofrecer una herramienta funcional y objetiva para la clasificación y denominación de esos fenómenos. Respondiendo a la necesidad de una comunicación intercultural y a la traducción de los conceptos, destaca el de ICOMOS-ISCS "Illustrated glossary on Stone deterioration patterns" $(2008)^{90}$. Este documento, elaborado a partir de una revisión de la terminología anglófona específica preexistente, es fruto de la labor interdisciplinaria entre profesionales de diferentes países que han compartido experiencias y conocimientos con el objetivo de generar un medio capaz de simplificar el manejo de las informaciones científicas a emplearse en las fases prácticas, estableciendo un lenguaje común en el área de la conservación de los materiales pétreos y poniendo las bases para la promoción de una cooperación internacional fundamental en este sector ${ }^{91}$, con traducción de los conceptos al inglés y francés. Con inquietudes similares se ha generado el "Diccionario Técnico de Conservación y Restauración de Bienes Culturales" (2006) ${ }^{92}$, respondiendo a la necesidad de brindar definiciones interculturales a los términos empleados en la labor de investigación y conservación del patrimonio cultural, que ofrece un valioso apoyo a la hora de compartir terminología técnica, regalando aportaciones en español, alemán, italiano, inglés y francés. En el campo de la pintura mural y de los recubrimientos arquitectónicos, destaca el "European Illustrated Glossary of Conservation Terms for Wall Paintings and Architectural Surfaces" $(2016)^{93}$, en dónde se trata un amplio abanico de términos específicos de técnicas artísticas, alteraciones y deterioros, con respectivo desglose de los mecanismos y de las posibles relaciones con los demás fenómenos citados en el documento. Este texto brinda la oportunidad a profesionales de habla, alemana, búlgara, croata, española, francesa, húngara, italiana, inglesa, polaca, rumana y turca de compartir conocimientos. Finalmente, en el campo de la conservación de la pintura de caballete y de la escultura policromada ha sido necesario recaudar terminologías referentes a los fenómenos de alteración y deterioro a través de la consulta de publicaciones del sector (Calvo, 2002; Calvo et al., 2018; Vivancos Ramón, 2007; Vivancos Ramón y Castell Agustí, 2010), generando una lista maestra

\footnotetext{
${ }^{90}$ ICOMOS-ISCS. Illustrated Glossary on Stone Deterioration Patterns.

$<$ https://www.icomos.org/publications/monuments_and_sites/15/pdf/Monuments_and_Sites_15_ISCS_Gl ossary_Stone.pdf> [Consulta: 3 de marzo de 2016].

${ }^{91}$ Ibídem.

92 MARTíNEZ CABETAS, C. y RICO MARTíNEZ, L. et al. (2003). Diccionario técnico Akal de conservación y restauración de bienes culturales. Español-Alemán-Inglés-Italiano-Francés. Madrid: Akal.

${ }^{93}$ HORNEMANN INSTITUT. European Illustrated Glossary for Conservation Terms of Wall Painting and Architectonic Surfaces. <https://www.hornemann-institut.de/doi/2016ewa2.pdf> [Consulta: 19 de mayo 2017].
} 
de palabras ${ }^{94}$. En este caso se han seleccionado fuentes pertenecientes a un entorno hispanohablante.

\section{$X$. Alfabetidad visual y teoría sistémica de la comunicación}

En la fase de registro de las informaciones inherentes el estado de conservación de una obra, los sentidos, en particular la vista, se dirigen a la observación y comprensión de los fenómenos. La calidad y el tamaño de datos elaborados y recibidos se ven influenciados por la experiencia, debido a que un mayor desarrollo de la misma ofrece una mayor amplitud de imágenes mentales y conceptos con los cuales comparar las manifestaciones en acto ${ }^{95}$.

Lo anterior destaca la importancia de poder fomentar una alfabetidad visual relacionada con las fenomenologías de deterioro a la que el profesional pueda recurrir en caso de necesidad.

Este tipo de concepto, derivado de la disciplina de la comunicación visual ayuda a describir y esclarecer el valor del aprendizaje incorporado en los procesos visuales mismos. Su valor, junto a la teoría sistémica de la comunicación, ha sido de gran inspiración para identificar los posibles elementos desvirtuantes en los métodos de acercamiento y comprensión de las fases preliminares de diagnóstico del patrimonio cultural.

Toda información de entrada y salida (input/output) del proceso visivo pasa a través de una red de interpretaciones ${ }^{96}$. A raíz de esto se puede afirmar que todo el conjunto de mensajes estructurados a través del lenguaje verbal o visual son sometidos a un filtro. Éste se constituye por un sistema de elaboración y comprensión de la información estrictamente relacionado con la experiencia práctica que, en nuestro caso, es la alcanzada en las fases de análisis e inspección visual de una obra de arte (diagrama 9). Por esto las referencias gráficas y fotográficas brindadas por los glosarios citados constituyen un medio óptimo de desarrollo de una alfabetidad visual de referencia para la identificación de los fenómenos de alteración.

\footnotetext{
${ }^{94}$ CALVO, A. (2002). Conservación y restauración de pintura sobre lienzo. Barcelona: El Serbal; CALVO, A., GARCíA FERNÁNDEZ-VILLA, S., BAILÃO, A. (2018). Terminología básica de conservación y restauración del patrimonio cultural. Madrid: Universidad Complutense de Madrid.

$<$ https://www.researchgate.net/publication/323613615_Terminologia_basica_de_conservacion_y_restaura cion_del_Patrimonio_Cultural> [Consulta: 12 marzo de 2019]; VIVANCOS RAMÓN, V. (2007). La conservación y restauración de la pintura de caballete. Pintura sobre tabla. Madrid: Tecnos; VIVANCOS RAMÓN, V. y CASTELL AGUSTÍ, M. (2010). Problemas y tratamientos del soporte de pintura de caballete. Valencia: Universidad Politécnica de Valencia.

95 Unos de los supuestos definidos en la metodología OVO fue la consideración de la experiencia como potencial elemento distorsionante en las fases de observación debido a que ésta suele basarse en el reconocimiento de aquello que se conoce, amenazando la neutralidad del examen visual (Pedelí entrevistado en RIVERA PÉREZ, 2015, op.cit.).

96 DONDIS, D.A., (2008). La sintaxis de la imagen, Introducción al alfabeto visual. Barcelona: Gustavo Gili, p.9.
} 


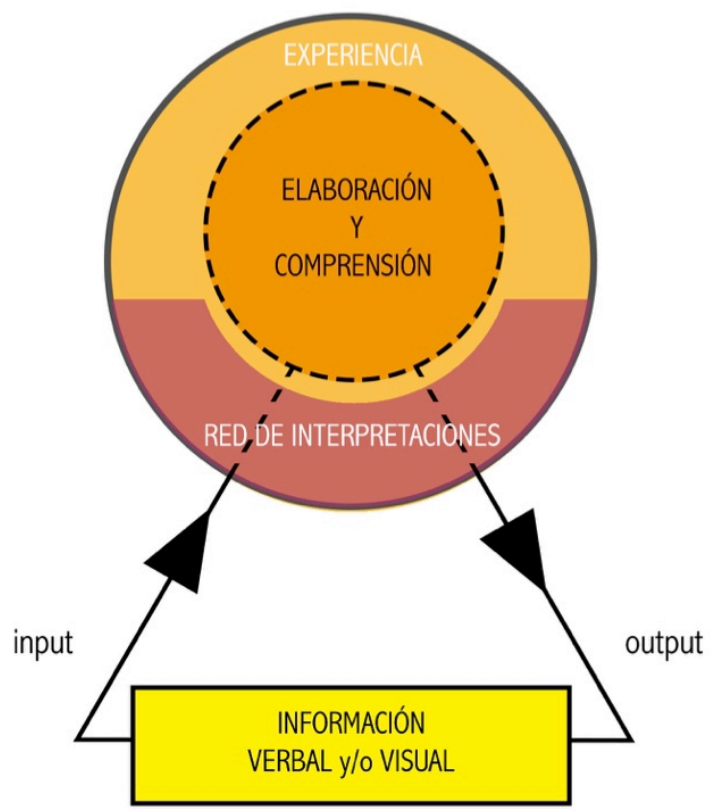

Diagrama 9 - Dinámica de elaboración de las informaciones a través del proceso visivo.

La Teoría Sistémica de la Comunicación ha logrado explicar parte de las dinámicas que acontecen en la desvirtuación de los mensajes ${ }^{97}$, introduciendo el concepto de ruido ${ }^{98}$ en los canales de transmisión. Este elemento puede compararse a la red de interpretaciones subjetivas que pueden llegar a distorsionar el contenido del mensaje, sin por ello inhibir su recepción. La comprensión y elaboración de los datos se expone a variaciones reconducibles a diferentes aspectos de la comunicación. Éstos pueden ser de tipo técnico, semántico o metodológico (diagrama 10). Aunado a esto, el resultado final del intercambio deriva de la construcción del mensaje emitido y recibido por parte de los participantes en la comunicación.

97 “Las teorías sistémicas de la comunicación se derivan de la deconstrucción de la teoría matemática de la comunicación y del modelo de transmisión de Claude Shannon y Warren Weaver. Refiriendo a la pregunta irresuelta sobre la identidad de un mensaje para distintos observadores [...] (el mensaje) debe ser construido por los participantes de la comunicación". BAECKER, D. (2017). "Teorías sistémicas de la comunicación" en REVISTA MAD, Magíster en Análisis Sistémico Aplicado a la Sociedad, №37, p. 1-20.

98 SHANNON, C. \& WEAVER, W. (1948). The Mathematical Theory of Communication. Illinois: Urbana. 


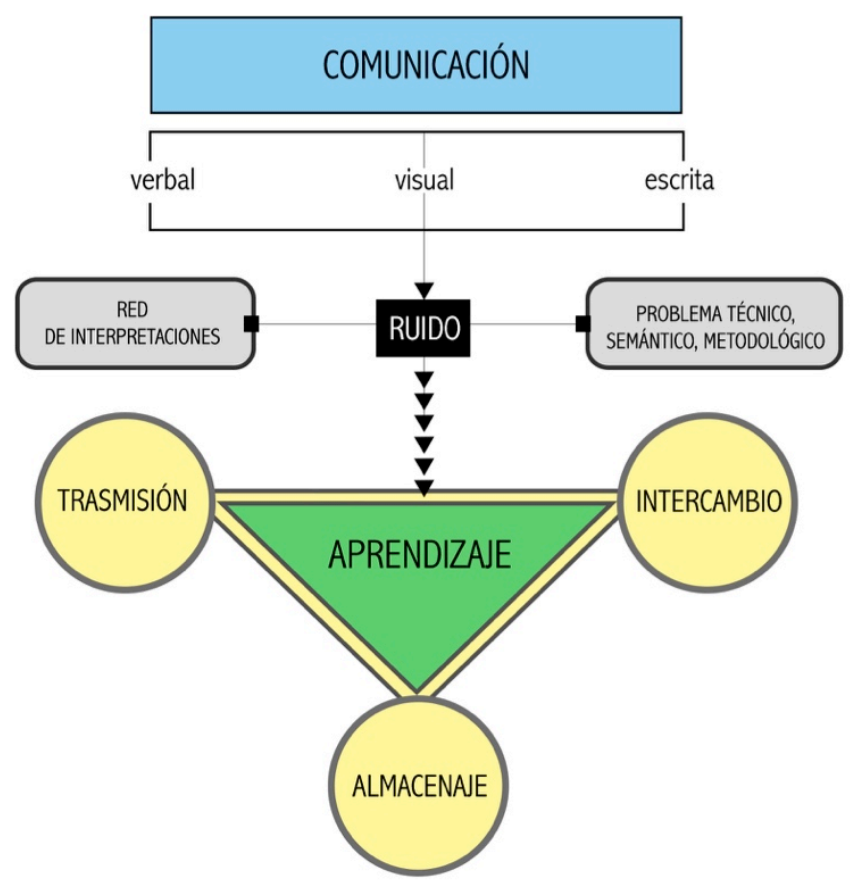

Diagrama 10 - Dinámicas de comunicación de la información y del aprendizaje.

El concepto de ruido ayuda a explicar la posibilidad de incurrir en posibles fallos a la hora de conocer y reconocer determinados fenómenos, como es el caso de los que acontecen en la evolución de un objeto en un contexto específico. Además de evidenciar los puntos que concurren a las erratas en fase de diagnóstico: una gestión poco eficaz técnicamente y con amplios márgenes de interpretaciones semánticas por parte del usuario. La existencia de un material visual de soporte en los glosarios consultados satisface una necesidad de tipo práctico, favoreciendo el proceso de identificación de determinados preceptos que pueden ser así registrados y analizados a través del método propuesto en esta investigación.

\section{Conclusiones}

Las diferentes disciplinas citadas en este apartado, representan un punto de partida para la ideación y estructuración del método, participando en definir sus alcances, metas y características. La herramienta que se pretende presentar en este estudio, es dirigida a la resolución de las fases de recolección, análisis y gestión de las informaciones derivadas del registro y observación de las fenomenologías de alteración y deterioro presentes en los materiales constitutivos del patrimonio 
cultural. Con una inversión mínima de recursos, se busca proponer una solución de tipo interdisciplinario en donde la ciencia, la crítica y la observación constructiva del estado de la cuestión - alrededor de las problemáticas encontradas al enfrentarse a un diagnóstico con escasez de medios y elevado número de elementos a examinar y la toma de consciencia de las dinámicas de observación y de la comunicación se encuentran. Lo anterior, con la finalidad de proponer un medio complementario y versátil de acercamiento a la comprensión de las exigencias del patrimonio cultural.

Un método que podrá complementar, según las exigencias del caso, las demás herramientas desarrolladas en años de investigación y estudio por parte de los profesionales de la conservación, particularmente adecuado a situaciones de escasez en términos de tiempo, personal, y medios técnicos que deja abierto el camino hacia una futura implementación de técnicas de análisis estadístico. 


\section{Referencias bibliográficas}

ARNHEIM, R. (2006). Arte y percepción visual. Madrid: Alianza Formas.

BADIA, F. (2012). “Monitoraggio e controllo della gestione dei siti UNESCO. II piano di gestione come opportunità mancata?" en Tafter Journal, Esperienze e strumenti per cultura e territorio, núm. 52.

$<$ http://www.tafterjournal.it/2012/10/01/monitoraggio-e-controllo-dellagestione-dei-siti-unesco-il-piano-di-gestione-come-opportunita-mancata/> [Consulta: 10 de junio de 2020].

BAECKER, D. (2017). "Teorías sistémicas de la comunicación" en REVISTA MAD, Magíster en Análisis Sistémico Aplicado a la Sociedad, N³7, p. 1-20.

CALVO, A. (2002). Conservación y restauración de pintura sobre lienzo. Barcelona: El Serbal.

CALVO, A., GARCÍA FERNÁNDEZ-VILLA, S., BAILÃO, A. (2018). Terminología básica de conservación y restauración del patrimonio cultural. Madrid: Universidad Complutense de Madrid.

$<$ https://www.researchgate.net/publication/323613615_Terminologia_basica_d e_conservacion_y_restauracion_del_Patrimonio_Cultural> [Consulta: 12 marzo de 2019].

CÁMARA DE DIPUTADOS. Nota N. 1510 (2019). INAH, INBA y Secretaría de Cultura, sin diagnósticos sobre estado del patrimonio cultural material e inmaterial que determinen necesidades de conservación y protección: ASF. $<$ http://www5.diputados.gob.mx/index.php/esl/Comunicacion/Agencia-deNoticias/2019/Febrero/23/1510-INAH-INBA-y-Secretaria-de-Cultura-sindiagnosticos-sobre-estado-del-patrimonio-cultural-material-e-inmaterial-quedeterminen-necesidades-de-conservacion-y-proteccion-ASF> [Consulta: 20 de abril de 2020].

CIENCIA Y TÉCNICA ADMINISTRATIVA CyTA. Herramientas para el Análisis, Cuantitativo y Cualitativo, Aplicables a sistemas de gestión de la calidad <http://www.cyta.com.ar/biblioteca/bddoc/bdlibros/herramientas_calidad/caus aefecto.htm > [Consulta: 20 de abril de 2020].

CLAUDIA E. MORENO, (2001). Métodos para medir la biodiversidad. M\&T-Manuales y Tesis SEA, vol. 1. Zaragoza: CYTED, ORCYT/UNESCO \& SEA.

CONACULTA, GOBIERNO DE MÉXICO, INAH. "Programa institucional de mediano plazo 2014-2018 del Instituto Nacional de Antropología e Historia". <https://www.inah.gob.mx/images/stories/Transparencia/2014/pimp_2014_201 8_institucional.pdf> [Consulta: 7 de marzo de 2019]. 
DONDIS, D.A., (2008). La sintaxis de la imagen, Introducción al alfabeto visual. Barcelona: Gustavo Gili.

ESTADOS UNIDOS MEXICANOS. "Constitución Política de los Estados Unidos Mexicanos". Diario Oficial de la Federación, 5 de febrero de 1917, p. 319. <http://www.diputados.gob.mx/LeyesBiblio/pdf/1_060320.pdf> [Consulta: 20 de abril de 2020].

FERNÁNDEZ MARTíNEZ, V.M. (2015). Arqueo estadística, métodos cuantitativos en arqueología. Madrid: Alianza.

FITZNER, B., HEINRICHS, K. (2002). "Damage diagnosis on stone monuments weathering forms, damage categories and damage indices" en Natural stones and weathering, Geological Institute. Aachen: University of Technology. $<$ http://citeseerx.ist.psu.edu/viewdoc/download?doi=10.1.1.610.6890\&rep=rep1 \&type $=p d f>$ [Consulta: 13 de mayo de 2019].

GARCÍA SANJUÁN, L. (2005). Introducción al reconocimiento y análisis arqueológico del territorio. Barcelona: Ariel.

GETTY CONSERVATION INSTITUTE (2007). Guiding Principles - Recording, Documentation and Information Management for Conservation of Heritage Places. $<$ https://www.getty.edu/conservation/publications_resources/pdf_publications/ recordim.html> [Consulta: 15 de mayo de 2020].

GETTY CONSERVATION INSTITUTE (2007). Recording, Documentation, and Information Management for the Conservation of Heritage Places. Illustrated Examples. $<$ https://www.getty.edu/conservation/publications_resources/pdf_publications/ recordim_vol2.html> [Consulta: 15 de mayo de 2020].

GOBIERNO DE MÉXICO. "Secretaría de Educación Pública" en Diario Oficial de la Federación, TOMO CDXXIII (4), 7 de diciembre de 1988, pp. 11- 14. $<$ http://dof.gob.mx/nota_to_imagen_fs.php?cod_diario=206408\&pagina $=11 \&$ se ccion $=0>$ [Consulta: 10 de diciembre de 2020].

GOBIERNO DE MÉXICO. "Secretaría de Educación Pública" en Diario Oficial de la Federación, 17 de diciembre de 2015.

$<$ http://www.dof.gob.mx/nota_detalle.php?codigo $=5420363 \&$ fecha $=17 / 12 / 201$

5> [Consulta: 10 de diciembre de 2020].

GOBIERNO DE MÉXICO. "Manual de Organización General de la Secretaría de Cultura" en Diario Oficial de la Federación, 12 de diciembre de 2017. $<$ https://www.dof.gob.mx/nota_detalle.php?codigo $=5501065 \&$ fecha $=12 / 10 / 201$ 7> [Consulta: 10 de diciembre de 2020]. 
GOMBRICH, E.H., HOCHBERG, J. y BLACK, M. (1996). Arte, percepción y realidad. Barcelona: Paidós estética.

HAMMER, Ø., HARPER, D. A. T., RYAN, P. D. (2001). "PAST: Paleontological Statistics Software Package for Education and Data Analysis" en Paleontología Electrónica, No4, 1. p. 9.

HODDER, I. y ORTON, C. (1990). Análisis espacial en arqueología. Barcelona: Crítica.

HORNEMANN INSTITUT (2015). European Illustrated Glossary for Conservation Terms of Wall Painting and Architectonic Surfaces. <https://www.hornemanninstitut.de/doi/2016ewa2.pdf> [Consulta: 19 de mayo 2017].

ICCROM, ICOMOS, IUCN, UNESCO, (2010). Managing disaster risks for World Heritage. $<$ https://whc.unesco.org/en/documents/115730> [Consulta: 15 de febrero 2019].

ICOMOS-ISCS (2008). Illustrated Glossary on Stone Deterioration Patterns. $<$ https://www.icomos.org/publications/monuments_and_sites/15/pdf/Monume nts_and_Sites_15_ISCS_Glossary_Stone.pdf> [Consulta: 3 de marzo de 2016].

INAH, GOBIERNO DE MÉXICO. Diagnóstico del plan de trabajo 2014-2018. $<$ https://inah.gob.mx/images/stories/Transparencia/programa_trabajo/diagnosti co.pdf $>$ [Consulta: 7 de marzo de 2019].

INAH, GOBIERNO DE MÉXICO. "Ley orgánica del Instituto Nacional de Antropología e Historia" en Diario Oficial de la Federación, 3 de febrero de 1939, p. 9. <http://www.diputados.gob.mx/LeyesBiblio/pdf/170_171215.pdf> [Consulta: 20 abril de 2020].

INAH, GOBIERNO DE MÉXICO. "Surge el Patronato del INAH A.C., puente entre la sociedad civil y el cuidado del patrimonio cultural de México" en Boletín de Noticias, 25 de octubre 2019. <https://www.inah.gob.mx/boletines/8613-surgeel-patronato-del-inah-a-c-puente-entre-la-sociedad-civil-y-el-cuidado-delpatrimonio-cultural-de-mexico> [Consulta: 10 de diciembre de 2020].

INAH, GOBIERNO DE MÉXICO. Zona Arqueológica Chicanná. <https://www.inah.gob.mx/zonas/63-zona-arqueologica-chicanna> [Consulta: 22 de abril de 2020].

KUKA, J. (2012). Monitoring cultural indicators, ICCPR, Barcelona. pp. 2-5.

LEG Eurostat (2000). "Cultural statistics in the EU" en Eurostat Working Paper, Population and Social Conditions Series, 3/2000/E/No1. Final report of the LEG. Luxembourg: Eurostat.

LEONARDO OVIEDO, G. (2004). "La Definición del Concepto de Percepción en Psicología con Base en la Teoría Gestalt" en Revista de Estudios Sociales UNIANDES. 
$<$ https://www.ufrgs.br/psicoeduc/gestalt/percepcion-en-la-teoria-gestalt/> [Consulta: 25 de abril de 2020].

MAGAR, V. y PEDELİ, C. (2008). "Training on Archaeological Conservation in Southeast Europe: an Approach to the Preliminary Condition Assessment" en ICCROM Newsletter, Diciembre 2008, n०34, p. 10-11.

MAGURRAN, A. E. (1988). Ecological diversity and its measurement. New Jersey: Princeton University Press.

MARTíNEZ CABETAS, C. y RICO MARTÍNEZ, L. et al. (2003). Diccionario técnico Akal de conservación y restauración de bienes culturales. Español-Alemán-Inglés-ItalianoFrancés. Madrid: Akal.

MASTROIACOVO, T., SORIANO SANCHO, M.P., REGIDOR ROS, J.L. (2017). "Índice de riesgo relacionado con factores de alteración y deterioro en las pinturas murales del siglo XX de San Luis Potosí (S.L.P., México)" en Archè, Instituto Universitario de Restauración del Patrimonio de la UPV - №. 11 y 12, p.157-162.

NICOLAS MEDINA, C. (2008). "La ciencia cognitiva y el estudio de la mente" en Revista IIPSI, Facultad de Psicología, UNMSM, Vol. 11, № 1. P. 183 - 198.

Patronato de Restauración y Conservación del Patrimonio Artístico del Centro Histórico. $<$ https://centrohistoricoslp.com/patronato-restauracion-conservacion/> [Consulta: 10 de diciembre d 2020].

PEDELÍ, C. (2013). "An interdisciplinary conservation module for condition survey on cultural heritages with a 3d information system" en International Archives of the Photogrammetry, Remote Sensing and Spatial Information Sciences, Volume XL5/W2, XXIV International CIPA Symposium. Strasbourg: P. Grussenmeyer. 483-487 Disponible en <https://doi.org/10.5194/isprsarchives-XL-5-W2-483-2013> [Consulta: 11 de mayo 2020].

PEDELÍ, C. (2014). "A methodology for an organised visual examination on condition assessment of cultural heritage" en e-dialogos, Annual digital journal on research in Conservation and Cultural Heritage, $\mathrm{n}^{\circ}$ 4, december, pp. 22-29. $<$ http://www.diadrasis.org/public/files/edialogos_004-PEDELI.pdf> [Consulta: 11 de mayo de 2020].

POOLE, N. (2015). Collections Management Performance Indicators. London: The Collections Trust.

RAND, E. y GARCÍA GRINDA, J.L. (2015). "Management documentation indicators \& good practice at cultural heritage places" en The International Archives of the Photogrammetry, Remote Sensing and Spatial Information Sciences, Volume XL5/W7, 25th International CIPA Symposium. Taiwan: Taipei. 
RIVERA PÉREZ, M.E. (2015). “OVO un mortero fluido”, en Conservación y Restauración, Boletín de la CNCPC, No 7, diciembre. P. 84-89.

SHANNON, C. \& WEAVER, W. (1948). The Mathematical Theory of Communication. Illinois: Urbana.

SIBILIO PARRI, B. (2011). “Uno strumento di gestione del patrimonio culturale: il caso dei siti UNESCO" en Economia e diritto del terziario, Vol. 23, núm. 2, pp. 307-333.

SPELLERBERG, I. F. (1991). Monitoring ecological change. Cambridge: University Press.

UNESCO. Diversidad de las expresiones culturales. $<$ https://es.unesco.org/creativity/indicadores-de-desarrollo/caja-deherramientas $>$ [Consulta: 10 de junio de 2020].

UNESCO. State of Conservation System (SOC). < https://whc.unesco.org/en/soc/> [Consulta: 10 de mayo de 2020].

UNESCO (1986). "The UNESCO Framework for Cultural Statistics. Statistical Commission and Economic Commission for Europe" en UNESCO, Conference of European Statisticians. Third Joint meeting on Cultural Statistics, 17-20 March 1986. CES/AC/44/11. 13 February 1986.

UNESCO (2009). Framework For Cultural Statistics. $<$ http://uis.unesco.org/sites/default/files/documents/unesco-framework-forcultural-statistics-2009-en_0.pdf> [Consulta: 15 de marzo de 2019].

UNESCO (2014). Indicadores UNESCO para la Cultura y el Desarrollo. Manual Metodológico.

$<$ https://es.unesco.org/creativity/sites/creativity/files/iucd_manual_metodologic o_1.pdf> [Consulta: 14 de marzo de 2019].

VIVANCOS RAMÓN, V. (2007). La conservación y restauración de la pintura de caballete. Pintura sobre tabla. Madrid: Tecnos.

VIVANCOS RAMÓN, V. y CASTELL AGUSTÍ, M. (2010). Problemas y tratamientos del soporte de pintura de caballete. Valencia: Universidad Politécnica de Valencia.

XARRIÉ, M. (2007). Diccionario de conservación y restauración de obras de arte 1 (A-Z). Barcelona: Balaam. 


\section{Capítulo 1 El Patrimonio Cultural Mexicano}

\subsection{Características generales}

La República Mexicana se ubica en el área norte y centro del continente americano, con una extensión territorial de 1.9 millones de kilómetros cuadrados, ocupando la sexta posición por amplitud de superficie del continente y la número catorce a nivel mundial ${ }^{99}$. Este área se caracteriza por una notable riqueza de climas que ha favorecido el desarrollo y conservación de una rica biodiversidad y recursos naturales, influyendo en la conformación de las características culturales, técnicas y materiales de los diferentes grupos sociales que en él se han desarrollado a lo largo del tiempo.

Las obras de arte producidas en el territorio mexicano se conforman por un amplio abanico de técnicas y materiales cuyas características han respondido a la disponibilidad de recursos del entorno y a las rutas comerciales establecidas a lo largo del tiempo entre las etnias existentes. Antes de la influencia europea, las culturas Olmeca, Tolteca, Zapoteca, Maya, Azteca y Teotihuacana ${ }^{100}$ volvieron tangibles los rasgos culturales, ideológicos y sociales derivados de su cosmogonía a través de la manipulación de los materiales presentes en su ambiente. Esto ofrece hoy en día un legado compuesto por un rico patrimonio cultural.

\footnotetext{
${ }^{99}$ TAMAYO, J.L., (1993). Geografía moderna de México. México: Trillas.

${ }^{100}$ Para un acercamiento y comprensión de los ricos rasgos culturales de México, KRICKEBERG, W. (1961). Las antiguas culturas mexicanas. México: FCE.
} 
Gracias a los recursos geológicos presentes en el sur de México, rico en calizas, en el área Maya se asistió a la creación de edificios ricos de estucos y revestimientos (imágenes 1 y 2), cuya característica blancura y luminosidad se debe al uso del $s a s c a b^{101}$. La riqueza en calizas favoreció el desarrollo de una tecnología de la cal ${ }^{102}$ muy avanzada, elevándola a elemento distintivo de esta cultura.

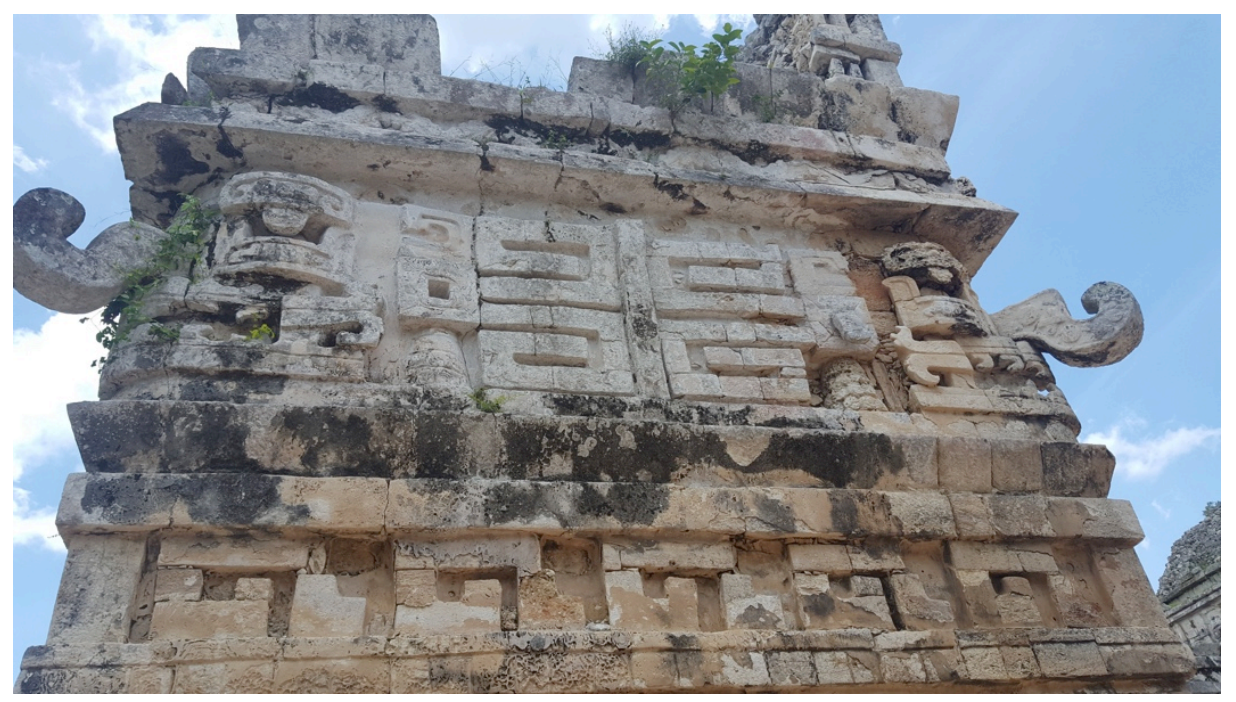

Imagen 1 - Detalle de la decoración del conjunto del Templo de las Monjas. Sitio arqueológico de Chichén Itzá (Yucatán, México).

${ }^{101}$ El sascab es conocido, en maya yucateco, como una tierra blanca compuesta por carbonato de calcio. Este material ha sido ampliamente utilizado, junto a la cal, para los revestimientos arquitectónicos de las estructuras de las Tierras Bajas Mayas del Norte que abarcan la parte superior de la península de Yucatán, en los estados de Quintana Roo, Campeche y Yucatán. VÁZQUEZ DE ÁGREDOS y HORCAJADA CAMPOS (2017). "La doble piel de la arquitectura Maya: el estuco y el color" en RA monográfico, pp. 84-97. <https://core.ac.uk/download/pdf/228598681.pdf> [Consulta: 2 de marzo de 2019].

102 El gran auge alcanzado por las estructuras arquitectónicas y urbanas en la época prehispánica se debe al nivel de desarrollo de la tecnología de la cal. En el área maya este recurso estaba muy presente, mientras que en las zonas centrales de México fue necesario transportarla. La presencia de este recurso favoreció la producción de arquitecturas esbeltas y elevadas en el área maya, a diferencia de la masiva y baja de Teotihuacán, en donde se empleaban arcilla y lodo como mortero de junta. La influencia ejercida por el abastecimiento de cal se observa en los espesores de estucos y revestimientos, que en el sur de México alcanzan decenas de milímetros de espesor a diferencia del área central en dónde se reducen a un grosor muy limitado. PINGARRÓN, L.B. (2013). “El uso de la cal en el mundo prehispánico mesoamericano” en La cal. Historia, propiedades y usos. México: UNAM, pp. 19-46. 


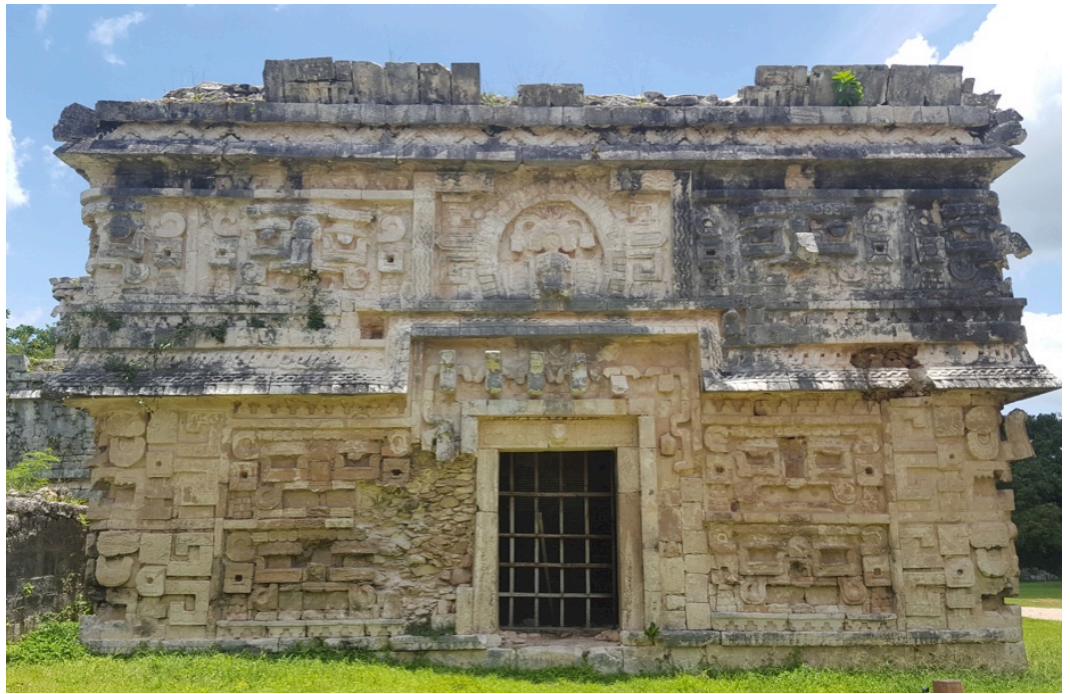

Imagen 2 - Templo de las Monjas, sitio arqueológico de Chichén Itzá (Yucatán, México).

Los suelos ricos en arcillas propiciaron la producción alfarera a lo largo de todo el territorio mesoamericano (imagen 3). La maestría técnica y la gran variedad de sujetos que caracterizan las cerámicas prehispánicas ${ }^{103}$ indican como ésta ha ido acompañando al hombre en diferentes facetas de su vida (imagen 4).
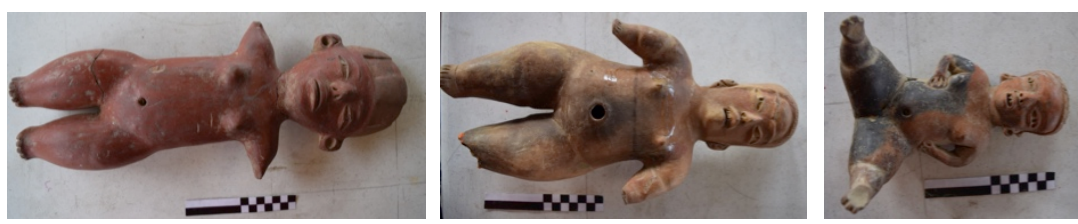

Imagen 3 - Esculturas prehispánicas en cerámica. Museo Arqueológico de Atlixco (Puebla, México) ${ }^{104}$.

\footnotetext{
103 Las cerámicas prehispánicas tenían un gran valor. Tenían carácter utilitario y ceremonial, empleándose en ritos funerarios y celebraciones. NOGUERA AUZA, E. (1967). "La cerámica funeraria y ritual en Mesoamérica" en Anales de Antropología, Revista del Instituto de Investigaciones Antropológicas UNAM, vol.1, núm.4, pp. 127140. Desde la llegada de los europeos la producción alfarera incorporó nuevas dimensiones y materiales, manteniendo a la vez rasgos identidarios propios. Para una aproximación al intercambio cultural, innovaciones y tradiciones se aconseja el volumen coordinado por LEONOR MERINO, B. y GARCÍA COOK, Á., (2007) La producción alfarera en el México Antiguo, vol. V, La alfarería en el Posclásico (1200-1521 d.C.) y el intercambio cultural y las permanencias. México: Instituto Nacional de Antropología e Historia.
}

${ }^{104}$ Estas obras ha sido parte del acervo rescatado en la emergencia del seísmo del centro de México de 2017. 


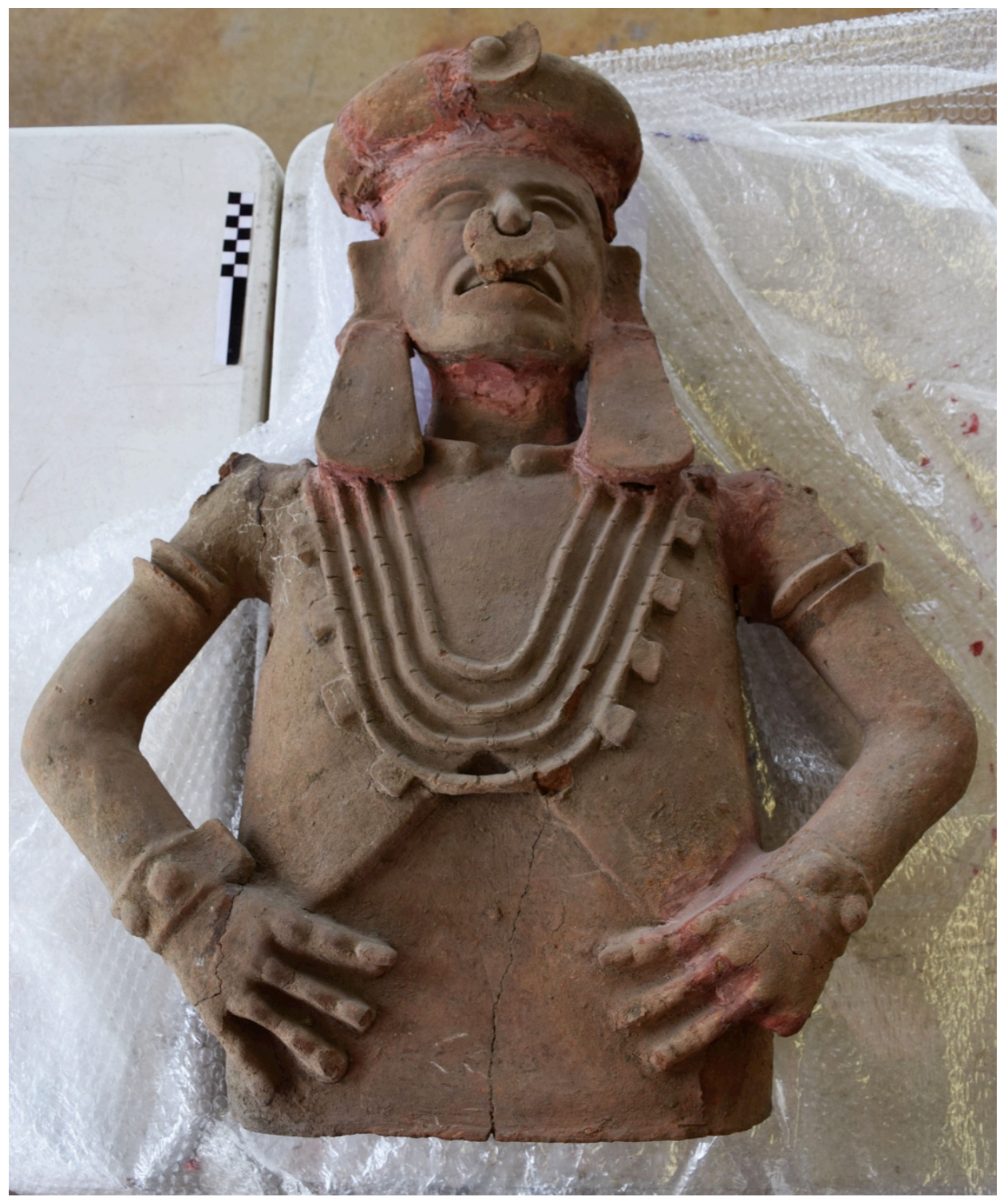

Imagen 4 - Escultura prehispánica perteneciente a la colección del Museo de Arqueología de Atlixco (Puebla, México) ${ }^{105}$.

105 Ibídem. 
La excepcional biodiversidad del medio natural, brindó la materia prima para crear objetos de varios tipo. A partir de fibras vegetales y colorantes, se materializaron los extraordinarios textiles ${ }^{106}$ que aun hoy marcan la identidad de las culturas mexicanas. A partir del mundo animal se establecieron conexiones simbólicas y rituales en donde las aves poseían un lugar especial. Rasgos de esto se puede apreciar en el legado del arte plumaria ${ }^{107}$. Las peculiaridades geográficas y naturales del país brindaron los elementos favorables para el desarrollo de una avanzada tecnología de elaboración de materiales pictóricos. Ésta, gracias a delicados y complejos procesos de transformación, ofreció como resultado unos colores artificiales estables y duraderos, como el conocido azul maya ${ }^{108}$ (imágenes 5 y 6).

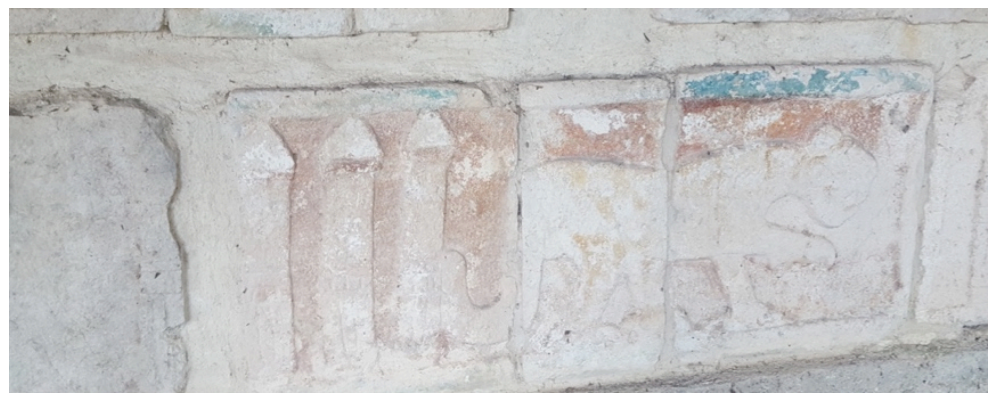

Imagen 5 - Detalle de los restos de policromía en donde se aprecia la presencia de azul maya y pigmento rojo. Sitio arqueológico de Chichén Itzá (Yucatán, México).

106 Un estudio importante para la comprensión del valor social y cultural de los textiles en México es el de STRESSER-PÉAN, C. (2012). De la vestimenta y los hombres. Una perspectiva histórica de la indumentaria indígena en México. La indumentaria precortesiana. México: FCE, CEMCA, Fundación Alfredo Harp Helú, Museo Textil de Oaxaca.

107 El arte plumaria representa una de las expresiones artísticas más características de México. Para su profundización, a través de los estudios del célebre penacho de Moctezuma custodiado en Austria, se propone el texto compuesto por aportaciones de varios autores (2012) El penacho del México antiguo. Viena: ZKF Publishers, Museum für Völkerkünde, CONACULTA-INAH.

${ }^{108} \mathrm{El}$ azul maya es el resultado de un proceso de síntesis que incluye componentes orgánicos e inorgánicos. El colorante índigo derivado de la especie tintórea Indigofera Suffruticosa es fijado sobre una arcilla (paligorskita) a través de diferentes procesos de cocción, dando como resultado un pigmento de extraordinaria resistencia y estabilidad. Este ha sido empleado desde la época prehispánica hasta los comienzos de la época colonial, siendo un elemento distintivo de la producción mural del área Maya. BEVILACQUA, N., BORGIOLI, L. Y ADROVER GARCÍA, I., (2010). I pigmenti nell'arte dalla preistoria alla rivoluzione industriale. Collana I Talenti. Padova: II Prato, pp.62-63. Para la comprensión de la dimensión material y técnica de la pintura mural maya se cita el valioso trabajo de MAGALONI KERPEL, D.I. (1996). Materiales y técnicas de la pintura mural Maya. México: UNAM. En pos de un conocimiento exhaustivo de la pintura mural prehispánica se cita el proyecto coordinado por De La Fuente, B. (1996), La pintura mural prehispánica en México, que investiga, a través de cuatro tomos, las principales áreas culturales del México precolombino y su producción mural bajo aspectos arqueológicos, antropológicos, materiales, técnicos y conservativos. 


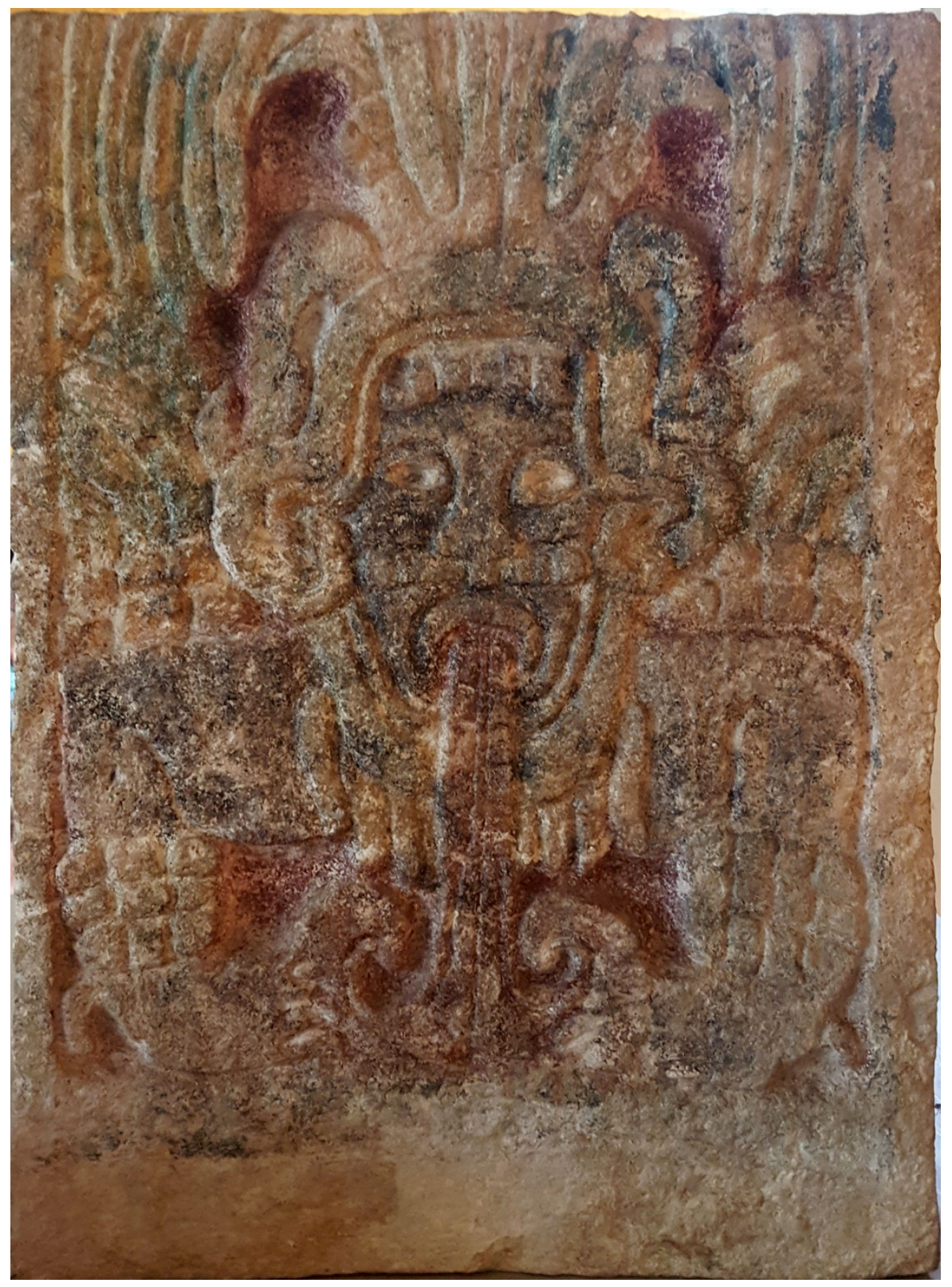

Imagen 6 - Detalle de relieve en material pétreo con restos de policromía, entre los cuales se aprecia el azul maya. Dzibilchaltún, Museo Arqueológico de sitio (Yucatán, México). 
En dónde el clima se imponía como un desafío para los trabajos con base cal, los indígenas generaron respuestas tecnológicas nuevas y en armonía con el contexto ${ }^{109}$, intuyendo las ventajas ofrecidas por el uso de aditivos y aglutinantes derivados de mucílagos vegetales ${ }^{110}$ (imagen 7).

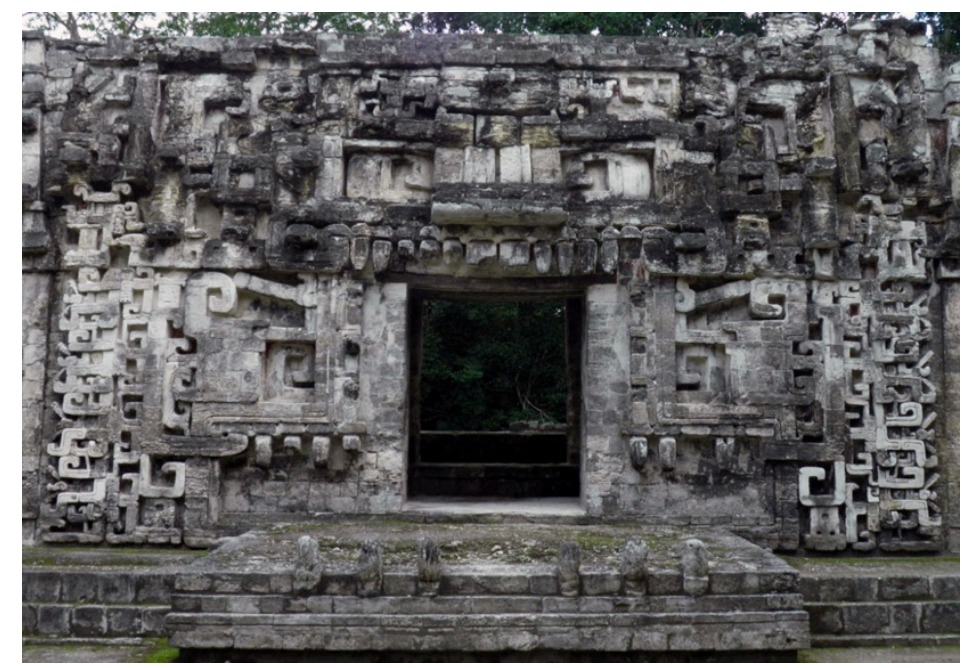

Imagen 7 - Vista frontal del Templo del Monstruo de la Tierra, sitio arqueológico de Chicanná (Campeche, Mexico). Es visible el rico conjunto de decoraciones realizado en estuco, cuya libertad expresiva ha sido alcanzada gracias al desarrollo de la tecnología de la cal.

109 La solubilidad del hidróxido de calcio a $20^{\circ} \mathrm{C}$ es de $1,7 \mathrm{~g} / \mathrm{l}$ y disminuye en relación al aumento de temperatura. A pesar de su baja solubilidad en agua, este material posee la característica de formar suspensiones que adquieren espesor conforme aumente su riqueza en $\mathrm{Ca}(\mathrm{OH})_{2}$ alcanzando la consistencia de una masa muy plástica. ARMESTO DÍAZ, J.A., y ARILLA AGÓRRIZ, E. (1999). La cal. Valencia: UPV, pp. 24-25. Las condiciones climáticas extremas de la selva tropical dificultan el trabajo con la cal, debido a las elevadas temperaturas. Llegando a los $40^{\circ} \mathrm{C}$ se ocasiona la precipitación de hidróxidos de calcio disminuyendo la capacidad cohesiva de la cal. MAGALONI KERPEL, D. (1995). "Técnicas de la pintura mural en Mesoamérica" en Arqueología Mexicana, vol. III, núm. 16, México: Raíces, pp. 16-23. Las gomas vegetales (polisacáridos) empleadas como aditivos en la tecnología de la cal maya favorecen la suspensión y solubilidad del hidróxido de calcio. Esto brinda un mortero de gran ligereza, plasticidad, baja dureza y versatilidad en su manejo que ha sido empleado para esculturas de bulto y pinturas murales (MAGALONI KERPEL, 1996, op.cit.).

${ }^{110}$ En el área maya la mezcla de cal y arenas calcíticas (sascab) se realizaba en seco con el objetivo de mejorar la distribución de los componentes. Sucesivamente se le agregaba agua que había estado en remojo con corteza de árbol, cuya naturaleza ha sido objeto de varios estudios. MAGALONI KERPEL, D. (2008). "Los colores de la selva" en Arqueología Mexicana, vol. XVI, núm. 93, México: Raíces, pp.46-50. Éstos arrojaron como resultado que el chucum (Phitecolobium albicans) tenía reacciones positivas en contacto con la cal. LITTMANN, E.R. (1960) "Ancient Mesoamerican Mortars, Plasters and Stuccos: The Use of Bark Extracts in Lime Plasters" en American Antiquity, vol. 25, núm. 4., pp. 593-597. La goma de esta especie (chucum) "se activa en contacto con el $\mathrm{pH}$ alcalino de la mezcla de cal, brindando un cementante altamente plástico y con buenas propiedades de fraguado y muy resistente" (MAGALONI KERPEL, 2008, op.cit., pp.46-50). 
La amplitud, tipología y variedad de la paleta cromática utilizada en las expresiones artísticas prehispánicas ${ }^{111}$ sigue siendo trasmisora del valor simbólico y ritual que revestía la dimensión del artista $^{112}$ en la concepción del mundo precortesiana. En el campo de la metalurgia, la realización de finos objetos de uso ritual y decorativo en oro y piedras preciosas dejó huellas tangibles del nivel de maestría alcanzado por los artesanos indígenas. Estas características han sido complementadas, tras la llegada de los europeos, con nuevos materiales y técnicas, generando inéditos testigos de esta sociedad en trasformación. Uno de los impulsos de los habitantes de México, tras el contacto con esta nueva cultura, fue el de volver a pintar y contar su historia y tradición. El resultado más importante de este esfuerzo fue la creación del Códice Florentino ${ }^{113}$. Paralelamente, como respuesta al impulso de conversión religiosa, se asiste al nacimiento de la imaginería religiosa novohispana, realizada con técnicas importadas y con otras hijas de la permanencia heredada de la época precolombina. A esta tipología pertenecen las realizadas en caña de maíz ${ }^{114}$, con un significado simbólico importante debido al valor social y cultural de esta planta en el mundo prehispánico. Gracias al intercambio cultural entre estos dos continentes se materializaron obras nuevas para la dimensión mexicana de entonces: las pinturas de caballete. Éstas alcanzaron un gran auge a lo largo de los siglos, realizándose sobre diferentes tipologías de soporte: lienzo, tabla y metal entre otros.

Siguiendo el hilo de las influencias económicas en el desarrollo de nuevos modelos de sociedad, se asistió al fenómeno de la proliferación de las llamadas haciendas de beneficio ${ }^{115}$, producto de la explotación agrícola, ganadera y minera del territorio por acción de las comunidades religiosas y de los poderes políticos

111 Un acercamiento a las principales características y diferencias entre la producción mural del área central de México (sitio arqueológico de Teotihuacán) y el área Maya se puede consultar en el artículo "Técnicas de la pintura mural en Mesoamérica" (MAGALONI KERPEL, 1995, op.cit., pp. 16-23).

112 El artista del mundo prehispánico era un sabio conocedor capaz de materializar los elementos de la tradición oral a través de un complicado sistema de elaboración simbólica y abstracción de los conceptos.

113 El Códice Florentino (1575-1577) fue concebido como una enciclopedia, redactada en náhuatl y español, que abarca todos los aspectos de la cultura nahuas del centro de México. Su creación se debe al franciscano Fray Bernardino de Sahagún y un grupo de intelectuales indígenas. MAGALONI KERPEL, D.I., (2016). Albores de la Conquista. La historia pintada del Códice Florentino. México: Artes de México y del Mundo, Secretaría de Cultura, p. 13-20.

${ }^{114}$ La técnica de realización de la imaginería en caña de maíz, junto a la profundización sobre las propiedades de sus materiales constitutivos, ha sido investigada por la Dra. Blasco Pérez, en su tesis doctoral "Nace, crece y envejece. La imaginería novohispana de caña de maíz. Una aproximación al comportamiento del material" (2015), València: UPV.

115 Para una comprensión de la dimensión histórica, social y funcional de las haciendas en el territorio del estado potosino: SALAZAR GONZÁLEZ, G. (2000). Las haciendas en el siglo XVI, en la región minera de San Luis Potosí. Su espacio, forma, función, material, significado y la estructuración regional. San Luis Potosí: Universidad Autónoma de San Luis Potosí, Facultad del Habitat. 
nacidos en la época virreinal y sucesivamente establecidos al mando de extendidas áreas y propiedades. A partir del siglo XVII, como consecuencia del auge económico derivado de las bonanzas en las actividades mineras, surgieron varios conjuntos arquitectónicos para los fines de las actividades productivas de estas corporaciones, llegando a contar, según una catalogación del INAH de 2014116, alrededor de mil quinientas en todo el país, de las cuales más de doscientas solo en el estado de San Luis Potosí17. Entre ellas, gracias a las actividades de docencia e investigación en la Universidad Autónoma de San Luis Potosí, ha sido posible estudiar las ubicadas en el municipio de Armadillo de los Infante, conocida como ex hacienda de Pozo del Carmen, y la ubicada en Villa Hidalgo, conocida con el nombre de ex hacienda de Peotillos. La prosperidad económica favoreció, como se ha mencionado en el apartado anterior, el nacimiento y desarrollo de nuevas realidades sociales, como el establecimiento de municipios en los territorios de conquista. La parroquia de San Pedro de Guadalcázar, en el estado de San Luis Potosí, es testigo de esta dinámica y custodia obras creadas para y por los feligreses de entonces. El impulso a la construcción y educación de esta nueva sociedad fomentó la construcción de templos y conventos. Un ejemplo de ello son los Conventos de San Martín en Huaquechula, el ex convento franciscano de Atlixco, y el convento del Carmen del estado de Puebla afectados por el sismo de $2017^{118}$ y en los cuales se pudieron llevar a cabo actividades de rescate con la Brigada de emergencia coordinada por el centro INAH de San Luis Potosí y la licenciatura en Conservación y Restauración de Bienes Culturales Muebles de la Facultad del Hábitat de la Universidad Autónoma de San Luis Potosí.

En algunas circunstancias, las órdenes religiosas activas en el territorio, junto a las nuevas generaciones de mexicanos de ascendencia europea, fomentaron la educación y desarrollo de las franjas más débiles de la sociedad. Un ejemplo destacable de este interesante fenómeno se encuentra en la institución, en 1792, del Colegio de San Ignacio de Loyola Vizcaínas en la Ciudad de México. Obra de la Cofradía de Aránzazu119, este colegio se proponía ofrecer amparo e instrucción a

\footnotetext{
${ }^{116}$ El Instituto Nacional de Antropología e Historia, además de las identificadas y catalogadas, contempla la posibilidad de que el número sea mayor y que no se pueda contar con un padrón total. "Llama INAH a preservar identidad de haciendas y casonas" en Informador.Mx del 4 de agosto de 2014. <https://www.informador.mx/Cultura/Llama-INAH-a-preservar-identidad-de-haciendas-y-casonas20140804-0067.html> [Consulta: 26 de noviembre de 2020].

117 INAH-CONACULTA (2010). Haciendas del Altiplano Potosino. México: EME ediciones.

${ }^{118}$ El INAH dictaminó que en el estado de Puebla, sobre un total de 631 bienes de interés cultural afectados por el sismo, 125 han sido dañados de forma grave, 335 de forma moderada y 161 de forma leve, sobre un total de 2,340 bienes perjudicados por el sismo de 2017. INAH, GOBIERNO DE MÉXICO. Acciones de restauración. <https://www.inah.gob.mx/sismos> [Consulta: 28 de noviembre de 2020].

${ }^{119}$ La cofradía de Aránzazu se componía por caballeros españoles de la provincia de Guipúzcoa, Álava, el Reino de Navarra y el señorío de Vizcaya. El Colegio San Ignacio de Loyola Vizcaínas es una institución que, desde
} 
mujeres y niñas necesitadas, ofreciéndole una educación y la posibilidad de acceder a un oficio. Este recinto cuenta con un amplio acervo de carácter histórico, cultural y artístico, resguardados en su propio Museo, además de poseer una capilla en los que se custodian varios testigos de arte novohispano, entre los cuales destaca el Retablo Mayor del colegio ${ }^{120}$ (imágenes 8 y 9).

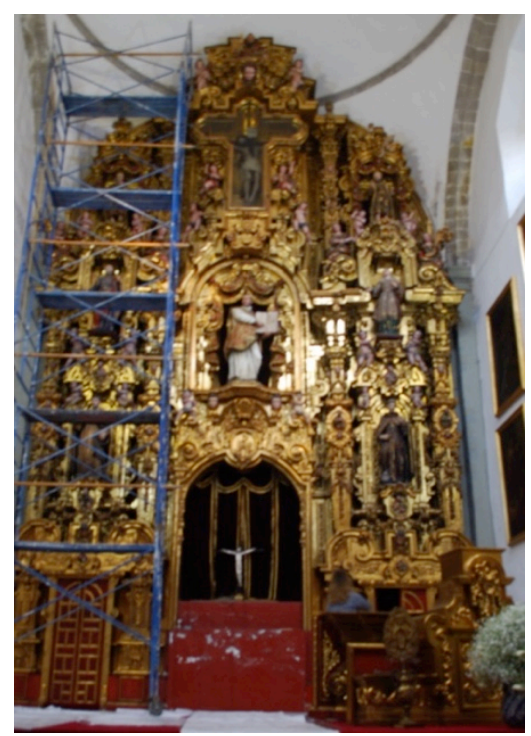

Imagen 8 - Retablo mayor del Colegio de San Ignacio de Loyola-Vizcaínas.

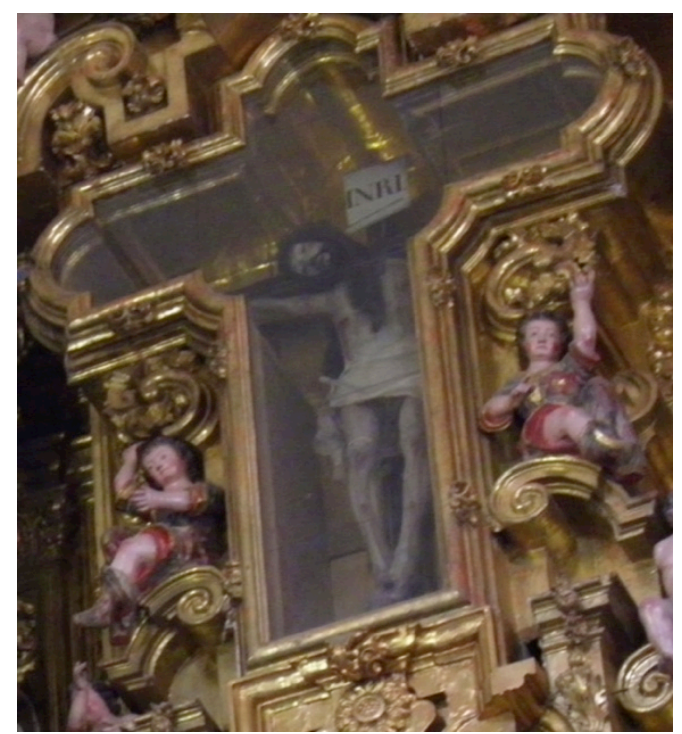

Imagen 9 - Detalle del Cristo de caña de maíz (siglo XVIII) custodiado en el remate del retablo.

su fundación, sigue activa hoy en día en elcampo de la educación. Colegio de San Ignacio de Loyola Vizcaínas <https://colegiovizcainas.edu.mx/historia-del-colegio\#1543601725966-583d5dbd-d76b> [Consulta: 20 de noviembre de 2020].

${ }^{120}$ Este importante testigo histórico artístico ha sido investigado en el desarrollo de las labores de docencia académica en el marco de las actividades formativas previstas para la asignatura "Taller de síntesis IV Diagnóstico" de la Licenciatura en Conservación y Restauración del Patrimonio Cultural de la Universidad Autónoma de San Luis Potosí. Por medio de las mismas se generaron importantes aportaciones inherentes el estado de conservación del conjunto y reflexiones sobre el valor de la colaboración institucional para el fomento de la investigación y formación en el campo de la conservación del patrimonio cultural. BLASCO PÉREZ, M.V., MASTROIACOVO, T., SOLBES GARCÍA, Á. (2017). "Tecnologías aplicadas al análisis de bienes culturales: el Retablo Mayor del Colegio San Ignacio de Loyola" en Seminario Internacional de Desarrollo de Nuevos Productos SIDNP de la Facultad del Hábitat, Universidad Autónoma de San Luis Potosí, S.L.P. México; MASTROIACOVO, T., BLASCO PÉREZ, M.V., NIETO VILLENA, A. (2017). "El valor de la colaboración interinstitucional como medio de investigación y didáctica: experiencias entre el Museo Colegio de las Vizcaínas y UASLP" en Seminario Internacional de Desarrollo de Nuevos Productos SIDNP de la Facultad del Hábitat, Universidad Autónoma de San Luis Potosí, S.L.P. México. 
La relación entre México y el nuevo continente se siguió manifestando a través de nuevos y ricos matices. También se importaron materiales desde el continente europeo, en particular mármoles de Carrara (Italia), de los cuales se encuentran testigos en la fachada de la Catedral Metropolitana de la ciudad de San Luis Potosí (imagen 10). Este caso, análogamente a los anteriores, representa un sincretismo no solo formal y material, sino también ideológico. Es altamente representativo de la sociedad mexicana del siglo XX, los elementos puestos en los nichos de la fachada son copias de los custodiados en Roma, en la Basílica de San Juan de Letrán ${ }^{121}$, y trasmiten la voluntad de modernización y afiliación a los cánones europeos por medio de materiales y formas.

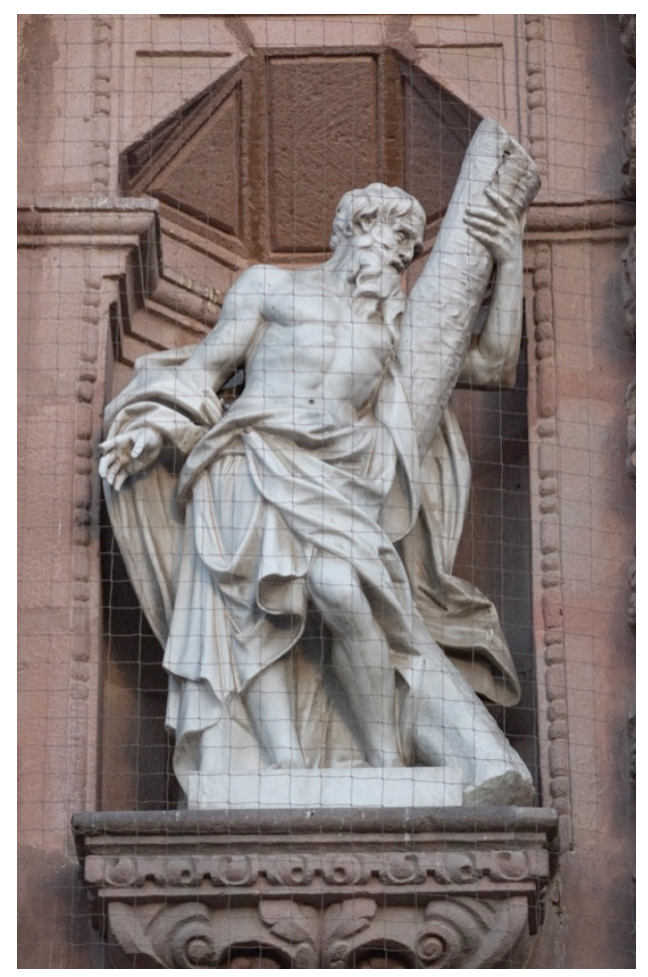

Imagen 10 - Apóstol Andrea ${ }^{122}$, Catedral Metropolitana (San Luis Potosí, México) ${ }^{123}$.

121 MASTROIACOVO, T., BLASCO PÉREZ, M.V., NIETO VILLENA, A. (2017). “Los hermanos Biagi y las esculturas de la Catedral Metropolitana Potosina" en Universitarios Potosinos, año 14, núm. 211, pp. 13-17. San Luis Potosí: UASLP.

122 Obra realizada en mármol de Carrara por el taller de los hermanos Biagi de San Luis Potosí. Es una reproducción del original creado por Camillo Rusconi en 1705-1709 para la Basílica de San Juan de Letrán 
Este mismo siglo fue testigo de la voluntad de autonomía, definición y enraizamiento de la identidad mexicana a través del movimiento muralista. Este estableció una conexión nueva con los rasgos de las antiguas civilizaciones prehispánicas, a través de la reinterpretación de sus términos expresivos, formales y materiales, para proyectarse hacia la época contemporánea (imágenes 11 y 12).

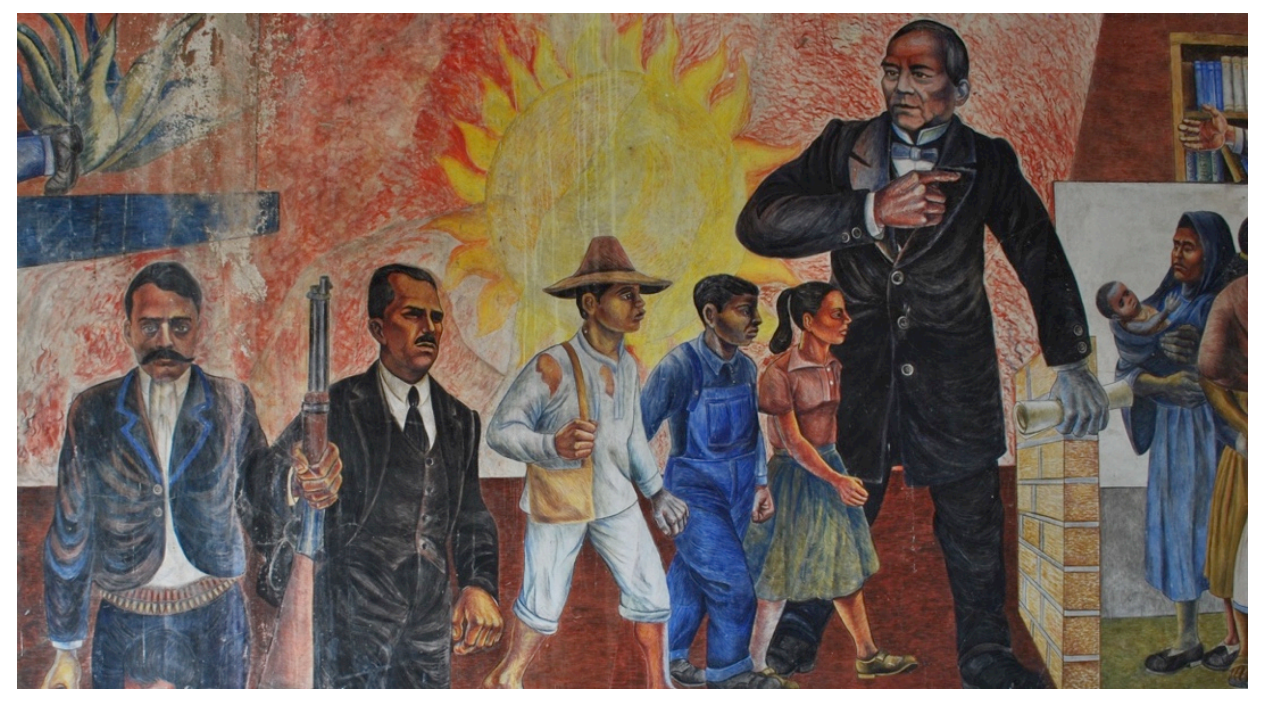

Imagen 11 - Detalle de la obra perteneciente al movimiento muralista, realizado en 1958-59 bajo la dirección de Xavier Íñiguez para el Internado Damián Carmona (San Luis Potosí, México) ${ }^{124}$.

(Roma, Italia). "Le statue degli apostoli in San Giovanni in Laterano", 21 febbraio 2019. $<$ https://www.italianways.com/it/le-statue-degli-apostoli-in-san-giovanni-in-laterano/> [Consulta: $10 \mathrm{de}$ diciembre de 2020].

${ }^{123}$ Foto: Blanca Sánchez Araujo.

124 GUERRERO URBINA, M.F., MASTROIACOVO, T. (2015). “Investigación, estudio y diagnóstico de las pinturas murales del Internado Damián Carmona en San Luis Potosí (S.L.P.)" en Inducción a la Ciencia, la Tecnología y la Innovación en la UASLP, Vol. III, nº 4, pp. 817-823. 


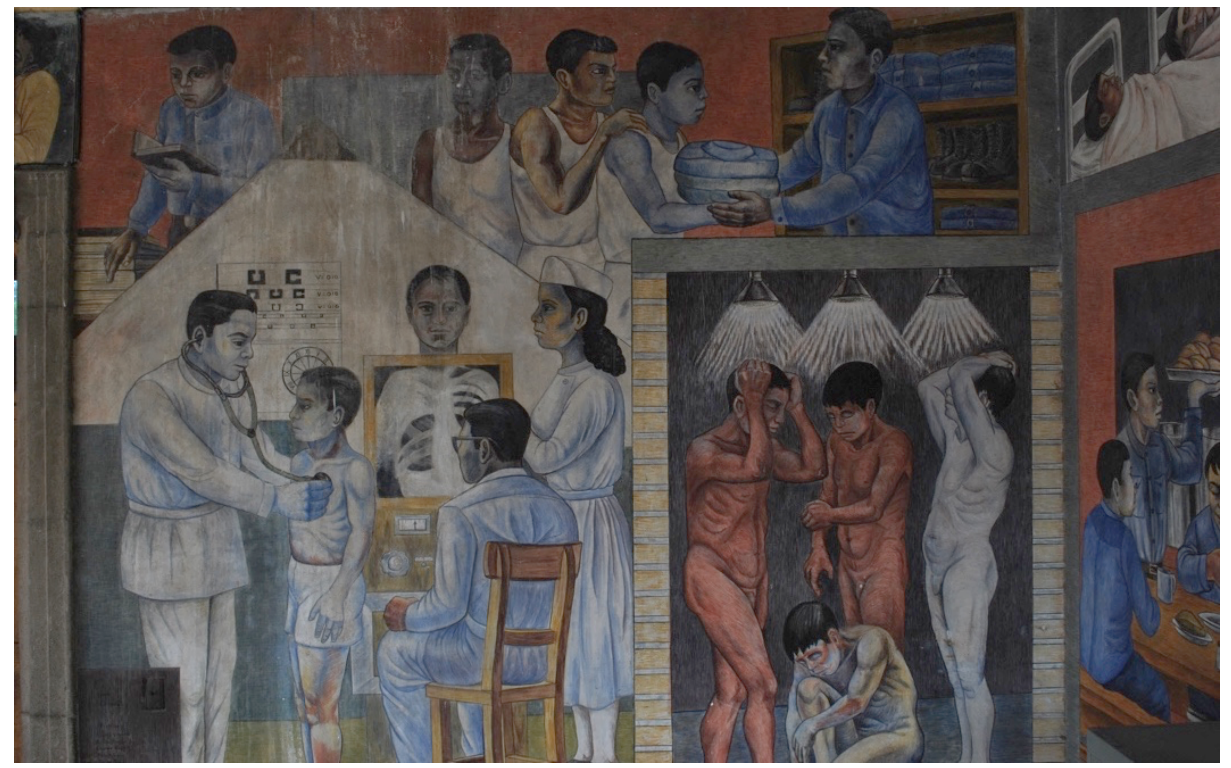

Imagen 12 - Detalle de la obra perteneciente al movimiento muralista, realizado en 1958-59 bajo la dirección de Xavier Iñiguez para el Internado Damián Carmona (San Luis Potosí, México) ${ }^{125}$.

La rica y compleja naturaleza del patrimonio cultural de la República Mexicana ${ }^{126}$ es hija de los acontecimientos que permearon las épocas prehispánica, colonial, moderna y contemporánea, hasta llegar a nuestros días. Un conjunto de obras y materiales que concurren a la creación de unos rasgos identidarios únicos cuyo resguardo y tutela son necesarios para su conservación y trasmisión hacia las generaciones futuras.

\subsection{Declaratorias, tutela y estado actual}

Según las estadísticas brindadas en el listado del Patrimonio Mundial de la UNESCO (2019) ${ }^{127}$, la región de Latinoamérica y Caribe, de la que México forma parte, ocupa el tercer lugar en el mundo. A partir de la cantidad de sitios (142)

\footnotetext{
125 Ibídem.

${ }^{126}$ El Patrimonio Cultural de la República mexicana se conforma por manifestaciones tangibles e intangibles. Éstas últimas, junto a la tradición oral que aun acompaña algunas comunidades en la trasmisión de su identidad y sabiduría, consta de doce reconocimientos por parte de la UNESCO. ICH, UNESCO (2019). Patrimonio Cultural Inmaterial. <https://ich.unesco.org/es/busqueda$00795 ? q=$ mexico\&criteriaSearch=element $\& p=1>$ [Consulta: 10 de junio de 2020].

127 WHC, UNESCO (2019). World heritage List Statistics. <https://whc.unesco.org/en/list/stat\#d1> [Consulta: 05 de junio de 2020].
} 
declarados Patrimonio de la Humanidad, la región LATAM representa el $12,67 \%$ del patrimonio total en el mundo (gráfica 1). Este conjunto patrimonial se compone por noventa y seis zonas de carácter cultural, treinta y ocho de tipo natural y ocho mixtos (tabla 7).
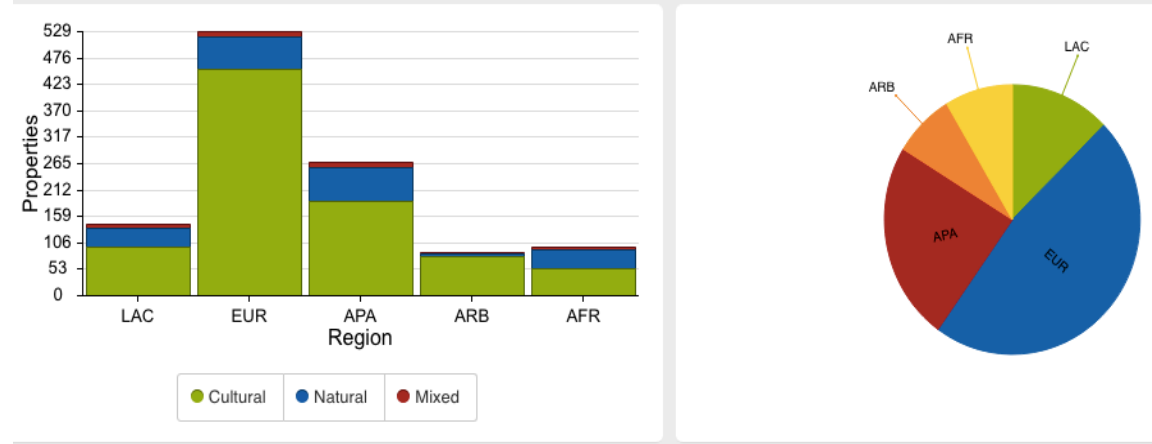

Gráfica 1 - Número de sitios declarados Patrimonio de la Humanidad (WHC, UNESCO, 2019) ${ }^{128}$ de acuerdo a las regiones de pertenencia: Latinoamérica y Caribe (LAC), Europa (EUR), Asia y Pacífico (APA), Estados Árabes (ARB) y África (AFR).

Tabla 7 - Panorámica de sitios declarados Patrimonio de la Humanidad (WHC, UNESCO 2019).

\begin{tabular}{|l|c|c|c|c|c|c|}
\hline \multicolumn{1}{|c|}{ Región } & Culturales & Naturales & Mixtos & Total & $\%$ & $\begin{array}{c}\text { Estados miembros } \\
\text { con propiedades } \\
\text { registradas }\end{array}$ \\
\hline $\begin{array}{l}\text { Latinoamérica y Caribe } \\
\text { (LAC) }\end{array}$ & 96 & 38 & 8 & $142 *$ & $12.67 \%$ & 28 \\
\hline $\begin{array}{l}\text { Europa y Norte América } \\
\text { (EUR) }\end{array}$ & 453 & 65 & 11 & $529 *$ & $47.19 \%$ & 50 \\
\hline $\begin{array}{l}\text { Asia y Pacífico } \\
\text { (APA) }\end{array}$ & 189 & 67 & 12 & $268 *$ & $23.91 \%$ & 36 \\
\hline $\begin{array}{l}\text { Estados Árabes } \\
\text { (ARB) }\end{array}$ & 78 & 5 & 3 & 86 & $7.67 \%$ & 18 \\
\hline $\begin{array}{l}\text { África } \\
\text { (AFR) }\end{array}$ & 869 & 213 & 39 & 1121 & $100 \%$ & 35 \\
\hline Total & & 38 & 5 & 96 & $8.56 \%$ & 167 \\
\hline
\end{tabular}

${ }^{128}$ WHC, UNESCO (2019). World heritage List Statistics. <https://whc.unesco.org/en/list/stat\#d1> [Consulta: 05 de junio de 2020]. 
Actualmente México se encuentra en el séptimo lugar a nivel mundial por sitios declarados Patrimonio de la Humanidad por la UNESCO (gráfica 2). Con treinta y cinco sitios de los cuales veintisiete son de carácter cultural, seis de tipo natural y dos mixtos ${ }^{129}$, es el primer país por número de lugares en América Latina y Caribe.

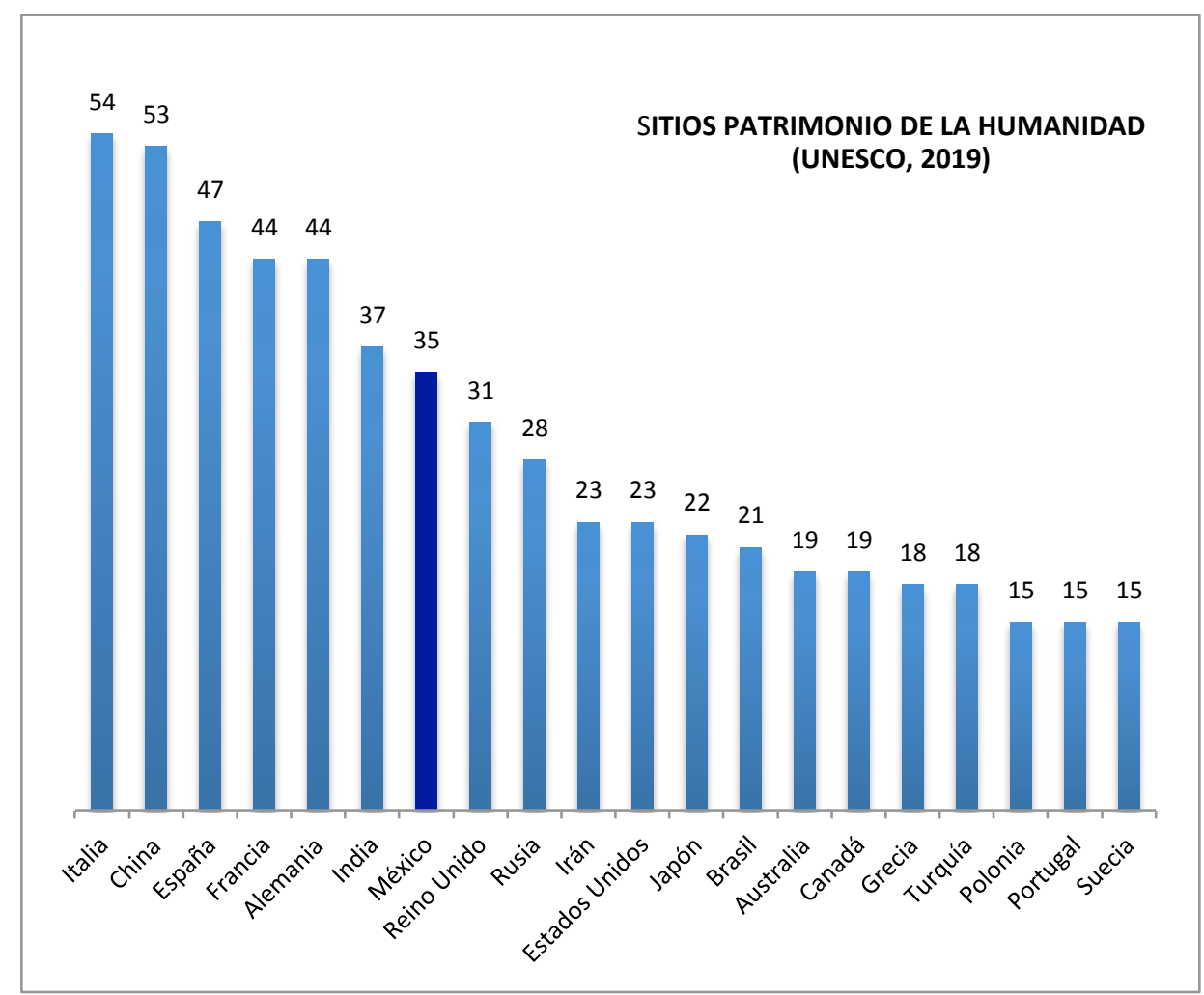

Gráfica 2 - Sitios Patrimonio de la Humanidad ${ }^{130}$ (UNESCO, 2019).

El reconocimiento del legado cultural y natural de México pone de manifiesto la gran extensión, por variedad, número y época, del conjunto de expresiones que hoy en día constituyen su patrimonio cultural (imagen 13).

\footnotetext{
129 UNESCO (2019). "Mexico, Properties inscribed in World Heritage List" en About World Heritage, The States Parties. <https://whc.unesco.org/en/statesparties/mx> [Consulta: 14 de febrero de 2019].

${ }^{130}$ Gráfico elaborado a partir de los datos brindados por el UNESCO (2019). En febrero 2021, estos datos aun siguen vigentes.
} 


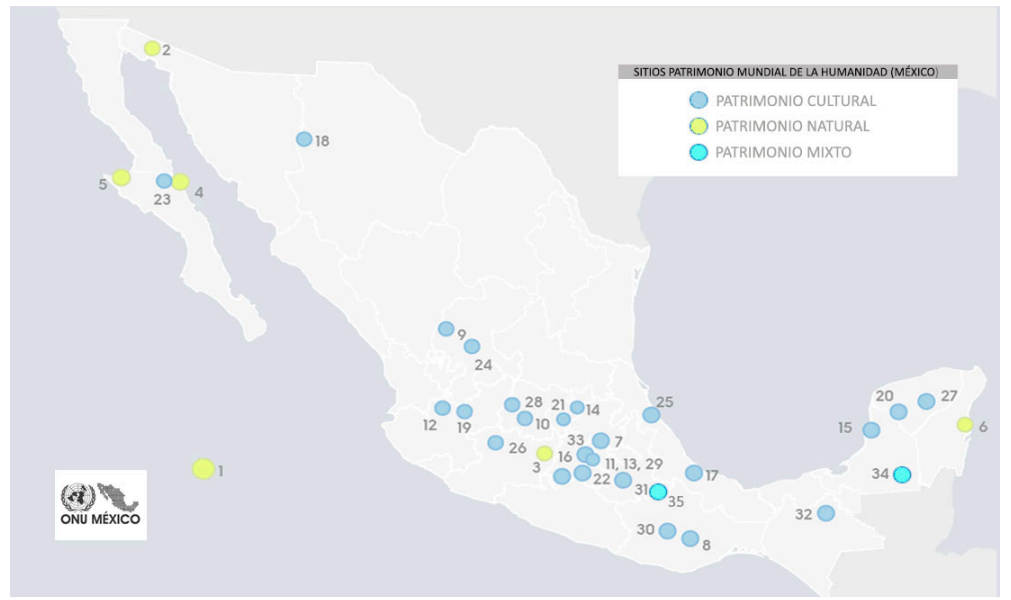

Imagen 13 - Sitios Patrimonio Mundial de la Humanidad por la UNESCO (modificado de ONU MÉXICO, $\left.2016^{131}\right)$.

La función de investigación, tutela y conservación del patrimonio cultural mexicano perteneciente a la época prehispánica, virreinal, hasta el siglo XIX es responsabilidad del Instituto Nacional de Antropología e Historia (INAH) al que corresponde la tutela del patrimonio paleontológico, histórico, y arqueológico de la nación ${ }^{132}$. Parte de esta institución es la Coordinación Nacional de Conservación del Patrimonio Cultural CNCPC, encargada de las tareas de investigación, conservación y estudio del patrimonio histórico artístico ${ }^{133}$ y la Dirección General de Sitios y Monumentos encargada del cuidado de las áreas arqueológicas y virreinales de tipo monumental. El patrimonio realizado en el siglo XX corresponde a la jurisdicción del Centro Nacional Conservación y Registro del Patrimonio Art́́stico Mueble

\footnotetext{
${ }^{131}$ NACIONES UNIDAS, MÉXICO (2016), “Descubre los 34 sitios de México inscritos en la Lista de Patrimonio" en Sitios Patrimonio Mundial de la humanidad en México. <http://www.onu.org.mx/descubre-los-34-sitios-demexico-inscritos-en-la-lista-de-patrimonio/> [Consulta: 15 de febrero de 2019].

132 El Instituto Nacional de Antropología e Historia se conforma por distintas coordinaciones encargadas del patrimonio, arqueológico, histórico, museos, registro, conservación, etc. y con varias funciones, de acuerdo a lo citado en su página institucional. GOBIERNO DE MÉXICO, INAH. "Quienes somos?". <https://www.inah.gob.mx/quienes-somos> [Consulta: 2 de mayo de 2021].

133 "La Coordinación Nacional de Conservación del Patrimonio Cultural es el área normativa y ejecutora del Instituto Nacional de Antropología e Historia (INAH) enfocada a la conservación de bienes muebles y bienes asociados a los inmuebles, de carácter paleontológico, arqueológico e histórico, que conforman el patrimonio cultural de México". SECRETARÍA DE CULTURA, CNCPC, INAH

$<$ https://conservacion.inah.gob.mx/index.php/2018-nosotros/> [Consulta: 2 de mayo de 2021].
} 
CENCROPAM ${ }^{134}$ del Instituto Nacional de Bellas Artes y Literatura (INBAL ${ }^{135}$ ) siempre y cuando éstas cuenten con una declaratoria de valor histórico y artístico ${ }^{136}$.

EI INAH es una entidad que se estructura en treinta y un centros distribuidos a lo largo de la República Mexicana que tienen como finalidad proteger, investigar, conservar y difundir el patrimonio arqueológico, antropológico, histórico y paleontológico de México.

La actividad del INAH y el INBAL es implementada por la acción de los organismos internacionales ICOMOS, ICCROM, UNESCO y otras entidades del gobierno de México que comparten la inquietud para la conservación del patrimonio cultural. A éstas se suman las iniciativas de carácter privado y religioso, que comparten los esfuerzos e intereses por parte de las comunidades que resguardan el patrimonio cultural, encargándose de coordinar las iniciativas dirigidas a conservar los testigos muebles o inmuebles reuniendo fondos a través de la constitución de patronatos. Por medio de estas entidades públicas y gubernamentales, y de las iniciativas de instituciones educativas de nivel superior, entre las cuales destacan las de la Universidad Nacional Autónoma de México UNAM y su Instituto de Investigaciones Estéticas IIE, hoy en día se cuenta con diferentes esfuerzos dirigidos a catalogar, estudiar, investigar y preservar por medio del estudio y difusión de catálogos, publicaciones y propuestas que tienen como objetivo común la preservación del patrimonio cultural de los Estados Unidos Mexicanos.

La institución de la "Inspección general de monumentos" nació en 1885 con la finalidad de preservar las antigüedades mexicanas del saqueo, un primer intento por parte de la sociedad para preservar su identidad cultural al que se sumó la

\footnotetext{
134 "El Centro Nacional Conservación y Registro del Patrimonio Artístico Mueble (CENCROPAM), es la dependencia del Instituto Nacional de Bellas Artes y Literatura (INBAL), encargada de velar por la preservación del patrimonio artístico nacional a través del fortalecimiento y actualización de los sistemas y mecanismos de catalogación, registro, conservación y restauración, tanto en los aspectos normativos, como en los técnicos y de gestión." GOBIERNO DE MÉXICO, SECRETARÍA DE CULTURA, INBAL. < https://inba.gob.mx/patrimonio> [Consulta: 2 de mayo de 2021].

135 El INBA decidió recuperar su original denominación "Insituto Nacional de Bellas Artes y Literatura INBAL" de forma extraoficial, es decir que se puede encontrar dicha nomenclatura en las páginas oficiales sin que esta haya sido aprobada de forma legal. Por esto a lo largo del texto se podrán encontrar ambas denominaciones. "INBA cambia a INBAL... y desata polémica" en Capital Mexico, 11 de enero de 2019. <https://www.capitalmexico.com.mx/nacional/inba-cambia-a-inbal-es-correcto/> [Consulta: 10 de junio de 2020].

136 "De conformidad con lo dispuesto en la Ley Federal sobre Monumentos y Zonas Arqueológicos, Artísticos e Históricos son monumentos artísticos los bienes muebles e inmuebles que revistan valor estético relevante. Tal valor se determina atendiendo a su representatividad, inserción en determinada corriente estilística, grado de innovación, materiales y técnicas utilizados y otras análogas. La declaratoria de monumento puede comprender toda la obra de un artista o sólo parte de ella. Esta puede ser expedida por el Presidente de la República o, en su caso, el Secretario de Cultura". INBAL, GOBIERNO DE MÉXICO <https://inba.gob.mx/transparencia/obra> [Consulta:10 de junio de 2020].
} 
cohesión de diferentes instancias preexistentes hasta conformar el Instituto en 1939 (INAH), con personalidad jurídica a las dependencias de la Secretaría de Educación Pública (SEP), al que se le otorgó la protección de los inmuebles significativos y sucesivamente la de los monumentos artísticos, arqueológicos e históricos pertenecientes al antiguo Departamento de Monumentos de la SEP, así como las colecciones, muebles y accesorios que albergaban. Los monumentos y sitios que se descubrieran en las exploraciones futuras y los que adquirió la institución por legado, herencia, donación o cualquier otro de carácter nacional también conforman el acervo bajo tutela de la institución (INAH, 2019) ${ }^{137}$.

Los diferentes acontecimientos que sufrió el país, como la independencia o las guerras cristeras, generaron un mercado oculto de obras robadas y expoliadas, fomentado por el estado de extrema pobreza de algunos grupos sociales y por el interés económico de pocos. Este aspecto ha ocasionado la pérdida de importantes conjuntos patrimoniales, que han mutilado el conocimiento del tamaño real de este legado histórico de interés mundial y fomentado el mercado ilegal de obras hacia el exterior. Uno de los aspectos que han favorecido esta dinámica ha sido la falta de documentación de las obras realmente presentes en el territorio, debido a la extensión del mismo y a las particulares realidades geográficas y sociales que lo constituyen.

La pluralidad de expresiones que componen el patrimonio artístico nacional ha dificultado la tarea de conocimiento de todas las obras que lo permean, así como el monitoreo de sus condiciones conservativas dificultando la respuesta a sus necesidades. La falta de un método de recolección de datos estandarizado ha inhibido parcialmente la gestión provechosa de las acciones conservativas y ha contribuido a la generación de esfuerzos dirigidos a mejorar algunos aspectos relacionados con el monitoreo del patrimonio. El mismo Instituto considera necesario generar un método de análisis de datos unificado y centralizado, así como resolver la dispersión y la diversidad de criterios para integrar dicha información ${ }^{138}$. Esta inquietud ha generado la creación del Sistema Único de Registro Público de Monumentos y Zonas Arqueológicas, Paleontológicas e Históricas (INAH-UNAMCONACULTA) como parte de las estrategias previstas en el plan de trabajo 20142018 dejando abierto el campo al posible desarrollo de formatos y medios para el registro y procesamiento de las informaciones, teniendo en cuenta la participación

\footnotetext{
137 INAH, GOBIERNO DE MÉXICO (2019). "80 años de proteger, investigar, conservar y difundir nuestro patrimonio cultural" en Boletín del Instituto Nacional de Antropología e Historia. <https://www.inah.gob.mx/boletines/7921-inah-80-anos-de-proteger-investigar-conservar-y-difundirnuestro-patrimonio-cultural $>$ [Consulta: 25 de febrero de 2019].

${ }^{138}$ INAH, GOBIERNO DE MÉXICO. Diagnóstico del plan de trabajo 2014-2018. <https://inah.gob.mx/images/stories/Transparencia/programa_trabajo/diagnostico.pdf> [Consulta: 7 de marzo de 2019].
} 
de personal no cualificado, apoyando la generación de una base de datos actualizadas de las obras distribuidas por el territorio ${ }^{139}$. Para evitar el mercado y tráfico ilegal de obras hacia el exterior ha sido recientemente instituido, gracias a una colaboración con el Arma de Carabineros de Italia y a su Comando para la Tutela de Patrimonio Cultural, la primera unidad de policía especializada en la protección de la propiedad cultural, un cuerpo de policía especializado en el resguardo del patrimonio cultural mexicano que colaborará con las instancias culturales, poniendo de manifiesto la necesidad de generar una base de datos que ayude a determinar los bienes posiblemente expuestos a daños o robos, facilitando la investigación, localización y recuperación de los mismos y haciendo énfasis en la tarea de conservación de este importante legado cultural a concebirse como responsabilidad común de todos los sectores de la sociedad.

Estas experiencias dejan claro el camino a seguir para prevenir la pérdida del patrimonio cultural, poniendo los procesos de catalogación y monitoreo como supuestos fundamentales para poder implementar correctas políticas de conservación y trasmisión al futuro, estableciéndolas como compromiso común a todos los estratos de la sociedad, desde las instituciones hasta llegar a la participación activa de la ciudadanía.

De acuerdo a estas premisas, la herencia cultural del país representa una ocasión de investigación única para corroborar la viabilidad de una metodología de recolección y análisis de datos unificada e inspirada en los modelos de tablas de contingencia empleadas para el análisis exploratorio de datos $\left(E D A^{140}\right)$. Para tal propósito, se han seleccionado unos casos de estudio, definidos como experienciaspiloto, cuyas características respondieran a las necesidades de aplicación y evaluación de la herramienta propuesta: una amplia heterogeneidad, dispersión geográfica y variedad técnico-material. Tras la fase inicial de experimentación y diseño del método, las tablas de recolección y análisis de datos han sido empleadas en la evaluación del estado conservativo de casos de estudio cuyo acercamiento e investigación han sido posibles gracias a la experiencia de actividad académica y docente en la Universidad Autónoma de San Luis Potosí (2014-2018).

Para las fases iniciales de desarrollo del método propuesto, el estado de San Luis Potosí brindó un medio de experimentación idóneo a tal propósito, presentando un amplio abanico de manufactos artísticos surgidos a raíz del sincretismo cultural florecido tras el contacto con la cultura europea que se sigue desarrollando hasta nuestros días. A partir de 2010 el Camino Real de Tierra Adentro (imagen 14),

\footnotetext{
${ }^{139}$ Ibídem.

${ }^{140}$ Sigla en inglés de Exploratory Data Analysis.
} 
también conocido como Ruta de la Plata, es parte de la declaratoria ${ }^{141}$ UNESCO mencionada anteriormente, poniendo de manifiesto el impacto socio-cultural derivado del crecimiento de la explotación minera llevado a cabo a partir del siglo $\mathrm{XVI}$, que ha fomentado el desarrollo de ciudades y comunidades relacionadas con las actividades y auges económicos surgidos a raíz de este fenómeno.

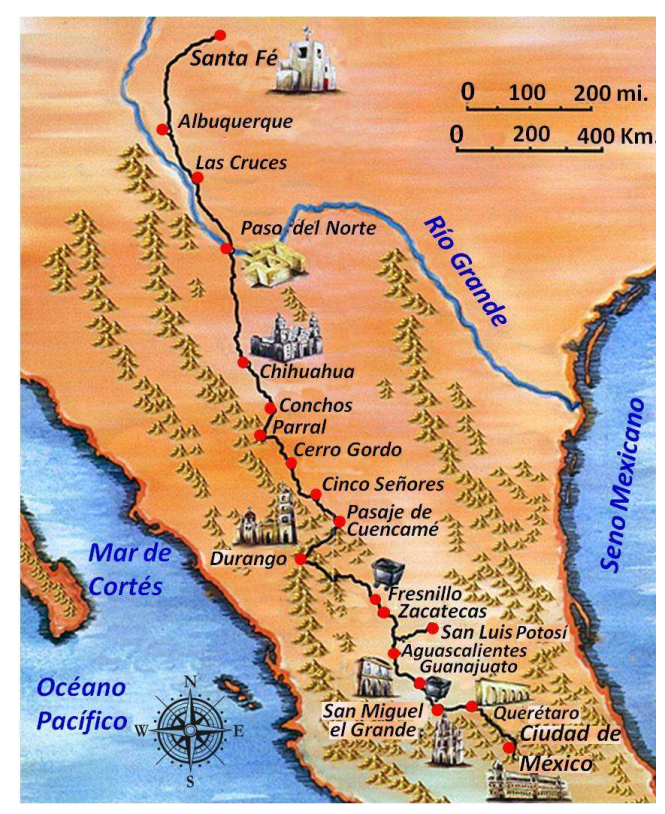

Imagen 14 - Camino Real de Tierra Adentro. Cultura y Gobierno de México, Patrimonio Mundial: Camino Real de Tierra Adentro (2010) ${ }^{142}$.

Debido a la explotación minera y a las políticas coloniales llevadas a cabo por medio de una complicada estructuración social y económica, el territorio mexicano ha sido objeto de profundas trasformaciones, las mismas que han llevado al nacimiento de diferentes núcleos urbanos, ubicados en diversas áreas de acuerdo al auge de los recursos mineros presentes. La búsqueda de oro y plata representó el motivo para que los europeos permearan el territorio, enfrentándose con diferencias culturales que en un segundo momento constituirán un sincretismo

\footnotetext{
${ }^{141}$ UNESCO (2010). “Camino Real de Tierra Adentro” en World Heritage List.

<https://whc.unesco.org/en/list/1351> [Consulta: 14 de febrero de 2019].

${ }^{142}$ GOBIERNO DE MÉXICO (2010). Camino Real de Tierra Adentro.

<https://patrimonioculturalyturismo.cultura.gob.mx/patrimonio_mundial/cultural/tierra_adentro/> [Consulta: 20 de febrero de 2020].
} 
social único. El municipio de Real de Guadalcázar y la ciudad de San Luis Potosí son directa consecuencia del desarrollo urbano a raíz de los medios presentes, fomentando la producción de obras de arte de acuerdo a las riquezas disponibles. Los aspectos económicos, históricos y sociales relacionados con la explotación de los recursos naturales y la consiguiente trasformación de la sociedad a través del tiempo quedan grabados en la morfología del tejido urbano y en las características técnico-materiales de dicho legado cultural, estrictamente ligado al estado de la economía y la riqueza de la sociedad de aquel entonces. 


\subsection{Experiencias-piloto}

Con la finalidad de delimitar las ventajas y las posibles limitaciones operativas del método propuesto, se llevaron a cabo unas experiencias piloto específicas para cada tipología de bien cultural. Persiguiendo la meta de ensayar y analizar la viabilidad del uso de las fichas de registro con criterios unificados, se seleccionaron unos elementos pertenecientes a un marco geocultural concreto. Éste, ubicado en el territorio del estado de San Luis Potosí, se encuentra relacionado con el nacimiento, desarrollo y auge de los productos artísticos que prosperaron, materializándose a través de diferentes formas y técnicas, como consecuencia del contacto con el mundo europeo.

El estado de San Luis Potosí posee la declaratoria como Patrimonio Mundial de la Humanidad (2010) por ser parte del Camino Real de Tierra Adentro, también conocido como "Ruta de la Plata", un recorrido que alcanza un total de $2.600 \mathrm{~km}$, conectando el norte de México con lo que hoy es parte de Estados Unidos: Texas y Nuevo México. Esta ruta comercial se empleó entre el siglo XVI y el XIX para transportar la plata que se extraía de las minas de Zacatecas, Guanajuato y San Luis Potosí ${ }^{143}$, estableciendo una línea de comunicación favorable a la creación e intercambio de productos artísticos fruto de este tejido socio-cultural.

Los casos seleccionados para el diseño e implementación de las tablas de contingencia presentadas en esta investigación se ubican en diferentes puntos del estado de San Luis Potosí y representan el fruto de los impulsos generados por los contactos establecidos en esta ruta y el auge económico y social de él derivado entre los siglos XVII y XX (imagen 15).

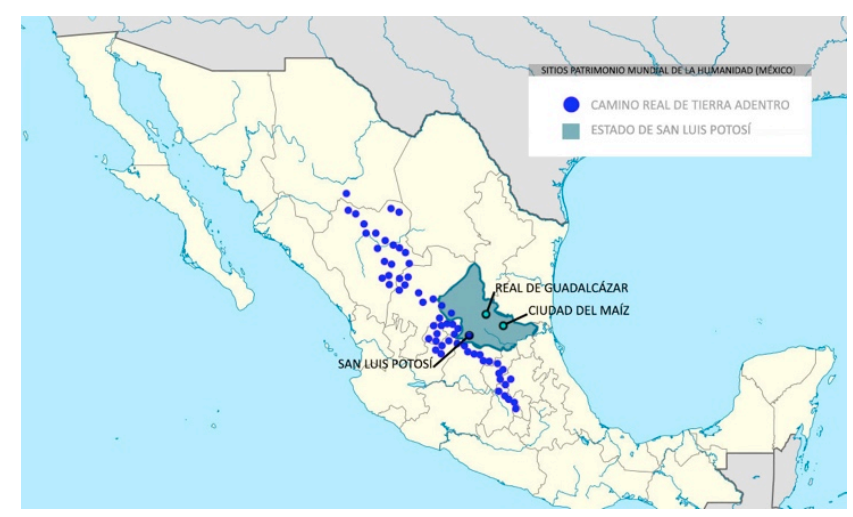

Imagen 15 - Ubicación de los casos de estudio: Real de Guadalcázar, San Luis Potosí y Ciudad del Maíz. Estado de San Luis Potosí, México.

\footnotetext{
143 UNESCO (2010). "Camino Real de Tierra Adentro" en World Heritage List.

$<$ https://whc.unesco.org/en/list/1351> [Consulta: 14 de febrero de 2019].
} 
Los casos escogidos se conservan en diferentes condiciones, y están compuestos por materiales de naturaleza orgánica e inorgánica, estructurados en obras de diferente tipología:

- Esculturas y monumentos pétreos;

- pinturas murales;

- pintura de caballete;

- esculturas en madera policromada.

De acuerdo a la clasificación del Instituto Nacional de Estadística y Geografía (INEGI), las condiciones climáticas a las que se conservan los casos de estudio expuestos a la intemperie poseen las características presentadas en la tabla 8 e imagen 16.

Tabla 8 - Climatología ${ }^{144}$ de las áreas en donde se ubican los casos de estudio de las experiencias piloto.

\begin{tabular}{|l|l|l|}
\hline CLIMA & CARACTERÍSTICAS & PRECIPITACIONES \\
\hline $\begin{array}{l}\text { Muy seco templado } \\
\text { *San Luis Potosí }\end{array}$ & $\begin{array}{l}\text { Temperaturas medias anual entre } 12^{\circ} \text { y } \\
18^{\circ} \mathrm{C} \text {, del mes más frío } \\
\text { entre }-3^{\circ} \text { y } 18^{\circ} \mathrm{C} \text { y del mes más } \\
\text { Cálido }>18^{\circ} \mathrm{C}\end{array}$ & $\begin{array}{l}\text { Régimen de lluvias de verano. } \\
\text { La precipitación total anual va de } \\
300 \text { a poco más de } 400 \mathrm{~mm}\end{array}$ \\
\hline $\begin{array}{l}\text { Semiseco semicálido } \\
\text { *Ciudad del Maíz }\end{array}$ & $\begin{array}{l}\text { Templado, temperaturas medias, anual } \\
\text { mayor de } 18^{\circ} \mathrm{C} \text {, el mes más frío inferior a } \\
18^{\circ}\end{array}$ & $\begin{array}{l}\text { Régimen de lluvias de verano. } \\
\text { Precipitación total anual de } 400 \text { y } \\
700 \mathrm{~mm} .\end{array}$ \\
\hline $\begin{array}{l}\text { Semicálido subhúmedo } \\
\text { *Guadalcázar }\end{array}$ & $\begin{array}{l}\text { Templado, temperaturas medias, } \\
\text { anual } 12^{\circ} \text { a } 18^{\circ} \mathrm{C} \text {, del mes más frío } \\
\text { entre }-3^{\circ} \text { y } 18^{\circ} \mathrm{C}\end{array}$ & $\begin{array}{l}\text { Régimen de lluvias de verano. } \\
\text { Precipitación total anual entre } 700 \\
\text { y } 1000 \text { mm }\end{array}$ \\
\hline
\end{tabular}

144 INEGI (2002). Síntesis de Información geográfica del estado de San Luis Potosí. <https://www.inegi.org.mx/contenidos/productos/prod_serv/contenidos/espanol/bvinegi/productos/histo ricos/2104/702825224240/702825224240_5.pdf> [Consulta: 27 de febrero de 2021]. 


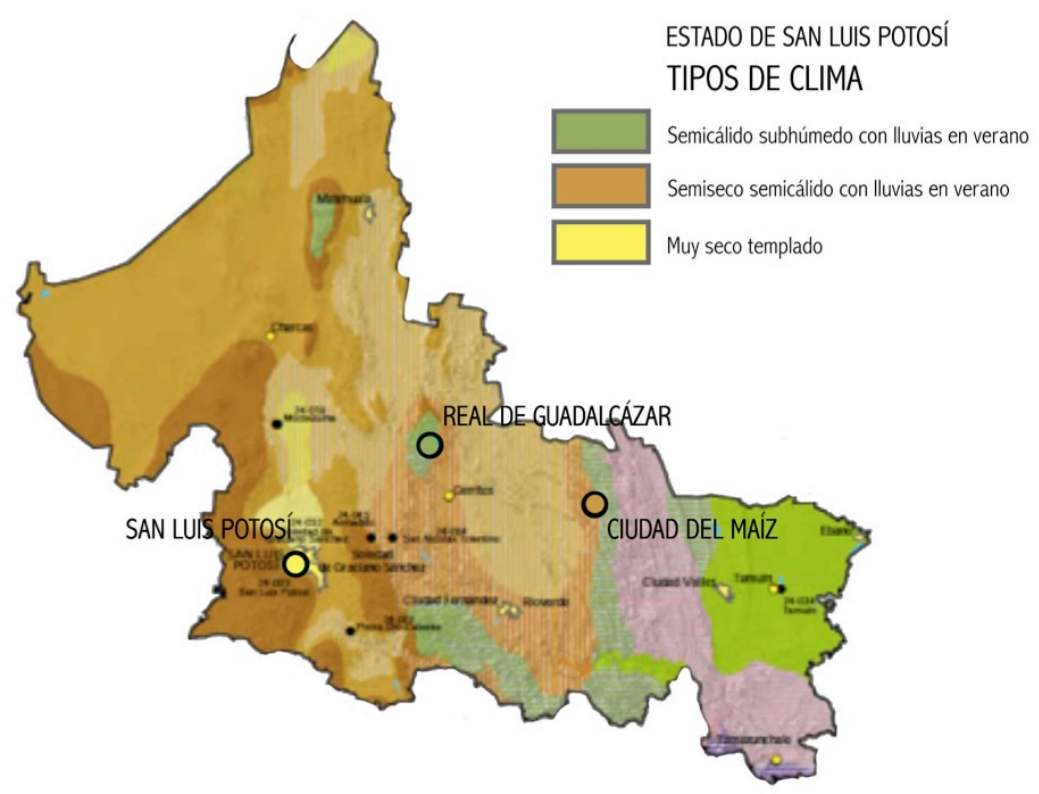

Imagen 16 - Climatología del estado de San Luis Potosi ${ }^{145}$.

La conformación de los sistemas y el medio en el que se conservan han ofrecido un conjunto de experiencias-piloto útil para analizar los procesos de toma de datos en términos de inversión de tiempo y recursos, y evaluar la calidad de informaciones arrojadas. De acuerdo a la meta propuesta, se ha buscado brindar un enfoque general del estado de las diferentes colecciones, destacando las causas de alteración y deterioro a partir del registro de los efectos y morfología de los mismos manifestados en los materiales, evaluando al mismo tiempo la calidad de las informaciones ofrecidas al profesional.

Los casos seleccionados a tal fin han sido el conjunto de pinturas murales pertenecientes al movimiento muralista del estado de San Luis Potosí, el Panteón Municipal del Saucito de la capital del omónimo estado y el Museo de Arte Sacro de Real de Guadalcázar (S.L.P.).

El valor de representatividad de los conjuntos patrimoniales escogidos, responde a la necesidad de aplicar el método implementado y determinar las

\footnotetext{
${ }^{145}$ Transformado de: INEGI: Continuo Nacional del Conjunto de Datos Geográficos de la Carta de Climas, serie I, en Clima del estado de San Luis Potosí del 15 de marzo de 2019. <https://www.paratodomexico.com/estados-demexico/estado-san-luis-potosi/clima-san-luis-potosi.html> [Consulta: 27 de febrero de 2021].
} 
posibles mejorías a considerarse, para que éste sea efectivo y genere informaciones representativas y funcionales a la determinación de una escala de riesgo, que pueda a su vez enfocar la atención y dirigir de forma provechosa las actividades y medidas conservativas, de diagnóstico y estudio específicas.

\subsubsection{Murales del siglo XX (San Luis Potosí y Ciudad del Maíz)}

Los murales realizados en México a partir del siglo XX constituyen un importante testigo de las temáticas sociales y políticas que animaron el país. El impulso de la educación y del arte junto a la valorización y exaltación de la cultura e historia mexicana fueron focos de inspiración para la producción de varias obras en diferentes ciudades, con mayor énfasis en la capital. El objetivo de difundir a todos los estratos sociales de la población este nuevo espíritu de reforma e innovación, favoreció la producción de un amplio abanico de obras, realizadas en mayor medida en edificios y espacios públicos empleados como medios de difusión de esta renovada energía cultural.

La manifestación muralista del estado potosino se compone por un conjunto heterogéneo de obras que, con finalidades de estudio, ha sido reunido en un único un grupo de elementos unificado (tabla 9).

Tabla 9 - Panorámica de las tipología de murales pertenecientes al conjunto de estudio. En donde especificado, "P" corresponde a la autoría del proyecto, " $E$ " a la ejecución técnica.

\begin{tabular}{|c|c|c|c|c|}
\hline \multirow[b]{2}{*}{ TíTULO } & \multicolumn{3}{|c|}{ TÉCNICA } & \multirow[b]{2}{*}{ UBICACIÓN } \\
\hline & $\begin{array}{l}\text { PINTURA } \\
\text { AL FRESCO }\end{array}$ & $\begin{array}{l}\text { PINTURA } \\
\text { ACRÍLICA }\end{array}$ & MOSAICO & \\
\hline $\begin{array}{l}\text { EL TRIUNFO DE LA } \\
\text { LOCOMOTORA (1943) } \\
\text { Fernando Leal }\end{array}$ & $\mathrm{X}$ & & & \multirow{4}{*}{$\begin{array}{l}\text { Museo Del Ferrocarril } \\
\text { "Jesús García Corona" } \\
\text { San Luis Potosí (S.L.P.) }\end{array}$} \\
\hline $\begin{array}{l}\text { LA EDAD DE LA MÁQUINA (1943) } \\
\text { Fernando Leal }\end{array}$ & $x$ & & & \\
\hline $\begin{array}{l}\text { ARQUITECTURA POTOSINA } \\
(1947) \\
\text { F. Leal (P) - Juan López (E) }\end{array}$ & $\mathrm{X}$ & & & \\
\hline $\begin{array}{l}\text { MAPA DEL ESTADO DE SAN LUIS } \\
\text { POTOSÍ (1947) } \\
\text { F. Leal (P) - Félix Rojas (E) }\end{array}$ & $\mathrm{X}$ & & & \\
\hline $\begin{array}{l}\text { LA GLORIFICACIÓN DE SANTO } \\
\text { DOMINGO DE GUZMÁN (1944- } \\
47) \\
\text { Fernando Leal }\end{array}$ & $x$ & & & $\begin{array}{l}\text { Templo de San Juna de Dios } \\
\text { (ex Iglesia de Santo } \\
\text { Domingo) } \\
\text { San Luis Potosí (S.L.P.) }\end{array}$ \\
\hline $\begin{array}{l}\text { ASUNTOS VARIOS (1958-59) } \\
\text { J.G. Íñiguez (P-D) - Varios (E) }\end{array}$ & $x$ & & & $\begin{array}{l}\text { Internado Damián Carmona, } \\
\text { San Luis Potosí (S.L.P.) }\end{array}$ \\
\hline
\end{tabular}




\begin{tabular}{|c|c|c|c|c|}
\hline \multirow[t]{2}{*}{ TÍTULO } & \multicolumn{3}{|c|}{ TÉCNICA } & \multirow{2}{*}{ UBICACIÓN } \\
\hline & $\begin{array}{c}\text { PINTURA } \\
\text { AL FRESCO }\end{array}$ & $\begin{array}{l}\text { PINTURA } \\
\text { ACRÍLICA }\end{array}$ & MOSAICO & \\
\hline $\begin{array}{l}\text { SOTOCORO sx (1960) } \\
\text { Juan Blanco Rodríguez de } \\
\text { la Cruz (P-E) }\end{array}$ & $x$ & & & \multirow{2}{*}{$\begin{array}{l}\text { Santuario de Nuestra Señora De } \\
\text { Guadalupe (o Basílica Menor) } \\
\text { San Luis Potosí (S.L.P.) }\end{array}$} \\
\hline $\begin{array}{l}\text { SOTOCORO dx (1960) } \\
\text { Juan Blanco Rodríguez de } \\
\text { la Cruz (P-E) }\end{array}$ & $x$ & & & \\
\hline $\begin{array}{l}\text { LA REVOLUCIÓN } \\
\text { MEXICANA Y LA } \\
\text { JUVENTUD POTOSINA } \\
\text { (1961) } \\
\text { Arturo Estrada (P - E) }\end{array}$ & $x$ & & & $\begin{array}{l}\text { Casa de la Juventud en San Luis } \\
\text { Potosí (CREA) } \\
\text { INPOJUVE } \\
\text { San Luis Potosí (S.L.P.) }\end{array}$ \\
\hline $\begin{array}{l}\text { ALEGORÍA RITUAL (1954) } \\
\text { Rosendo Soto }\end{array}$ & & & $x$ & \multirow{2}{*}{$\begin{array}{l}\text { Muro Exterior Del Rancho } \\
\text { "El Tepeyac" } \\
\text { Ciudad del Maíz (S.L.P.) }\end{array}$} \\
\hline $\begin{array}{l}\text { TRANSFORMACIÓN DEL } \\
\text { TEPEYAC (1954) } \\
\text { Rosendo Soto - Jorge Best }\end{array}$ & & & $x$ & \\
\hline $\begin{array}{l}\text { LA DANZA DE } \\
\text { XOCHIQUETZALLI (1958) } \\
\text { F. Leal (P) - Ramón } \\
\text { Sánchez (MOS) }\end{array}$ & & & $x$ & \multirow[t]{4}{*}{$\begin{array}{l}\text { Teatro de La Paz, } \\
\text { San Luis Potosí (S.L.P.) }\end{array}$} \\
\hline $\begin{array}{l}\text { REPRESENTACIÓN DE LA } \\
\text { CELESTINA (1958) } \\
\text { F. Leal (P) - Ramón } \\
\text { Sánchez (MOS) }\end{array}$ & & & $x$ & \\
\hline $\begin{array}{l}\text { UNA PASTORCILLA A } \\
\text { FINES DE LA COLONIA } \\
\text { (1958) } \\
\text { F. Leal (P) - Ramón } \\
\text { Sánchez (MOS) }\end{array}$ & & & $x$ & \\
\hline $\begin{array}{l}\text { LA GORDA Y EL FLACO EN } \\
\text { UNA CARPA (1958) } \\
\text { F. Leal (P) - Ramón } \\
\text { Sánchez (MOS) }\end{array}$ & & & $x$ & \\
\hline $\begin{array}{l}\text { HOTEL FIESTA INN (1959) } \\
\text { Juan Blanco Rodríguez de } \\
\text { la Cruz }\end{array}$ & & & $x$ & $\begin{array}{l}\text { Hotel Fiesta INN } \\
\text { San Luis Potosí (S.L.P.) }\end{array}$ \\
\hline $\begin{array}{l}\text { CAPILLA } \\
\text { Juan Blanco Rodríguez de } \\
\text { la Cruz }\end{array}$ & & $x$ & & $\begin{array}{l}\text { Capilla del Cristo Rey } \\
\text { San Luis Potosí (S.L.P.) }\end{array}$ \\
\hline
\end{tabular}




\begin{tabular}{|l|c|c|c|c|}
\hline \multirow{2}{*}{ TíTULO } & \multicolumn{2}{|c|}{ TÉCNICA } & \multirow{2}{*}{ UBICACIÓN } \\
\cline { 2 - 4 } & $\begin{array}{c}\text { PINTURA } \\
\text { AL FRESCO }\end{array}$ & $\begin{array}{c}\text { PINTURA } \\
\text { ACRÍLICA }\end{array}$ & MOSAICO & \\
\hline $\begin{array}{l}\text { EL SAUCE EN FORMA DE } \\
\text { CRUZ (1943) Juan Blanco } \\
\text { Rodríguez de la Cruz }\end{array}$ & & $X$ & & $\begin{array}{l}\text { Nave del Santuario } \\
\text { de Nuestro Señor del Saucito, } \\
\text { San Luis Potosí (S.L.P.) }\end{array}$ \\
\hline $\begin{array}{l}\text { LA TRANSLACIÓN DEL } \\
\text { ÁRBOL (1943) Juan Blanco } \\
\text { Rodríguez de la Cruz }\end{array}$ & & X & & \\
\hline $\begin{array}{l}\text { LA FE EN CRISTO } \\
\text { REDENTOR (1943) Juan } \\
\text { Blanco Rodríguez de la } \\
\text { Cruz }\end{array}$ & & & & \\
\hline $\begin{array}{l}\text { LA IDEA DE TALLAR LA } \\
\text { IMAGEN DE CRISTO CON } \\
\text { DICHA MADERA (1943) } \\
\text { Juan Blanco Rodríguez de } \\
\text { la Cruz }\end{array}$ & & & & \\
\hline TOTAL OBRAS & & & & \\
\hline
\end{tabular}

Con el propósito de tutelar y conservar este Patrimonio de inmenso valor social, cultural y artístico destaca la importancia y la necesidad de llevar a cabo una labor de recolección y actualización de las informaciones sobre el estado de salud de este conjunto, para planificar de forma provechosa actividades de gestión, protección y conservación. Para lograr dichos objetivos y cubrir las exigencias de conservación y protección de las obras presentes en el territorio es necesario alcanzar un profundo conocimiento de las mismas. La documentación y estudio exhaustivos de los murales constituye sin duda el primer paso para aprovechar y emplear los recursos de forma funcional y exitosa, por ello el diseño y aplicación del método vio luz por primera vez en 2015-2016 en ocasión del desarrollo del proyecto de investigación "Pinturas murales del siglo XX: estudio, análisis e índice de riesgo" llevado a cabo en la Universidad Autónoma de San Luis Potosí gracias a los Fondos de Apoyo a la Investigación ${ }^{146}$.

El grupo de murales creados en el siglo XX con varias técnicas de muralismo en auge en aquel entonces, ofrecen la posibilidad de corroborar la viabilidad en la aplicación del método sobre obras ubicadas en diferentes áreas geográficas

\footnotetext{
146 Fondos de Apoyo a la Investigación FAI 2015 otorgados a través de la Secretaría de Investigación y Posgrado SIP de la Universidad Autónoma de San Luis Potosí.
} 
(imágenes 17 y 18) y expuestas a condiciones conservativas variadas ${ }^{147}$ (tabla 10, imágenes 19 y 20), contemplándose la comparación entre los resultados y permitiendo llevar a cabo un análisis de informaciones globales a nivel estatal.

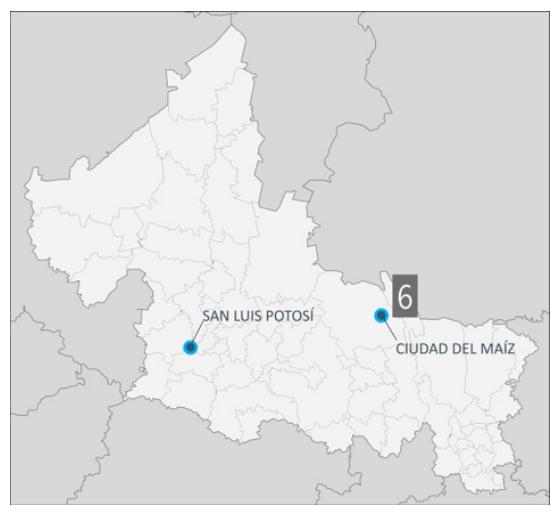

Imagen 17 - Ubicación de los murales en el estado de San Luis Potosí.

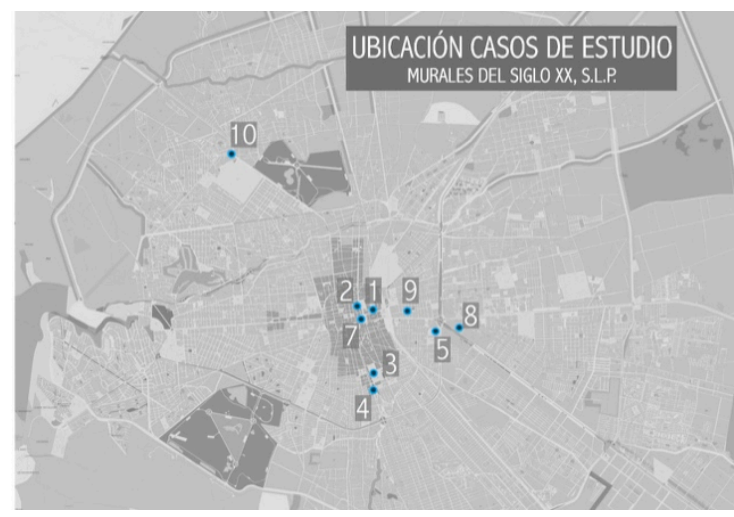

Imagen 18 - Ubicación de los murales en la capital del estado $^{148}$

Tabla 10 - Condiciones de conservación de los testigos del movimiento muralista potosino.

\begin{tabular}{|l|c|c|c|}
\hline \multirow{2}{*}{ TíTULO } & \multicolumn{1}{|c|}{ CONTEXTO DE CONSERVACIÓN EN RELACIÓN AL EDIFICIO } \\
\cline { 2 - 4 } & INTERIOR & \multicolumn{2}{|c|}{ EXTERIOR } \\
\cline { 2 - 4 } & & $\begin{array}{c}\text { PROTEGIDO POR } \\
\text { ESTRUCTURAS } \\
\text { ARQUITECTÓNICAS }\end{array}$ & $\begin{array}{c}\text { EXPESTO } \\
\text { DIRECTAMENTE A } \\
\text { LA INTEMPERIE }\end{array}$ \\
\hline $\begin{array}{l}\text { EL TRIUNFO DE LA LOCOMOTORA (1943) } \\
\text { Fernando Leal }\end{array}$ & $\mathrm{X}$ & \\
\hline $\begin{array}{l}\text { LA EDAD DE LA MÁQUINA (1943) } \\
\text { Fernando Leal }\end{array}$ & $\mathrm{X}$ & \\
\hline
\end{tabular}

147 Los murales se encuentran en condiciones conservativas variadas, debido a la pluralidad de contextos en los que se conservan: en el interior de edificios, al exterior, parcialmente protegidos por las estructuras arquitectónicas o en estado de abandono.

${ }^{148}$ Mapa modificado de CONSEJO DEL CENTRO HISTÓRICO DE SAN LUIS POTOSÍ. "La ciudad de San Luis en la actualidad" en La fundación de San Luis Potosí. <https://centrohistoricoslp.com/planos-historicos/> [Consulta: 15 de agosto de 2018]. 


\begin{tabular}{|c|c|c|c|}
\hline \multirow{3}{*}{ TítULO } & \multicolumn{3}{|c|}{ CONTEXTO DE CONSERVACIÓN EN RELACIÓN AL EDIFICIO } \\
\hline & \multirow{2}{*}{ INTERIOR } & \multicolumn{2}{|c|}{ EXTERIOR } \\
\hline & & $\begin{array}{l}\text { PROTEGIDO POR } \\
\text { ESTRUCTURAS } \\
\text { ARQUITECTOONICAS }\end{array}$ & $\begin{array}{l}\text { EXPUESTO } \\
\text { DIRECTAMENTE A } \\
\text { LA INTEMPERIE }\end{array}$ \\
\hline $\begin{array}{l}\text { ARQUITECTURA POTOSINA (1947) } \\
\text { F. Leal (P) - Juan López (E) }\end{array}$ & $x$ & & \\
\hline $\begin{array}{l}\text { MAPA DEL ESTADO DE SAN LUIS POTOSÍ } \\
(1947) \\
\text { F. Leal (P) - Félix Rojas (E) }\end{array}$ & $\mathrm{x}$ & & \\
\hline $\begin{array}{l}\text { LA GLORIFICACIÓN DE SANTO DOMINGO } \\
\text { DE GUZMÁN (1944-47) } \\
\text { Fernando Leal }\end{array}$ & $\mathrm{x}$ & & \\
\hline $\begin{array}{l}\text { ASUNTOS VARIOS (1958-59) } \\
\text { J.G. Î̃niguez (P-D) - Varios (E) }\end{array}$ & & $\mathrm{x}$ & \\
\hline $\begin{array}{l}\text { SOTOCORO sx (1960) } \\
\text { Juan Blanco Rodríguez de la Cruz (P-E) }\end{array}$ & $\mathrm{x}$ & & \\
\hline $\begin{array}{l}\text { SOTOCORO dx (1960) } \\
\text { Juan Blanco Rodríguez de la Cruz (P-E) }\end{array}$ & $\mathrm{x}$ & & \\
\hline $\begin{array}{llll}\text { LA } & \text { REVOLUCIÓN MEXICANA } & \text { Y } & \text { LA } \\
\text { JUVENTUD POTOSINA (1961) } & & \\
\text { Arturo Estrada (P - E) } & & \end{array}$ & $\mathrm{x}$ & & \\
\hline $\begin{array}{l}\text { ALEGORÍA RITUAL (1954) } \\
\text { Rosendo Soto }\end{array}$ & & & $\mathrm{x}$ \\
\hline $\begin{array}{l}\text { TRANSFORMACIÓN DEL TEPEYAC (1954) } \\
\text { Rosendo Soto - Jorge Best }\end{array}$ & & & $x$ \\
\hline $\begin{array}{l}\text { LA DANZA DE XOCHIQUETZALLI (1958) } \\
\text { F. Leal (P) - Ramón Sánchez (MOS) }\end{array}$ & $\mathrm{x}$ & & \\
\hline $\begin{array}{l}\text { REPRESENTACIÓN DE LA CELESTINA (1958) } \\
\text { F. Leal (P) - Ramón Sánchez (MOS) }\end{array}$ & $\mathrm{x}$ & & \\
\hline $\begin{array}{l}\text { UNA PASTORCILLA A FINES DE LA } \\
\text { COLONIA (1958) } \\
\text { F. Leal (P) - Ramón Sánchez (MOS) }\end{array}$ & $\mathrm{x}$ & & \\
\hline $\begin{array}{l}\text { LA GORDA Y EL FLACO EN UNA CARPA } \\
\text { (1958) } \\
\text { F. Leal (P) - Ramón Sánchez (MOS) }\end{array}$ & $\mathrm{x}$ & & \\
\hline $\begin{array}{l}\text { HOTEL FIESTA INN (1959) } \\
\text { Juan Blanco Rodríguez de la Cruz }\end{array}$ & & & $x$ \\
\hline $\begin{array}{l}\text { CAPILLA } \\
\text { Juan Blanco Rodríguez de la Cruz }\end{array}$ & $\mathrm{x}$ & & \\
\hline
\end{tabular}




\begin{tabular}{|c|c|c|c|}
\hline \multirow{3}{*}{ TítULO } & \multicolumn{3}{|c|}{ CONTEXTO DE CONSERVACIÓN EN RELACIÓN AL EDIFICIO } \\
\hline & \multirow{2}{*}{ INTERIOR } & \multicolumn{2}{|c|}{ EXTERIOR } \\
\hline & & $\begin{array}{c}\text { PROTEGIDO POR } \\
\text { ESTRUCTURAS } \\
\text { ARQUITECTÓNICAS }\end{array}$ & $\begin{array}{c}\text { EXPUESTO } \\
\text { DIRECTAMENTE A } \\
\text { LA INTEMPERIE }\end{array}$ \\
\hline $\begin{array}{l}\text { EL SAUCE EN FORMA DE CRUZ (1943) Juan } \\
\text { Blanco Rodríguez de la Cruz }\end{array}$ & $\mathrm{x}$ & & \\
\hline $\begin{array}{l}\text { LA TRANSLACIÓN DEL ÁRBOL (1943) Juan } \\
\text { Blanco Rodríguez de la Cruz }\end{array}$ & $\mathrm{x}$ & & \\
\hline $\begin{array}{l}\text { LA FE EN CRISTO REDENTOR (1943) Juan } \\
\text { Blanco Rodríguez de la Cruz }\end{array}$ & $\mathrm{x}$ & & \\
\hline $\begin{array}{l}\text { LA IDEA DE TALLAR LA IMAGEN DE CRISTO } \\
\text { CON DICHA MADERA (1943) } \\
\text { Juan Blanco Rodríguez de la Cruz }\end{array}$ & $\mathrm{x}$ & & \\
\hline TOTAL OBRAS & 17 & 2 & 2 \\
\hline
\end{tabular}

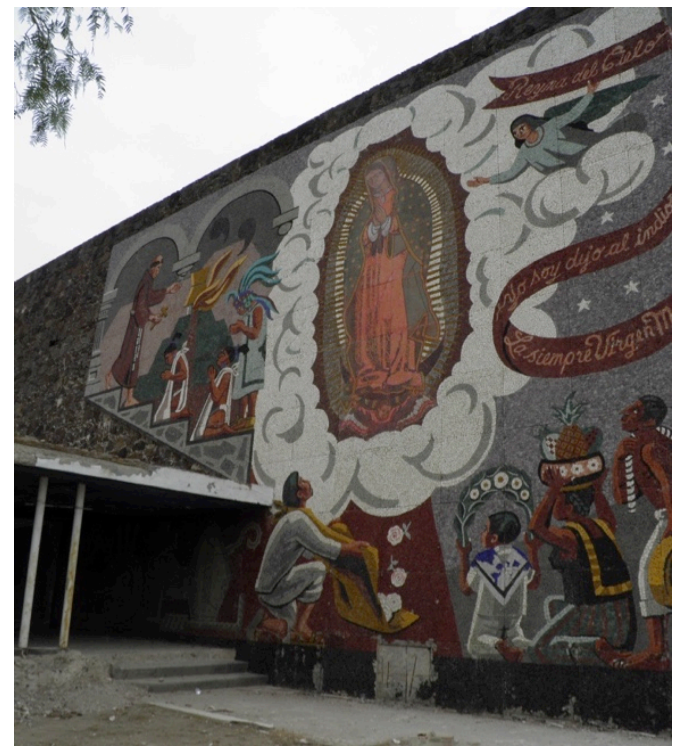

Imagen 19 - Mural realizado en mosaico pétreo (Ciudad del Maíz, S.L.P.), en estado de abandono y expuesto a la intemperie.

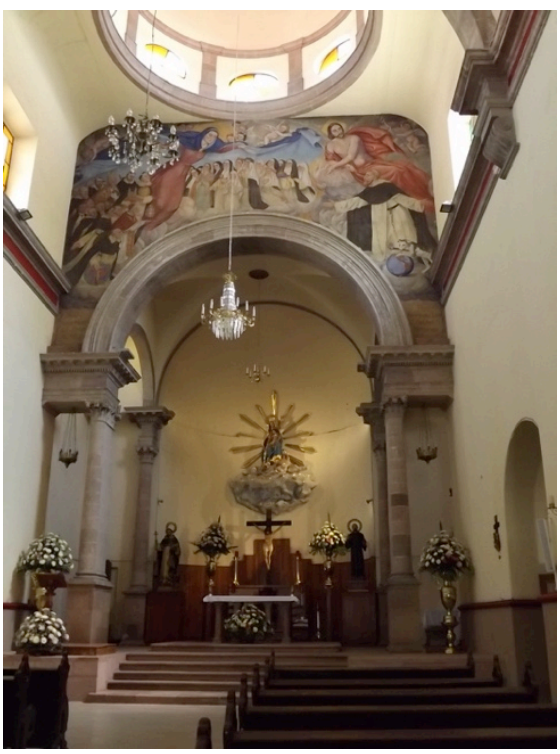

Imagen 20 - Pintura mural al fresco custodiada en el templo de San Juan de Dios, en el centro histórico de la ciudad. 


\subsubsection{Panteón Municipal del Saucito (San Luis Potosí, S.L.P.)}

El Panteón Monumental de Saucito se encuentra en la homónima localidad de la ciudad capital del estado de San Luis Potosí. Este recinto funerario ha sido realizado a partir del año $1889^{149}$, como resultado de las políticas de salubridad adoptadas por la ciudad, y en conformidad con las tendencias adoptadas en ámbito europeo de ubicar las áreas destinadas a cementerio en las afueras de los recintos urbanos.

El conjunto de monumentos funerarios ubicados en el Panteón del Saucito, compuestos por diferentes materiales pétreos y creados a lo largo del siglo XIX y XX, ofrecen la posibilidad de contrastar las hipótesis derivadas del análisis y formulación de índices de riesgos de obras expuestas a la intemperie en un recinto definido (imágenes 21 y 22), con peculiaridades que responden a las exigencias de la investigación como el elevado número de obras, la variedad de deterioros presentes y la necesidad de establecer áreas de riesgo en vista de unas posibles acciones de conservación.

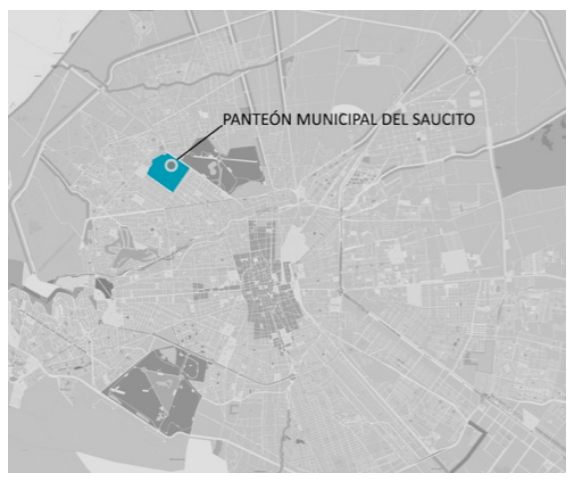

Imagen 21 - Ubicación del Panteón Municipal del Saucito ${ }^{150}$ en la traza urbana de la ciudad de San Luis Potosí.

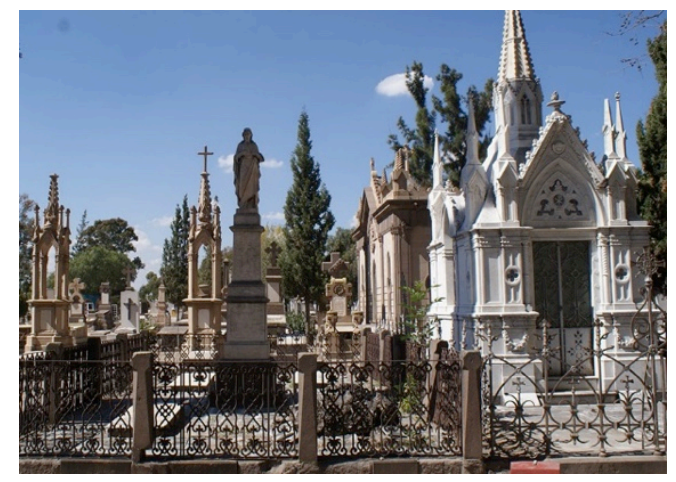

Imagen 22 - Imagen general ${ }^{151}$ del contexto de estudio.

${ }^{149}$ VÁZQUEZ SALGUERO, D. y CORRAL BUSTOS, A., (2004). Monumentos funerarios del Saucito, San Luis Potosí, 1889-1916. San Luis Potosí: El Colegio de San Luis COLSAN.

150 Mapa modificado de CONSEJO DEL CENTRO HISTÓRICO DE SAN LUIS POTOSÍ. "La ciudad de San Luis en la actualidad" en La fundación de San Luis Potosí. <https://centrohistoricoslp.com/planos-historicos/> [Consulta: 15 de agosto de 2018].

151 "Panteón del Saucito, 127 años de historia" en Plano informativo, 02 de noviembre de 2016 <http://planoinformativo.com/488447/panteon-del-saucito-127-anos-de-historia-slp> [Consulta: 15 de agosto de 2018]. 
Las obras funerarias se encuentran expuestas a la intemperie y gozan de un sistema de mantenimiento organizado según los reglamentos de cuidado al que se ciñen los operadores del cementerio ${ }^{152}$, junto a acciones extraordinarias de conservación que dependen de los herederos o tutores legales de las obras ${ }^{153}$.

Debido a la extensión del panteón, que alcanza una superficie ${ }^{154}$ total de 66.33 hectáreas de las cuales 6.44 corresponden a la sola área monumental ${ }^{155}$, éste se organiza por cuadrantes distribuidos alrededor de ejes viales que corresponden a las calles internas (imagen 23 y 24). El núcleo principal conecta la entrada con el templo y custodia obras de valor histórico-artístico destacable, cuyo estado de conservación es mejor frente a las demás áreas. Con fines de estudio se elijieron manzanas colindantes con el eje principal y caracterizadas por una elevada variedad de elementos y fenómenos de deterioro.

152 Las acciones de mantenimiento y cuidado del recinto del cementerio se llevan a cabo gracias a la coordinación de diferentes dependencias municipales de la ciudad de San Luis Potosí: Dirección del Cementerio del Saucito, Dirección de Servicios Municipales, Ecología y Aseo Público, Obras Públicas, Imagen Urbana y Parques y Jardines. GOBIERNO MUNICIPAL SAN LUIS POTOSÍ, H. AYUNTAMIENTO DE SAN LUIS POTOSÍ 2018-2021. Ayuntamiento da mantenimiento al Panteón del Saucito con motivo del día de las madres. $<$ https://sanluis.gob.mx/ayuntamiento-da-mantenimiento-al-panteon-del-saucito-con-motivo-del-dia-delas-madres/> [Consulta: 16 de junio de 2020].

153 Cabe destacar que, por razones derivadas de la época de pertenencia de los monumentos custodiados en el panteón, los mismos dependen de la tutela de diferentes instituciones. Para los realizados en el siglo XIX su conservación depende del INAH, mientras los del siglo XX se reúnen bajo la protección del INBALCENCROPAM. Desde hace varios años hubo varias iniciativas dirigidas a la conservación y restauración de los testigos de arte funerario custodiados en el cementerio y en la actualidad la situación sigue a la espera de una toma de acción coordenada entre los agentes encargados de su protección. "El Saucito, cementerio de San Luis, tendrá su museo a partir de agosto" en Crónica Cultura, 26 de abril de 2015. <https://www.cronica.com.mx/notas/2015/895571.html> [Consulta 16 de junio de 2020].

154 La extensión superficial ha sido elaborada por medio de la herramienta de cálculo de Google Maps <https://www.calcmaps.com/es/map-area/> [Consulta: 27 de febrero de 2021].

155 Estas áreas corresponden respectivamente a una extensión de $0.66 \mathrm{~km}^{2}$ para la superficie total y de 0.06 $\mathrm{km}^{2}$ para los cuadrantes a carácter monumental. 


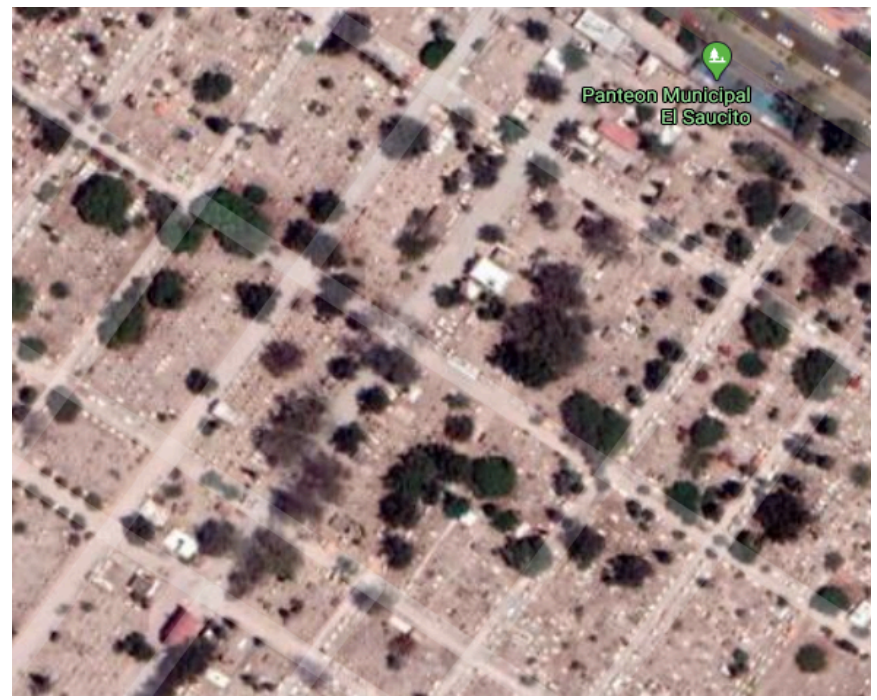

Imagen 23 - Visión satelital ${ }^{156}$ del Panteón del Saucito. En esta toma se puede apreciar la densidad de elementos presentes en los cuadrantes. El eje central correspone a la avenida en la que se custodian los monumentos mejor conservados.

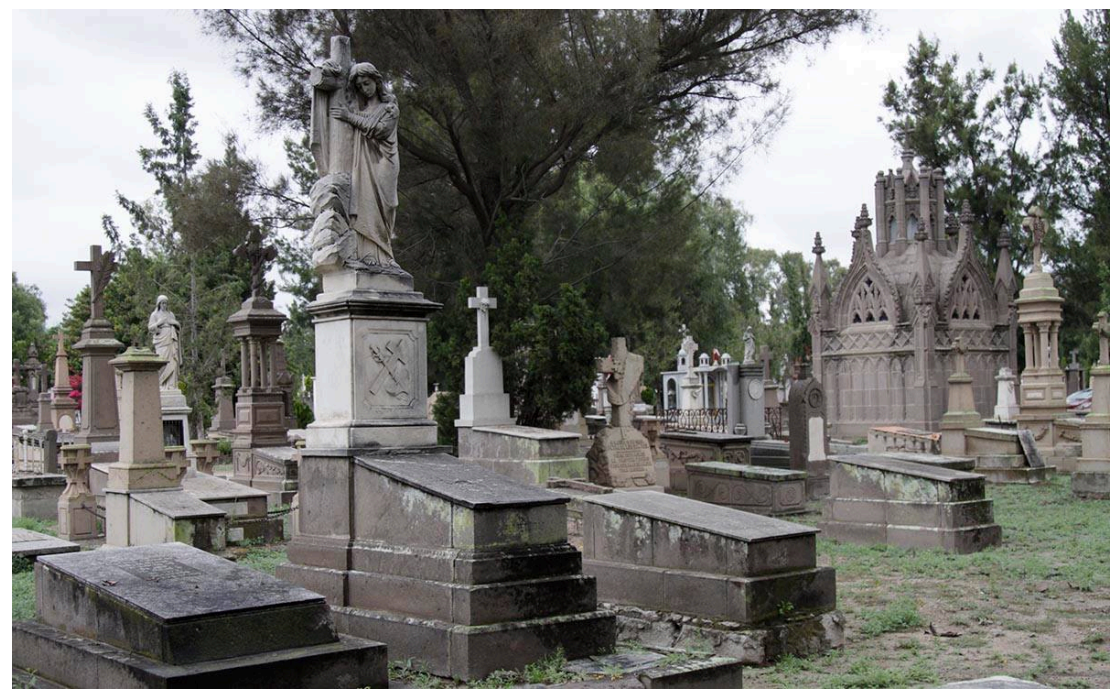

Imagen 24 - Visual ${ }^{157}$ de la densidad de monumentos funerarios presentes en el área monumental.

156 Google Maps, vista satelital online. Panteón del Saucito. <https://www.google.com/maps/@22.18112,$100.9997383,280 \mathrm{~m} /$ data=!3m1!1e3> [Consulta: 17 de junio de 2020]. 


\subsubsection{Museo de Arte Sacro (Real de Guadalcázar, S.L.P.)}

El municipio, fundado en 1608 con el título de "Villa y minas de San Pedro", recibe el nombre de "Real de Guadalcázar" en 1614, a partir de las palabras árabes guada (río) y alcázar (fortaleza) ${ }^{158}$. Se ubica a unos $94 \mathrm{~km}$ al noreste de la capital del estado de San Luis Potosí. El conjunto parroquial, realizado en el siglo XVIII, ha sido el foco espiritual de las comunidades cercanas y custodia hoy en día importantes testigos histórico-artísticos de la actividad religiosa, económica y devocional de la comunidad. Estos vestigios se resguardan en el Museo de Arte Sacro, fundado en diciembre de $2011^{159}$, gracias a la adaptación de un área del edificio histórico perteneciente al conjunto parroquial. Éste cuenta con dos espacios comunicantes, formados por una nave de bóveda de arista que confluye en una capilla cerrada al culto. En este recinto se custodian varias tipologías de obras de arte sacro, constituidas por materiales cuales metales, textiles, madera policromada y lienzos entre otros, además de elementos de mobiliarios, misales, candelabros, ornamentos, casullas bordadas en oro y plata y vestimentas litúrgicas. La mayoría de los objetos pertenecen al siglo XVIII y una pequeña porción a los siglos XVII y XIX. Las obras fueron creadas para los templos del entonces Real de Guadalcázar, por lo que se puede afirmar que se encuentran en su contexto casi original ${ }^{160}$.

El conjunto de pinturas sobre lienzo y esculturas en madera policromada seleccionadas para la aplicación del método de registro propuesto se custodian indistintamente en las dos alas que componen el Museo de Arte Sacro (imagen 25 y 26), cuyo acceso se encuentra en un ala lateral independiente.

157 "Panteón de El Saucito cumple 127 años" en Código San Luis, 2 de noviembre de 2016. $<$ https://archivo.codigosanluis.com/panteon-de-el-saucito-cumple-127-anos/> [Consulta: 27 de febrero de 2021].

${ }^{158}$ INAFED, GOBIERNO DE MÉXICO. "Estado de San Luis Potosí" en Enciclopedia de los Municipios y Delegaciones de México. <http://siglo.inafed.gob.mx/enciclopedia/EMM24sanluispotosi/municipios/24017a.html> [Consulta: 10 de junio de 2020].

159 SIC, GOBIERNO DE MÉXICO (2019). "Museo de Arte Sacro de San Pedro de Guadalcázar" en Museos, San Luis Potosí. <https://sic.cultura.gob.mx/ficha.php?table=museo\&table_id=1110> [Consulta: 20 de febrero de 2019].

${ }^{160}$ Ibídem. 


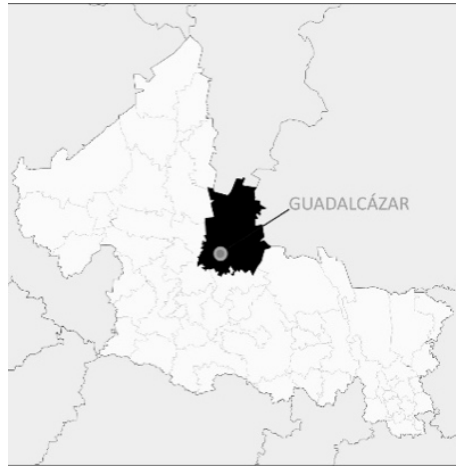

Imagen 25 - Ubicación del caso de estudio.

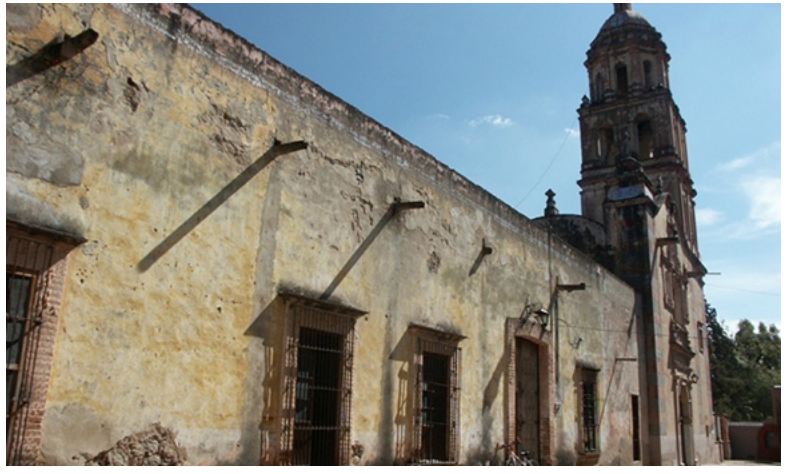

Imagen 26 - vista del edificio (Foto: SIC-GOBIERNO DE MÉXICO, 2019) que alberga el Museo de Arte Sacro de la Parroquia de San Pedro (Real de Guadalcázar, S.L.P.).

Las obras elegidas como experiencias piloto han sido realizadas en los siglos XVIII y XIX. Las esculturas policromadas son de autor anónimo y representan santos y figuras religiosas (imagen 27), mientras la colección de pinturas se compone por lienzos de diferente tipología. Parte de ellos representan escenas de la vida de la Virgen, cuya autoría pertenece al pintor novohispano Francisco Martínez ${ }^{161}$ (imágenes 28 y 29) y otros, de sujeto devocional, son de autores desconocidos.

\footnotetext{
${ }^{161}$ Francisco Martínez, fue un pintor novohispano, ensamblador y dorador de retablos, decorador de fiestas efímeras. Gozó de grande prestigio, su periodo de actividad se concentra entre 1717 y 1758, dejando testigos de su producción sobre todo en Ciudad de México: en la Catedral de la ciudad se ubica el retablo Mayor (1743) y en la Iglesia de Regina Coeli, se resguardan algunas de sus pinturas. A partir de 1737, como evidencia de su relevancia profesional, ocupó el puesto de calificador del Santo Oficio. ALCALÁ DONEGONI, L.E. (1999). "La obra del pintor novohispano Francisco Martínez" en Anales del Museo de América, no 7, UAM, Departamento de Historia y Teoría del Arte, Ministerio de Educación Cultura y Deporte, Subdirección General de Documentación y Publicaciones, Gobierno de España, pp. 175-187. <https://repositorio.uam.es/bitstream/handle/10486/671800/obra_alcala_ama_1999.pdf?sequence=1\&isAll owed $=\mathrm{y}>$ [Consulta: 10 de enero de 2021].
} 


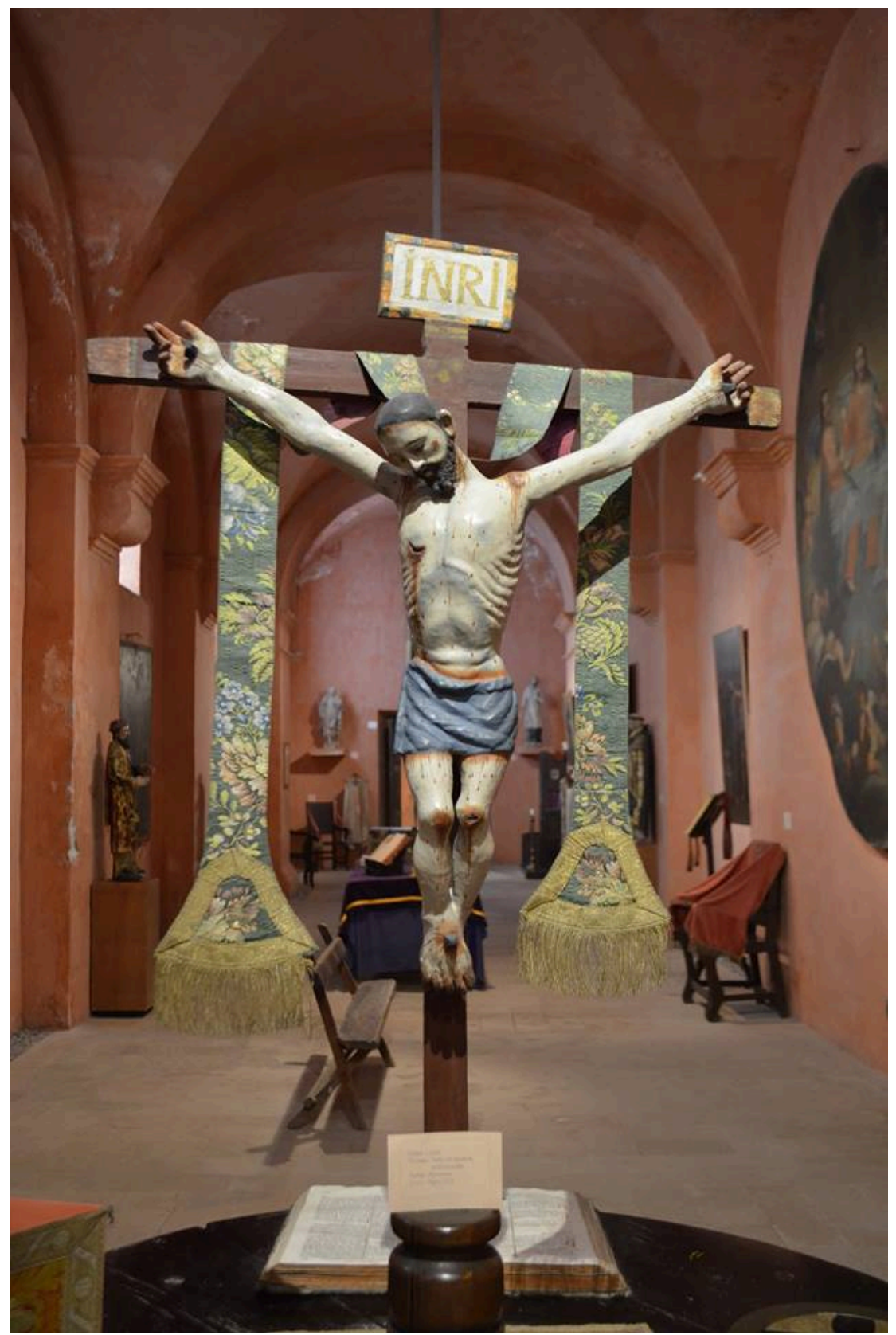

Imagen 27 - Escultura en madera policromada (siglo XVIII) custodiada en el Museo de Arte Sacro de Guadalcázar. 


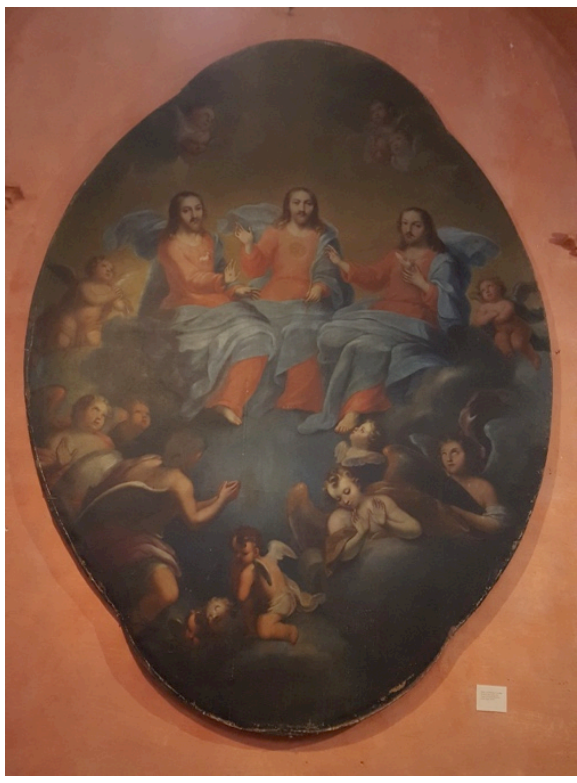

Imagen 28 - "La Santísima Trinidad", óleo sobre lienzo de Francisco Martínez, siglo XVIII.

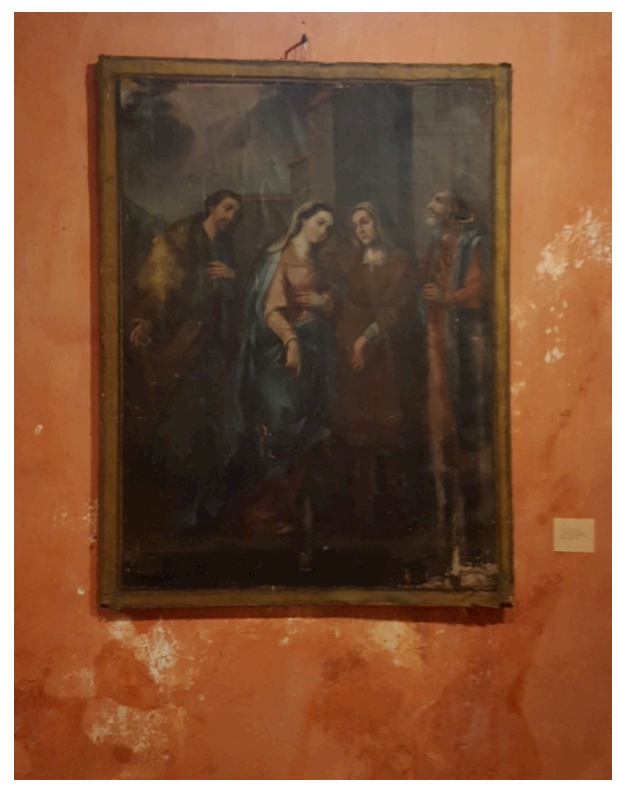

Imagen 29 - "La visitación de la Virgen", óleo sobre lienzo de Francisco Martínez, siglo XVIII.

El ambiente museal (imagen 30 y 31 ) ofrece un medio de estudio ideal para la aplicación del método, en vista de la generación de una escala de riesgo, debido a las peculiaridades técnico-materiales de los elementos en él custodiados y a las condiciones conservativas en las que se encuentran. Lo anterior se debe al contexto que caracteriza el área del edificio histórico designada al museo, cuyas condiciones no cumplen con los requerimientos básicos sugeridos por el Código de Deontología de ICOM para Museos (2017) ${ }^{162}$.

162 Entre los requerimientos mínimos exigidos para un Museo, evidenciado por el Inistuto Nacional de Antropología e Historia en su documento "Código de Deontología del ICOM para los Museos" se cita que "el órgano rector de un museo tiene el deber ético de mantener y desarrollar todos sus aspectos, colecciones y servicios. En particular, debe procurar que todas las colecciones que custodia estén almacenadas, conservadas y documentadas de forma adecuada". INAH, Código de Deontología del ICOM para los Museos, p. 4. <https://conservacion.inah.gob.mx/normativa/wp-content/uploads/Documento59.pdf> [Consulta: 10 de febrero de 2021]. Entre los requerimiento básicos exigidos para un recinto museal, se contempla la ejecución de actividades específicas que permitan la tutela del acervo en él custodiado, en términos de protección y monitoreo de las obras. La medición y control de los parámetros de conservación, dirigida al mantenimiento en estado optimal de los materiales constitutivos, se focaliza a la evaluación de: temperatura, humedad relativa, contaminantes gaseosos y materia particulada, velocidad y flujo del aire. A complemento, entre otros aspectos, se sugiere dotar los ambientes museales de sistemas de control, vitrinas, personal especializado y espacios para la investigación con la meta de impulsar el conocimiento de las colecciones y fomentar el crecimiento social de la comunidad de pertenencia. ICOM (2017). Código de 


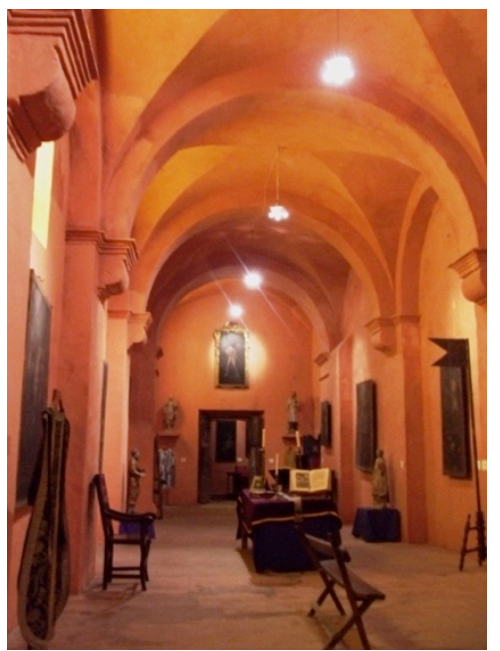

Imagen 30 - - Interior del Museo de Arte Sacro $^{163}$. Vista desde la entrada.

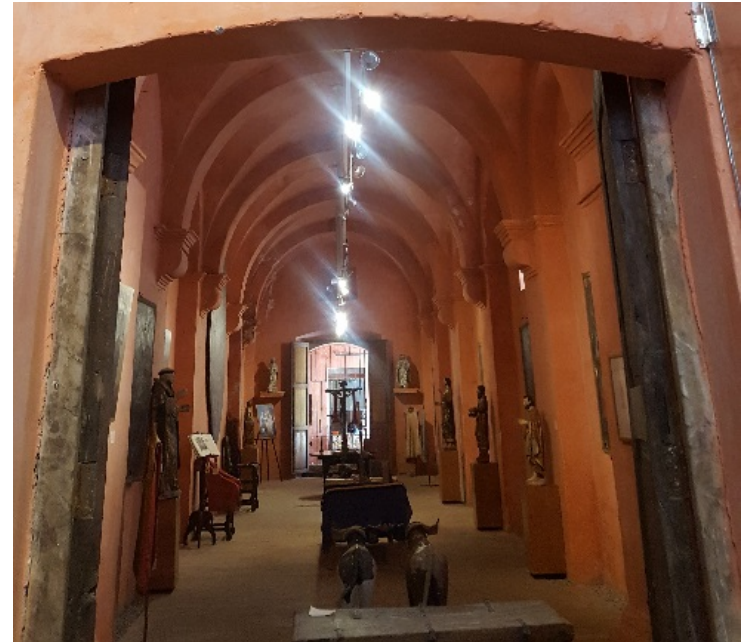

Imagen 31 - Vista del interior del Museo de Arte Sacro con el acceso al fondo.

El conjunto de pinturas sobre lienzo se ubican a lo largo de las paredes del edificio, a una altura aproximada de 1,20 m del suelo y en contacto directo con su superficie. Su anclaje es de tipo fijo, por medio de clavos insertados en los muros a los que se sujetan los bastidores, sea por medio de hojuelas metálicas, sea por medio de cuerdas ancladas a dichos elementos. Debido al tipo de estructura de la construcción, se pueden apreciar problemas de humedad por filtración, en correspondencia de los arranques de bóvedas (imágenes 33 y 34), y por capilaridad, cuyo frente de subida es visible en las zonas inferiores de los muros (imagen 32). Ésto se debe al estancamiento de humedad en las cubiertas y a la posible presencia de alteraciones en la homogeneidad de las estructuras debido al natural asentamiento del edificio con el paso del tiempo.

Deontología de ICOM para Museos. París: Consejo Internacional de Museos, UNESCO. <> [Consulta: 10 de febrero de 2021]. MECD (2014). Manual de seguimiento y análisis de condiciones ambientales. Madrid: Secretaría General Técnica, Subdirección General de Documentación y Publicaciones, pp. 108-110. <http://www.culturaydeporte.gob.es/planes-nacionales/dam/jcr:3312b805-4c20-46b6-a89771 cead432bf7/manual-condiciones-amb-2018.pdf> [Consulta: 10 de febrero de 2021].

163 SIC, GOBIERNO DE MÉXICO (2019). Op. cit. 


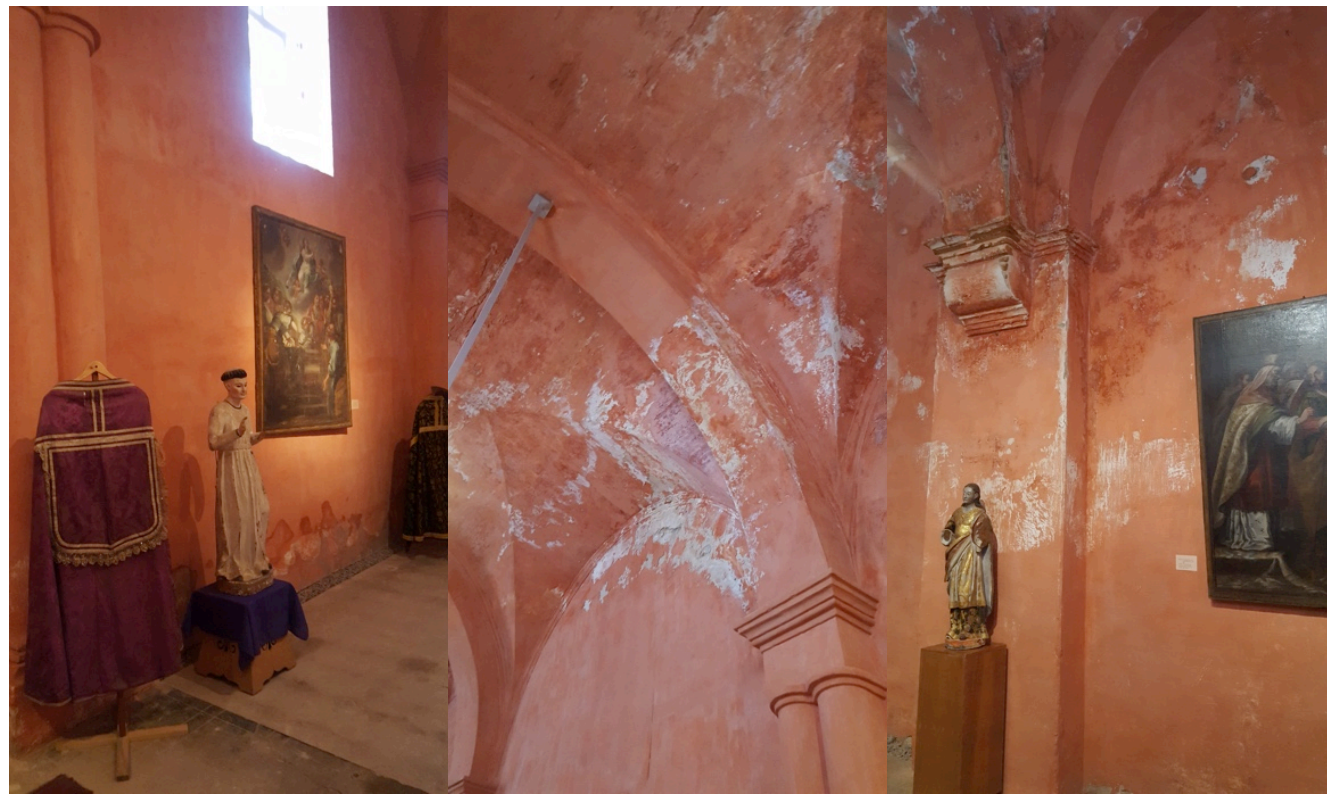

Imagen 32 - Detalle de los problemas de humedad presentes en la estructura del edificio (abril de 2019)
Imagen 33 -Detalle de los problemas de humedad presentes en la estructura del edificio (abril de 2019).
Imagen 34 - Detalle de los problemas de humedad presentes en la estructura del edificio (abril de 2019).

Las esculturas se encuentran sobre pedestales de madera, a excepción de las dispuestas en el pasillo central directamente en contacto con el suelo. Análogamente a las pinturas de caballete su posición sigue las laderas de los ambientes, hallándose dispuestas cerca de las paredes del edificio, con una distancia máxima aproximada de $20 \mathrm{~cm}$ de las mismas. Las alturas son variables, encontrándose la mayoría a una aproximada de 1,20 m, junto a otros ejemplares dispuestos a un nivel mayor, puestos alrededor de las entradas.

El Museo de Arte Sacro carece de sistemas de monitoreo y control de humedad y temperatura ${ }^{164}$. Este aspecto puede ofrecer la oportunidad de corroborar las aportaciones del método en vista de una estimación del historial conservativo.

\footnotetext{
164 Cuenta con una inspección del estado de las obras a cadencia anual, bajo la supervisión del párroco asesorado por un miembro del centro INAH de San Luis Potosí S.L.P.
} 


\section{Referencias bibliográficas}

ALCALÁ DONEGONI, L.E. (1999). "La obra del pintor novohispano Francisco Martínez" en Anales del Museo de América, n 7, UAM, Departamento de Historia y Teoría del Arte, Ministerio de Educación Cultura y Deporte, Subdirección General de Documentación y Publicaciones, Gobierno de España, pp. 175-187. <https://repositorio.uam.es/bitstream/handle/10486/671800/obra_alcala_ama_ 1999.pdf?sequence $=1$ \&isAllowed $=y>$ [Consulta: 10 de enero de 2021].

ARMESTO DÍAZ, J.A., ARILLA AGÓRRIZ, E. (1999). La cal. Valencia: UPV.

BEVILACQUA, N., BORGIOLI, L. y ADROVER GARCÍA, I. (2010). I pigmenti nell'arte dalla preistoria alla rivoluzione industriale. Collana I Talenti. Padova: II Prato.

BLASCO PÉREZ, M.V. (2015). Nace, crece y envejece. La imaginería novohispana de caña de maíz. Una aproximación al comportamiento del material. Tesis doctoral. Valencia: Universitat Politècnica de València. <https://riunet.upv.es/handle/10251/59418> [Consulta: 5 de junio de 2020].

BLASCO PÉREZ, M.V., MASTROIACOVO, T., SOLBES GARCÍA, Á. (2017). “Tecnologías aplicadas al análisis de bienes culturales: el Retablo Mayor del Colegio San Ignacio de Loyola" en Seminario Internacional de Desarrollo de Nuevos Productos SIDNP de la Facultad del Hábitat, Universidad Autónoma de San Luis Potosí, S.L.P. México.

"INBA cambia a INBAL... y desata polémica" en Capital Mexico, 11 de enero de 2019. $<$ https://www.capitalmexico.com.mx/nacional/inba-cambia-a-inbal-escorrecto/> [Consulta: 10 de junio de 2020].

Colegio de San Ignacio de Loyola Vizcaínas. <https://colegiovizcainas.edu.mx/historiadel-colegio\#1543601725966-583d5dbd-d76b> [Consulta: 20 de noviembre de 2020].

CONSEJO DEL CENTRO HISTÓRICO DE SAN LUIS POTOSÍ. “La ciudad de San Luis en la actualidad" en La fundación de San Luis Potosí.

$<$ https://centrohistoricoslp.com/planos-historicos/> [Consulta: 15 de agosto de 2018].

Crónica, Cultura. "El Saucito, cementerio de San Luis, tendrá su museo a partir de agosto" en Crónica, Cultura, 26 de abril de 2015.

<https://www.cronica.com.mx/notas/2015/895571.html> [Consulta: 16 de junio de 2020].

DE LA FUENTE, B., coord. (1996). La pintura mural prehispánica en México. México: UNAM-IIE. 
"Francisco Martínez, activo 1718-1758" en Colección Blaisten. <https://museoblaisten.com/artista.php?id=286\&url=Francisco-Martinez> [Consulta: 10 de enero 2021].

FUNDACIÓN PARA LA CULTURA Y EL DESARROLLO, ASOCIACIÓN DE AMIGOS DEL PAÍS (2004). Diccionario histórico biográfico de Guatemala . Guatemala: Asociación de Amigos del País y Fundación para la Cultura y el Desarrollo.

GOBIERNO MUNICIPAL SAN LUIS POTOSÍ, H. AYUNTAMIENTO DE SAN LUIS POTOSÍ 2018-2021. Ayuntamiento da mantenimiento al Panteón del Saucito con motivo del día de las madres. <https://sanluis.gob.mx/ayuntamiento-da-mantenimiento-alpanteon-del-saucito-con-motivo-del-dia-de-las-madres/> [Consulta: 16 de junio de 2020].

GOBIERNO DE MÉXICO (2010). Camino Real de Tierra Adentro. $<$ https://patrimonioculturalyturismo.cultura.gob.mx/patrimonio_mundial/cultur al/tierra_adentro/> [Consulta: 20 de febrero de 2020].

GOBIERNO DE MÉXICO, INAH. "Quienes somos?". <https://www.inah.gob.mx/quienes-somos> [Consulta: 2 de mayo de 2021].

GOBIERNO DE MÉXICO, SECRETARÍA DE CULTURA, INBAL. <https://inba.gob.mx/patrimonio> [Consulta: 2 de mayo de 2021].

Google Maps vista satelital online. Panteón del Saucito. <https://www.google.com/maps/@22.18112,100.9997383,280m/data=!3m1!1e3> [Consulta: 17 de junio de 2020].

GUERRERO URBINA, M.F., MASTROIACOVO, T. (2015). "Investigación, estudio y diagnóstico de las pinturas murales del Internado Damián Carmona en San Luis Potosí (S.L.P.)" en Inducción a la Ciencia, la Tecnología y la Innovación en la UASLP, Vol. III, no 4, pp. 817-823.

GUYE, L. (1976). Reseña de "Cinco haciendas mexicanas" de Jan Bazant en Nueva Antropología, I (4), pp. 121-124.

<https://www.redalyc.org/articulo.oa?id=159/15900408> [Consulta: 26 de Noviembre de 2020].

HAAG, S., DE MARIA Y CAMPOS, A., RIVERO WEBER, L., FEEST, C., coord. (2012). EI penacho del México antiguo. Viena: ZKF Publishers, Museum für Völkerkünde, CONACULTA-INAH.

Calculadora de Área. Google Maps <https://www.calcmaps.com/es/map-area/> [Consulta: 27 de febrero de 2021]. 
ICH, UNESCO (2019). Patrimonio Cultural Inmaterial. $<$ https://ich.unesco.org/es/busqueda00795? $q=$ mexico\&criteriaSearch $=$ element $\& p=1>$ [Consulta: 10 de junio de 2020].

ICOM (2017). Código de Deontología de ICOM para Museos. París: Consejo Internacional de Museos, UNESCO.

INAFED, GOBIERNO DE MÉXICO. "Estado de San Luis Potosí" en Enciclopedia de los Municipios y Delegaciones de México.

$<$ http://siglo.inafed.gob.mx/enciclopedia/EMM24sanluispotosi/municipios/2401 7a.html> [Consulta: 10 de junio de 2020].

INAH, Código de Deontología del ICOM para los Museos, p. 4. $<$ https://conservacion.inah.gob.mx/normativa/wpcontent/uploads/Documento59.pdf> [Consulta: 10 de febrero de 2021].

INEGI (2002). Síntesis de Información geográfica del estado de San Luis Potosí. $<$ https://www.inegi.org.mx/contenidos/productos/prod_serv/contenidos/espan ol/bvinegi/productos/historicos/2104/702825224240/702825224240_5.pdf> [Consulta: 27 de febrero de 2021].

INEGI: Continuo Nacional del Conjunto de Datos Geográficos de la Carta de Climas, serie I, en Clima del estado de San Luis Potosí del 15 de marzo de 2019. $<$ https://www.paratodomexico.com/estados-de-mexico/estado-san-luispotosi/clima-san-luis-potosi.html> [Consulta: 27 de febrero de 2021].

INAH-CONACULTA (2010). Haciendas del Altiplano Potosino. México: EME ediciones.

INAH, GOBIERNO DE MÉXICO. Diagnóstico del plan de trabajo 2014-2018. $<$ https://inah.gob.mx/images/stories/Transparencia/programa_trabajo/diagnosti co.pdf $>$ [Consulta: 7 de marzo de 2019].

INAH, GOBIERNO DE MÉXICO. “Ley Federal sobre Monumentos y Zonas Arqueológicas, Artísticas e Históricas" en Diario Oficial de la Federación del 6 de mayo de 1972, p. 20.

<https://www.ucol.mx/content/cms/13/file/federal/LEY_FED_SOBRE_MONUMEN TOS.pdf > [Consulta: 10 junio de 2020].

INAH, GOBIERNO DE MÉXICO (2019). "80 años de proteger, investigar, conservar y difundir nuestro patrimonio cultural" en Boletín del Instituto Nacional de Antropología e Historia. <https://www.inah.gob.mx/boletines/7921-inah-80-anosde-proteger-investigar-conservar-y-difundir-nuestro-patrimonio-cultural> [Consulta: 25 de febrero de 2019].

INAH, GOBIERNO DE MÉXICO. Acciones de restauración. $<$ https://www.inah.gob.mx/sismos> [Consulta: 28 de noviembre de 2020]. 
INBAL, GOBIERNO DE MÉXICO <https://inba.gob.mx/transparencia/obra> [Consulta:10 de junio de 2020].

INEGI, GOBIERNO DE MÉXICO (s.f.). Referencias geográficas y extensión territorial de México. <https://www.inegi.org.mx/inegi/spc/doc/internet/1geografiademexico/man_refgeog_extterr_vs_enero_30_2088.pdf> [Consulta: 25 de febrero de 2019].

INEGI, GOBIERNO DE MÉXICO (2005). "Información de Climas (escala 1: 1000 000)" en Guía para la Interpretación de Cartografía Climatológica.<http://internet.contenidos.inegi.org.mx/contenidos/productos/pr od_serv/contenidos/espanol/bvinegi/productos/geografia/publicaciones/guiascarto/clima/CLIMATIII.pdf> [Consulta: 25 de febrero de 2019].

KRICKEBERG, W. (1961). Las antiguas culturas mexicanas. México: FCE.

LEONOR MERINO, B. y GARCÍA COOK, Á., coord. (2007). La producción alfarera en el México Antiguo vol. V, La alfarería en el Posclásico (1200-1521 d.C.) y el intercambio cultural y las permanencias. México: Instituto Nacional de Antropología e Historia.

"Le statue degli apostoli in San Giovanni in Laterano", 21 febbraio 2019. $<$ https://www.italianways.com/it/le-statue-degli-apostoli-in-san-giovanni-inlaterano/> [Consulta: 10 de diciembre de 2020].

LITTMANN, E.R. (1960). "Ancient Mesoamerican Mortars, Plasters and Stuccos: The Use of Bark Extracts in Lime Plasters" en American Antiquity, vol. 25, núm. 4., pp. 593-597. <https://doi.org/10.2307/276642> [Consulta: 5 de junio de 2020].

"Llama INAH a preservar identidad de haciendas y casonas" en Informador.Mx del 4 de agosto de 2014. <https://www.informador.mx/Cultura/Llama-INAH-apreservar-identidad-de-haciendas-y-casonas-20140804-0067.html> [Consulta: 26 de noviembre de 2020].

MAGALONI KERPEL, D.I. (1995). "Técnicas de la pintura mural en Mesoamérica" en Arqueología Mexicana, vol. III, núm. 16, pp. 16-23. México: Raíces.

MAGALONI KERPEL, D.I. (1996). Materiales y técnicas de la pintura mural Maya. De la Fuente, B., directora. Tesis de maestría en Historia del Arte, México, Facultad de Filosofía y letras, UNAM. México: UNAM-IIE.

MAGALONI KERPEL, D.I. (2008). "Los colores de la selva" en Arqueología Mexicana, vol. XVI, núm. 93, pp.46-50 México: Raíces.

MAGALONI KERPEL, D.I., (2016). Albores de la Conquista. La historia pintada del Códice Florentino. México: Artes de México y del Mundo, Secretaría de Cultura. 
MASTROIACOVO, T., BLASCO PÉREZ, M.V., NIETO VILLENA, A. (2017). "El valor de la colaboración interinstitucional como medio de investigación y didáctica: experiencias entre el Museo Colegio de las Vizcaínas y UASLP" en Seminario Internacional de Desarrollo de Nuevos Productos SIDNP de la Facultad del Hábitat, Universidad Autónoma de San Luis Potosí, S.L.P. México.

MASTROIACOVO, T., BLASCO PÉREZ, M.V., NIETO VILLENA, A. (2017). “Los hermanos Biagi y las esculturas de la Catedral Metropolitana Potosina" en Universitarios Potosinos, año 14, núm. 211, pp. 13-17. San Luis Potosí: UASLP.

MECD (2014). Manual de seguimiento y análisis de condiciones ambientales. Madrid: Secretaría General Técnica, Subdirección General de Documentación y Publicaciones. $\quad<$ http://www.culturaydeporte.gob.es/planesnacionales/dam/jcr:3312b805-4c20-46b6-a897-71cead432bf7/manualcondiciones-amb-2018.pdf> [Consulta: 10 de febrero de 2021].

MILLER, M.E. (2009). Arte y arquitectura maya. México: FCE.

MORALES BOCARDO, R. (s.f.), Museo de Arte Sacro, Parroquia de San Pedro de Guadalcázar, Diócesis de Matehuala, S.L.P.

NACIONES UNIDAS, MÉXICO (2016), “Descubre los 34 sitios de México inscritos en la Lista de Patrimonio" en Sitios Patrimonio Mundial de la humanidad en México. $<$ http://www.onu.org.mx/descubre-los-34-sitios-de-mexico-inscritos-en-la-listade-patrimonio/> [Consulta: 15 de febrero de 2019].

NOGUERA AUZA, E. (1967). "La cerámica funeraria y ritual en Mesoamérica" en Anales de Antropología, Revista del Instituto de Investigaciones Antropológicas UNAM, vol.1, núm.4, pp. 127-140

$<$ http://www.revistas.unam.mx/index.php/antropologia/article/view/17459/pdf_ 362> [Consulta: 10 de junio de 2020].

"Panteón del Saucito, 127 años de historia" en Plano informativo, 02 de noviembre de 2016 <http://planoinformativo.com/488447/panteon-del-saucito-127-anosde-historia-slp> [Consulta: 15 de agosto de 2018].

"Panteón de El Saucito cumple 127 años" en Código San Luis, 2 de noviembre de 2016. <https://archivo.codigosanluis.com/panteon-de-el-saucito-cumple-127anos/> [Consulta: 27 de febrero de 2021].

PINGARRÓN, L.B. (2013). “El uso de la cal en el mundo prehispánico mesoamericano" en La cal. Historia, propiedades y usos. México: UNAM.

POLICÍA FEDERAL DEL GOBIERNO DE MÉXICO (2018). "La Comisión Nacional de Seguridad y la Secretaría de Cultura firman convenio de colaboración para proteger el patrimonio cultural" en Nota de prensa, 28 de marzo de 2018. 
$<$ https://www.gob.mx/policiafederal/prensa/la-comision-nacional-de-seguridady-la-secretaria-de-cultura-firman-convenio-de-colaboracion-para-proteger-elpatrimonio-cultural> [Consulta: 14 de febrero de 2019].

SALAZAR GONZÁLEZ, G. (2000). Las haciendas en el siglo XVI, en la región minera de San Luis Potosí. Su espacio, forma, función, material, significado y la estructuración regional. San Luis Potosí: Universidad Autónoma de San Luis Potosí, Facultad del Hábitat.

SECRETARÍA DE CULTURA, CNCPC, INAH. "Nosotros somos". $<$ https://conservacion.inah.gob.mx/index.php/2018-nosotros/> [Consulta: 2 de mayo de 2021].

SIC, GOBIERNO DE MÉXICO (2019). "Museo de Arte Sacro de San Pedro de Guadalcázar" en Museos, San Luis Potosí. $<$ https://sic.cultura.gob.mx/ficha.php?table=museo\&table_id=1110 $>$ [Consulta: 20 de febrero de 2019].

STRESSER-PÉAN, C. (2012). De la vestimenta y los hombres. Una perspectiva histórica de la indumentaria indígena en México. La indumentaria precortesiana. México: FCE, CEMCA, Fundación Alfredo Harp Helú, Museo Textil de Oaxaca.

SUÁREZ, O. S. (1968). Inventario del muralismo mexicano, siglo VII-1968. México D.F.: Universidad nacional Autónoma de México UNAM.

TAMAYO, J. L., (1993). Geografía moderna de México. México: Trillas.

UNESCO, (2018). "Mexico, Properties inscribed in World Heritage List" en About World Heritage, The States Parties. <https://whc.unesco.org/en/statesparties/mx> [Consulta: 14 de febrero de 2019].

UNESCO (2010). "Camino Real de Tierra Adentro" en World Heritage List. <https://whc.unesco.org/en/list/1351> [Consulta: 14 de febrero de 2020].

VÁZQUEZ DE ÁGREDOS y HORCAJADA CAMPOS (2017). "La doble piel de la arquitectura Maya: el estuco y el color" en RA monográfico, pp. 84-97. $<$ https://core.ac.uk/download/pdf/228598681.pdf> [Consulta: 2 de marzo de 2019].

VÁZQUEZ SALGUERO, D. y CORRAL BUSTOS, A., (2004). Monumentos funerarios del Saucito, San Luis Potosí, 1889-1916. San Luis Potosí: El Colegio de San Luis COLSAN.

WHC, UNESCO (2019). "World heritage List Statistics".

$<$ https://whc.unesco.org/en/list/stat\#d1> [Consulta: 05 de junio de 2020]. 


\section{Capítulo 2 Diseño del método}

\subsection{Generalidades sobre análisis estadístico}

Con el fin de esclarecer la función y objetivos del modelo de tablas propuestos en este estudio se vuelve necesario abordar un acercamiento a las técnicas de análisis de datos comúnmente usadas en varias áreas del conocimiento. Una aproximación a las técnicas estadísticas y a sus generalidades, junto a una correlación de las mismas con parámetros y características propios del área de estudio de interés, ayuda a enmarcar los alcances de este estudio, suponiendo las bases para futuras profundizaciones y desarrollos.

La estadística ${ }^{165}$ es una rama de las matemáticas que permite obtener y analizar críticamente y de forma clara la información perteneciente a un sistema. Su ventaja reside en la posibilidad ofrecida por el análisis de una elevada cantidad de datos que se revela útil a la comprensión y toma de decisiones en un vasto abanico de disciplinas, representando una herramienta transversal para la resolución de una amplia variedad de problemáticas a partir de datos numéricos. El objetivo principal de la estadística es hacer inferencias sobre características de una población con base en la información contenida en una muestra, siendo su aplicación indispensable en

165 La palabra estadística deriva del alemán Statistik. Este termino fue acuñado por el economista Gottfred Achenwall (Prusia, 1719-1772) que vislumbraba las posibilidades ofrecidas por esta disciplinas para la resolución de problemáticas de gestión del estado. Específicamente, el vocablo posee sus raíces en la palabra latina "status", que responden a estado o situación, enfatizando el valor añadido de este método: ofrecer un análisis cualitativo arrojando datos sobre una determinada situación. 
aquellos casos en los cuales es necesario conocer rápidamente el comportamiento o procesos de un universo de elementos en relación a determinados parámetros ${ }^{166}$ como es el caso representado por los numerosos materiales y obras que constituyen el patrimonio cultural. Para la implementación de las técnicas de análisis estadístico al ámbito conservativo del patrimonio cultural es necesario determinar:

- la ubicación de los puntos de muestreo;

- la tipología de matriz de datos a escoger;

- el tamaño de muestra a emplearse;

- la tipología de análisis de datos más idónea.

Se han analizado un conjunto de casos afectados por varias problemáticas con la finalidad de llevar a cabo una experiencia piloto. Ésta, dirigida a crear una comparativa entre las informaciones, posee la finalidad de establecer metas, alcances y mejoras para la recolección de datos.

Se define población o universo el conjunto de individuos o unidades estadísticas. Ésta puede ser finita o infinita, según se conozca más o menos el número de elementos que la compone. Dichos componentes pueden ser unitarios, definiéndose como simples, o por grupales, siendo definidos como colectivos. Aunque se conozca el tamaño de la población puede ser imposible abarcar la recolección de datos contenidos en la misma debido a limitaciones en los recursos técnicos, humanos, económicos y temporales, por lo cual se analizará solo una porción representativa de la misma, que se define como muestra. El número de elementos que la compone definirá su tamaño. Cada una de las características bajo las cuales puede ser clasificado un elemento, se define como carácter y puede ser ordenado en diferentes categorías llamadas modalidades. Éstas tienen que ser incompatibles y exhaustivas, determinando la unicidad de pertenencia a la modalidad indicada y su ejemplificación absoluta. Para cada carácter pueden presentarse numerosas y diferentes categorías. Los caracteres pueden pertenecer a dos tipologías: cuantitativo, cuando se determina por un valor numérico representativo de una característica medible o numerable, y cualitativos, cuando sus características se ejemplifican por medio de formas alternativas. En el primer caso, el valor numérico asociado a cada modalidad de un determinado elemento se define como variable estadística ${ }^{167}$ (diagrama 11).

\footnotetext{
166 PÉREZ GALINDO, R. (2013). Estadística aplicada: para ciencias económicas, administrativas y sociales. México: Trillas.

167 VARGAS SABADÍAS, A. (1995). Estadística descriptiva e inferencial. Cuenca: Universidad de Castilla-La Mancha.
} 


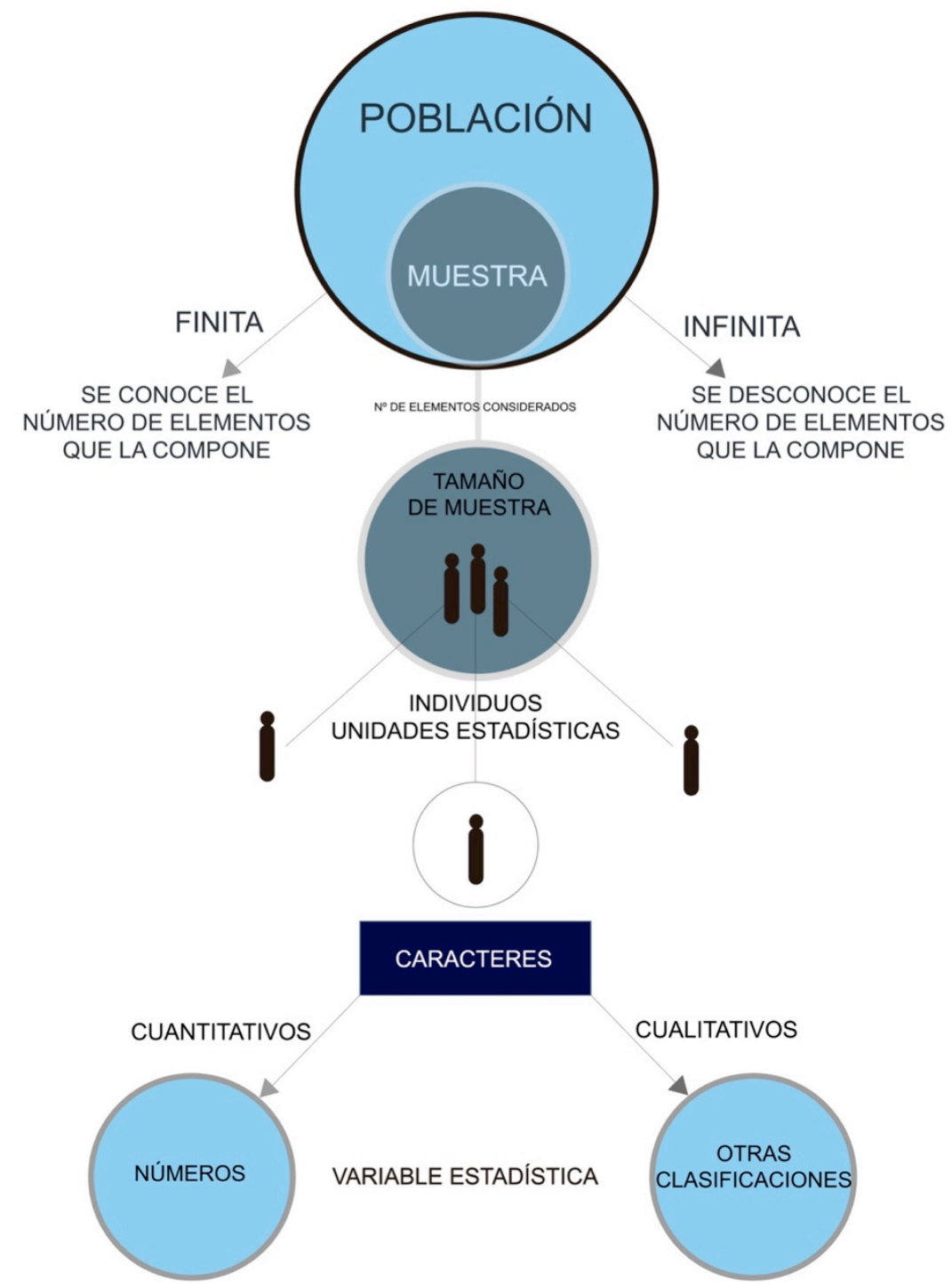

Diagrama 11 - Representación de los conceptos empleados para la estructuración de los estudios estadísticos de la información.

Tomando de ejemplo el caso de una colección de obras resguardadas en un recinto museístico, éste será considerado como población, las obras que la componen determinarán los individuos que a su vez constituirán un conjunto poblacional finito, debido a que se conoce el número total de los mismos. A su vez, los bienes 
podrán clasificarse como elementos simples, cuando se constituyen por una sola obra, o colectivos, si se consideran grupos o piezas articuladas por varios objetos (diagrama 12).

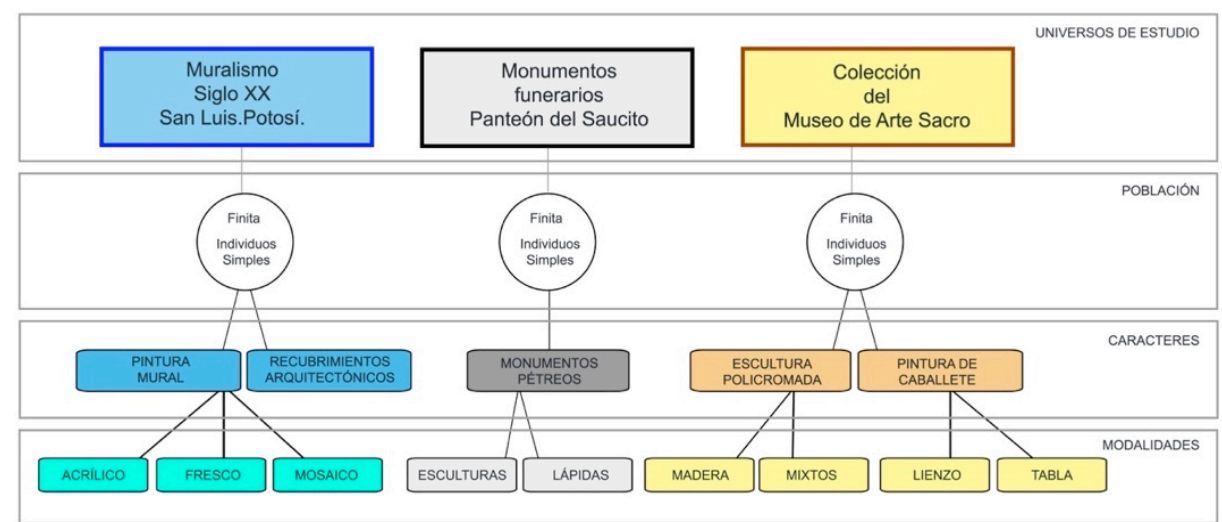

Diagrama 12 - Generalidades estadísticas aplicadas a los casos de estudio.

Los conceptos de universo de estudio, población, caracteres y modalidades, dependiendo de las características del conjunto de estudio en examen, pueden ser clasificados de acuerdo a los ejemplos propuestos en las tablas 11, 12, 13 y los diagramas 12 y 13 .

Tabla 11 - Especificación de características y criterios. Muralismo del siglo XX.

\begin{tabular}{|l|l|}
\hline CASO DE ESTUDIO 1 \\
\hline DEFINICIÓN ESTADÍSTICA & ESPECIFICACIONES \\
\hline UNIVERSO DE ESTUDIO & MURALISMO DEL SIGLO XX (SAN LUIS POTOSÍ) \\
\hline POBLACIÓN & FINITA \\
\hline INDIVIDUOS & SIMPLES \\
\hline TAMAÑO MUESTRAL INDIVIDUOS & 21 \\
\hline CARACTERES & PINTURAS MURALES (PM) \\
\hline MODALIDADES & ACRÍLICO (ACR), PINTURA AL FRESCO (FRE), MOSAICO (MOS) \\
\hline ÁREAS & CIUDAD CAPITAL Y ESTADO \\
\hline TIPOLOGÍA & EDIFICIOS RELIGIOSOS, PRIVADOS Y PÚBLICOS \\
\hline NÚMERO & 11 \\
\hline
\end{tabular}


Tabla 12 - Especificación de características y criterios. Panteón Municipal del Saucito.

\begin{tabular}{|l|l|}
\hline \multicolumn{2}{|l|}{ CASO DE ESTUDIO 2} \\
\hline DEFINICIÓN ESTADÍSTICA & ESPECIFICACIONES \\
\hline UNIVERSO DE ESTUDIO & $\begin{array}{l}\text { MONUMENTOS FUNERARIOS DEL PANTEÓN MUNICIPAL DEL SAUCITO } \\
\text { (SAN LUIS POTOSI) }\end{array}$ \\
\hline POBLACIÓN & FINITA \\
\hline INDIVIDUOS & SIMPLES \\
\hline TAMAÑO MUESTRAL INDIVIDUOS & 63 \\
\hline CARACTERES & MONUMENTOS PÉTREOS (MP) \\
\hline MODALIDADES & ESCULTURAS (ESC), LÁPIDAS (LAP) \\
\hline ÁREAS & ÁREA MONUMENTAL DEL RECINTO FUNERARIO DEL PANTEÓN \\
\hline TIPOLOGÍA & $\begin{array}{l}\text { CUADRANTES DERIVADOS DE LA ORDENACIÓN URBANÍSTICA DEL } \\
\text { ÁREA }\end{array}$ \\
\hline NÚMERO & 3 (A, B, C) \\
\hline
\end{tabular}

Tabla 13 - Especificación de características y criterios. Museo de Arte sacro de Guadalcázar.

\begin{tabular}{|l|l|}
\hline CASO DE ESTUDIO 3 \\
\hline DEFINICIÓN ESTADÍSTICA & ESPECIFICACIONES \\
\hline UNIVERSO DE ESTUDIO & MUSEO DE ARTE SACRO DE GUADALCÁZAR (S.L.P.) \\
\hline POBLACIÓN & FINITA \\
\hline INDIVIDUOS & SIMPLES \\
\hline TAMAÑO MUESTRAL INDIVIDUOS & 34 \\
\hline CARACTERES & ESCULTURA POLICROMADA (EP), PINTURA DE CABALLETE (PC) \\
\hline MODALIDADES & MADERA (MAD), MIXTOS (MIX), LIENZO (LIE), TABLA (TAB) \\
\hline ÁREAS & SECTOR INTERIOR DEL EDIFICIO HISTÓRICO \\
\hline TIPOLOGÍA & ESPACIO EMPLEADO COMO ÁREA MUSEAL \\
\hline NÚMERO & 1 \\
\hline
\end{tabular}




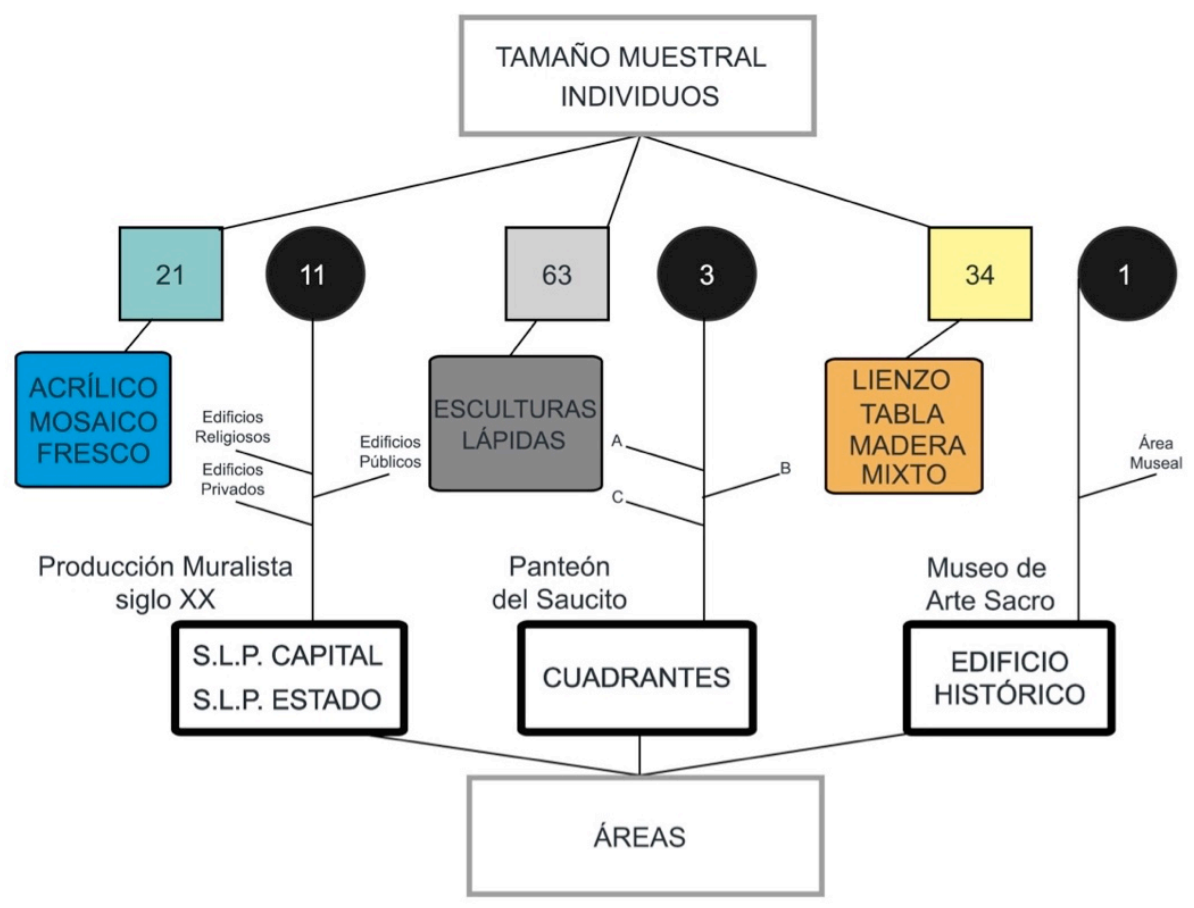

Diagrama 13 - Tamaño muestral de los casos de estudio y áreas de ubicación de los individuos.

Los posibles caracteres que definen la pertenencia a grupos específicos derivan de las características técnicas y materiales: escultura lígnea, pintura de caballete o textiles entre otros. De acuerdo a lo ejemplificado anteriormente, la pertenencia a un carácter excluye automáticamente su posible relación con otro, determinando así su unicidad y exhaustividad, descartando posibles alteraciones por repetición de los conceptos en el análisis de datos. Dependiendo de las propiedades de los caracteres, éstos darán lugar a un muestreo de tipo cualitativo, cuando se pueden describir de forma alternativa a los números, o cuantitativo, cuando sus propiedades serán medibles o estimables y por ende representables por medio de valores numéricos. Un ejemplo de la tipología cualitativa será el color, material, estilo de una obra, mientras su posible estimación cuantitativa podrán ser el tamaño, la antigüedad, la extensión de determinadas características de superficie, por ejemplo, las derivadas de los procesos de alteración y deterioro. El valor numérico asociado a estos conceptos se define como variable estadística.

De las diferentes posibilidades ofrecidas por las técnicas de muestreo, éste puede ser de tipo aleatorio (simple, sistemático, estratificado, por conglomerados) y no aleatorio (diagrama 14). 


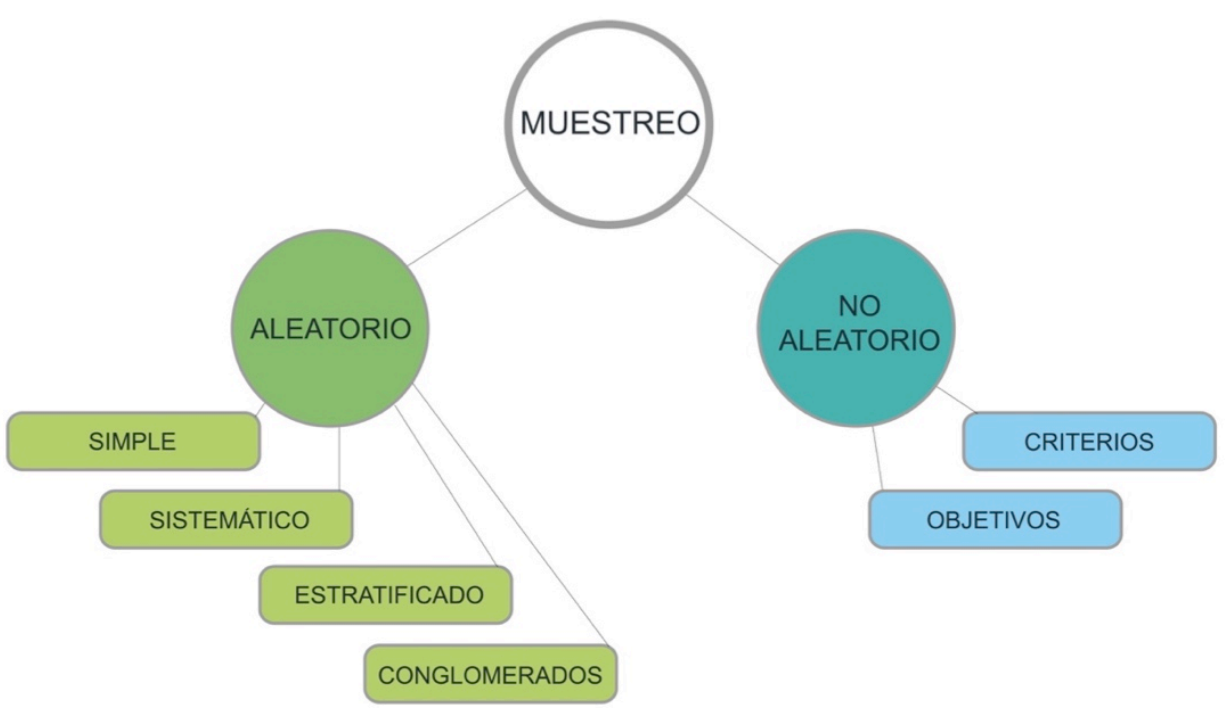

Diagrama 14 - Tipologías de muestreo.

El aleatorio simple se suele aplicar a poblaciones finitas, es decir, aquellas de las cuales se conoce el número de individuos (N) que la componen y cuyo tamaño es limitado. Este tipo de población se suele diferenciar de las infinitas debido a que éstas no podrían enumerarse en un plazo de tiempo razonable ${ }^{168}$. El muestreo sistemático responde a una selección de las muestras según intervalos uniformes en términos de tiempo, orden, espacio. Dicho intervalo se define como ciclo muestral, cuya constante $(k)$ se puede determinar a partir del tamaño de la población $(\mathrm{N})$ y del tamaño de muestra $(\mathrm{n})$, y puede presentar limitaciones a la hora de aplicarse a sistemas caracterizados por patrones secuenciales. El muestreo estratificado consta de una división de la población según criterios que se definen como estratos que sucesivamente se someten a una selección interna de tipo aleatorio de un número específico de elementos que corresponden a la proporción del estrato con respecto al total de la población o, se someten a la selección de un número igual de elementos por cada estrato, dándole peso a los resultados de

\footnotetext{
${ }^{168}$ Pérez Galindo (2013), op. cit. pp. 17-18.
} 
acuerdo a la proporción de los estratos en relación a la población total. La ventaja ofrecida por este método reside en la mayor precisión ofrecida en la determinación de las características del sistema. Finalmente, el muestreo por conglomerados responde a una división de la población en grupos, los mismos que serán seleccionados de forma aleatoria, asumiendo que cada conglomerado es representativo de la población total (tabla 14). Esta forma de muestreo responde también a una selección por áreas, ideal cuando hay que estudiar zonas definidas o cuya delimitación espacial resulte sencilla.

Tabla 14 - Tipos y características de muestreo aleatorio.

\begin{tabular}{|l|l|l|}
\hline \multicolumn{2}{|l|}{ MUESTREO ALEATORIO } \\
\hline TIPO & SELECCIÓN DE MUESTRA & VENTAJAS \\
\hline SIMPLE & NÚMEROS ALEATORIOS & $\begin{array}{l}\text { Cada muestra tiene la misma probabilidad de ser } \\
\text { seleccionada }\end{array}$ \\
\hline SISTEMÁTICO & CICLO MUESTRAL & $\begin{array}{l}\text { Fácil gestión y aplicación, menor inversión de recursos } \\
\text { temporales y económicos }\end{array}$ \\
\hline ESTRATIFICADO & ESTRATOS & $\begin{array}{l}\text { Refleja las características de la población con una mayor } \\
\text { precisión, ideal para analizar grupos con pequeñas } \\
\text { variaciones internas y grandes variaciones entre sí }\end{array}$ \\
\hline CONGLOMERADO & CONGLOMERADOS & $\begin{array}{l}\text { Ideal para estudiar grupos similares con grandes } \\
\text { variaciones internas }\end{array}$ \\
\hline
\end{tabular}

El muestreo no aleatorio responde a una selección de los casos de estudio sujeto a la decisión, discreción o experiencia del operador, se define como muestreo a juicio, y siendo susceptible del criterio de la persona involucrada presenta un elevado riesgo en la toma de decisiones inherentes a los datos y resultados a investigar. También ofrece la ventaja de centrarse en determinados casos de estudio según los objetivos establecidos en la aplicación del método.

A continuación, se propone la posible relación entre los casos de estudio y los diferentes métodos de toma de muestras presentados, dependiendo de la problemática a analizar, las características del sistema y los recursos disponibles. 
a) Muestreo aleatorio simple, para casos de estudio en los cuales se conoce el número total de individuos que componen la población y que pueden ofrecer la posibilidad de llevar a cabo una selección de muestras de acuerdo a ciclos numéricos aleatorios. Responden a estos ejemplos los acervos de obras o conjuntos patrimoniales clasificados y ordenados, o grupos pequeños de materiales, ya que permiten ser seleccionados de acuerdo a los supuestos presentados o son de fácil enumeración.

b) Muestreo aleatorio sistemático, para casos de estudio cuyas características puedan brindar los supuestos necesarios a una selección sistemática de las muestras respetando constantes establecidas en fase preliminar de tiempo, orden o espacio. Todos los conjuntos de obras de arte pueden ser sometidos al muestreo aleatorio sistemático ya que no suelen presentar patrones secuenciales.

c) Muestreo aleatorio estratificado, para casos de estudio que presenten la peculiaridad de poder someterse a diferentes clasificaciones dependiendo del criterio seleccionado en fase de planeación, y de los cuales se quiera conocer características. Un ejemplo de ello es la posible división por estratos temporales de un conjunto de obras de arte. Tras generar estos grupos se seleccionan aleatoriamente unos individuos para registrar sus características, respondiendo a la ley de probabilidades y representatividad del sistema en cuestión.

d) Muestreo aleatorio por conglomerados, también definido por áreas, para llevar a cabo un análisis de las características presentes en zonas delimitadas o fácilmente gestionables a nivel espacial. Un ejemplo de ello podría ser representado por obras custodiadas en recintos museales, en donde cada ambiente representaría un conglomerado, o en áreas urbanas, como por ejemplo monumentos ubicados en entornos delimitados por calles, como podrían ser las manzanas de una ciudad o de un cementerio monumental.

e) Muestreo no aleatorio, según el criterio del profesional involucrado o los alcances propuestos por el estudio. De acuerdo a las premisas citadas anteriormente, dirigidas a determinar las posibles interferencias representadas por la experiencia o selección de casos, este método puede ofrecer una valiosa aplicación siempre y cuando se aplique a situaciones o problemáticas de estudio en dónde la selección de muestra por parte del 
profesional represente un recurso. Por ejemplo, en un conjunto de obras afectadas por un evento sísmico y de las cuales hay que llevar a cabo una escala de riesgo, podría ser útil escoger las muestras atendiendo a la toma de datos de los objetos mayormente afectados. El supuesto que hay que tener en cuenta a la hora de registrar y elaborar los datos será el de equilibrar el tamaño muestral, sea extrayendo el mismo número de muestras, sea procesando los datos dependiendo de la proporción del sistema general al que pertenecen.

El primer paso consta en delimitar el problema, identificando cuáles serán los procesos o población a estudiar en relación a una serie de tiempo, y la selección de datos a tomar en consideración que representarán la muestra de estudio para proceder, en un segundo momento, a su recolección. Para los propósitos de la investigación se ha llevado a cabo una planeación de muestreos basada en caracteres, modalidades y áreas con el objetivo de obtener un diagnóstico y una estimación del índice de riesgo (diagramas 15 y 16).

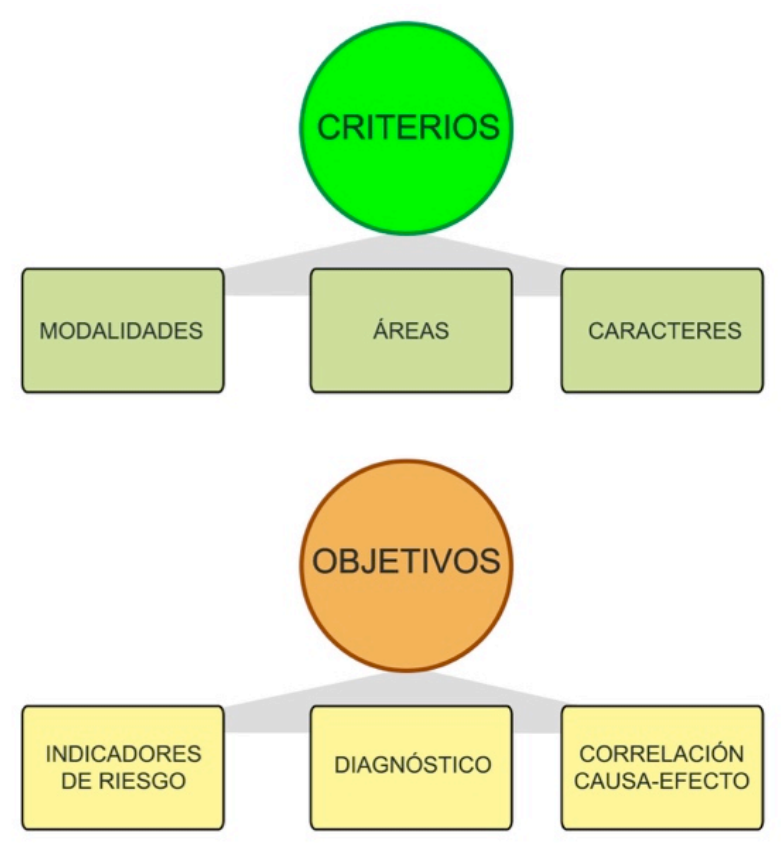




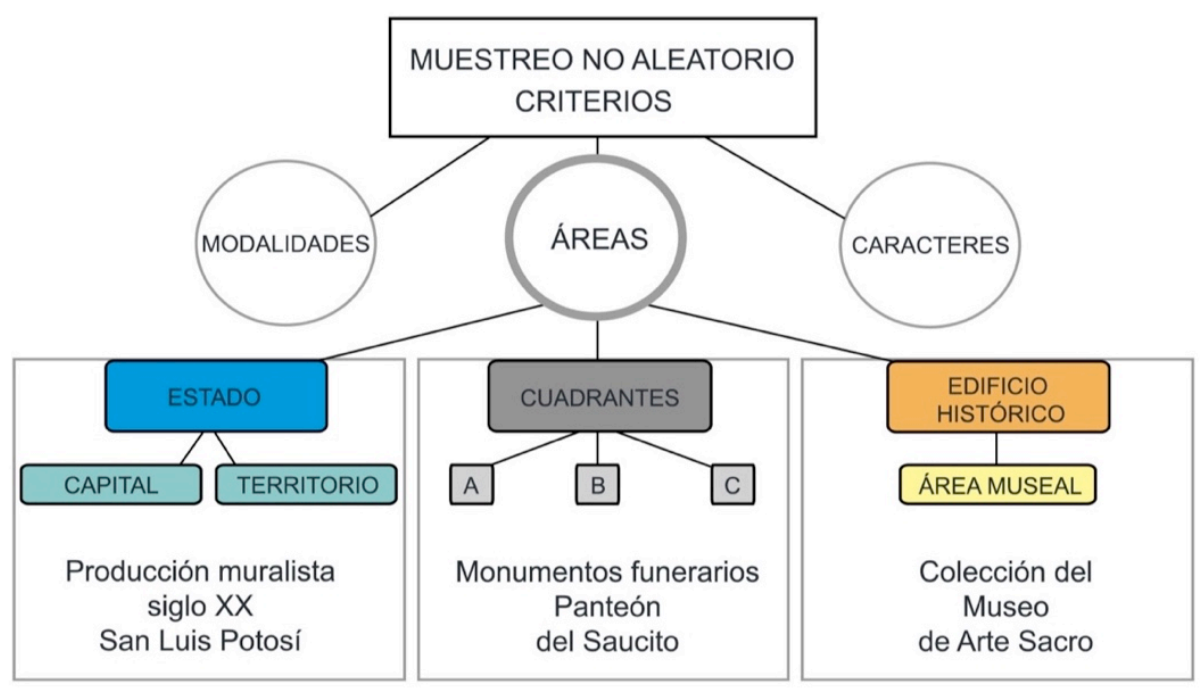

Diagrama 16 - Especificaciones sobre las áreas de muestreo escogidas para el diseño del método (experiencias-piloto).

El análisis exploratorio de datos (EDA de sus siglas en inglés) es una rama de la estadística que busca describir un conjunto de datos con el objetivo de formular hipótesis dirigidas al diseño de sucesivas fases experimentales o a la profundización y recogida de ulteriores informaciones ${ }^{169}$. Mientras la estadística confirmatoria utiliza sobre todo la deducción, por medio de la EDA se logran extraer hipótesis a partir de los datos recolectados, que a su vez pueden ser traducidos en diagramas representativos de las informaciones. En el ámbito del análisis y diagnóstico del patrimonio Cultural esta tipología de análisis podrá brindar informaciones cuantitativas y cualitativas que, una vez sometidas a la interpretación por parte del profesional, ofrecen una hipótesis sobre el estado de conservación de las obras examinadas.

Para la realización de este tipo de análisis es necesario recolectar las informaciones en una ficha, cuya estructuración responda a los criterios y tipologías de informaciones a las que se dirige la exploración. Para este fin existe la que se define tabla de contingencia, un documento estructurado alrededor de dos ejes en donde se distribuyen informaciones de tipo cualitativo y cuantitativo.

169 FERNÁNDEZ MARTíNEZ, V.M. (2015). Arqueo estadística, métodos cuantitativos en arqueología. Madrid: Alianza. 
Esta ficha, se define matriz de datos o tabla de registro. Dependiendo de las características de las variables e informaciones en ella registradas, puede adquirir diferentes modalidades y funciones:

- Matriz de presencia/ausencia (1/0), en donde se registrarán únicamente la existencia o falta de los fenómenos reunidos en la tabla. El valor 1 es asociado a la presencia de un criterio, mientras el 0 indica su ausencia.

- Matriz de abundancia, con estimaciones expresadas en valores numéricos establecidos según las directrices de estudio. De acuerdo al vocablo que la define, por medio de esta tabla es posible cuantificar la existencia de los fenómenos elencados en las fichas de registro.

Dependiendo del uso de una u otra modalidad de recolección de datos, se obtendrán respectivamente:

- Estimaciones sobre la variedad o riqueza de fenómenos existentes en relación a una determinada muestra de estudio.

- Estimaciones sobre la abundancia y/o extensión de los fenómenos en relación a una muestra de estudio.

El planteamiento de los métodos de ordenamiento y gestión de la información a analizar depende del objetivo (¿para qué?), las variables a considerar (¿qué?), y el diseño de muestreo (¿cómo?). Lo anterior determina la estructuración de los datos referentes a las especies y la tipología de matriz a escoger entre la de abundancia y de presencia/ausencia (diagrama 17).

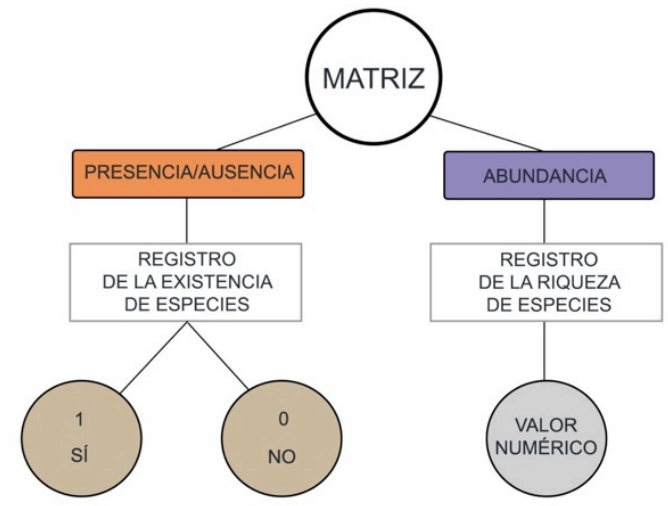


La matriz de presencia/ausencia ofrece una estimación cualitativa sobre la existencia o falta de una especie en el área de muestreo. La matriz de abundancia ofrece una estimación cuantitativa de las especies presentes relacionada con el número de observaciones y el parámetro cuantitativo predeterminado, permitiendo conocer la relación entre las especies presentes y el total posible de las mismas. La elección de registrar la existencia de los fenómenos se fundamenta en la practicidad del método, pensado para recolectar rápidamente las características conservativas del conjunto de obras sin incurrir en estimaciones derivadas de extensión y medición de los daños.

Para generar un sistema de evaluación unificado que pudiera aplicarse de forma objetiva al universo de elementos en examen se debería de regular la observación de acuerdo a escalas de superficie o de evaluaciones in situ por parte del personal. Este aspecto necesita una mayor implementación de recursos humanos, temporales y técnicos y se reserva para fases de análisis pormenorizadas en dónde sea posible apoyarse en los medios indicados.

\subsection{Diseño de matrices de datos}

En el marco del proyecto "Patrimonio Mural del Siglo XX en San Luis Potosí (S.L.P.): catalogación, estudio y análisis de riesgo", uno de los objetivos ha sido generar una escala de riesgo que permitiera establecer prioridades en las acciones de conservación de las obras ubicadas en varios puntos del estado potosino ${ }^{170}$. Por ello, fue necesario elaborar un método de registro y análisis de los datos relacionados con el estado de conservación de las pinturas, ubicadas en diferentes contextos y expuestas a diferentes condiciones climáticas, que permitiera estructurar una gran cantidad de información de manera ordenada, objetiva y representativa.

Para las finalidades propuestas en esta investigación se crearon unas matrices de datos en Excel $^{\circledR}$ basadas en las empleadas para el control y manejo de datos de Biodiversidad en el campo de la Ecología ${ }^{171}$, adaptando especies y muestras a las variables y problemáticas propias del campo de la conservación. Para la ocasión se adoptaron como especies las fuentes de deterioro (especies tipo 1, tabla 15) y las fenomenologías de deterioro y alteración (especies tipo 2, tabla 15), mientras cada obra se puso en correspondencia de una muestra relacionada con una coordenada numérica (tabla 15).

\footnotetext{
170 MASTROIACOVO, T., SORIANO SANCHO, M.P., REGIDOR ROS, J.L. (2017). "Índice de riesgo relacionado con factores de alteración y deterioro en las pinturas murales del siglo XX de San Luis Potosí (S.L.P., México)" en Archè, Instituto Universitario de Restauración del Patrimonio de la UPV, №. 11 y 12, pp.157-162.

${ }^{171}$ La relación entre estimación de Biodiversidad y Conservación del Patrimonio Cultural es tratada en los apartados introductorios de esta investigación.
} 


\begin{tabular}{|c|c|c|c|}
\hline $\begin{array}{l}\text { ESPECIES } \\
\text { FUENTES DE DETERIORO } \\
\text { (Tipo 1) }\end{array}$ & MUESTRA 1 & MUESTRA 2 & MUESTRA 3 \\
\hline Fuente de deterioro $\mathrm{A}$ & $1 / 0$ & $1 / 0$ & $1 / 0$ \\
\hline Fuente de deterioro $B$ & $1 / 0$ & $1 / 0$ & $1 / 0$ \\
\hline Fuente de deterioro $\mathrm{C} \ldots$ & $1 / 0$ & $1 / 0$ & $1 / 0$ \\
\hline $\begin{array}{l}\text { FENOMENOLOGÍA DE DETERIORO } \\
\text { (Tipo 2) }\end{array}$ & MUESTRA 1 & MUESTRA 2 & MUESTRA 3 \\
\hline Fenomenología de deterioro $\mathrm{A}$ & $1 / 0$ & $1 / 0$ & $1 / 0$ \\
\hline Fenomenología de deterioro $B$ & $1 / 0$ & $1 / 0$ & $1 / 0$ \\
\hline Fenomenología de deterioro $C$. & $1 / 0$ & $1 / 0$ & $1 / 0$ \\
\hline
\end{tabular}

La primera implementación de la matriz de datos se generó a partir de "European Illustrated Glossary of Conservation Terms for Wall Painting and Architectural Surfaces" (2016) ${ }^{173}$ con el propósito de ofrecer una base de referencia con terminología normalizada que pudiera aplicarse a otros casos de estudio y generar resultados representativos y comparativos. La selección de las fuentes de deterioro y fenomenologías que aparecen en la primera versión del método se ha basado en los criterios y ordenación propuestos en el glosario mencionado.

En la matriz de datos las especies se acomodaron verticalmente según dos grupos, el de fuentes de deterioro y el de las fenomenologías de alteración y deterioro, estructurados según el glosario citado, mientras las muestras (M) respondieron a las obras en examen (tabla 16).

\footnotetext{
${ }^{172}$ Los valores reportados en la tabla son solamente representativos de los campos a rellenar en la matriz de datos y no corresponden a ningún caso de estudio.

173 HORNEMANN INSTITUT (2015). European Illustrated Glossary for Conservation Terms of Wall Painting and Architectonic Surfaces. <https://www.hornemann-institut.de/doi/2016ewa2.pdf> [Consulta: 19 de mayo 2017].
} 
Tabla 16 - Matriz de datos derivada del Glosario EwaGLOS (2016) generada en la primera versión del método ${ }^{174}$.

\begin{tabular}{|c|c|c|c|}
\hline ESPECIES & & & MUESTRA \\
\hline FUENTES DE DETERIORO & 1 & 2 & 3 \\
\hline Causas intrínsecas de deterioro & $1 / 0$ & $1 / 0$ & $1 / 0$ \\
\hline Causas extrínsecas de deterioro & $1 / 0$ & $1 / 0$ & $1 / 0$ \\
\hline Suciedad & $1 / 0$ & $1 / 0$ & $1 / 0$ \\
\hline Humedad & $1 / 0$ & $1 / 0$ & $1 / 0$ \\
\hline Condensación & $1 / 0$ & $1 / 0$ & $1 / 0$ \\
\hline Higroscopicidad & $1 / 0$ & $1 / 0$ & $1 / 0$ \\
\hline Filtraciones de humedad & $1 / 0$ & $1 / 0$ & $1 / 0$ \\
\hline Humedad capilar & $1 / 0$ & $1 / 0$ & $1 / 0$ \\
\hline Gelividad & $1 / 0$ & $1 / 0$ & $1 / 0$ \\
\hline Ciclos de humedad & $1 / 0$ & $1 / 0$ & $1 / 0$ \\
\hline Deterioro ambiental & $1 / 0$ & $1 / 0$ & $1 / 0$ \\
\hline Contaminación atmosférica & $1 / 0$ & $1 / 0$ & $1 / 0$ \\
\hline Sales solubles & $1 / 0$ & $1 / 0$ & $1 / 0$ \\
\hline Aerosoles & $1 / 0$ & $1 / 0$ & $1 / 0$ \\
\hline Crecimiento de agentes biológicos & $1 / 0$ & $1 / 0$ & $1 / 0$ \\
\hline Deterioros por agentes antropogénicos & $1 / 0$ & $1 / 0$ & $1 / 0$ \\
\hline Intervenciones anteriores inapropiadas & $1 / 0$ & $1 / 0$ & $1 / 0$ \\
\hline Repintes & $1 / 0$ & $1 / 0$ & $1 / 0$ \\
\hline Intervenciones estructurales & $1 / 0$ & $1 / 0$ & $1 / 0$ \\
\hline FENOMENOLOGÍA DE DETERIORO & MUESTRA 1 & MUESTRA 2 & MUESTRA 3 \\
\hline Laguna & $1 / 0$ & $1 / 0$ & $1 / 0$ \\
\hline Oquedad & $1 / 0$ & $1 / 0$ & $1 / 0$ \\
\hline Disgregación & $1 / 0$ & $1 / 0$ & $1 / 0$ \\
\hline Abrasión & $1 / 0$ & $1 / 0$ & $1 / 0$ \\
\hline Corrosión & $1 / 0$ & $1 / 0$ & $1 / 0$ \\
\hline Peeling/Delaminación & $1 / 0$ & $1 / 0$ & $1 / 0$ \\
\hline Exfoliación & $1 / 0$ & $1 / 0$ & $1 / 0$ \\
\hline Descamación & $1 / 0$ & $1 / 0$ & $1 / 0$ \\
\hline
\end{tabular}

${ }^{174}$ En el modelo de matriz propuesto los valores $1 / 0$ son indicativos de la modalidad de cumplimentación de la ficha según el criterio de presencia/ausencia. 


\begin{tabular}{|c|c|c|c|}
\hline Pulverización & $1 / 0$ & $1 / 0$ & $1 / 0$ \\
\hline Deformación & $1 / 0$ & $1 / 0$ & $1 / 0$ \\
\hline Abolsamiento & $1 / 0$ & $1 / 0$ & $1 / 0$ \\
\hline Grietas estructurales & $1 / 0$ & $1 / 0$ & $1 / 0$ \\
\hline Grietas & $1 / 0$ & $1 / 0$ & $1 / 0$ \\
\hline Microfisura & $1 / 0$ & $1 / 0$ & $1 / 0$ \\
\hline Craquelado & $1 / 0$ & $1 / 0$ & $1 / 0$ \\
\hline Pátina & $1 / 0$ & $1 / 0$ & $1 / 0$ \\
\hline Velo blanquecino & $1 / 0$ & $1 / 0$ & $1 / 0$ \\
\hline Amarilleamiento & $1 / 0$ & $1 / 0$ & $1 / 0$ \\
\hline Oscurecimiento & $1 / 0$ & $1 / 0$ & $1 / 0$ \\
\hline Saturación de color & $1 / 0$ & $1 / 0$ & $1 / 0$ \\
\hline Blanqueamiento & $1 / 0$ & $1 / 0$ & $1 / 0$ \\
\hline Debilitamiento & $1 / 0$ & $1 / 0$ & $1 / 0$ \\
\hline Alteración de pigmentos & $1 / 0$ & $1 / 0$ & $1 / 0$ \\
\hline Eflorescencia salina & $1 / 0$ & $1 / 0$ & $1 / 0$ \\
\hline Erosión & $1 / 0$ & $1 / 0$ & $1 / 0$ \\
\hline
\end{tabular}

Para el diseño de los demás modelos de fichas, de acuerdo a la primera implementación del método, se escogieron unos diccionarios de carácter intercultural generados para el área de conservación de materiales pétreos, pinturas murales y recubrimientos arquitectónicos y publicaciones específicas del sector de pintura de caballete sobre lienzo y tabla, con el propósito de proporcionar una herramienta estructurada sobre la base de terminologías universales en dónde se pudieran hallar definiciones, traducciones y explicaciones de los mecanismos junto a un apoyo de tipo gráfico y fotográfico.

Para generar el registro de los fenómenos indicados en los materiales pétreos presentes en el Panteón Municipal del Saucito se diseñó una matriz de datos a partir del glosario "Illustrated glossary of stone deterioration patterns" ICOMOS-ISCS $(2008)^{175}$. Las informaciones contenidas se estructuraron por niveles de acuerdo a los temas propuestos en el documento, respondiendo a la fenomenología (nivel 1), tipología (nivel 2) y morfología específica de deterioro (nivel 3), representando las

175 ICOMOS-ISCS (2008). Illustrated Glossary on Stone Deterioration Patterns.

<https://www.icomos.org/publications/monuments_and_sites/15/pdf/Monuments_and_Sites_15_ISCS_GI ossary_Stone.pdf> [Consulta: 3 de marzo de 2016]. 
especies. De acuerdo a la organización del método, las muestras correspondieron a los casos de estudio cuya identificación se llevó a cabo por medio de referencias numéricas y registro fotográfico ${ }^{176}$ (tabla 17).

Tabla 17 - Matriz de datos para materiales pétreos derivada del glosario ICOMOS-ICSC (2008) elaborada para la primera implementación del método ${ }^{177}$.

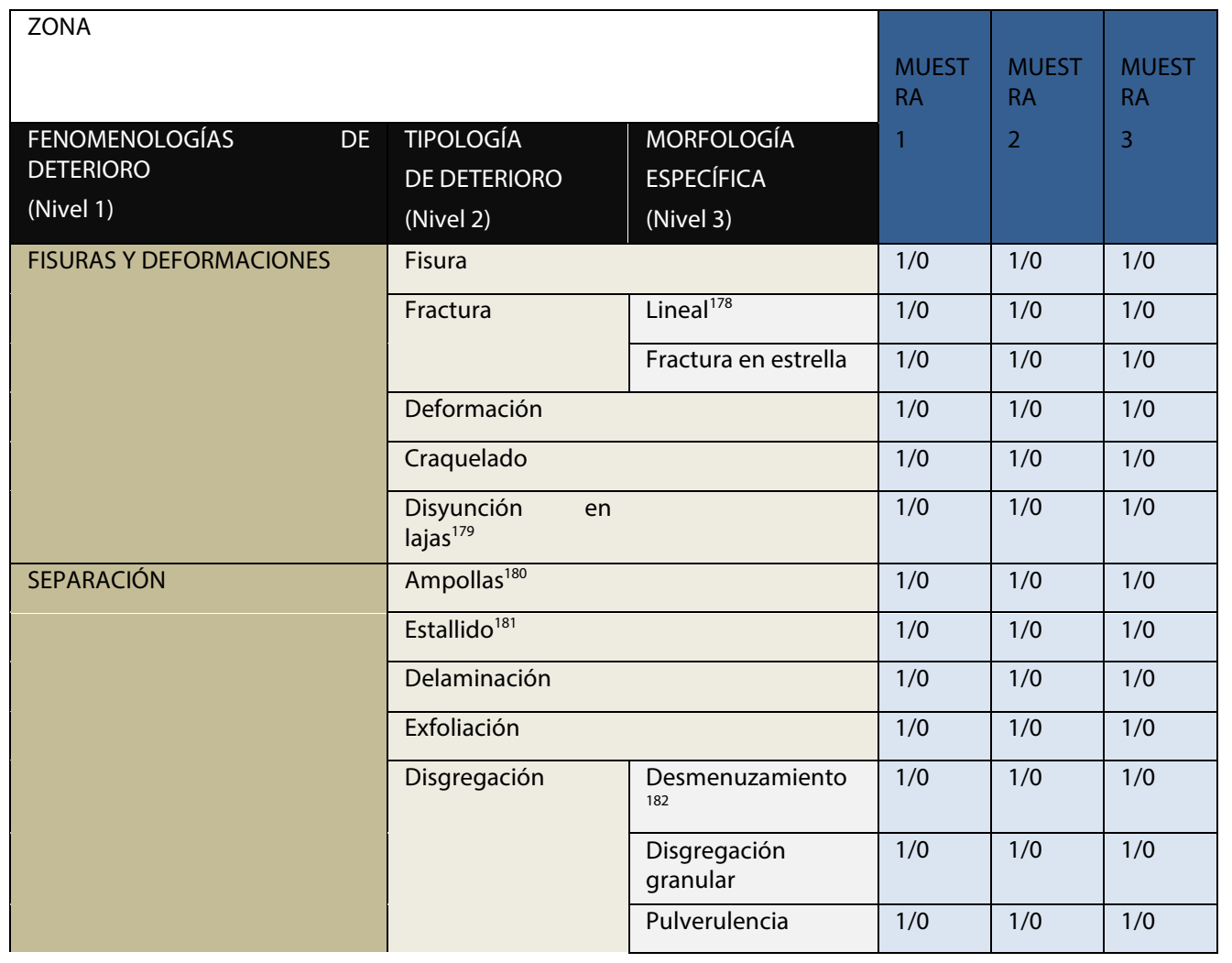

${ }^{176}$ El registro fotográfico se contempla en modalidad digital.

${ }^{177}$ En el modelo de matriz propuesto los valores $1 / 0$ son indicativos de la modalidad de cumplimentación de la ficha según el criterio de presencia/ausencia.

${ }^{178}$ Criterio agregado en fase de diseño de la ficha con el propósito de proveer el registro de la información inherente el fenómeno de ruptura del material pétreo con características lineales, lo cual se ha considerado indicativo de dinámicas de deterioro específicas.

179 Trad. del inglés splitting.

${ }^{180}$ Trad. del inglés blistering.

${ }^{181}$ Trad. del inglés bursting.

182 Trad. del inglés crumbling. 


\begin{tabular}{|c|c|c|c|c|c|}
\hline & & Arenización & $1 / 0$ & $1 / 0$ & $1 / 0$ \\
\hline & & $\begin{array}{l}\text { Disgregación } \\
\text { sacaroidea }^{183}\end{array}$ & $1 / 0$ & $1 / 0$ & $1 / 0$ \\
\hline & \multicolumn{2}{|l|}{ Fragmentación } & $1 / 0$ & $1 / 0$ & $1 / 0$ \\
\hline & \multicolumn{2}{|c|}{ Fragmentación en esquirlas ${ }^{184}$} & $1 / 0$ & $1 / 0$ & $1 / 0$ \\
\hline & \multicolumn{2}{|l|}{$\begin{array}{l}\text { Disyunción en } \\
\text { películas }^{185}\end{array}$} & $1 / 0$ & $1 / 0$ & $1 / 0$ \\
\hline & \multicolumn{2}{|l|}{ Descamación } & $1 / 0$ & $1 / 0$ & $1 / 0$ \\
\hline \multirow{15}{*}{$\begin{array}{l}\text { MORFOLOGÍAS INDUCIDAS POR } \\
\text { PÉRDIDAS }\end{array}$} & \multicolumn{2}{|l|}{ Alveolización } & $1 / 0$ & $1 / 0$ & $1 / 0$ \\
\hline & \multirow[t]{4}{*}{ Erosión } & Erosión differencial & $1 / 0$ & $1 / 0$ & $1 / 0$ \\
\hline & & $\begin{array}{ll}\text { Pérdida } & \text { de } \\
\text { componentes } & \end{array}$ & $1 / 0$ & $1 / 0$ & $1 / 0$ \\
\hline & & Pérdida de matriz & $1 / 0$ & $1 / 0$ & $1 / 0$ \\
\hline & & Redondeamiento & $1 / 0$ & $1 / 0$ & $1 / 0$ \\
\hline & \multicolumn{2}{|l|}{$\begin{array}{l}\text { Aumento de la } \\
\text { rugosidad }\end{array}$} & $1 / 0$ & $1 / 0$ & $1 / 0$ \\
\hline & \multirow[t]{5}{*}{ Daños mecánicos } & Impacto directo & $1 / 0$ & $1 / 0$ & $1 / 0$ \\
\hline & & Incisión & $1 / 0$ & $1 / 0$ & $1 / 0$ \\
\hline & & Rayado & $1 / 0$ & $1 / 0$ & $1 / 0$ \\
\hline & & Abrasión & $1 / 0$ & $1 / 0$ & $1 / 0$ \\
\hline & & Repicado $^{186}$ & $1 / 0$ & $1 / 0$ & $1 / 0$ \\
\hline & \multicolumn{2}{|l|}{ Microkarst ${ }^{187}$} & $1 / 0$ & $1 / 0$ & $1 / 0$ \\
\hline & \multirow[t]{3}{*}{ Faltantes } & Agujero & $1 / 0$ & $1 / 0$ & $1 / 0$ \\
\hline & & Perforación & $1 / 0$ & $1 / 0$ & $1 / 0$ \\
\hline & & Agujereado $^{188}$ & $1 / 0$ & $1 / 0$ & $1 / 0$ \\
\hline
\end{tabular}

183 Trad. del término inglés sugaring indica la disgregación sacaroidea típica de los procesos de alteración y deterioro de los mármoles cristalinos.

184 Trad. del inglés splintering.

185 Trad. del inglés peeling, indica una delaminación por capas muy finas en comparación con las que caracterizan el término delaminación.

186 Trad. del inglés keying.

${ }^{187}$ Microkarst es un término derivado del campo de la geología. En el glosario ICOMOS-ICSC (2008) indica una morfología de deterioro superficial del material pétreo análogo a las características que adquieren los relieves del área geográfica en piedra caliza del Carso (Noreste de Italia). Su etimología deriva del alemán Karst, en español "cárstico". Word reference <https://www.wordreference.com/definition/karst> [Consulta: 10 de febrero de 2021].

188 Trad. del inglés pitting. 


\begin{tabular}{|c|c|c|c|c|c|}
\hline & & Volumétricos $^{189}$ & $1 / 0$ & $1 / 0$ & $1 / 0$ \\
\hline \multirow{16}{*}{$\begin{array}{ll}\text { ALTERACIÓN } & \text { CROMÁTICA } \\
\text { DEPÓSITOS } & \end{array}$} & \multirow[t]{4}{*}{ Costra } & Costra negra & $1 / 0$ & $1 / 0$ & $1 / 0$ \\
\hline & & Costra salina & $1 / 0$ & $1 / 0$ & $1 / 0$ \\
\hline & & Concrección & $1 / 0$ & $1 / 0$ & $1 / 0$ \\
\hline & & Encrustación & $1 / 0$ & $1 / 0$ & $1 / 0$ \\
\hline & \multicolumn{2}{|l|}{ Depósito } & $1 / 0$ & $1 / 0$ & $1 / 0$ \\
\hline & \multirow{5}{*}{$\begin{array}{l}\text { Alteración } \\
\text { cromática }\end{array}$} & Coloración & $1 / 0$ & $1 / 0$ & $1 / 0$ \\
\hline & & Decoloración & $1 / 0$ & $1 / 0$ & $1 / 0$ \\
\hline & & $\begin{array}{l}\text { Manchas de } \\
\text { humedad }\end{array}$ & $1 / 0$ & $1 / 0$ & $1 / 0$ \\
\hline & & Tinción & $1 / 0$ & $1 / 0$ & $1 / 0$ \\
\hline & & Aumento del brillo & $1 / 0$ & $1 / 0$ & $1 / 0$ \\
\hline & \multicolumn{2}{|l|}{ Graffiti } & $1 / 0$ & $1 / 0$ & $1 / 0$ \\
\hline & \multicolumn{2}{|l|}{ Eflorescencias } & $1 / 0$ & $1 / 0$ & $1 / 0$ \\
\hline & \multicolumn{2}{|l|}{ Subflorescencias } & $1 / 0$ & $1 / 0$ & $1 / 0$ \\
\hline & \multirow[t]{2}{*}{ Patina } & Pátina ferruginosa & $1 / 0$ & $1 / 0$ & $1 / 0$ \\
\hline & & Pátina de oxalato & $1 / 0$ & $1 / 0$ & $1 / 0$ \\
\hline & \multicolumn{2}{|l|}{ Suciedad } & $1 / 0$ & $1 / 0$ & $1 / 0$ \\
\hline \multirow[t]{5}{*}{ COLONIZACIÓN BIOLÓGICA } & \multicolumn{2}{|l|}{ Algas } & $1 / 0$ & $1 / 0$ & $1 / 0$ \\
\hline & \multicolumn{2}{|l|}{ Líquenes } & $1 / 0$ & $1 / 0$ & $1 / 0$ \\
\hline & \multicolumn{2}{|l|}{ Musgo } & $1 / 0$ & $1 / 0$ & $1 / 0$ \\
\hline & \multicolumn{2}{|l|}{ Moho, hongos } & $1 / 0$ & $1 / 0$ & $1 / 0$ \\
\hline & \multicolumn{2}{|l|}{ Plantas } & $1 / 0$ & $1 / 0$ & $1 / 0$ \\
\hline
\end{tabular}

En ocasión del estudio del conjunto de obras de arte ubicadas en el Museo de Arte Sacro de Guadalcázar (San Luis Potosí), las tablas propuestas para la toma de informaciones han sido estructuradas de acuerdo a las características de la pintura de caballete (sobre lienzo o tabla) y de la escultura lígnea policromada. La matriz de datos ha sido organizada a partir de una recolección previa de las terminologías relacionadas con las fenomenologías de alteración y deterioro propias de esta clase de obras y, tras una revisión bibliográfica de las publicaciones del sector de la

${ }^{189}$ Criterio agregado en fase de diseño del método, tomando en consideración la posibilidad de tener que registrar faltantes volumétricos específicos para obras escultóricas u ornamentales. De acuerdo a la naturaleza de patrimonio al que un profesional de la conservación puede enfrentarse, se ha considerado útil proveer la tabla de registro de un criterio especial dedicado a los faltantes que pueden afectar en el específico los volúmenes escultóricos de los monumentos. 
conservación y restauración de pintura de caballete ${ }^{190}$, los términos han sido ordenados de acuerdo a la composición estratigráfica del sistema-tipo de esta tipología de bienes (imagen 35) ${ }^{191}$.

\section{TECNOLOGÍA DE LAS OBRAS PICTÓRICAS Y ESCULTÓRICAS: SISTEMA-TIPO DE LAS CAPAS CONSTITUTIVAS}

\section{PINTURA SOBRE TABLA (hasta siglo XVI)}

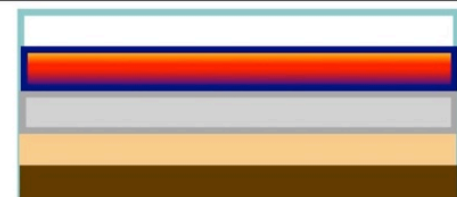

5 - CAPA DE PROTECCIÓN - BARNIZ

4 - PELÍCULA PICTÓRICA

3 - PREPARACIÓN

2 - LIENZO (ENCAÑAMADO/ENTELADO)

1 - TABLA - SOPORTE

PINTURA SOBRE LIENZO (desde siglo XVI)

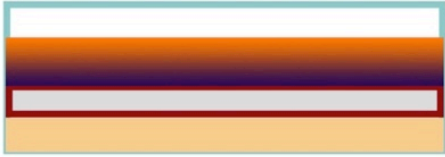

4 - CAPA DE PROTECCIÓN - BARNIZ

3 - PELÍCULA PICTÓRICA

2 - IMPRIMACIÓN Y/O PREPARACIÓN

1 - LIENZO - SOPORTE

ESCULTURA POLICROMADA (desde siglo XI)

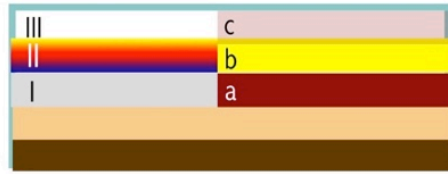

5 - BARNIZ(III)/CORLA(C)

4 - POLICROMÍA(II)/DORADO(b)

3 - PREPARACIÓN(I)/BOL(a)

2 - ENTELADO

1 - MADERA - SOPORTE

Imagen 35 - Representación del sistema constitutivo de las tipologías de obras examinadas en este estudio.

${ }^{190}$ CALVO, A. (2002). Conservación y restauración de pintura sobre lienzo. Barcelona: El Serbal. CALVO, A., GARCÍA FERNÁNDEZ-VILLA, S., BAILÃO, A. (2018). Terminología básica de conservación y restauración del patrimonio cultural. Madrid: Universidad Complutense de Madrid. VIVANCOS RAMÓN, V. (2007). La conservación y restauración de la pintura de caballete. Pintura sobre tabla. Madrid: Tecnos. VIVANCOS RAMÓN, V. y CASTELL AGUSTÍ, M. (2010). Problemas y tratamientos del soporte de pintura de caballete. Valencia: Universidad Politécnica de Valencia.

191 Por sistema-tipo se entiende la representación ideal de las capas constitutivas de la tipología de bienes culturales en examen. Ésta, diseñada a partir de las características más comunes en la creación de las obras pertenecientes a la pintura de caballete y escultura policromada, responde a las exigencias de unificación de los criterios como base de diseño de las fichas. Para su representación se han seleccionado los más difusos en dicha clase de bienes culturales, tomando en cuenta la existencia de múltiples variantes en las características tecnológicas de cada obra que, por razones de esquematización, no pueden ser contempladas en la propuesta de este modelo de registro de datos. Ulteriores reflexiones sobre el sistema de estratos que compone nel patrimonio cultural y su puesta en relación con las finalidades propuestas para las fichas de registro unificadas se presentan en el apartado de "Resultados y discusión". 
La matriz se estructuró de acuerdo a las capas compositivas, ubicando cada fenómeno en el estrato de pertenencia o manifestación: soporte de tela, soporte de madera, preparación, película pictórica y capa de protección. En este modelo, los datos a recolectar se han estructurado en dos niveles, correspondientes a la tipología del fenómeno (nivel 1) y a su morfología específica (nivel 2). Las muestras, conforme a las experiencias anteriores, han sido identificadas con coordenadas numéricas y fotografías (tablas 18, 19, 20, 21, 22).

Tabla 18 - Matriz de datos elaborada para los soportes o elementos estructurales en madera (M) derivada de la revisión bibliográfica.

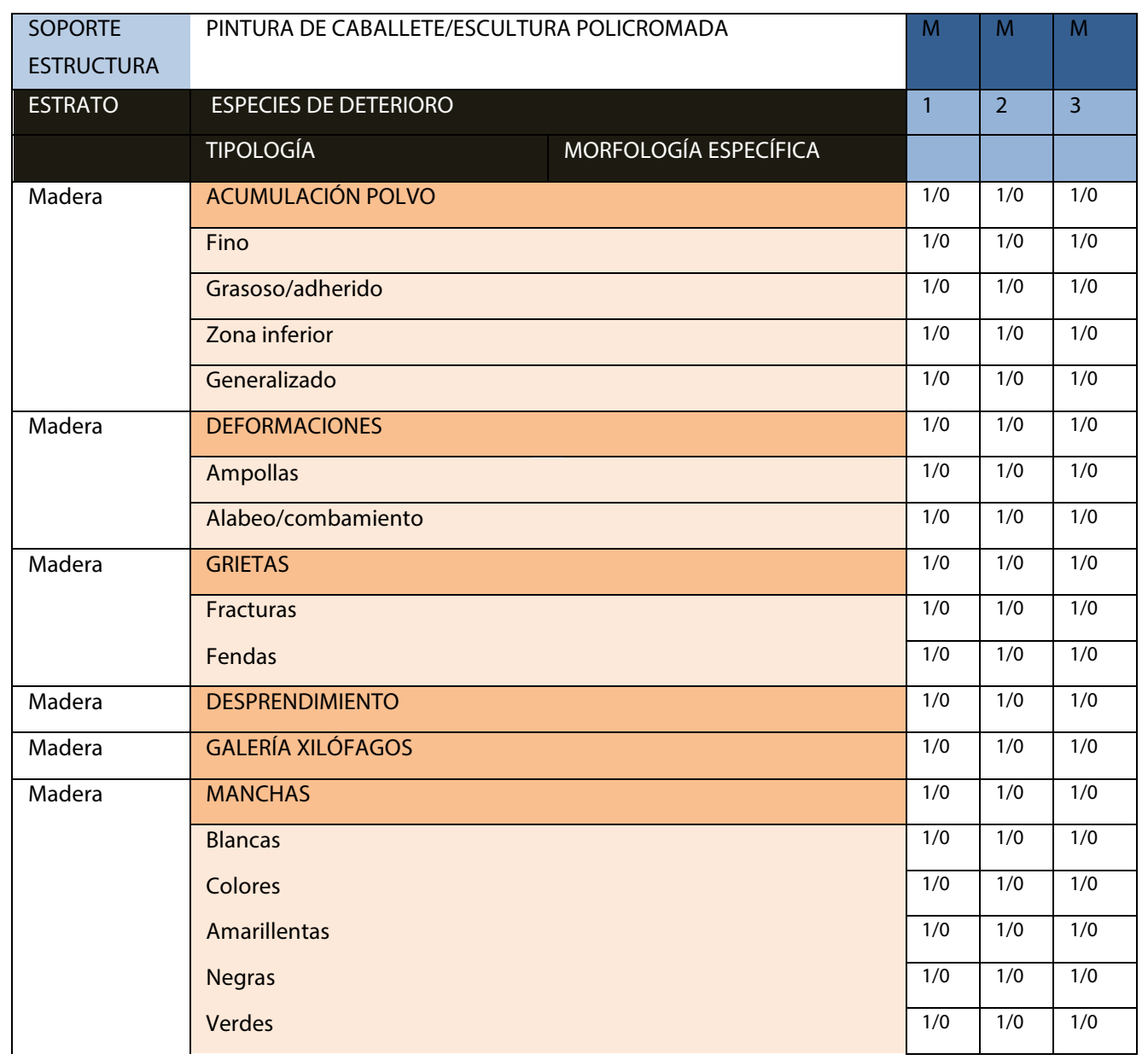




\begin{tabular}{|c|c|c|c|c|}
\hline & \multirow{4}{*}{$\begin{array}{l}\text { Agrisamiento } \\
\text { Decoloración } \\
\text { Filamentos }^{192} \\
\text { Pulverulencia }^{193}\end{array}$} & \multirow{2}{*}{$\begin{array}{l}1 / 0 \\
1 / 0\end{array}$} & \multirow{2}{*}{$\begin{array}{l}1 / 0 \\
1 / 0\end{array}$} & \multirow{2}{*}{$\begin{array}{l}1 / 0 \\
1 / 0\end{array}$} \\
\hline & & & & \\
\hline & & $1 / 0$ & $1 / 0$ & $1 / 0$ \\
\hline & & $1 / 0$ & $1 / 0$ & $1 / 0$ \\
\hline \multirow[t]{3}{*}{ Madera } & ALTERACIÓN ESTRUCTURAL & $1 / 0$ & $1 / 0$ & $1 / 0$ \\
\hline & Exhudación de resina & $1 / 0$ & $1 / 0$ & $1 / 0$ \\
\hline & Pérdida y/o movimiento de nudos, lagunas del soporte & $1 / 0$ & $1 / 0$ & $1 / 0$ \\
\hline \multirow[t]{6}{*}{ Madera } & MODIFICACIONES ESTRUCTURALES & $1 / 0$ & $1 / 0$ & $1 / 0$ \\
\hline & División de soportes bifaces & $1 / 0$ & $1 / 0$ & $1 / 0$ \\
\hline & Eliminación de elementos estructurales y/o de partes de la mazonería & $1 / 0$ & $1 / 0$ & $1 / 0$ \\
\hline & Aligeramiento del soporte & $1 / 0$ & $1 / 0$ & $1 / 0$ \\
\hline & Engatillado/embarrotado & $1 / 0$ & $1 / 0$ & $1 / 0$ \\
\hline & Trasposición a otro soporte & $1 / 0$ & $1 / 0$ & $1 / 0$ \\
\hline Madera & INTERVENCIONES ANTERIORES & $1 / 0$ & $1 / 0$ & $1 / 0$ \\
\hline
\end{tabular}

Tabla 19 - Matriz de datos para el soporte o elementos estructurales en tela (L).

\begin{tabular}{|c|c|c|c|c|}
\hline $\begin{array}{l}\text { SOPORTE } \\
\text { LIENZO }\end{array}$ & PINTURAS DE CABALLETE/ESCULTURA POLICROMADA & M & M & M \\
\hline ESTRATO & ESPECIES DE DETERIORO & 1 & 2 & 3 \\
\hline \multirow[t]{5}{*}{ Lienzo } & ACUMULACIÓN POLVO & $1 / 0$ & $1 / 0$ & $1 / 0$ \\
\hline & Fino & $1 / 0$ & $1 / 0$ & $1 / 0$ \\
\hline & Graso/adherido & $1 / 0$ & $1 / 0$ & $1 / 0$ \\
\hline & Zona inferior & $1 / 0$ & $1 / 0$ & $1 / 0$ \\
\hline & Generalizado & $1 / 0$ & $1 / 0$ & $1 / 0$ \\
\hline \multirow[t]{4}{*}{ Lienzo } & DEFORMACIÓN PLANIMÉTRICA & $1 / 0$ & $1 / 0$ & $1 / 0$ \\
\hline & Arrugas en las esquinas & $1 / 0$ & $1 / 0$ & $1 / 0$ \\
\hline & Marcas elem estructurales & $1 / 0$ & $1 / 0$ & $1 / 0$ \\
\hline & Perímetro & $1 / 0$ & $1 / 0$ & $1 / 0$ \\
\hline
\end{tabular}

192 Criterio agregado en fase de diseño de la tabla, tomando en consideración que la presencia de esta característica, en combinación con otras fenomenologías, es indicativa de un posible ataque biológico.

193 Criterio agregado en fase de diseño de la tabla, tomando en consideración que la presencia de esta peculiaridad, en combinación con otras fenomenologías, puede ser indicativa de un ataque biológico. 


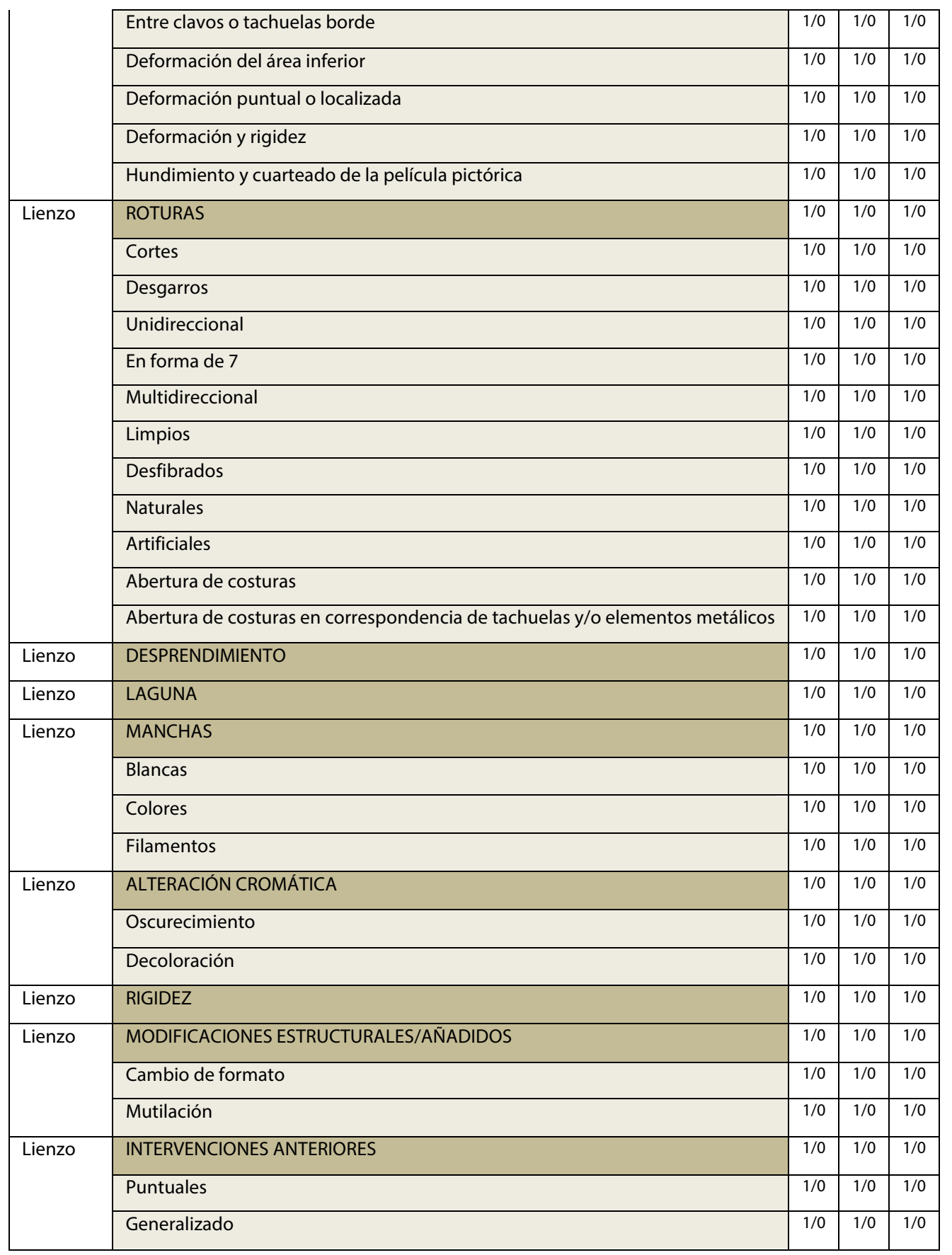


Tabla 20 - Matriz de datos para la capa de preparación (Pr).

\begin{tabular}{|c|c|c|c|c|}
\hline PREPARACIÓN & PINTURAS DE CABALLETE/ESCULTURA POLICROMADA & M & M & M \\
\hline ESTRATO & ESPECIES DE DETERIORO & 1 & 2 & 3 \\
\hline \multirow[t]{4}{*}{ Preparación } & DEFORMACIONES DE LA SUPERFICIE & $1 / 0$ & $1 / 0$ & $1 / 0$ \\
\hline & Ampollas & $1 / 0$ & $1 / 0$ & $1 / 0$ \\
\hline & Abolsamientos & $1 / 0$ & $1 / 0$ & $1 / 0$ \\
\hline & Levantamientos & $1 / 0$ & $1 / 0$ & $1 / 0$ \\
\hline Preparación & DESPRENDIMIENTOS & $1 / 0$ & $1 / 0$ & $1 / 0$ \\
\hline Preparación & LAGUNAS & $1 / 0$ & $1 / 0$ & $1 / 0$ \\
\hline Preparación & MANCHAS & $1 / 0$ & $1 / 0$ & $1 / 0$ \\
\hline Preparación & CUARTEADO & $1 / 0$ & $1 / 0$ & $1 / 0$ \\
\hline Preparación & PÉRDIDA DE ADHESIÓN CON LA PELÍCULA PICTÓRICA & $1 / 0$ & $1 / 0$ & $1 / 0$ \\
\hline Preparación & PULVERULENCIA & $1 / 0$ & $1 / 0$ & $1 / 0$ \\
\hline
\end{tabular}

Tabla 21 - Matriz de datos para la película pictórica (PP).

\begin{tabular}{|c|c|c|c|c|}
\hline PELÍCULA PICTÓRICA & PINTURAS DE CABALLETE/ESCULTURA POLICROMADA & M & M & M \\
\hline ESTRATO & ESPECIES DE DETERIORO & 1 & 2 & 3 \\
\hline \multirow{4}{*}{$\begin{array}{l}\text { Película } \\
\text { Pictórica }\end{array}$} & ACUMULACIÓN DE POLVO & $1 / 0$ & $1 / 0$ & $1 / 0$ \\
\hline & & & & \\
\hline & Fino & $1 / 0$ & $1 / 0$ & $1 / 0$ \\
\hline & Grasoso/adherido & $1 / 0$ & $1 / 0$ & $1 / 0$ \\
\hline \multirow{8}{*}{$\begin{array}{l}\text { Película } \\
\text { Pictórica }\end{array}$} & DEFORMACIONES DE LA SUPERFICIE & $1 / 0$ & $1 / 0$ & $1 / 0$ \\
\hline & Descamación & $1 / 0$ & $1 / 0$ & $1 / 0$ \\
\hline & Levantamientos & $1 / 0$ & $1 / 0$ & $1 / 0$ \\
\hline & Cordilleras & $1 / 0$ & $1 / 0$ & $1 / 0$ \\
\hline & Ampollas & $1 / 0$ & $1 / 0$ & $1 / 0$ \\
\hline & Cazoletas & $1 / 0$ & $1 / 0$ & $1 / 0$ \\
\hline & Abolsamientos & $1 / 0$ & $1 / 0$ & $1 / 0$ \\
\hline & Impresión de la trama del lienzo en la superficie & $1 / 0$ & $1 / 0$ & $1 / 0$ \\
\hline
\end{tabular}




\begin{tabular}{|c|c|c|c|c|}
\hline & Hundimientos & \multirow{2}{*}{$\begin{array}{l}1 / 0 \\
1 / 0\end{array}$} & \multirow{2}{*}{$\begin{array}{l}1 / 0 \\
1 / 0\end{array}$} & \multirow{2}{*}{$\begin{array}{l}1 / 0 \\
1 / 0\end{array}$} \\
\hline & Desprendimientos & & & \\
\hline & Solapamientos & $1 / 0$ & $1 / 0$ & $1 / 0$ \\
\hline $\begin{array}{l}\text { Película } \\
\text { Pictórica }\end{array}$ & GRIETAS (puntuales/intracapas) & $1 / 0$ & $1 / 0$ & $1 / 0$ \\
\hline \multirow{5}{*}{$\begin{array}{l}\text { Película } \\
\text { Pictórica }\end{array}$} & LAGUNAS & $1 / 0$ & $1 / 0$ & $1 / 0$ \\
\hline & & & & \\
\hline & Numerosas pequeñas en esquinas cuarteados & $1 / 0$ & $1 / 0$ & $1 / 0$ \\
\hline & Grandes áreas & $1 / 0$ & $1 / 0$ & $1 / 0$ \\
\hline & Área inferior & $1 / 0$ & $1 / 0$ & $1 / 0$ \\
\hline \multirow{10}{*}{$\begin{array}{l}\text { Película } \\
\text { Pictórica }\end{array}$} & ALTERACIÓN CROMÁTICA & $1 / 0$ & $1 / 0$ & $1 / 0$ \\
\hline & Blanqueamiento & $1 / 0$ & $1 / 0$ & $1 / 0$ \\
\hline & Azulado & $1 / 0$ & $1 / 0$ & $1 / 0$ \\
\hline & Tono café-marrón & $1 / 0$ & $1 / 0$ & $1 / 0$ \\
\hline & Oscurecimiento & $1 / 0$ & $1 / 0$ & $1 / 0$ \\
\hline & Amarilleamiento & $1 / 0$ & $1 / 0$ & $1 / 0$ \\
\hline & Opacidad & $1 / 0$ & $1 / 0$ & $1 / 0$ \\
\hline & Repintes & $1 / 0$ & $1 / 0$ & $1 / 0$ \\
\hline & Trasparentado de áreas de color & $1 / 0$ & $1 / 0$ & $1 / 0$ \\
\hline & Piel de naranja & $1 / 0$ & $1 / 0$ & $1 / 0$ \\
\hline \multirow{9}{*}{$\begin{array}{l}\text { Película } \\
\text { Pictórica }\end{array}$} & CUARTEADOS & $1 / 0$ & $1 / 0$ & $1 / 0$ \\
\hline & En los ángulos & $1 / 0$ & $1 / 0$ & $1 / 0$ \\
\hline & Perimetrales & $1 / 0$ & $1 / 0$ & $1 / 0$ \\
\hline & A contacto con los elementos estructurales y/o el bastidor & $1 / 0$ & $1 / 0$ & $1 / 0$ \\
\hline & En áreas de color específicas & $1 / 0$ & $1 / 0$ & $1 / 0$ \\
\hline & Forma circular o telaraña & $1 / 0$ & $1 / 0$ & $1 / 0$ \\
\hline & Forma de espina de pez & $1 / 0$ & $1 / 0$ & $1 / 0$ \\
\hline & En correspondencia con la deformación de plano & $1 / 0$ & $1 / 0$ & $1 / 0$ \\
\hline & Generalizados & $1 / 0$ & $1 / 0$ & $1 / 0$ \\
\hline $\begin{array}{l}\text { Película } \\
\text { Pictórica }\end{array}$ & CRAQUELADO & $1 / 0$ & $1 / 0$ & $1 / 0$ \\
\hline $\begin{array}{l}\text { Película } \\
\text { Pictórica }\end{array}$ & PULVERULENCIA & $1 / 0$ & $1 / 0$ & $1 / 0$ \\
\hline Película & QUEMADURAS & $1 / 0$ & $1 / 0$ & $1 / 0$ \\
\hline
\end{tabular}




\begin{tabular}{|c|c|c|c|c|}
\hline Pictórica & & & & \\
\hline \multirow{5}{*}{$\begin{array}{l}\text { Película } \\
\text { Pictórica }\end{array}$} & TRAUMATISMOS & $1 / 0$ & $1 / 0$ & $1 / 0$ \\
\hline & Rayados & $1 / 0$ & $1 / 0$ & $1 / 0$ \\
\hline & Abrasión & $1 / 0$ & $1 / 0$ & $1 / 0$ \\
\hline & Desgaste & $1 / 0$ & $1 / 0$ & $1 / 0$ \\
\hline & Arañazos & $1 / 0$ & $1 / 0$ & $1 / 0$ \\
\hline $\begin{array}{l}\text { Película } \\
\text { Pictórica }\end{array}$ & MATERIALES AJENOS & $1 / 0$ & $1 / 0$ & $1 / 0$ \\
\hline
\end{tabular}

Tabla 22 - Matriz de datos para la capa de protección (B).

\begin{tabular}{|c|c|c|c|c|}
\hline CAPA DE PROTECCIÓN & PINTURAS DE CABALLETE/ESCULTURA POLICROMADA & M & M & M \\
\hline ESTRATO & ESPECIES DE DETERIORO & 1 & 2 & 3 \\
\hline Barniz & CUARTEADO & $1 / 0$ & $1 / 0$ & $1 / 0$ \\
\hline \multirow[t]{7}{*}{ Barniz } & ALTERACIÓN CROMÁTICA & $1 / 0$ & $1 / 0$ & $1 / 0$ \\
\hline & Oscurecimiento & $1 / 0$ & $1 / 0$ & $1 / 0$ \\
\hline & Amarilleamiento & $1 / 0$ & $1 / 0$ & $1 / 0$ \\
\hline & Pérdida de trasparencia & $1 / 0$ & $1 / 0$ & $1 / 0$ \\
\hline & Blanqueamiento & $1 / 0$ & $1 / 0$ & $1 / 0$ \\
\hline & Zonas a diferente brillo & $1 / 0$ & $1 / 0$ & $1 / 0$ \\
\hline & Manchas & $1 / 0$ & $1 / 0$ & $1 / 0$ \\
\hline Barniz & DAÑOS MECÁNICOS & $1 / 0$ & $1 / 0$ & $1 / 0$ \\
\hline Barniz & FRAGILIDAD/QUEBRADIZO & $1 / 0$ & $1 / 0$ & $1 / 0$ \\
\hline
\end{tabular}

Tras el análisis cuantitativo y cualitativo de los datos se obtuvieron informaciones referentes a los productos de alteración y su presencia derivadas de su incidencia, poniendo de manifiesto la exigencia de encontrar un medio de estimación complementario que pudiera ofrecer una evaluación de la extensión de los deterioros, para así favorecer el proceso de comprensión y ordenamiento de la gravedad de los fenómenos en acto. 


\subsection{Aplicación del método y análisis de datos}

La aplicación del método cuenta con el desarrollo de cuatro fases operativas:

I. Cumplimentación de las fichas por medio de inspección visual por observación directa o, en su alternativa, por medio de inspección de registros fotográficos o video.

II. Vaciado de los datos en hojas de cálculo de la suite Office de Microsoft Excel ${ }^{\circledR}$ previamente estructuradas para la elaboración matemática de los parámetros requeridos.

III. Elaboración matemática de los datos y generación de índices de riesgo a partir de las informaciones numéricas y cualitativas arrojadas.

IV. Interpretación de los resultados por parte del profesional de la conservación y restauración de bienes culturales.

En la primera fase, el encargado de la recolección de informaciones llevará a cabo un registro de la presencia de las fenomenologías de deterioro elencadas en las fichas (1 presente -0 ausente), de acuerdo a la clase de obra a la que se enfrenta: pintura mural, materiales pétreos, pintura de caballete o escultura policromada (ejemplo en la tabla 23).

Tabla 23 - Ejemplo de cumplimentación de fichas ${ }^{194}$ por medio de la matriz de presencia (1) ausencia (0). Detalle de una porción de la ficha de registro perteneciente a pintura de caballete y escultura policromada, estrato de referencia: película pictórica (PP).

\begin{tabular}{|l|l|l|l|l|}
\hline PELÍCULA PICTÓRICA & PINTURAS DE CABALLETE/ESCULTURA POLICROMADA & $M$ & $M$ & $M$ \\
\hline ESTRATO & ESPECIES DE DETERIORO & 1 & 2 & 3 \\
\hline \multirow{2}{*}{$\begin{array}{l}\text { Película } \\
\text { Pictórica }\end{array}$} & ACUMULACIÓN DE POLVO & $1 / 0$ & $1 / 0$ & $1 / 0$ \\
& & & & \\
\cline { 2 - 6 } & Fino & $1 / 0$ & $1 / 0$ & $1 / 0$ \\
\cline { 2 - 6 } & Grasoso/adherido & $1 / 0$ & $1 / 0$ & $1 / 0$ \\
\hline
\end{tabular}

Cada código alfanumérico de muestra ( $M 1, M 2, M 3$, etc...) que encabeza la tabla corresponderá a una obra; para fines de registro, se llenará una tabla de referencia en donde se reportan los datos de cada bien examinado y el código a él asociado

\footnotetext{
${ }^{194}$ En el modelo de matriz propuesto los valores 1/0 son indicativos de la modalidad de cumplimentación de la ficha según el criterio de presencia/ausencia. La enumeración de las muestras (M1, M2, M3) en la tabla se presentan a modo de ejemplo y no se refieren, en este caso, a ninguna obra en específico.
} 
(tabla 24). En esta fase se contempla la toma de un registro fotográfico de referencia, necesario para la identificación del bien.

Tabla 24 - Ejemplo de tabla de referencia para la identificación de los códigos alfanuméricos asociados a cada obra examinada.

\begin{tabular}{|l|l|}
\hline MUESTRA & Título de la obra/identificación \\
\hline 1 & $\begin{array}{l}\text { Modelo de cumplimentación propuesta como ejemplo: } \\
\text { Pintura de caballete "Crucifixión, óleo sobre lienzo (120x20cm), siglo XVIII" } \\
\text { Escultura policromada "Cristo penitente, talla en madera policromada y dorada, 200x40x70cm, } \\
\text { siglo XIX" } \\
\text { Recubrimientos arquitectónicos, estucos, argamasa, pinturas murales "Área norte-decoración } \\
\text { floreal, } 5 \mathrm{mx10m} \text { siglo XVII } \\
\text { Escultura en materiales pétreos "Ángel", mármol de Carrara, 2x1x0,5m, siglo XX. }\end{array}$ \\
\hline 2 & \\
\hline 3 & \\
\hline 4 & \\
\hline 5
\end{tabular}

Se contempla la posibilidad de realizar la cumplimentación de las fichas de forma virtual, tomando en cuenta la existencia de circunstancias particulares, cuales pueden ser la imposibilidad de traslado presencial al lugar de conservación de los bienes, o peligro para la integridad del personal involucrado ${ }^{195}$. En este caso las actividades de registro de las informaciones se podrán realizar sobre la base de medios digitales, como documentación fotográfica o videos.

En la segunda fase se vaciarán los datos en las hojas de cálculo previamente preparadas con las fórmulas necesarias para la elaboración de los datos numéricos (tabla 25).

\footnotetext{
195 La consideración de esta modalidad de cumplimentación de las fichas responde a las casuísticas de posibilidades presentes en el cumplimiento de las tareas de conservación y monitoreo del territorio. Toma en consideración circunstancias extraordinarias, como acontece en ocasión de los sismos, en donde el personal no puede extender el tiempo dedicado a las tareas de documentación inherentes al estado de conservación del patrimonio en el sitio, sea por falta de seguridad del inmueble, sea por los medios disponibles. En este caso, tener la posibilidad de documentar fotográficamente y ejecutar el diagnóstico en un segundo momento puede representar un recurso interesante.
} 
Tabla 25 - Matriz de registro de datos adaptada a las hojas de cálculo Excel @empleada para el caso de estudio del Panteón Municipal del Saucito (2019). Zona A.

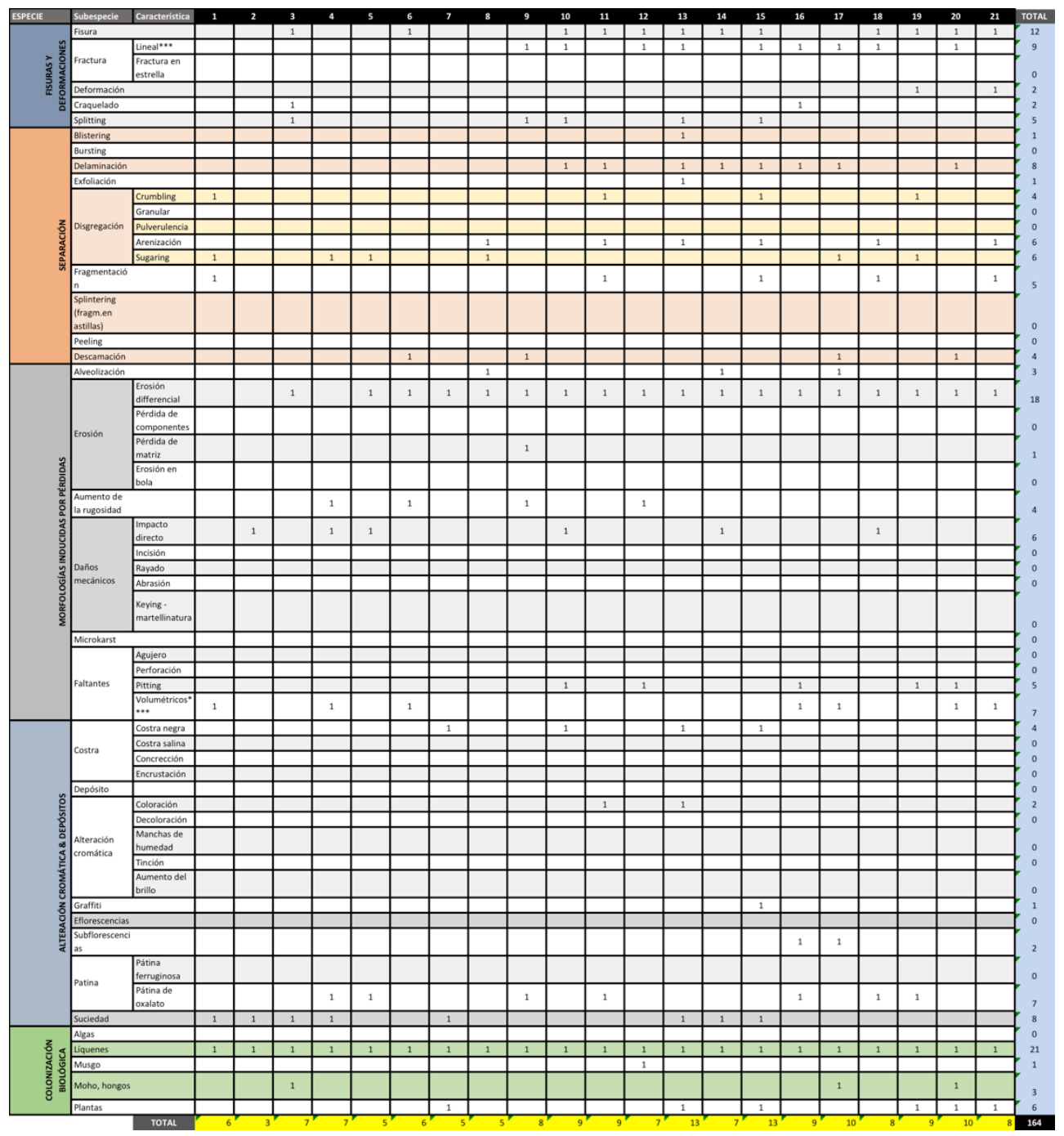

Las informaciones analizadas serán elaboradas a través de cálculos sencillos, cuales suma de los valores de cada celda y ordenación de los resultados en orden decreciente. Tomando en cuenta el ejemplo anterior (tabla 25), los resultados arrojados serán el fruto de la sumatoria en sentido horizontal (eje correspondiente a las especies de deterioro) y vertical (eje correspondiente a las muestras de estudio) de la matriz propuesta (tabla 26). 
Tabla 26 - Ejemplo ${ }^{196}$ del análisis de datos por medio de sumatoria de los ejes horizontales (especies de deterioro) y verticales (muestras de estudio).

\begin{tabular}{|c|c|c|c|c|c|c|}
\hline ESTRATO & TIPOLOGÍA ESPECIE & MORFOLOGÍA ESPECÍFICA & M1 & M2 & M3 & TOTAL \\
\hline \multirow[t]{2}{*}{$P P$} & \multirow[t]{2}{*}{ ACUMULACIÓN DE POLVO } & Fino & 1 & 0 & 0 & 1 \\
\hline & & Grasoso/Adherido & 0 & 1 & 1 & 2 \\
\hline \multirow[t]{7}{*}{$P P$} & \multirow[t]{7}{*}{ CUARTEADOS } & En los ángulos & 1 & 0 & 1 & 2 \\
\hline & & Perimetrales & 1 & 0 & 0 & 1 \\
\hline & & $\begin{array}{l}\text { A contacto con los elementos } \\
\text { estructurales del bastidor }\end{array}$ & 0 & 0 & 0 & 0 \\
\hline & & En áreas de color & 1 & 0 & 0 & 1 \\
\hline & & Forma circular o telaraña & 0 & 1 & 1 & 2 \\
\hline & & Forma de espina de pez & 0 & 0 & 0 & 0 \\
\hline & & Generalizados & 1 & 0 & 0 & 1 \\
\hline & & TOTAL & 5 & 2 & 3 & 10 \\
\hline
\end{tabular}

Tras este sencillo análisis matemático será posible ordenar las especies de deterioro presentes en el conjunto de obras (tabla 27) y generar una escala de riesgo de conservación sustentada en la base de la incidencia cuantitativa de las mismas en cada muestra de estudio (tabla 28) a partir de la cual se desglosarán las problemáticas presentes en cada elemento analizado (tabla 29).

La elaboración de los datos así ejemplificada permite la realización de representaciones gráficas, de barra o circulares, útiles a la trasmisión y comprensión de los resultados obtenidos (gráficas 3, 4 y 5).

Tabla 27 - Ejemplo de los resultados arrojados a partir de la presencia de especies de deterioro en la colección.

\begin{tabular}{|l|l|l|l|}
\hline ESTRATO & ESPECIE & ESPECIFICACIONES & TOTAL \\
\hline PP & ACUMULACIÓN DE POLVO & Grasoso/Adherido & 2 \\
\hline PP & CUARTEADOS & En los ángulos & 2 \\
\hline PP & CUARTEADOS & Forma circular o telaraña & 2 \\
\hline
\end{tabular}

196 Los datos presentados en la tabla son indicativos únicamente del ejemplo de elaboración de las informaciones y no se refieren a casos de estudios reales. 


\begin{tabular}{|l|l|l|l|}
\hline PP & ACUMULACIÓN DE POLVO & Fino & 1 \\
\hline PP & CUARTEADOS & Perimetrales & 1 \\
\hline PP & CUARTEADOS & En áreas de color & 1 \\
\hline PP & CUARTEADOS & Generalizados & 1 \\
\hline PP & CUARTEADOS & $\begin{array}{l}\text { A contacto con los elementos estructurales } \\
\text { del bastidor }\end{array}$ & 0 \\
\hline PP & CUARTEADOS & Forma de espina de pez & 0 \\
\hline
\end{tabular}

Tabla 28 - Ejemplo de escala de riesgo de la colección. Ésta, basada en la cantidad de especies de deterioro presentes, ofrece una panorámica del estado de las obras en la colección a partir del total de especies registrados.

\begin{tabular}{|l|l|}
\hline MUESTRAS & TOTAL \\
\hline M1 & 5 \\
\hline M3 & 3 \\
\hline$M 2$ & 2 \\
\hline
\end{tabular}

Tabla 29 - Ejemplo de las problemáticas específicas para la muestra 1 (M1) que resultó ser la más afectada en la colección-muestra con un total de 5 especies de deterioro presente ${ }^{197}$ s. Éstas, corresponden a un acumulación de polvo fino y presencia de cuarteados en la película pictórica en: zonas perimetrales, ángulos y áreas de color.

\begin{tabular}{|l|l|l|}
\hline M1 & TOTAL ESPECIES DE DETERIORO & 5 \\
\hline TIPOLOGÍA DE DETERIORO & MORFOLOGÍA ESPECÍFICA & TOTAL \\
\hline ACUMULACIÓN DE POLVO & Fino & 1 \\
\hline CUARTEADOS & En los ángulos & 1 \\
\hline CUARTEADOS & Perimetrales & 1 \\
\hline CUARTEADOS & En áreas de color & 1 \\
\hline CUARTEADOS & Generalizados & 1 \\
\hline
\end{tabular}

197 Análogamente a los demás ejemplos propuestos en las tablas, los datos aquí proporcionados poseen la única finalidad de fungir como ejemplo de la elaboración de la información. 


\begin{tabular}{|l|l|l|}
\hline ACUMULACIÓN DE POLVO & Grasoso/Adherido & 0 \\
\hline CUARTEADOS & A contacto con los elementos estructurales del bastidor & 0 \\
\hline CUARTEADOS & Forma circular o telaraña & 0 \\
\hline CUARTEADOS & Forma de espina de pez & 0 \\
\hline
\end{tabular}

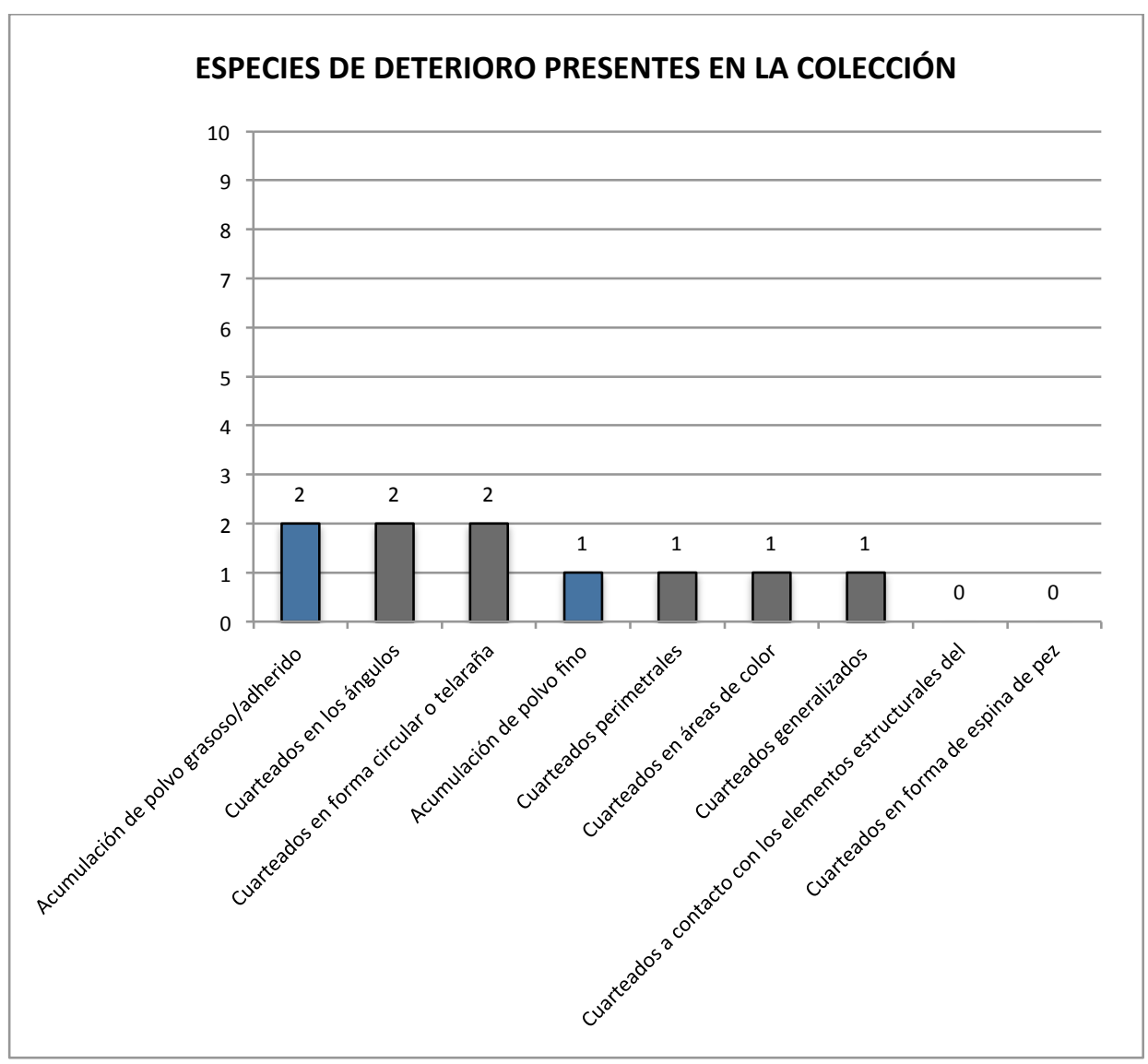

Gráfica 3 - Ejemplo de representación por medio de gráfica de barras del índice de riesgo de la colección estructurada a partir de las especies de deterioro registradas ${ }^{198}$.

198 Las gráficas puestas como ejemplo de la elaboración y representación de resultados se refieren al análisis de una porción de la matriz propuesta para el registro de las especies de deterioro específicas de la película pictórica. Lo anterior se realizó para tres muestras (M1, M2, M3) con el único objetivo de ejemplificar el proceso de aplicación del método. 


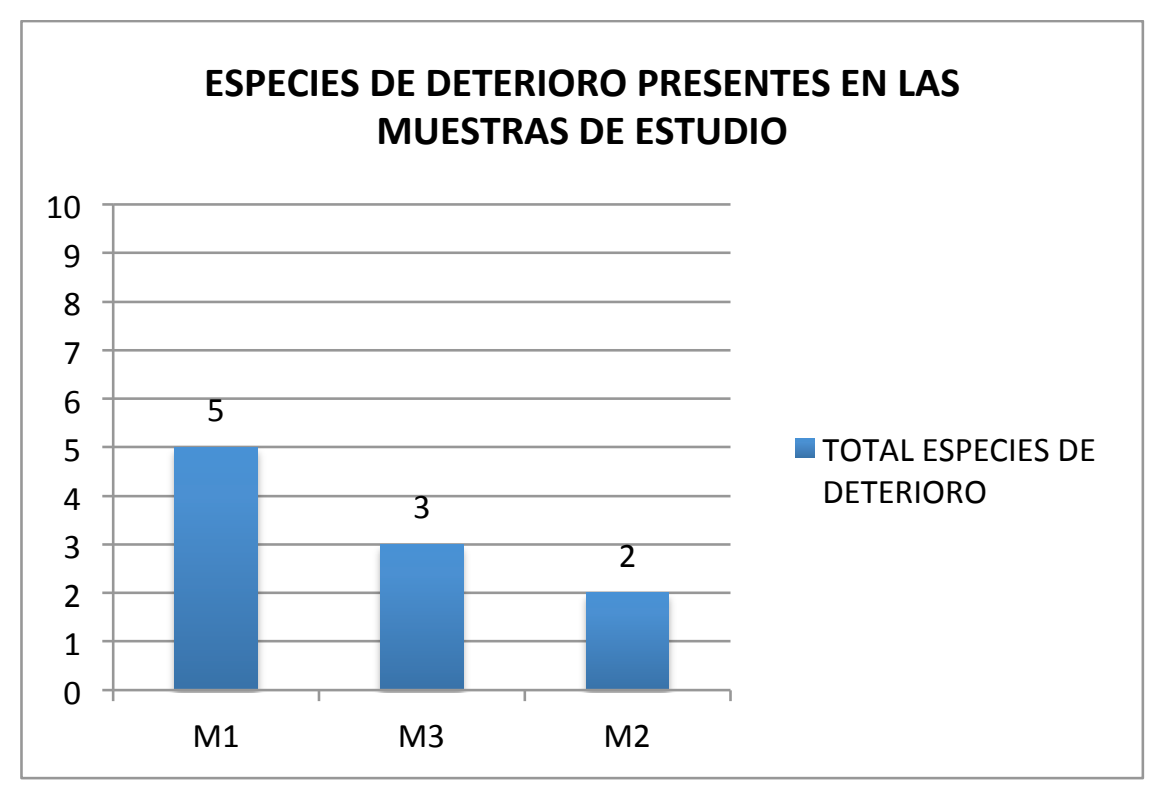

Gráfica 4 - Total de especies de deterioro presentes en la colección-ejemplo. 


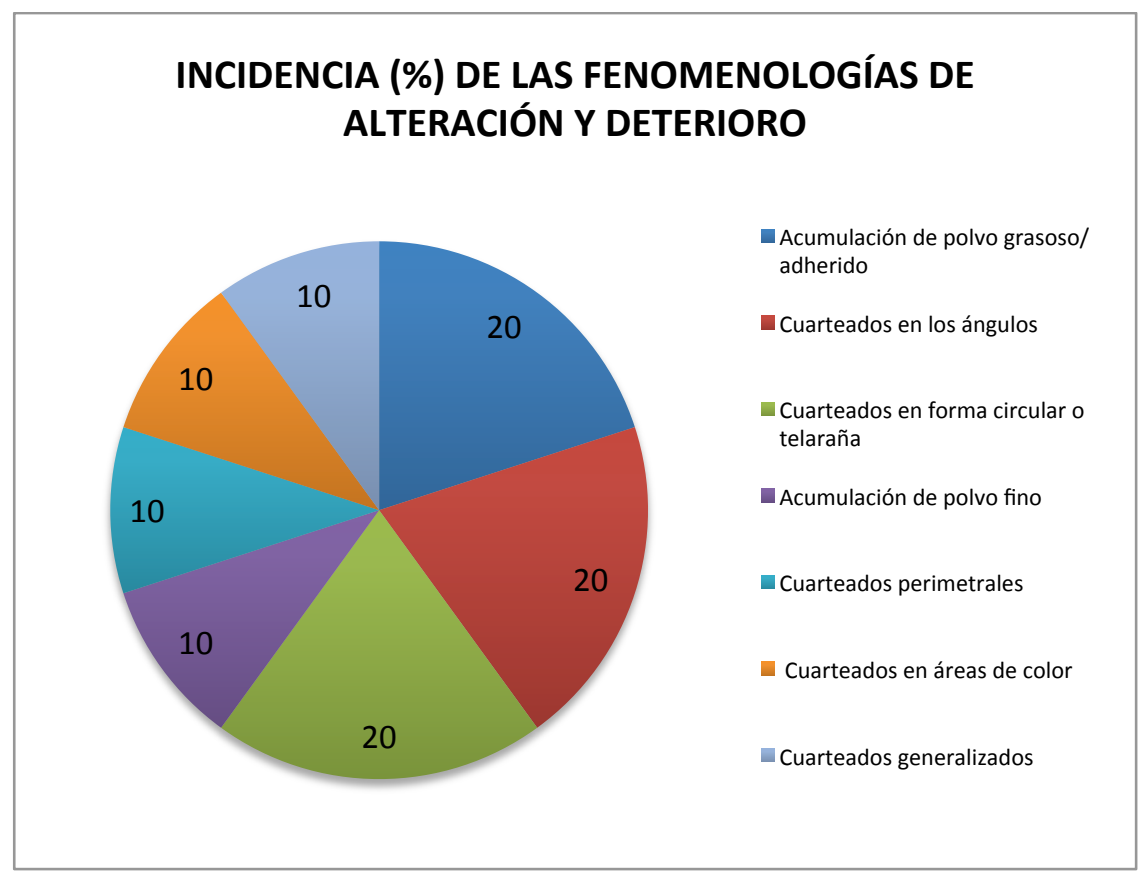

Gráfica 5 - Incidencia (\%) de las fenomenologías de lateración y deterioro.

Finalmente, en la cuarta y última fase, los datos serán analizados e interpretados a la luz de la experiencia del profesional de la conservación y restauración de bienes culturales, quién será responsable de obtener directrices útiles para la toma de decisiones.

\subsubsection{Murales del siglo XX en San Luis Potosí}

La aplicación de la primera versión del método se llevó a cabo en 2016, sobre el conjunto de obras murales realizadas en el siglo XX en el estado y capital de San Luis Potosí (tabla 30). En esta ocasión, debido a la distribución de las obras objeto de estudio, el análisis se realizó sobre una documentación fotográfica realizada previamente. 
Tabla 30 - Detalles de la primera implementación del método sobre pinturas murales.

\begin{tabular}{|l|l|}
\hline CONJUNTO DE PINTURAS MURALES DEL SIGLO XX, SAN LUIS POTOSÍ \\
\hline Registro realizado en: & Marzo 2016 \\
\hline Objeto de estudio: & Pinturas murales y mosaicos \\
\hline Tiempo de registro de datos: & 2 horas sobre documentación fotográfica \\
\hline Total de obras analizadas: & 21 , ubicadas en la capital y estado de S.L.P. (imagen 36) \\
\hline Profesionales empleados: & 1 \\
\hline Tiempo para el análisis de datos & 1 hora \\
\hline
\end{tabular}

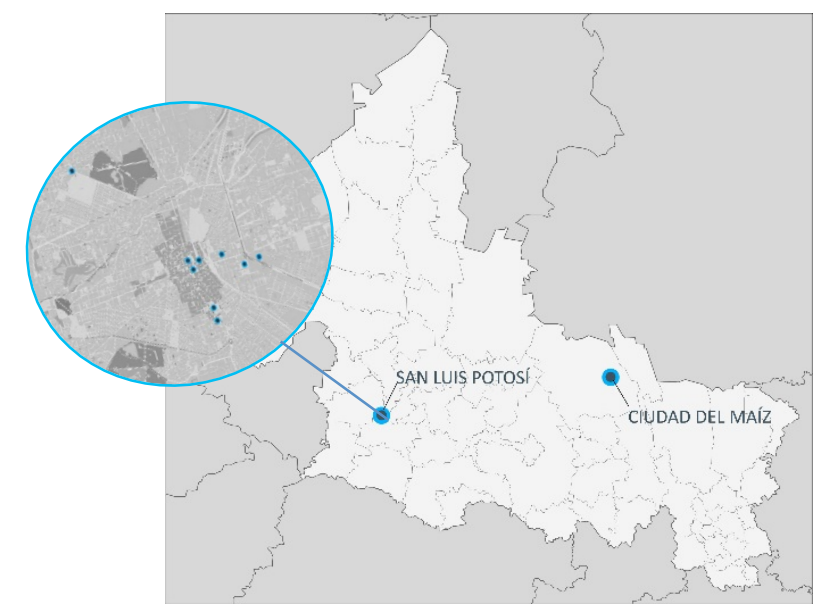

Imagen 36 - Panorámica de la ubicación de los murales escogidos para los casos de estudio.

Este conjunto de obras representó la ocasión para el primer diseño y aplicación de las tablas de registro. Se generó una primera matriz de datos sobre el modelo especificado (apartado "Diseño de matrices de datos") aplicando un estudio de las informaciones que brindó datos a diferentes niveles (diagrama 8), capaces de crear un indicador de riesgo y una estimación de las fenomenologías y causas de alteración y deterioro presentes (tablas 31 y 32). 


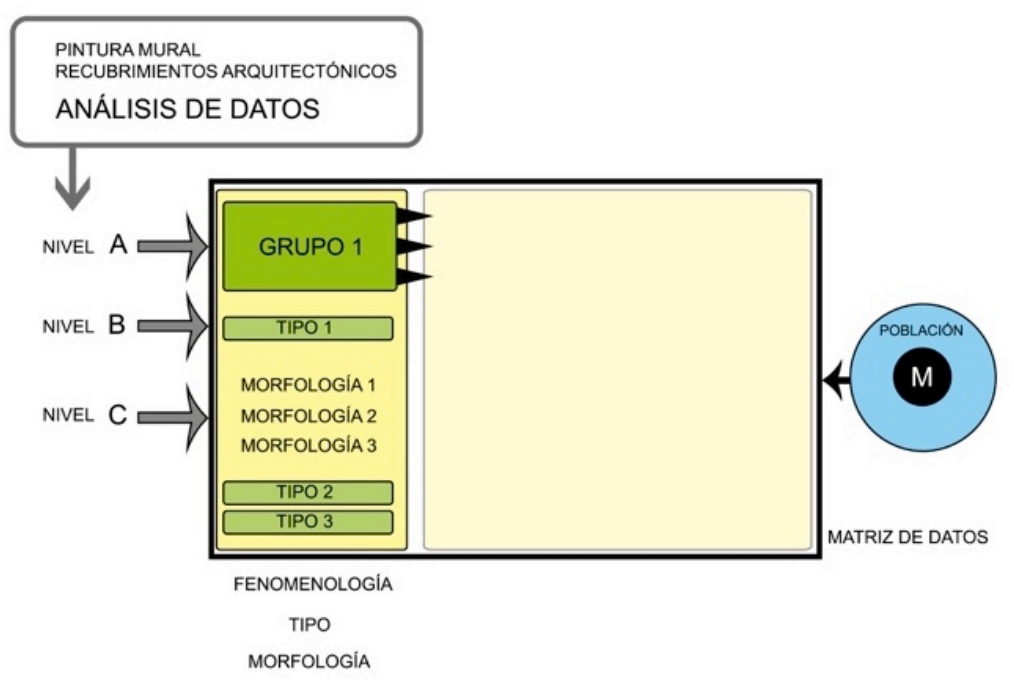

Primera implementación del método derivado de EWAGlos (Ed. 2016)

Diagrama 18 - Estructuración de los conceptos en la matriz y niveles de análisis de datos (A, B, C) ofrecido por el sistema. Pintura Mural.

Los datos arrojados brindaron informaciones cuya interpretación estaba vinculada al nivel de estudio (diagrama 18) de acuerdo a la estructura de la matriz de datos empleada para la recolección de los deterioros.

Tabla 31 - Análisis de datos: incidencia de las fuentes de deterioro. Conjunto de estudio: producción Muralista del siglo XX.

\begin{tabular}{|l|l|}
\hline Fuentes de deterioro & Total \\
\hline Causas extrínsecas de deterioro & 18 \\
\hline Suciedad & 18 \\
\hline Deterioros por agentes antropogénicos & 10 \\
\hline Sales solubles & 8 \\
\hline Intervenciones anteriores inapropiadas & 6 \\
\hline Humedad & 5 \\
\hline Humedad capilar & 5 \\
\hline Intervenciones estructurales & 4 \\
\hline
\end{tabular}




\begin{tabular}{|l|l|}
\hline Filtraciones de humedad & 3 \\
\hline Deterioro ambiental & 3 \\
\hline Repintes & 3 \\
\hline Causas intrínsecas de deterioro & 1 \\
\hline Ciclos de humedad & 1 \\
\hline Condensación & 0 \\
\hline Higroscopicidad & 0 \\
\hline Gelividad & 0 \\
\hline Contaminación atmosférica & 0 \\
\hline Aerosoles & 0 \\
\hline Crecimiento de agentes biológicos & 0 \\
\hline
\end{tabular}

Tabla 32 - Análisis de datos: incidencia de las fenomenologías de alteración y deterioro. Conjunto de estudio: producción Muralista del siglo XX.

\begin{tabular}{|l|l|}
\hline Fenomenologías de alteración y deterioro & Total \\
\hline Grietas estructurales & 14 \\
\hline Laguna & 13 \\
\hline Grietas & 12 \\
\hline Microfisura & 10 \\
\hline Velo blanquecino & 7 \\
\hline Blanqueamiento & 7 \\
\hline Eflorescencia salina & 7 \\
\hline Oquedad & 6 \\
\hline Corrosión & 4 \\
\hline Deformación & 3 \\
\hline Saturación de color & 3 \\
\hline Disgregación & 2 \\
\hline Descamación & 2 \\
\hline Oscurecimiento & 2 \\
\hline Debilitamiento & 2 \\
\hline Erosión & 2 \\
\hline Abrasión & 1 \\
\hline Pulverización & 1 \\
\hline
\end{tabular}




\begin{tabular}{|l|l|}
\hline Abolsamiento & 1 \\
\hline Peeling/Delaminación & 0 \\
\hline Exfoliación & 0 \\
\hline Craquelado & 0 \\
\hline Pátina & 0 \\
\hline Amarilleamiento & 0 \\
\hline Alteración de pigmentos & 0 \\
\hline
\end{tabular}

Los pasos ejemplificados se trasladaron finalmente a unos gráficos, según el nivel de análisis requerido de las informaciones y/o finalidad del estudio. En este caso se obtuvo un indicador de las fuentes de alteración y deterioro existentes cuantitativo y porcentual (gráfica 6 y 7), un índice de las fenomenologías de alteración y deterioro presentes en las obras (gráfica 8 y 9) y una escala de riesgo (gráfica 10).

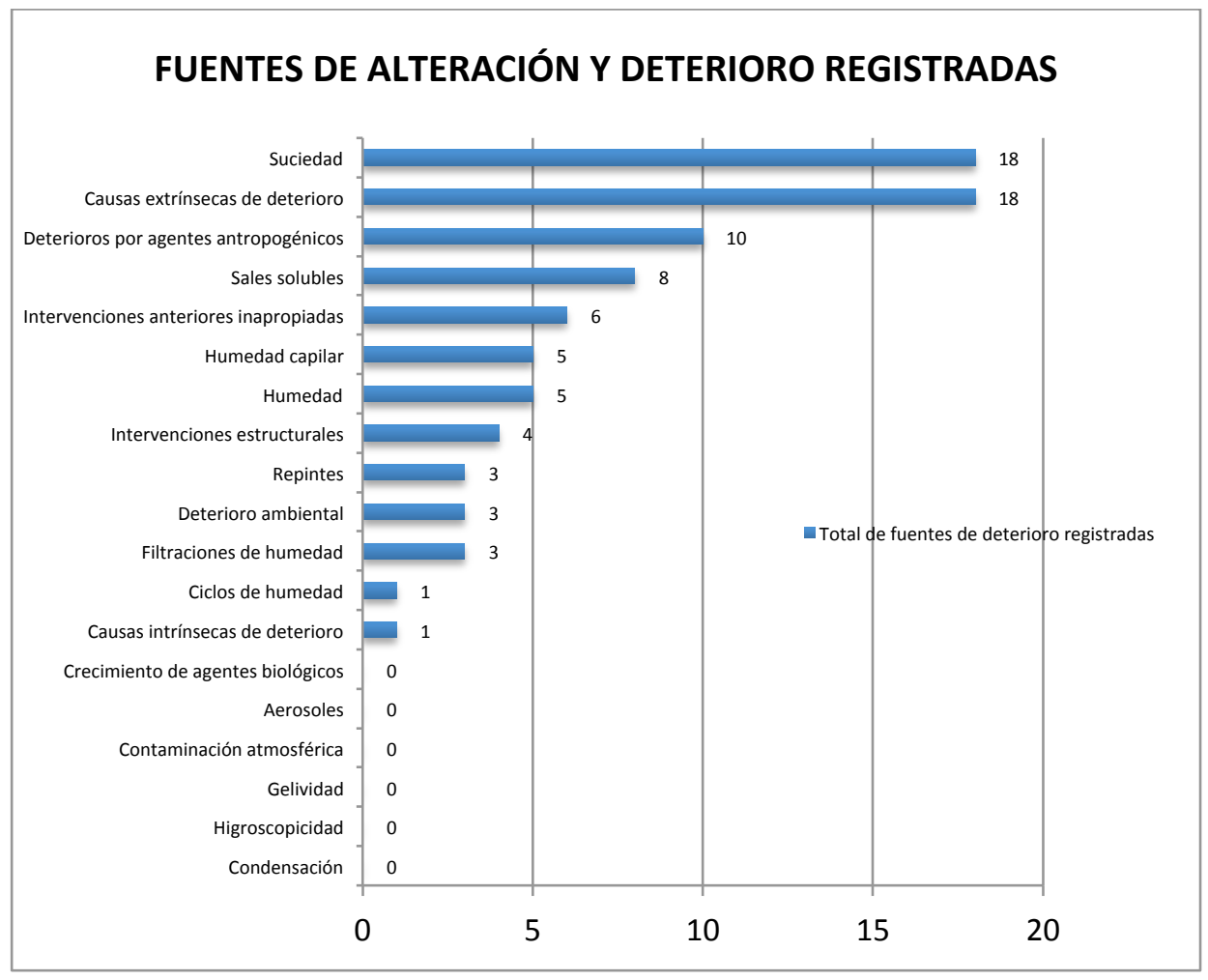

Gráfica 6 - Incidencia de las fuentes de alteración y deterioro existentes. 


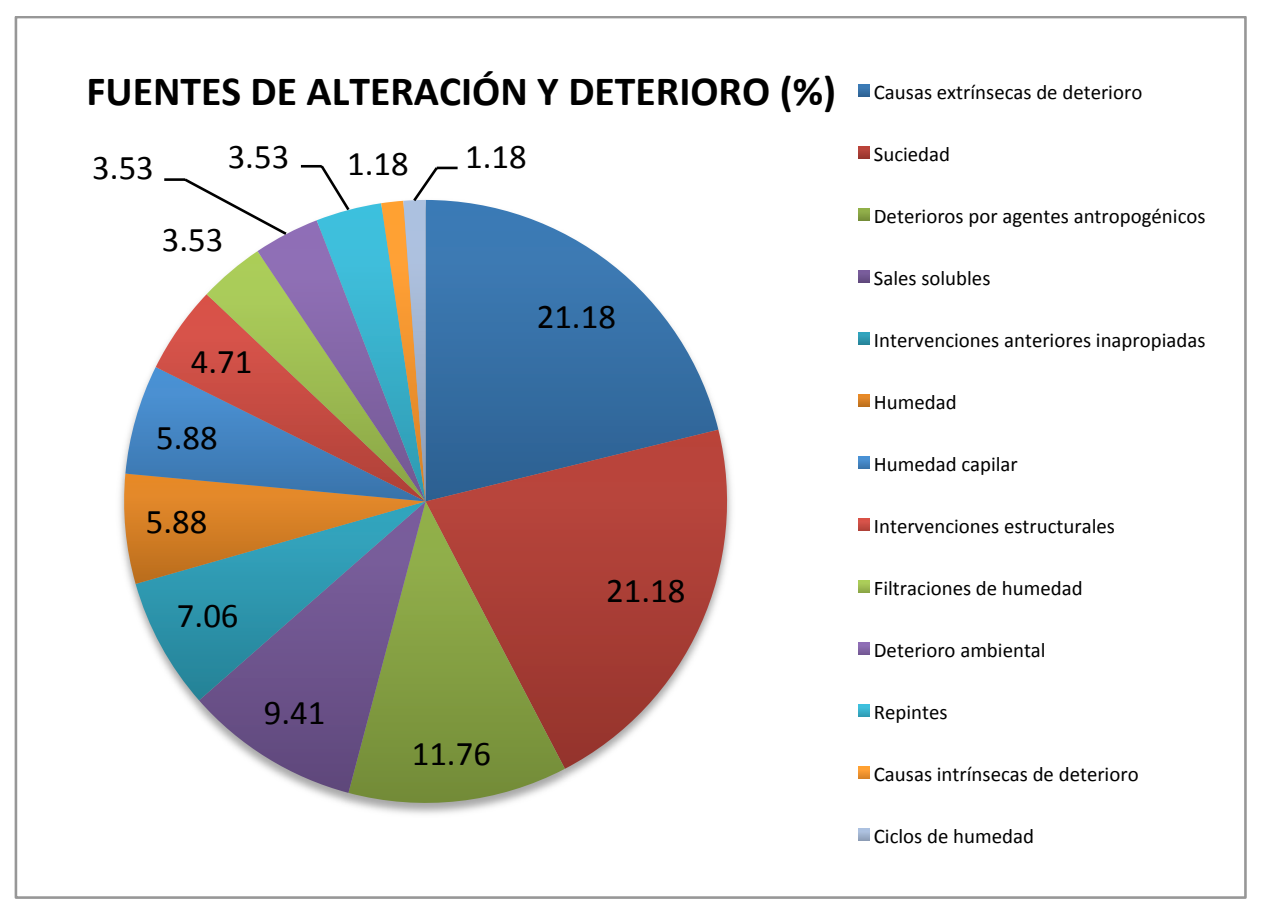

Gráfica 7 - Incidencia de las fuentes de alteración y deterioro existentes (\%). 


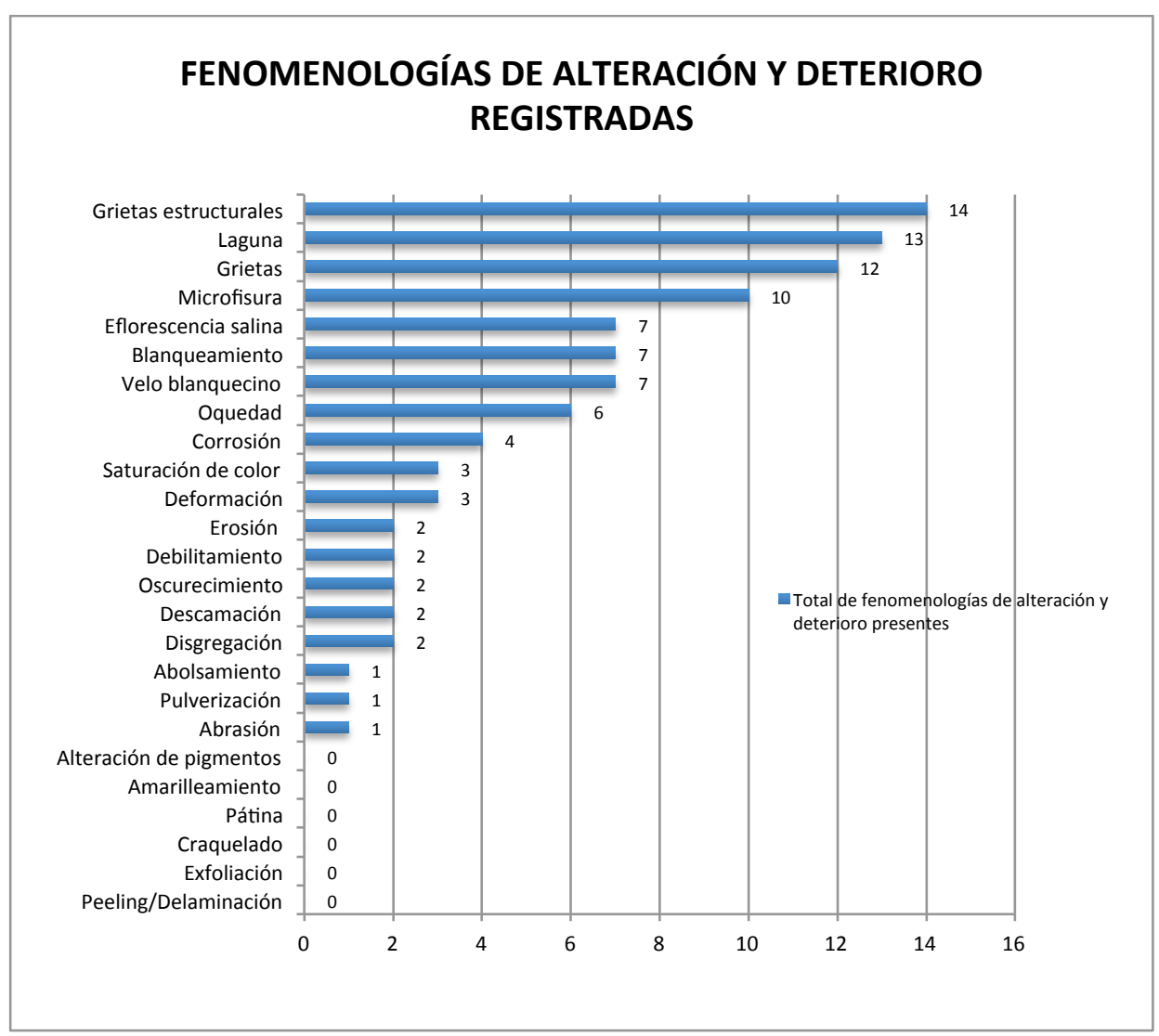

Gráfica 8 - Incidencia de las fenomenologías de alteración y deterioro presentes. 


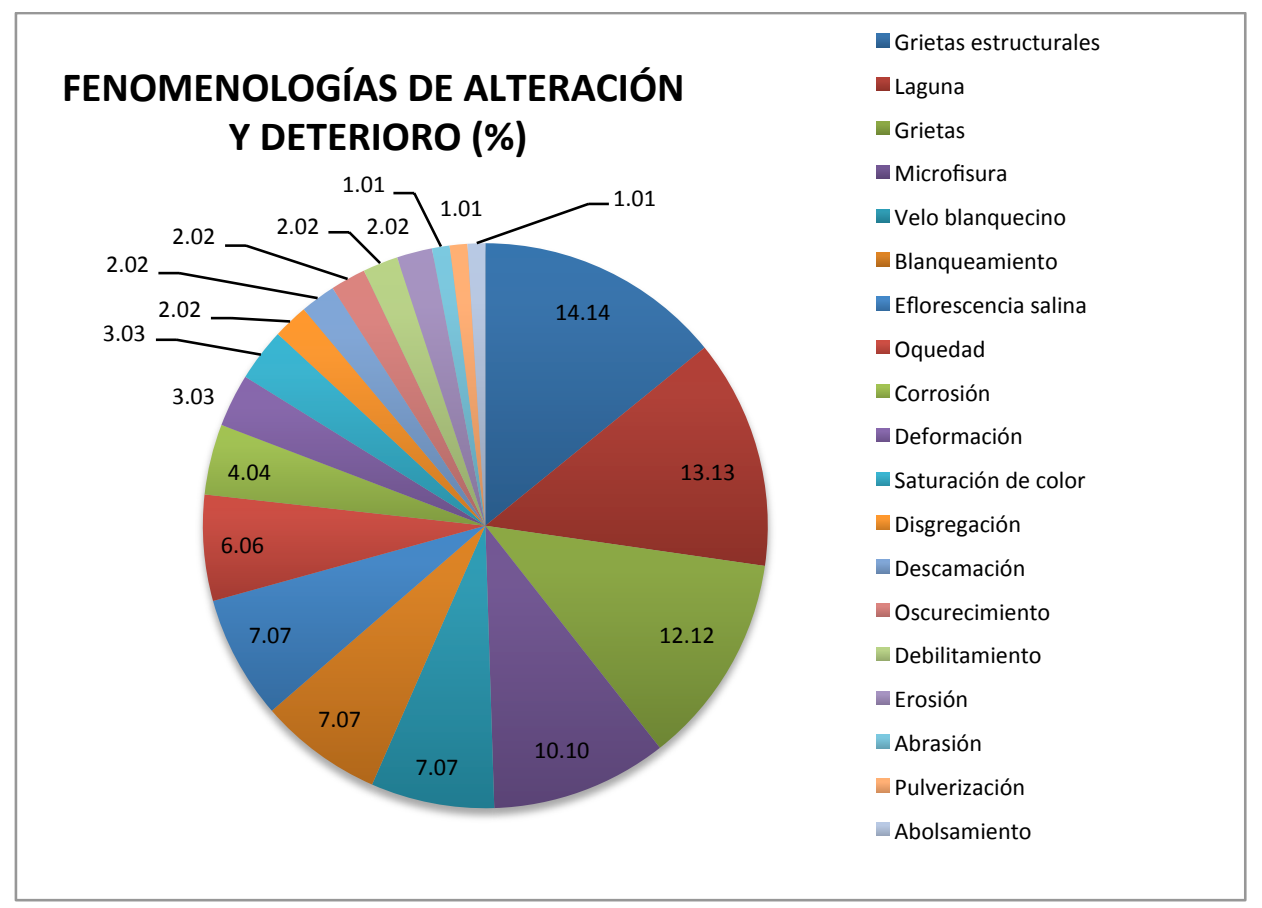

Gráfica 9 - Incidencia de las fenomenologías de alteración y deterioro presentes (\%).

Por medio de la ordenación de los resultados cuantitativos obtenidos a partir del análisis de incidencias, ha sido posible establecer una escala de riesgo de conservación (gráfica 10), representativa de las obras con mayor necesidad de intervención ${ }^{199}$.

La obra con mayor indicador de riesgo resultó ser la "Transormación del Tepeyac" (imágenes 37, 38 y 39), cuyas problemáticas específicas se presentan en la tabla 33.

${ }^{199}$ MASTROIACOVO, T., SORIANO SANCHO, M.P., REGIDOR ROS, J.L., (2016-2017), op. cit., pp. 157-162. 


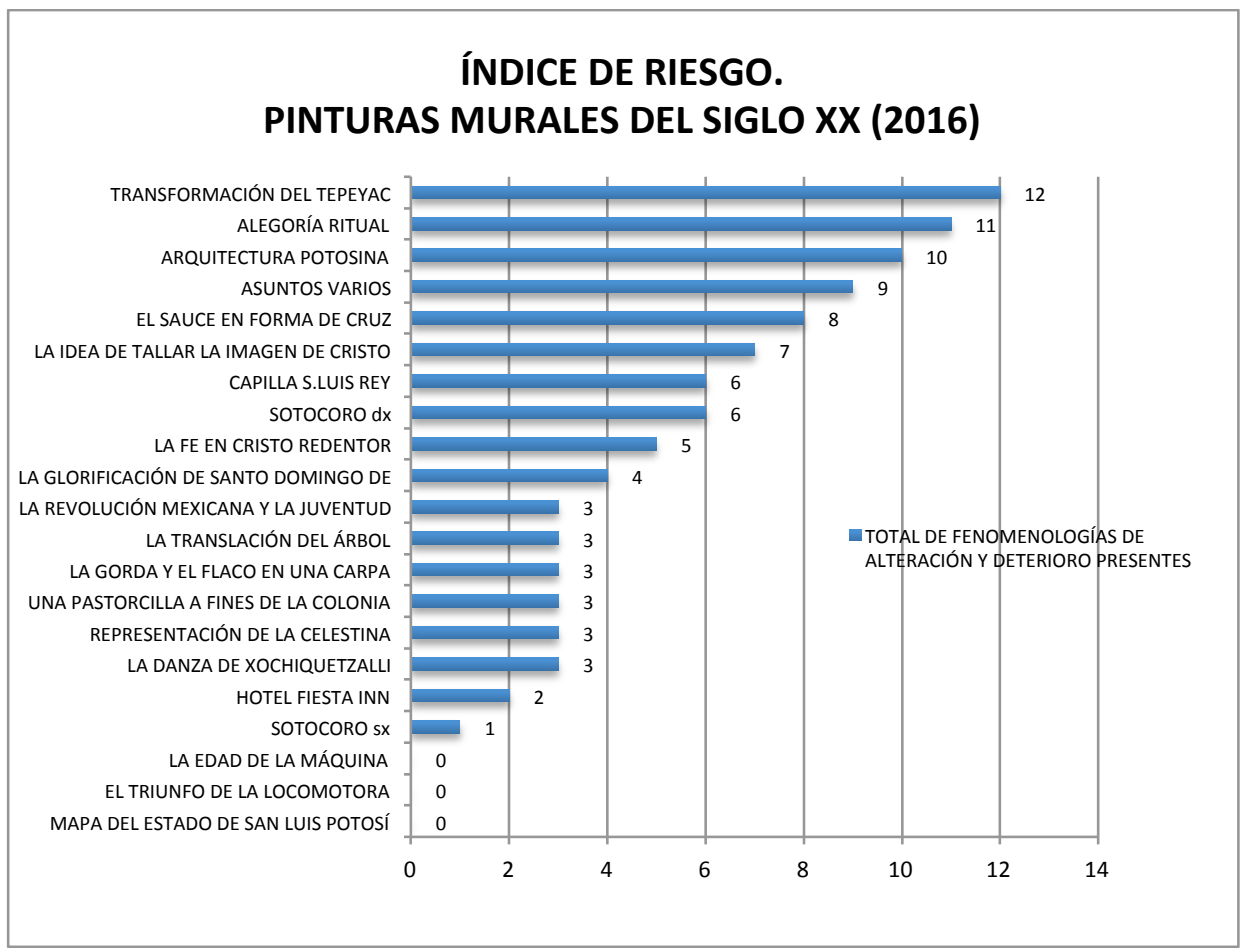

Gráfica 10 - Representación con gráfica de barras de los indicadores de riesgo y prioridades.

El mural "Transformación del Tepeyac" (imagen 37) ha sido realizado en 1954 por Rosendo Soto y Jorge Best. Junto a la obra "Alegoría Ritual" pertenece al conjunto creado para el rancho El Tepeyac (Ciudad del Maíz, San Luis Potosí) por encargo del propietario Jorge Pasquel Casanueva, quién aparece en la representación de las actividades desarrolladas en el lugar.La obra se conforma por un mosaico en teselas vítreas adherido sobre un soporte independiente de las demás estructuras arquitectónicas, constituido por hormigón armado y ladrillos (imagen 38). Actualmente el conjunto se encuentra en estado de total abandono. El mural, ubicado al exterior (imagen 39), está expuesto a la intemperie y al azar de posibles actos vandálicos. 


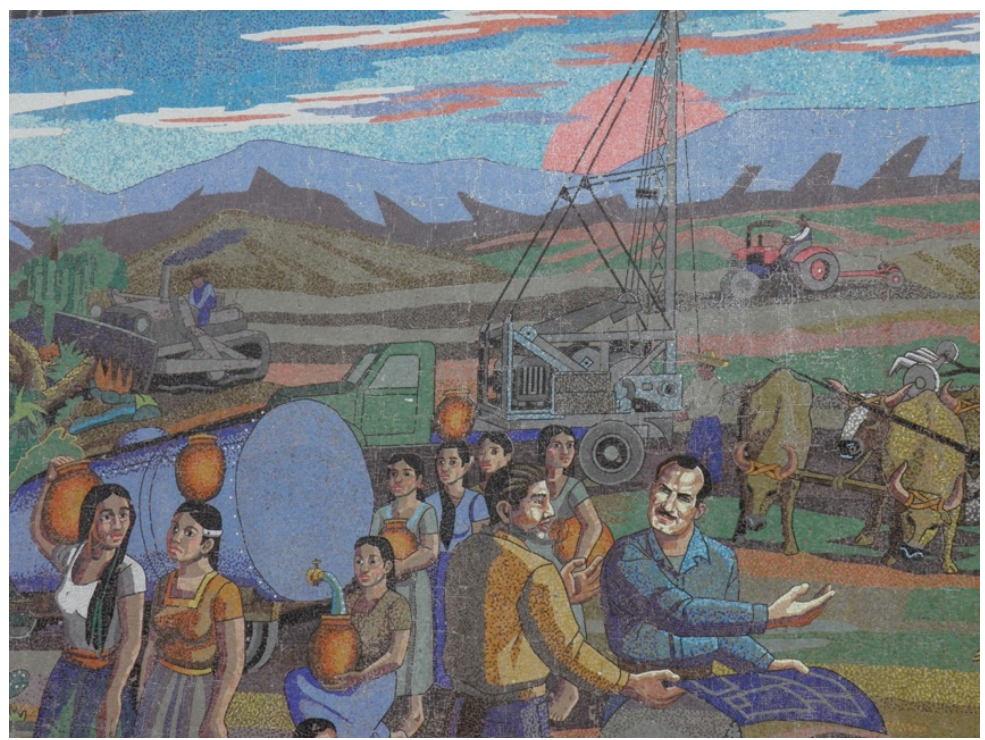

Imagen 37 - Detalle de la porción central del mosaico.

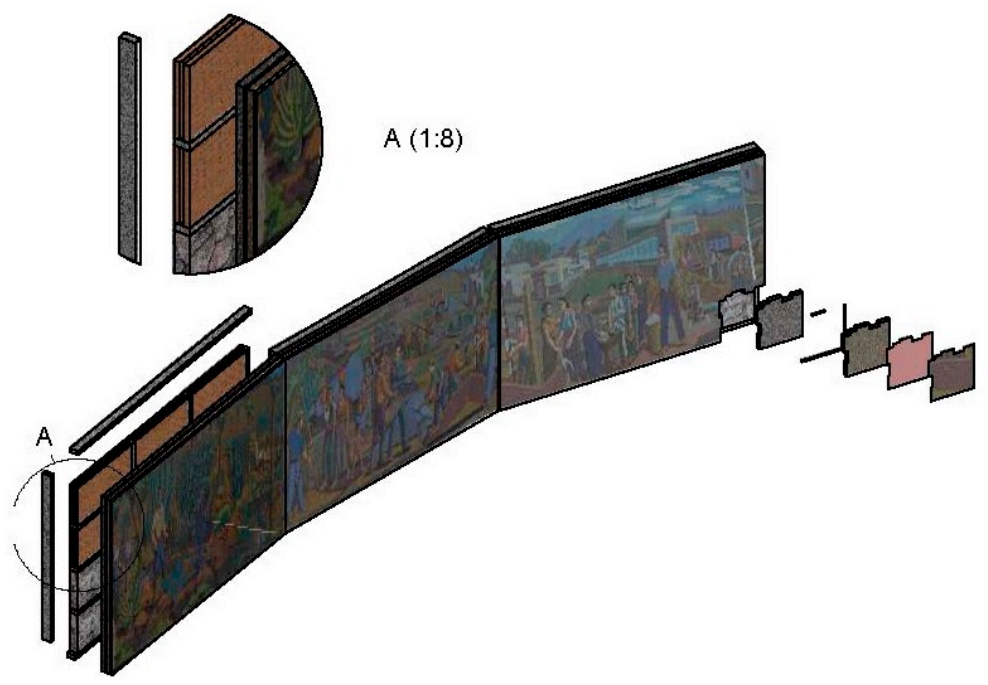

Imagen 38 - Renderizado de las capas constitutivas de la estructura que alberga el mural ${ }^{200}$.

\footnotetext{
200 Render realizado por la alumna de Servicio Social Mariana Padilla en el marco del proyecto desarrollado gracias a los Fondos de Apoyo a la investigación (FAI 2015) de la Universidad Autónoma de San Luis Potosí "Pinturas murales de San Luis Potosí: análisis, estudio e índice de riesgo".
} 


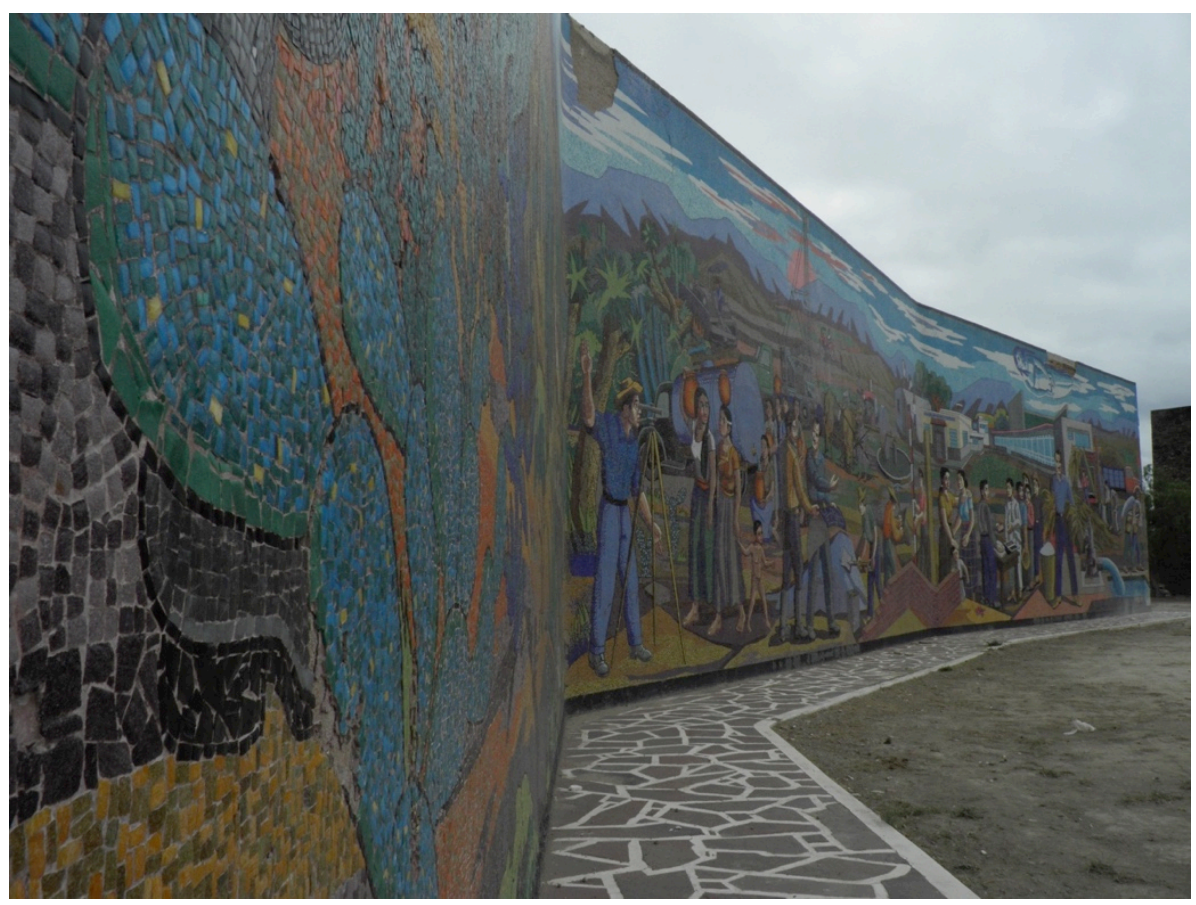

Imagen 39 - Vista lateral de parte del mural realizados con teselas vítreas sobre losas precoladas.

Tabla 33 - Panorámica de las problemáticas conservativas de la obra con mayor índice de riesgo.

\begin{tabular}{|l|l|}
\hline CIUDAD DEL MAIZZ & MUESTRA: LA TRANSFORMACIÓN DEL TEPEYAC \\
\hline TOTAL DE FUENTES DE ALTERACIÓN Y DETERIORO: 5 \\
\hline & Causas extrínsecas de deterioro \\
& Suciedad \\
& Humedad capilar \\
& Deterioro ambiental \\
& Deterioros por agentes antropogénicos \\
\hline TOTAL DE FENOMENOLOGÍAS DE ALTERACIÓN Y DETERIORO: 12 \\
\hline & Laguna \\
& Oquedad \\
& Disgregación \\
& Descamación \\
& Deformación \\
& Abolsamiento \\
\hline
\end{tabular}




\begin{tabular}{|l|l|}
\hline & Grietas estructurales \\
& Grietas \\
& Microfisura \\
& Velo blanquecino \\
& Debilitamiento \\
& Erosión \\
\hline
\end{tabular}

\section{Interpretación de resultados}

Como se puede apreciar en la gráfica 4, los factores que están influyendo en el deterioro de los murales realizados en el siglo XX son casi en su totalidad (98.82\%) de naturaleza extrínseca. Entre ellos, la presencia de suciedad y de alteraciones derivadas de agentes externos son los de mayor relevancia (21,18\%). A continuación, destaca el agente de deterioro representado por la acción antropogénica directa $(11,76 \%)$ que llega a alcanzar una incidencia total del $27,11 \%$ si se considerara la totalidad de fuentes de deterioro en el que participa:

- intervenciones anteriores inapropiadas (7,06\%);

- intervenciones estructurales (4,76\%);

- repintes (3.53\%);

Por lo relacionado con la presencia de humedad, se registra una incidencia general del $16,47 \%$, compuesta a su vez por:

- $\quad$ humedad (5,88\%);

- $\quad$ humedad capilar (5,88\%);

- filtraciones de humedad (3,53\%);

- ciclos de humedad (1,18\%).

De su presencia deriva la acción y presencia de sales solubles registrada en el 9,41\% de los casos. El deterioro ambiental se registró en el 3,53\% de los casos. Las fuentes de alteración y deterioro de naturaleza intrínseca tuvieron una escasa influencia en la conservación de las obras, siendo presente en tan sólo el 1,18\% de ellas.

De acuerdo al análisis de datos específica para los efectos de alteración y deterioro del conjunto (gráfica 7), se pudo averiguar que la mayoría padece un deterioro relacionado con fenómenos de naturaleza estructural que afectan la dimensión estética de las obras.

Se registraron:

- $\quad$ grietas (estructurales $14,14 \%$ y superficiales $12,12 \%$ ); 
- lagunas (13,13\%);

- microfisuraciones (10,10\%);

- alteraciones estéticas (velos blanquecinos y blanqueamiento 7,07\%);

- cristalización de sales (7,07\%).

La obra más afectada del conjunto corresponde al mural titulado "La transformación del Tepeyac", ubicada en Ciudad del Maíz (imágenes 37, 38 y 39). Ésta es un mosaico compuesto por teselas vítreas adheridas sobre losas precoladas.

De acuerdo a los fenómenos observados, se puede deducir que:

- La presencia de lagunas y oquedades indica que la obra ha sufridos accidentes y/o impactos de tipo mecánico. Éstos han afectado su continuidad estética y estructural, ampliando los efectos derivados de problemáticas de adhesión con el sustrato. Esta problemática se debe a la combinación de diferentes factores cuales desgaste/erosión por la exposición a la acción de factores físico-mecánicos y migración de sales solubles.

- El fenómeno de disgregación pone de manifiesto la existencia de un deterioro de tipo físico, químico o biológico que ha acarreado una pérdida de cohesión del material. Es más pronunciada en presencia de humedad y puede favorecer el deterioro de la obra debido a la mayor exposición de los materiales constitutivos a los agentes externos.

- La existencia de descamación revela la acción combinada de sales solubles, humedad y solicitaciones de tipo físico-químico como las derivadas de la exposición a la intemperie. Puede ser un efecto secundario de la pérdida de adhesión entre las capas constitutivas del mural.

- El fenómeno de deformación de la superficie puede ser el resultado de la acción de humedad, sales solubles y exposición a la intemperie, más acentuada en caso de solicitaciones térmicas derivadas de la exposición continua a una fuerte insolación. Puede ser favorecida por la naturaleza intrínseca de los materiales y por estrés causados por la exposición a cargas o fuerzas de compresión en el edificio.

- Los abolsamientos revelan la existencia de una presión interna a la estructura de la obra. Ésta puede deberse a la presencia de sales solubles debajo de la superficie (criptoeflorescencias).

- La presencia de grietas estructurales indica una variación del equilibrio estático del sistema consituido por un edificio o por un soporte arquitectónico. Puede ser favorecido por eventos sísmicos o problemáticas en los cimientos. 
- La existencia de grietas es causada por estrés de tipo físico-mecánico, causas medioambientales, vibraciones, variaciones en el equilibrio estático del sistema y en la distribución de las fuerzas, exposición a gradientes térmicos extremos.

- Las microfisuras suelen aparecer como consecuencia de la exposición a la intemperie, vibraciones, tensiones internas, defectos en la ejecución técnica, exposición a gradientes térmicos.

- La formación de un velo blanquecino sobre la superficie revela la existencia de depósitos (partículas atmosféricas, polvo, ceniza) o de sales cristalizadas, que pueden ser de diferente naturaleza (sales solubles derivados de la contaminación, migración de elementos constitutivos del mural, intervenciones de restauración con silicatos).

- El debilitamiento de los materiales contitutivos suele ser causado por la exposición directa de los materiales a las inclemencias de la intemperie o ser el resultado de reacciones químicas desarrolladas a raíz de intervenciones inadecuadas.

- La erosión de los materiales constitutivos puede indicar la exposición de los mismos al impacto con partículas arrastradas por el viento y suele afectar a las obras custodiadas en el exterior.

Tras la interpretación de la información arrojada por el estudio, se puede afirmar que las causas responsables del actual estado de conservación de la obra responden a las condiciones reales de su contexto. El mural se encuentra en estado de abandono, expuesto de forma directa a la acción climática. Esto ha favorecido el contacto con fuentes de humedad, con consiguiente disolución y migración de sales solubles en los materiales constitutivos. Las peculiaridades climáticas de la zona, caracterizada por unos grandes cambios de temperatura y una fuerte insolación, ha sometido la obra a ciclos de estrés derivados de las fases de cristalización y disolución de las sales, con consiguiente pérdida de cohesión superficial y adhesión entre las capas, además de fomentar el desgaste mecánico de la estructura. El mural, compuesto por un mosaico de teselas vítreas adheridas en forma de losas precoladas $^{201}$ por medio de cemento y mortero, se realizó sobre una estructura a

${ }^{201}$ Varios exponentes del Muralismo Mexicano, entre los cuales Diego Rivera y Clemente Orozco, emplearon la técnica de las losas precoladas; uno de los resultados más espectaculares es el mural "Representación Histórica de la Cultura" (1950-56) realizado por por Juan O'Gorman para la Biblioteca Central de la Ciudad Universitaria de la Universidad Nacional Autónoma de México (Ciudad de México). Este majestuoso mosaico se compone por diferentes tipología de materiales pétreos y teselas vítreas provenientes de varios lugares de la República Mexicana, alcanzando una extensión superficial de $4000 \mathrm{~m}^{2}$, correspondiente a los lados externos del edificio. Para su creación, se organizaron cuadrantes de losas coladas previamente con cemento para fijar los componentes de mosaico correspondientes a las porciones de mural. Este 
vela independiente (imagen 38) que puede haber favorecido el desarrollo de las problemáticas estructurales. La exposición a la intemperie ha favorecido la pérdida de porciones de teselas, acarreando un daño estético. La acción del viento y la naturaleza del territorio han generado un desgaste de la superficie a lo largo del tiempo, erosionándola y proporcionando la acumulación de depósitos de tipo terroso.

\subsubsection{Panteón municipal del Saucito, San Luis Potosí}

La aplicación de la primera versión del método propuesto para conjuntos patrimoniales realizados en materiales pétreos se realizó en abril 2019 (tabla 34) en ocasión del estudio y profundización dirigido al entendimiento de las dinámicas conservativas propias de los monumentos expuestos a la intemperie. Como valor añadido, parte de la profundización ha sido enfocada a la observación de la pluralidad de reacciones de tipo físico-químico desarrolladas en los materiales pétreos, siendo este conjunto un acervo importante no sólo a nivel histórico, artístico y social, si no también como muestrario al aire libre de las fenomenologías de alteración y deterioro propias de esta clase de elementos.

Tabla 34 - Detalle de la primera implementación del método sobre materiales pétreos.

\section{PANTEÓN MONUMENTAL DEL SAUCITO, SAN LUIS POTOSÍ}

\begin{tabular}{|l|l|}
\hline Registro realizado en: & Abril 2019 \\
\hline Objeto de estudio: & Materiales pétreos, esculturas, elementos decorativos y lápidas \\
\hline Tiempo de registro de datos: & 2 horas, presencial \\
\hline Total de obras analizadas: & 63 , escogidas en tres zonas del recinto $(\mathrm{A}, \mathrm{B}, \mathrm{C})^{202} ;$ imagen 40 \\
\hline Profesionales empleados: & $2^{203}$ \\
\hline Tiempo para el análisis de datos & 1 hora \\
\hline
\end{tabular}

procedimiento permitió agilizar la ejecución de la obra, dando lugar a una producción coordinada y eficiente, en donde los materiales y técnicas tradicionales se funden con los productos y medios de la ingeniería, en pleno espíritu modernista. Desde 2007 este sitio, junto con el Campus Central de la Ciudad Universitaria, ha sido declarado Patrimonio Cultural de la Humanidad por la UNESCO. UNESCO (2007). Campus Central de la Ciudad Universitaria de la Universidad Nacional Autónoma de México. $<$ https://whc.unesco.org/es/list/1250> [Fecha de consulta: 21 de febrero de 2021].

${ }^{202}$ Cada área de estudio se compone por diferentes cantidades de monumentos funerarios. Debido a que la fase presentada en este apartado es dirigida al diseño del método y a la delimitación de sus ventajas y limitaciones, para cada cuadrante han sido seleccionadas 23 obras. Este aspecto ha permitido destacar las dinámicas presentes, facilitando las fases de análisis y comparativa de la información recolectada con las tablas de registro unificadas.

203 Se agradece la participación en esta fase de aplicación del método a la arqueóloga y restauradora Karla María Castro Chong para el estudio de los materiales pétreos resguardados en el cuadrante B: registro de las condiciones conservativas y documentación fotográfica. 


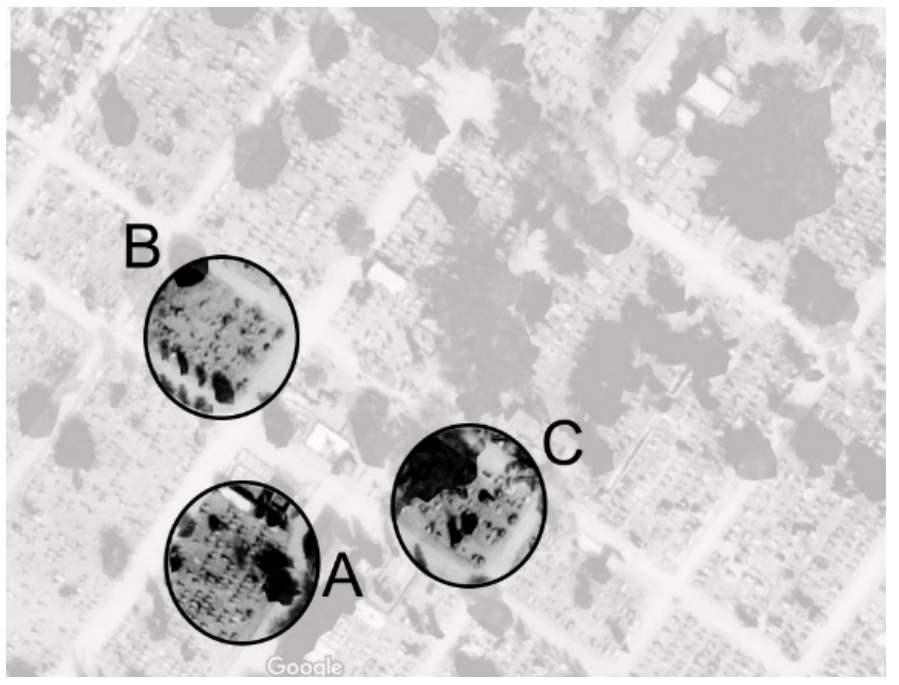

Imagen 40 - Cuadrantes del cementerio municipal escogidas para la aplicación del método. Modificada de imagen satelital.

La aplicación de la matriz de alteración y deterioro al caso de estudio propuesto tuvo la finalidad de delimitar los posibles alcances ofrecidos por el método, en función de una estimación global ordenada en base numérica del estado de conservación de parte de los materiales pétreos presentes en el cementerio. Lo anterior ofreció la posibilidad de tomar en cuenta un conjunto de obras expuestas a condiciones conservativas similares, con la finalidad de registrar y evaluar el estado de las mismas, brindando informaciones sobre los efectos de deterioro presentes y considerar la posible estimación de sus causas.

En preparación al estudio se realizó una matriz de datos, análogamente a cuanto creado para la experiencia del Museo de Arte Sacro, aportando cambios dirigidos a mejorar los límites encontrados en dicha experiencia. En este caso, los conceptos se han estructurado en grupos y subgrupos, por un total de tres niveles de despliegue de la información, a su vez estructurada de forma cromática para favorecer su lectura y comprensión. Las columnas han sido completadas con los números referentes a las muestras con la finalidad de ubicar de la mejor manera las informaciones de registro en el sitio. El listado universal así estructurado se ha obtenido a partir de la terminología empleada en el campo de la conservación del 
patrimonio cultural pétreo, concretamente, el glosario creado por ICOMOS-ISCS $(2008)^{204}$.

Los términos se han agrupado a partir de los efectos generales propuestos por el glosario ilustrado (fisuras y deformaciones, separación, morfologías inducidas por pérdida de material, alteración cromática y depósitos y colonización biológica), organizados por grupos de fenomenologías, divididos en tipologías específicas que a su vez pueden ser identificadas según su morfología a fines de una mayor comprensión de la información recolectadas (diagrama 19).

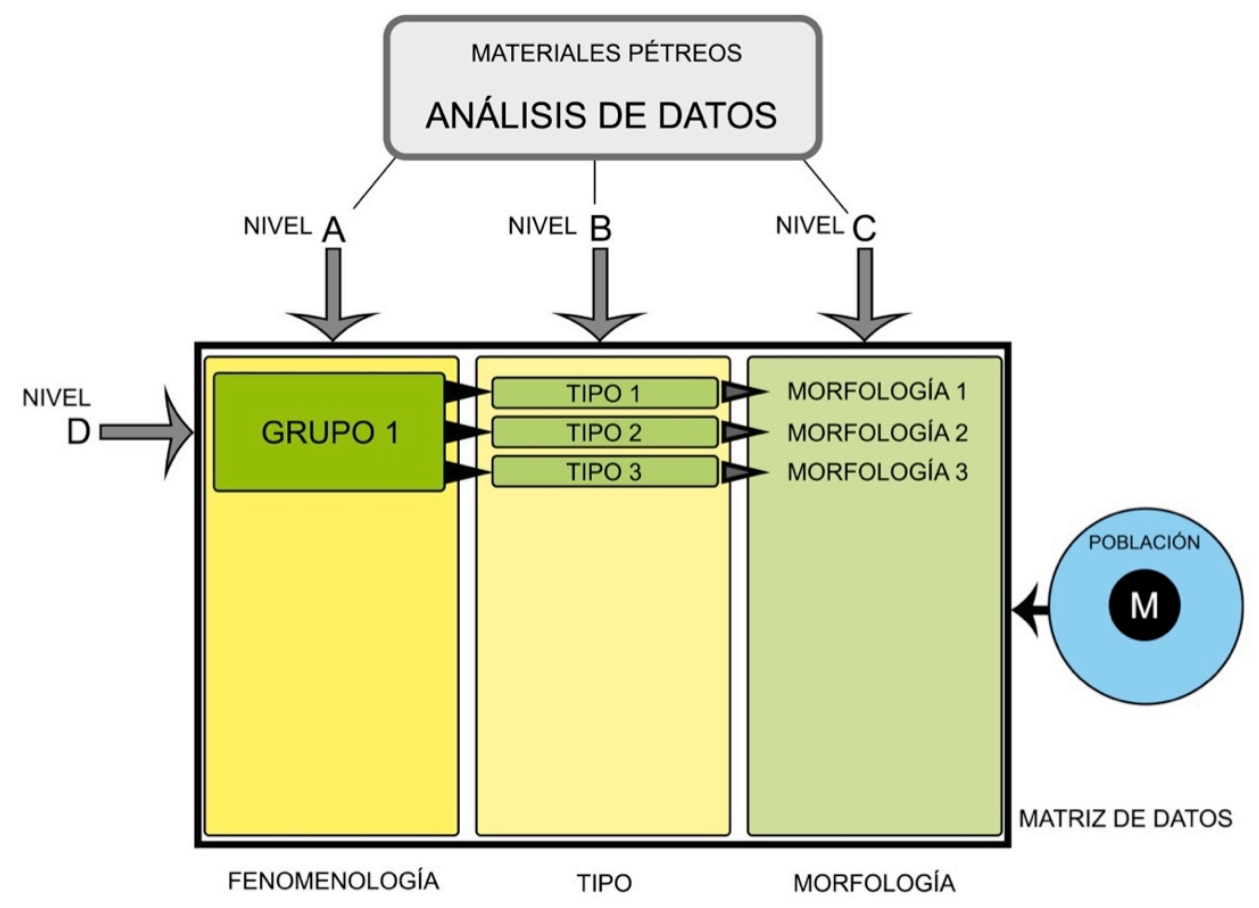

Primera implementación del método derivado de ICOMOS-ISCS

${ }^{204}$ ICOMOS-ISCS (2008). Illustrated Glossary on Stone Deterioration Patterns.

<https://www.icomos.org/publications/monuments_and_sites/15/pdf/Monuments_and_Sites_15_ISCS_GI ossary_Stone.pdf> [Consulta: 3 de marzo de 2016]. 
Tras el análisis de las informaciones, fue posible obtener una panorámica (imágenes 41,42 y 43) sobre las fenomenologías de alteración y deterioro presentes en las diferentes manzanas (gráficas 11-16), junto a una estimación del indicador de riesgo de las obras existentes en cada área (tabla 35). Ha sido posible comparar los resultados entre las zonas analizadas (gráfica 17), pudiendo identificar la obra más inestable (imagen 44-48) evidenciando sus problemáticas (tabla 36). La estructura de la matriz de datos empleada para la recolección de los deterioros ha generado datos representativos sobre el estado de conservación del conjunto, con la ventaja de brindar un acercamiento a la tipología de alteración y deterioro presente y sus especificaciones. La representación del índice de riesgo conservativo para el área con mayor indicador de riesgo se encuentra en la imagen 49.

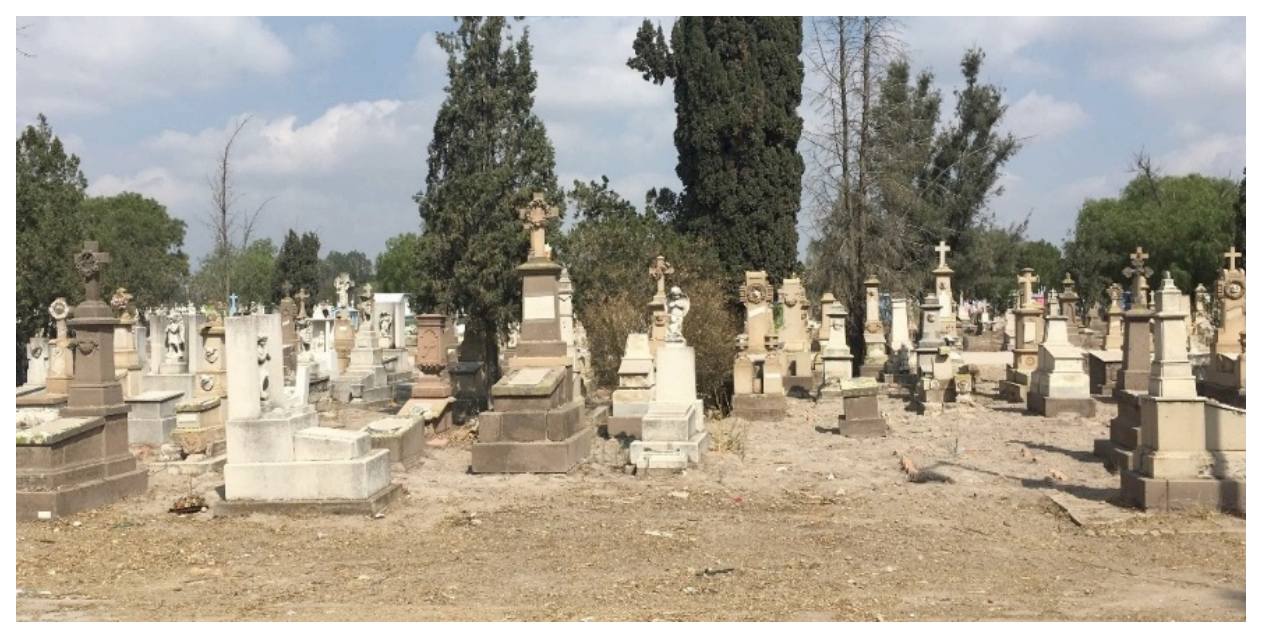

Imagen 41 - Panorámica de la zona A. Panteon Municipal del Saucito (S.L.P.). 


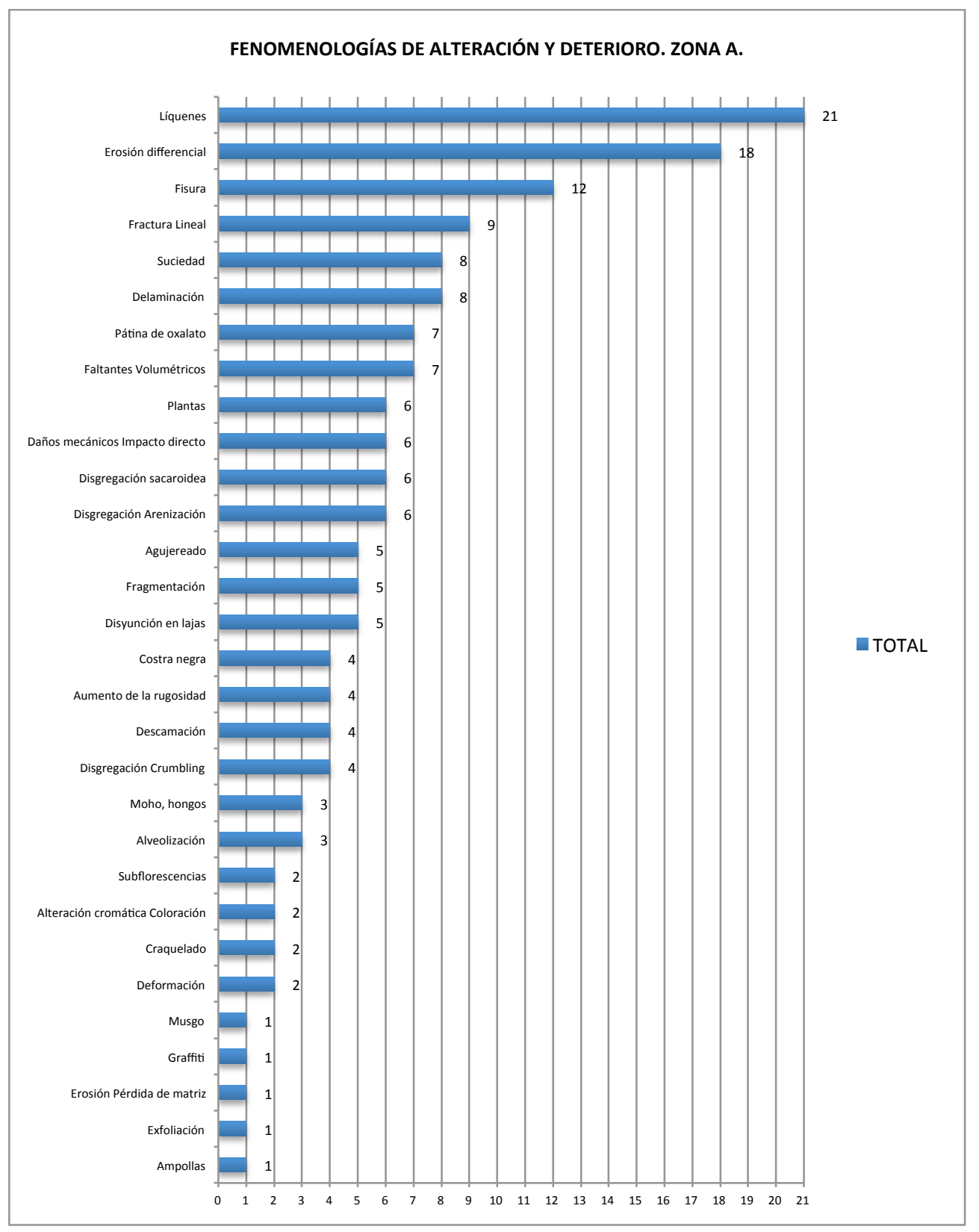

Gráfica 11 - Total de fenomenologías de alteración y deterioro registradas sobre un total de 21 obras. Zona A. 


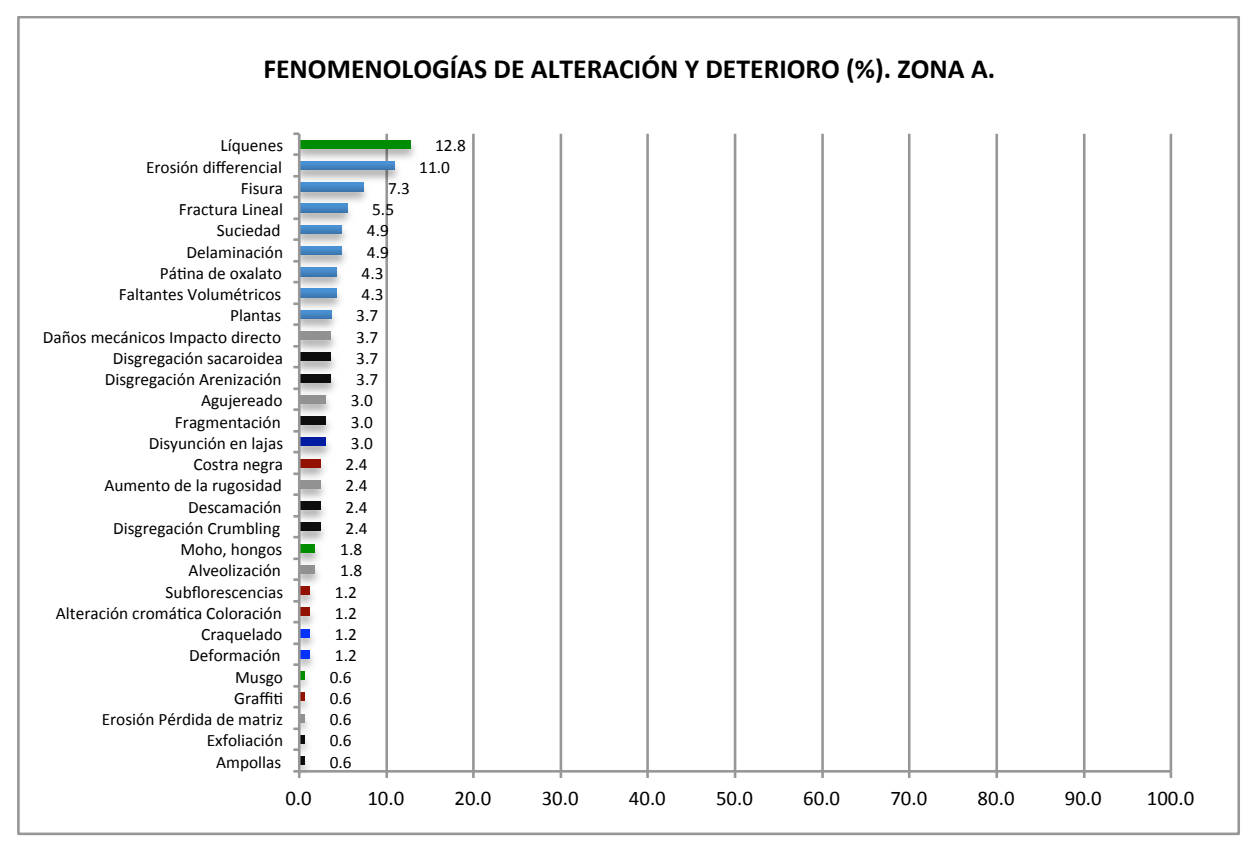

Gráfica 12 - Fenomenologías de alteración y deterioro (\%) de la zona A. Incidencia (\%) sobre el total de las alteraciones registradas en el área.

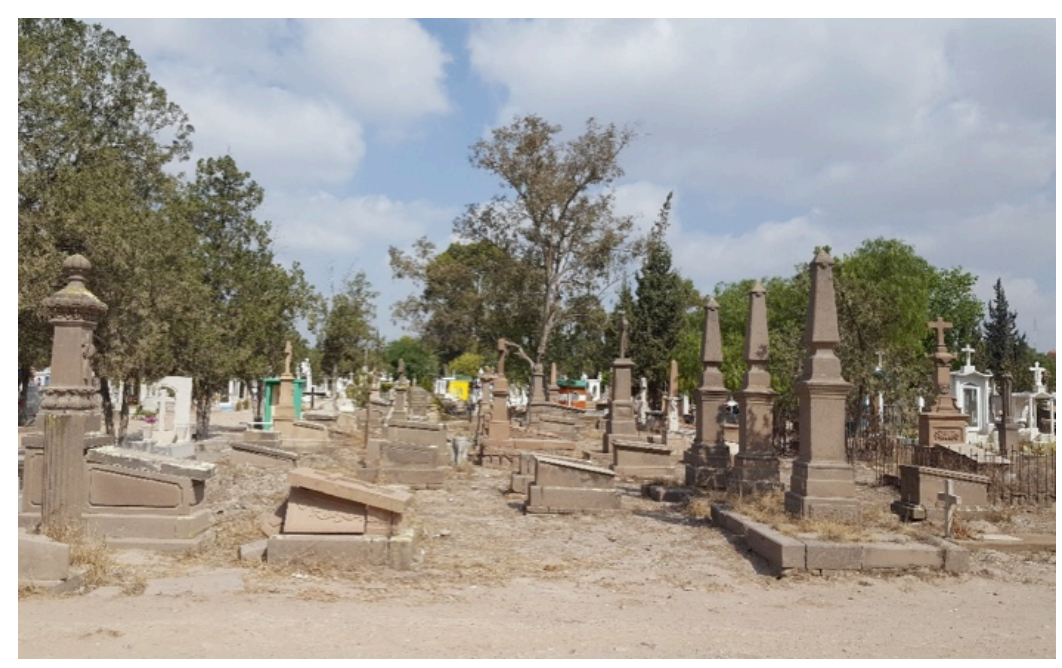

Imagen 42 - Panorámica de la zona B. Panteon Municipal del Saucito (S.L.P.). 


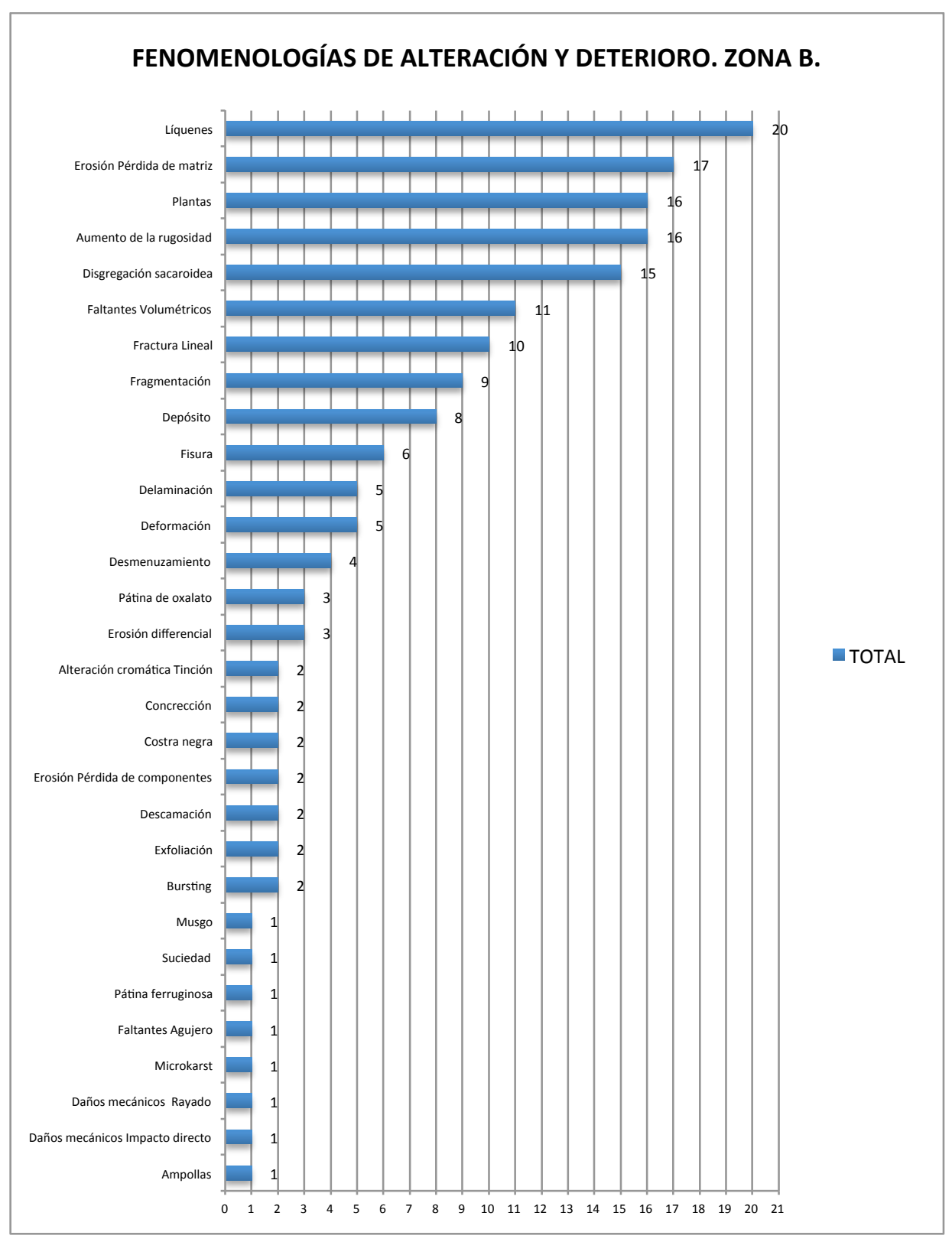

Gráfica 13 - Total de fenomenologías de alteración y deterioro registradas sobre un total de 21 obras. Zona B. 
FENOMENOLOGÍAS DE ALTERACIÓN Y DETERIORO (\%). ZONA B.

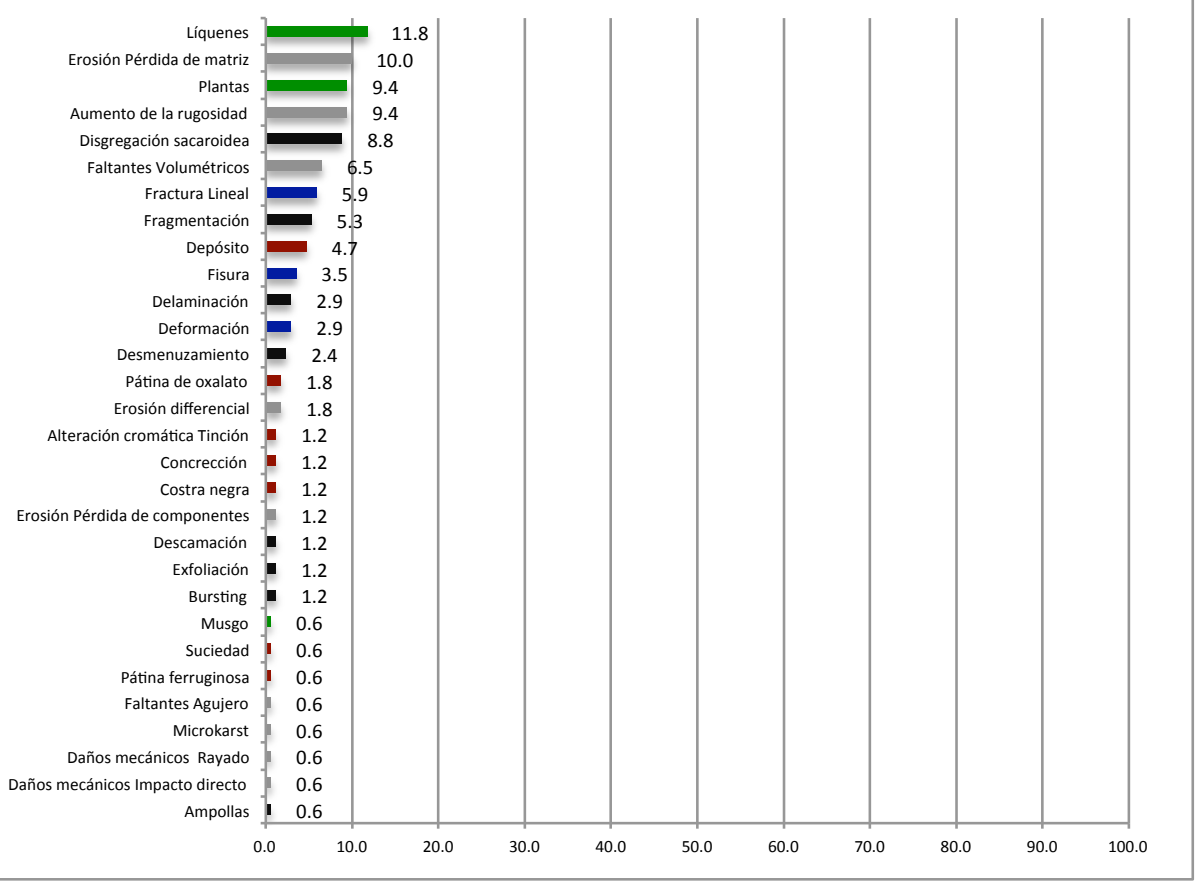

Gráfica 14 - Fenomenologías de alteración y deterioro (\%) de la zona B. Incidencia (\%) sobre el total de las alteraciones registradas en el área.

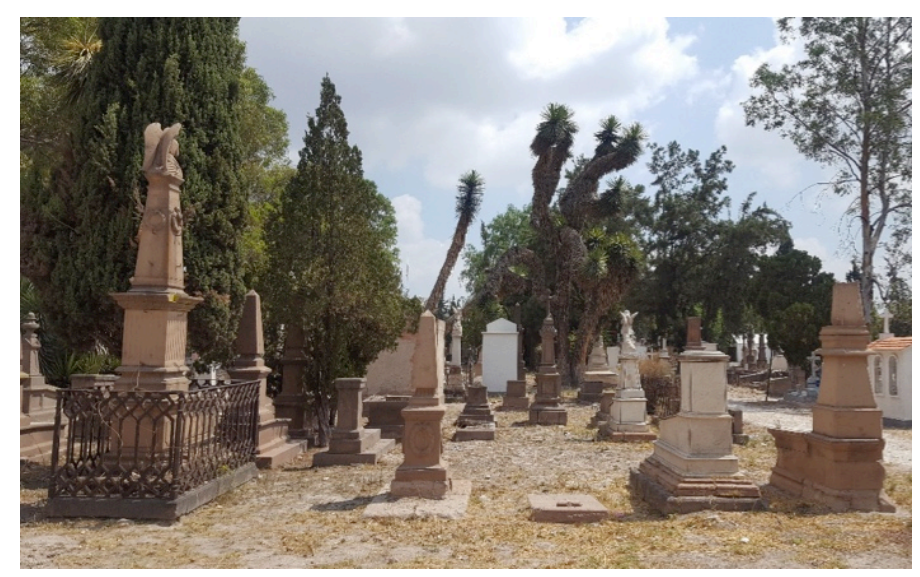

Imagen 43 - Panorámica de la zona C. Panteon Municipal del Saucito (S.L.P.). 


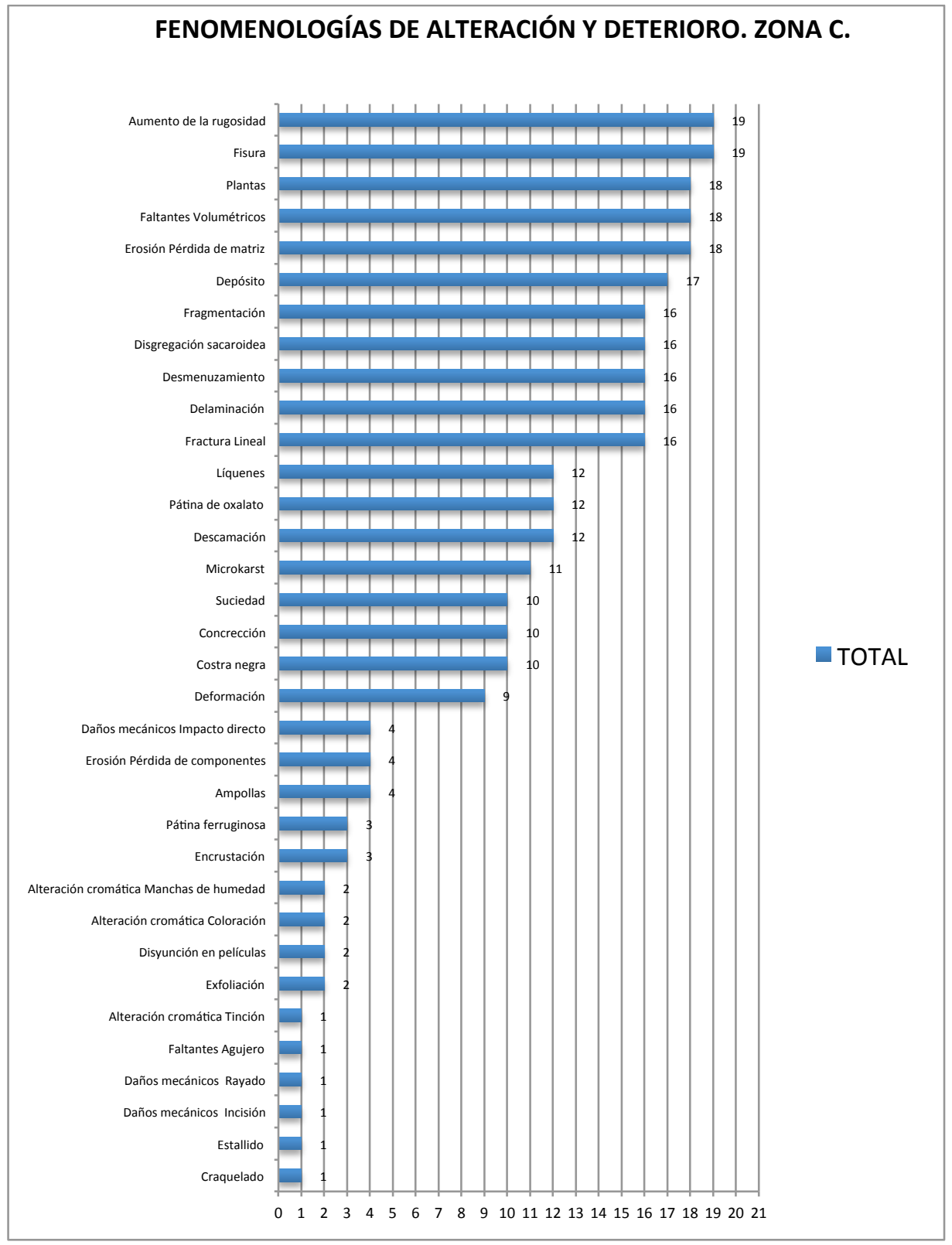

Gráfica 15 - Total de fenomenologías de alteración y deterioro registradas sobre un total de 21 obras. Zona C. 
FENOMENOLOGÍAS DE ALTERACIÓN Y DETERIORO (\%). ZONA

C.

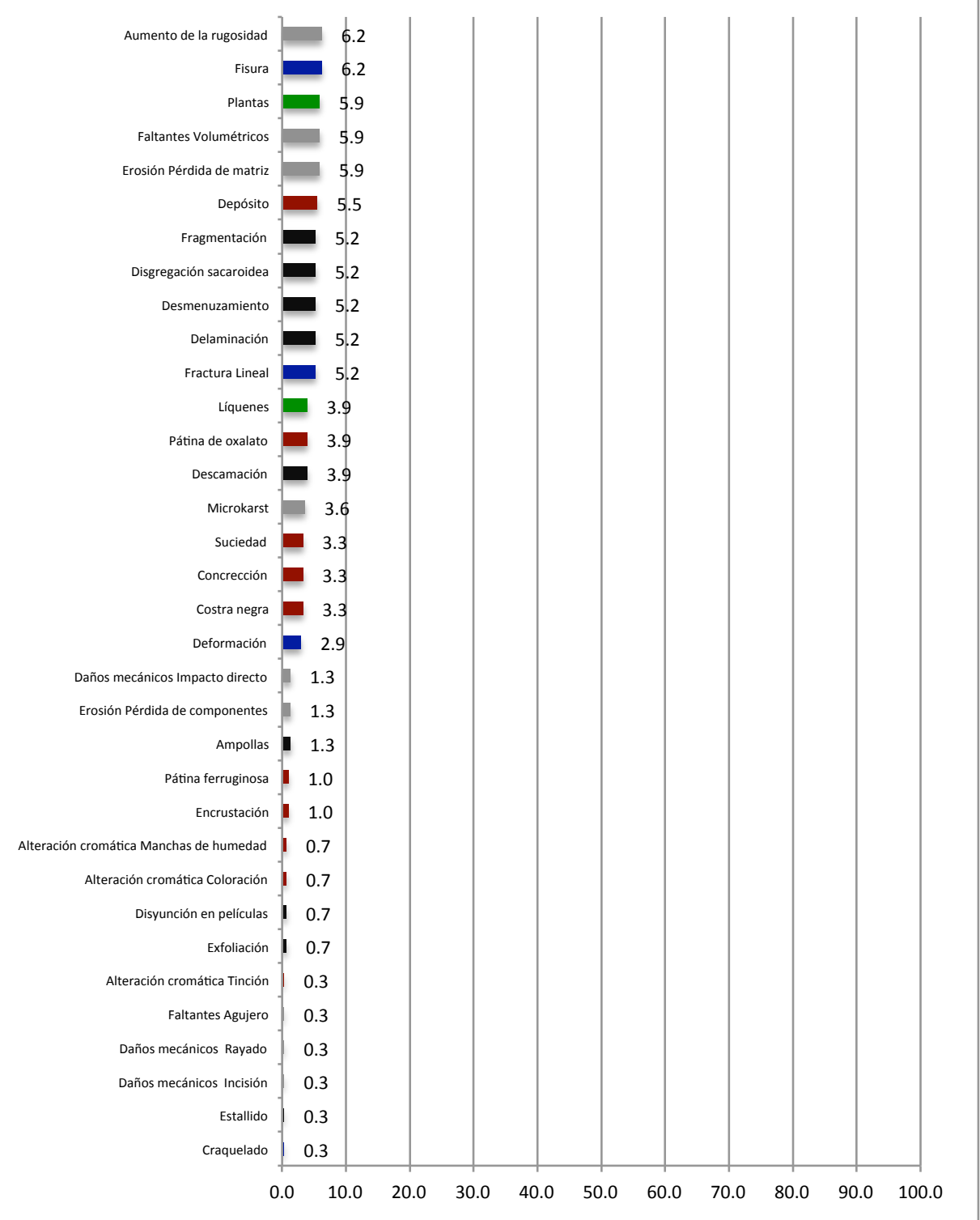

Gráfica 16 - Fenomenologías de alteración y deterioro (\%) de la zona C. Incidencia (\%) sobre el total de las alteraciones registradas en el área. 


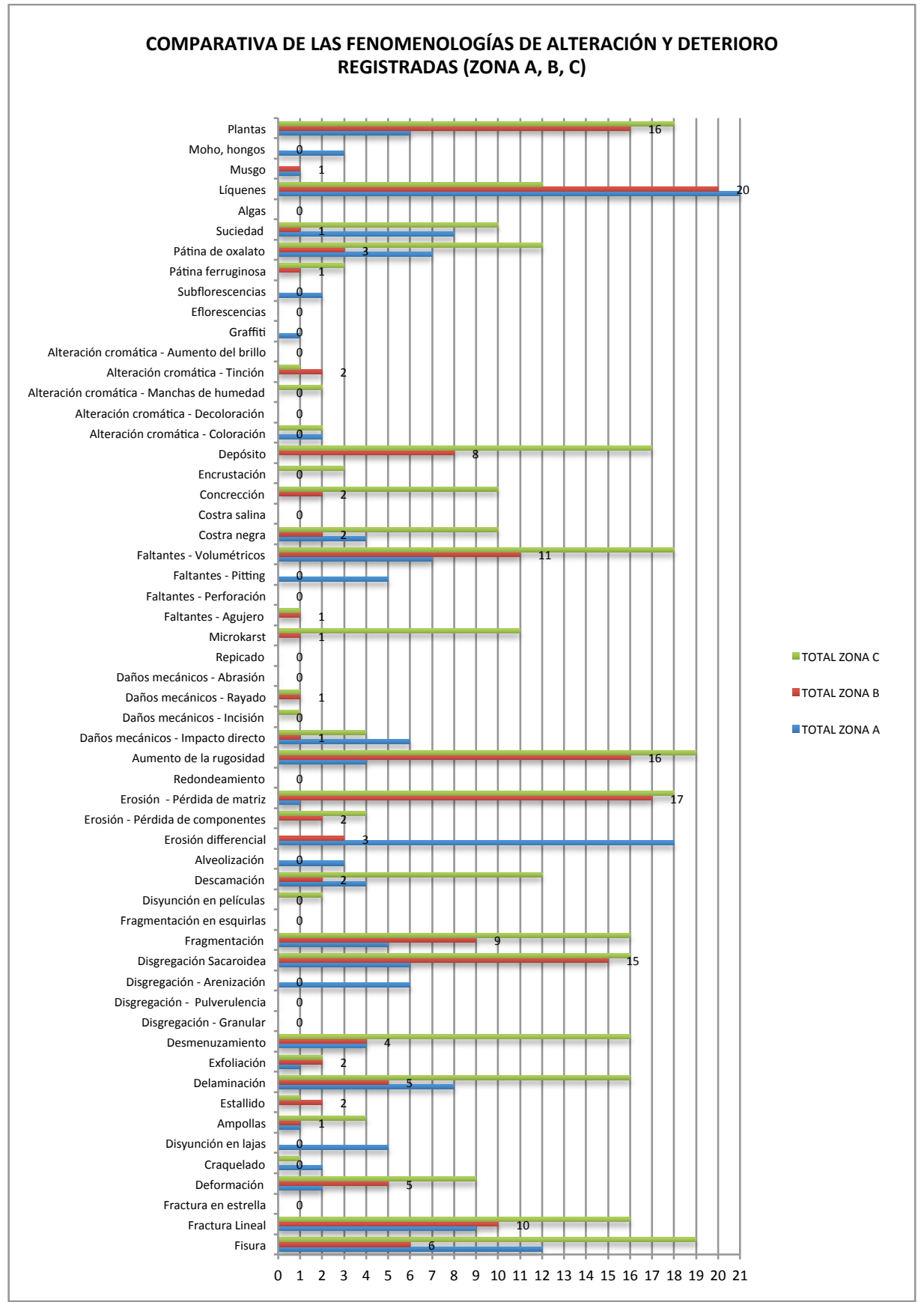

Gráfica 17 - Panorámica comparativa de las fenomenologías de alteración y deterioro presentes en las '1 áreas de aplicación del método. 


\begin{tabular}{|c|c|c|c|c|c|c|}
\hline & ESCALA & RIESGO & & & & \\
\hline$\stackrel{\breve{w}}{\widetilde{\mu}}$ & ZONA A & TOTAL: 164 & ZONA B & TOTAL: 170 & ZONAC & TOTAL: 307 \\
\hline 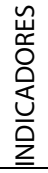 & MUESTRA & $\begin{array}{l}\text { FENOMENOLOGÍAS } \\
\text { DE ALTERACIÓN Y } \\
\text { DETERIORO }\end{array}$ & MUESTRA & $\begin{array}{l}\text { FENOMENOLOGÍAS } \\
\text { DE ALTERACIÓN Y } \\
\text { DETERIORO }\end{array}$ & MUESTRA & $\begin{array}{l}\text { FENOMENOLOGÍAS } \\
\text { DE ALTERACIÓN Y } \\
\text { DETERIORO }\end{array}$ \\
\hline 1 & 13 & 13 & 20 & 13 & 8 & 26 \\
\hline 2 & 15 & 13 & 21 & 13 & 14 & 21 \\
\hline 3 & 17 & 10 & 1 & 12 & 1 & 20 \\
\hline 4 & 20 & 10 & 13 & 12 & 21 & 19 \\
\hline 5 & 10 & 9 & 16 & 12 & 10 & 17 \\
\hline 6 & 11 & 9 & 6 & 11 & 12 & 16 \\
\hline 7 & 16 & 9 & 7 & 11 & 13 & 16 \\
\hline 8 & 19 & 9 & 17 & 11 & 15 & 16 \\
\hline 9 & 9 & 8 & 10 & 9 & 20 & 16 \\
\hline 10 & 18 & 8 & 19 & 9 & 5 & 15 \\
\hline 11 & 21 & 8 & 14 & 8 & 9 & 15 \\
\hline 12 & 3 & 7 & 15 & 7 & 4 & 14 \\
\hline 13 & 4 & 7 & 4 & 6 & 11 & 14 \\
\hline 14 & 12 & 7 & 9 & 6 & 17 & 14 \\
\hline 15 & 14 & 7 & 12 & 6 & 16 & 13 \\
\hline 16 & 1 & 6 & 3 & 5 & 2 & 12 \\
\hline 17 & 6 & 6 & 5 & 5 & 18 & 12 \\
\hline 18 & 5 & 5 & 8 & 5 & 3 & 9 \\
\hline 19 & 7 & 5 & 18 & 5 & 6 & 9 \\
\hline 20 & 8 & 5 & 2 & 3 & 7 & 9 \\
\hline 21 & 2 & 3 & 11 & 1 & 19 & 4 \\
\hline
\end{tabular}

Tras el análisis de la información ha sido posible identificar la obra con mayor indicador de riesgo. Éste, estimado sobre la base de la cantidad de tipologías de alteraciones y deterioros registrados, ha evidenciado el monumento funerario correspondiente a la muestra número 8 como el más rico en alteraciones. A pesar de la sencillez de su elaboración, éste se compone por un conjunto de materiales pétreos de diferente naturaleza, labrados con delicados bajorelieves fitomorfos en correspondencia de los bloques superiores (imágenes 44-46). Remata la estructura una lápida en mármol, cuyos lineamientos y epígrafes has sufrido el paso del tiempo 
y la exposición a la intemperie, dejando tan sólo un leve rastro de su apariencia original (imagen 47,48 ). Los elementos decorativos constituyen el caparazón de la estructura rectangular, cuyo relleno se compone con mucha probabilidad por mortero, tierra y elementos pétreos de menor valor estético.

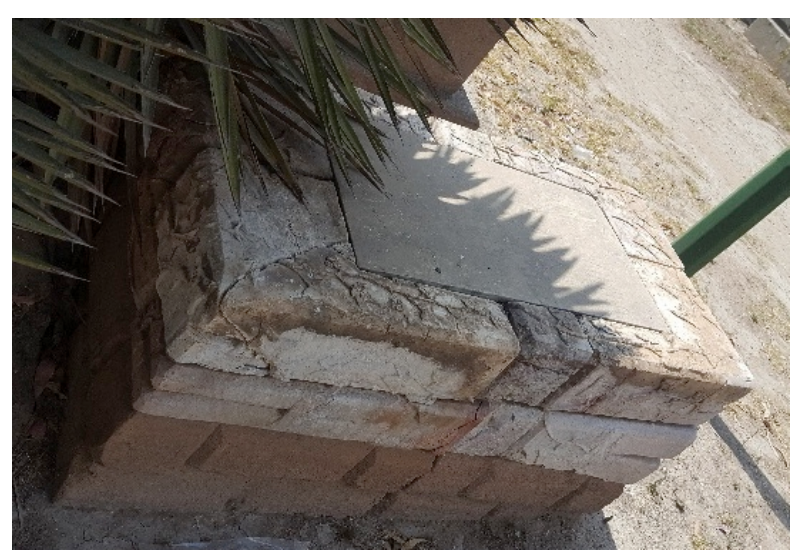

Imagen 44 - Tumba con mayor indicador de riesgo. Zona C, muestra 8, total de fenomenologías de alteración y deterioro registradas: 26.

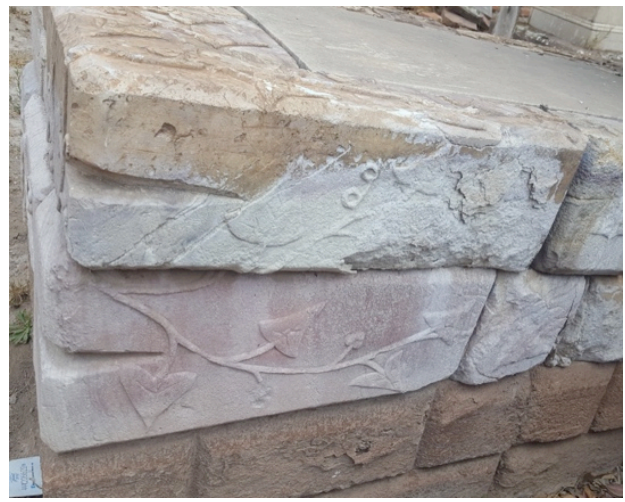

Imagen 45 Acercamiento a las morfologías de alteración y deterioro.

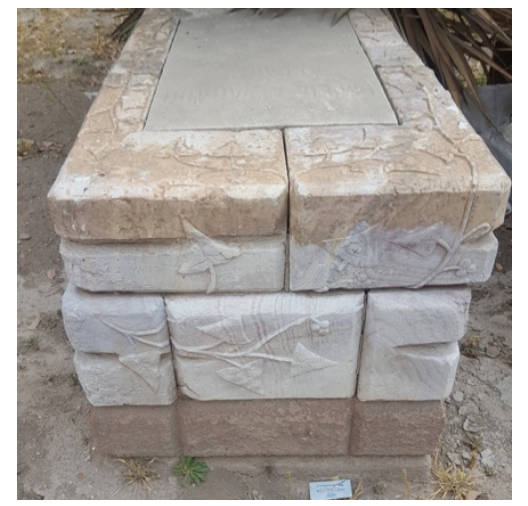

Imagen 46 Vista lateral del monumento. Se aprecian rasgos de la decoración fitomorfa en relieve. 


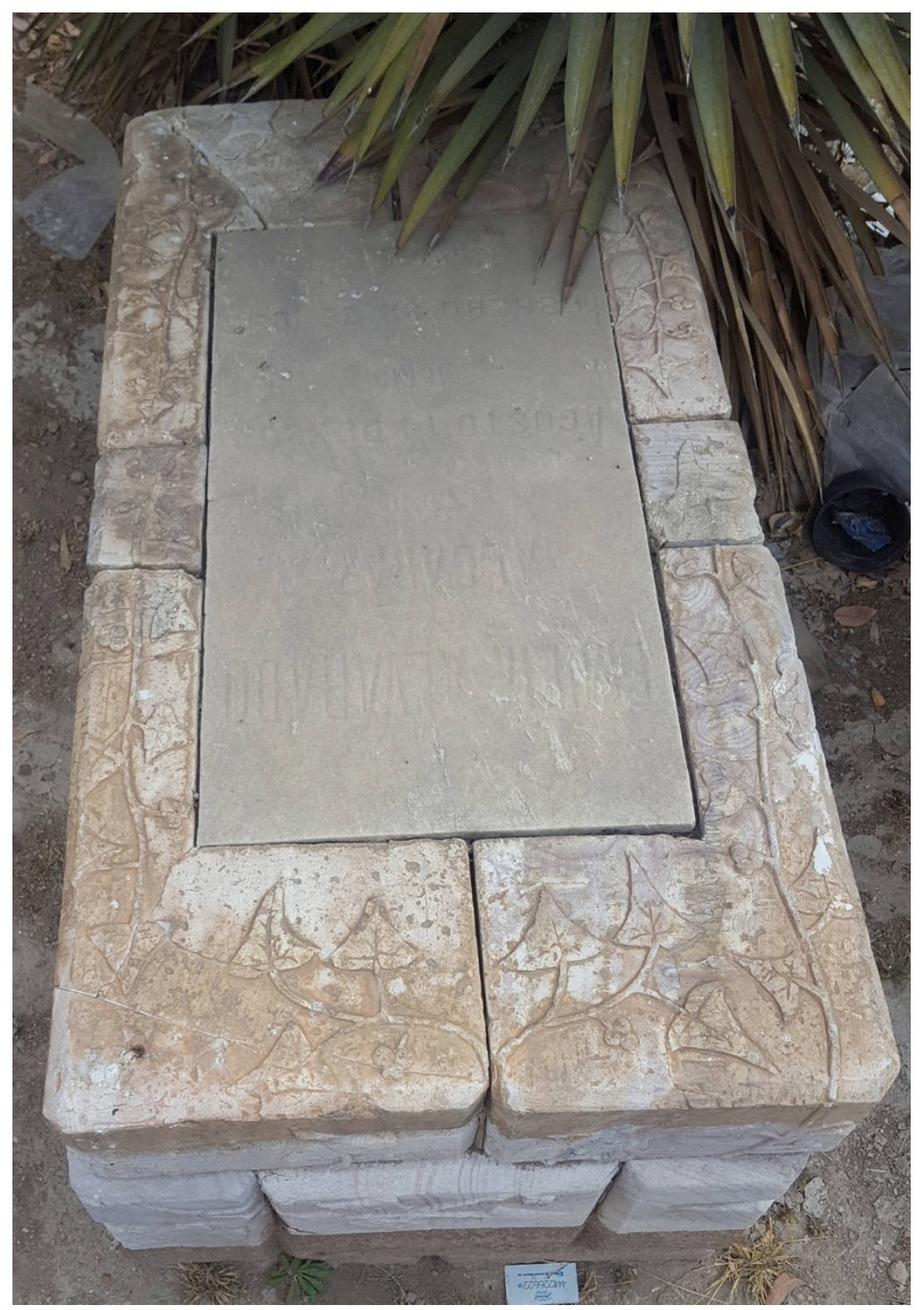

Imagen 47 - Vista superior del monumento. 


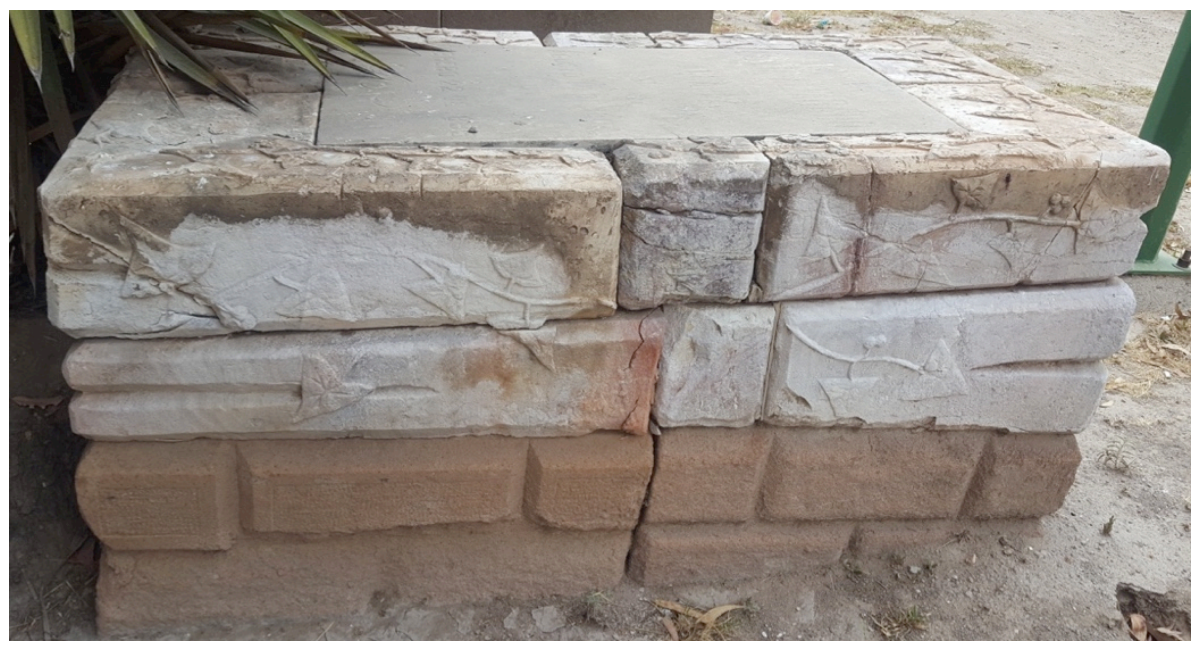

Imagen 48 - Detalle lateral de la obra con mayor indicador de riesgo.

ESCALA DE RIESGO Y PRIORIDADES - ZONA C - PANTEON MUNICIPAL DEL SAUCITO (S.L.P.)

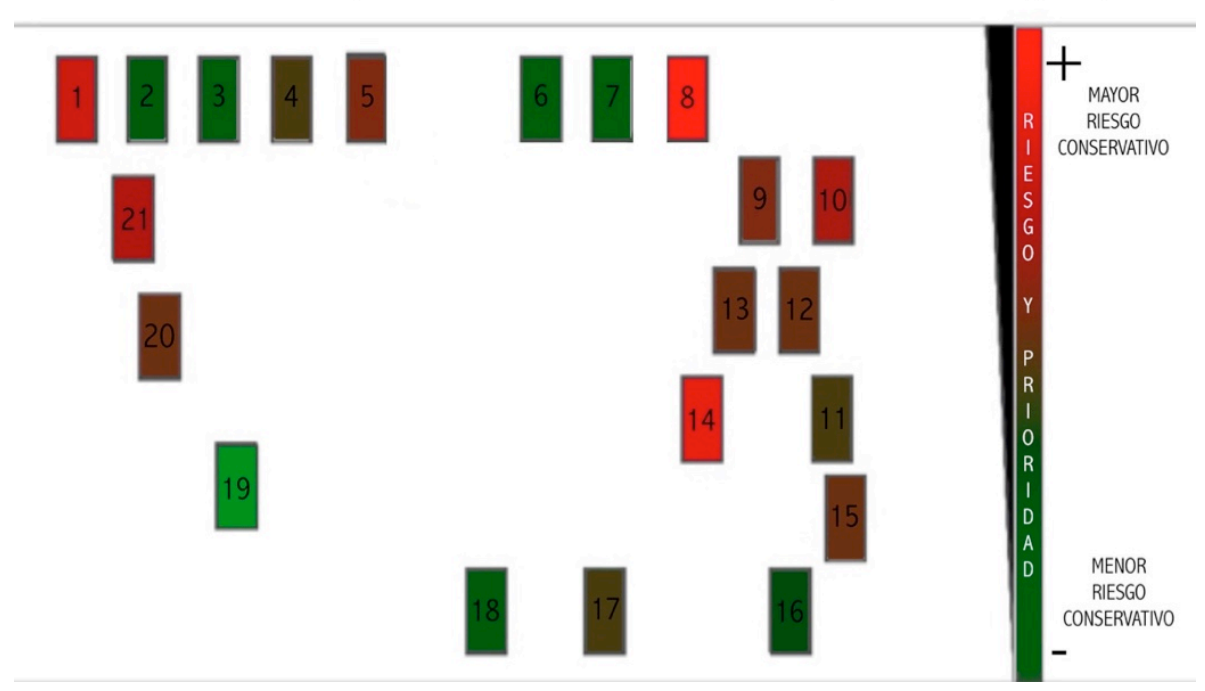

Imagen 49 - Representación de la escala de riesgo con ubicación de las obras. Zona C. 
Tabla 36 - Análisis de la obra con mayor incidencia de fenomenologías de alteración y deterioro. Zona C, muestra 8, total de fenómenos registrados: 26 .

\begin{tabular}{|l|l|}
\hline ZONA C & MUESTRA 8 \\
\hline TOTAL DE FENOMENOLOGÍAS DE ALTERACIÓN Y DETERIORO: 26 \\
\hline FISURAS Y DEFORMACIONES (2) & Fisura \\
& Fractura Lineal \\
\hline SEPARACIÓN (9) & Ampollas \\
& Estallido \\
& Delaminación \\
& Exfoliación \\
& Desmenuzamiento \\
& Disgregación sacaroidea \\
& Fragmentación \\
\hline MORFOLOGÍAS INDUCIDAS POR PÉRDIDAS (7) & Disyunción en películas \\
& Descamación \\
\hline COLONIZACIÓN BIOLÓGICA (1) & Erosión Pérdida de componentes \\
& Erosión Pérdida de matriz \\
& Aumento de la rugosidad \\
& Daños mecánicos Incisión \\
& Daños mecánicos Rayado \\
& Microkarst \\
\hline DEPÓSITOS Y ALTERACIÓN CROMÁTICA (7) & Faltantes Volumétricos \\
\hline & Depósito \\
& Pátina ferruginosa \\
& Pátina de oxalato \\
& Suciedad \\
\hline & Costra negra \\
Concrección \\
Encrustación \\
\hline
\end{tabular}

A la luz de los datos arrojados por esta primera experiencia en el campo de los materiales pétreos ha sido posible identificar, a través de la incidencia de las fenomenologías de alteración y deterioro presentes, el área con más problemáticas conservativas. La zona C, destaca con un total de 307 fenomenologías, seguida por la zona B (170) y A (164).

Las fenomenologías de alteración y deterioro existentes en el segmento C (tabla 35) pertenecen a la tipología de: fisuras y deformaciones, separación, morfologías inducidas por pérdidas, depósitos y alteración cromática y colonización biológica. 
Tomando como ejemplo para la interpretación de datos el área más dañada (zona C), se generaron reflexiones sobre sus problemáticas conservativas. A partir de las fenomenologías encontradas, se llevó a cabo una interpretación de los datos analizados, empleando como referencia las informaciones contenidas en el glosario ICOMOS-ISCS (2008) ${ }^{205}$ empleado como recurso para la creación de la matriz.

\subsubsection{Interpretación de resultados}

La presencia de fisuras y fracturas lineales pueden ser causadas por la exposición a la intemperie, defectos en la piedra, problemas estáticos, presencia de anclajes de hierro oxidados, o rejuntados con morteros demasiado duros.

El fenómeno de las ampollas tiene su origen en la acción de las sales solubles acompañada por una expansión de la superficie sometida a intemperismo, con posible pérdida parcial de la lámina desprendida. El estallido es una pérdida local de la superficie de la piedra debida a tensiones internas que se manifiestan normalmente por desprendimientos en forma de un cráter con bordes irregulares. A veces, tiene su origen en una fracturación radial. Esta forma de deterioro se debe al incremento en el volumen de inclusiones minerales (arcillas, minerales de hierro, etc.) que forman parte del contenido original de la piedra y que se encuentran cerca de su superficie. La corrosión de metales de refuerzo también puede inducir el estallido, por expansión volumétrica asociada al proceso de oxidación. La delaminación corresponde a un proceso de desprendimiento que sigue la laminación sedimentaria o los planos de esquistosidad de la piedra. Se presenta fundamentalmente en rocas sedimentarias o en algunas rocas metamórficas. El espesor y aspecto de las láminas es variable, así como su orientación respecto a la superficie de la piedra. Puede acompañarse por eflorescencias y biocolonización entre las láminas y empeorar tras ciclos de hielo-deshielo. Hay exfoliación, manifiesta a través de la separación en múltiples capas muy finas subparalelas a la superficie de la piedra, desmenuzamiento o disgregación granular, y disgregación sacaroidea, cuya causa principal es la dilatación térmica relacionada con la exposición a ciclos de variación extrema y repetida de la temperatura. Ésto ha ocasionado una fuerte pérdida de cohesión en el tejido cristalino del material pétreo, acompañándose además por fenómenos de fragmentación. Éste consiste en la rotura parcial o total de la piedra en trozos o partes de dimensiones variables, con formas, volúmenes y tamaños irregulares. Puede aparecer cuando los bloques de piedra están sujetos a sobrecargas.

La presencia de disyunción en películas se aprecia gracias a la separación de películas (desde submilimétricas a milimétricas) con aspecto de recubrimiento superficial. Puede relacionarse a la aplicación de tratamientos superficiales y/o

${ }^{205}$ ICOMOS-ISCS (2008), op.cit. 
cristalización de sales. El fenómeno de la descamación, con desprendimiento de laminillas de piedras (de espesor milimétrico o centimétrico), se caracteriza por ubicarse cerca de la superficie del material pétreo. La cristalización de las sales induce disgregación granular y descamación perimetral de la piedra.

La muestra en examen (M1) también presenta diferentes morfologías inducidas por pérdida de materiales, derivadas de procesos de erosión que han favorecido una pérdida de componentes con eliminación selectiva o parcial de componentes blandos (lentes de arcilla, nódulos de limonita, etc) o compactos de la piedra (guijarros, fragmentos de fósiles, concreciones geológicas, fragmentos de lava). Este fenómeno puede presentarse especialmente en areniscas ricas en hierro. Puede tener causas naturales o antrópicas, y ser el resultado de procesos químicos, físicos y/o biológicos. La pérdida de matriz deriva de la eliminación selectiva o parcial de la matriz o cemento de la piedra dando como resultado un aumento de la rugosidad. Se registra la presencia de daños mecánicos, cuales incisiones y rayados, probable resultado de acciones accidentales o voluntarias ejecutadas por medio de herramientas cortantes.

Se ha registrado la presencia de microkarstificación, una formación de pequeñas depresiones interconectadas entre sí. Éstas se deben a procesos de disolución de los compuestos solubles del material pétreo y a su exposición a escurrencias de agua. Finalmente, como parte de las morfologías inducidas por pérdidas de material, destaca la presencia de faltantes volumétricos en correspondencia con los resaltes y salientes de la tumba.

Se observó la existencia de depósitos y suciedad, resultados de una acumulación de material exogénico derivado del desprendimiento del bloque y restos vegetales. También existen concreciones, derivadas de procesos de precipitación seguida de lixiviación de cualquier tipo, e incrustaciones, firmemente adheridas y formadas en correspondencia a zonas con percolación de agua.

Entre las alteraciones cromáticas destaca la presencia de una pátina ferruginosa, generalmente relacionada con la presencia en la composición de la piedra de minerales arcillosos con contenido en hierro que, expuestos a la intemperie, pueden llegar a constituir una veladura rojiza u ocre oscura uniforme. Este fenómeno suele aparecer en areniscas ferruginosas conservadas en ambientes exteriores. Se registró la presencia de costra negra, que, generalmente, se trata de una acumulación coherente de material en la superficie, de color gris oscuro y con un espesor apreciable. Otra pátina observada en la muestra de estudio es la de oxalato. Este tipo de pátina se puede encontrar en ambientes exteriores, a menudo sobre mármoles o calizas. Finalmente, se registra la presencia de plantas, casi en contacto con la base del monumento. 
A conclusión de las observaciones arrojadas por el análisis de datos y de las informaciones brindadas por el glosario ICOMOS-ISCS ${ }^{206}$, se puede considerar satisfactoria la panorámica de causas intrínsecas y extrínsecas implicadas en el actual estado de conservación de la obra-muestra ofrecida por el método. La composición del material pétreo responde con mucha probabilidad a la de una roca sedimentaria, concretamente a una arenisca con inclusiones ferruginosas y arcillosas. Parte del monumento fúnebre se compone por mármol. Estos aspectos se relacionan con los fenómenos de alteración y deterioro propios de este tipo de materiales (estallido, delaminación, desmenuzamiento o disgregación granular, y disgregación sacaroidea, pérdida de componentes, pérdida de matriz, microkarstificación, pátina ferruginosa). Entre las causas intrínsecas relacionadas con los deterioros presentes, se cita la modalidad constructiva del bien que ha favorecido la aparición de fragmentación. Las condiciones del contexto de conservación, como la exposición a la intemperie (gradientes térmicos, ciclos de hielo-deshielo, insolación y precipitaciones entre otros), la presencia de sales solubles y las problemáticas de tipo estático del suelo de construcción, coinciden con los efectos de alteración registrados (fisuras y fracturas, ampollas, disyunción en películas, descamación, incisiones y rayados, microkarstificación, faltantes volumétricos), a los que se suman los ocasionados por descuido y falta de mantenimiento (depósitos y suciedad, plantas).

\subsubsection{Museo de Arte Sacro de Guadalcázar, San Luis Potosí}

La aplicación de la primera versión del método se ha llevado a cabo el 21 de marzo 2019 incluyendo un total de 35 obras de arte pertenecientes a la categoría mencionada. El registro, realizado de forma presencial, se ha realizado en un término temporal de dos horas y media (tabla 37).

Tabla 37 - Detalle de la primera implementación del método.

COLECCIÓN DEL MUSEO DE ARTE SACRO DEL TEMPLO DE GUADALCÁZAR, SAN LUIS POTOSÍ

\begin{tabular}{|l|l|}
\hline Registro realizado en: & Marzo 2019 \\
\hline Objeto de estudio: & Pinturas sobre lienzo y esculturas en madera policromada \\
\hline Tiempo de registro de datos: & 2 horas, presencial \\
\hline Total de obras analizadas: & 34 (18 lienzos y 16 esculturas); imagen 50 \\
\hline Profesionales empleados: & $2^{207}$ \\
\hline Tiempo para el análisis de datos & 1 hora \\
\hline
\end{tabular}

${ }^{206}$ Ibídem.

207 Se agradece la participación en esta fase de aplicación del método a la Lic. en Restauración Stephany Natalie Juárez Rodríguez para el estudio de la colección de escultura policromada: registro de las condiciones conservativas y documentación fotográfica. 


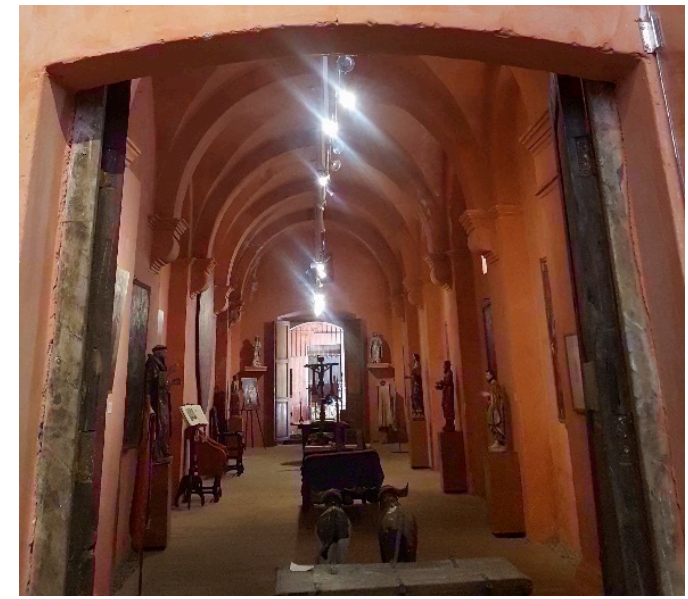

Imagen 50 - Interior del Museo de Arte Sacro, Real de Guadalcázar, S.L.P.

Como preparación al estudio se realizó una matriz de datos, útil para la toma de informaciones relacionadas con el estado de las obras. El primer paso cuenta con la creación de un listado universal, obtenido y estructurado a partir de las informaciones y terminologías empleadas en el campo de la conservación del patrimonio cultural, específicamente en relación a la pintura de caballete y escultura policromada.

La información se estructuró de acuerdo a la composición estructural del sistema de capas que compone este tipo de obras de arte (diagrama 20). Por ello, la terminología se ha agrupado a partir del soporte, preparación, película pictórica y capa de protección, teniendo en cuenta la posible presencia de todas o parte de las capas citadas. En este último caso, sólo se tomarán en cuenta los datos de los estratos existentes, además de registrar únicamente los fenómenos visibles, quedando así excluidos los componentes ocultos debajo de lo que la vista puede registrar. 


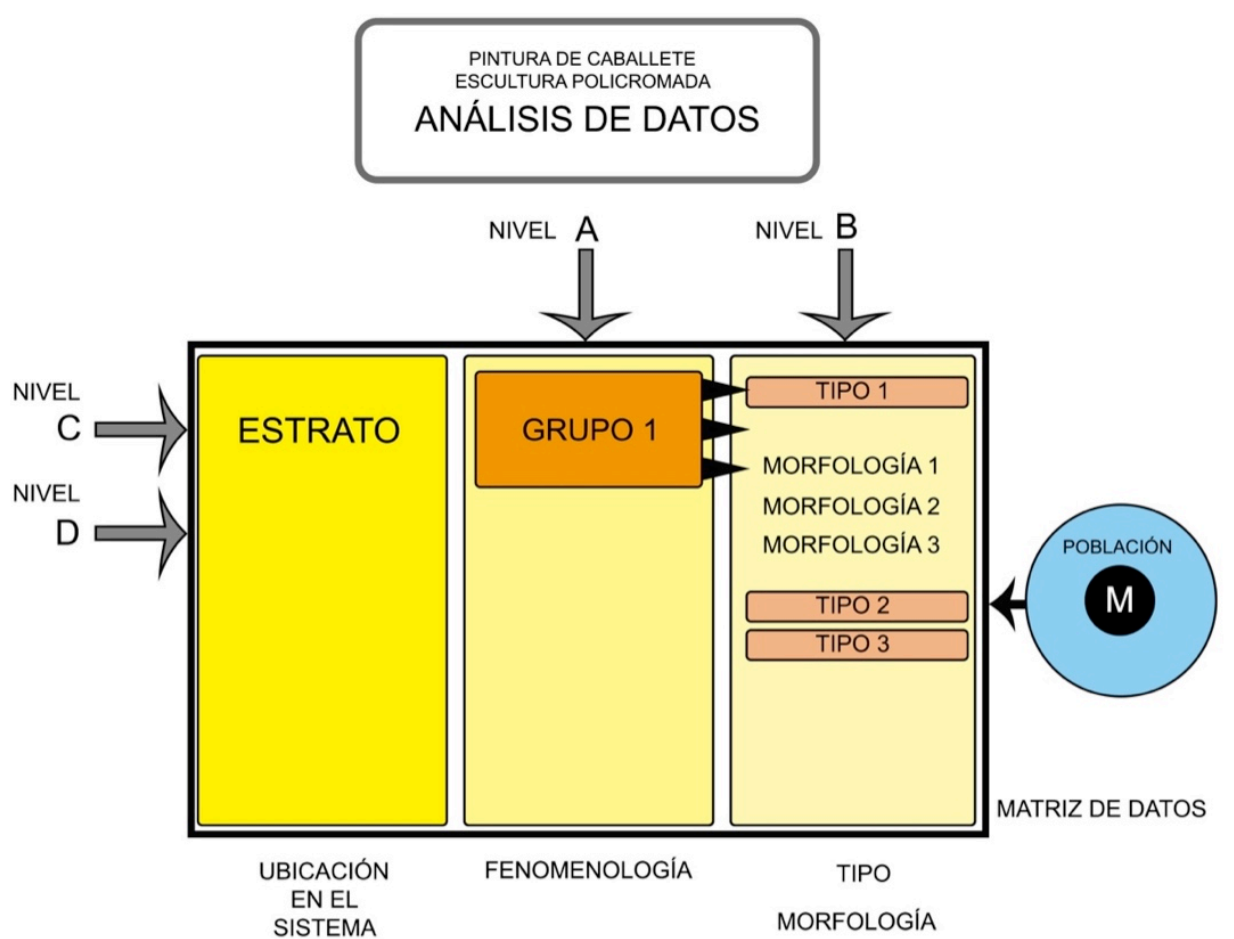

Primera implementación del método derivado de AAVV

Diagrama 20 - Estructuración de los conceptos en la matriz y niveles de análisis de datos (A, B, C, D) ofrecido por el sistema. En el nivel A se encuentran los grupos de fenomenologías de deterioro, seguidos por sus especificaciones: tipología y morfología (nivel B). Los demás niveles se refieren a la posibilidad de lectura de la información en relación a la capa de pertenencia (C) o global (D).

Tras la recolección y análisis de los datos se logró obtener una panorámica sobre las fenomenologías de alteración y deterioro presentes en cada grupo de obras (gráficas 18 y 19), junto a una estimación del indicador de riesgo de las mismas (tabla 38). Ha sido posible comparar los resultados entre las colecciones, pudiendo identificar la obra más inestable de cada tipología (imágenes 52 y 54 ) y evidenciando sus problemáticas específicas (tablas 39-40). La estructura de la matriz de datos empleada para la recolección de los deterioros ha generado datos representativos sobre el estado de conservación del conjunto, con la ventaja de brindar un 
acercamiento cualitativo (gráficas 18 y 19) y cuantitativo (tabla 39-40) a la tipología de alteración y deterioro presente en cada estrato compositivo del sistema.

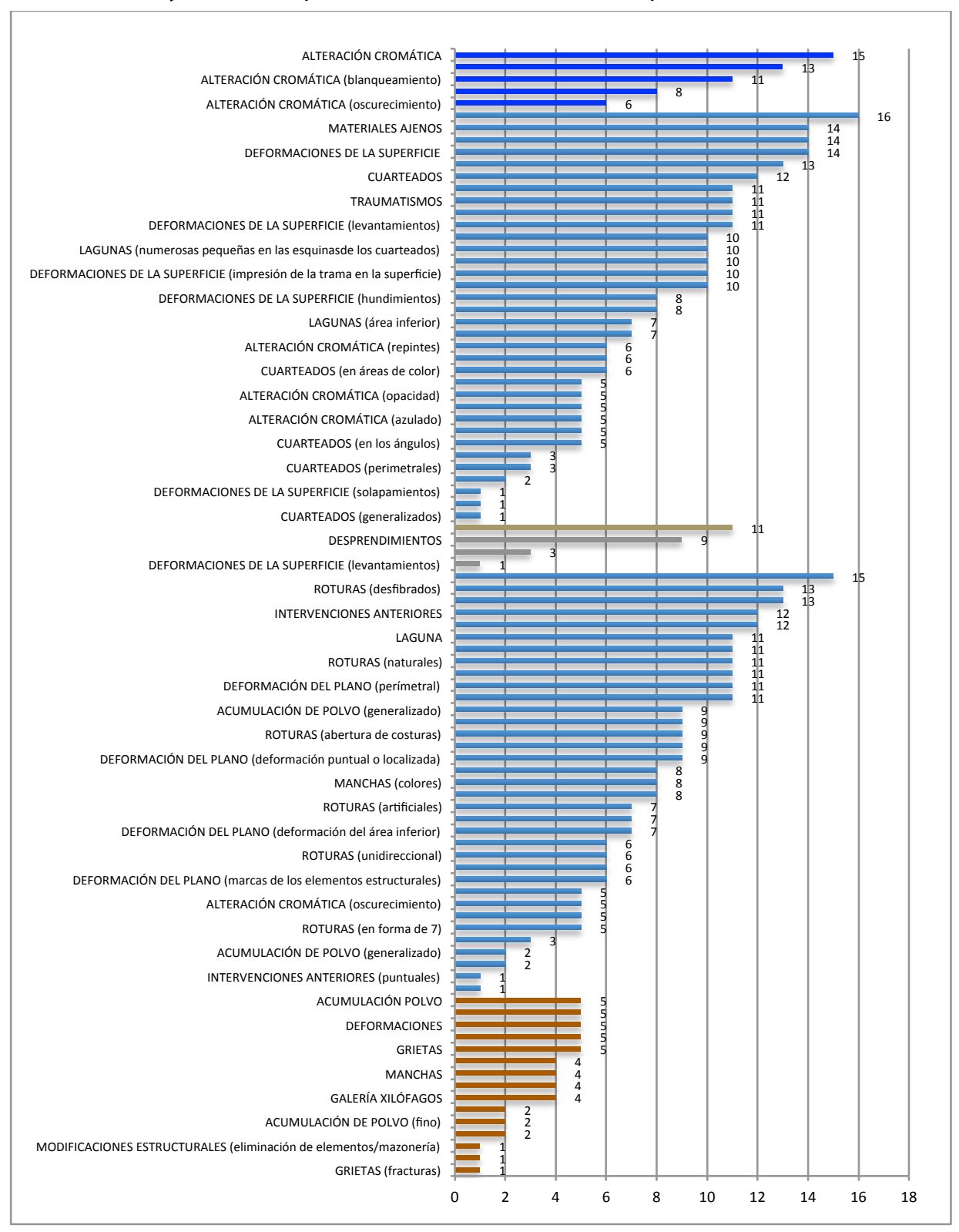

Gráfica 18 - Panorámica de las alteraciones y deterioro registradas en la colección de pintura de caballete. 


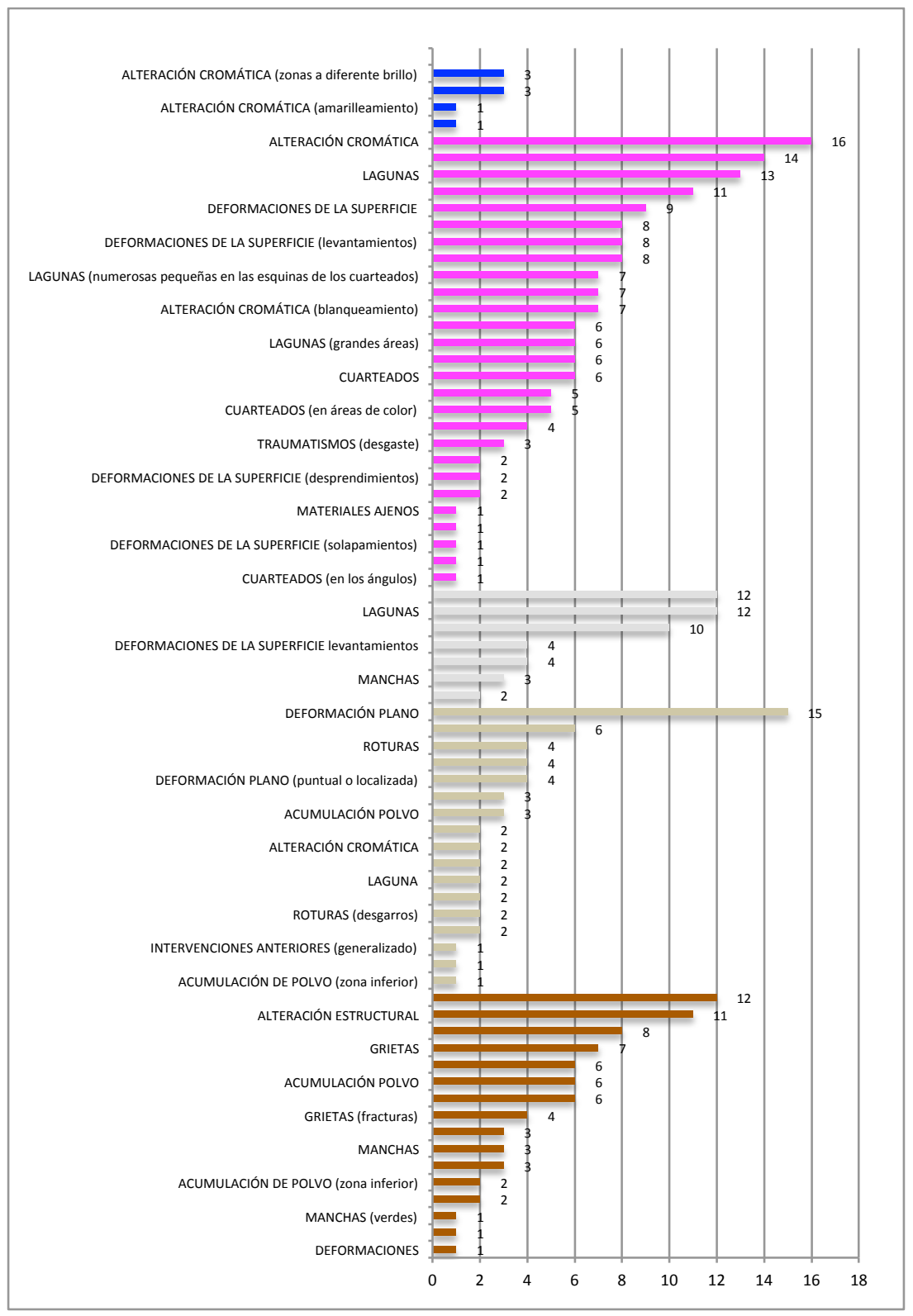

Gráfica 19 - Panorámica de las alteraciones y deterioro registradas en la colección de escultura policromada. 
Tabla 38 - Escala de riesgo de la colección del Museo de Arte Sacro: pintura de caballete y escultura policromada.

\begin{tabular}{|c|c|c|c|c|}
\hline \multirow[b]{3}{*}{$\begin{array}{l}\text { 岁 } \\
\text { 岂 } \\
\underline{\underline{\underline{u}}}\end{array}$} & \multicolumn{4}{|c|}{ ESCALA DE RIESGO } \\
\hline & PINTURAS & TOTAL: & ESCULTURAS & TOTAL: \\
\hline & MUESTRA & $\begin{array}{c}\text { FENOMENOLOGÍAS DE } \\
\text { ALTERACIÓN Y } \\
\text { DETERIORO }\end{array}$ & MUESTRA & $\begin{array}{c}\text { FENOMENOLOGÍAS DE } \\
\text { ALTERACIÓNY } \\
\text { DETERIORO }\end{array}$ \\
\hline 1 & 1 & 74 & 9 & 37 \\
\hline 2 & 2 & 67 & 7 & 34 \\
\hline 3 & 5 & 57 & 14 & 34 \\
\hline 4 & 9 & 55 & 10 & 33 \\
\hline 5 & 7 & 53 & 5 & 27 \\
\hline 6 & 17 & 53 & 1 & 26 \\
\hline 7 & 15 & 50 & 6 & 24 \\
\hline 8 & 8 & 47 & 2 & 21 \\
\hline 9 & 16 & 41 & 15 & 20 \\
\hline 10 & 10 & 40 & 4 & 19 \\
\hline 11 & 4 & 34 & 3 & 16 \\
\hline 12 & 3 & 32 & 11 & 16 \\
\hline 13 & 12 & 20 & 8 & 15 \\
\hline 14 & 11 & 14 & 13 & 11 \\
\hline 15 & 6 & 13 & 16 & 9 \\
\hline 16 & 14 & 9 & 12 & 5 \\
\hline 17 & 13 & 8 & - & - \\
\hline 18 & 18 & 0 & - & - \\
\hline
\end{tabular}

Tabla 39 - Panorámica de las fenomenologías de alteración y deterioro registradas en cada muestra de la colección de pintura de caballete, separadas por capas constitutivas: bastidor (M), soporte textil (L), preparación (Pr), película pictórica (PP), y capa de protección (B).

\begin{tabular}{|lll|l|l|l|l|l|l|l|l|l|l|l|l|l|l|l|l|l|}
\hline ESTRATO & 1 & 2 & 3 & 4 & 5 & 6 & 7 & 8 & 9 & 10 & 11 & 12 & 13 & 14 & 15 & 16 & 17 & 18 & TOTAL \\
\hline M & 13 & 9 & 0 & 0 & 5 & 0 & 2 & 3 & 0 & 0 & 7 & 0 & 0 & 3 & 3 & 3 & 2 & 0 & 50 \\
\hline L & 30 & 30 & 13 & 12 & 21 & 3 & 25 & 20 & 25 & 16 & 3 & 12 & 2 & 0 & 25 & 13 & 24 & 0 & 274 \\
\hline Pr & 3 & 3 & 2 & 2 & 2 & 0 & 2 & 2 & 2 & 2 & 0 & 0 & 0 & 0 & 1 & 1 & 2 & 0 & 24 \\
\hline PP & 25 & 21 & 12 & 17 & 24 & 6 & 20 & 20 & 24 & 18 & 4 & 6 & 3 & 6 & 18 & 21 & 21 & 0 & 266 \\
\hline B & 3 & 4 & 5 & 3 & 5 & 4 & 4 & 2 & 4 & 4 & 0 & 2 & 3 & 0 & 3 & 3 & 4 & 0 & 53 \\
\hline TOTAL & 74 & 67 & 32 & 34 & 57 & 13 & 53 & 47 & 55 & 40 & 14 & 20 & 8 & 9 & 50 & 41 & 53 & 0 & 667 \\
\hline
\end{tabular}


Tabla 40 - Panorámica de las fenomenologías de alteración y deterioro registradas en cada muestra de la colección de escultura policromada, separadas por capas constitutivas: soporte lígneo (M), entelado (L), preparación (Pr), policromía (PP), y capa de protección (B).

\begin{tabular}{|lll|l|l|l|l|l|l|l|l|l|l|l|l|l|l|l|l|l|}
\hline ESTRATO & 1 & 2 & 3 & 4 & 5 & 6 & 7 & 8 & 9 & 10 & 11 & 12 & 13 & 14 & 15 & 16 & 17 & 18 & TOTAL \\
\hline M & 8 & 7 & 4 & 2 & 0 & 9 & 8 & 2 & 12 & 10 & 2 & 2 & 5 & 5 & 0 & 0 & - & - & 76 \\
\hline L & 0 & 0 & 0 & 4 & 9 & 0 & 2 & 0 & 5 & 4 & 0 & 0 & 0 & 19 & 9 & 4 & - & - & 56 \\
\hline Pr & 7 & 3 & 0 & 5 & 5 & 3 & 6 & 3 & 4 & 4 & 3 & 0 & 0 & 2 & 2 & 0 & - & - & 47 \\
\hline PP & 11 & 11 & 12 & 8 & 10 & 10 & 17 & 10 & 16 & 15 & 11 & 3 & 6 & 8 & 9 & 3 & - & - & 160 \\
\hline B & 0 & 0 & 0 & 0 & 3 & 2 & 1 & 0 & 0 & 0 & 0 & 0 & 0 & 0 & 0 & 2 & - & - & 8 \\
\hline TOTAL & 26 & 21 & 16 & 19 & 27 & 24 & 34 & 15 & 37 & 33 & 16 & 5 & 11 & 34 & 20 & 9 & - & - & 347 \\
\hline
\end{tabular}

Tras la aplicación del método a la colección, ha sido posible generar una panorámica de las fenomenologías de alteración y deterioro presentes en las obras, junto a una estimación del índice de riesgo y prioridad. Gracias a estos datos, se pudieron identificar los elementos con mayores problemáticas de conservación: la muestra número 1 para el grupo de pintura de caballete (imagen 52) y la muestra número 9 para la sección de escultura policromada (imagen 54). La organización de la matriz de datos ha generado resultados de tipo global, inherentes al estado de la colección, y específicos, cuales la incidencia de los deterioros para cada obra, junto a su ubicación en las capas constitutivas del sistema. Una vez elaborados los datos, empleando como referencia las publicaciones citadas para la creación de la tabla de registro, se ha generado una interpetación de la información recaudada en esta experiencia.

En las imágenes 53 y 55 se representa el croquis del indicador de riesgo conservativo para cada colección.

Tabla 41 - Problemáticas conservativas de la obra con mayor índice de riesgo: muestra 1, colección de pintura de caballete. Total fenomenologías de alteración y deterioro registradas: 74 .

\begin{tabular}{|c|c|}
\hline PINTURAS DE CABALLETE & MUESTRA 1 \\
\hline \multicolumn{2}{|c|}{ TOTAL DE FENOMENOLOGÍAS DE ALTERACIÓN Y DETERIORO: 74} \\
\hline BASTIDOR & $\begin{array}{l}\text { Galerías de insectos xilófagos. } \\
\text { Grietas: fracturas y fendas. } \\
\text { Desprendimiento. } \\
\text { Deformaciones: alabeo y/o combamiento. } \\
\text { Manchas: colores. } \\
\text { Acumulación de polvo: fino y generalizado. } \\
\text { Intervenciones anteriores. }\end{array}$ \\
\hline SOPORTE - LIENZO & $\begin{array}{l}\text { Deformación planimétrica: arrugas en las esquinas, marcas de los } \\
\text { elementos estructurales, a lo largo del perímetro, entre clavos o tachuelas }\end{array}$ \\
\hline
\end{tabular}




\begin{tabular}{|c|c|}
\hline & $\begin{array}{l}\text { del borde, puntual o localizada, deformación acompañada por rigidez. } \\
\text { Roturas: cortes, desgarros, unidireccionales, en forma de 7, } \\
\text { multidireccionales, limpios, desfibrados, naturales y artificiales. } \\
\text { Desprendimiento. } \\
\text { Laguna. } \\
\text { Rigidez. } \\
\text { Manchas: de colores. } \\
\text { Alteración cromática: oscurecimiento, decoloración. } \\
\text { Acumulación polvo: generalizado. } \\
\text { Modificaciones estructurales. } \\
\text { Intervenciones anteriores: generalizadas. }\end{array}$ \\
\hline PREPARACIÓN & $\begin{array}{l}\text { Lagunas. } \\
\text { Desprendimientos. } \\
\text { Deformaciones de la superficie: levantamientos. }\end{array}$ \\
\hline PELÍCULA PICTÓRICA & $\begin{array}{l}\text { Acumulación de polvo. } \\
\text { Cuarteados: en los ángulos, perimetrales, en contacto con los elementos } \\
\text { estructurales del bastidor y generalizados. } \\
\text { Craquelado. } \\
\text { Alteración cromática: blanqueamiento, azulado, oscurecimiento y } \\
\text { opacidad. } \\
\text { Deformaciones de la superficie: levantamientos, impresión de la trama en } \\
\text { la superficie, desprendimientos y solapamientos. } \\
\text { Grietas (puntuales e intracapas). } \\
\text { Lagunas: numerosas y pequeñas en correspondencia de las esquinas de los } \\
\text { cuarteados, en grandes áreas, en el área inferior. } \\
\text { Traumatismos: abrasión. } \\
\text { Materiales ajenos. }\end{array}$ \\
\hline CAPA DE PROTECCIÓN - BARNIZ & Alteración cromática: oscurecimiento y zonas a diferente brillo. \\
\hline
\end{tabular}




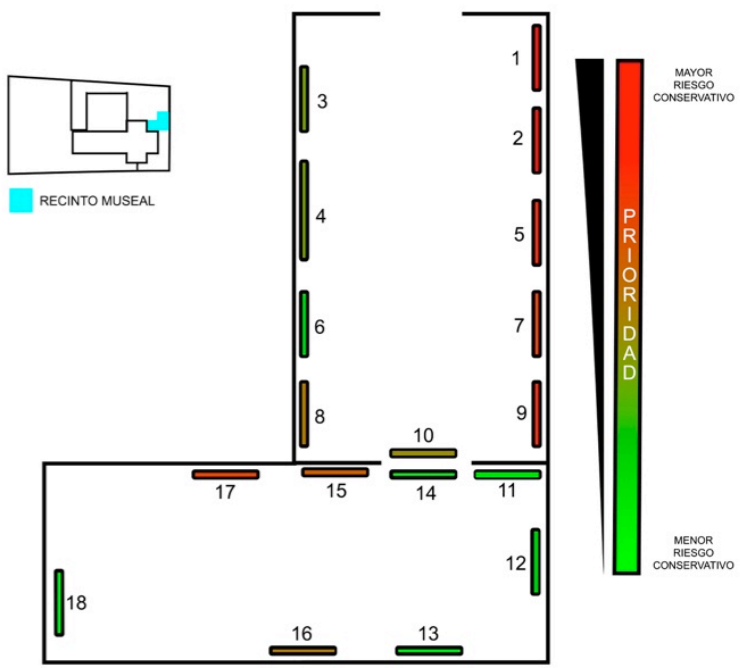

PINTURAS - MUSEO DE ARTE SACRO

Los datos obtenidos tras la elaboración de la información inherente la colección de pintura de caballete evidenciaron que la muestra número 1 es la con mayor indicador de riesgo. Esta obra, representante la "Huida a Egipto" (imagen 52), pertenece al conjunto realizado en el siglo XVIII por Francisco Martínez. Se compone por una pintura sobre lienzo y un bastidor. Desde el anverso de la película pictórica, por medio de tachuelas metálicas y un adhesivo de naturaleza desconocida, el soporte se vincula a un bastidor lígneo. Presenta varias problemáticas conservativas que afectan la totalidad de las capas constitutivas del sistema, cuyas características se exponen a continuación (tabla 42). 


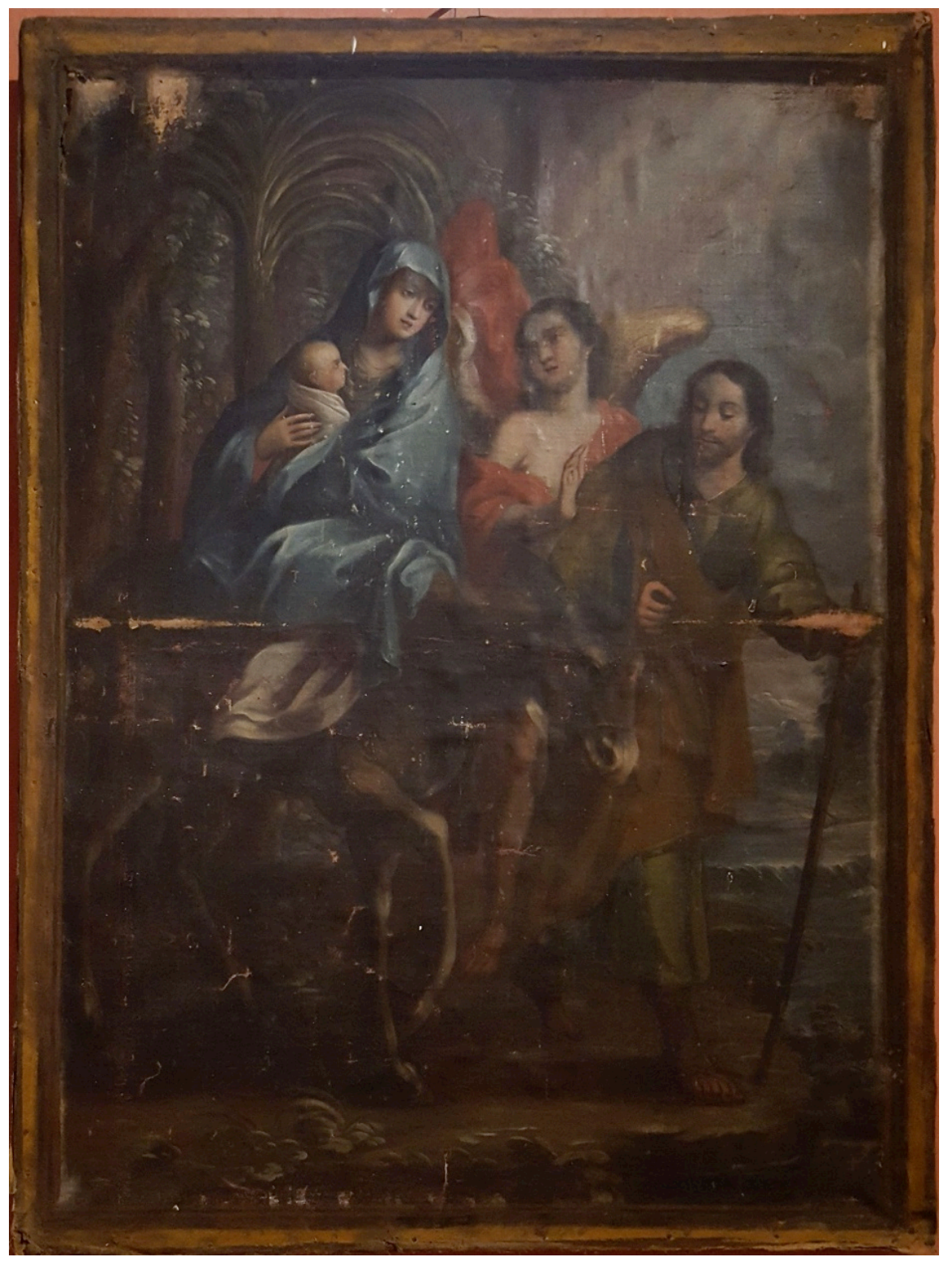

Imagen 52 - Pintura con mayor índice de riesgo. Muestra 1. Colección de pintura de caballete, Museo de Arte Sacro. 
Tabla 42 - Problemáticas conservativas de la obra con mayor índice de riesgo: muestra 9, colección de escultura policromada. Total fenomenologías de alteración y deterioro registradas: 37.

\begin{tabular}{|c|c|}
\hline ESCULTURAS POLICROMADAS & MUESTRA 9 \\
\hline \multicolumn{2}{|c|}{ TOTAL DE FENOMENOLOGÍAS DE ALTERACIÓN Y DETERIORO: 37} \\
\hline SOPORTE - MADERA & Alteración estructural: pérdida y movimientos de nudos. \\
\hline SOPORTE - LIENZO/ENTELADO & $\begin{array}{l}\text { Deformación de plano: puntual y localizada, acompañada por rigidez. } \\
\text { Roturas: desfibrados. } \\
\text { Desprendimiento. }\end{array}$ \\
\hline PREPARACIÓN & $\begin{array}{l}\text { Manchas. } \\
\text { Lagunas. } \\
\text { Pérdida de adhesión con la película pictórica. } \\
\text { Desprendimiento. }\end{array}$ \\
\hline PELÍCULA PICTÓRICA & $\begin{array}{l}\text { Acumulación de polvo. } \\
\text { Cuarteado: en áreas de color, en forma circular o de telaraña. } \\
\text { Craquelado. } \\
\text { Alteración cromática: blanqueamiento y oscurecimiento. } \\
\text { Deformaciones de la superficie: levantamientos. } \\
\text { Grietas puntuales e intracapas. } \\
\text { Lagunas: en grandes áreas. } \\
\text { Traumatismos: abrasión y desgaste. }\end{array}$ \\
\hline CAPA DE PROTECCIÓN - BARNIZ & - \\
\hline
\end{tabular}




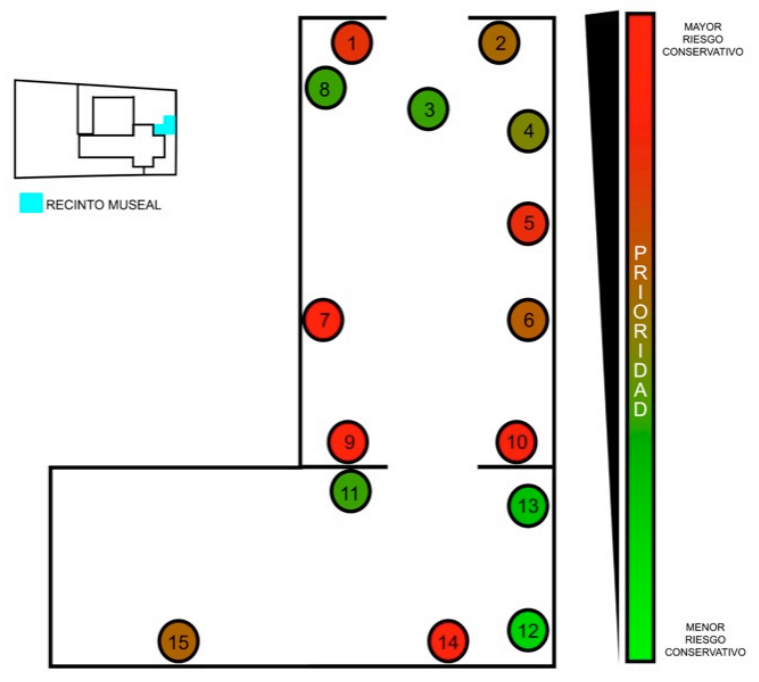

ESCULTURAS - MUSEO DE ARTE SACRO

De acuerdo a la información arrojada tras el análisis, la obra con mayor indicador de riesgo de la colección de escultura policromada ha resultado ser la muestra número 9. Ésta se compone por una talla en madera de bulto redondo, cuya policromía original aun se llega a apreciar por debajo de los bastos repintes bicromáticos. Dichas intervenciones, aplicadas en correspondencia de las áreas que coinciden con la vestimenta, ocultan los dorados con estofados y burilados que adornaban la talla. Actualmente se encuentra en un estado de conservación lamentable, por los numerosos faltantes volumétricos, aunados a la pluralidad de alteraciones y deterioros que lo afectan (imagen 54). 


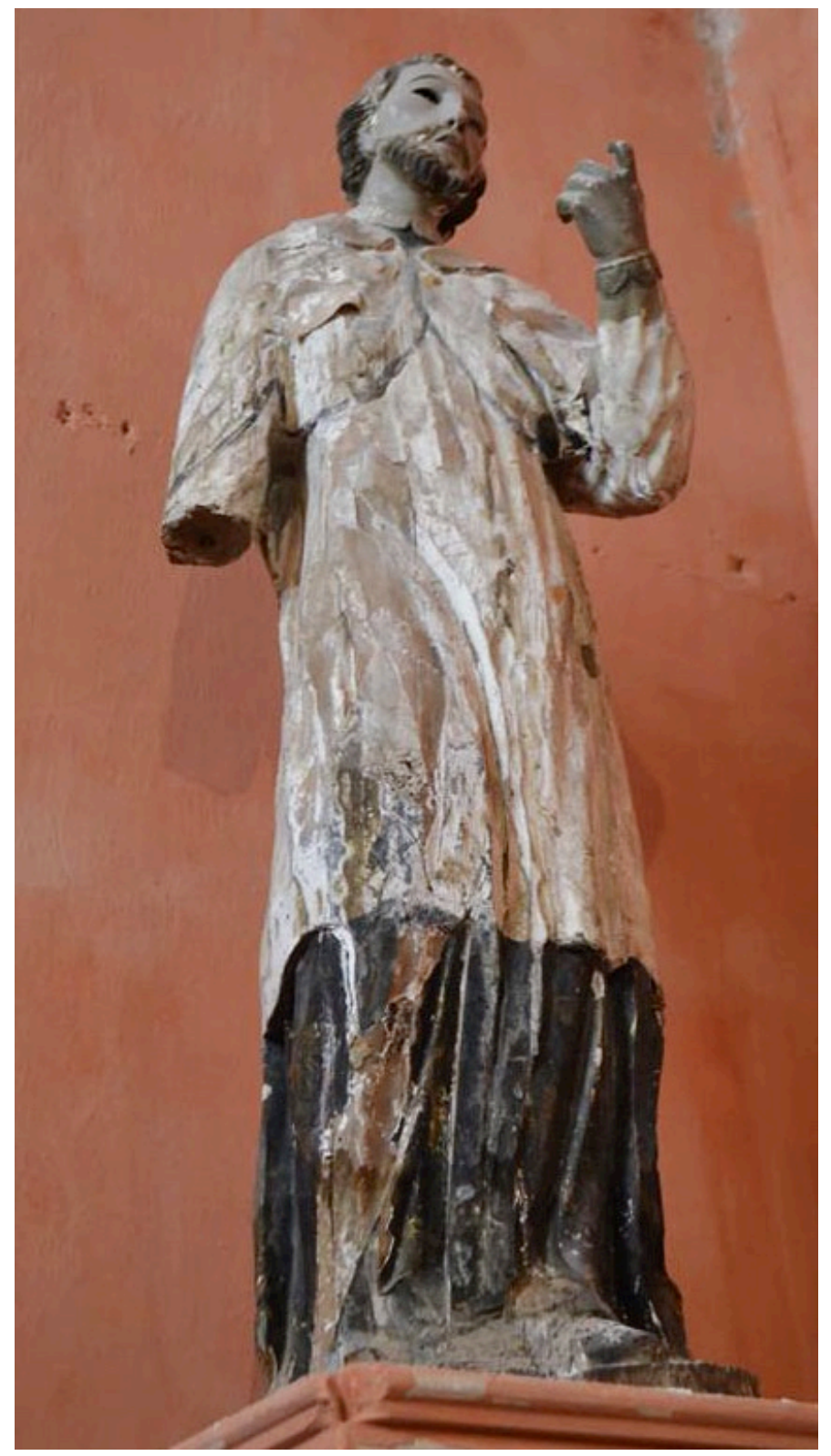

Imagen 54 - Escultura con mayor índice de riesgo. Muestra 9. Colección de escultura policromada, Museo de Arte Sacro. 
Para la interpretación de la información recaudada en esta experiencia, se han tomado como ejemplo de estudio las dos obras con mayor incidencia de alteraciones y deterioro registradas.

Las informaciones arrojadas han sido relacionadas con las dinámicas de causa efecto propuestas por las fuentes bibliográficas consultadas para el diseño de las fichas ${ }^{208}$.

\section{Interpretación de la información, muestra 1, colección de pintura de caballete}

A continuación, se exponen los datos perteneciente al estado de conservación de la muestra número 1 (M1) de la colección de pintura de caballete.

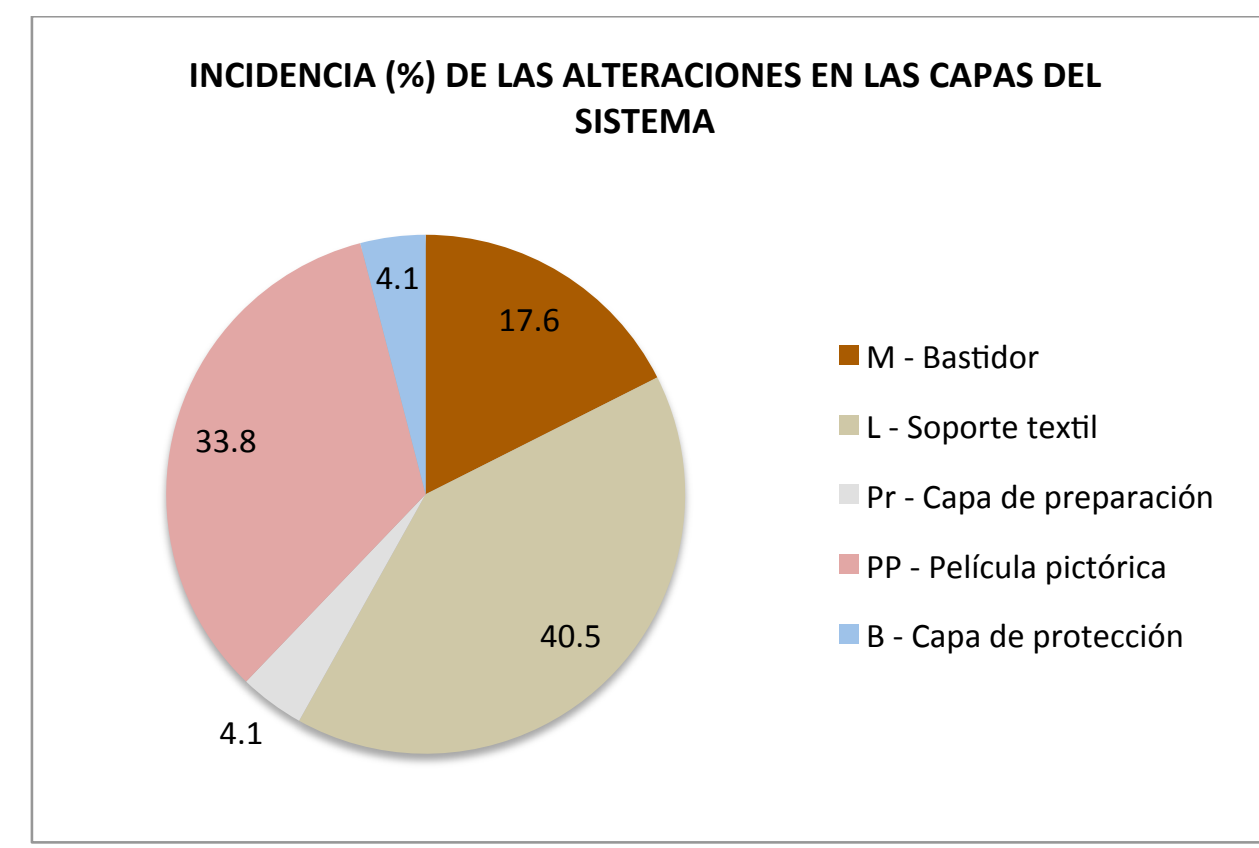

Gráfica 20 - Incidencia (\%) de los fenómenos de alteración y deterioro de acuerdo a las capas que conforman el sistema. Pintura de caballete, muestra número 1 (M1).

Desde una estimación (\%) de las incidencias de los fenómenos de alteración y deterioro (gráfica 20) se pudo observar que la capa con más problemáticas es la constituida por el soporte textil (40.5\%), seguida por la película pictórica (33.8\%), el bastidor (17.6\%), y las capas de preparación y protección (ambas con 4.1\%).

\footnotetext{
${ }^{208}$ CALVO, A. (2002), op. cit., pp. 134-155. VIVANCOS RAMÓN, V. (2007), op. cit., pp. 121-184.
} 
De acuerdo a la ordenación de la matriz de datos, la interpretación de los resultados empieza desde el elemento auxiliar del soporte textil: el bastidor. Éste presenta una acumulación de suciedad ambiental que se relaciona con falta de mantenimiento y progresiva acumulación de partículas atmosféricas. Esto pudo haber favorecido el desarrollo de deterioros de tipo biológico entre otros, ya que se ha registrado la presencia de galerías de insectos xilófagos de forma circular de un tamaño comprendido entre 1-4 $\mathrm{mm}$. Esto podría indicar la presencia de anobium punctatum y unas condiciones en el lugar de conservación favorables para su desarrollo: elevada humedad relativa y temperatura entre $22^{\circ}-24^{\circ} \mathrm{C}$. La presencia de deformaciones (alabeo/combamiento) y fracturas indica la exposición de la obra a ciclos de variación termohigrométrica. Es posible que ésta haya sido sometida a una variación drástica del contenido de humedad en el lugar de conservación favoreciendo el desarrollo de un campo de tensión interno que, sobretodo en correspondencia con vínculos de tipo estructural, ha generado las fracturas y expuesto la superficie a una mayor interacción con el entorno conservativo. La presencia de fendas indica un agotamiento del material por sobrepasar su límite de elasticidad. Esto se debe al envejecimiento de la madera acompañado por ciclos de variaciones de temperatura y humedad que han ocasionado una deformación plástica irreversible del bastidor. La presencia de desprendimientos puede relacionarse a la exposición a la radiación ultravioleta con consiguiente degradación de la lignina; también pueden ser indicativos de la presencia de hongos de pudrición blanda, reconducibles a soportes en contacto con el suelo, probablemente encharcado o con elevada presencia de humedad, necesaria para su desarrollo. Su presencia ha facilitado la colonización del material por otros xilófagos. La presencia de manchas alimenta la hipótesis de la probable presencia de hongos. El bastidor ha sido intervenido anteriormente, probablemente para proveer una mayor estabilidad a la obra ${ }^{209}$.

El soporte textil presenta varias morfologías de deformación planimétrica:

- arrugas en las esquinas;

- marcas de los elementos estructurales;

- pérdida de planaridad en el área perimetral;

- pérdida de planaridad entre los elementos de sujección al bastidor;

- deformación localizada acompañada por rigidez;

Estas fenomenologías de alteración manifiestan una problemática de tensado debida a la probable falta de cuñas de tensión (por modificaciones, ausencia o pérdida de las mismas), y condiciones del contenido termohigrométrico del lugar

${ }^{209}$ VIVANCOS RAMÓN, V. (2007), op. cit., pp. 154-158, 170-184. 
incorrectas o inestables. La marca de los elementos estructurales indica la existencia de un bastidor con borde sin aristas rebajadas y/o la presencia de travesaños. Debido probablemente a una proceso de acidificación y oxidación del lienzo, favorecido por la presencia y oxidación de los elementos metálicos de sujeción, se ha acelerado el envejecimiento de la tela, que ha llegado a desprenderse. Pliegues y ondas pueden deberse a la presencia de parches y bandas de tensión aplicados en intervenciones anteriores, mientras las deformaciones puntuales son el resultado de una presión continua y prolongada de un elemento rígido sobre el lienzo y/o posibles arañazos o rasguños practicados en el reverso por algún accidente. La rigidez del soporte se debe a la posible oxidación y endurecimiento de los aglutinantes (óleo o cola animal) empleados en la capa de preparación e imprimación del lienzo ${ }^{210}$.

La presencia de roturas (artificiales) indica la exposición de la obra a eventos traumáticos $\mathrm{y} / \mathrm{o}$ actos vandálicos (cortes). Son indicativas de golpes con herramientas o superficies con hilo (cortes limpios) y sin hilo (desgarros). La existencia de desfibrados (roturas naturales) puede ser el resultado de la degradación fotoquímica de la tela por efectos de la luz UV que favoreció la despolimerización de la celulosa, con consiguiente oscurecimiento de la tela y aumento de la rigidez. Esta clase de deterioro es favorecido por la exposición del material a ciclos de variación termohigrométrica. Éstos cambios hacen posible que el lienzo alcance su límite de fatiga mecánica, favoreciendo, a la larga, su ruptura. Tiene un efecto acumulativo y acarrea daños mayores cuanto más repentinos sean los cambios en un corto plazo de tiempo. La presencia de elementos de sujección oxidados ha acelerado las dinámicas mencionadas, favoreciendo el desprendimiento de la tela y la formación de lagunas. Ésto ha influido en las problemáticas de tensión registradas. La presencia de manchas de colores puede indicar un ataque biológico por microorganismos que ha sido favorecido por la acumulación de polvo fino generalizado. Éste favorece y acelera el desarrollo biológico, reteniendo humedad y volviéndose un medio útil para la aparición de otros fenómenos dañinos. La presencia de modificaciones estructurales e intervenciones generalizadas sobre el soporte, indica que la obra ha sido sometida a acciones de conservación. Éstas pueden haber acarreado importantes alteraciones sobre el sistema:

- desgaste y abrasión de la tela;

- encogimiento;

- pliegues y ondas en parches y bandas de tensión;

- telas dobladas para reducir el tamaño;

${ }^{210}$ CALVO, A. (2002), op. cit., pp. 135-140. 
- recortes del formato original;

- impregnación en aceites;

- barnices que aceleran la oxidación, modificaciones en el aspecto o adhesión de polvo;

- entelados con ocultación de firmas, marcas o inscripciones en el reverso;

- impresión de la trama sobre la pintura;

- pérdida de la textura y de la naturaleza flexible de la tela;

- movimiento de las maderas;

- cuarteados de la pintura;

- abolsamientos por despegados parciales ${ }^{211}$.

La capa de preparación presenta lagunas, desprendimientos y levantamientos. Éstos son el resultado de la exposición de la obra a ciclos de variación termohigrométrica que han generado variaciones y respuestas dimensionales diferentes entre soporte textil, adhesivos/médiums y preparación. Puede reconducirse a una pérdida del poder adhesivo del aglutinante, como podría ser el caso de colas animales expuestas a condiciones de elevada humedad o contacto con agua. Estos factores ocasionan un hinchamiento de la cola animal, generando una pérdida de consistencia y adquiriendo un estado gelatinoso de bajas propiedades y resistencia mecánica ${ }^{212}$. Las oscilaciones del contenido termohigrométrico del lugar de conservación con la consiguiente variación de tensión y dimensión del soporte que modifica su comportamiento mecánico, suele ir asociado íntimamente con alteraciones en la película pictórica, por lo tanto en ambas capas se pueden presentar: cuarteados, levantamientos, lagunas. Estas dinámicas, si van asociadas a problemáticas intrínsecas de tipo técnico, favorecen la formación de lagunas y desprendimientos. Es el caso una mala ejecución de las preparaciones, con la aplicación de capas demasiado gruesas sobre el soporte textil, o el uso de capas magras aplicadas sobre aglutinantes grasos.

La película pictórica presenta diferentes tipologías de cuarteado ${ }^{213}$ :

- en los ángulos, debidos a la interacción entre tela y bastidor y relacionados al tensado de las cuñas;

\footnotetext{
${ }^{211}$ Ibídem.

${ }^{212}$ ACROYD, P., YOUNG, CH. (1999). “The preparation of artists' canvases: factors that affect adhesión between ground and canvas" en 12th Triennal Meeting, ICOM-CC, Lyon, pp. 265-270.

${ }^{213}$ Para la interpretación de las dinámicas de causa-efecto de los cuarteados véase CALVO, A. (2002), op. cit., pp. 142-152.
} 
- perimetrales, generalmente asociadas a la presencia de ondas en los bordes, derivan del clavado de las tachuelas;

- en contacto con los elementos estructurales del bastidor: relacionadas con las zonas de roce del bastidor;

- generalizados, debidos a ciclos de variación termohigrométrica que genera diferentes respuestas dimensionales por parte de los elementos que conforman el sistema de la pintura: el soporte reacciona con mayor flexibilidad, mientras la pintura, más rígida, suele cuartearse. ${ }^{214}$ Se deben a la presencia de fuerzas de contracción derivados de la preparación, imprimación, capa pictórica o de gruesas capas de barniz y recubrimientos de algún tipo que ejercen fuerzas de tracción. El incorrecto o inestable mantenimiento de las condiciones termohigrométricas del lugar de conservación fomenta el desarrollo de problemáticas de tensión en el lienzo y su interacción con los elementos del bastidor que pueden marcar el soporte y la pintura con o sin craquelados asociados.

La presencia de craquelados $^{215}$ se relaciona con el envejecimiento de los materiales, aunada a las características de la técnica pictórica empleada, en particular del aglutinante, y los movimientos del soporte. La presencia de tensiones locales en el soporte se refleja en las capas sobrepuestas ${ }^{216}$ por su reacción al entorno conservativo. Esta fenomenología de deterioro es el resultado del estrés generado por la interacción entre técnica pictórica, materiales, soporte, uso y microclima.

Hay diferentes tipologías de alteración cromática en la capa pictórica:

- blanqueamiento: es el resultado de la formación de microgrietas en la estructura de la película pictórica debido a la disociación del aglutinante. Ésto puede deberse a: elevados niveles de humedad relativa, cambios bruscos de temperatura, limpiezas inadecuadas ${ }^{217}$;

- azulado: puede tener origen en la misma técnica pictórica o en la acción de la humedad ${ }^{218}$.

- Oscurecimiento: está relacionado con el envejecimiento natural del aglutinante, sobretodo el aceite de linaza que, bajo la acción combinada de

\footnotetext{
${ }^{214}$ KECK, S. (1969). “Mechanical alteration of the Paint Film”, en Studies en Conservation, 14, IIC, London, p. 9.

215 Para la profundización de las dinámicas de causa-efecto responsables de la formación de craquelados, véase VIVANCOS RAMÓN, V. (2007), op. cit., p. 121.

${ }^{216}$ MARIJNISSEN, R. (1985). Tableaux. Authentiques. Maquillés. Faux. L'expertise des tableaux et les methodes de laboratoire. Bruxelles: Elsevier.

${ }^{217}$ VIVANCOS RAMÓN, V. (2007), op. cit., p. 137.

${ }^{218}$ CALVO, A. (2002), op. cit., pp. 152.
} 
una elevada humedad ambiental y poca luz, oscurece de forma muy acusada $^{219}$. Indica el posible resguardo de las obras en almacenes 0 entornos con oscuridad absoluta y elevada humedad ambiental ${ }^{220}$. Si el oscurecimiento se limita a las zonas perimetrales puede considerarse la posibilidad de que éstas hayan sido cubiertas por marcos o estructuras, generando las condiciones mencionadas anteriormente pero de forma localizada ${ }^{221}$.

El levantamiento de la película pictórica es otro elemento indicativo de la pérdida del poder adhesivo del aglutinante. Puede ir asociado a grietas, desprendimientos, lagunas. Puede indicar la presencia de elementos de sujeción metálicos que, expuestos a elevados niveles de humedad, se oxidan ocasionando una variación dimensional y volumétrica por la formación de productos de alteración ${ }^{222}$; es indicativo de problemáticas de tipo técnico derivadas de una mala ejecución de las preparaciones. Puede deberse a la pérdida de adhesión hacia las capas inferiores o a la presencia de tensiones superficiales, como las producidas por exceso de cola en la superficie durante algún tratamiento. Las fluctuaciones termohigrométricas ocasionan una variación dimensional en el lienzo y los materiales constitutivos de la capa de preparación y su forma de aplicación, como el encolado del lienzo por medio de impregnación a pincel con cola de piel caliente o fría, son determinantes para la formación de este tipo de alteraciones ${ }^{223}$.

La existencia del fenómeno de la impresión de la trama en la superficie es una alteración característica del empleo de planchas calientes acompañadas por presión excesiva, y más recientemente, de un uso inadecuado de las mesas calientes. Ambas posibles causas están relacionadas con la pericia del operador en la ejecución del proceso e indican la realización de algún tratamiento de restauración sobre la obra ${ }^{224}$.

La existencia de desprendimientos puede asociarse a movimientos de nudos por contracciones del soporte debidos a fluctuaciones termohigrométricas y a posibles intervenciones de modificación o refuerzo estructural del soporte ${ }^{225}$. Las ejecución técnica de la pintura puede acarrear esta problemática. Es el caso de las

\footnotetext{
${ }^{219}$ VIVANCOS RAMÓN, V. (2007), op. cit., pp. 130.

${ }^{220}$ DÍAZ MARTOS, A. (1975) Restauración y conservación del arte pictórico. Madrid: Arte restauro, p.107.

${ }^{221}$ Ibídem.

222 VIVANCOS RAMÓN, V. (2007), op. cit., pp. 124-125, 140-141.

${ }^{223}$ CALVO, A. (2002), op. cit., p. 145.

${ }^{224}$ CALVO, A. (2002), op. cit., p. 150.

${ }^{225}$ VIVANCOS RAMÓN, V. (2007), op. cit., pp. 153-154.
} 
preparaciones oleosas aplicadas en capa gruesa. Éstas suelen presentar problemas de adhesión, favoreciendo la separación de la película pictórica ${ }^{226}$.

Los solapamientos son el resultado de los desprendimientos de las capas pictóricas junto a una merma del soporte. Pueden deberse a antiguas intervenciones de restauración, en donde algunas partículas quedan adheridas en fijaciones o empapelados defectuosos, solapando otras áreas de la pintura ${ }^{227}$.

Las grietas pueden ser el resultado de defectos en la ejecución técnica, del envejecimiento del aglutinante. Se deben a la edad cuando afectan a la película pictórica y los estratos subyacentes. Puede asociarse a contracciones del soporte debidos a fluctuaciones termohigrométricas ${ }^{228}$. Son alteraciones puntuales que se pueden presentar en zonas de excesiva tensión de la tela o en fondos resbalosos como los constituidos por betunes. Puede afectar total o parcialmente a la pintura ${ }^{229}$.

También se registró la presenucia de lagunas, pequeñas en correspondencia de las esquinas de los cuarteados; este fenómeno es típico de las pinturas antiguas, y su morfología corresponde a las zonas de cruce de las líneas de los cuarteados y/o craquelados. Puede deberse a una pérdida del poder aglutinante de la capa de preparación, como podría ser en el caso de condiciones de exposición a altos contenidos de humedad ambiental ${ }^{230}$.

La presencia de lagunas en el área inferior suele deberse a situaciones de abandono de las obras en sótanos con humedades en el suelo o por su alcance a la acción humana (abrasiones o actos vandálicos, entre otros) ${ }^{231}$.

La existencia de traumatismos (abrasión) se relaciona con posibles intervenciones anteriores inadecuadas entre las cuales destacan las acciones de mantenimiento y limpieza incorrectas, por ejemplo con paños de limpieza inadecuados al eliminar frotando - el polvo superficial ${ }^{232}$.

La presencia de materiales ajenos y de la acumulación de polvo puede deberse a posibles actos de origen antrópico sin previa protección o resguardo de las pinturas,

\footnotetext{
${ }^{226}$ CALVO, A. (2002), op. cit., pp. 140-142.

${ }^{227}$ CALVO, A. (2002), op. cit., pp. 150.

${ }^{228}$ VIVANCOS RAMÓN, V. (2007), op. cit., p. 121.

${ }^{229}$ CALVO, A. (2002), op. cit., pp. 145-147.

${ }^{230}$ CALVO, A. (2002), op. cit., p. 150.

231 Ibídem.

${ }^{232}$ CALVO, A. (2002), op. cit., p. 151.
} 
falta de mantenimiento ${ }^{233}$, presencia de suciedad suspendida en el aire. La superficie irregular y la orientación de la superficie favorecen la adhesión del polvo ${ }^{234}$.

El oscurecimiento de la capa de barniz puede indicar la realización de intervenciones de restauración anteriores con uso de cera para reavivar el brillo y saturación; ésta se oxida con el paso del tiempo oscureciendo ${ }^{235}$. Puede relacionarse con:

- impregnación en aceites o aplicación de barnices en antiguas intervenciones que aceleran la oxidación y modifican el aspecto o atraen el polvo.

- Efecto del envejecimiento natural de las resinas (duras y blandas) empleadas en los recubrimientos.

- Posible uso de aceite como vehículo o, posible aplicación del mismo en intervenciones anteriores.

- Posible fijación de suciedad, humo y polvo graso en la superficie, sobre todo si se han empleado ceras y betunes en la composición del barniz o en intervenciones posteriores ${ }^{236}$.

- Posible efecto de la alteración y pudrición de sustancias orgánicas empleadas en intervenciones de restauración y/o mantenimiento de las obras. Esto puede ir acompañado o favorecer el desarrollo de microorganismos. Puede ser indicativo observar su mayor concentración en las áreas correspondientes a los cuarteados, craquelados, fisuras, relieves de la superficie.

- $\quad$ Alteración de materiales de restauración (colas, adhesivos)237.

La existencia de zonas con diferente brillo se debe a la pérdida de elasticidad del barniz. Ésto ocasiona la formación de pequeñas grietas que desvían la refracción de la luz, originando una superficie mate, ausente de claridad ${ }^{238}$. Posible resultado de una variación en el grosor de las capas de protección aplicada junto a una diferente absorción por parte de los pigmentos empleados en las diferentes tonalidades de colores $^{239}$.

\footnotetext{
233 Ibídem.

${ }^{234}$ VIVANCOS RAMÓN, V. (2007), op. cit., pp. 139-140.

${ }^{235}$ VIVANCOS RAMÓN, V. (2007), op. cit., pp. 150-153.

${ }^{236}$ CALVO, A. (2002), op. cit., pp. 154.

${ }^{237}$ Ibídem.

${ }^{238}$ VIVANCOS RAMÓN, V. (2007), op. cit., p. 151.

${ }^{239}$ CALVO, A. (2002), op. cit., pp. 154.
} 
A continuación se exponen las reflexiones derivadas de la elaboración de los datos obtenidos tras el registro y análisis de las fenomenologías de alteración y deterioro presentes.

\section{Interpretación de la información, muestra 9, colección de escultura policromada}

La muestra número 9 (M9) de la colección de escultura policromada resultó ser la más inestable del conjunto.

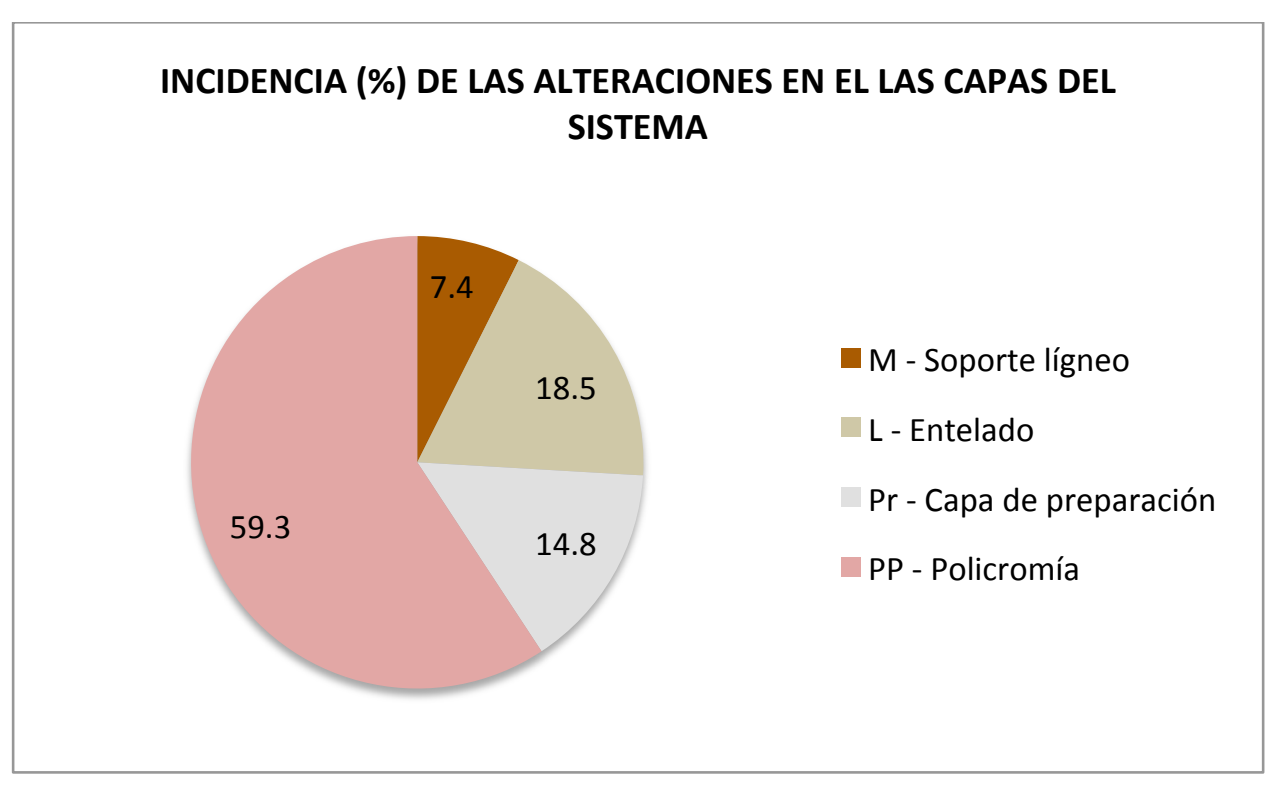

Gráfica 21 - Incidencia (\%) de los fanómenos de alteración y deterioro de acuerdo a las capas que conforman el sistema. Escultura policromada, muestra número 9 (M9).

La incidencia (\%) de los fenómenos de alteración y deterioro observados (gráfica 21) pone de manifiesto que la policromía es la capa mayormente afectada (59.3\%) del sistema, seguida por los elementos en tela (18.5\%), la capa de preparación (14.8\%) y el soporte en madera (7.4\%).

Empezando el análisis de datos del soporte, se registra la presencia de alteraciones estructurales (pérdida y movimiento de nudos). Resultado de unas contracciones del soporte debidos a fluctuaciones termohigrométricas, excesivo calor, puede ser 
acompañado por exudación de resina. Se asocia a deformaciones de la superficie pictórica cuales grietas, desplazamientos y hasta desprendimientos y lagunas ${ }^{240}$.

Los elementos textiles que conforman los entelados de la escultura presentan deformaciones planimétricas puntuales y localizadas, acompañadas por rigidez. Éstos fenómenos se suelen deber a una presión continua y prolongada de un elemento rígido sobre la obra, acompañada por la posible oxidación y endurecimiento de los aglutinantes (óleo o cola animal) empleados en la capa de preparación e imprimación del lienzo. Se registró la existencia de roturas (desfibrados) y desprendimientos. Éstos se pueden relacionar a la degradación fotoquímica del texil por efecto de la luz UV. Este agente puede acarrear una pérdida de elasticidad, aumentando los riesgos en caso de impactos mecánicos. Los ciclos repetidos de variación en los niveles termohigrométricos del ambiente pueden llegar a sobrepasar el límite de fatiga mecánica del material y favorecer su ruptura, asociándose con desprendimiento del material ${ }^{241}$.

Para la capa de preparación ${ }^{242}$ se reporta la existencia de alteraciones cromáticas (manchas), como resultado de la posible exposición a condiciones de humedad favorecedoras para la proliferación de mohos y/o la pudrición de la tela. Se registra una pérdida de adhesión con la película pictórica, resultado de la combinación entre el envejecimiento natural de los materiales (pérdida de elasticidad y podher adhesivo) a causa de las variaciones termohigrométricas del lugar. En particular elevados niveles (\%) de humedad relativa o el contacto con el agua, ocasionan un hinchamiento de la cola animal empleada como adhesivo o aglutinante. También los materiales y técnicas constitutivas, junto a sus características (espesor y medios de aplicación entre otros) confiere características específicas y una mayor afinidad y adherencia con el soporte o con la capa pictórica, favoreciendo el desprendimiento con mayor o menor facilidad de una capa $u$ otra ${ }^{243}$. Las preparaciones oleosas aplicadas en capa gruesa favorecen la separación de la película pictórica. Así como una mala ejecución de las preparaciones como las ejecutadas con la aplicación de capas magras aplicadas sobre grasos. Estas deficiencias técnicas han favorecido la aparición de desprendimientos y lagunas, unos fenómenos que, junto a las demás alteraciones registradas en esta capa, pueden ser indicativos de una posible preparación con harina.

\footnotetext{
${ }^{240}$ VIVANCOS RAMÓN, V. (2007), op. cit., pp. 153.

${ }^{241}$ CALVO, A. (2002), op. cit., pp. 135-140.

242 Para la interpretación de las dinámicas de causa-efecto propias de la capa de preparación presentadas en este párrafo, véase CALVO, A. (2002), op. cit., pp. 140-142.

243 BERGER, G.A., RUSSEL, W.H. (1988). "An evaluation of the preparation of canvas painting using stress measurements" en Studies in Conservation, n³3, IIC London, p. 187-204.
} 
La capa de policromía presenta una acumulación de polvo, signo de la presencia de suciedad y partículas atmosféricas suspendidas en el ambiente, acompañada por falta de mantenimiento y limpiezas periódicas. Paralelamente, se registra la presencia de craquelados y cuarteados en correspondencia con áreas de color y en forma circular. Los craquelados pueden deberse a la edad o a una ejecución técnica deficiente ${ }^{244}$. En el primer caso están relacionados con un estrés generado por la interacción entre técnica pictórica, materiales, soporte, uso y microclima. La presencia de tensiones locales en el soporte se refleja en las capas superpuestas ${ }^{245}$ como resultado de su reacción al entorno conservativo. Con el envejecimiento, las capas pictóricas pierden elasticidad, endureciéndose, mientras el soporte se mueve a través de ciclos de contracción y dilatación bajo los influjos de factores cuáles: humedad, temperatura y solicitaciones mecánicas directas. Los cuarteados en áreas de color específicas son indicativos del uso de una mayor cantidad de aglutinante (colores oscuros), de desperfectos en la realización pictórica. El uso de betunes, el empleo de aceites de adormidera y nuez (más friables), la aplicación de tiempos de secado errónea, la realización de mezclas de colores inestables o incompatibles, el uso de pigmentos de granulometría muy fina, o compuestos por óxidos de hierro son sólo algunos de los aspectos tecnológicos que favorecen la aparición de este tipo de fenómeno ${ }^{246}$. Un impacto puntual sobre la obra, o la existencia de puntos de tensión del soporte (presencia de nudos de la tela) junto a la forma de aplicación de algunas preparaciones favorecen la aparición de los craquelados en forma circular - de telaraña ${ }^{247}$. Los traumatismos derivados de la manipulación de la obra, o de malas acciones de limpieza son el origen de abrasiones y desgastes ${ }^{248}$. La existencia de grietas puntuales e intracapas (íntimamente asociadas con la formación y evolución de los craquelados) indican defectos en la ejecución técnica, envejecimiento del aglutinante, movimientos de nudos por contracciones del soporte debidos a fluctuaciones termohigrométricas ${ }^{249}$. Son alteraciones puntuales que se pueden presentar en zonas de excesiva tensión de la tela o en fondos resbalosos como los constituidos por betunes ${ }^{250}$. Los levantamientos suelen ser consecuencia de una pérdida del poder adhesivo del aglutinante y de la posible presencia de elementos estructurales metálicos que, expuestos a elevados niveles

\footnotetext{
244 VIVANCOS RAMÓN, V. (2007), op.cit., p.123, remite al texto de DÍAZ MARTOS, A. (1975), op.cit., p.109 y MARIJNISSEN, R. (1987), op. cit.

${ }^{245}$ MARIJNISSEN, R. (1987), op. cit., pp. 114-116.

${ }^{246}$ VIVANCOS RAMÓN, V. (2007), op. cit., pp. 121-123.

${ }^{247}$ CALVO, A. (2002), op. cit., pp. 148-149.

${ }^{248}$ CALVO, A. (2002), op. cit., p. 151.

249 VIVANCOS RAMÓN, V. (2007), op. cit., pp. 121.

${ }^{250}$ CALVO, A. (2002), op. cit., pp. 145-147.
} 
de humedad, sufren una variación dimensional y volumétrica por la formación de productos de alteración ${ }^{251}$. Las variaciones en los contenidos de humedad y temperatura son responsables de los movimientos de nudos por contracción del soporte ${ }^{252}$ además de generar cambios y respuestas dimensionales diferentes entre soporte, adhesivos/médiums y preparación. Los levantamientos pueden relacionarse con la pérdida de adhesión hacia las capas inferiores o a la existencia de tensiones superficiales, como las producidas por exceso de cola en la superficie durante algún tratamiento ${ }^{253}$. La presencia de lagunas extendidas por grandes áreas de la obra es signo de acciones de mutilación o de alta degradación que, en ocasiones, afectan a partes fundamentales de la obra y atestiguan situaciones de grave abandono, negligencia o intervenciones invasivas ${ }^{254}$. Los ciclos de variación en los contenidos de humedad del ambiente son responsables de las alteraciones cromáticas presentes en la policromía ${ }^{255}$. El blanqueamiento constituye el resultado óptico de la formación de unas microgrietas en la estructura de la película pictórica a causa de la disociación del aglutinante. Estas fisuras desvían la reflexión de la luz dando lugar al efecto blanquecino. Entre las posibles causas se encuentran elevados niveles de humedad relativa, cambios bruscos de temperatura, limpiezas inadecuadas, por ejemplo por medio del uso de disolventes orgánicos (lixiviación por migración de los plastificantes hacia la superficie a causa de la acción de disolventes con elevado poder de retención) ${ }^{256}$. Esta alteración puede tener origen en la misma técnica pictórica presentándose con mayor frecuencia en áreas compuestas por colores oscuros o en el ultramarino, debido a la mayor necesidad de aglutinante ${ }^{257}$. El efecto de oscurecimiento se suele relacionar con el envejecimiento natural del aglutinante, sobretodo el aceite de linaza ${ }^{258}$. Este aglutinante, bajo la acción combinada de una elevada humedad ambiental y poca luz, oscurece de forma muy acusada ${ }^{259}$. Ésto puede indicar un posible resguardo de la obra en almacenes o entornos con oscuridad absoluta y elevada humedad ambiental ${ }^{260}$. Esta tipología de alteración cromática puede ser consecuencia del uso de ceras y aceites

\footnotetext{
${ }^{251}$ VIVANCOS RAMÓN, V. (2007), op. cit., pp. 124-125.

252 VIVANCOS RAMÓN, V. (2007), op. cit., p. 153.

${ }^{253}$ CALVO, A. (2002), op. cit., p. 145.

${ }^{254}$ CALVO, A. (2002), op. cit., p. 150.

${ }^{255}$ CALVO, A. (2002), op. cit., p. 142.

${ }^{256}$ VIVANCOS RAMÓN, V. (2007), op. cit., pp. 137.

${ }^{257}$ CALVO, A. (2002), op. cit., p. 143.

${ }^{258}$ VIVANCOS RAMÓN, V. (2007), op. cit., p. 130.

${ }^{259}$ DÍAZ MARTOS, A. (1975), op. cit., p. 107.

${ }^{260}$ Ibídem.
} 
en intervenciones antiguas, comunmente empleadas para acciones de consolidación, protección, abrillantado de superficies, o del empleo de cirios devocionales ${ }^{261}$. La impregnación con estas sustancias o la aplicación de barnices en intervenciones anteriores, acelera la oxidación y modifica el aspecto estético atrayendo y reteniendo el polvo y la suciedad ambientales ${ }^{262}$.

Finalmente, la capa de protección no presenta fenómenos de alteración. Este aspecto debe de considerarse en relación a la naturaleza estética de la obra, ya que barniz y policromía están íntimamente relacionadas a nivel tecnológico y visual. Por lo cual puede ser difícil separar las alteraciones en la capa correspondiente a través de una simple inspección visual.

Las causas responsables de los fenómenos registrados corresponden a:

- ciclos de variación termohigrométrica del ambiente;

- condiciones prolongadas de humedad relativa (\%) elevada y temperatura entre $22^{\circ}-24^{\circ} \mathrm{C}$;

- exposición de la obra a la acción de la radiación UV;

- condiciones favorables para el desarrollo de microorganismos (hongos y sucesivamente insectos xilófagos);

- soportes en contacto con el suelo o pared, probablemente encharcado o con elevada presencia de humedad;

- realización de intervenciones de restauración anteriores: intervención del soporte, empapelados defectuosos, uso de calor y presión excesivos, limpiezas incorrectas y aplicación de recubrimientos;

- falta de mantenimiento, abandono de la obra en lugares en contacto con mucha humedad, exposición a eventos traumáticos;

- conservación de la obra en almacenes o lugares con escasa iluminación ${ }^{263}$;

- cambios bruscos de temperatura;

- naturaleza técnica de la obra: capas de preparación muy gruesas aplicadas sobre un textil fino, uso de betunes, uso de tierras verdes o pigmentos oscuros;

- envejecimiento natural de los materiales;

\footnotetext{
${ }^{261}$ VIVANCOS RAMÓN, V. (2007), op. cit., p. 140.

${ }^{262}$ CALVO, A. (2002), op. cit., pp. 154.

${ }^{263}$ En este contexto se indica la escasa iluminación como posible causa del oscurecimiento de los aglutinantes y de la proliferación de posibles agentes de deterioro biológico, de acuerdo a las fuentes bibliográficas citadas para la interpretación de los resultados.
} 
El Museo de Arte Sacro se encuentra en un área lateral del inmueble histórico perteneciente al conjunto religioso de la parroquia de San Pedro. El lugar no cuenta con sistemas de control termohigrométrico, ni con medios de adecuación de dichos factores a la clase de obras en él custodiadas ${ }^{264}$. Las obras analizadas se albergan en contacto con la pared, afectada por importantes problemáticas de humedad; los fenómenos de capilaridad y flitración de agua son los que mayormente proveen el lugar de los contenidos termohigrométricos necesarios para e desarrollo de los fenómenos de alteración y deterioro presentados, favorecidos por eventos de probable contacto entre escurrimientos de agua y obras. Las condiciones estructurales del inmueble, junto a las peculiaridades climáticas de la zona en la que se encuentra el recinto museal, confirman las hipótesis de la probable existencia de ciclos de variación termohigrométrica brindadas por la interpetación de los resultados. La existencia de los efectos de deterioro resultantes de gradientes térmicos se relaciona con las oscilaciones de temperatura propias del área climática de pertenencia ${ }^{265}$. Éstos factores han generado un óptimum en las condiciones favorables al desarrollo de deterioro de tipo biológico. La exposición de la obra a la acción de la radiación UV se debe a la insolación o a fuentes de iluminación incorrectas. De acuerdo con los fenómenos observados, es posible determinar la existencia de intervenciones de restauración y mantenimiento realizadas tras épocas de abandono. En estos períodos, es posible que las obras hayan sido resguardadas en lugares en contacto con mucha humedad, expuestas a eventos traumáticos, o conservadas en lugares con escasa iluminación. La naturaleza técnica de las mismas, junto al envejecimiento natural de los materiales, son elementos comunes a la colección examinada y propician la aparición de los fenómenos analizados.

A la luz de los datos ofrecidos por la primera implementación del sistema, se puede afirmar que la panorámica de causas y efectos expuestos corresponde con las condiciones del entorno conservativo, ofreciendo una hipótesis sobre el historial y características generales de los parámetros de conservación que, en relación a los medios y tiempos invertidos, se revela representativo de las condiciones reales en las que se custodian las obras.

\footnotetext{
264 Para apreciar las condiciones mencionadas, véase la presentación del caso de estudio.

${ }^{265} \mathrm{El}$ estado de San Luis Potosí se caracteriza por experimentar gradientes térmicos diarios que pueden alcanzar diferencias entre $30^{\circ} \mathrm{C}$ (febrero de 2017) y $19^{\circ} \mathrm{C}$ (julio 2017) para la zona de la capital, hasta llegar a variaciones de $33.5^{\circ} \mathrm{C}$ en la zona huasteca. Guadalcázar se encuentra en el área comprendida entre las sierras y se caracteriza por ser un área con clima templado sub-húmedo con lluvias en verano, rodeado por una amplia zona de clima semiseco semicálido. GOBIERNO DEL ESTADO DE SAN LUIS POTOSÍ, INEGI (2017). Anuario estadístico y geográfico de San Luis Potosí 2017. México: INEGI. <https://datatur.sectur.gob.mx/ITxEF_Docs/SLP_ANUARIO_PDF.pdf> [Consulta: 20 de noviembre de 2020].
} 


\subsection{Análisis de ventajas y limitaciones}

Gracias a las primeras experiencias de aplicación del método, ha sido posible reunir reflexiones útiles para su mejora.

En la aplicación de la ficha de registro sobre el conjunto de pinturas murales del siglo XX (diagrama 21) se ha puesto en evidencia la necesidad de estructurar el conjunto de datos en un único nivel de observación: el registro de las fenomenologías de deterioro. En esta primera experiencia de recolección de datos, la tabla diseñada se estructuró en dos secciones, en donde se elencaba la información a recaudarse para las fuentes de deterioro (nivel 1, diagrama 21) y, separadamente, la relacionada con los efectos de alteración y deterioro presentes (nivel 2, diagrama 21).

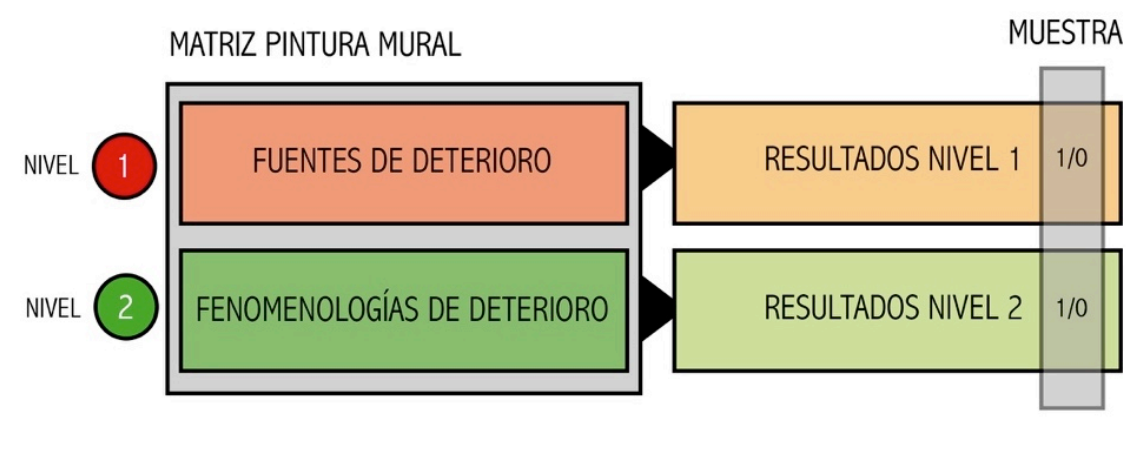

Diagrama 21 - Estructura de la matriz de datos creada para la primera implementación del método sobre pinturas murales.

Tras el análisis de los datos, se produjo una información específica sobre la incidencia de las causas $y$, de forma independiente y paralela, otra para la estimación de sus efectos. Siendo éstos presentados como elementos independientes, se relacionaban con cada muestra de estudio de forma autónoma (diagrama 22), limitando la comprensión de las relaciones de causa-efecto existentes en el sistema y generando una reiteración de conceptos. 
PINTURA MURAL

RECUBRIMIENTOS ARQUITECTÓNICOS

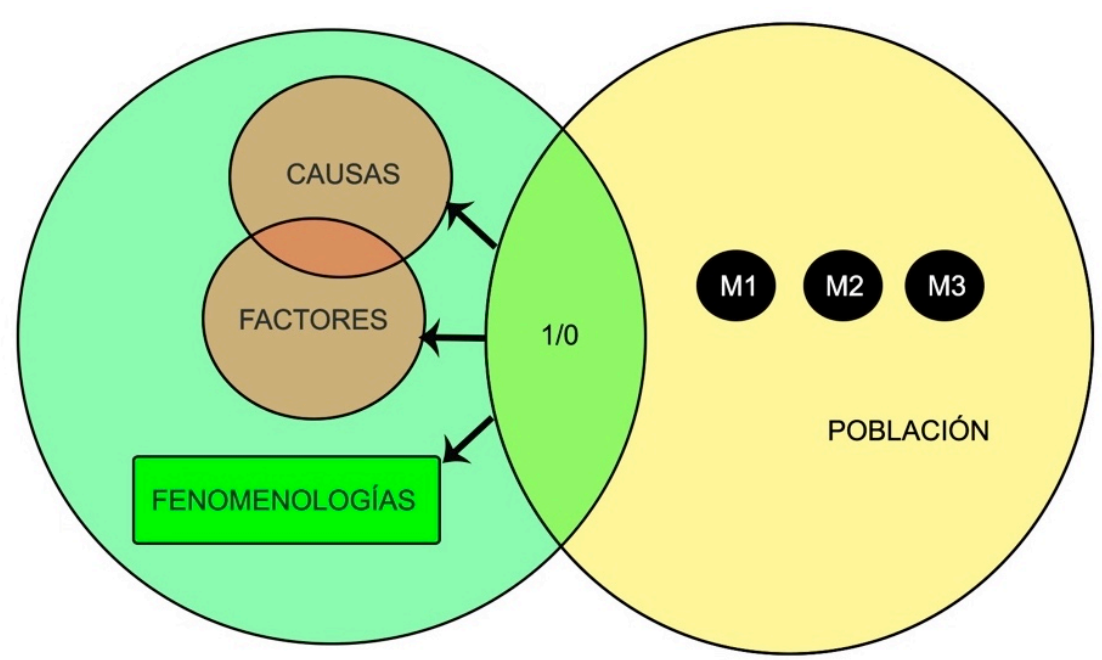

ESQUEMA CONCEPTUAL DE LA PRIMERA MATRIZ DE DATOS - EWAGlos (2016)

Diagrama 22 - Primera estructuración del método. Se aprecia la vinculación aislada entre matriz de datos $(1 / 0)$ y los fenómenos a registrar. Para cada muestra de estudio existe un registro de causas, de factores y efectos de alteración y deterioro.

Esta experiencia fue valiosa para implementar mejoras en el método propuesto, para generar una matriz de datos más efectiva en términos de calidad y posibilidad de análisis de los fenómenos. Esto favoreció la profundización de un método dirigido a ordenar causas-factores-mecanismos-efectos en dónde a partir del registro de los últimos se pudiera arrojar una estimación correlacional de las variables involucradas en el origen y desarrollo de las alteraciones de los materiales.

Como primera medida se decidió eliminar el registro de las fuentes de alteración y deterioro, centrando la recolección de datos únicamente en los fenómenos visibles de alteración y deterioro de los materiales, organizando así la matriz en una única clase de informaciones y dejando la interpretación de las causas para otras fases de estudio.

Estos aspectos han sido implementados en la experiencia de análisis de los monumentos funerarios del Panteón Municipal del Saucito. En esta matriz de datos los conceptos han sido reunidos según los grupos de pertenencia propuestos por el 
glosario ICOMOS-ISCS 266 y ordenados por tamaño decreciente para su mejor identificación (diagrama 23).

MATRIZ MATERIALES PÉTREOS

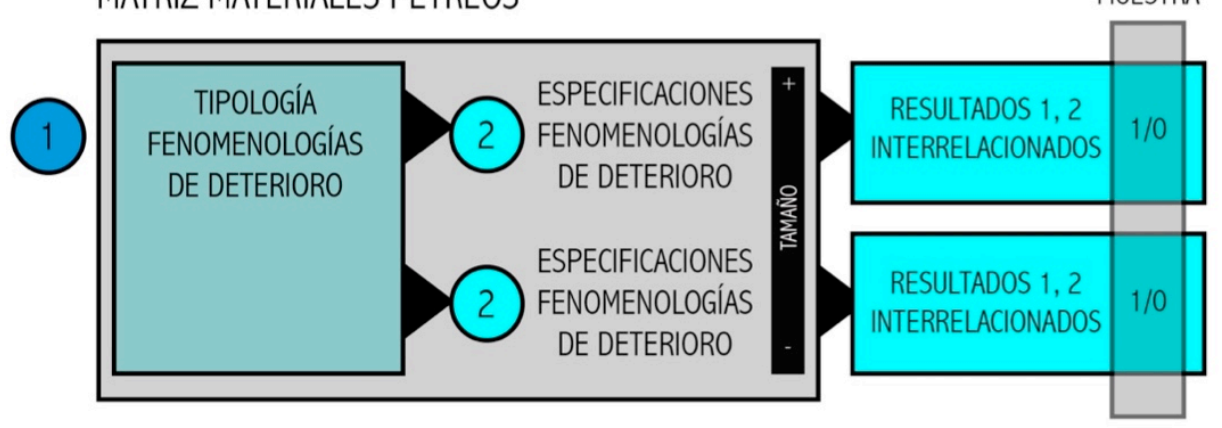

Diagrama 23 - Implementación de las primeras mejoras en las fichas de registro para el estudio del conjunto de materiales pétreos.

Gracias a este modelo de ficha ha sido posible evidenciar la importancia del orden de registro de los fenómenos. Con el objetivo de facilitar su visión y así disminuir la inversión de tiempo necesaria para el cumplimiento de los estudios preliminares, se ha brindando una mejora en el orden de las fenomenologías, ordenándolas de mayor a menor tamaño morfológico.

Tras la aplicación de este modelo se descartaron las reiteraciones de los conceptos (diagrama 24) siendo éstos estructurados en escala jerárquica, empezando por el grupo de pertenencia de las fenomenologías de alteración y deterioro, se desglosaron los conceptos hasta llegar a la tipología y su morfología específica ordenada de forma decreciente (tamaño).

${ }^{266}$ ICOMOS-ISCS (2008), op.cit. 


\section{MATERIALES PÉTREOS}

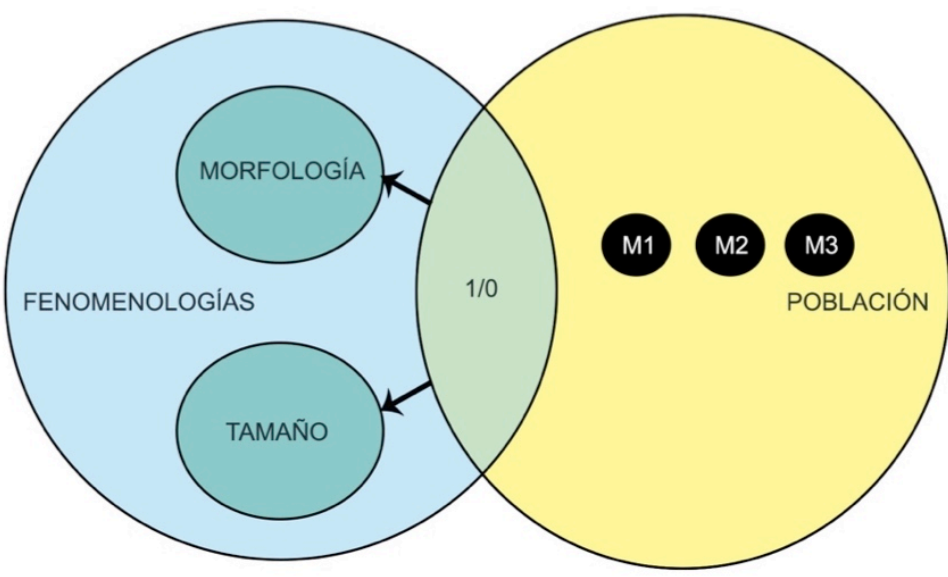

ESQUEMA CONCEPTUAL DE LA PRIMERA MATRIZ DE DATOS - ICOMOS ISCS (2008)

Diagrama 24 - En esta matriz de datos la relación entre los datos a recolectar se ha establecido en escala jerárquica, intentando eliminar las eventuales reiteraciones de conceptos en las sucesivas fase de análisis.

Para el diseño y aplicación del método a colecciones de pintura de caballete o escultura policromada, los casos de estudio del Museo de Arte Sacro han permitido comprender nuevamente el valor del orden de recolección de los datos, y las potencialidades ofrecidas por la fisiología de la visión como elemento para su estructuración. En este caso, la matriz de datos se ha dividido según las capas constitutivas del sistema-tipo de esta clase de obras, permitiendo extraer informaciones globales (colección y obra) y también específicas del estrato de pertenencia (diagrama 25). Tras el estudio de los datos, ha sido posible identificar el posible valor añadido por la estimación de la extensión de los fenómenos en pos de una más precisa evaluación de su gravedad y evaluación en la escala de riesgo. 


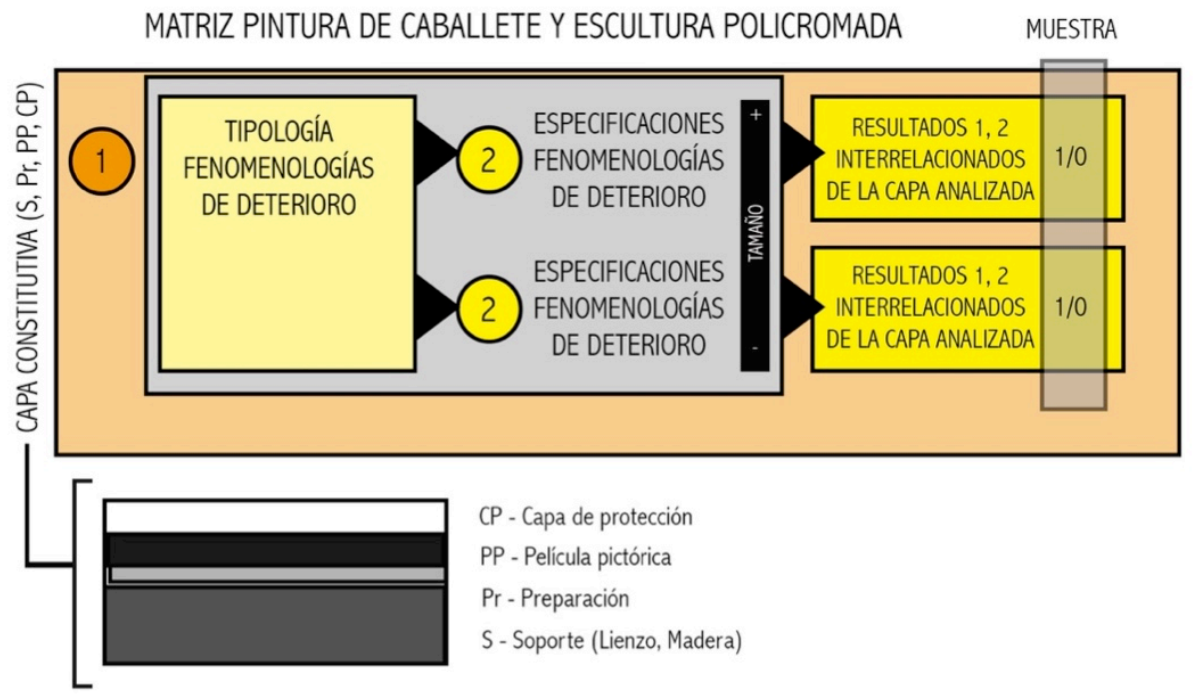

Diagrama 25 - Estructura propuesta para el análisis de conjuntos constituidos por pintura de caballete y escultura policromada de acuerdo al sistema-tipo de esta clase de obras. La observación empieza desde el soporte hasta llegara a las capas superficiales.

En esta experiencia ha sido posible darse cuenta de las complicaciones derivadas de la estructuración de los conceptos en la tabla (diagramas 25 y 26). En esta ocasión la matriz ha sido diseñada para que el registro se llevara a cabo desde el soporte hacia la película de protección. 


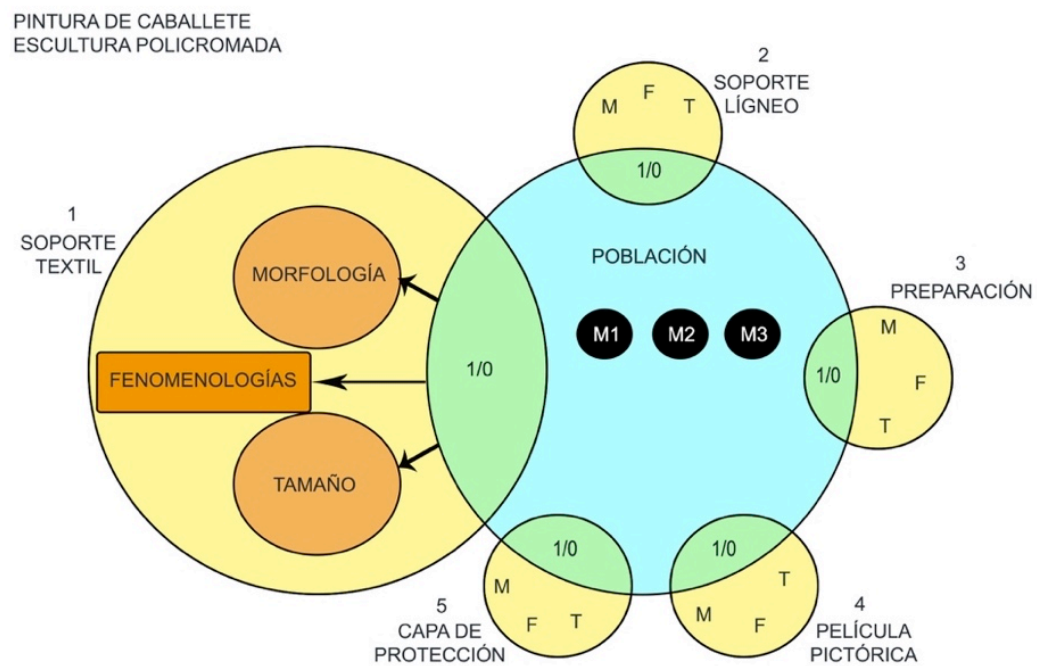

ESQUEMA CONCEPTUAL DE LA PRIMERA MATRIZ DE DATOS - (AAVV)

Esto influyó negativamente en los tiempos necesarios para el registro, debido a la dificultad derivada del tener que estructurar la observación y el registro según prioridades racionales (estructura de la obra) y no fisiológicas de la visión (lo visible en lo inmediato).

Este modelo de matriz, estructurado con un orden jerárquico de grupo de deterioro y subgrupos presentó, en fases de análisis, reiteraciones de conceptos significativas. Dicho aspecto volvió a evidenciar la importancia de la organización de los fenómenos en la tabla, para facilitar la interpretación de los datos tras el estudio de la información.

Los casos de estudio citados han permitido identificar ventajas y aspectos a mejorar en cada uno de los modelos de tablas de contingencia propuesto (tabla 43). 


\begin{tabular}{|c|c|c|}
\hline VENTAJAS & LIMITACIONES & MEJORAS PROPUESTAS \\
\hline $\begin{array}{l}\text { La existencia de glosarios } \\
\text { ilustrados con terminología } \\
\text { unificada ha facilitado la } \\
\text { estructuración de la matriz de } \\
\text { datos así como la interpretación } \\
\text { de resultados. } \\
\text { Los tiempos y recursos necesarios } \\
\text { para el registro se han revelado } \\
\text { idóneos a los parámetros de } \\
\text { efectividad, velocidad y personal } \\
\text { necesario propuestos en los } \\
\text { objetivos del estudio. } \\
\text { Los resultados arrojados se } \\
\text { consideran representativos de las } \\
\text { reales condiciones conservativas } \\
\text { reales a las que se exponen las } \\
\text { obras. }\end{array}$ & $\begin{array}{l}\text { Presencia de fuentes (causas) y } \\
\text { fenomenologías de deterioro } \\
\text { (efectos) en la matriz de datos. } \\
\text { Estructuración de los conceptos } \\
\text { en la matriz de datos poco } \\
\text { funcional para el análisis. } \\
\text { Reiteración de conceptos en los } \\
\text { resultados del análisis de } \\
\text { incidencia de los fenómenos. }\end{array}$ & $\begin{array}{l}\text { Eliminación de las tareas de } \\
\text { registro y observación de las } \\
\text { fuentes de alteración y deterioro. } \\
\text { Eliminación de los grupos y } \\
\text { tipologías de pertenencia de los } \\
\text { fenómenos de alteración y } \\
\text { deterioro de la tabla de } \\
\text { recolección de datos. } \\
\text { Implementación de una ficha de } \\
\text { registro focalizada únicamente en } \\
\text { la morfología específica de } \\
\text { alteración y deterioro. } \\
\text { Evaluación de los criterios previa a } \\
\text { su aplicación a conjuntos de } \\
\text { estudio compuestos por } \\
\text { materiales mixtos (p.e.mosaicos). } \\
\text { Diseño de un método } \\
\text { complementario para la } \\
\text { estimación aproximada de la } \\
\text { extensión superficial de los } \\
\text { fenómenos de alteración y } \\
\text { deterioro presentes. }\end{array}$ \\
\hline \multicolumn{3}{|l|}{ Panteón Municipal del Saucito } \\
\hline VENTAJAS & LIMITACIONES & MEJORAS PROPUESTAS \\
\hline $\begin{array}{l}\text { Existencia de glosarios ilustrados } \\
\text { con terminología unificada ha } \\
\text { facilitado la estructuración de la } \\
\text { matriz de datos así como la } \\
\text { interpretación de resultados. } \\
\text { Los tiempos y recursos necesarios } \\
\text { para el registro se han revelado } \\
\text { idóneos a los parámetros de } \\
\text { efectividad, velocidad y personal } \\
\text { necesario propuestos en los }\end{array}$ & $\begin{array}{l}\text { Estructuración de los conceptos } \\
\text { en la matriz de datos poco } \\
\text { funcional para el análisis. } \\
\text { Reiteración de conceptos en los } \\
\text { resultados del análisis de } \\
\text { incidencia de los fenómenos. }\end{array}$ & $\begin{array}{l}\text { Eliminación de los grupos y } \\
\text { tipologías de pertenencia de los } \\
\text { fenómenos de alteración y } \\
\text { deterioro de la tabla de } \\
\text { recolección de datos. } \\
\text { Implementación de una ficha de } \\
\text { registro focalizada únicamente en } \\
\text { la morfología específica de } \\
\text { alteración y deterioro. }\end{array}$ \\
\hline
\end{tabular}




\begin{tabular}{|c|c|c|}
\hline $\begin{array}{l}\text { objetivos del estudio. } \\
\text { Los resultados arrojados se } \\
\text { consideran representativos de las } \\
\text { reales condiciones conservativas } \\
\text { reales a las que se exponen las } \\
\text { obras. }\end{array}$ & & $\begin{array}{l}\text { Diseño de un método } \\
\text { complementario para la } \\
\text { estimación aproximada de la } \\
\text { extensión superficial de los } \\
\text { fenómenos de alteración y } \\
\text { deterioro presentes. }\end{array}$ \\
\hline \multicolumn{3}{|l|}{ Museo de Arte Sacro de Guadalcázar } \\
\hline VENTAJAS & LIMITACIONES & MEJORAS PROPUESTAS \\
\hline $\begin{array}{l}\text { Los tiempos y recursos necesarios } \\
\text { al registro se han revelado } \\
\text { idóneos a los parámetros de } \\
\text { efectividad, velocidad y personal } \\
\text { necesario propuestos en los } \\
\text { objetivos del estudio. } \\
\text { Los resultados arrojados se } \\
\text { consideran representativos de las } \\
\text { reales condiciones conservativas } \\
\text { reales a las que se exponen las } \\
\text { obras. }\end{array}$ & $\begin{array}{l}\text { La falta de glosarios unificados } \\
\text { con terminologías específicas de } \\
\text { las alteraciones y deterioros para } \\
\text { pintura de caballete y escultura } \\
\text { policromada ha representado un } \\
\text { reto para la selección de términos } \\
\text { y su estructuración en las tablas de } \\
\text { datos. } \\
\text { Estructuración de los conceptos } \\
\text { en la matriz de datos limitativo en } \\
\text { términos de observación y } \\
\text { registro. } \\
\text { Estructuración de los conceptos } \\
\text { en la matriz de datos poco } \\
\text { funcional para el análisis. } \\
\text { Reiteración de conceptos en los } \\
\text { resultados del análisis de } \\
\text { incidencia de los fenómenos. }\end{array}$ & $\begin{array}{l}\text { Estructuración de los conceptos } \\
\text { en la tabla acordes a su } \\
\text { accesibilidad visual: desde las } \\
\text { capas más externas hacia el } \\
\text { soporte. } \\
\text { Eliminación de los grupos y } \\
\text { tipologías de pertenencia de los } \\
\text { fenómenos de alteración y } \\
\text { deterioro de la tabla de } \\
\text { recolección de datos. } \\
\text { Implementación de una ficha de } \\
\text { registro focalizada únicamente en } \\
\text { la morfología específica de } \\
\text { alteración y deterioro. } \\
\text { Diseño de un método } \\
\text { complementario para la } \\
\text { estimación aproximada de la } \\
\text { extensión superficial de los } \\
\text { fenómenos de alteración y } \\
\text { deterioro presentes. }\end{array}$ \\
\hline
\end{tabular}

A continuación se presentan los modelos de fichas diseñados a partir de las reflexiones generadas en las experiencias-piloto y empleadas en los casos de estudio propuestos para la implementación del método (capítulo 3), según la naturaleza técnico-material de las obras objeto de estudio:

- pintura mural y recubrimientos arquitectónicos (tabla 44);

- materiales pétreos (tabla 45); 
- pintura de caballete y escultura policromada (tablas 46, 47, 48, 49, 50);

Tabla 44 - Matriz de datos para pintura mural y recubrimientos arquitectónicos.

\begin{tabular}{|c|c|c|c|c|}
\hline \multicolumn{5}{|c|}{ PINTURA MURAL y RECUBRIMIENTOS ARQUITECTÓNICOS } \\
\hline FENOMENOLOGÍA DE ALTERACIÓN Y DETERIORO & ESPECIFICACIONES & M1 & M2 & M3 \\
\hline \multirow[t]{10}{*}{ MORFOLOGÍAS INDUCIDAS POR PÉRDIDAS } & Laguna & $1 / 0$ & $1 / 0$ & $1 / 0$ \\
\hline & Oquedad & $1 / 0$ & $1 / 0$ & $1 / 0$ \\
\hline & Disgregación & $1 / 0$ & $1 / 0$ & $1 / 0$ \\
\hline & Abrasión & $1 / 0$ & $1 / 0$ & $1 / 0$ \\
\hline & Corrosión & $1 / 0$ & $1 / 0$ & $1 / 0$ \\
\hline & Delaminación & $1 / 0$ & $1 / 0$ & $1 / 0$ \\
\hline & Exfoliación & $1 / 0$ & $1 / 0$ & $1 / 0$ \\
\hline & Descamación & $1 / 0$ & $1 / 0$ & $1 / 0$ \\
\hline & Pulverización & $1 / 0$ & $1 / 0$ & $1 / 0$ \\
\hline & Erosión eólica & $1 / 0$ & $1 / 0$ & $1 / 0$ \\
\hline \multirow[t]{4}{*}{ SEPARACIÓN } & Disgregación & $1 / 0$ & $1 / 0$ & $1 / 0$ \\
\hline & Peeling/Delaminación & $1 / 0$ & $1 / 0$ & $1 / 0$ \\
\hline & Exfoliación & $1 / 0$ & $1 / 0$ & $1 / 0$ \\
\hline & Descamación & $1 / 0$ & $1 / 0$ & $1 / 0$ \\
\hline \multirow[t]{7}{*}{ FISURAS Y DEFORMACIÓN } & Deformación & $1 / 0$ & $1 / 0$ & $1 / 0$ \\
\hline & Craquelado & $1 / 0$ & $1 / 0$ & $1 / 0$ \\
\hline & Microfisura & $1 / 0$ & $1 / 0$ & $1 / 0$ \\
\hline & Grietas & $1 / 0$ & $1 / 0$ & $1 / 0$ \\
\hline & Grietas estructurales & $1 / 0$ & $1 / 0$ & $1 / 0$ \\
\hline & Deformación & $1 / 0$ & $1 / 0$ & $1 / 0$ \\
\hline & Abolsamiento & $1 / 0$ & $1 / 0$ & $1 / 0$ \\
\hline \multirow[t]{4}{*}{ ALTERACIÓN CROMÁTICA Y DEPÓSITOS } & Pátina & $1 / 0$ & $1 / 0$ & $1 / 0$ \\
\hline & Velo blanquecino & $1 / 0$ & $1 / 0$ & $1 / 0$ \\
\hline & Amarilleado & $1 / 0$ & $1 / 0$ & $1 / 0$ \\
\hline & Oscurecimiento & $1 / 0$ & $1 / 0$ & $1 / 0$ \\
\hline
\end{tabular}




\begin{tabular}{|l|l|l|l|l|}
\hline & Saturación de color & $1 / 0$ & $1 / 0$ & $1 / 0$ \\
\cline { 2 - 5 } & Blanqueamiento & $1 / 0$ & $1 / 0$ & $1 / 0$ \\
\cline { 2 - 5 } & Decoloración & $1 / 0$ & $1 / 0$ & $1 / 0$ \\
\cline { 2 - 5 } & Alteración de pigmentos & $1 / 0$ & $1 / 0$ & $1 / 0$ \\
\cline { 2 - 5 } & Eflorescencia salina & $1 / 0$ & $1 / 0$ & $1 / 0$ \\
\cline { 2 - 5 } & Repintes & $1 / 0$ & $1 / 0$ & $1 / 0$ \\
\cline { 2 - 5 } & Depósitos & $1 / 0$ & $1 / 0$ & $1 / 0$ \\
\hline \multirow{2}{*}{ INTERVENCIONES EXTERNAS } & Intervenciones estructurales & $1 / 0$ & $1 / 0$ & $1 / 0$ \\
\cline { 2 - 4 } & Modificaciones & $1 / 0$ & $1 / 0$ & $1 / 0$ \\
\hline
\end{tabular}

Tabla 45 - Matriz de datos para materiales pétreos.

\begin{tabular}{|c|c|c|c|c|c|}
\hline \multicolumn{3}{|l|}{ MATERIALES PÉTREOS } & \multirow[b]{2}{*}{$\begin{array}{l}M \\
1\end{array}$} & \multirow[b]{2}{*}{$\begin{array}{l}M \\
2\end{array}$} & \multirow[b]{2}{*}{$\begin{array}{l}M \\
3\end{array}$} \\
\hline FENOMENOLOGÍAS DE DETERIORO & TIPOLOGÍA & CARACTERÍSTICA & & & \\
\hline \multirow[t]{6}{*}{ FISURAS Y DEFORMACIONES } & \multicolumn{2}{|l|}{ Fisura } & $1 / 0$ & $1 / 0$ & $1 / 0$ \\
\hline & \multirow[t]{2}{*}{ Fractura } & Lineal & $1 / 0$ & $1 / 0$ & $1 / 0$ \\
\hline & & Fractura en estrella & $1 / 0$ & $1 / 0$ & $1 / 0$ \\
\hline & \multicolumn{2}{|l|}{ Deformación } & $1 / 0$ & $1 / 0$ & $1 / 0$ \\
\hline & \multicolumn{2}{|l|}{ Craquelado } & $1 / 0$ & $1 / 0$ & $1 / 0$ \\
\hline & \multicolumn{2}{|c|}{ Disyunción en lajas } & $1 / 0$ & $1 / 0$ & $1 / 0$ \\
\hline \multirow[t]{11}{*}{ SEPARACIÓN } & \multicolumn{2}{|l|}{ Ampollas } & $1 / 0$ & $1 / 0$ & $1 / 0$ \\
\hline & \multicolumn{2}{|l|}{ Estallido } & $1 / 0$ & $1 / 0$ & $1 / 0$ \\
\hline & \multicolumn{2}{|l|}{ Delaminación } & $1 / 0$ & $1 / 0$ & $1 / 0$ \\
\hline & \multicolumn{2}{|l|}{ Exfoliación } & $1 / 0$ & $1 / 0$ & $1 / 0$ \\
\hline & \multirow[t]{5}{*}{ Disgregación } & Desmenuzamiento & $1 / 0$ & $1 / 0$ & $1 / 0$ \\
\hline & & Disgregación granular & $1 / 0$ & $1 / 0$ & $1 / 0$ \\
\hline & & Pulverulencia & $1 / 0$ & $1 / 0$ & $1 / 0$ \\
\hline & & Arenización & $1 / 0$ & $1 / 0$ & $1 / 0$ \\
\hline & & $\begin{array}{l}\text { Disgregación } \\
\text { sacaroidea }\end{array}$ & $1 / 0$ & $1 / 0$ & $1 / 0$ \\
\hline & \multicolumn{2}{|l|}{ Fragmentación } & $1 / 0$ & $1 / 0$ & $1 / 0$ \\
\hline & \multicolumn{2}{|c|}{ Fragmentación en esquirlas } & $1 / 0$ & $1 / 0$ & $1 / 0$ \\
\hline
\end{tabular}




\begin{tabular}{|c|c|c|c|c|c|c|c|}
\hline & & & \multicolumn{2}{|l|}{$\begin{array}{l}\text { Disyunción } \\
\text { películas }\end{array}$} & $1 / 0$ & $1 / 0$ & $1 / 0$ \\
\hline & & & \multicolumn{2}{|l|}{ Descamación } & $1 / 0$ & $1 / 0$ & $1 / 0$ \\
\hline \multirow{16}{*}{\multicolumn{3}{|c|}{$\begin{array}{l}\text { MORFOLOGÍAS } \\
\text { PÉRDIDAS }\end{array}$}} & \multicolumn{2}{|l|}{ Alveolización } & $1 / 0$ & $1 / 0$ & $1 / 0$ \\
\hline & & & \multirow[t]{4}{*}{ Erosión } & Erosión differencial & $1 / 0$ & $1 / 0$ & $1 / 0$ \\
\hline & & & & $\begin{array}{l}\text { Pérdida de } \\
\text { componentes }\end{array}$ & $1 / 0$ & $1 / 0$ & $1 / 0$ \\
\hline & & & & Pérdida de matriz & $1 / 0$ & $1 / 0$ & $1 / 0$ \\
\hline & & & & Redondeamiento & $1 / 0$ & $1 / 0$ & $1 / 0$ \\
\hline & & & \multicolumn{2}{|c|}{$\begin{array}{l}\text { Aumento de la } \\
\text { rugosidad }\end{array}$} & $1 / 0$ & $1 / 0$ & $1 / 0$ \\
\hline & & & \multirow[t]{5}{*}{ Daños mecánicos } & Impacto directo & $1 / 0$ & $1 / 0$ & $1 / 0$ \\
\hline & & & & Incisión & $1 / 0$ & $1 / 0$ & $1 / 0$ \\
\hline & & & & Rayado & $1 / 0$ & $1 / 0$ & $1 / 0$ \\
\hline & & & & Abrasión & $1 / 0$ & $1 / 0$ & $1 / 0$ \\
\hline & & & & Repicado & $1 / 0$ & $1 / 0$ & $1 / 0$ \\
\hline & & & \multicolumn{2}{|l|}{ Microkarst } & $1 / 0$ & $1 / 0$ & $1 / 0$ \\
\hline & & & \multirow[t]{4}{*}{ Faltantes } & Agujero & $1 / 0$ & $1 / 0$ & $1 / 0$ \\
\hline & & & & Perforación & $1 / 0$ & $1 / 0$ & $1 / 0$ \\
\hline & & & & Agujereado & $1 / 0$ & $1 / 0$ & $1 / 0$ \\
\hline & & & & Volumétricos & $1 / 0$ & $1 / 0$ & $1 / 0$ \\
\hline \multirow{14}{*}{\multicolumn{3}{|c|}{$\begin{array}{l}\text { ALTERACIÓN } \\
\text { DEPÓSITOS }\end{array}$}} & \multirow[t]{4}{*}{ Costra } & Costra negra & $1 / 0$ & $1 / 0$ & $1 / 0$ \\
\hline & & & & Costra salina & $1 / 0$ & $1 / 0$ & $1 / 0$ \\
\hline & & & & Concrección & $1 / 0$ & $1 / 0$ & $1 / 0$ \\
\hline & & & & Encrustación & $1 / 0$ & $1 / 0$ & $1 / 0$ \\
\hline & & & \multicolumn{2}{|l|}{ Depósito } & $1 / 0$ & $1 / 0$ & $1 / 0$ \\
\hline & & & \multirow[t]{5}{*}{ Alteración cromática } & Coloración & $1 / 0$ & $1 / 0$ & $1 / 0$ \\
\hline & & & & Decoloración & $1 / 0$ & $1 / 0$ & $1 / 0$ \\
\hline & & & & Manchas de humedad & $1 / 0$ & $1 / 0$ & $1 / 0$ \\
\hline & & & & Tinción & $1 / 0$ & $1 / 0$ & $1 / 0$ \\
\hline & & & & Aumento del brillo & $1 / 0$ & $1 / 0$ & $1 / 0$ \\
\hline & & & \multicolumn{2}{|l|}{ Graffiti } & $1 / 0$ & $1 / 0$ & $1 / 0$ \\
\hline & & & \multicolumn{2}{|l|}{ Eflorescencias } & $1 / 0$ & $1 / 0$ & $1 / 0$ \\
\hline & & & \multicolumn{2}{|l|}{ Subflorescencias } & $1 / 0$ & $1 / 0$ & $1 / 0$ \\
\hline & & & Patina & Pátina ferruginosa & $1 / 0$ & $1 / 0$ & $1 / 0$ \\
\hline
\end{tabular}




\begin{tabular}{|c|c|c|c|c|c|}
\hline & & Pátina de oxalato & $1 / 0$ & $1 / 0$ & $1 / 0$ \\
\hline & \multicolumn{2}{|l|}{ Suciedad } & $1 / 0$ & $1 / 0$ & $1 / 0$ \\
\hline \multirow[t]{5}{*}{ COLONIZACIÓN BIOLÓGICA } & \multicolumn{2}{|l|}{ Algas } & $1 / 0$ & $1 / 0$ & $1 / 0$ \\
\hline & \multicolumn{2}{|l|}{ Líquenes } & $1 / 0$ & $1 / 0$ & $1 / 0$ \\
\hline & \multicolumn{2}{|l|}{ Musgo } & $1 / 0$ & $1 / 0$ & $1 / 0$ \\
\hline & \multicolumn{2}{|l|}{ Moho, hongos } & $1 / 0$ & $1 / 0$ & $1 / 0$ \\
\hline & \multicolumn{2}{|l|}{ Plantas } & $1 / 0$ & $1 / 0$ & $1 / 0$ \\
\hline
\end{tabular}

Tabla 46 - Matriz de datos para pintura de caballete y escultura policromada (estrato: barniz).

\begin{tabular}{|ll|l|l|l|l|}
\hline CAPA DE PROTECCIÓN & PINTURAS DE CABALLETE/ESCULTURA POLICROMADA & $\mathrm{M}$ & $\mathrm{M}$ & $\mathrm{M}$ \\
\hline ESTRATO & ESPECIES DE DETERIORO & Oscurecimiento & 1 & 2 & 3 \\
\hline Barniz & CUARTEADO & Amarilleamiento & $1 / 0$ & $1 / 0$ & $1 / 0$ \\
\hline Barniz & ALTERACIÓN CROMÁTICA & $1 / 0$ & $1 / 0$ & $1 / 0$ \\
\cline { 3 - 5 } & & Pérdida de trasparencia & $1 / 0$ & $1 / 0$ & $1 / 0$ \\
\cline { 3 - 5 } & & Blanqueamiento & $1 / 0$ & $1 / 0$ & $1 / 0$ \\
\cline { 2 - 5 } & & Zonas a diferente brillo & $1 / 0$ & $1 / 0$ & $1 / 0$ \\
\cline { 2 - 5 } & & Manchas & $1 / 0$ & $1 / 0$ & $1 / 0$ \\
\hline Barniz & & & $1 / 0$ & $1 / 0$ & $1 / 0$ \\
\hline Barniz & DAÑOS MECÁNICOS & & $1 / 0$ & $1 / 0$ & $1 / 0$ \\
\hline
\end{tabular}

Tabla 47 - Matriz de datos para pintura de caballete y escultura policromada (estrato: película pictórica/policromía).

\begin{tabular}{|c|c|c|c|c|c|}
\hline PELÍCULA PICTÓRICA & \multicolumn{2}{|c|}{ PINTURAS DE CABALLETE/ESCULTURA POLICROMADA } & M & M & M \\
\hline ESTRATO & \multicolumn{2}{|l|}{ ESPECIES DE DETERIORO } & 1 & 2 & 3 \\
\hline \multirow{3}{*}{$\begin{array}{l}\text { Película } \\
\text { Pictórica }\end{array}$} & \multirow[t]{3}{*}{ ACUMULACIÓN DE POLVO } & Fino & $1 / 0$ & $1 / 0$ & $1 / 0$ \\
\hline & & & & & \\
\hline & & Grasoso/adherido & $1 / 0$ & $1 / 0$ & $1 / 0$ \\
\hline \multirow{4}{*}{$\begin{array}{l}\text { Película } \\
\text { Pictórica }\end{array}$} & \multirow[t]{4}{*}{ DEFORMACIONES DE LA SUPERFICIE } & Descamación & $1 / 0$ & $1 / 0$ & $1 / 0$ \\
\hline & & & & & \\
\hline & & Levantamientos & $1 / 0$ & $1 / 0$ & $1 / 0$ \\
\hline & & Cordilleras & $1 / 0$ & $1 / 0$ & $1 / 0$ \\
\hline
\end{tabular}




\begin{tabular}{|c|c|c|c|c|c|}
\hline & & Ampollas & $1 / 0$ & $1 / 0$ & $1 / 0$ \\
\hline & & Cazoletas & $1 / 0$ & $1 / 0$ & $1 / 0$ \\
\hline & & Abolsamientos & $1 / 0$ & $1 / 0$ & $1 / 0$ \\
\hline & & $\begin{array}{l}\text { Impresión de la trama del } \\
\text { lienzo en la superficie }\end{array}$ & $1 / 0$ & $1 / 0$ & $1 / 0$ \\
\hline & & Hundimientos & $1 / 0$ & $1 / 0$ & $1 / 0$ \\
\hline & & Desprendimientos & $1 / 0$ & $1 / 0$ & $1 / 0$ \\
\hline & & Solapamientos & $1 / 0$ & $1 / 0$ & $1 / 0$ \\
\hline $\begin{array}{l}\text { Película } \\
\text { Pictórica }\end{array}$ & GRIETAS (puntuales/intracapas) & & $1 / 0$ & $1 / 0$ & $1 / 0$ \\
\hline $\begin{array}{l}\text { Película } \\
\text { Pictórica }\end{array}$ & LAGUNAS & $\begin{array}{l}\text { Numerosas pequeñas en } \\
\text { esquinas cuarteados }\end{array}$ & $1 / 0$ & $1 / 0$ & $1 / 0$ \\
\hline & & Grandes áreas & $1 / 0$ & $1 / 0$ & $1 / 0$ \\
\hline & & Área inferior & $1 / 0$ & $1 / 0$ & $1 / 0$ \\
\hline Película & ALTERACIÓN CROMÁTICA & Blanqueamiento & $1 / 0$ & $1 / 0$ & $1 / 0$ \\
\hline & & Azulado & $1 / 0$ & $1 / 0$ & $1 / 0$ \\
\hline & & Tono café-marrón & $1 / 0$ & $1 / 0$ & $1 / 0$ \\
\hline & & Oscurecimiento & $1 / 0$ & $1 / 0$ & $1 / 0$ \\
\hline & & Amarilleamiento & $1 / 0$ & $1 / 0$ & $1 / 0$ \\
\hline & & Opacidad & $1 / 0$ & $1 / 0$ & $1 / 0$ \\
\hline & & Repintes & $1 / 0$ & $1 / 0$ & $1 / 0$ \\
\hline & & $\begin{array}{l}\text { Trasparentado de áreas de } \\
\text { color }\end{array}$ & $1 / 0$ & $1 / 0$ & $1 / 0$ \\
\hline & & Piel de naranja & $1 / 0$ & $1 / 0$ & $1 / 0$ \\
\hline Película & CUARTEADOS & En los ángulos & $1 / 0$ & $1 / 0$ & $1 / 0$ \\
\hline & & Perimetrales & $1 / 0$ & $1 / 0$ & $1 / 0$ \\
\hline & & $\begin{array}{l}\text { A contacto con los elementos } \\
\text { estructurales y/o el bastidor }\end{array}$ & $1 / 0$ & $1 / 0$ & $1 / 0$ \\
\hline & & En áreas de color específicas & $1 / 0$ & $1 / 0$ & $1 / 0$ \\
\hline & & Forma circular o telaraña & $1 / 0$ & $1 / 0$ & $1 / 0$ \\
\hline & & Forma de espina de pez & $1 / 0$ & $1 / 0$ & $1 / 0$ \\
\hline & & $\begin{array}{l}\text { En correspondencia con la } \\
\text { deformación de planimétrica } \\
\text { del soporte }\end{array}$ & $1 / 0$ & $1 / 0$ & $1 / 0$ \\
\hline & & Generalizados & $1 / 0$ & $1 / 0$ & $1 / 0$ \\
\hline
\end{tabular}




\begin{tabular}{|c|c|c|c|c|c|}
\hline $\begin{array}{l}\text { Película } \\
\text { Pictórica }\end{array}$ & \multicolumn{2}{|l|}{ CRAQUELADO } & $1 / 0$ & $1 / 0$ & $1 / 0$ \\
\hline $\begin{array}{l}\text { Película } \\
\text { Pictórica }\end{array}$ & \multicolumn{2}{|l|}{ PULVERULENCIA } & $1 / 0$ & $1 / 0$ & $1 / 0$ \\
\hline $\begin{array}{l}\text { Película } \\
\text { Pictórica }\end{array}$ & \multicolumn{2}{|l|}{ QUEMADURAS } & $1 / 0$ & $1 / 0$ & $1 / 0$ \\
\hline \multirow{4}{*}{$\begin{array}{l}\text { Película } \\
\text { Pictórica }\end{array}$} & \multirow[t]{4}{*}{ TRAUMATISMOS } & Rayados & $1 / 0$ & $1 / 0$ & $1 / 0$ \\
\hline & & Abrasión & $1 / 0$ & $1 / 0$ & $1 / 0$ \\
\hline & & Desgaste & $1 / 0$ & $1 / 0$ & $1 / 0$ \\
\hline & & Arañazos & $1 / 0$ & $1 / 0$ & $1 / 0$ \\
\hline $\begin{array}{l}\text { Película } \\
\text { Pictórica }\end{array}$ & \multicolumn{2}{|c|}{ MATERIALES AJENOS } & $1 / 0$ & $1 / 0$ & $1 / 0$ \\
\hline
\end{tabular}

Tabla 48 - Matriz de datos para pintura de caballete y escultura policromada (estrato: preparación/imprimación).

\begin{tabular}{|c|c|c|c|c|c|}
\hline PREPARACIÓN & \multicolumn{2}{|c|}{ PINTURAS DE CABALLETE/ESCULTURA POLICROMADA } & M & M & M \\
\hline ESTRATO & \multicolumn{2}{|l|}{ ESPECIES DE DETERIORO } & 1 & 2 & 3 \\
\hline \multirow[t]{3}{*}{ Preparación } & \multirow[t]{3}{*}{ DEFORMACIONES DE LA SUPERFICIE } & Ampollas & $1 / 0$ & $1 / 0$ & $1 / 0$ \\
\hline & & Abolsamientos & $1 / 0$ & $1 / 0$ & $1 / 0$ \\
\hline & & Levantamientos & $1 / 0$ & $1 / 0$ & $1 / 0$ \\
\hline Preparación & \multicolumn{2}{|l|}{ DESPRENDIMIENTOS } & $1 / 0$ & $1 / 0$ & $1 / 0$ \\
\hline Preparación & \multicolumn{2}{|l|}{ LAGUNAS } & $1 / 0$ & $1 / 0$ & $1 / 0$ \\
\hline Preparación & \multicolumn{2}{|l|}{ MANCHAS } & $1 / 0$ & $1 / 0$ & $1 / 0$ \\
\hline Preparación & \multicolumn{2}{|l|}{ CUARTEADO } & $1 / 0$ & $1 / 0$ & $1 / 0$ \\
\hline Preparación & \multicolumn{2}{|c|}{ PÉRDIDA DE ADHESIÓN CON LA PELÍCULA PICTÓRICA } & $1 / 0$ & $1 / 0$ & $1 / 0$ \\
\hline Preparación & \multicolumn{2}{|l|}{ PULVERULENCIA } & $1 / 0$ & $1 / 0$ & $1 / 0$ \\
\hline
\end{tabular}

Tabla 49 - Matriz de datos para pintura de caballete y escultura policromada (estrato: soporte textil/entelado).

\begin{tabular}{|l|l|l|l|l|}
\hline $\begin{array}{l}\text { SOPORTE } \\
\text { LIENZO }\end{array}$ & PINTURAS DE CABALLETE/ESCULTURA POLICROMADA & $M$ & $M$ & $M$ \\
\hline ESTRATO & ESPECIES DE DETERIORO & 1 & 2 & 3 \\
\hline
\end{tabular}




\begin{tabular}{|c|c|c|c|c|c|}
\hline \multirow[t]{4}{*}{ Lienzo } & \multirow[t]{4}{*}{ ACUMULACIÓN POLVO } & Fino & $1 / 0$ & $1 / 0$ & $1 / 0$ \\
\hline & & Graso/adherido & $1 / 0$ & $1 / 0$ & $1 / 0$ \\
\hline & & Zona inferior & $1 / 0$ & $1 / 0$ & $1 / 0$ \\
\hline & & Generalizado & $1 / 0$ & $1 / 0$ & $1 / 0$ \\
\hline \multirow[t]{8}{*}{ Lienzo } & \multirow[t]{8}{*}{ DEFORMACIÓN PLANIMÉTRICA } & Arrugas en las esquinas & $1 / 0$ & $1 / 0$ & $1 / 0$ \\
\hline & & Marcas elem estructurales & $1 / 0$ & $1 / 0$ & $1 / 0$ \\
\hline & & Perímetro & $1 / 0$ & $1 / 0$ & $1 / 0$ \\
\hline & & $\begin{array}{l}\text { Entre clavos o tachuelas } \\
\text { borde }\end{array}$ & $1 / 0$ & $1 / 0$ & $1 / 0$ \\
\hline & & $\begin{array}{l}\text { Deformación del área } \\
\text { inferior }\end{array}$ & $1 / 0$ & $1 / 0$ & $1 / 0$ \\
\hline & & $\begin{array}{l}\text { Deformación puntual o } \\
\text { localizada }\end{array}$ & $1 / 0$ & $1 / 0$ & $1 / 0$ \\
\hline & & Deformación y rigidez & $1 / 0$ & $1 / 0$ & $1 / 0$ \\
\hline & & $\begin{array}{l}\text { Hundimiento y cuarteado de } \\
\text { la película pictórica }\end{array}$ & $1 / 0$ & $1 / 0$ & $1 / 0$ \\
\hline \multirow[t]{11}{*}{ Lienzo } & ROTURAS & Cortes & $1 / 0$ & $1 / 0$ & $1 / 0$ \\
\hline & & Desgarros & $1 / 0$ & $1 / 0$ & $1 / 0$ \\
\hline & & Unidireccional & $1 / 0$ & $1 / 0$ & $1 / 0$ \\
\hline & & En forma de 7 & $1 / 0$ & $1 / 0$ & $1 / 0$ \\
\hline & & Multidireccional & $1 / 0$ & $1 / 0$ & $1 / 0$ \\
\hline & & Limpios & $1 / 0$ & $1 / 0$ & $1 / 0$ \\
\hline & & Desfibrados & $1 / 0$ & $1 / 0$ & $1 / 0$ \\
\hline & & Naturales & $1 / 0$ & $1 / 0$ & $1 / 0$ \\
\hline & & Artificiales & $1 / 0$ & $1 / 0$ & $1 / 0$ \\
\hline & & Abertura de costuras & $1 / 0$ & $1 / 0$ & $1 / 0$ \\
\hline & & $\begin{array}{l}\text { Abertura de costuras en } \\
\text { correspondencia } \\
\text { tachuelas y/o elementos } \\
\text { metálicos }\end{array}$ & $1 / 0$ & $1 / 0$ & $1 / 0$ \\
\hline Lienzo & \multicolumn{2}{|l|}{ DESPRENDIMIENTO } & $1 / 0$ & $1 / 0$ & $1 / 0$ \\
\hline Lienzo & \multicolumn{2}{|l|}{ LAGUNA } & $1 / 0$ & $1 / 0$ & $1 / 0$ \\
\hline \multirow[t]{3}{*}{ Lienzo } & \multirow[t]{3}{*}{ MANCHAS } & Blancas & $1 / 0$ & $1 / 0$ & $1 / 0$ \\
\hline & & Colores & $1 / 0$ & $1 / 0$ & $1 / 0$ \\
\hline & & Filamentos & $1 / 0$ & $1 / 0$ & $1 / 0$ \\
\hline \multirow[t]{2}{*}{ Lienzo } & \multirow[t]{2}{*}{ ALTERACIÓN CROMÁTICA } & Oscurecimiento & $1 / 0$ & $1 / 0$ & $1 / 0$ \\
\hline & & Decoloración & $1 / 0$ & $1 / 0$ & $1 / 0$ \\
\hline
\end{tabular}




\begin{tabular}{|l|l|l|c|c|c|}
\hline Lienzo & \multicolumn{2}{|l|}{ RIGIDEZ } & $1 / 0$ & $1 / 0$ & $1 / 0$ \\
\hline Lienzo & MODIFICACIONES ESTRUCTURALES/AÑADIDOS & Cambio de formato & $1 / 0$ & $1 / 0$ & $1 / 0$ \\
\cline { 3 - 6 } & & Mutilación & $1 / 0$ & $1 / 0$ & $1 / 0$ \\
\hline Lienzo & INTERVENCIONES ANTERIORES & Puntuales & $1 / 0$ & $1 / 0$ & $1 / 0$ \\
\cline { 3 - 6 } & & Generalizado & $1 / 0$ & $1 / 0$ & $1 / 0$ \\
\hline
\end{tabular}

Tabla 50 - Matriz de datos para pintura de caballete y escultura policromada (estrato: bastidor/soporte lígneo).

\begin{tabular}{|c|c|c|c|c|c|}
\hline $\begin{array}{l}\text { SOPORTE } \\
\text { ESTRUCTURA }\end{array}$ & \multicolumn{2}{|c|}{ PINTURA DE CABALLETE/ESCULTURA POLICROMADA } & M & M & M \\
\hline \multirow{2}{*}{ ESTRATO } & \multicolumn{2}{|l|}{ ESPECIES DE DETERIORO } & 1 & 2 & 3 \\
\hline & TIPOLOGÍA & MORFOLOGÍA ESPECÍFICA & & & \\
\hline \multirow[t]{4}{*}{ Madera } & \multirow[t]{4}{*}{ ACUMULACIÓN POLVO } & Fino & $1 / 0$ & $1 / 0$ & $1 / 0$ \\
\hline & & Grasoso/adherido & $1 / 0$ & $1 / 0$ & $1 / 0$ \\
\hline & & Zona inferior & $1 / 0$ & $1 / 0$ & $1 / 0$ \\
\hline & & Generalizado & $1 / 0$ & $1 / 0$ & $1 / 0$ \\
\hline \multirow[t]{2}{*}{ Madera } & \multirow[t]{2}{*}{ DEFORMACIONES } & Ampollas & $1 / 0$ & $1 / 0$ & $1 / 0$ \\
\hline & & Alabeo/combamiento & $1 / 0$ & $1 / 0$ & $1 / 0$ \\
\hline \multirow[t]{2}{*}{ Madera } & \multirow[t]{2}{*}{ GRIETAS } & Fracturas & $1 / 0$ & $1 / 0$ & $1 / 0$ \\
\hline & & Fendas & $1 / 0$ & $1 / 0$ & $1 / 0$ \\
\hline Madera & \multicolumn{2}{|l|}{ DESPRENDIMIENTO } & $1 / 0$ & $1 / 0$ & $1 / 0$ \\
\hline Madera & \multicolumn{2}{|l|}{ GALERÍA XILÓFAGOS } & $1 / 0$ & $1 / 0$ & $1 / 0$ \\
\hline \multirow[t]{9}{*}{ Madera } & \multirow[t]{9}{*}{ MANCHAS } & Blancas & $1 / 0$ & $1 / 0$ & $1 / 0$ \\
\hline & & Colores & $1 / 0$ & $1 / 0$ & $1 / 0$ \\
\hline & & Amarillentas & $1 / 0$ & $1 / 0$ & $1 / 0$ \\
\hline & & Negras & $1 / 0$ & $1 / 0$ & $1 / 0$ \\
\hline & & Verdes & $1 / 0$ & $1 / 0$ & $1 / 0$ \\
\hline & & Agrisamiento & $1 / 0$ & $1 / 0$ & $1 / 0$ \\
\hline & & Decoloración & $1 / 0$ & $1 / 0$ & $1 / 0$ \\
\hline & & Filamentos & $1 / 0$ & $1 / 0$ & $1 / 0$ \\
\hline & & Pulverulencia & $1 / 0$ & $1 / 0$ & $1 / 0$ \\
\hline Madera & ALTERACIÓN ESTRUCTURAL & Exhudación de resina & $1 / 0$ & $1 / 0$ & $1 / 0$ \\
\hline
\end{tabular}




\begin{tabular}{|l|l|l|l|l|l|}
\cline { 3 - 5 } & & $\begin{array}{l}\text { Pérdida y/o movimiento de } \\
\text { nudos, lagunas del soporte }\end{array}$ & $1 / 0$ & $1 / 0$ & $1 / 0$ \\
\hline Madera & MODIFICACIONES ESTRUCTURALES & División de soportes bifaces & $1 / 0$ & $1 / 0$ & $1 / 0$ \\
\cline { 3 - 5 } & & $\begin{array}{l}\text { Eliminación de elementos } \\
\text { estructurales y/o de partes de la } \\
\text { mazonería }\end{array}$ & $1 / 0$ & $1 / 0$ & $1 / 0$ \\
\cline { 3 - 6 } & & Aligeramiento del soporte & $1 / 0$ & $1 / 0$ & $1 / 0$ \\
\cline { 3 - 6 } & & Engatillado/embarrotado & $1 / 0$ & $1 / 0$ & $1 / 0$ \\
\cline { 3 - 5 } & & Trasposición a otro soporte & $1 / 0$ & $1 / 0$ & $1 / 0$ \\
\hline Madera & INTERVENCIONES ANTERIORES & & $1 / 0$ & $1 / 0$ & $1 / 0$ \\
\hline
\end{tabular}

\subsection{Implementación de las mejoras operativas}

En conformidad con las observaciones recaudadas tras las experiencias piloto y las mejoras sugeridas a raíz de éstas, el método de registro se ha estructurado de acuerdo a las fases e indicaciones generales expuestas a continuación:

1. Cada muestra y su referencia alfanumérica se aclarará en la tabla correspondiente "TABLA DE OPERACIONES PRELIMINARES - M/Título de la obra ${ }^{267}$ identificación" (ejemplo en la tabla 51) para poder identificar en cualquier momento el objeto de estudio y su relación con los demás elementos de la colección.

Tabla 51 - Operación preliminar - Llenado de la tabla de referencias.

\begin{tabular}{|l|l|}
\hline \multicolumn{2}{|c|}{ TABLA DE OPERACIONES PRELIMINARES } \\
\hline$M$ & Título de la obra/identificación \\
\hline 1 & $\begin{array}{l}\text { Ejemplo de cumplimentación de la ficha: } \\
\text { A. (pintura de caballete) "Crucifixión, óleo sobre lienzo (120x20cm), siglo XVIII"; } \\
\text { B. (escultura policromada) "Cristo penitente, talla en madera policromada y dorada, 200x40x70cm, } \\
\text { siglo XIX"; } \\
\text { C. (recubrimientos arquitectónicos, estucos, argamasa, pinturas murales) "Área norte-decoración } \\
\text { floreal, } 5 \mathrm{mx} 10 \mathrm{~m} \text { siglo XVII; }\end{array}$ \\
\hline 2 & \\
\hline 3 & \\
\hline 4 & \\
\hline 5 & \\
\hline
\end{tabular}

267 En el caso de pinturas murales o recubrimientos arquitectónicos con una superficie muy extensa, dicha muestra puede relacionarse con un área del mismo; por ejemplo, se podría relacionar M1 con el mural ubicado en el lado norte, M2 con el mural ubicado en el lado sur, etc. 


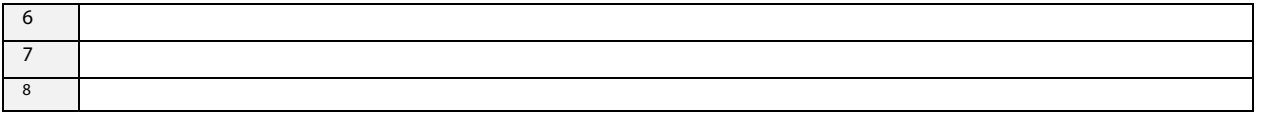

2. En la matriz para la recolección de datos, cada columna corresponde a una obramuestra (M), nombrada $M 1, M 2, M 3$, etc.

3. La ficha propuesta permite el registro indicativo de 10 obras-muestras. Si se poseen más obras es suficiente con seguir nombrando las muestras con los números crecientes sucesivos (M11, M12, M13, etc. hasta agotar los casos de estudio).

4. A cada muestra corresponde una toma fotográfica o video de la obra o área objeto de estudio.

5. Como modalidad de cumplimentación de las tablas se contempla una evaluación cuantitativa de la gravedad de las alteraciones observada. Ésta se considera en términos de extensión superficial de las alteraciones. Los indicadores numéricos propuestos contemplan el uso de una escala numérica de referencia de 1 a 4 (tabla 52).

Tabla 52 - Ejemplo de las estimaciones visuales de un deterioro propuestas por el método.

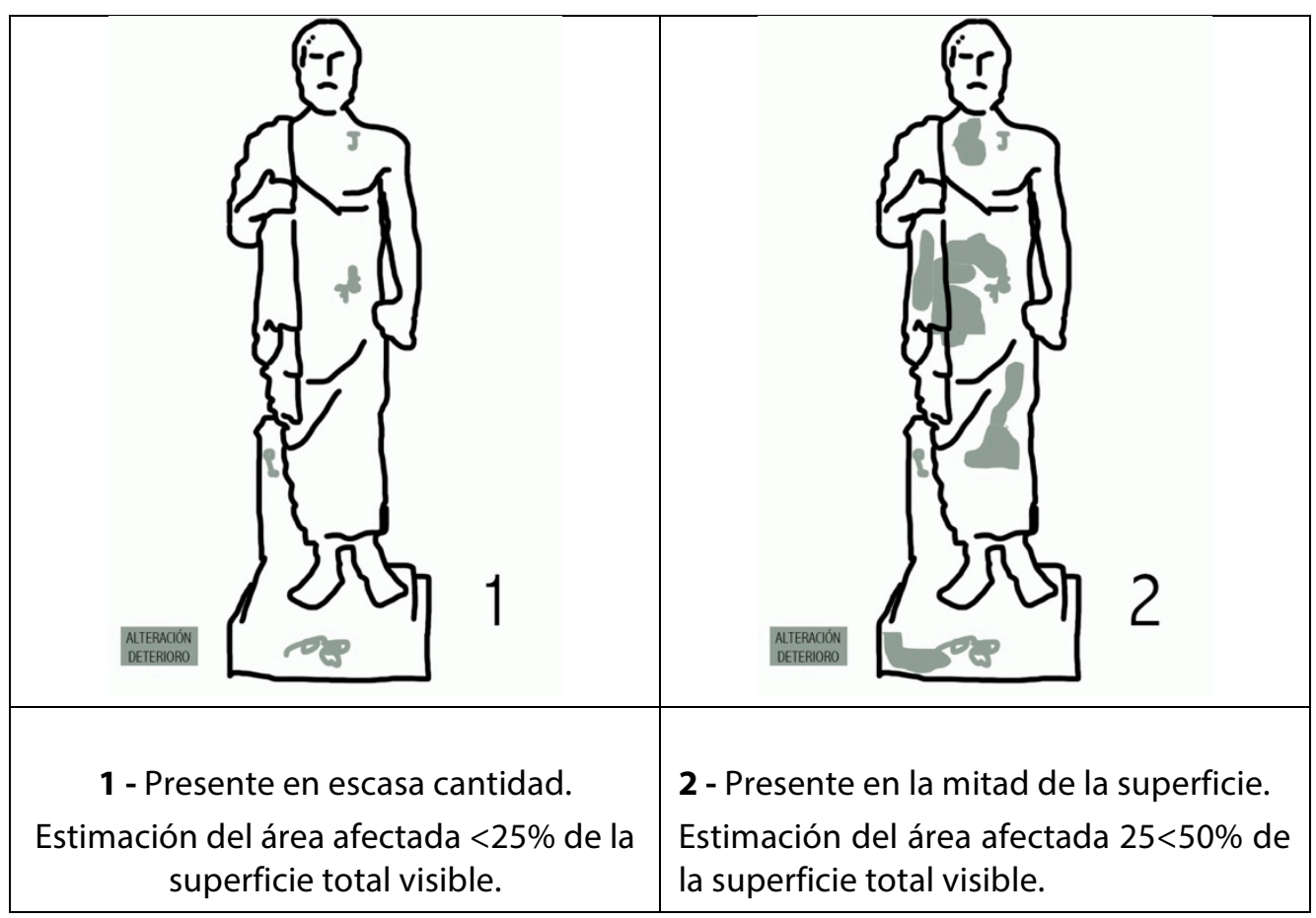




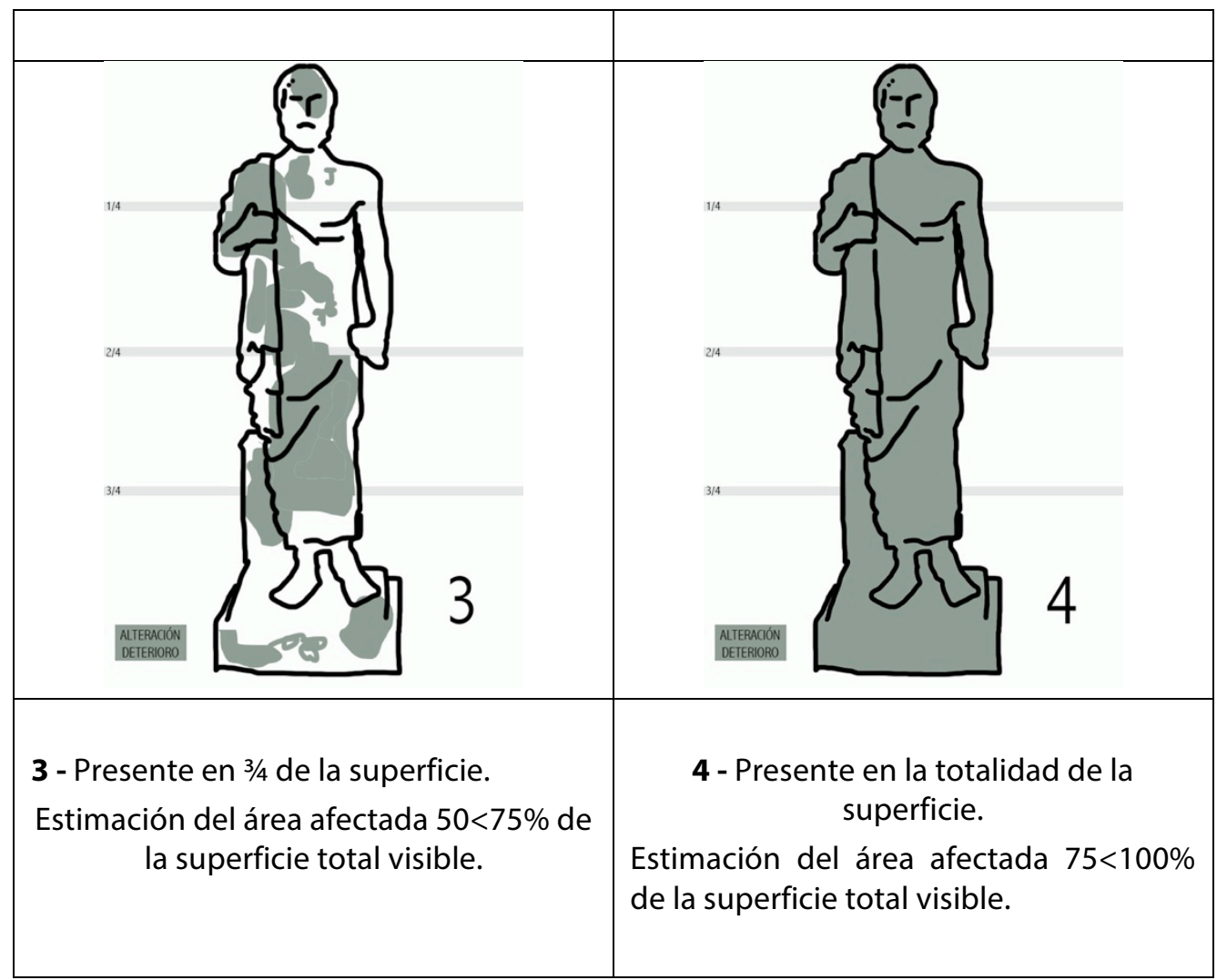

6. Cuando un deterioro no está presente, o la capa no sea accesible visualmente, se dejará la celda vacía (0), de acuerdo al ejemplo propuesto (tabla 53).

Tabla 53 - Ejemplo de llenado de las tablas por medio de una evaluación cuantitativa de la extensión de los deterioros (1-4).

\begin{tabular}{|l|l|l|l|l|l|}
\hline \multirow{2}{*}{ ESTRATO } & $\begin{array}{l}\text { IIPOLOGÍA } \\
\text { ESPCIE DE DETERIORO }\end{array}$ & MORFOLOGÍA ESPECÍFICA & M1 & M2 & M3 \\
\hline $\begin{array}{l}\text { Película } \\
\text { Pictórica }\end{array}$ & \multirow{2}{*}{ ACUMULACIÓN DE POLVO } & Fino & $\mathbf{1 - 4}$ & $\mathbf{1 - 4}$ & $\mathbf{1 - 4}$ \\
\cline { 3 - 7 } & Grasoso/Adherido & $\mathbf{1 - 4}$ & $\mathbf{1 - 4}$ & $\mathbf{1 - 4}$ \\
\hline
\end{tabular}


Para los casos de estudio compuestos por pinturas de caballete y esculturas lígneas policromadas, la observación y registro se llevarán a cabo a partir del estrato más externo (capa de protección) hasta llegar al soporte, según el orden propuesto en las fichas y elaborado de acuerdo al sistema-tipo de esta tipología de obras y su accesibilidad visual:
1. B-Barniz
2. PP-Película Pictórica
3. Pr-Preparación
4. L-Lienzo
5. M-Madera.

Una vez recaudada la información, ésta se vacía en unas hojas de cálculo (tabla XX) previamente diseñadas para la elaboración de los parámetros necesarios para el estudio:

- Incidencia cuantitativa y porcentual de las fenomenologías de deterioro en la colección.

- Incidencia cuantitativa de las fenomenologías de deterioro para cada muestra de estudio.

A través de estas informaciones, será posible obtener datos sobre:

- Fenomenologías de alteración y deterioro activas.

- Índice de riesgo de la colección según la incidencia de los fenómenos.

- Panorámica específica de las alteraciones y deterioros presentes en cada obra/área.

- Estimación de la superficie afectada por cada fenómeno.

Por medio de la información citada será posible identificar las problemáticas conservativas que inciden en el estado de la colección, complementándolas una representación de los datos a través de:

- tablas

- gráficos

- mapas de riesgo. 


\section{Referencias bibliográficas}

ACROYD, P., YOUNG, CH. (1999). "The preparation of artists' canvases: factors that affect adhesión between ground and canvas" en 12th Triennal Meeting, ICOM-CC, Lyon, p. 265-270.

ARNHEIM, R. (2006). Arte y percepción visual. Madrid: Alianza Formas.

BASELGA, A. y GÓMEZ RODRÍGUEZ, C. (2019). “Diversidad alfa, beta y gamma: ¿cómo medimos diferencias entre comunidades biológicas?" en Nova Acta Científica Compostelana (Bioloxía), 26, p. 39-45.

[http://webspersoais.usc.es/export9/sites/persoais/persoais/carola.gomez/pdfs/B aselga_y_Gomez-Rodriguez2019.pdf] <Fecha de consulta: 19 de julio de 2020>

BERGER, G.A., RUSSEL, W.H. (1988). "An evaluation of the preparation of canvas painting using stress measurements" en Studies in Conservation, n³3, IIC London, p. 187-204.

CALVO, A. (2002). Conservación y restauración de pintura sobre lienzo. Barcelona: El Serbal.

CALVO, A., GARCÍA FERNÁNDEZ-VILLA, S., BAILÃO, A. (2018). Terminología básica de conservación y restauración del patrimonio cultural. Madrid: Universidad Complutense de Madrid. <https://www.researchgate.net/publication/323613615_Terminologia_basica_d e_conservacion_y_restauracion_del_Patrimonio_Cultural> [Consulta: 12 marzo de 2019].

CLAUDIA E. MORENO, (2001). Métodos para medir la biodiversidad. M\&T-Manuales y Tesis SEA, vol. 1. Zaragoza: CYTED, ORCYT/UNESCO \& SEA.

DÍAZ MARTOS, A. (1975). Restauración y conservación del arte pictórico. Madrid: Arte restauro.

DONDIS, D.A., (2008). La sintaxis de la imagen, Introducción al alfabeto visual. Barcelona: Gustavo Gili.

FERNÁNDEZ MARTíNEZ, V.M. (2015). Arqueo estadística, métodos cuantitativos en arqueología. Madrid: Alianza.

GOBIERNO DEL ESTADO DE SAN LUIS POTOSÍ, INEGI (2017). Anuario estadístico y geográfico de San Luis Potosí 2017. México: INEGI.

<https://datatur.sectur.gob.mx/ITxEF_Docs/SLP_ANUARIO_PDF.pdf>

[Consultado el: 20 de noviembre de 2020]. 
HORNEMANN INSTITUT (2015). European Illustrated Glossary for Conservation Terms of Wall Painting and Architectonic Surfaces. <https://www.hornemanninstitut.de/doi/2016ewa2.pdf> [Consulta: 19 de mayo 2017].

ICOMOS-ISCS (2008). Illustrated Glossary on Stone Deterioration Patterns. $<$ https://www.icomos.org/publications/monuments_and_sites/15/pdf/Monume nts_and_Sites_15_ISCS_Glossary_Stone.pdf> [Consulta: 3 de marzo de 2016].

INSTITUTO DE INVESTIGACIÓN DE RECURSOS BIOLÓGICOS ALEXANDER VON HUMBOLDT (2014). Métodos para el análisis de datos: una aplicación para resultados provenientes de caracterizaciones de biodiversidad. [http://www.bionica.info/biblioteca/HumboldtAnalisisDatos.pdf] <Consulta: 20 de marzo de 2019>.

KECK, S. (1969). "Mechanical alteration of he Paint Film", en Studies en Conservation, 14, IIC, London, p. 9.

MARIJNISSEN, R. (1985). Tableaux. Authentiques. Maquillés. Faux. L'expertise des tableaux et les methodes de laboratoire. Bruxelles: Elsevier.

MASTROIACOVO, T., SORIANO SANCHO, M.P., REGIDOR ROS, J.L. (2017). "Índice de riesgo relacionado con factores de alteración y deterioro en las pinturas murales del siglo XX de San Luis Potosí (S.L.P., México)" en Archè, Instituto Universitario de Restauración del Patrimonio de la UPV - № 11 y 12, pp.157-162.

PÉREZ GALINDO, R. (2013). Estadística aplicada: para ciencias económicas, administrativas y sociales. México : Trillas.

UNESCO (2007). Campus Central de la Ciudad Universitaria de la Universidad Nacional Autónoma de México. <https://whc.unesco.org/es/list/1250> [Fecha de consulta: 21 de febrero de 2021].

VARGAS SABADÍAS, A. (1995). Estadística descriptiva e inferencial. Cuenca: Universidad de Castilla-La Mancha.

VIVANCOS RAMÓN, V. (2007). La conservación y restauración de la pintura de caballete. Pintura sobre tabla. Madrid: Tecnos.

VIVANCOS RAMÓN, V. y CASTELL AGUSTÍ, M. (2010). Problemas y tratamientos del soporte de pintura de caballete. Valencia: Universidad Politécnica de Valencia.

WHITTAKER, R.H. (1960). "Vegetation of the Siskiyou Mountains, Oregon and California" en Ecological Monographs, Vol. 30-3, p. 279-338.

Word reference <https://www.wordreference.com/definition/karst> [Consulta: 10 de febrero de 2021]. 


\section{Capítulo 3 Implementación del método}

En este apartado se exponen las experiencias llevadas a cabo tras el diseño final del método, con el objetivo de generar indicadores de riesgo para colecciones y conjuntos de obras de arte de variada tipología. Esta fase, definida como implementación del método, ha sido realizada sobre otras realidades artísticoconservativas escogiendo entre un abanico de experiencias derivadas de la actividad formativa y docente desarrollada en la Universidad Autónoma de San Luis Potosí (2014-2018), a lo largo de la cual ha sido posible acercarse a la investigación de conjuntos históricos y artísticos de gran valor cultural. Éstos, muy representativos de lo que hoy conforma parte del legado patrimonial de México, se han tomado como ejemplos concretos de aplicación del método y evualuación de los resultados de él arrojados.

\subsection{Ex hacienda de Peotillos}

La hacienda de Peotillos se ubica a unos sesenta kilómetros al norte de la capital del estado de San Luis Potosí, en el municipio de Villa de Hidalgo (imagen 55 y 56). Colinda con el camino que comunicaba el pueblo minero de Guadalcázar ${ }^{268}$ con la ciudad. Su existencia se registra a partir de la segunda mitad del siglo XVII, mientras la realización de las decoraciones murales es fechada a comienzo del siglo XIX. Las pinturas objeto de este estudio se ubican en el patio central porticado de la casa de

${ }^{268}$ Sobre Guadalcázar, véase el apartado "Experiencias piloto" y el acercamiento al caso de estudio propuestos en este escrito. 
los hacendados, compuesto por un espacio abierto frontal a modo de atrio ${ }^{269}$ (imágenes 57-62). A partir del año 2016 se llevaron a cabo estudios dirigidos a investigar el estado de las pinturas decorativas ${ }^{270}$. El recinto no cuenta actualmente con medidas de monitoreo de las condiciones de las pinturas. Para la implementación del método se han analizado, sobre documentación fotográfica, un total de catorce áreas organizadas en cuatro muros (imagen 63, tabla 55).

Tabla 54 - Datos de las modalidades de registro y análisis.

\section{PINTURAS MURALES DECORATIVAS - EX HACIENDA DE PEOTILLOS}

\begin{tabular}{|l|l|}
\hline Registro realizado en: & Marzo 2017 \\
\hline Objeto de estudio: & Pintura mural al fresco y mezzo fresco \\
\hline Tiempo de registro de datos: & 2 horas, sobre documentación fotográfica \\
\hline Total de superficies analizadas: & 4 áreas de $40 \mathrm{~m} \times 5 \mathrm{~m}$ (vanos incluidos) \\
\hline Profesionales empleados: & 1 \\
\hline Tiempo para el análisis de datos & 1 hora \\
\hline
\end{tabular}

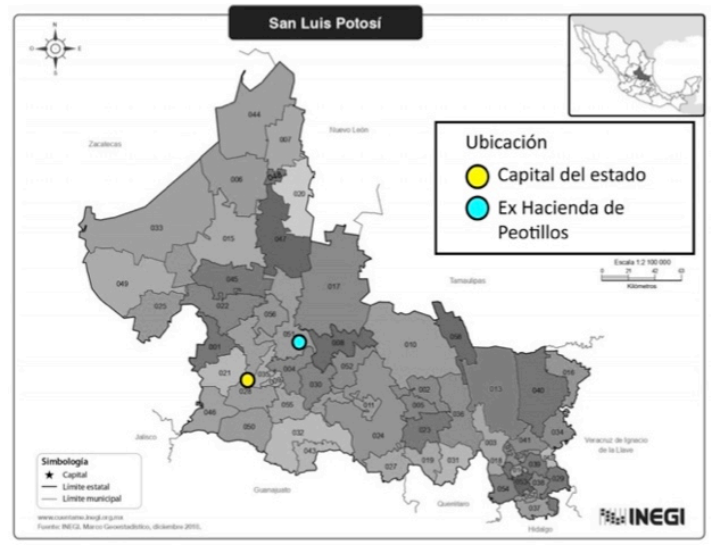

Imagen 55 - Ubicación del caso de estudio 271

269 INAH-CONACULTA (2010). Haciendas del Altiplano Potosino. México: EME ediciones, p. 209.

270 Las actividades se desarrollaron en el marco de la asignatura de Conservación y Restauración de Pintura Mural de la Licenciatura en Conservación y Restauración de Bienes Culturales Muebles de la UASLP gracias al interés del propietario Don Ignacio Muriel García. Resultados de los estudios preliminares se encuentran en MASTROIACOVO, T., et al. (2016-2017). “Estudio termográfico y diagnóstico de las pinturas decorativas del patio interior de la hacienda de Peotillos (Villa Hidalgo, San Luis Potosí, México)" en Archè, Revista del Instituto de Restauración del Patrimonio, núm. 11 y 12, 2016-2017, pp. 163-168.

271 Imagen modificada de: INEGI, Marco Geoestadístico, diciembre 2018. <www.cuentame.inegi.org.mx> [Consulta 15 de noviembre de 2020]. 


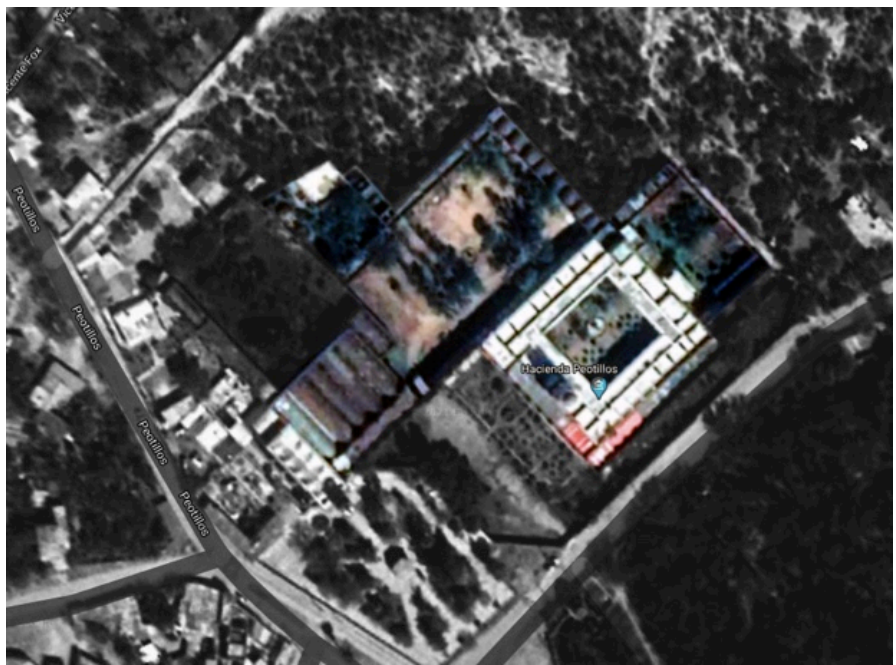

Imagen 56 - Visión aérea de la hacienda ${ }^{272}$ de Peotillos (Villa Hidalgo, San Luis Potosí).

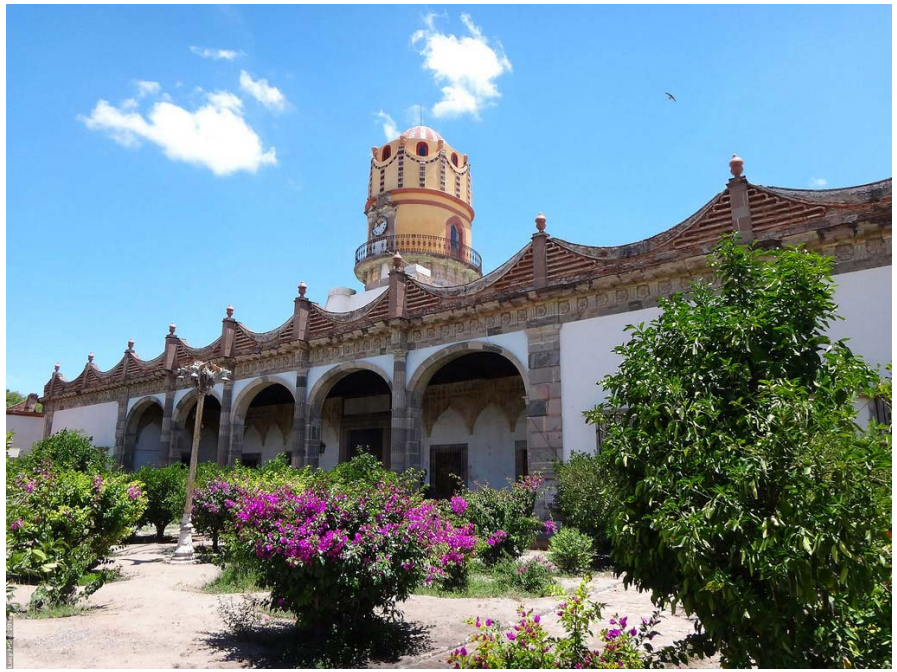

Imagen 57 - Acceso principal al edificio, ex hacienda de Peotillos ${ }^{273}$ (Villa de Hidalgo, S.L.P.).

272 Imagen satelital. <https://www.google.com/maps/place/Peotillos,+S.L.P./@22.4970736,-

$100.6105749,211 \mathrm{~m} /$ data $=! 3 \mathrm{~m} 1$ !1 e3!4m5!3m4!1 s0x867fe2a762131af1:0x4c0c9235dfbab464!8m2!3d22.49555 59!4d-100.610556> [Consulta: 08 de mayo de 2017].

${ }^{273}$ Haciendas de México: ex hacienda de Peotillos. <https://www.haciendasmexico.mx/ex-hacienda-depeotillos/> [Consulta: 20 de noviembre de 2020]. 


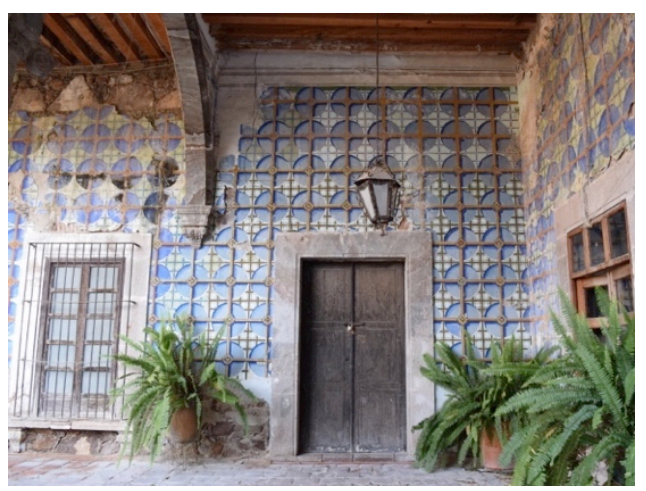

Imagen 58 - Visión de la esquina sur del patio.

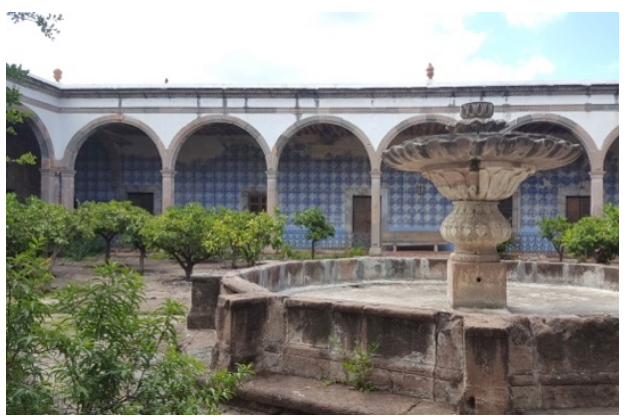

Imagen 60 - Panorámica del lado sureste de las decoraciones.

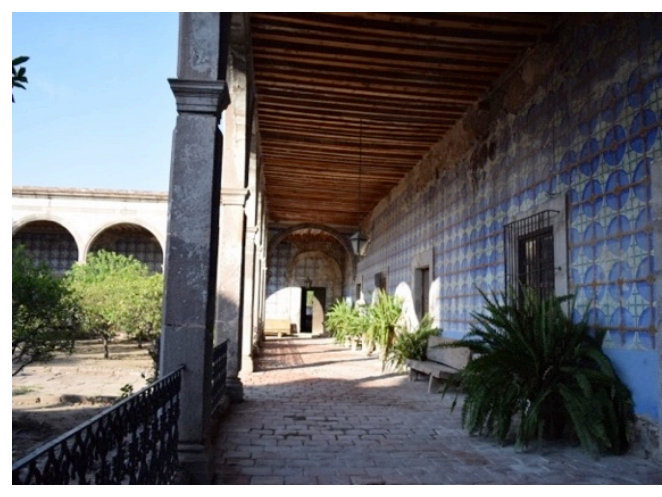

Imagen 59 - Visual del lado sureste de las pinturas decorativas

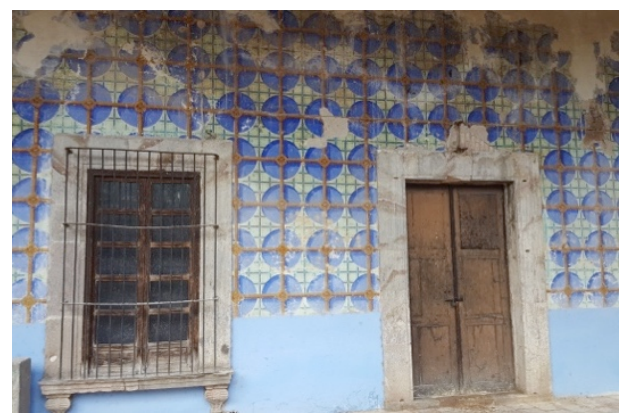

Imagen 61 -Detalle de las decoraciones. 


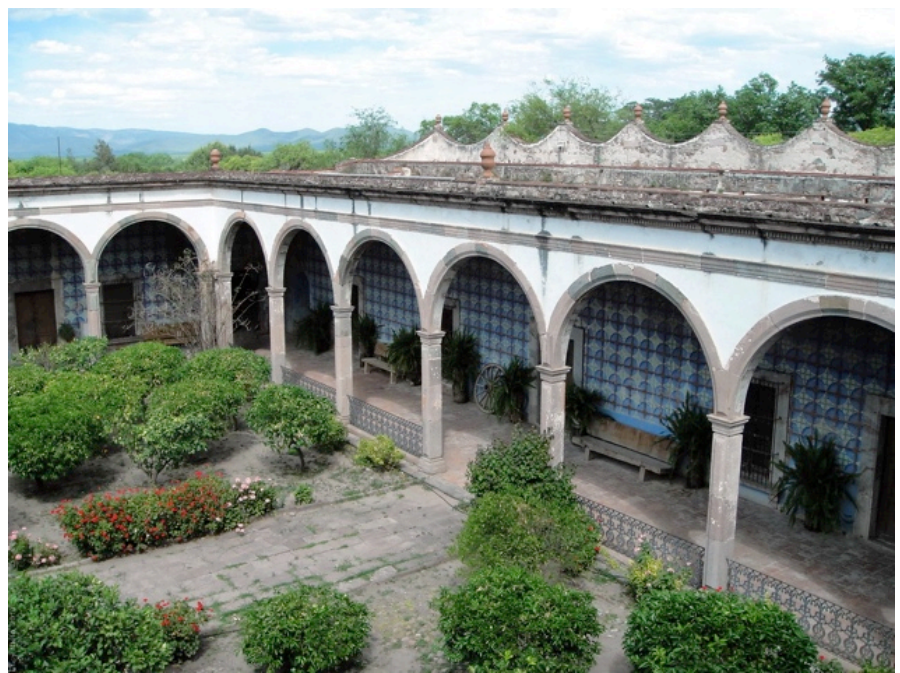

Imagen 62 - Panorámica del patio interior, ex hacienda de Peotillos ${ }^{274}$ (Villa de Hidalgo, S.L.P.).

Para agilizar las tareas de estudio e implementación del método, el área correspondiente a las pinturas murales decorativas ha sido fragmentada en porciones:

- 4 áreas generales correspndientes a los muros perimetrales del patio que alberga los murales; éstas se han definido muros $(M)$ y han sido clasificados de forma creciente en M1 (muro sureste), M2 (muro suroeste), M3 (muro noroeste), M4 (muro noreste).

- Cada muro ha sido repartido en diferentes zonas, denominadas áreas; éstas han sido enumeradas de 1 a 14 de acuerdo a la imagen 65 y cuya referencia se explica en la tabla 55.

${ }^{274}$ Ibídem. 


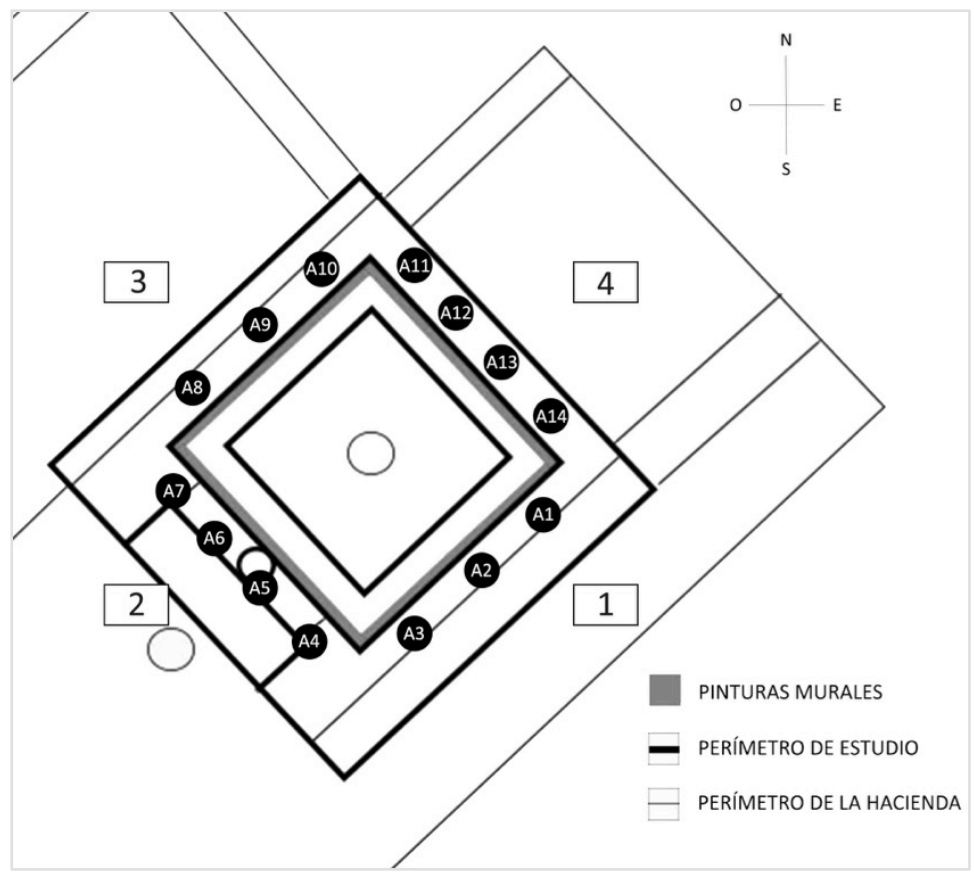

Imagen 63 - Identificación de las áreas de estudio presentadas en la tabla 1.

Tabla 55 - Referencia de muestras y áreas de estudio.

\begin{tabular}{|c|c|}
\hline \multicolumn{2}{|c|}{ EX HACIENDA DE PEOTILLOS } \\
\hline M & DESCOMPOSICIÓN DE LAS ÁREAS PARA FINES DE ESTUDIO ${ }^{275}$ \\
\hline 1 & Pintura mural: área 1 (A1), muro 1 (M1), $5 \mathrm{~m} \times 12.5 \mathrm{~m}$, siglo XIX. \\
\hline 2 & Pintura mural: área 2 (A2), muro 1 (M1), 5 m x 12.5 m, siglo XIX. \\
\hline 3 & Pintura mural: área 3 (A3), muro 1 (M1), $5 \mathrm{~m} \times 12.5$ m, siglo XIX. \\
\hline 4 & Pintura mural: área 4 (A4), muro 2 (M2), $5 \mathrm{~m} \times 10 \mathrm{~m}$, siglo XIX. \\
\hline 5 & Pintura mural: área 5 (A5), muro 2 (M2), $5 \mathrm{~m} \times 10 \mathrm{~m}$, siglo XIX. \\
\hline 6 & Pintura mural: área 6 (A6), muro 2 (M2), $5 \mathrm{~m} \times 10 \mathrm{~m}$, siglo XIX. \\
\hline 7 & Pintura mural: área 7 (A7), muro 2 (M2), $5 \mathrm{~m}$ x 10 m, siglo XIX. \\
\hline 8 & Pintura mural: área 8 (A8), muro 3 (M3), $5 \mathrm{~m} \times 12.5$ m, siglo XIX. \\
\hline 9 & Pintura mural: área 9 (A9), muro 3 (M3), $5 \mathrm{~m} \times 12.5$ m, siglo XIX. \\
\hline 10 & Pintura mural: área 10 (A10), muro 3 (M3), $5 \mathrm{~m} \times 12.5$ m, siglo XIX. \\
\hline 11 & Pintura mural: área 11 (A11), muro 4 (M4), $5 \mathrm{~m} \times 10 \mathrm{~m}$, siglo XIX. \\
\hline 12 & Pintura mural: área 12 (A12), muro 4 (M4), $5 \mathrm{~m}$ x 10 m, siglo XIX. \\
\hline
\end{tabular}

${ }^{275}$ Las mediciones de superficie se consideran incluyendo los vanos. 


\begin{tabular}{|l|l|}
\hline 13 & Pintura mural: área 13 (A13), muro 4 (M4), $5 \mathrm{~m} \times 10 \mathrm{~m}$, siglo XIX. \\
\hline 14 & Pintura mural: área 14 (A14), muro 4 (M4), $5 \mathrm{~m} \times 10 \mathrm{~m}$, siglo XIX. \\
\hline
\end{tabular}

Tras el análisis de datos, ha sido posible generar información sobre:

- fenomenologías de alteración y deterioro activas (tabla 56) junto a su estimación cuantitativa y porcentual (gráfica 22);

- indicador de riesgo (tabla 57);

- alteraciones y deterioros presentes en cada obra/área complementada por una estimación de la superficie afectada por cada fenómeno (tablas 58-71);

- croquis representativo de las áreas con mayor indicador de riesgo y prioridad (imagen 64).

- identificación de las áreas con mayor problemática conservativa (imágenes 65-68);

Esta información ha sido finalmente complementada por una propuesta de interpretación de los datos arrojados pr el método.

Tabla 56 - Panorámica de las dinámicas de alteración que están afectando la decoración mural.

\begin{tabular}{|c|c|}
\hline FENOMENOLOGÍA DE ALTERACIÓN Y DETERIORO & $\begin{array}{l}\text { TOTAL } \\
\text { INCIDENCIA DE DETERIORO }\end{array}$ \\
\hline Morfologías inducidas por pérdidas - Laguna & 14 \\
\hline Morfologías inducidas por pérdidas - Disgregación & 14 \\
\hline Morfologías inducidas por pérdidas - Abrasión & 14 \\
\hline Fisuras y deformación - Deformación & 14 \\
\hline Fisuras y deformación - Abolsamiento & 14 \\
\hline Alteración cromática y depositos - Decoloración & 14 \\
\hline Intervenciones externas - Intervenciones estructurales & 9 \\
\hline Alteración cromática y depositos - Amarilleamiento & 6 \\
\hline Fisuras y deformación - Grietas & 5 \\
\hline Alteración cromática y depositos - Oscurecimiento & 4 \\
\hline Alteración cromática y depositos - Repintes & 3 \\
\hline Intervenciones externas - Modificaciones & 3 \\
\hline Morfologías inducidas por pérdidas - Oquedad & 2 \\
\hline Fisuras y deformación - Grietas estructurales & 2 \\
\hline Alteración cromática y depositos - Velo blanquecino & 2 \\
\hline Alteración cromática y depositos - Eflorescencia salina & 2 \\
\hline Alteración cromática y depositos - Depósitos & 2 \\
\hline Alteración cromática y depositos - Blanqueamiento & 1 \\
\hline
\end{tabular}




\section{INCIDENCIA DE LAS FENOMENOLOGÍAS DE ALTERACIÓN Y DETERIORO}

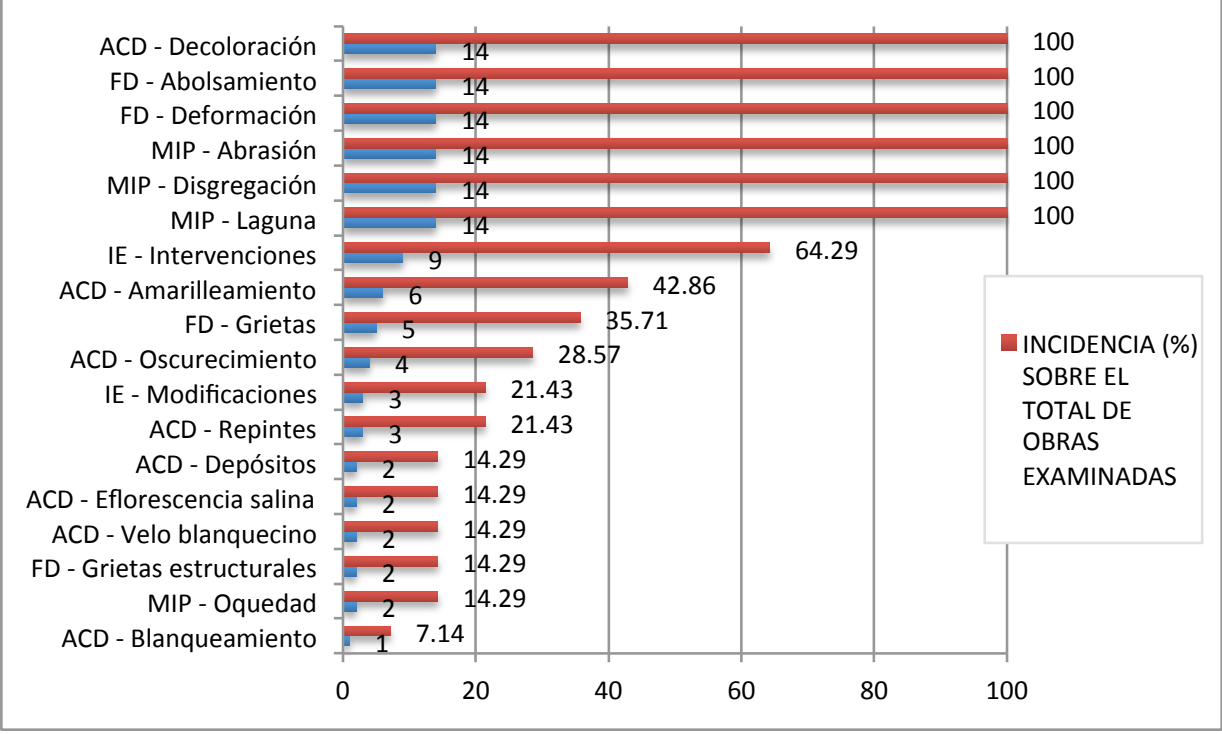

Gráfica 22 - Incidencia de las fenomenologías de alteración y deterioro y presencia (\%) en relación a la totalidad de muestras analizadas (14).

Tabla 57 - Indicador de riesgo obtenido a partir de la incidencia cuantitativa de las fenomenologías de alteración y deterioro registradas.

\begin{tabular}{|l|l|}
\hline \multicolumn{2}{|l|}{ INDICADOR DE RIESGO } \\
\hline MUESTRA & TOTAL INCIDENCIA DE DETERIORO \\
\hline 3 & 13 \\
\hline 2 & 12 \\
\hline 7 & 11 \\
\hline 1 & 10 \\
\hline 4 & 10 \\
\hline 14 & 9 \\
\hline 5 & 8 \\
\hline 6 & 8 \\
\hline 11 & 8 \\
\hline 13 & 8 \\
\hline 8 & 7 \\
\hline 10 & 7 \\
\hline
\end{tabular}




\begin{tabular}{|l|l|}
\hline 12 & 7 \\
\hline 9 & 6 \\
\hline
\end{tabular}

Tabla 58 - Extensión superficial (\%) de las fenomenologías de alteración y deterioro registradas. Muestra 3.

\begin{tabular}{|l|l|l|}
\hline M3 (total incidencia de deterioro: 13) & \multicolumn{2}{l|}{$\begin{array}{l}\text { EXTENSIÓN SUPERFICIAL (\%) } \\
\text { SUPERFICIAL }\end{array}$} \\
\hline FENOMENOLOGÍA DE ALTERACIÓN Y DETERIORO & 4 & $75-100$ \\
\hline Alteración cromática y depositos - Repintes & 4 & $75-100$ \\
\hline Intervenciones externas - Intervenciones estructurales & 4 & $75-100$ \\
\hline Intervenciones externas - Modificaciones & 2 & $25-50$ \\
\hline Fisuras y deformación - Deformación & 2 & $25-50$ \\
\hline Fisuras y deformación - Abolsamiento & 1 & $0-25$ \\
\hline Morfologías inducidas por pérdidas - Laguna & 1 & $0-25$ \\
\hline Morfologías inducidas por pérdidas - Disgregación & 1 & $0-25$ \\
\hline Morfologías inducidas por pérdidas - Abrasión & 1 & $0-25$ \\
\hline Fisuras y deformación - Grietas & 1 & $0-25$ \\
\hline Fisuras y deformación - Grietas estructurales & 1 & $0-25$ \\
\hline Alteración cromática y depositos - Velo blanquecino & 1 & $0-25$ \\
\hline Alteración cromática y depositos - Decoloración & 1 & $0-25$ \\
\hline Alteración cromática y depositos - Eflorescencia salina & \\
\hline
\end{tabular}

Tabla 59 - Extensión superficial (\%) de las fenomenologías de alteración y deterioro registradas. Muestra 2.

\begin{tabular}{|l|l|l|}
\hline \multicolumn{2}{|l|}{ M2 (total incidencia de deterioro: 12) } \\
\hline FENOMENOLOGÍA DE ALTERACIÓN Y DETERIORO & $\begin{array}{l}\text { INCIDENCIA } \\
\text { SUPERFICIAL }\end{array}$ & EXTENSIÓN SUPERFICIAL (\%) \\
\hline Morfologías inducidas por pérdidas - Laguna & 2 & $25-50$ \\
\hline Morfologías inducidas por pérdidas - Disgregación & 2 & $25-50$ \\
\hline Morfologías inducidas por pérdidas - Abrasión & 2 & $25-50$ \\
\hline Fisuras y deformación - Deformación & 2 & $25-50$ \\
\hline Fisuras y deformación - Abolsamiento & 2 & $25-50$ \\
\hline Alteración cromática y depositos - Oscurecimiento & 2 & $25-50$ \\
\hline Fisuras y deformación - Grietas & 1 & $0-25$ \\
\hline Fisuras y deformación - Grietas estructurales & 1 & $0-25$ \\
\hline Alteración cromática y depositos - Decoloración & 1 & $0-25$ \\
\hline Alteración cromática y depositos - Depósitos & 1 & $0-25$ \\
\hline
\end{tabular}


Tabla 60 - Extensión superficial (\%) de las fenomenologías de alteración y deterioro registradas. Muestra 7.

\begin{tabular}{|l|l|l|}
\hline M7 (total incidencia de deterioro: 11) & $\begin{array}{l}\text { INCIDENCIA } \\
\text { SUPERFICIAL }\end{array}$ & $\begin{array}{l}\text { EXTENSIÓN } \\
\text { (\%) }\end{array}$ \\
\hline FENOMENOLOGÍA DE ALTERACIÓN Y DETERIORO & 2 & $25-50$ \\
\hline Morfologías inducidas por pérdidas - Disgregación & 1 & $0-25$ \\
\hline Morfologías inducidas por pérdidas - Laguna & 1 & $0-25$ \\
\hline Morfologías inducidas por pérdidas - Abrasión & 1 & $0-25$ \\
\hline Fisuras y deformación - Grietas & 1 & $0-25$ \\
\hline Fisuras y deformación - Deformación & 1 & $0-25$ \\
\hline Fisuras y deformación - Abolsamiento & 1 & $0-25$ \\
\hline Alteración cromática y depositos - Amarilleamiento & 1 & $0-25$ \\
\hline Alteración cromática y depositos - Oscurecimiento & 1 & $0-25$ \\
\hline Alteración cromática y depositos - Blanqueamiento & 1 & $0-25$ \\
\hline Alteración cromática y depositos - Decoloración & 1 & $0-25$ \\
\hline Intervenciones externas - Intervenciones estructurales & \\
\hline
\end{tabular}

Tabla 61 - Extensión superficial (\%) de las fenomenologías de alteración y deterioro registradas. Muestra 1.

\begin{tabular}{|l|l|l|}
\hline M1 (total incidencia de deterioro: 10) & \multicolumn{2}{l|}{} \\
\hline FENOMENOLOGÍA DE ALTERACIÓN Y DETERIORO & $\begin{array}{l}\text { INCIDENCIA } \\
\text { SUPERFICIAL } \\
\text { (\%) }\end{array}$ & $\begin{array}{l}\text { EXTENSIÓN SUPERFICIAL } \\
\text { SUA }\end{array}$ \\
\hline Morfologías inducidas por pérdidas - Laguna & 2 & $25-50$ \\
\hline Morfologías inducidas por pérdidas - Disgregación & 2 & $25-50$ \\
\hline Morfologías inducidas por pérdidas - Abrasión & 2 & $25-50$ \\
\hline Fisuras y deformación - Deformación & 2 & $25-50$ \\
\hline Fisuras y deformación - Abolsamiento & 2 & $25-50$ \\
\hline Morfologías inducidas por pérdidas - Oquedad & 1 & $0-25$ \\
\hline Fisuras y deformación - Grietas & 1 & $0-25$ \\
\hline Alteración cromática y depositos - Decoloración & 1 & $0-25$ \\
\hline Alteración cromática y depositos - Depósitos & 1 & $0-25$ \\
\hline Intervenciones externas - Intervenciones estructurales & 1 & $0-25$ \\
\hline
\end{tabular}


Tabla 62 - Extensión superficial (\%) de las fenomenologías de alteración y deterioro registradas. Muestra 4.

\begin{tabular}{|l|l|l|}
\hline M4 (total incidencia de deterioro: 10) & EXTENSIÓN SUPERFICIAL \\
\hline FENOMENOLOGÍA DE ALTERACIÓN Y DETERIORO & $\begin{array}{l}\text { INCIDENCIA } \\
\text { SUPERFICIAL }\end{array}$ \\
\hline Alteración cromática y depositos - Decoloración & 3 & $50-75$ \\
\hline Morfologías inducidas por pérdidas - Laguna & 2 & $25-50$ \\
\hline Morfologías inducidas por pérdidas - Disgregación & 2 & $25-50$ \\
\hline Fisuras y deformación - Deformación & 2 & $25-50$ \\
\hline Fisuras y deformación - Abolsamiento & 2 & $25-50$ \\
\hline Morfologías inducidas por pérdidas - Abrasión & 1 & $0-25$ \\
\hline Fisuras y deformación - Grietas & 1 & $0-25$ \\
\hline Alteración cromática y depositos - Velo blanquecino & 1 & $0-25$ \\
\hline Alteración cromática y depositos - Eflorescencia salina & 1 & $0-25$ \\
\hline Intervenciones externas - Intervenciones estructurales & 1 & $0-25$ \\
\hline
\end{tabular}

Tabla 63 - Extensión superficial (\%) de las fenomenologías de alteración y deterioro registradas. Muestra 14.

\begin{tabular}{|l|l|l|}
\hline \multicolumn{2}{|l|}{ M14 (total incidencia de deterioro: 9) } \\
\hline FENOMENOLOGÍA DE ALTERACIÓN Y DETERIORO & $\begin{array}{l}\text { INCIDENCIA } \\
\text { SUPERFICIAL }\end{array}$ & EXTENSIÓN SUPERFICIAL (\%) \\
\hline Alteración cromática y depositos - Repintes & 3 & $50-75$ \\
\hline Intervenciones externas - Modificaciones & 3 & $50-75$ \\
\hline Morfologías inducidas por pérdidas - Laguna & 1 & $0-25$ \\
\hline Morfologías inducidas por pérdidas - Disgregación & 1 & $0-25$ \\
\hline Morfologías inducidas por pérdidas - Abrasión & 1 & $0-25$ \\
\hline Fisuras y deformación - Deformación & 1 & $0-25$ \\
\hline Fisuras y deformación - Abolsamiento & 1 & $0-25$ \\
\hline Alteración cromática y depositos - Decoloración & 1 & $0-25$ \\
\hline Intervenciones externas - Intervenciones estructurales & 1 & $0-25$ \\
\hline
\end{tabular}


Tabla 64 - Extensión superficial (\%) de las fenomenologías de alteración y deterioro registradas. Muestra 5.

\begin{tabular}{|l|l|l|}
\hline \multicolumn{2}{|l|}{ M5 (total incidencia de deterioro: 8) } \\
\hline FENOMENOLOGÍA DE ALTERACIÓN Y DETERIORO & $\begin{array}{l}\text { INCIDENCIA } \\
\text { SUPERFICIAL }\end{array}$ & EXTENSIÓN SUPERFICIAL (\%) \\
\hline Morfologías inducidas por pérdidas - Laguna & 2 & $25-50$ \\
\hline Morfologías inducidas por pérdidas - Disgregación & 2 & $25-50$ \\
\hline Fisuras y deformación - Deformación & 2 & $25-50$ \\
\hline Fisuras y deformación - Abolsamiento & 2 & $25-50$ \\
\hline Alteración cromática y depositos - Decoloración & 2 & $25-50$ \\
\hline Morfologías inducidas por pérdidas - Abrasión & 1 & $0-25$ \\
\hline Alteración cromática y depositos - Repintes & 1 & $0-25$ \\
\hline Intervenciones externas - Intervenciones estructurales & 1 & $0-25$ \\
\hline
\end{tabular}

Tabla 65 - Extensión superficial (\%) de las fenomenologías de alteración y deterioro registradas. Muestra 6.

\begin{tabular}{|l|l|l|}
\hline \multicolumn{2}{|l|}{ M6 (total incidencia de deterioro: 8) } \\
\hline FENOMENOLOGÍA DE ALTERACIÓN Y DETERIORO & $\begin{array}{l}\text { INCIDENCIA } \\
\text { SUPERFICIAL }\end{array}$ & EXTENSIÓN SUPERFICIAL (\%) \\
\hline Morfologías inducidas por pérdidas - Laguna & 1 & $0-25$ \\
\hline Morfologías inducidas por pérdidas - Disgregación & 1 & $0-25$ \\
\hline Morfologías inducidas por pérdidas - Abrasión & 1 & $0-25$ \\
\hline Fisuras y deformación - Deformación & 1 & $0-25$ \\
\hline Fisuras y deformación - Abolsamiento & 1 & $0-25$ \\
\hline Alteración cromática y depositos - Amarilleamiento & 1 & $0-25$ \\
\hline Alteración cromática y depositos - Oscurecimiento & 1 & $0-25$ \\
\hline Alteración cromática y depositos - Decoloración & 1 & $0-25$ \\
\hline
\end{tabular}


Tabla 66 - Extensión superficial (\%) de las fenomenologías de alteración y deterioro registradas. Muestra 11.

\begin{tabular}{|l|l|l|}
\hline M11 (total incidencia de deterioro: 8 ) & \multicolumn{2}{l|}{} \\
\hline FENOMENOLOGÍA DE ALTERACIÓN Y DETERIORO & $\begin{array}{l}\text { INCIDENCIA } \\
\text { SUPERFICIAL }\end{array}$ & EXTENSIÓN SUPERFICIAL (\%) \\
\hline Morfologías inducidas por pérdidas - Laguna & 1 & $0-25$ \\
\hline Morfologías inducidas por pérdidas - Oquedad & 1 & $0-25$ \\
\hline Morfologías inducidas por pérdidas - Disgregación & 1 & $0-25$ \\
\hline Morfologías inducidas por pérdidas - Abrasión & 1 & $0-25$ \\
\hline Fisuras y deformación - Deformación & 1 & $0-25$ \\
\hline Fisuras y deformación - Abolsamiento & 1 & $0-25$ \\
\hline Alteración cromática y depositos - Amarilleamiento & 1 & $0-25$ \\
\hline Alteración cromática y depositos - Decoloración & 1 & $0-25$ \\
\hline
\end{tabular}

Tabla 67 - Extensión superficial (\%) de las fenomenologías de alteración y deterioro registradas. Muestra 13.

\begin{tabular}{|l|l|l|}
\hline M13 (total incidencia de deterioro: 8) & \multicolumn{2}{l|}{} \\
\hline FENOMENOLOGÍA DE ALTERACIÓN Y DETERIORO & $\begin{array}{l}\text { INCIDENCIA } \\
\text { SUPERFICIAL }\end{array}$ & EXTENSIÓN SUPERFICIAL (\%) \\
\hline Intervenciones externas - Modificaciones & 4 & $75-100$ \\
\hline Morfologías inducidas por pérdidas - Laguna & 1 & $0-25$ \\
\hline Morfologías inducidas por pérdidas - Disgregación & 1 & $0-25$ \\
\hline Morfologías inducidas por pérdidas - Abrasión & 1 & $0-25$ \\
\hline Fisuras y deformación - Deformación & 1 & $0-25$ \\
\hline Fisuras y deformación - Abolsamiento & 1 & $0-25$ \\
\hline Alteración cromática y depositos - Decoloración & 1 & $0-25$ \\
\hline Intervenciones externas - Intervenciones estructurales & 1 & $0-25$ \\
\hline
\end{tabular}


Tabla 68 - Extensión superficial (\%) de las fenomenologías de alteración y deterioro registradas. Muestra 8.

\begin{tabular}{|l|l|l|}
\hline \multicolumn{2}{|l|}{ M8 (total incidencia de deterioro: 7) } \\
\hline FENOMENOLOGÍA DE ALTERACIÓN Y DETERIORO & $\begin{array}{l}\text { INCIDENCIA } \\
\text { SUPERFICIAL }\end{array}$ & EXTENSIÓN SUPERFICIAL (\%) \\
\hline Morfologías inducidas por pérdidas - Disgregación & 2 & $25-50$ \\
\hline Alteración cromática y depositos - Amarilleamiento & 2 & $25-50$ \\
\hline Morfologías inducidas por pérdidas - Laguna & 1 & $0-25$ \\
\hline Morfologías inducidas por pérdidas - Abrasión & 1 & $0-25$ \\
\hline Fisuras y deformación - Deformación & 1 & $0-25$ \\
\hline Fisuras y deformación - Abolsamiento & 1 & $0-25$ \\
\hline Alteración cromática y depositos - Decoloración & 1 & $0-25$ \\
\hline
\end{tabular}

Tabla 69 - Extensión superficial (\%) de las fenomenologías de alteración y deterioro registradas. Muestra 10.

\begin{tabular}{|l|l|l|}
\hline \multicolumn{2}{|l|}{ M10 (total incidencia de deterioro: 7) } \\
\hline FENOMENOLOGÍA DE ALTERACIÓN Y DETERIORO & $\begin{array}{l}\text { INCIDENCIA } \\
\text { SUPERFICIAL }\end{array}$ & EXTENSIÓN SUPERFICIAL (\%) \\
\hline Morfologías inducidas por pérdidas - Laguna & 1 & $0-25$ \\
\hline Morfologías inducidas por pérdidas - Disgregación & 1 & $0-25$ \\
\hline Morfologías inducidas por pérdidas - Abrasión & 1 & $0-25$ \\
\hline Fisuras y deformación - Deformación & 1 & $0-25$ \\
\hline Fisuras y deformación - Abolsamiento & 1 & $0-25$ \\
\hline Alteración cromática y depositos - Amarilleamiento & 1 & $0-25$ \\
\hline Alteración cromática y depositos - Decoloración & 1 & $0-25$ \\
\hline
\end{tabular}


Tabla 70 - Extensión superficial (\%) de las fenomenologías de alteración y deterioro registradas. Muestra 12.

\begin{tabular}{|l|l|l|}
\hline M12 (total incidencia de deterioro: 7) \\
\hline FENOMENOLOGÍA DE ALTERACIÓN Y DETERIORO & $\begin{array}{l}\text { INCIDENCIA } \\
\text { SUPERFICIAL }\end{array}$ & EXTENSIÓN SUPERFICIAL (\%) \\
\hline Morfologías inducidas por pérdidas - Laguna & 1 & $0-25$ \\
\hline Morfologías inducidas por pérdidas - Disgregación & 1 & $0-25$ \\
\hline Morfologías inducidas por pérdidas - Abrasión & 1 & $0-25$ \\
\hline Fisuras y deformación - Deformación & 1 & $0-25$ \\
\hline Fisuras y deformación - Abolsamiento & 1 & $0-25$ \\
\hline Alteración cromática y depositos - Decoloración & 1 & $0-25$ \\
\hline Intervenciones externas - Intervenciones estructurales & 1 & $0-25$ \\
\hline
\end{tabular}

Tabla 71 - Extensión superficial (\%) de las fenomenologías de alteración y deterioro registradas. Muestra 9.

\begin{tabular}{|l|l|l|}
\hline M9 (total incidencia de deterioro: 6) \\
\hline FENOMENOLOGÍA DE ALTERACIÓN Y DETERIORO & $\begin{array}{l}\text { INCIDENCIA } \\
\text { SUPERFICIAL }\end{array}$ & EXTENSIÓN SUPERFICIAL (\%) \\
\hline Morfologías inducidas por pérdidas - Disgregación & 2 & $25-50$ \\
\hline Morfologías inducidas por pérdidas - Laguna & 1 & $0-25$ \\
\hline Morfologías inducidas por pérdidas - Abrasión & 1 & $0-25$ \\
\hline Fisuras y deformación - Deformación & 1 & $0-25$ \\
\hline Fisuras y deformación - Abolsamiento & 1 & $0-25$ \\
\hline Alteración cromática y depositos - Decoloración & 1 & $0-25$ \\
\hline
\end{tabular}

Tras el análisis de la información ha sido posible identificar las áreas con mayor inestabilidad en términos de conservación. Éstas se presentan, en relación con su ubicación en el contexto de estudio, en la imagen 66. Detalles inherentes el estado de conservación del área con mayor afectación en términos de fenomenologías de alteración y deterioro registradas se exponen en las imágenes 67-70. En ellas se puede apreciar la presencia de grietas estructurales, deterioro de tipo biológico, eflorescencias salinas entre otros. El conjunto de fenómenos, que se exponen en los apartados sucesivos, son indicativo de un deterioro a nivel estructural del edificio que ha favorecido el paso de agua, por filtración sobre todo, desatando una pluralidad de efectos secundarios cuya gravedad en términos conservativos ponde de manifiesto la necesidad de una acción de tutela urgente. 


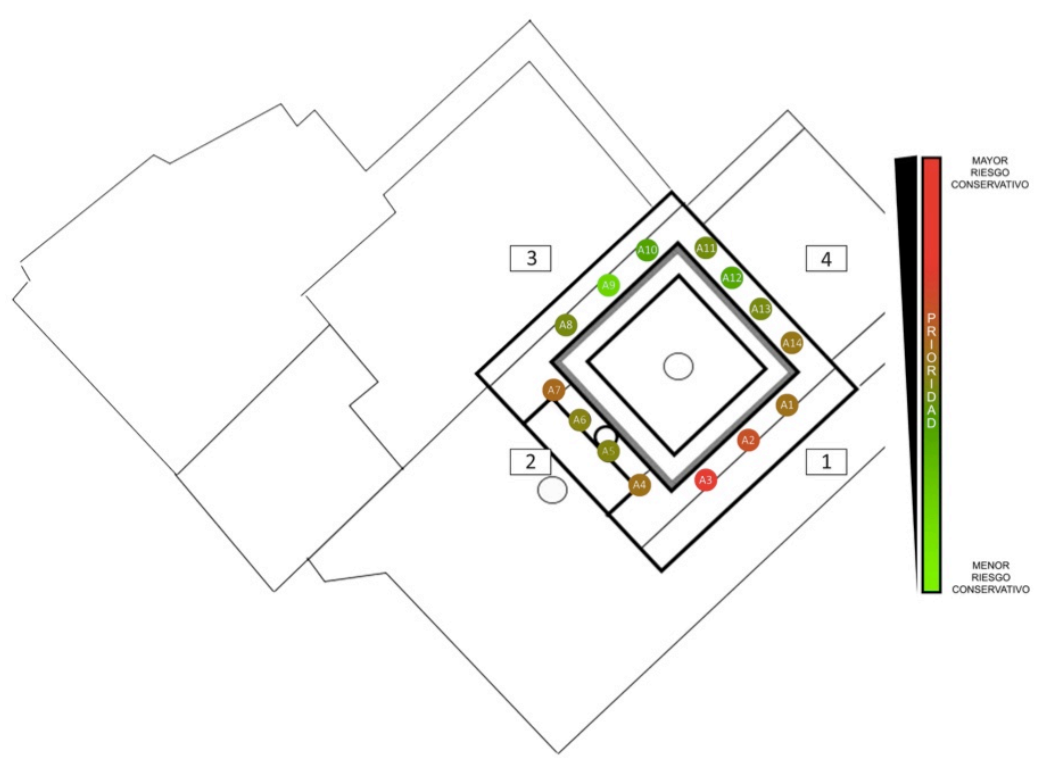

Imagen 64 - Indicador de áreas a mayor riesgo conservativo y prioridades.

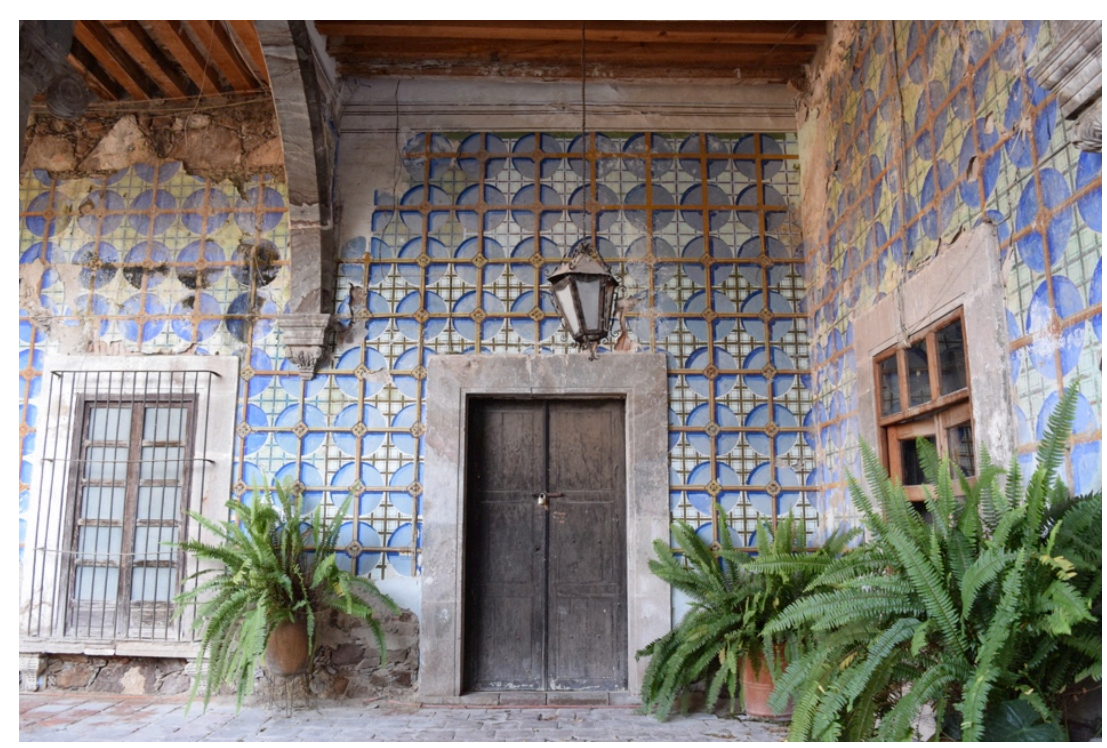

Imagen 65 - Área 14. 


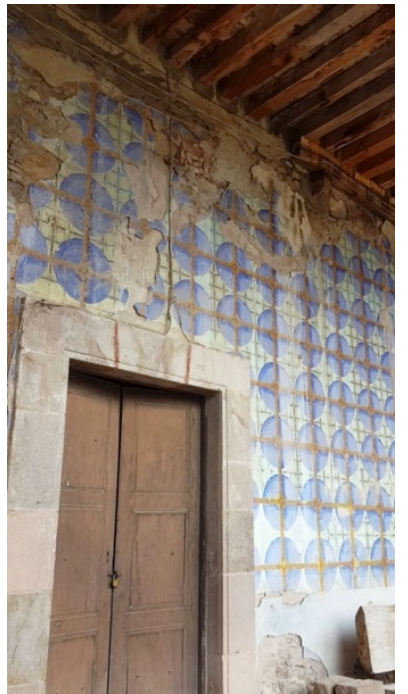

Imagen 66 - Área 1.

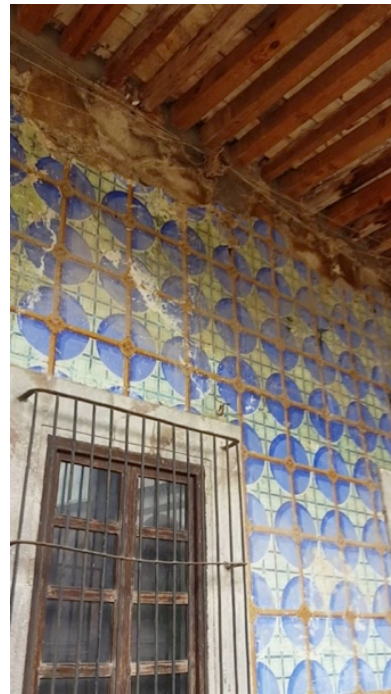

Imagen 67 - Área 2.

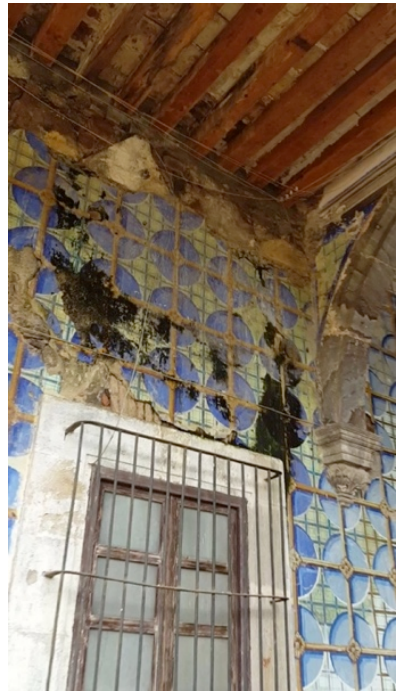

Imagen 68 - Área 3.

De acuerdo con la información obtenida, se puede concluir que las pinturas decorativas estuvieron expuestas a las siguientes dinámicas ${ }^{276}$ :

- Deterioro químico, físico o biológico con disolución gradual del ligante. Puede deberse a la presencia y acción de sales o la humedad y es responsable del fenómeno de desintegración.

- La existencia de abrasiones es resultado de una acción mecánica (fricción) causada por el uso, por la acción humana (limpiezas incorrectas) o por el arrastre de unas partículas por el viento.

- Las deformaciones suelen ser el resultado de la aplicación de una fuerza, sin pérdida de la continuidad entre sus partes (sin rotura). Se debe a factores medioambientales como: humedad, calor producido por un fuego, influencia directa de la luz solar y el uso de determinados materiales de construcción o conservación.

- La presencia de abolsamientos suelen indicar la acción de una presión derivada de la acción de criptoflorescencias entre los estratos de revoques.

\footnotetext{
${ }^{276}$ La interpretación de los resultados se fundamenta en las informaciones brindadas por European Illustrated Glossary for Conservation Terms of Wall Painting and Architectonic Surfaces (2015), op.cit.
} 
- La decoloración de la película pictórica es el resultado de reacciones químicas y/o de una exposición directa a la insolación, con sucesiva pérdida de saturación y aumento de la luminosidad.

- La presencia de intervenciones estructurales suele indicar actuaciones sobre el bien inmueble que persiguen el objetivo de recuperar la estabilidad o integridad de la estructura.

- El amarilleamiento constituye una alteración cromática derivada de la presencia de materiales orgánicos, como pueden ser los medios aglutinantes y los barnices, materiales de conservación, protecciones hechas con caseína y con resinas naturales y sintéticas, acumulación de depósitos muy finos de suciedad o contaminantes; puede indicar la presencia de microorganismos que generan productos químicos amarillos; en algunos casos es representativo de transformaciones mineralógicas que conducen, por ejemplo, a la formación de oxihidróxidos de hierro.

- Las grietas se deben a causas medioambientales, vibraciones, estrés interno y/o externo, defectos en las superficies arquitectónicas, problemas estáticos, gradientes térmicos resultados de la acción del fuego o del hielo.

- El oscurecimiento puede ser producto de un depósito (acumulación de hollín, humo, polvo y alquitrán) que, si no es tratada, podría endurecerse hasta formar una costra negra; esta alteración cromática puede ser el resultado del envejecimiento de los materiales de consolidación o restauración (ligante orgánico a base de aceite o barniz), indicar la presencia de humedad localizada, la presencia de colonización biológica o ser el fruto de la transformación mineralógica de un pigmento.

- La presencia de repintes, puede deberse a numerosas razones: para producir un cambio de significado histórico-cultural en la obra, para seguir la corriente estilística del momento, o también puede entenderse como una reparación tras una intervención desfavorable o un deterioro.

- Las oquedades suelen presentarse principalmente por el desgaste, erosión, migración de sales solubles o por otros factores físicos.

- La formación de grietas estructurales suelen depender de un cambio en la distribución de las fuerzas estáticas de la estructura de construcción y/o de movimientos de una parte de la estructura del edificio debido a problemas en los cimientos, y que originan serias modificaciones en la estructura; pueden presentarse por problemas con las capas subyacentes de la construcción (por ejemplo, si están hechas con arcilla o arena); las grietas estructurales suelen originarse también en circunstancias de calamidades naturales. 
- La formación de un velo blanquecino indica la acumulación de un depósito fino de partículas pequeñas: polvo, depósitos atmosféricos, sales cristalizadas. Tras el uso de silicatos alcalinos en intervenciones de conservación suele registrarse la presencia de una capa calcítica sobre la superficie.

- Las eflorescencias salinas se deben a una migración de sales hacia la superficie, en donde la evaporación de agua permite su cristalización. Suele indicar que el agua ha encontrado un punto de entrada de la que introduce sales en los muros y origina su migración. La acción capilar también puede originar sales derivadas del terreno. Las eflorescencias salinas pueden indicar la presencia de sales acumuladas cerca de la superficie (criptoeflorescencias) potencialmente dañinas.

- La presencia de depósitos es el resultado de la acumulación de material exogénico tal como polvo o deyecciones, sobre la superficie.

- El blanqueamiento es debido a un aclarado de los materiales constituyentes, causado por la exposición directa de un material a la climatología, o bien por una reacción química que favorece la lixiviación de los componentes de la superficie pictórica.

Relacionando la información obtenida con la extensión superficial de los fenómenos de alteración y deterioro, se puede concluir que el área sureste del patio se caracteriza por ser la que tiene mayor indicador de riesgo.

Hay registro de intervenciones de modificación estructural en correspondencia con las pinturas decorativas, que, junto a la presencia de grietas superficiales y estructurales, confirman la existencia de problemáticas de tipo estático en esta parte de la estructura. Éstas pueden haber favorecido el desarrollo de fenómenos secundarios, la mayoría ligados a la acción de la humedad por la penetración de agua de filtración en la estructura y superficie: blanqueamiento y decoloración, presencia de eflorescencias salinas, disgregación, abolsamientos, lagunas. Estos fenómenos, junto a la existencia de depósitos de diferente naturaleza, proveen la superficie pictórica de nutrientes y condiciones idóneas al desarrollo de un posible biodeterioro.

\subsection{Templo de San Martín de Tours (Huaquechula, Puebla)}

El templo de San Martín de Tours (imagen 69) se ubica en el municipio de Huaquechula, en el estado de Puebla, a unos $55 \mathrm{~km}$ de la capital (imagen 70). Su construcción data del siglo XVI y representa uno de los ejemplos más antiguos de edificaciones religiosas en México (imagen 71). Fue construida entre 1531 y 1580, 
bajo diseño del arquitecto fray Juan de Alameda ${ }^{277}$. Su importancia reside en ser testigo de la época de la conquista, no sólo territorial, también espiritual del país. Al exterior, cuenta con unas capillas abiertas ${ }^{278}$ de diseño ojival de dos plantas, claustro, huerto, mientras el templo se compone por unas majestuosas bóvedas de nervaduras (imagen 73). Entre el considerable acervo de tipo histórico artístico del recinto religioso, se cita la existencia de pinturas murales virreinales, esculturas y pinturas de los siglos XVI-XIX y retablos. De éstos, destaca el retablo mayor, conformado por diecisiete pinturas sobre tela, creadas en 1675 por el pintor novohispano Cristobal de Villalpando ${ }^{279}$.

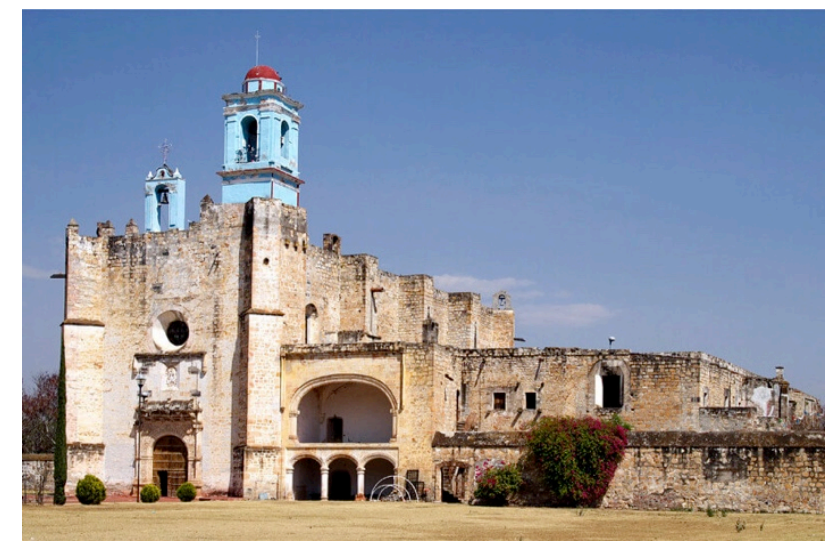

Imagen 69 - Visión general del conjunto ${ }^{280}$.

277 INAH, GOBIERNO DE MÉXICO. "Secretaría de Cultura, INAH y Embajada de Estados Unidos recuperan conjunto conventual de Huaquechula, Puebla" en Boletín de Noticias, 18 de septiembre de 2018. <https://inah.gob.mx/boletines/7560-secretaria-de-cultura-inah-y-embajada-de-estados-unidos-recuperanconjunto-conventual-de-huaquechula-puebla> [Consulta: 27 de noviembre de 2020].

278 Las capillas abiertas son unos espacios creados especialmente en la época de evangelización de la Nueva España, para adoctrinar las poblaciones autóctonas: "resulta indudable y admitido por todos que la génesis de las capillas abiertas debe mucho a la especial conyuntura de las primeras décadas de evangelización en América y al deseo de concertar la funcionalidad requerida con la parquedad de medios, tanto humanos como materiales, a la hora de la construcción en esta etapa inicial". MEDIANERO HERNÁNDEZ, J.M. (1992). "Un ejemplo de capilla abierta en la Universidad de Mareantes de Triana" en Laboratorio de Arte, 5-1992, pp. 223-239.

279 INAH-GOBIERNO DE MÉXICO. "Restaura INAH retablo centenario de Puebla”, en Boletín de Noticias, 1 de marzo de 2012. <https://inah.gob.mx/boletines/1596-restaura-inah-retablo-centenario-de-puebla> [Fecha de consulta: 27 de noviembre de 2020]; "INAH restaura retablo con pinturas de Villalpando", en Boletín de Noticias, 8 de noviembre de 2012. <https://inah.gob.mx/boletines/2140-inah-restaura-retablo-con-pinturasde-villalpando> [Consulta: 27 de noviembre de 2020].

280 Huaquechula. <https://www.corazondepuebla.com.mx/descubre/huaquechula/> [Consulta: 27 de noviembre de 2020]. 
Tras el sismo que sacudió el centro de México el 19 de septiembre de 2017, este importante recinto religioso sufrió ingentes daños que afectaron parte de la estructura edificada (imágenes 72,74 y 75) y de las obras albergadas en su interior (imágenes 76 y 77). Debido a los efectos ocasionados por los movimientos sísmicos sobre el patrimonio cultural, se implementó una colaboración entre las diversas coordinaciones nacionales, los centros estatales del $\mathrm{INAH}^{281}$ y las instituciones educativas de nivel superior del país ${ }^{282}$, con el objetivo de enfrentar un reto común para proteger y rescatar el patrimonio en esta situación de emergencia. Actualmente, gracias al esfuerzo del INAH y al apoyo de fondos de la embajada de Estados Unidos, el conjunto conventual está en fase de recuperación ${ }^{283}$.

Para la implementación del método se han analizado, sobre documentación fotográfica, un total de 27 elementos constituidos por 19 componentes del retablo de la Virgen de la Luz, 4 esculturas en madera policromada y 4 pinturas al óleo sobre lienzo (tabla 72).

Tabla 72 - Datos de las modalidades de registro y análisis.

\section{RETABLO DE LA VIRGEN DE LA LUZ - TEMPLO DE SAN MARTíN DE TOURS (HUAQUECHULA, PUEBLA)}

\begin{tabular}{|l|l|}
\hline Registro realizado en: & Octubre 2020 \\
\hline Objeto de estudio: & $\begin{array}{l}\text { Retablo policromado } \\
\text { Pintura de caballete (soporte textil) } \\
\text { Escultura policromada }\end{array}$ \\
\hline Tiempo de registro de datos: & 2 horas, sobre documentación fotográfica \\
\hline Total de obras analizadas: & $\begin{array}{l}27, \text { de las cuales: 19 componentes de un retablo, } 4 \text { esculturas } \\
\text { (madera policromada y dorada) y 4 pinturas (óleo sobre lienzo) }\end{array}$ \\
\hline Profesionales empleados: & 1 \\
\hline Tiempo para el análisis de datos & 2 horas \\
\hline
\end{tabular}

281 INAH, GOBIERNO DE MÉXICO. "Alistan diagnóstico para restauración integral del conjunto conventual de Huaquechula, Puebla", en Boletín de Noticias, 7 de agosto de 2019. <https://inah.gob.mx/boletines/8367alistan-diagnostico-para-restauracion-integral-del-conjunto-conventual-de-huaquechula-puebla> [Consulta: 27 de noviembre de 2020].

${ }^{282}$ Las acciones de salvaguarda de las obras custodiadas en el Templo del ex Convento de San Martín de Tours han sido parte de la labor desempeñada por la brigada de Rescate INAH SLP-UASLP en el estado de Puebla, a raíz del sismo del 19 de septiembre de 2017. En este contexto, los trabajos han sido realizados bajo la organización del Restaurador Pablo Vidal Tapia de la Coordinación Nacional de Conservación del Patrimonio Cultural CNCPC-INAH. Entre las operaciones de rescate realizadas, se citan también las ejecutadas en el Museo del ex-convento del Carmen y en el templo de San Francisco de Atlixco (Puebla).

283 INAH, GOBIERNO DE MÉXICO. "Secretaría de Cultura, INAH y Embajada de Estados Unidos recuperan conjunto conventual de Huaquechula, Puebla", op.cit. 


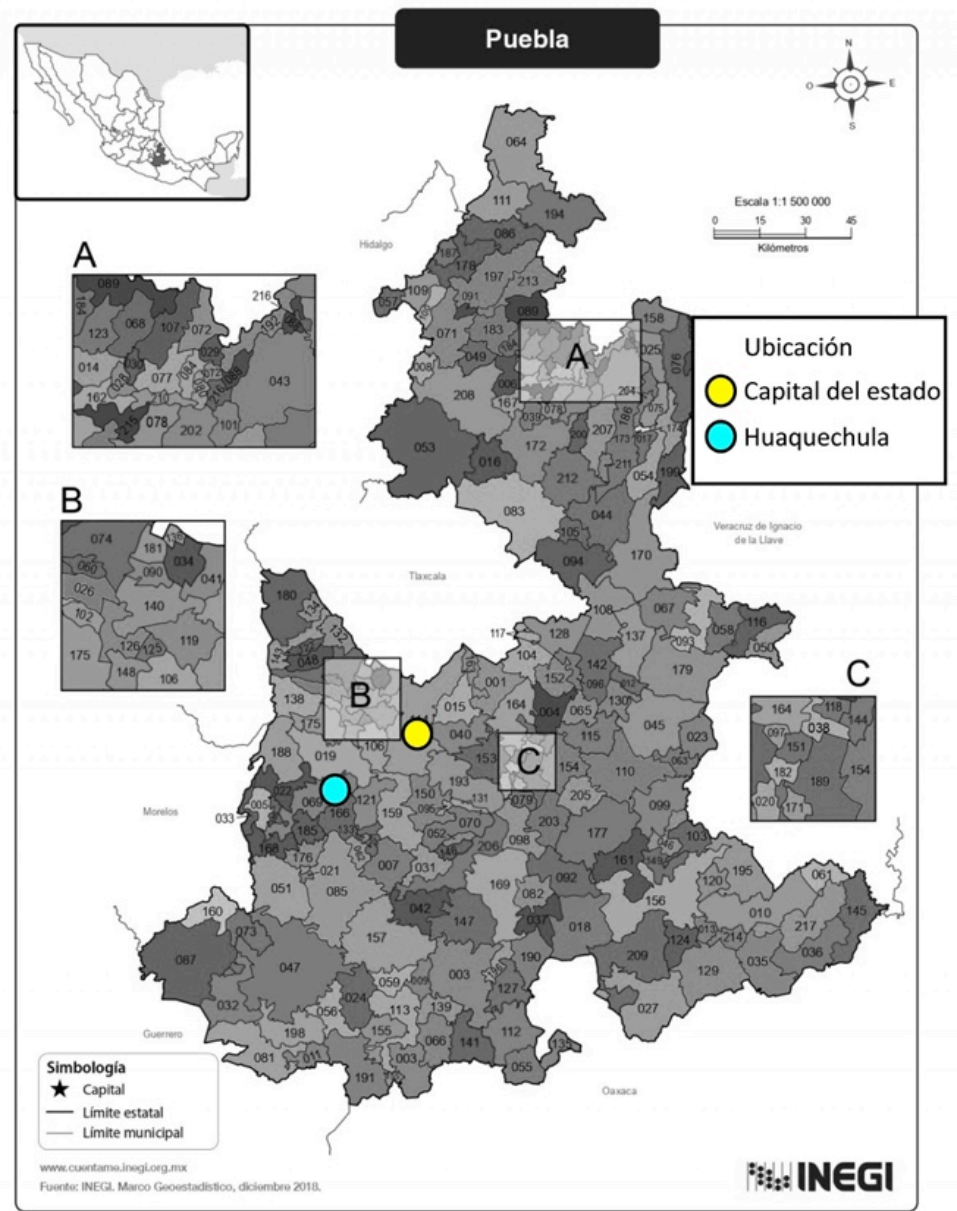

Imagen 70 - Ubicación del caso de estudio, estado de Puebla ${ }^{284}$.

284 Imagen modificada de: INEGI, Marco Geoestadístico, diciembre 2018. <www.cuentame.inegi.org.mx> [Consulta: 15 de noviembre de 2020]. 


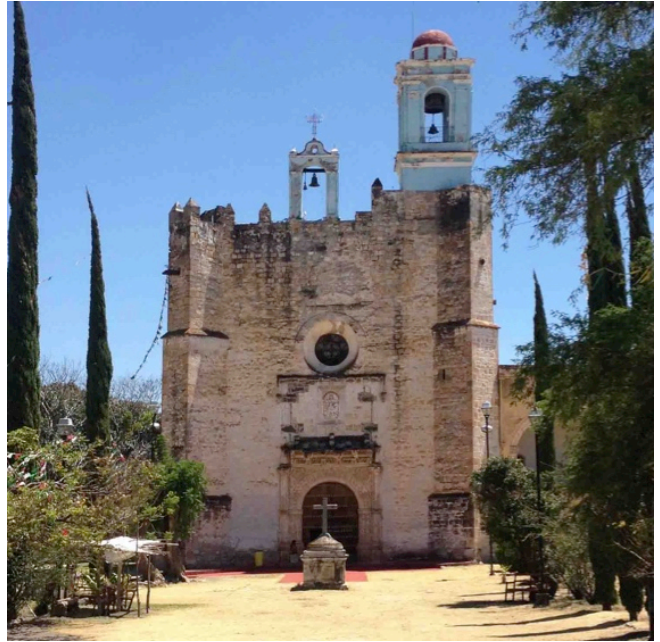

Imagen 71 - Portada del Templo de San Martín antes ${ }^{285}$ del seísmo de 2017.

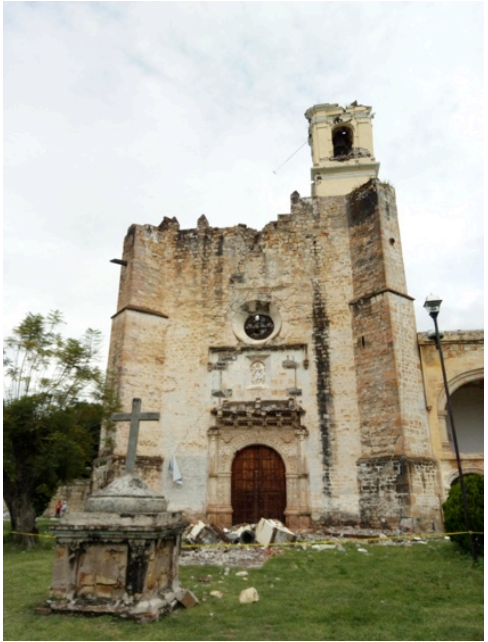

Imagen 72 - El Templo de San Martín de Tours después del seísmo de 2017.

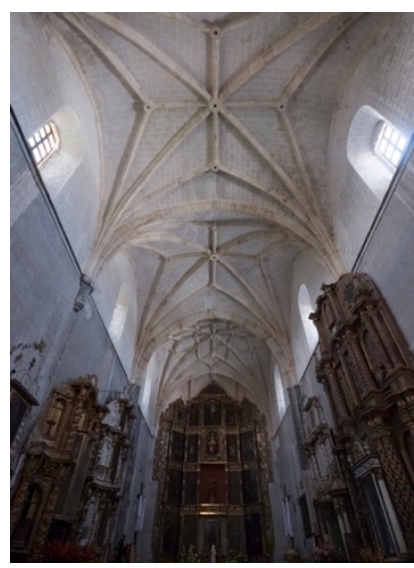

Imagen 73 - Interior de

Templo de San Martín antes ${ }^{286}$ del terremoto de 2017.

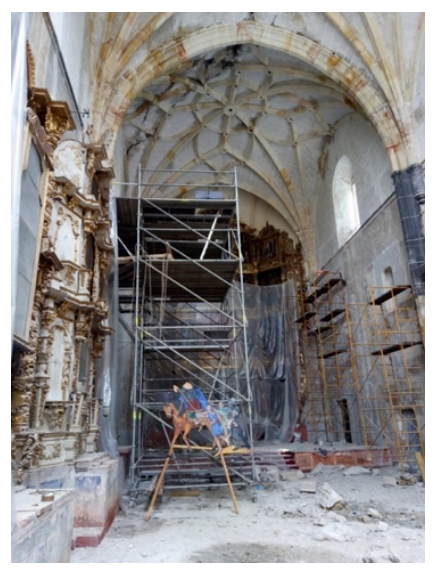

Imagen 74 - El templo después del seísmo.

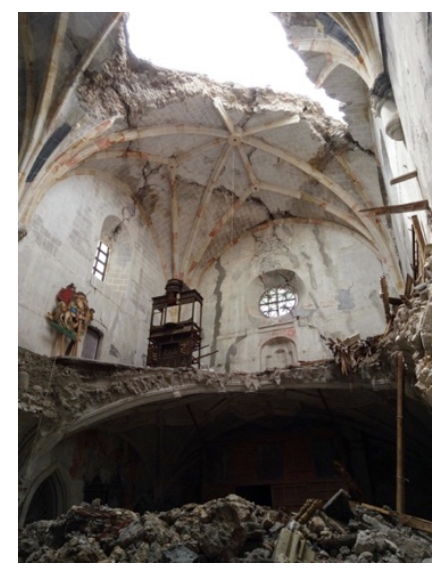

Imagen 75 - El templo después del seísmo.

${ }^{285}$ Foto: Paula Slim Tecuanhuey. "Huaquechula: la vida después del sismo", 26 de septiembre de 2017.<https://manati.mx/2017/09/26/el-renacer-del-convento-de-huaquechula/> [Consulta: 20 de noviembre de 2020].

${ }^{286}$ El gótico en Mexico: Huaquechula. <https://www.elgoticoenmexico.org/huaquechula> [Consulta: 20 de noviembre de 2020]. 


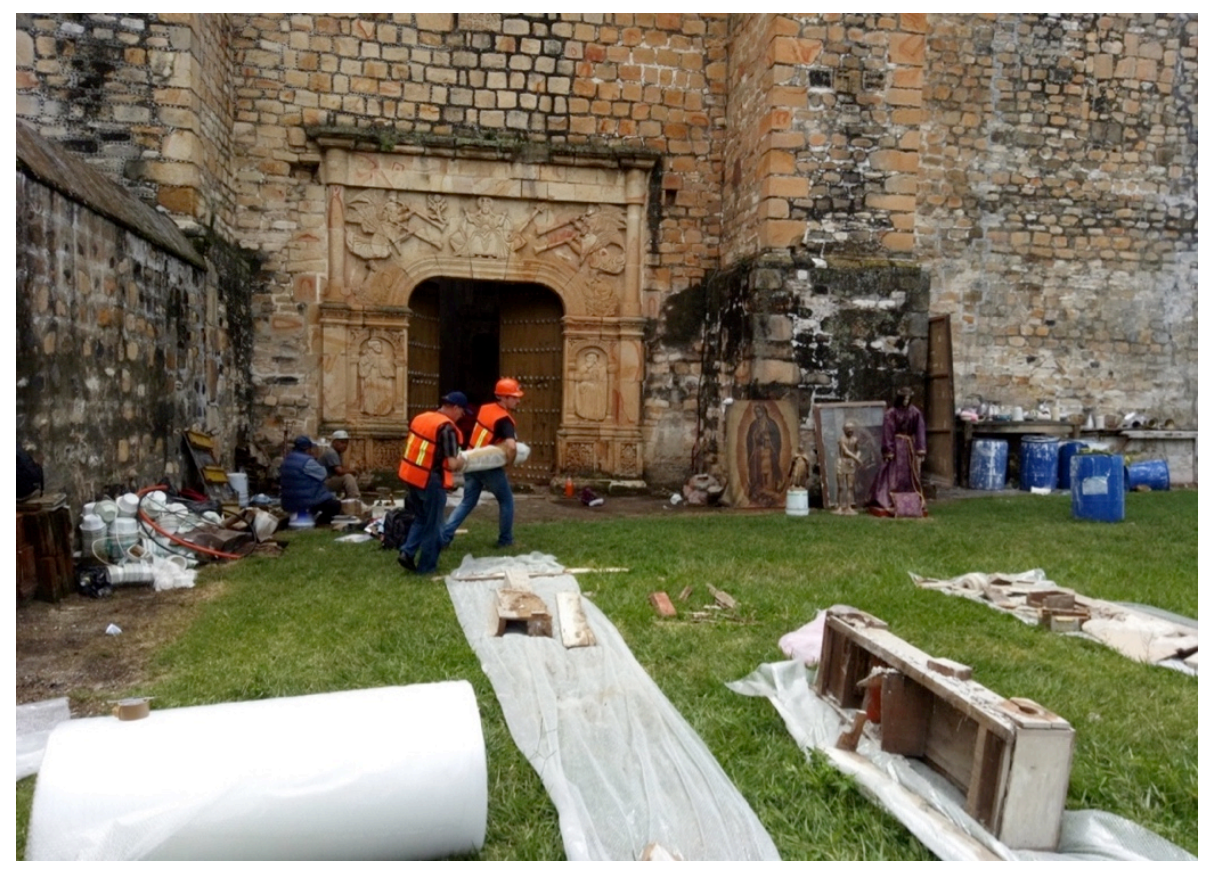

Imagen 76 - Fases de resguardo de las obras.

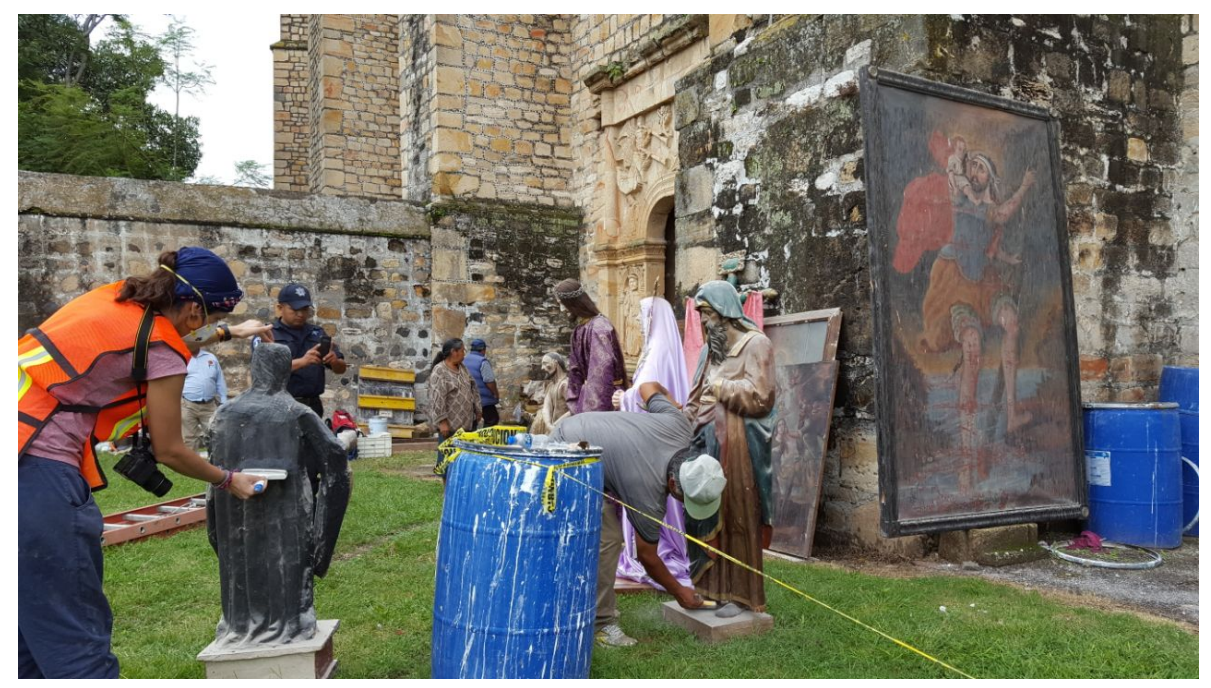

Imagen 77 - Limpieza preliminar de las obras antes de su resguardo. 


\subsubsection{Retablo de la Virgen de la Luz}

El retablo de la Virgen de la Luz (imagen 78) se compone por un conjunto de elementos en madera policromada y dorada que conforman una estructura compuesta por una calle central, enmarcada por columnas salomónicas ricamente decoradas con motivos vegetales. La composición se erige sobre un banco cuyo frente recuerda órdenes arquitectónicas de inspiración clásica cuya reminiscencia, es rematada por las rosetas doradas puestas al centro de los tableros y en las trabeaciones que separan los pisos. El guardapolvo, compuesto por líneas onduladas y simétricas, enmarca la estructura central en las que se albergan dos pinturas sobre lienzo. Presenta diferentes escenas en los óvalos. El remate, en donde se corona el retablo con un círculo en el que se representa una estrella, es coronado por una cruz en madera.

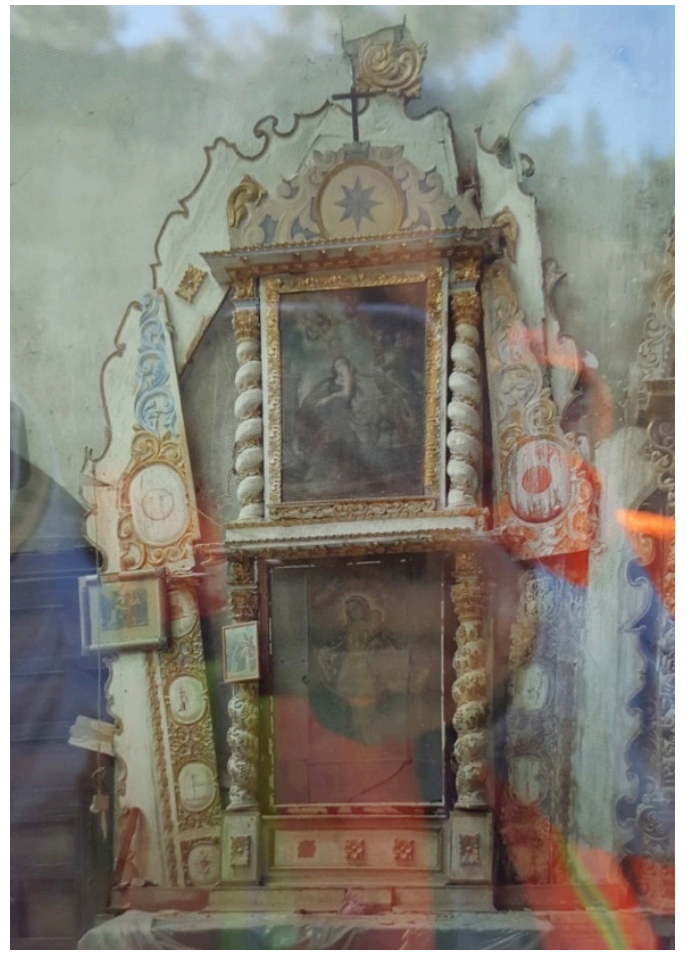

Imagen 78 - Retablo de la Virgen de la Luz tras el sismo ${ }^{287}$

${ }^{287}$ La calidad de la imagen se debe a que fue tomada a partir de una imagen digital mostrada en una pantalla, esto se debió a la situación extraordinaria del contexto de trabajo (evento sísmico en aquel entonces aun activo). 
Esta obra se ubicaba en la parte lateral de la nave del templo y, tras el terremoto que afectó gravemente la estructura arquitectónica que lo custodiaba, ha sido desmontado y resguardado como medida de emergencia dirigida a la salvaguarda del rico patrimonio cultural del recinto religioso.

Los elementos que componen su estructura han sido anlizados en este apartado, mientras los lienzos se han estudiado separadamente, en conjunto con las obras muebles del templo ${ }^{288}$. Las pinturas representan la "Virgen de la Luz", para el primer piso, y "Santa Bárbara", segundo piso.

Para llevar a cabo el estudio de las problemáticas del retablo, ha sido necesario identificar cada elemento constitutivo a partir de la documentación fotográfica realizada en las fases de rescate de emergencia (imagen 78 ), relacionándolo con la respectiva coordenada alfanumérica (tabla 73) y posición en la estructura (imagen 79).

Tabla 73 - Referencia de muestras y componentes del retablo.

\begin{tabular}{|c|c|}
\hline \multicolumn{2}{|r|}{ RETABLO DE LA VIRGEN DE LA LUZ - TEMPLO DE SAN MARTÍN DE TOURS } \\
\hline M & DESCOMPOSICIÓN DE LA OBRA PARA SU ESTUDIO (imagen 81) \\
\hline 1 & Madera dorada y policromada: remate, retablo, siglo XIX. \\
\hline 2 & Madera dorada y policromada: remate trasero, retablo, siglo XIX. \\
\hline 3 & Madera dorada y policromada: guardapolvo izquierdo, segundo piso, retablo, siglo XIX. \\
\hline 4 & Madera dorada y policromada: guardapolvo izquierdo, primer piso, retablo, siglo XIX. \\
\hline 5 & Madera dorada y policromada: guardapolvo derecho, segundo piso, retablo, siglo XIX. \\
\hline 6 & Madera dorada y policromada: guardapolvo derecho, primer piso, retablo, siglo XIX. \\
\hline 7 & Madera dorada y policromada: guardapolvo derecho con medallones, primer piso, retablo, siglo XIX. \\
\hline 8 & Madera dorada y policromada: guardapolvo derecho perimetral, primer piso, siglo XIX. \\
\hline 9 & Madera dorada y policromada: guardapolvo izquierdo, segundo piso, retablo, siglo XIX. \\
\hline 10 & Madera dorada y policromada: guardapolvo derecho, segundo piso, retablo, siglo XIX. \\
\hline 11 & Madera dorada y policromada: columna derecha, segundo piso, retablo, siglo XIX. \\
\hline 12 & Madera dorada y policromada: columna izquierda, segundo piso, retablo, siglo XIX. \\
\hline 13 & Madera dorada y policromada: cornisa, primer piso, retablo, siglo XIX. \\
\hline 14 & Madera dorada y policromada: base decoración segundo piso, retablo, siglo XIX. \\
\hline 15 & Madera dorada y policromada: cornisa, segundo piso, retablo, siglo XIX. \\
\hline 16 & Madera dorada y policromada: columna izquierda, primer piso, retablo, siglo XIX. \\
\hline 17 & Madera dorada y policromada: banco, retablo, siglo XIX. \\
\hline 18 & Madera dorada y policromada: guardapolvo parte perimetral, segundo piso, retablo, siglo XIX. \\
\hline 19 & Madera dorada y policromada: columna derecha, primer piso, retablo, siglo XIX. \\
\hline
\end{tabular}

${ }^{288}$ Ver apartado sucesivo. 


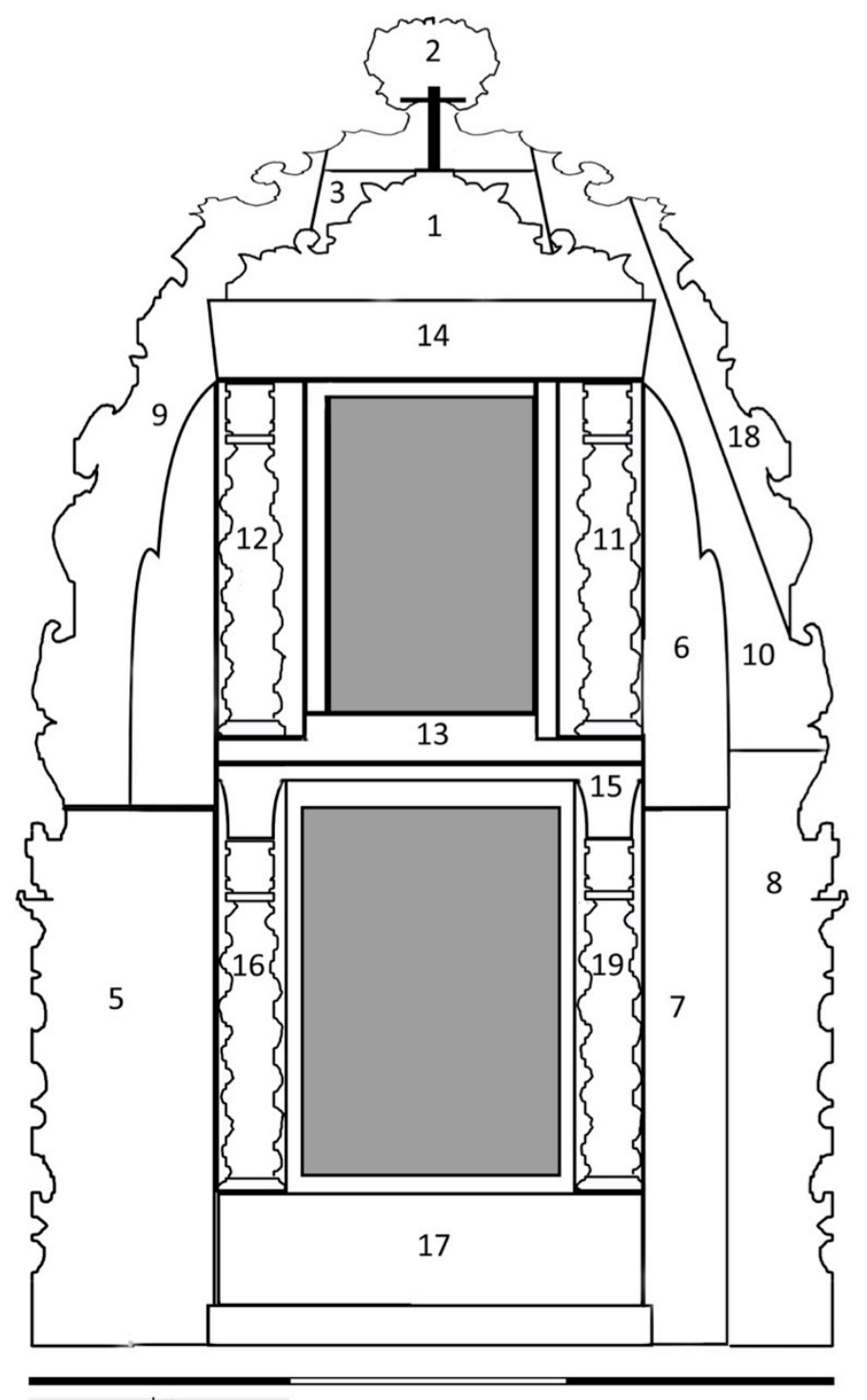

RETABLO DE LA VIRGEN DE LA LUZ - TEMPLO DE SAN MARTÍN DE TOURS HUAQUECHULA (PUEBLA)

Imagen 79 - Retablo de la Virgen de la luz. 
Tras el análisis de la información, ha sido posible identificar:

- fenomenologías de alteración y deterioro activas (tabla 74) junto a su estimación cuantitativa y porcentual (gráfica 23);

- incidencia de las alteraciones y deterioro desglosada según las capas constitutivas del sistema (tabla 75);

- indicador de riesgo del conjunto (tabla 76);

- croquis representativo de las áreas con mayor índice de riesgo y prioridad (imagen 80).

- elementos con mayor índicador de riesgo y prioridad (imagen 81 y 82);

- alteraciones y deterioros presentes en cada obra/área complementada por una estimación de la superficie afectada por cada fenómeno (tablas 77-95);

La información obtenida ha sido complementada por una propuesta de interpretación de los datos arrojados pr el método.

Tabla 74 - Fenomenologías de alteración y deterioro presentes y su incidencia total (B - Barniz, PP Película pictórica, $\mathrm{Pr}$ - preparación, L - lienzo/entelado, M - Madera/bastidor).

\begin{tabular}{|l|l|}
\hline FENOMENOLOGÍA DE ALTERACIÓN Y DETERIORO & $\begin{array}{l}\text { TOTAL } \\
\text { INCIDENCIA } \\
\text { DETERIORO }\end{array}$ \\
\hline Película pictórica - Deformaciones de la superficie: Levantamientos & 19 \\
\hline Película pictórica - Deformaciones de la superficie: Desprendimientos & 19 \\
\hline Película pictórica - Traumatismos: Rayados & 19 \\
\hline Preparación - Deformaciones de la superficie: Levantamientos & 19 \\
\hline Película pictórica - Acumulación de polvo fino & 19 \\
\hline Película pictórica - Grietas puntuales/intracapas & 18 \\
\hline Película pictórica - Presencia de materiales ajenos & 18 \\
\hline Preparación: Lagunas & 18 \\
\hline Película pictórica - Lagunas: Numerosas pequeñas en esquinas cuarteados & 17 \\
\hline Preparación: Desprendimientos & 17 \\
\hline Madera - Grietas: Fendas & 17 \\
\hline Madera - Desprendimiento & 17 \\
\hline Película pictórica - Craquelado & 16 \\
\hline Película pictórica - Traumatismos: Abrasión & 16 \\
\hline Madera - Presencia de galerías de xilófagos & 16 \\
\hline Madera - Grietas: Fracturas & 16 \\
\hline
\end{tabular}




\begin{tabular}{|c|c|}
\hline Barniz - Alteración cromática: Manchas & 16 \\
\hline Película pictórica - Traumatismos: Desgaste & 15 \\
\hline Película pictórica - Cuarteados perimetrales & 13 \\
\hline Película pictórica - Cuarteados a contacto con los elementos estructurales del bastidor & 13 \\
\hline Película pictórica - Deformaciones de la superficie: Descamación & 12 \\
\hline Preparación - Cuarteado & 12 \\
\hline Película pictórica - Alteración cromática: Tono café-marrón & 11 \\
\hline Película pictórica - Acumulación de polvo grasoso/adherido & 10 \\
\hline Película pictórica - Cuarteados generalizados & 10 \\
\hline Madera - Acumulación de polvo: Fino & 10 \\
\hline Película pictórica - Lagunas: Grandes áreas & 9 \\
\hline Película pictórica - Deformaciones de la superficie: Cordilleras & 8 \\
\hline Película pictórica - Deformaciones de la superficie: Cazoletas & 6 \\
\hline Preparación: Manchas & 5 \\
\hline Preparación - Pérdida de adhesión con la película pictórica & 5 \\
\hline Madera - Manchas: Negras & 5 \\
\hline Madera - Alteración estructural: pérdida/movimiento de nudos & 4 \\
\hline Barniz - Daños mecánicos & 3 \\
\hline Película pictórica - Alteración cromática: Oscurecimiento & 3 \\
\hline Película pictórica - Quemaduras & 3 \\
\hline Madera - Manchas: Colores & 3 \\
\hline Madera - Manchas: con filamentos & 3 \\
\hline Barniz - Alteración cromática: Oscurecimiento & 3 \\
\hline Película pictórica - Lagunas: Área inferior & 2 \\
\hline Madera - Acumulación de polvo: Grasoso/adherido & 2 \\
\hline Película pictórica - Deformaciones de la superficie: Solapamientos & 1 \\
\hline Preparación: Pulverulencia & 1 \\
\hline Madera - Acumulación de polvo: Zona inferior & 1 \\
\hline
\end{tabular}




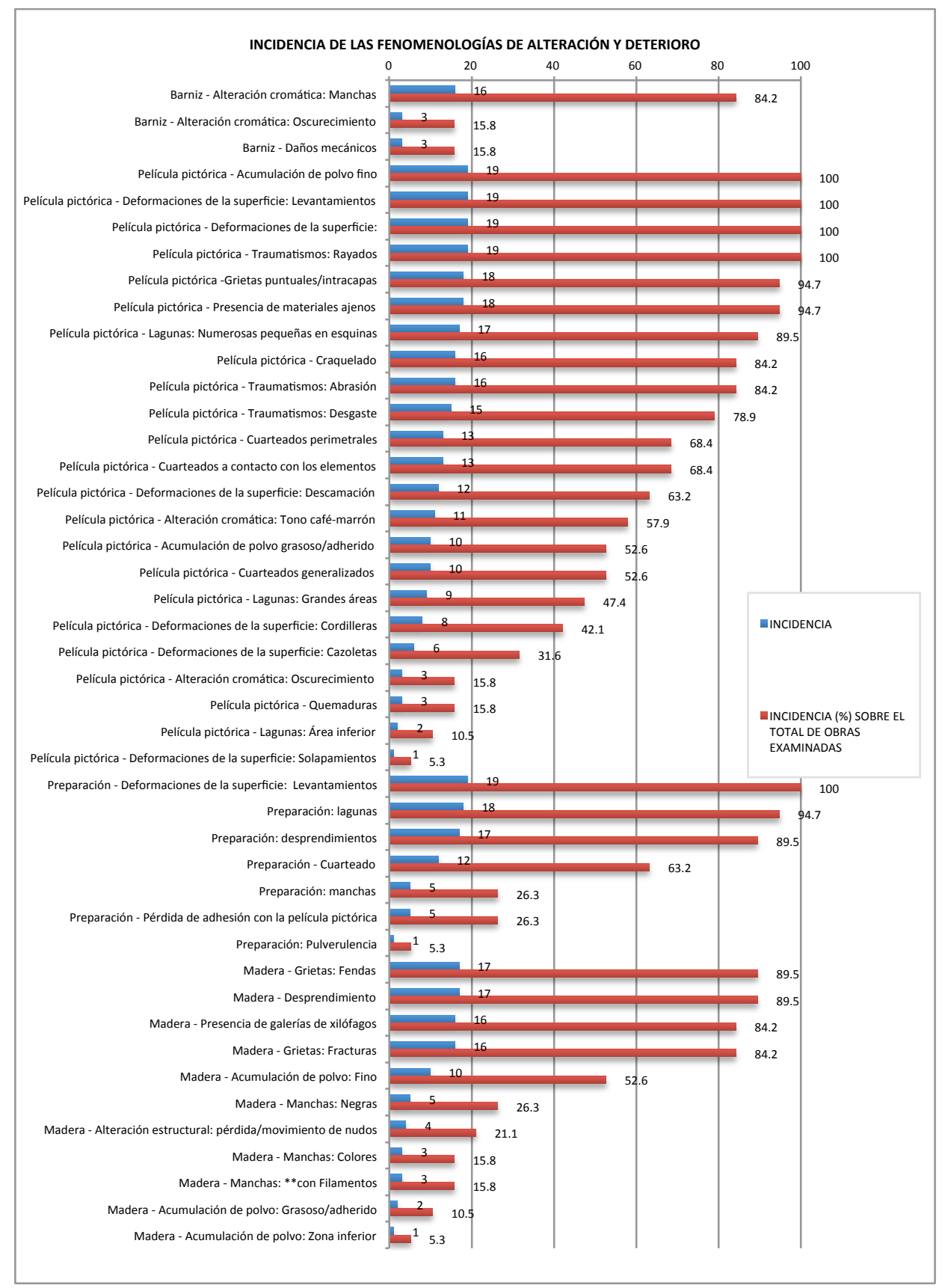

Gráfica 23 - Panorámica de las alteraciones y deterioros que están afectando el retablo. 


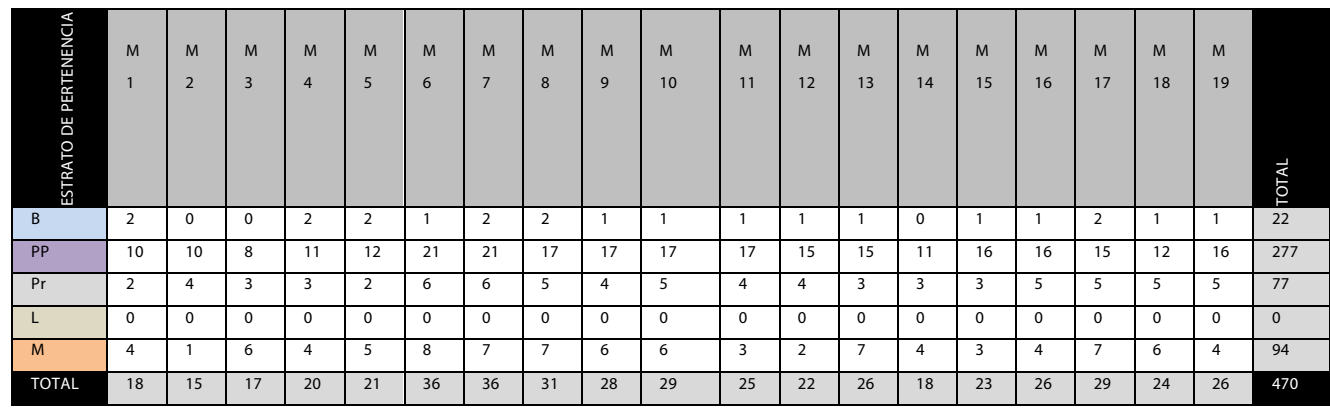

Tabla 76 - Escala de riesgo de los componentes del retablo.

\begin{tabular}{|l|l|}
\hline \multicolumn{2}{|l|}{ INDICADOR DERIESGO } \\
\hline MUESTRA & TOTAL INCIDENCIA DE DETERIORO \\
\hline 6 & 36 \\
\hline 7 & 36 \\
\hline 8 & 31 \\
\hline 10 & 29 \\
\hline 17 & 29 \\
\hline 9 & 28 \\
\hline 13 & 26 \\
\hline 16 & 26 \\
\hline 19 & 26 \\
\hline 11 & 25 \\
\hline 18 & 24 \\
\hline 15 & 23 \\
\hline 12 & 22 \\
\hline 5 & 21 \\
\hline 4 & 20 \\
\hline 1 & 18 \\
\hline 14 & 18 \\
\hline 3 & 17 \\
\hline 2 & 15 \\
\hline & \\
\hline
\end{tabular}




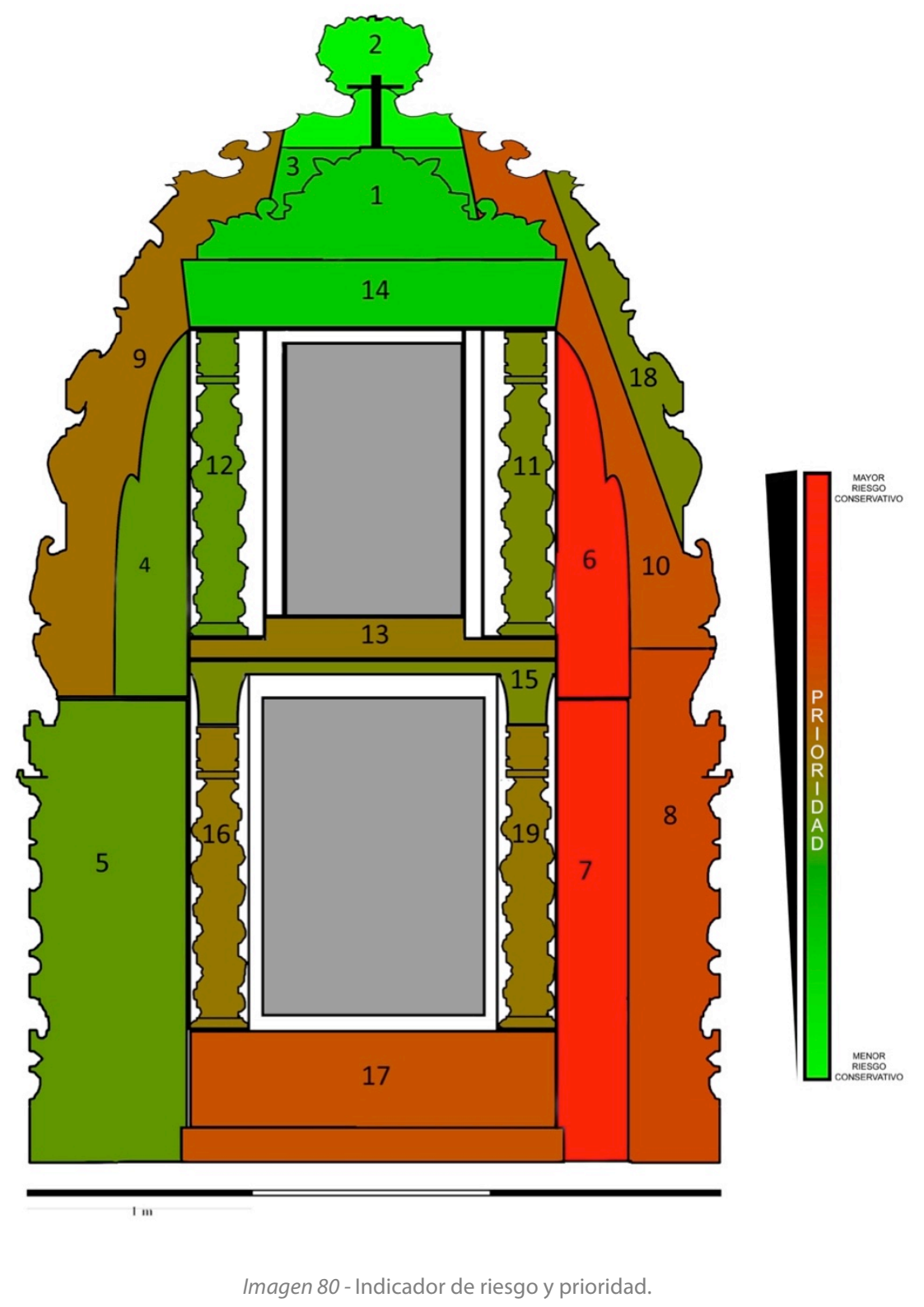


A continuación se presentan las imágenes inherentes los elementos con mayor indicador de riesgo.

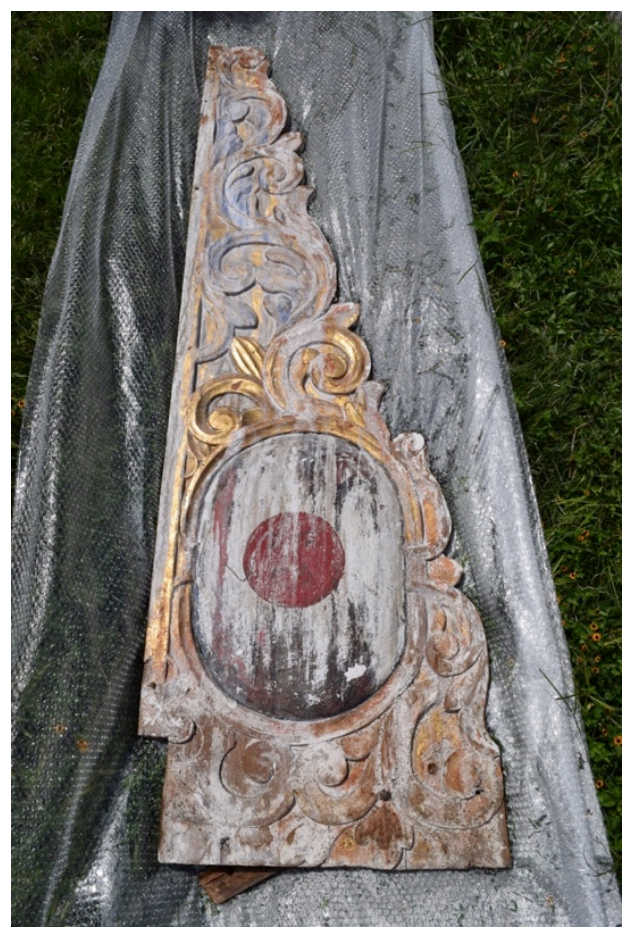

Imagen 81 - Obras con mayor índice de riesgo: M6. Incidencia total de las fenomenologías de alteración y deterioro: 36

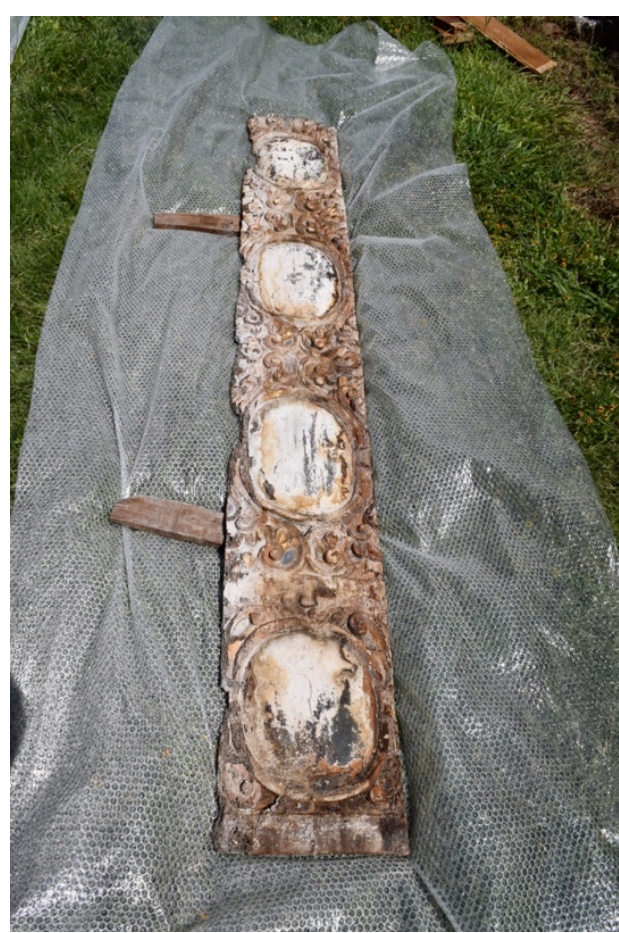

Imagen 82 - Obras con mayor índice de riesgo: M7 (derecha). Incidencia total de las fenomenologías de alteración y deterioro: 36 .

Tabla 77 - Extensión superficial (\%) de las fenomenologías de alteración y deterioro registradas. Muestra 6.

\begin{tabular}{|l|l|l|}
\hline M6 (incidencia de deterioros: 36) & \\
\hline BARNIZ/CAPA DE PROTECCIÓN & $\begin{array}{l}\text { INCIDENCIA } \\
\text { SUPERFICIAL } \\
\text { FENOMENOLOGÍA DE ALTERACIÓN Y DETERIORO }\end{array}$ & $\begin{array}{l}\text { EXTENSIÓN SUPERFICIAL } \\
(\%)\end{array}$ \\
\hline Barniz - Alteración cromática: Manchas & 1 & $0-25$ \\
\hline
\end{tabular}




\section{PELICULA PICTÓRICA}

FENOMENOLOGÍA DE ALTERACIÓN Y DETERIORO

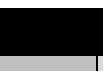

\begin{tabular}{|l|} 
\\
\hline Película pictórica - Lagunas: Área inferior \\
\hline Película pictórica - Cuarteados generalizados \\
\hline Película pictórica - Craquelado \\
\hline Película pictórica - Acumulación de polvo fino
\end{tabular}

Película pictórica - Deformaciones de la superficie:

Descamación

\begin{tabular}{|l|l|}
\hline $\begin{array}{l}\text { INCIDENCIA } \\
\text { SUPERFICIAL }\end{array}$ & $\begin{array}{l}\text { EXTENSIÓN SUPERFICIAL } \\
(\%)\end{array}$ \\
\hline 4 & $75-100$ \\
\hline 3 & $50-75$
\end{tabular}

Película pictórica - Deformaciones de la superficie:

Levantamientos
Pelicula

Película pictórica - Deformaciones de la superficie: Cazoletas

Película pictórica - Deformaciones de la superficie:

Desprendimientos

Película pictórica - Grietas puntuales/intracapas

Película pictórica - Lagunas: Numerosas pequeñas en esquinas cuarteados

Película pictórica - Lagunas: Grandes áreas

\begin{tabular}{|l|l}
\hline Película pictórica - Traumatismos: Abrasión & 2 \\
\hline
\end{tabular}

\begin{tabular}{l|l|}
\hline Película pictórica - Traumatismos: Desgaste & \\
\hline $\begin{array}{l}\text { Película pictórica - Acumulación de polvo } \\
\text { grasoso/adherido }\end{array}$ &
\end{tabular}

\begin{tabular}{|l|l|l|}
\hline grasoso/adherido & & $0-25$ \\
\hline Película pictórica - Cuarteados perimetrales & 1 & $0-25$ \\
\hline $\begin{array}{l}\text { Película pictórica - Alteración cromática: Tono café- } \\
\text { marrón }\end{array}$ & 1 & $0-25$ \\
\hline Película pictórica - Alteración cromática: Oscurecimiento & 1 & $0-25$ \\
\hline $\begin{array}{l}\text { Película pictórica - Deformaciones de la superficie: } \\
\text { Cordilleras }\end{array}$ & 1 & $0-25$ \\
\hline Película pictórica - Quemaduras & 1 & $0-25$ \\
\hline Película pictórica - Traumatismos: Rayados & 1 & $0-25$ \\
\hline Película pictórica - Presencia de materiales ajenos & 1 & $0-25$ \\
\hline PREPARAcion & & \\
\hline
\end{tabular}

\begin{tabular}{|c|c|c|}
\hline \multicolumn{3}{|l|}{ PREPARACIÓN } \\
\hline FENOMENOLOGÍA DE ALTERACIÓN Y DETERIORO & $\begin{array}{l}\text { INCIDENCIA } \\
\text { SUPERFICIAL }\end{array}$ & $\begin{array}{l}\text { EXTENSIÓN SUPERFICIAL } \\
(\%)\end{array}$ \\
\hline Preparación: Lagunas & 2 & $25-50$ \\
\hline Preparación: Pulverulencia & 2 & $25-50$ \\
\hline Preparación: Desprendimientos & 2 & $25-50$ \\
\hline $\begin{array}{l}\text { Preparación }-\quad \text { Deformaciones } \\
\text { superficie: Levantamientos }\end{array}$ & 2 & $25-50$ \\
\hline Preparación - Cuarteado & 2 & $25-50$ \\
\hline
\end{tabular}




\begin{tabular}{|l|l|l|}
\hline Preparación: Pérdida de adhesión con la película pictórica & 1 & $0-25$ \\
\hline SOPORTE LíGNEO & $\begin{array}{l}\text { INCIDENCIA } \\
\text { SUPERFICIAL }\end{array}$ & $\begin{array}{l}\text { EXTENSIÓN } \\
(\%)\end{array}$ \\
\hline FENOMENOLOGÍA DE ALTERACIÓN Y DETERIORO & 1 & $0-25$ \\
\hline Madera - Presencia de galerías de xilófagos & 1 & $0-25$ \\
\hline Madera - Grietas: Fracturas & 1 & $0-25$ \\
\hline Madera - Grietas: Fendas & 1 & $0-25$ \\
\hline Madera - Desprendimiento & 1 & $0-25$ \\
\hline Madera - Manchas: Colores & 1 & $0-25$ \\
\hline Madera - Manchas: Negras & 1 & $0-25$ \\
\hline Madera - Manchas: con filamentos & 1 & $0-25$ \\
\hline $\begin{array}{l}\text { Madera - Alteración estructural: pérdida/movimiento de } \\
\text { nudos }\end{array}$ & & \\
\hline
\end{tabular}

Tabla 78 - Extensión superficial (\%) de las fenomenologías de alteración y deterioro registradas. Muestra 7.

M7 (incidencia de deterioros: 36 )

\section{BARNIZ/CAPA DE PROTECCIÓN}

\begin{tabular}{|l|l|l|}
\hline FENOMENOLOGÍA DE ALTERACIÓN Y DETERIORO & $\begin{array}{l}\text { INCIDENCIA } \\
\text { SUPERFICIAL }\end{array}$ & EXTENSIÓN SUPERFICIAL (\%) \\
\hline Barniz - Alteración cromática: Oscurecimiento & 3 & $50-75$ \\
\hline Barniz - Alteración cromática: Manchas & 2 & $25-50$ \\
\hline \begin{tabular}{l} 
PELÍCULA PICTÓRICA \\
\hline FENOMENOLOGÍA DE ALTERACIÓN Y DETERIORO
\end{tabular} & $\begin{array}{l}\text { INCIDENCIA } \\
\text { SUPERFICIAL }\end{array}$ & EXTENSIÓN SUPERFICIAL (\%) \\
\hline Película pictórica - Cuarteados perimetrales & 4 & $75-100$ \\
\hline Película pictórica - Cuarteados generalizados & 4 & $75-100$ \\
\hline Película pictórica - Craquelado & 4 & $75-100$ \\
\hline Película pictórica - Alteración cromática: Tono café-marrón & 4 & $75-100$ \\
\hline $\begin{array}{l}\text { Película pictórica - Deformaciones de la superficie: } \\
\text { Descamación }\end{array}$ & 4 & $75-100$ \\
\hline $\begin{array}{l}\text { Película pictórica - Deformaciones de la superficie: } \\
\text { Levantamientos }\end{array}$ & 4 & $75-100$ \\
\hline Película pictórica - Lagunas: Área inferior & 4 & $75-100$ \\
\hline $\begin{array}{l}\text { Película pictórica - Deformaciones de la superficie: } \\
\text { Desprendimientos }\end{array}$ & 3 & $50-75$ \\
\hline
\end{tabular}




\begin{tabular}{|c|c|c|}
\hline $\begin{array}{l}\text { Película pictórica - Lagunas: Numerosas pequeñas en } \\
\text { esquinas cuarteados }\end{array}$ & 3 & $50-75$ \\
\hline Película pictórica - Lagunas: Grandes áreas & 3 & $50-75$ \\
\hline Película pictórica - Acumulación de polvo fino & 2 & $25-50$ \\
\hline Película pictórica - Alteración cromática: Oscurecimiento & 2 & $25-50$ \\
\hline $\begin{array}{l}\text { Película pictórica - Deformaciones de la superficie: } \\
\text { Cazoletas }\end{array}$ & 2 & $25-50$ \\
\hline Película pictórica - Grietas puntuales/intracapas & 2 & $25-50$ \\
\hline Película pictórica - Traumatismos: Desgaste & 2 & $25-50$ \\
\hline $\begin{array}{l}\text { Película pictórica } \\
\text { grasoso/adherido }\end{array}$ & 1 & $0-25$ \\
\hline $\begin{array}{l}\text { Película pictórica - Deformaciones de la superficie: } \\
\text { Cordilleras }\end{array}$ & 1 & $0-25$ \\
\hline Película pictórica - Quemaduras & 1 & $0-25$ \\
\hline Película pictórica - Traumatismos: Rayados & 1 & $0-25$ \\
\hline Película pictórica - Traumatismos: Abrasión & 1 & $0-25$ \\
\hline Película pictórica - Presencia de materiales ajenos & 1 & $0-25$ \\
\hline \multicolumn{3}{|l|}{ PREPARACIÓN } \\
\hline FENOMENOLOGÍA DE ALTERACIÓN Y DETERIORO & $\begin{array}{l}\text { INCIDENCIA } \\
\text { SUPERFICIAL }\end{array}$ & EXTENSIÓN SUPERFICIAL (\%) \\
\hline Preparación: Lagunas & 3 & $50-75$ \\
\hline Preparación: Pérdida de adhesión con la película pictórica & 2 & $25-50$ \\
\hline Preparación: Desprendimientos & 2 & $25-50$ \\
\hline $\begin{array}{l}\text { Preparación }-\quad \text { Deformaciones } \\
\text { superficie: Levantamientos }\end{array}$ & 2 & $25-50$ \\
\hline Preparación - Cuarteado & 2 & $25-50$ \\
\hline Preparación: Manchas & 1 & $0-25$ \\
\hline \multicolumn{3}{|l|}{ SOPORTE LÍGNEO } \\
\hline FENOMENOLOGÍA DE ALTERACIÓN Y DETERIORO & $\begin{array}{l}\text { INCIDENCIA } \\
\text { SUPERFICIAL }\end{array}$ & EXTENSIÓN SUPERFICIAL (\%) \\
\hline Madera - Acumulación de polvo: Fino & 4 & $75-100$ \\
\hline Madera - Presencia de galerías de xilófagos & 3 & $50-75$ \\
\hline Madera - Manchas: Colores & 2 & $25-50$ \\
\hline Madera - Grietas: Fracturas & 1 & $0-25$ \\
\hline Madera - Grietas: Fendas & 1 & $0-25$ \\
\hline Madera - Desprendimiento & 1 & $0-25$ \\
\hline Madera - Manchas: Negras & 1 & $0-25$ \\
\hline
\end{tabular}


Tabla 79 - Extensión superficial (\%) de las fenomenologías de alteración y deterioro registradas. Muestra 8.

\begin{tabular}{|c|c|c|}
\hline \multicolumn{3}{|l|}{ M8 (incidencia de deterioros: 31 ) } \\
\hline \multicolumn{3}{|l|}{ BARNIZ/CAPA DE PROTECCIÓN } \\
\hline FENOMENOLOGÍA DE ALTERACIÓN Y DETERIORO & $\begin{array}{l}\text { INCIDENCIA } \\
\text { SUPERFICIAL }\end{array}$ & EXTENSIÓN SUPERFICIAL (\%) \\
\hline Barniz - Alteración cromática: Oscurecimiento & 1 & $0-25$ \\
\hline Barniz - Alteración cromática: Manchas & 1 & $0-25$ \\
\hline \multicolumn{3}{|l|}{ PELÍCULA PICTÓRICA } \\
\hline FENOMENOLOGÍA DE ALTERACIÓN Y DETERIORO & $\begin{array}{l}\text { INCIDENCIA } \\
\text { SUPERFICIAL }\end{array}$ & EXTENSIÓN SUPERFICIAL (\%) \\
\hline Película pictórica - Cuarteados perimetrales & 3 & $50-75$ \\
\hline Película pictórica - Acumulación de polvo fino & 2 & $25-50$ \\
\hline $\begin{array}{l}\text { Película pictórica - Cuarteados a contacto con los } \\
\text { elementos estructurales del bastidor }\end{array}$ & 2 & $25-50$ \\
\hline Película pictórica - Craquelado & 2 & $25-50$ \\
\hline $\begin{array}{l}\text { Película pictórica - Alteración cromática: Tono café- } \\
\text { marrón }\end{array}$ & 2 & $25-50$ \\
\hline $\begin{array}{l}\text { Película pictórica - Deformaciones de la superficie: } \\
\text { Descamación }\end{array}$ & 2 & $25-50$ \\
\hline $\begin{array}{l}\text { Película pictórica - Deformaciones de la superficie: } \\
\text { Levantamientos }\end{array}$ & 2 & $25-50$ \\
\hline $\begin{array}{l}\text { Película pictórica - Deformaciones de la superficie: } \\
\text { Desprendimientos }\end{array}$ & 2 & $25-50$ \\
\hline $\begin{array}{l}\text { Película pictórica - Lagunas: Numerosas pequeñas en } \\
\text { esquinas cuarteados }\end{array}$ & 2 & $25-50$ \\
\hline Película pictórica - Alteración cromática: Oscurecimiento & 1 & $0-25$ \\
\hline $\begin{array}{l}\text { Película pictórica - Deformaciones de la superficie: } \\
\text { Cordilleras }\end{array}$ & 1 & $0-25$ \\
\hline $\begin{array}{l}\text { Película pictórica - Deformaciones de la superficie: } \\
\text { Cazoletas }\end{array}$ & 1 & $0-25$ \\
\hline Película pictórica - Grietas puntuales/intracapas & 1 & $0-25$ \\
\hline Película pictórica - Traumatismos: Rayados & 1 & $0-25$ \\
\hline Película pictórica - Traumatismos: Abrasión & 1 & $0-25$ \\
\hline Película pictórica - Traumatismos: Desgaste & 1 & $0-25$ \\
\hline Película pictórica - Presencia de materiales ajenos & 1 & $0-25$ \\
\hline \multicolumn{3}{|l|}{ PREPARACIÓN } \\
\hline FENOMENOLOGÍA DE ALTERACIÓN Y DETERIORO & $\begin{array}{l}\text { INCIDENCIA } \\
\text { SUPERFICIAL }\end{array}$ & EXTENSIÓN SUPERFICIAL (\%) \\
\hline $\begin{array}{l}\text { Preparación }-\quad \text { Deformaciones } \\
\text { superficie: Levantamientos }\end{array}$ & 2 & $25-50$ \\
\hline Preparación - Cuarteado & 2 & $25-50$ \\
\hline
\end{tabular}




\begin{tabular}{|l|l|l|}
\hline Preparación: Manchas & 1 & $0-25$ \\
\hline Preparación: Lagunas & 1 & $0-25$ \\
\hline Preparación: Pérdida de adhesión con la película pictórica & 1 & $0-25$ \\
\hline $\begin{array}{l}\text { SOPORTE LíGNEO } \\
\text { FENOMENOLOGÍA DE ALTERACIÓN Y DETERIORO }\end{array}$ & $\begin{array}{l}\text { INCIDENCIA } \\
\text { SUPERFICIAL }\end{array}$ & \multicolumn{2}{|l|}{ EXTENSIÓN SUPERFICIAL (\%) } \\
\hline Madera - Acumulación de polvo: Fino & 4 & $75-100$ \\
\hline Madera - Presencia de galerías de xilófagos & 2 & $25-50$ \\
\hline Madera - Grietas: Fracturas & 1 & $0-25$ \\
\hline Madera - Grietas: Fendas & 1 & $0-25$ \\
\hline Madera - Desprendimiento & 1 & $0-25$ \\
\hline Madera - Manchas: Colores & 1 & $0-25$ \\
\hline Madera - Manchas: Negras & 1 & $0-25$ \\
\hline
\end{tabular}

Tabla 80 - Extensión superficial (\%) de las fenomenologías de alteración y deterioro registradas. Muestra 10.

\begin{tabular}{|c|c|c|}
\hline \multicolumn{3}{|l|}{ M10 (incidencia de deterioros: 29 ) } \\
\hline \multicolumn{3}{|l|}{ BARNIZ/CAPA DE PROTECCIÓN } \\
\hline FENOMENOLOGÍA DE ALTERACIÓN Y DETERIORO & $\begin{array}{l}\text { INCIDENCIA } \\
\text { SUPERFICIAL }\end{array}$ & EXTENSIÓN SUPERFICIAL (\%) \\
\hline Barniz - Alteración cromática: Manchas & 1 & $0-25$ \\
\hline \multicolumn{3}{|l|}{ PELICULA PICTÓRICA } \\
\hline FENOMENOLOGÍA DE ALTERACIÓN Y DETERIORO & $\begin{array}{l}\text { INCIDENCIA } \\
\text { SUPERFICIAL }\end{array}$ & EXTENSIÓN SUPERFICIAL (\%) \\
\hline $\begin{array}{l}\text { Película pictórica - Deformaciones de la superficie: } \\
\text { Descamación }\end{array}$ & 3 & $50-75$ \\
\hline Película pictórica - Lagunas: Grandes áreas & 3 & $50-75$ \\
\hline Película pictórica - Acumulación de polvo fino & 2 & $25-50$ \\
\hline Película pictórica - Cuarteados generalizados & 2 & $25-50$ \\
\hline Película pictórica - Craquelado & 2 & $25-50$ \\
\hline $\begin{array}{l}\text { Película pictórica - Deformaciones de la superficie: } \\
\text { Levantamientos }\end{array}$ & 2 & $25-50$ \\
\hline $\begin{array}{l}\text { Película pictórica - Deformaciones de la superficie: } \\
\text { Cordilleras }\end{array}$ & 2 & $25-50$ \\
\hline $\begin{array}{l}\text { Película pictórica - Deformaciones de la superficie: } \\
\text { Desprendimientos }\end{array}$ & 2 & $25-50$ \\
\hline
\end{tabular}




\begin{tabular}{|c|c|c|}
\hline Película pictórica - Grietas puntuales/intracapas & 2 & $25-50$ \\
\hline $\begin{array}{l}\text { Película pictórica - Cuarteados a contacto con los } \\
\text { elementos estructurales del bastidor }\end{array}$ & 1 & $0-25$ \\
\hline $\begin{array}{l}\text { Película pictórica - Alteración cromática: Tono café- } \\
\text { marrón }\end{array}$ & 1 & $0-25$ \\
\hline $\begin{array}{l}\text { Película pictórica - Deformaciones de la superficie: } \\
\text { Cazoletas }\end{array}$ & 1 & $0-25$ \\
\hline $\begin{array}{l}\text { Película pictórica - Lagunas: Numerosas pequeñas en } \\
\text { esquinas cuarteados }\end{array}$ & 1 & $0-25$ \\
\hline Película pictórica - Traumatismos: Rayados & 1 & $0-25$ \\
\hline Película pictórica - Traumatismos: Abrasión & 1 & $0-25$ \\
\hline Película pictórica - Traumatismos: Desgaste & 1 & $0-25$ \\
\hline Película pictórica - Presencia de materiales ajenos & 1 & $0-25$ \\
\hline \multicolumn{3}{|l|}{ PREPARACIÓN } \\
\hline FENOMENOLOGÍA DE ALTERACIÓN Y DETERIORO & $\begin{array}{l}\text { INCIDENCIA } \\
\text { SUPERFICIAL }\end{array}$ & EXTENSIÓN SUPERFICIAL (\%) \\
\hline Preparación: Lagunas & 2 & $25-50$ \\
\hline Preparación: Desprendimientos & 2 & $25-50$ \\
\hline $\begin{array}{llll}\text { Preparación } & \text { Deformaciones } & \text { de } & \text { la } \\
\text { superficie: Levantamientos } & & & \end{array}$ & 2 & $25-50$ \\
\hline Preparación: Manchas & 1 & $0-25$ \\
\hline Preparación - Cuarteado & 1 & $0-25$ \\
\hline \multicolumn{3}{|l|}{ SOPORTE LÍGNEO } \\
\hline FENOMENOLOGÍA DE ALTERACIÓN Y DETERIORO & $\begin{array}{l}\text { INCIDENCIA } \\
\text { SUPERFICIAL }\end{array}$ & EXTENSIÓN SUPERFICIAL (\%) \\
\hline Madera - Acumulación de polvo: Fino & 4 & $75-100$ \\
\hline Madera - Presencia de galerías de xilófagos & 2 & $25-50$ \\
\hline Madera - Grietas: Fracturas & 1 & $0-25$ \\
\hline Madera - Grietas: Fendas & 1 & $0-25$ \\
\hline Madera-Desprendimiento & 1 & $0-25$ \\
\hline Madera - Manchas: Negras & 1 & $0-25$ \\
\hline
\end{tabular}




\begin{tabular}{|c|c|c|}
\hline \multicolumn{3}{|l|}{ M17 (incidencia de deterioros: 29) } \\
\hline \multicolumn{3}{|l|}{ BARNIZ/CAPA DE PROTECCIÓN } \\
\hline FENOMENOLOGÍA DE ALTERACIÓN Y DETERIORO & $\begin{array}{l}\text { INCIDENCIA } \\
\text { SUPERFICIAL }\end{array}$ & EXTENSIÓN SUPERFICIAL (\%) \\
\hline Barniz - Alteración cromática: Manchas & 1 & $0-25$ \\
\hline Barniz - Daños mecánicos & 1 & $0-25$ \\
\hline \multicolumn{3}{|l|}{ PELÍCULA PICTÓRICA } \\
\hline FENOMENOLOGÍA DE ALTERACIÓN Y DETERIORO & $\begin{array}{l}\text { INCIDENCIA } \\
\text { SUPERFICIAL }\end{array}$ & EXTENSIÓN SUPERFICIAL (\%) \\
\hline Película pictórica - Acumulación de polvo fino & 2 & $25-50$ \\
\hline Película pictórica - Cuarteados generalizados & 2 & $25-50$ \\
\hline Película pictórica - Craquelado & 2 & $25-50$ \\
\hline $\begin{array}{l}\text { Película pictórica - Cuarteados a contacto con los } \\
\text { elementos estructurales del bastidor }\end{array}$ & 1 & $0-25$ \\
\hline $\begin{array}{l}\text { Película pictórica - Alteración cromática: Tono café- } \\
\text { marrón }\end{array}$ & 1 & $0-25$ \\
\hline $\begin{array}{l}\text { Película pictórica - Deformaciones de la superficie: } \\
\text { Levantamientos }\end{array}$ & 1 & $0-25$ \\
\hline $\begin{array}{l}\text { Película pictórica - Deformaciones de la superficie: } \\
\text { Cordilleras }\end{array}$ & 1 & $0-25$ \\
\hline $\begin{array}{l}\text { Película pictórica - Deformaciones de la superficie: } \\
\text { Cazoletas }\end{array}$ & 1 & $0-25$ \\
\hline $\begin{array}{l}\text { Película pictórica - Deformaciones de la superficie: } \\
\text { Desprendimientos }\end{array}$ & 1 & $0-25$ \\
\hline Película pictórica - Grietas puntuales/intracapas & 1 & $0-25$ \\
\hline Película pictórica - Lagunas: Grandes áreas & 1 & $0-25$ \\
\hline Película pictórica - Traumatismos: Rayados & 1 & $0-25$ \\
\hline Película pictórica - Traumatismos: Abrasión & 1 & $0-25$ \\
\hline Película pictórica - Traumatismos: Desgaste & 1 & $0-25$ \\
\hline Película pictórica - Presencia de materiales ajenos & 1 & $0-25$ \\
\hline \multicolumn{3}{|l|}{ PREPARACIÓN } \\
\hline FENOMENOLOGÍA DE ALTERACIÓN Y DETERIORO & $\begin{array}{l}\text { INCIDENCIA } \\
\text { SUPERFICIAL }\end{array}$ & EXTENSIÓN SUPERFICIAL (\%) \\
\hline Preparación - Cuarteado & 2 & $25-50$ \\
\hline Preparación: Manchas & 1 & $0-25$ \\
\hline Preparación: Lagunas & 1 & $0-25$ \\
\hline Preparación: Desprendimientos & 1 & $0-25$ \\
\hline $\begin{array}{lll}\text { Preparación } & - & \text { Deformaciones }\end{array}$ & 1 & $0-25$ \\
\hline
\end{tabular}




\begin{tabular}{|l|l|l|}
\hline superficie: Levantamientos & \multicolumn{2}{|l|}{} \\
\hline SOPORTE LígNEO & $\begin{array}{l}\text { INCIDENCIA } \\
\text { SUPERFICIAL }\end{array}$ & EXTENSIÓN SUPERFICIAL (\%) \\
\hline FENOMENOLOGÍA DE ALTERACIÓN Y DETERIORO & 4 & $75-100$ \\
\hline Madera - Acumulación de polvo: Fino & 1 & $0-25$ \\
\hline Madera - Presencia de galerías de xilófagos & 1 & $0-25$ \\
\hline Madera - Grietas: Fracturas & 1 & $0-25$ \\
\hline Madera - Grietas: Fendas & 1 & $0-25$ \\
\hline Madera - Desprendimiento & 1 & $0-25$ \\
\hline Madera - Manchas: con filamentos & 1 & $0-25$ \\
\hline Madera - Acumulación de polvo: Grasoso/adherido & & \\
\hline
\end{tabular}

Tabla 82 - Extensión superficial (\%) de las fenomenologías de alteración y deterioro registradas. Muestra 9.

\begin{tabular}{|c|c|c|}
\hline \multicolumn{3}{|l|}{ M9 (incidencia de deterioros: 28 ) } \\
\hline \multicolumn{3}{|l|}{ BARNIZ/CAPA DE PROTECCIÓN } \\
\hline FENOMENOLOGÍA DE ALTERACIÓN Y DETERIORO & $\begin{array}{l}\text { INCIDENCIA } \\
\text { SUPERFICIAL }\end{array}$ & EXTENSIÓN SUPERFICIAL (\%) \\
\hline Barniz - Alteración cromática: Manchas & 3 & $50-75$ \\
\hline \multicolumn{3}{|l|}{ PELÍCULA PICTÓRICA } \\
\hline FENOMENOLOGÍA DE ALTERACIÓN Y DETERIORO & $\begin{array}{l}\text { INCIDENCIA } \\
\text { SUPERFICIAL }\end{array}$ & EXTENSIÓN SUPERFICIAL (\%) \\
\hline Película pictórica - Acumulación de polvo fino & 2 & $25-50$ \\
\hline Película pictórica - Cuarteados perimetrales & 2 & $25-50$ \\
\hline Película pictórica - Craquelado & 2 & $25-50$ \\
\hline $\begin{array}{l}\text { Película pictórica - Cuarteados a contacto con los } \\
\text { elementos estructurales del bastidor }\end{array}$ & 1 & $0-25$ \\
\hline Película pictórica - Cuarteados generalizados & 1 & $0-25$ \\
\hline $\begin{array}{l}\text { Película pictórica - Deformaciones de la superficie: } \\
\text { Descamación }\end{array}$ & 1 & $0-25$ \\
\hline $\begin{array}{l}\text { Película pictórica - Deformaciones de la superficie: } \\
\text { Levantamientos }\end{array}$ & 1 & $0-25$ \\
\hline $\begin{array}{l}\text { Película pictórica - Deformaciones de la superficie: } \\
\text { Cordilleras }\end{array}$ & 1 & $0-25$ \\
\hline $\begin{array}{l}\text { Película pictórica - Deformaciones de la superficie: } \\
\text { Cazoletas }\end{array}$ & 1 & $0-25$ \\
\hline $\begin{array}{l}\text { Película pictórica - Deformaciones de la superficie: } \\
\text { Desprendimientos }\end{array}$ & 1 & $0-25$ \\
\hline Película pictórica - Grietas puntuales/intracapas & 1 & $0-25$ \\
\hline Película pictórica - Lagunas: Numerosas pequeñas en & 1 & $0-25$ \\
\hline
\end{tabular}




\begin{tabular}{|c|c|c|}
\hline \multicolumn{3}{|l|}{ esquinas cuarteados } \\
\hline Película pictórica - Lagunas: Grandes áreas & 1 & $0-25$ \\
\hline Película pictórica - Traumatismos: Rayados & 1 & $0-25$ \\
\hline Película pictórica - Traumatismos: Abrasión & 1 & $0-25$ \\
\hline Película pictórica - Traumatismos: Desgaste & 1 & $0-25$ \\
\hline Película pictórica - Presencia de materiales ajenos & 1 & $0-25$ \\
\hline \multicolumn{3}{|l|}{ PREPARACIÓN } \\
\hline FENOMENOLOGÍA DE ALTERACIÓN Y DETERIORO & $\begin{array}{l}\text { INCIDENCIA } \\
\text { SUPERFICIAL }\end{array}$ & EXTENSIÓN SUPERFICIAL (\%) \\
\hline Preparación: Lagunas & 1 & $0-25$ \\
\hline Preparación: Desprendimientos & 1 & $0-25$ \\
\hline 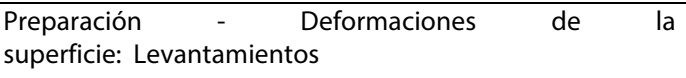 & 1 & $0-25$ \\
\hline Preparación - Cuarteado & 1 & $0-25$ \\
\hline \multicolumn{3}{|l|}{ SOPORTE LÍGNEO } \\
\hline FENOMENOLOGÍA DE ALTERACIÓN Y DETERIORO & $\begin{array}{l}\text { INCIDENCIA } \\
\text { SUPERFICIAL }\end{array}$ & EXTENSIÓN SUPERFICIAL (\%) \\
\hline Madera - Acumulación de polvo: Fino & 4 & $75-100$ \\
\hline Madera - Presencia de galerías de xilófagos & 1 & $0-25$ \\
\hline Madera - Grietas: Fracturas & 1 & $0-25$ \\
\hline Madera - Grietas: Fendas & 1 & $0-25$ \\
\hline Madera - Desprendimiento & 1 & $0-25$ \\
\hline Madera - Manchas: Negras & 1 & $0-25$ \\
\hline
\end{tabular}

Tabla 83 - Extensión superficial (\%) de las fenomenologías de alteración y deterioro registradas. Muestra 13.

\begin{tabular}{|c|c|c|}
\hline \multicolumn{3}{|l|}{ M13 (incidencia de deterioros: 26 ) } \\
\hline \multicolumn{3}{|l|}{ BARNIZ/CAPA DE PROTECCIÓN } \\
\hline FENOMENOLOGÍA DE ALTERACIÓN Y DETERIORO & $\begin{array}{l}\text { INCIDENCIA } \\
\text { SUPERFICIAL }\end{array}$ & EXTENSIÓN SUPERFICIAL (\%) \\
\hline Barniz - Alteración cromática: Manchas & 1 & $0-25$ \\
\hline \multicolumn{3}{|l|}{ PELÍCULA PICTÓRICA } \\
\hline FENOMENOLOGÍA DE ALTERACIÓN Y DETERIORO & $\begin{array}{l}\text { INCIDENCIA } \\
\text { SUPERFICIAL }\end{array}$ & EXTENSIÓN SUPERFICIAL (\%) \\
\hline Película pictórica - Acumulación de polvo fino & 2 & $25-50$ \\
\hline Película pictórica - Lagunas: Grandes áreas & 2 & $25-50$ \\
\hline Película pictórica - Traumatismos: Abrasión & 2 & $25-50$ \\
\hline
\end{tabular}




\begin{tabular}{|c|c|c|}
\hline Película pictórica - Traumatismos: Desgaste & 2 & $25-50$ \\
\hline $\begin{array}{l}\text { Película pictórica } \\
\text { grasoso/adherido }\end{array}$ & 1 & $0-25$ \\
\hline Película pictórica - Cuarteados perimetrales & 1 & $0-25$ \\
\hline $\begin{array}{l}\text { Película pictórica - Cuarteados a contacto con los } \\
\text { elementos estructurales del bastidor }\end{array}$ & 1 & $0-25$ \\
\hline Película pictórica - Craquelado & 1 & $0-25$ \\
\hline $\begin{array}{l}\text { Película pictórica - Alteración cromática: Tono café- } \\
\text { marrón }\end{array}$ & 1 & $0-25$ \\
\hline $\begin{array}{l}\text { Película pictórica - Deformaciones de la superficie: } \\
\text { Levantamientos }\end{array}$ & 1 & $0-25$ \\
\hline $\begin{array}{l}\text { Película pictórica - Deformaciones de la superficie: } \\
\text { Desprendimientos }\end{array}$ & 1 & $0-25$ \\
\hline Película pictórica - Grietas puntuales/intracapas & 1 & $0-25$ \\
\hline $\begin{array}{l}\text { Película pictórica - Lagunas: Numerosas pequeñas en } \\
\text { esquinas cuarteados }\end{array}$ & 1 & $0-25$ \\
\hline Película pictórica - Traumatismos: Rayados & 1 & $0-25$ \\
\hline Película pictórica - Presencia de materiales ajenos & 1 & $0-25$ \\
\hline \multicolumn{3}{|l|}{ PREPARACIÓN } \\
\hline FENOMENOLOGÍA DE ALTERACIÓN Y DETERIORO & $\begin{array}{l}\text { INCIDENCIA } \\
\text { SUPERFICIAL }\end{array}$ & EXTENSIÓN SUPERFICIAL (\%) \\
\hline Preparación: Lagunas & 1 & $0-25$ \\
\hline Preparación: Desprendimientos & 1 & $0-25$ \\
\hline $\begin{array}{llll}\text { Preparación } & \text { Deformaciones } & \text { de } & \text { la } \\
\text { superficie: Levantamientos } & & & \end{array}$ & 1 & $0-25$ \\
\hline \multicolumn{3}{|l|}{ SOPORTE LIGGNO } \\
\hline FENOMENOLOGÍA DE ALTERACIÓN Y DETERIORO & $\begin{array}{l}\text { INCIDENCIA } \\
\text { SUPERFICIAL }\end{array}$ & EXTENSIÓN SUPERFICIAL (\%) \\
\hline Madera - Acumulación de polvo: Grasoso/adherido & 4 & $75-100$ \\
\hline Madera - Presencia de galerías de xilófagos & 1 & $0-25$ \\
\hline Madera - Grietas: Fracturas & 1 & $0-25$ \\
\hline Madera - Grietas: Fendas & 1 & $0-25$ \\
\hline Madera - Desprendimiento & 1 & $0-25$ \\
\hline Madera - Manchas: con filamentos & 1 & $0-25$ \\
\hline Madera - Acumulación de polvo: Zona inferior & 1 & $0-25$ \\
\hline
\end{tabular}




\begin{tabular}{|c|c|c|}
\hline \multicolumn{3}{|l|}{ M16 (incidencia de deterioros: 26 ) } \\
\hline \multicolumn{3}{|l|}{ BARNIZ/CAPA DE PROTECCIÓN } \\
\hline FENOMENOLOGÍA DE ALTERACIÓN Y DETERIORO & $\begin{array}{l}\text { INCIDENCIA } \\
\text { SUPERFICIAL }\end{array}$ & EXTENSIÓN SUPERFICIAL (\%) \\
\hline Barniz - Alteración cromática: Manchas & 1 & $0-25$ \\
\hline \multicolumn{3}{|l|}{ PELICULA PICTÓRICA } \\
\hline FENOMENOLOGÍA DE ALTERACIÓN Y DETERIORO & $\begin{array}{l}\text { INCIDENCIA } \\
\text { SUPERFICIAL }\end{array}$ & EXTENSIÓN SUPERFICIAL (\%) \\
\hline Película pictórica - Acumulación de polvo fino & 4 & $75-100$ \\
\hline Película pictórica - Cuarteados generalizados & 3 & $50-75$ \\
\hline Película pictórica - Grietas puntuales/intracapas & 3 & $50-75$ \\
\hline $\begin{array}{lllll}\begin{array}{l}\text { Película pictórica } \\
\text { grasoso/adherido }\end{array} & \text { Acumulación } & \text { de } & \text { polvo } \\
\end{array}$ & 1 & $0-25$ \\
\hline Película pictórica - Cuarteados perimetrales & 1 & $0-25$ \\
\hline $\begin{array}{l}\text { Película pictórica - Cuarteados a contacto con los } \\
\text { elementos estructurales del bastidor }\end{array}$ & 1 & $0-25$ \\
\hline Película pictórica - Craquelado & 1 & $0-25$ \\
\hline $\begin{array}{l}\text { Película pictórica - Alteración cromática: Tono café- } \\
\text { marrón }\end{array}$ & 1 & $0-25$ \\
\hline $\begin{array}{l}\text { Película pictórica - Deformaciones de la superficie: } \\
\text { Descamación }\end{array}$ & 1 & $0-25$ \\
\hline $\begin{array}{l}\text { Película pictórica - Deformaciones de la superficie: } \\
\text { Levantamientos }\end{array}$ & 1 & $0-25$ \\
\hline $\begin{array}{l}\text { Película pictórica - Deformaciones de la superficie: } \\
\text { Desprendimientos }\end{array}$ & 1 & $0-25$ \\
\hline $\begin{array}{l}\text { Película pictórica - Lagunas: Numerosas pequeñas en } \\
\text { esquinas cuarteados }\end{array}$ & 1 & $0-25$ \\
\hline Película pictórica - Traumatismos: Rayados & 1 & $0-25$ \\
\hline Película pictórica - Traumatismos: Abrasión & 1 & $0-25$ \\
\hline Película pictórica - Traumatismos: Desgaste & 1 & $0-25$ \\
\hline Película pictórica - Presencia de materiales ajenos & 1 & $0-25$ \\
\hline \multicolumn{3}{|l|}{ PREPARACIÓN } \\
\hline FENOMENOLOGÍA DE ALTERACIÓN Y DETERIORO & $\begin{array}{l}\text { INCIDENCIA } \\
\text { SUPERFICIAL }\end{array}$ & EXTENSIÓN SUPERFICIAL (\%) \\
\hline Preparación: Lagunas & 1 & $0-25$ \\
\hline Preparación: Desprendimientos & 1 & $0-25$ \\
\hline
\end{tabular}




\begin{tabular}{|l|l|l|}
\hline $\begin{array}{l}\text { Preparación - la de } \\
\text { superficie: Levantamientos }\end{array}$ & 1 & $0-25$ \\
\hline Preparación - Cuarteado & 1 & $0-25$ \\
\hline SOPORTE LíGNEO & $\begin{array}{l}\text { INCIDENCIA } \\
\text { SUPERFICIAL }\end{array}$ & \multicolumn{2}{|l|}{ EXTENSIÓN SUPERFICIAL (\%) } \\
\hline FENOMENOLOGÍA DE ALTERACIÓN Y DETERIORO & 1 & $0-25$ \\
\hline Madera - Presencia de galerías de xilófagos & 1 & $0-25$ \\
\hline Madera - Grietas: Fracturas & 1 & $0-25$ \\
\hline Madera - Grietas: Fendas & 1 & $0-25$ \\
\hline Madera - Desprendimiento & & \\
\hline
\end{tabular}

M19 (incidencia de deterioros: 26)

\section{BARNIZ/CAPA DE PROTECCIÓN}

\begin{tabular}{|c|c|c|}
\hline FENOMENOLOGÍA DE ALTERACIÓN Y DETERIORO & $\begin{array}{l}\text { INCIDENCIA } \\
\text { SUPERFICIAL }\end{array}$ & EXTENSIÓN SUPERFICIAL (\%) \\
\hline Barniz - Alteración cromática: Manchas & 1 & $0-25$ \\
\hline \multicolumn{3}{|l|}{ PELICULA PICTÓRICA } \\
\hline FENOMENOLOGÍA DE ALTERACIÓN Y DETERIORO & $\begin{array}{l}\text { INCIDENCIA } \\
\text { SUPERFICIAL }\end{array}$ & EXTENSIÓN SUPERFICIAL (\%) \\
\hline Película pictórica - Acumulación de polvo fino & 4 & $75-100$ \\
\hline Película pictórica - Cuarteados generalizados & 3 & $50-75$ \\
\hline Película pictórica - Grietas puntuales/intracapas & 3 & $50-75$ \\
\hline $\begin{array}{l}\text { Película pictórica }- \text { Acumulación de polvo } \\
\text { grasoso/adherido }\end{array}$ & 1 & $0-25$ \\
\hline Película pictórica - Cuarteados perimetrales & 1 & $0-25$ \\
\hline $\begin{array}{l}\text { Película pictórica - Cuarteados a contacto con los } \\
\text { elementos estructurales del bastidor }\end{array}$ & 1 & $0-25$ \\
\hline Película pictórica - Craquelado & 1 & $0-25$ \\
\hline $\begin{array}{l}\text { Película pictórica - Alteración cromática: Tono café- } \\
\text { marrón }\end{array}$ & 1 & $0-25$ \\
\hline $\begin{array}{l}\text { Película pictórica - Deformaciones de la superficie: } \\
\text { Descamación }\end{array}$ & 1 & $0-25$ \\
\hline $\begin{array}{l}\text { Película pictórica - Deformaciones de la superficie: } \\
\text { Levantamientos }\end{array}$ & 1 & $0-25$ \\
\hline $\begin{array}{l}\text { Película pictórica - Deformaciones de la superficie: } \\
\text { Desprendimientos }\end{array}$ & 1 & $0-25$ \\
\hline
\end{tabular}




\begin{tabular}{|l|l|l|}
\hline $\begin{array}{l}\text { Película pictórica - Lagunas: Numerosas pequeñas en } \\
\text { esquinas cuarteados }\end{array}$ & 1 & $0-25$ \\
\hline Película pictórica - Traumatismos: Rayados & 1 & $0-25$ \\
\hline Película pictórica - Traumatismos: Abrasión & 1 & $0-25$ \\
\hline Película pictórica - Traumatismos: Desgaste & 1 & $0-25$ \\
\hline Película pictórica - Presencia de materiales ajenos & 1 & $0-25$ \\
\hline PREPARACIÓN & $\begin{array}{l}\text { INCIDENCIA } \\
\text { SUPERFICIAL }\end{array}$ & EXTENSIÓN SUPERFICIAL (\%) \\
\hline \begin{tabular}{l} 
FENOMENOLOGÍA DE ALTERACIÓN Y DETERIORO \\
\multicolumn{1}{|c|}{ de }
\end{tabular} & 1 & $0-25$ \\
\hline Preparación: Lagunas & 1 & $0-25$ \\
\hline Preparación: Desprendimientos & 1 & $0-25$ \\
\hline $\begin{array}{l}\text { Preparación } \\
\text { superficie: Levantamientos }\end{array}$ & 1 & $0-25$ \\
\hline Preparación - Cuarteado & $\begin{array}{l}\text { INCIDENCIA } \\
\text { SOPORTE LíGNEO }\end{array}$ & EXTENSIÓN SUPERFICIAL (\%) \\
\hline FENOMENOLOGÍA DE ALTERACIÓN Y DETERIORO & 1 & $0-25$ \\
\hline Madera - Presencia de galerías de xilófagos & 1 & $0-25$ \\
\hline Madera - Grietas: Fracturas & 1 & $0-25$ \\
\hline Madera - Grietas: Fendas & 1 & $0-25$ \\
\hline Madera - Desprendimiento & \\
\hline
\end{tabular}

Tabla 86 - Extensión superficial (\%) de las fenomenologías de alteración y deterioro registradas. Muestra 11.

\begin{tabular}{|l|l|l|}
\hline \multicolumn{2}{|l|}{ M11 (incidencia de deterioros: 25) } \\
\hline BARNIZ/CAPA DE PROTECCIÓN & $\begin{array}{l}\text { INCIDENCIA } \\
\text { SUPERFICIAL }\end{array}$ & EXTENSIÓN SUPERFICIAL (\%) \\
\hline FENOMENOLOGÍA DE ALTERACIÓN Y DETERIORO & 1 & $0-25$ \\
\hline Barniz - Alteración cromática: Manchas & $\begin{array}{l}\text { INCIDENCIA } \\
\text { SUPERFICIAL }\end{array}$ & EXTENSIÓN SUPERFICIAL (\%) \\
\hline PELÍCULA PICTÓRICA & 4 & $75-100$ \\
\hline FENOMENOLOGÍA DE ALTERACIÓN Y DETERIORO & $25-50$ \\
\hline Película pictórica - Acumulación de polvo fino & 2 & $25-50$ \\
\hline $\begin{array}{l}\text { Película pictórica - Cuarteados a contacto con los } \\
\text { elementos estructurales del bastidor }\end{array}$ & 2 & $25-50$ \\
\hline Película pictórica - Cuarteados generalizados & 2 & \\
\hline Película pictórica - Grietas puntuales/intracapas &
\end{tabular}




\begin{tabular}{|c|c|c|}
\hline $\begin{array}{l}\text { Película pictórica }- \text { Acumulación de polvo } \\
\text { grasoso/adherido }\end{array}$ & 1 & $0-25$ \\
\hline Película pictórica - Cuarteados perimetrales & 1 & $0-25$ \\
\hline Película pictórica - Craquelado & 1 & $0-25$ \\
\hline $\begin{array}{l}\text { Película pictórica - Alteración cromática: Tono café- } \\
\text { marrón }\end{array}$ & 1 & $0-25$ \\
\hline $\begin{array}{l}\text { Película pictórica - Deformaciones de la superficie: } \\
\text { Descamación }\end{array}$ & 1 & $0-25$ \\
\hline $\begin{array}{l}\text { Película pictórica - Deformaciones de la superficie: } \\
\text { Levantamientos }\end{array}$ & 1 & $0-25$ \\
\hline $\begin{array}{l}\text { Película pictórica - Deformaciones de la superficie: } \\
\text { Desprendimientos }\end{array}$ & 1 & $0-25$ \\
\hline $\begin{array}{l}\text { Película pictórica - Lagunas: Numerosas pequeñas en } \\
\text { esquinas cuarteados }\end{array}$ & 1 & $0-25$ \\
\hline Película pictórica - Lagunas: Grandes áreas & 1 & $0-25$ \\
\hline Película pictórica - Traumatismos: Rayados & 1 & $0-25$ \\
\hline Película pictórica - Traumatismos: Abrasión & 1 & $0-25$ \\
\hline Película pictórica - Traumatismos: Desgaste & 1 & $0-25$ \\
\hline Película pictórica - Presencia de materiales ajenos & 1 & $0-25$ \\
\hline \multicolumn{3}{|l|}{ PREPARACIÓN } \\
\hline FENOMENOLOGÍA DE ALTERACIÓN Y DETERIORO & $\begin{array}{l}\text { INCIDENCIA } \\
\text { SUPERFICIAL }\end{array}$ & EXTENSIÓN SUPERFICIAL (\%) \\
\hline Preparación: Lagunas & 1 & $0-25$ \\
\hline Preparación: Desprendimientos & 1 & $0-25$ \\
\hline $\begin{array}{l}\text { Preparación }- \text { Deformaciones } \\
\text { superficie: Levantamientos }\end{array}$ & 1 & $0-25$ \\
\hline Preparación - Cuarteado & 1 & $0-25$ \\
\hline \multicolumn{3}{|l|}{ SOPORTE LÍGNEO } \\
\hline FENOMENOLOGÍA DE ALTERACIÓN Y DETERIORO & $\begin{array}{l}\text { INCIDENCIA } \\
\text { SUPERFICIAL }\end{array}$ & EXTENSIÓN SUPERFICIAL (\%) \\
\hline Madera - Grietas: Fracturas & 1 & $0-25$ \\
\hline Madera - Grietas: Fendas & 1 & $0-25$ \\
\hline $\begin{array}{l}\text { Madera - Alteración estructural: pérdida/movimiento de } \\
\text { nudos }\end{array}$ & 1 & $0-25$ \\
\hline Madera - Grietas: Fracturas & 1 & $0-25$ \\
\hline
\end{tabular}




\begin{tabular}{|c|c|c|}
\hline \multicolumn{3}{|l|}{ M18 (incidencia de deterioros: 24 ) } \\
\hline \multicolumn{3}{|l|}{ BARNIZ/CAPA DE PROTECCIÓN } \\
\hline FENOMENOLOGÍA DE ALTERACIÓN Y DETERIORO & $\begin{array}{l}\text { INCIDENCIA } \\
\text { SUPERFICIAL }\end{array}$ & EXTENSIÓN SUPERFICIAL (\%) \\
\hline Barniz - Alteración cromática: Manchas & 1 & $0-25$ \\
\hline \multicolumn{3}{|l|}{ PELÍCULA PICTÓRICA } \\
\hline FENOMENOLOGÍA DE ALTERACIÓN Y DETERIORO & $\begin{array}{l}\text { INCIDENCIA } \\
\text { SUPERFICIAL }\end{array}$ & EXTENSIÓN SUPERFICIAL (\%) \\
\hline Película pictórica - Cuarteados generalizados & 3 & $50-75$ \\
\hline $\begin{array}{l}\text { Película pictórica - Deformaciones de la superficie: } \\
\text { Desprendimientos }\end{array}$ & 3 & $50-75$ \\
\hline Película pictórica - Grietas puntuales/intracapas & 3 & $50-75$ \\
\hline Película pictórica - Lagunas: Grandes áreas & 3 & $50-75$ \\
\hline Película pictórica - Traumatismos: Desgaste & 3 & $50-75$ \\
\hline Película pictórica - Acumulación de polvo fino & 2 & $25-50$ \\
\hline Película pictórica - Traumatismos: Abrasión & 2 & $25-50$ \\
\hline Película pictórica - Craquelado & 1 & $0-25$ \\
\hline $\begin{array}{l}\text { Película pictórica - Alteración cromática: Tono café- } \\
\text { marrón }\end{array}$ & 1 & $0-25$ \\
\hline $\begin{array}{l}\text { Película pictórica - Deformaciones de la superficie: } \\
\text { Descamación }\end{array}$ & 1 & $0-25$ \\
\hline $\begin{array}{l}\text { Película pictórica - Deformaciones de la superficie: } \\
\text { Levantamientos }\end{array}$ & 1 & $0-25$ \\
\hline Película pictórica - Traumatismos: Rayados & 1 & $0-25$ \\
\hline \multicolumn{3}{|l|}{ PREPARACIÓN } \\
\hline FENOMENOLOGÍA DE ALTERACIÓN Y DETERIORO & $\begin{array}{l}\text { INCIDENCIA } \\
\text { SUPERFICIAL }\end{array}$ & EXTENSIÓN SUPERFICIAL (\%) \\
\hline Preparación: Lagunas & 3 & $50-75$ \\
\hline Preparación: Desprendimientos & 3 & $50-75$ \\
\hline Preparación: Manchas & 1 & $0-25$ \\
\hline $\begin{array}{l}\text { Preparación }-\quad \text { Deformaciones } \\
\text { superficie: Levantamientos }\end{array}$ & 1 & $0-25$ \\
\hline Preparación - Cuarteado & 1 & $0-25$ \\
\hline \multicolumn{3}{|l|}{ SOPORTE LIGGNEO } \\
\hline FENOMENOLOGÍA DE ALTERACIÓN Y DETERIORO & $\begin{array}{l}\text { INCIDENCIA } \\
\text { SUPERFICIAL }\end{array}$ & EXTENSIÓN SUPERFICIAL (\%) \\
\hline Madera - Grietas: Fendas & 4 & $75-100$ \\
\hline Madera - Acumulación de polvo: Fino & 4 & $75-100$ \\
\hline
\end{tabular}




\begin{tabular}{|l|l|l|}
\hline Madera - Presencia de galerías de xilófagos & 3 & $50-75$ \\
\hline Madera - Grietas: Fracturas & 1 & $0-25$ \\
\hline Madera - Desprendimiento & 1 & $0-25$ \\
\hline $\begin{array}{l}\text { Madera - Alteración estructural: pérdida/movimiento de } \\
\text { nudos }\end{array}$ & 1 & $0-25$ \\
\hline
\end{tabular}

\begin{tabular}{|c|c|c|}
\hline \multicolumn{3}{|l|}{ M15 (incidencia de deterioros: 23 ) } \\
\hline \multicolumn{3}{|l|}{ BARNIZ/CAPA DE PROTECCIÓN } \\
\hline FENOMENOLOGÍA DE ALTERACIÓN Y DETERIORO & $\begin{array}{l}\text { INCIDENCIA } \\
\text { SUPERFICIAL }\end{array}$ & EXTENSIÓN SUPERFICIAL (\%) \\
\hline Barniz - Alteración cromática: Manchas & 1 & $0-25$ \\
\hline \multicolumn{3}{|l|}{ PELICULA PICTÓRICA } \\
\hline FENOMENOLOGÍA DE ALTERACIÓN Y DETERIORO & $\begin{array}{l}\text { INCIDENCIA } \\
\text { SUPERFICIAL }\end{array}$ & EXTENSIÓN SUPERFICIAL (\%) \\
\hline Película pictórica - Acumulación de polvo fino & 2 & $25-50$ \\
\hline $\begin{array}{l}\text { Película pictórica - Acumulación de polvo } \\
\text { grasoso/adherido }\end{array}$ & 1 & $0-25$ \\
\hline Película pictórica - Cuarteados perimetrales & 1 & $0-25$ \\
\hline $\begin{array}{l}\text { Película pictórica - Cuarteados a contacto con los } \\
\text { elementos estructurales del bastidor }\end{array}$ & 1 & $0-25$ \\
\hline Película pictórica - Craquelado & 1 & $0-25$ \\
\hline $\begin{array}{l}\text { Película pictórica - Alteración cromática: Tono café- } \\
\text { marrón }\end{array}$ & 1 & $0-25$ \\
\hline $\begin{array}{l}\text { Película pictórica - Deformaciones de la superficie: } \\
\text { Descamación }\end{array}$ & 1 & $0-25$ \\
\hline $\begin{array}{l}\text { Película pictórica - Deformaciones de la superficie: } \\
\text { Levantamientos }\end{array}$ & 1 & $0-25$ \\
\hline $\begin{array}{l}\text { Película pictórica - Deformaciones de la superficie: } \\
\text { Desprendimientos }\end{array}$ & 1 & $0-25$ \\
\hline Película pictórica - Grietas puntuales/intracapas & 1 & $0-25$ \\
\hline $\begin{array}{l}\text { Película pictórica - Lagunas: Numerosas pequeñas en } \\
\text { esquinas cuarteados }\end{array}$ & 1 & $0-25$ \\
\hline Película pictórica - Lagunas: Grandes áreas & 1 & $0-25$ \\
\hline Película pictórica - Traumatismos: Rayados & 1 & $0-25$ \\
\hline Película pictórica - Traumatismos: Abrasión & 1 & $0-25$ \\
\hline Película pictórica - Traumatismos: Desgaste & 1 & $0-25$ \\
\hline Película pictórica - Presencia de materiales ajenos & 1 & $0-25$ \\
\hline
\end{tabular}




\begin{tabular}{|l|l|l|}
\hline FENOMENOLOGÍA DE ALTERACIÓN Y DETERIORO & $\begin{array}{l}\text { INCIDENCIA } \\
\text { SUPERFICIAL }\end{array}$ & EXTENSIÓN SUPERFICIAL (\%) \\
\hline Preparación: Lagunas & 1 & $0-25$ \\
\hline Preparación: Desprendimientos & 1 & $0-25$ \\
\hline $\begin{array}{l}\text { Preparación Deformaciones de la } \\
\text { superficie: Levantamientos }\end{array}$ & 1 & $0-25$ \\
\hline $\begin{array}{l}\text { SOPORTE LÍGNEO } \\
\text { FENOMENOLOGÍA DE ALTERACIÓN Y DETERIORO }\end{array}$ & $\begin{array}{l}\text { INCIDENCIA } \\
\text { SUPERFICIAL }\end{array}$ & EXTENSIÓN SUPERFICIAL (\%) \\
\hline Madera - Presencia de galerías de xilófagos & 1 & $0-25$ \\
\hline Madera - Grietas: Fendas & 1 & $0-25$ \\
\hline Madera - Desprendimiento & 1 & $0-25$ \\
\hline
\end{tabular}

Tabla 89 - Extensión superficial (\%) de las fenomenologías de alteración y deterioro registradas. Muestra 12.

\begin{tabular}{|l|l|l|}
\hline \multicolumn{2}{|l|}{ M12 (incidencia de deterioros: 22) } \\
\hline \multicolumn{2}{|l|}{ BARNIZ/CAPA DE PROTECCIÓN } \\
\hline FENOMENOLOGÍA DE ALTERACIÓN Y DETERIORO & $\begin{array}{l}\text { INCIDENCIA } \\
\text { SUPERFICIAL }\end{array}$ & EXTENSIÓN SUPERFICIAL (\%) \\
\hline Barniz - Alteración cromática: Manchas & 1 & $0-25$ \\
\hline PELÍCULA PICTÓRICA & $\begin{array}{l}\text { INCIDENCIA } \\
\text { SUPERFICIAL }\end{array}$ & EXTENSIÓN SUPERFICIAL (\%) \\
\hline \begin{tabular}{l} 
FENOMENOLOGÍA DE ALTERACIÓN Y DETERIORO \\
\hline Película pictórica - Acumulación de polvo fino
\end{tabular} & 2 & $25-50$ \\
\hline Película pictórica - Grietas puntuales/intracapas & 2 & $25-50$ \\
\hline $\begin{array}{l}\text { Película pictórica - Acumulación de polvo } \\
\text { grasoso/adherido }\end{array}$ & 1 & $0-25$ \\
\hline Película pictórica - Cuarteados perimetrales & 1 & $0-25$ \\
\hline $\begin{array}{l}\text { Película pictórica - Cuarteados a contacto con los } \\
\text { elementos estructurales del bastidor }\end{array}$ & 1 & $0-25$ \\
\hline Película pictórica - Craquelado & 1 & $0-25$ \\
\hline $\begin{array}{l}\text { Película pictórica - Deformaciones de la superficie: } \\
\text { Descamación }\end{array}$ & 1 & $0-25$ \\
\hline $\begin{array}{l}\text { Película pictórica - Deformaciones de la superficie: } \\
\text { Levantamientos }\end{array}$ & 1 & $0-25$ \\
\hline $\begin{array}{l}\text { Película pictórica - Deformaciones de la superficie: } \\
\text { Cordilleras }\end{array}$ & 1 & $0-25$ \\
\hline Película pictórica - Deformaciones de la superficie: & 1 & $0-25$ \\
\hline
\end{tabular}




\begin{tabular}{|c|c|c|}
\hline \multicolumn{3}{|l|}{ Desprendimientos } \\
\hline $\begin{array}{l}\text { Película pictórica - Lagunas: Numerosas pequeñas en } \\
\text { esquinas cuarteados }\end{array}$ & 1 & $0-25$ \\
\hline Película pictórica - Traumatismos: Rayados & 1 & $0-25$ \\
\hline Película pictórica - Traumatismos: Abrasión & 1 & $0-25$ \\
\hline Película pictórica - Traumatismos: Desgaste & 1 & $0-25$ \\
\hline Película pictórica - Presencia de materiales ajenos & 1 & $0-25$ \\
\hline \multicolumn{3}{|l|}{ PREPARACIÓN } \\
\hline FENOMENOLOGÍA DE ALTERACIÓN Y DETERIORO & $\begin{array}{l}\text { INCIDENCIA } \\
\text { SUPERFICIAL }\end{array}$ & EXTENSIÓN SUPERFICIAL (\%) \\
\hline Preparación: Lagunas & 1 & $0-25$ \\
\hline Preparación: Desprendimientos & 1 & $0-25$ \\
\hline 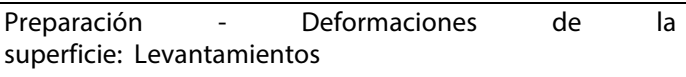 & 1 & $0-25$ \\
\hline Preparación - Cuarteado & 1 & $0-25$ \\
\hline \multicolumn{3}{|l|}{ SOPORTE LÍGNEO } \\
\hline FENOMENOLOGÍA DE ALTERACIÓN Y DETERIORO & $\begin{array}{l}\text { INCIDENCIA } \\
\text { SUPERFICIAL }\end{array}$ & EXTENSIÓN SUPERFICIAL (\%) \\
\hline Madera - Grietas: Fracturas & 1 & $0-25$ \\
\hline Madera - Grietas: Fendas & 1 & $0-25$ \\
\hline
\end{tabular}

M12 (incidencia de deterioros: 22)

\section{BARNIZ/CAPA DE PROTECCIÓN}

\begin{tabular}{|l|l|l|}
\hline FENOMENOLOGÍA DE ALTERACIÓN Y DETERIORO & $\begin{array}{l}\text { INCIDENCIA } \\
\text { SUPERFICIAL }\end{array}$ & EXTENSIÓN SUPERFICIAL (\%) \\
\hline Barniz - Alteración cromática: Manchas & 1 & $0-25$ \\
\hline Barniz - Daños mecánicos & 1 & $0-25$ \\
\hline PELÍ́CULA PICTÓRICA & $\begin{array}{l}\text { INCIDENCIA } \\
\text { SUPERFICIAL }\end{array}$ & EXTENSIÓN SUPERFICIAL (\%) \\
\hline FENOMENOLOGÍA DE ALTERACIÓN Y DETERIORO & 2 & $25-50$ \\
\hline Película pictórica - Acumulación de polvo fino & 2 & $25-50$ \\
\hline Película pictórica - Traumatismos: Abrasión & 2 & $25-50$ \\
\hline Película pictórica - Traumatismos: Desgaste & 1 & $0-25$ \\
\hline Película pictórica - Cuarteados perimetrales & 1 & $0-25$ \\
\hline Película pictórica - Cuarteados a contacto con los &
\end{tabular}




\begin{tabular}{|c|c|c|}
\hline \multicolumn{3}{|l|}{ elementos estructurales del bastidor } \\
\hline $\begin{array}{l}\text { Película pictórica - Deformaciones de la superficie: } \\
\text { Levantamientos }\end{array}$ & 1 & $0-25$ \\
\hline $\begin{array}{l}\text { Película pictórica - Deformaciones de la superficie: } \\
\text { Cordilleras }\end{array}$ & 1 & $0-25$ \\
\hline $\begin{array}{l}\text { Película pictórica - Deformaciones de la superficie: } \\
\text { Desprendimientos }\end{array}$ & 1 & $0-25$ \\
\hline Película pictórica - Grietas puntuales/intracapas & 1 & $0-25$ \\
\hline $\begin{array}{l}\text { Película pictórica - Lagunas: Numerosas pequeñas en } \\
\text { esquinas cuarteados }\end{array}$ & 1 & $0-25$ \\
\hline Película pictórica - Traumatismos: Rayados & 1 & $0-25$ \\
\hline Película pictórica - Presencia de materiales ajenos & 1 & $0-25$ \\
\hline \multicolumn{3}{|l|}{ PREPARACIÓN } \\
\hline FENOMENOLOGÍA DE ALTERACIÓN Y DETERIORO & $\begin{array}{l}\text { INCIDENCIA } \\
\text { SUPERFICIAL }\end{array}$ & EXTENSIÓN SUPERFICIAL (\%) \\
\hline Preparación: Desprendimientos & 1 & $0-25$ \\
\hline $\begin{array}{lccc}\text { Preparación } & \text { Deformaciones } & \text { de } & \text { la } \\
\text { superficie: Levantamientos } & & & \end{array}$ & 1 & $0-25$ \\
\hline \multicolumn{3}{|l|}{ SOPORTE LÍGNEO } \\
\hline FENOMENOLOGÍA DE ALTERACIÓN Y DETERIORO & $\begin{array}{l}\text { INCIDENCIA } \\
\text { SUPERFICIAL }\end{array}$ & EXTENSIÓN SUPERFICIAL (\%) \\
\hline Madera - Acumulación de polvo: Fino & 4 & $75-100$ \\
\hline Madera - Presencia de galerías de xilófagos & 1 & $0-25$ \\
\hline Madera - Grietas: Fracturas & 1 & $0-25$ \\
\hline Madera - Grietas: Fendas & 1 & $0-25$ \\
\hline Madera - Desprendimiento & 1 & $0-25$ \\
\hline
\end{tabular}

Tabla 91 - Extensión superficial (\%) de las fenomenologías de alteración y deterioro registradas. Muestra 4.

M4 (incidencia de deterioros: 20 )

BARNIZ/CAPA DE PROTECCIÓN

\begin{tabular}{|l|l|l|}
\hline FENOMENOLOGÍA DE ALTERACIÓN Y DETERIORO & $\begin{array}{l}\text { INCIDENCIA } \\
\text { SUPERFICIAL }\end{array}$ & EXTENSIÓN SUPERFICIAL (\%) \\
\hline Barniz - Alteración cromática: Manchas & 2 & $25-50$ \\
\hline Barniz - Alteración cromática: Oscurecimiento & 1 & $0-25$ \\
\hline PELÍCULA PICTÓRICA & $\begin{array}{l}\text { INCIDENCIA } \\
\text { SUPERFICIAL }\end{array}$ & EXTENSIÓN SUPERFICIAL (\%) \\
\hline FENOMENOLOGÍA DE ALTERACIÓN Y DETERIORO & \\
\hline
\end{tabular}




\begin{tabular}{|c|c|c|}
\hline Película pictórica - Acumulación de polvo fino & 2 & $25-50$ \\
\hline $\begin{array}{l}\text { Película pictórica } \\
\text { grasoso/adherido }\end{array}$ & 1 & $0-25$ \\
\hline Película pictórica - Cuarteados perimetrales & 1 & $0-25$ \\
\hline Película pictórica - Craquelado & 1 & $0-25$ \\
\hline $\begin{array}{l}\text { Película pictórica - Deformaciones de la superficie: } \\
\text { Levantamientos }\end{array}$ & 1 & $0-25$ \\
\hline $\begin{array}{l}\text { Película pictórica - Deformaciones de la superficie: } \\
\text { Desprendimientos }\end{array}$ & 1 & $0-25$ \\
\hline Película pictórica - Grietas puntuales/intracapas & 1 & $0-25$ \\
\hline $\begin{array}{l}\text { Película pictórica - Lagunas: Numerosas pequeñas en } \\
\text { esquinas cuarteados }\end{array}$ & 1 & $0-25$ \\
\hline Película pictórica - Quemaduras & 1 & $0-25$ \\
\hline Película pictórica - Traumatismos: Rayados & 1 & $0-25$ \\
\hline Película pictórica - Presencia de materiales ajenos & 1 & $0-25$ \\
\hline \multicolumn{3}{|l|}{ PREPARACIÓN } \\
\hline FENOMENOLOGÍA DE ALTERACIÓN Y DETERIORO & $\begin{array}{l}\text { INCIDENCIA } \\
\text { SUPERFICIAL }\end{array}$ & EXTENSIÓN SUPERFICIAL (\%) \\
\hline Preparación: Lagunas & 1 & $0-25$ \\
\hline Preparación: Desprendimientos & 1 & $0-25$ \\
\hline 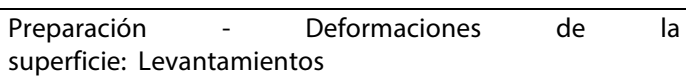 & 1 & $0-25$ \\
\hline \multicolumn{3}{|l|}{ SOPORTE LIGGNEO } \\
\hline FENOMENOLOGÍA DE ALTERACIÓN Y DETERIORO & $\begin{array}{l}\text { INCIDENCIA } \\
\text { SUPERFICIAL }\end{array}$ & EXTENSIÓN SUPERFICIAL (\%) \\
\hline Madera - Acumulación de polvo: Fino & 4 & $75-100$ \\
\hline Madera - Presencia de galerías de xilófagos & 1 & $0-25$ \\
\hline Madera - Grietas: Fracturas & 1 & $0-25$ \\
\hline Madera - Desprendimiento & 1 & $0-25$ \\
\hline
\end{tabular}

Tabla 92 - Extensión superficial (\%) de las fenomenologías de alteración y deterioro registradas. Muestra 1.

\begin{tabular}{|l|l|l|}
\hline M1 (incidencia de deterioros: 18) \\
\hline BARNIZ/CAPA DE PROTECCIÓN & $\begin{array}{l}\text { INCIDENCIA } \\
\text { SUPERFICIAL }\end{array}$ & EXTENSIÓN SUPERFICIAL (\%) \\
\hline FENOMENOLOGÍA DE ALTERACIÓN Y DETERIORO & 1 & $0-25$ \\
\hline Barniz - Alteración cromática: Manchas & 1 & $0-25$ \\
\hline Barniz - Daños mecánicos & INCIDENCIA & EXTENSIÓN SUPERFICIAL (\%) \\
\hline PELÍCULA PICTÓRICA & & \\
\hline FENOMENOLOGÍA DE ALTERACIÓN Y DETERIORO &
\end{tabular}




\begin{tabular}{|c|c|c|}
\hline & SUPERFICIAL & \\
\hline Película pictórica - Acumulación de polvo fino & 4 & $75-100$ \\
\hline Película pictórica - Cuarteados generalizados & 1 & $0-25$ \\
\hline Película pictórica - Craquelado & 1 & $0-25$ \\
\hline $\begin{array}{l}\text { Película pictórica - Deformaciones de la superficie: } \\
\text { Levantamientos }\end{array}$ & 1 & $0-25$ \\
\hline $\begin{array}{l}\text { Película pictórica - Deformaciones de la superficie: } \\
\text { Desprendimientos }\end{array}$ & 1 & $0-25$ \\
\hline $\begin{array}{l}\text { Película pictórica - Deformaciones de la superficie: } \\
\text { Solapamientos }\end{array}$ & 1 & $0-25$ \\
\hline $\begin{array}{l}\text { Película pictórica - Lagunas: Numerosas pequeñas en } \\
\text { esquinas cuarteados }\end{array}$ & 1 & $0-25$ \\
\hline Película pictórica - Traumatismos: Rayados & 1 & $0-25$ \\
\hline Película pictórica - Traumatismos: Abrasión & 1 & $0-25$ \\
\hline Película pictórica - Presencia de materiales ajenos & 1 & $0-25$ \\
\hline \multicolumn{3}{|l|}{ PREPARACIÓN } \\
\hline FENOMENOLOGÍA DE ALTERACIÓN Y DETERIORO & $\begin{array}{l}\text { INCIDENCIA } \\
\text { SUPERFICIAL }\end{array}$ & EXTENSIÓN SUPERFICIAL (\%) \\
\hline Preparación: Lagunas & 1 & $0-25$ \\
\hline $\begin{array}{llll}\text { Preparación } & \text { Deformaciones } & \text { de } & \text { la } \\
\text { superficie: Levantamientos } & & & \end{array}$ & 1 & $0-25$ \\
\hline \multicolumn{3}{|l|}{ SOPORTE LÍGNEO } \\
\hline FENOMENOLOGÍA DE ALTERACIÓN Y DETERIORO & $\begin{array}{l}\text { INCIDENCIA } \\
\text { SUPERFICIAL }\end{array}$ & EXTENSIÓN SUPERFICIAL (\%) \\
\hline Madera - Acumulación de polvo: Fino & 4 & $75-100$ \\
\hline Madera - Presencia de galerías de xilófagos & 1 & $0-25$ \\
\hline Madera - Grietas: Fendas & 1 & $0-25$ \\
\hline Madera - Desprendimiento & 1 & $0-25$ \\
\hline
\end{tabular}

Tabla 93 - Extensión superficial (\%) de las fenomenologías de alteración y deterioro registradas. Muestra 14.

M14 (incidencia de deterioros: 18)

\section{PELÍCULA PICTÓRICA}

\begin{tabular}{|l|l|l|}
\hline FENOMENOLOGÍA DE ALTERACIÓN Y DETERIORO & $\begin{array}{l}\text { INCIDENCIA } \\
\text { SUPERFICIAL }\end{array}$ & EXTENSIÓN SUPERFICIAL (\%) \\
\hline Película pictórica - Acumulación de polvo fino & 2 & $25-50$ \\
\hline Película pictórica - Presencia de materiales ajenos & 2 & $25-50$ \\
\hline $\begin{array}{l}\text { Película pictórica - Acumulación de polvo } \\
\text { grasoso/adherido }\end{array}$ & 1 & $0-25$ \\
\hline
\end{tabular}




\begin{tabular}{|c|c|c|}
\hline Película pictórica - Cuarteados perimetrales & 1 & $0-25$ \\
\hline $\begin{array}{l}\text { Película pictórica - Deformaciones de la superficie: } \\
\text { Levantamientos }\end{array}$ & 1 & $0-25$ \\
\hline $\begin{array}{l}\text { Película pictórica - Deformaciones de la superficie: } \\
\text { Desprendimientos }\end{array}$ & 1 & $0-25$ \\
\hline Película pictórica - Grietas puntuales/intracapas & 1 & $0-25$ \\
\hline $\begin{array}{l}\text { Película pictórica - Lagunas: Numerosas pequeñas en } \\
\text { esquinas cuarteados }\end{array}$ & 1 & $0-25$ \\
\hline Película pictórica - Traumatismos: Rayados & 1 & $0-25$ \\
\hline Película pictórica - Traumatismos: Abrasión & 1 & $0-25$ \\
\hline Película pictórica - Traumatismos: Desgaste & 1 & $0-25$ \\
\hline \multicolumn{3}{|l|}{ PREPARACIÓN } \\
\hline FENOMENOLOGÍA DE ALTERACIÓN Y DETERIORO & $\begin{array}{l}\text { INCIDENCIA } \\
\text { SUPERFICIAL }\end{array}$ & EXTENSIÓN SUPERFICIAL (\%) \\
\hline Preparación: Lagunas & 1 & $0-25$ \\
\hline Preparación: Desprendimientos & 1 & $0-25$ \\
\hline $\begin{array}{l}\begin{array}{l}\text { Preparación }- \\
\text { superficie: Levantamientos }\end{array}\end{array}$ & 1 & $0-25$ \\
\hline \multicolumn{3}{|l|}{ SOPORTE LIGNEO } \\
\hline FENOMENOLOGÍA DE ALTERACIÓN Y DETERIORO & $\begin{array}{l}\text { INCIDENCIA } \\
\text { SUPERFICIAL }\end{array}$ & EXTENSIÓN SUPERFICIAL (\%) \\
\hline Madera - Presencia de galerías de xilófagos & 1 & $0-25$ \\
\hline Madera - Grietas: Fracturas & 1 & $0-25$ \\
\hline Madera - Grietas: Fendas & 1 & $0-25$ \\
\hline Madera - Desprendimiento & 1 & $0-25$ \\
\hline
\end{tabular}

Tabla 94 - Extensión superficial (\%) de las fenomenologías de alteración y deterioro registradas. Muestra 3.

\begin{tabular}{|l|l|l|}
\hline M3 (incidencia de deterioros: 17) \\
\hline PELÍCULA PICTÓRICA & $\begin{array}{l}\text { EXTENSIÓN SUPERFICIAL (\%) } \\
\text { SUPERFICIAL }\end{array}$ & $25-50$ \\
\hline Película pictórica - Acumulación de polvo fino & 2 & $0-25$ \\
\hline $\begin{array}{l}\text { Película pictórica - Cuarteados a contacto con los } \\
\text { elementos estructurales del bastidor }\end{array}$ & 1 & $0-25$ \\
\hline $\begin{array}{l}\text { Película pictórica - Deformaciones de la superficie: } \\
\text { Levantamientos }\end{array}$ & 1 & $0-25$ \\
\hline $\begin{array}{l}\text { Película pictórica - Deformaciones de la superficie: } \\
\text { Desprendimientos }\end{array}$ & 1 & $0-25$ \\
\hline Película pictórica - Grietas puntuales/intracapas & 1 & \\
\hline
\end{tabular}




\begin{tabular}{|l|l|l|}
\hline $\begin{array}{l}\text { Película pictórica - Lagunas: Numerosas pequeñas en } \\
\text { esquinas cuarteados }\end{array}$ & 1 & $0-25$ \\
\hline Película pictórica - Traumatismos: Rayados & 1 & $0-25$ \\
\hline Película pictórica - Presencia de materiales ajenos & 1 & $0-25$ \\
\hline PREPARACIÓN & $\begin{array}{l}\text { INCIDENCIA } \\
\text { SUPERFICIAL }\end{array}$ & EXTENSIÓN SUPERFICIAL (\%) \\
\hline $\begin{array}{l}\text { FENOMENOLOGÍA DE ALTERACIÓN Y DETERIORO } \\
\text { Preparación: Lagunas de la }\end{array}$ & 1 & $0-25$ \\
\hline Preparación: Desprendimientos & 1 & $0-25$ \\
\hline $\begin{array}{l}\text { Preparación Deformaciones } \\
\text { superficie: Levantamientos }\end{array}$ & 1 & $0-25$ \\
\hline SOPORTE LíGNEO & INCIDENCIA & EXTENSIÓN SUPERFICIAL (\%) \\
\hline $\begin{array}{l}\text { FENOMENOLOGÍA DE ALTERACIÓN Y DETERIORO } \\
\text { SUPERFICIAL }\end{array}$ & 4 & $75-100$ \\
\hline Madera - Acumulación de polvo: Fino & 4 & $0-25$ \\
\hline Madera - Presencia de galerías de xilófagos & 1 & $0-25$ \\
\hline Madera - Grietas: Fracturas & 1 & $0-25$ \\
\hline Madera - Grietas: Fendas & 1 & $0-25$ \\
\hline Madera - Desprendimiento & 1 & $0-25$ \\
\hline $\begin{array}{l}\text { Madera - Alteración estructural: pérdida/movimiento de } \\
\text { nudos }\end{array}$ & 1 & \\
\hline
\end{tabular}

Tabla 95 - Extensión superficial (\%) de las fenomenologías de alteración y deterioro registradas. Muestra 2.

M2 (incidencia de deterioros: 15)

PELÍCULA PICTÓRICA

\begin{tabular}{|l|l|l|}
\hline FENOMENOLOGÍA DE ALTERACIÓN Y DETERIORO & $\begin{array}{l}\text { INCIDENCIA } \\
\text { SUPERFICIAL }\end{array}$ & EXTENSIÓN SUPERFICIAL (\%) \\
\hline $\begin{array}{l}\text { Película pictórica - Acumulación de polvo fino } \\
\begin{array}{l}\text { Película pictórica - Cuarteados a contacto con los } \\
\text { elementos estructurales del bastidor }\end{array}\end{array}$ & 2 & $25-50$ \\
\hline $\begin{array}{l}\text { Película pictórica - Craquelado } \\
\text { Película pictórica - Deformaciones de la superficie: } \\
\text { Levantamientos }\end{array}$ & 2 & $25-50$ \\
\hline $\begin{array}{l}\text { Película pictórica - Deformaciones de la superficie: } \\
\text { Desprendimientos }\end{array}$ & 2 & $25-50$ \\
\hline $\begin{array}{l}\text { Película pictórica - Deformaciones de la superficie: } \\
\text { Descamación }\end{array}$ & 1 & $25-50$ \\
\hline $\begin{array}{l}\text { Película pictórica - Grietas puntuales/intracapas } \\
\text { Película pictórica - Lagunas: Numerosas pequeñas en }\end{array}$ & 1 & $0-25$ \\
\hline
\end{tabular}




\begin{tabular}{|l|l|l|}
\hline esquinas cuarteados & \multicolumn{1}{|l|}{} & \\
\hline Película pictórica - Traumatismos: Rayados & 1 & $0-25$ \\
\hline Película pictórica - Presencia de materiales ajenos & 1 & $0-25$ \\
\hline PREPARACIÓN & $\begin{array}{l}\text { INCIDENCIA } \\
\text { SUPERFICIAL }\end{array}$ & EXTENSIÓN SUPERFICIAL (\%) \\
\hline FENOMENOLOGÍA DE ALTERACIÓN Y DETERIORO & 2 & $25-50$ \\
\hline Preparación - Cuarteado & 1 & $0-25$ \\
\hline Preparación: Lagunas de la & 1 & $0-25$ \\
\hline Preparación: Desprendimientos & 1 & $0-25$ \\
\hline $\begin{array}{l}\text { Preparación Deformaciones - } \\
\text { superficie: Levantamientos }\end{array}$ & $\begin{array}{l}\text { INCIDENCIA } \\
\text { SOPORTE LÍGNEO }\end{array}$ & EXTENSIÓN SUPERFICIAL (\%) \\
\hline $\begin{array}{l}\text { FENOMENOLOGÍA DE ALTERACIÓN Y DETERIORO } \\
\text { Madera - Desprendimiento }\end{array}$ & 1 & $0-25$ \\
\hline
\end{tabular}

Tras el análisis de la incidencia de las fenomenologías de alteración y deterioro existentes en el conjunto que compone el retablo, se puede afirmar que ha sido expuesto a las condiciones ${ }^{289}$ que se presentan a continuación:

- Envejecimiento natural de los materiales compositivos; oxidación de los aglutinantes oleosos y resinas; esto favorece la formación de microfisuras y craquelados debido a una pérdida de elasticidad. La variación en la reflexión de la luz genera un cambio en la apreciación estética de la obra.

- Intervenciones de remodelación del retablo. Aplicación de pintura blanca, probablemente junto a sustancias de naturaleza oleosa y/o ceras. Esto puede haber favorecido la adhesión de partículas de suciedad y polvo además de la formación de áreas con diferente brillo y manchas.

- Uso de cirios y velas en proximidad de la obra con finalidad devocional. Esto podría ser el origen de trazas de quemaduras y la acumulación de polvo grasoso y adherido.

${ }^{289}$ La interpretación de los resultados se fundamenta en las informaciones brindadas por: CALVO, A. (2002). Conservación y restauración de pintura sobre lienzo. Barcelona: El Serbal; VIVANCOS RAMÓN, V. (2007). La conservación y restauración de la pintura de caballete. Pintura sobre tabla. Madrid: Tecnos. Op.cit. 
- Acumulación de polvo y sustancias ajenas se relacionan con una falta de mantenimiento y limpieza periódicos, aunque en esta circunstancia ha sido agravada por el evento sísmico extraordinario. A este episodio, junto a acciones de manipulación y mantenimiento erróneas, se asocia la presencia de abrasiones, rayados, desgastes y de materiales ajenos sobre la superficie.

- Exposición de la obra a ciclos de variación termohigrométrica, con probable exposición a contenidos de humedad relativa elevado o escurrimientos de agua. Esto ocasiona la pérdida del poder adhesivo de la cola animal, generando problemáticas de adhesión y cohesión entre la película pictórica y las capas subyacentes con formación de: pulverulencia, descamación, levantamientos, desprendimientos, grietas, cordilleras, lagunas (a nivel pictórico y de preparación).

- La oxidación de los materiales aglutinantes tiene como efecto una variación cromática de la superficie pictórica hacia una tonalidad marrón-café. Este fenómeno es favorecido por parámetros conservativos caracterizados por una elevada humedad relativa y escasa iluminación.

- La presencia de galerías de insectos xilófagos es indicativo de la existencia de condiciones de conservación óptimas para el desarrollo de esta tipología de deterioro biológico. El debilitamiento del soporte se ha reflejado negativamente en las capas superpuestas.

- La presencia de lagunas en grandes áreas se suele relacionar a una alta degradación de la misma. Su concentración en el área inferior puede ser indicativa de unas situaciones de abandono de las obras en sótanos con humedades en el suelo o por su alcance a la acción humana (abrasiones, actos vandálicos, entre otros).

- La existencia de grietas y fendas asociadas a pérdidas y movimientos de nudos, con desprendimientos del soporte lígneo, atestigua la exposición del material a condiciones de elevada humedad o al contacto directo con el agua. Unas variaciones drásticas del contenido termohigrométrico del lugar de conservación, junto al envejecimiento de la madera, podría haber sobrepasado el límite de resistencia mecánica del material. Entre las 
posibles causas destaca una distribución incorrecta de las fuerzas en la estructura y la presencia de elementos de vínculo.

- La presencia de manchas de colores oscuras, asociada a filamentos puede ser indicativa de una colonización de tipo microbiológica (hongos) y de la existencia de las condiciones necesarias para su desarrollo (elevada humedad relativa y temperatura superior a $5^{\circ} \mathrm{C}$ ).

Observando los fenómenos en relación a la extensión superficial estimada, se puede afirmar que las problemáticas principales derivan de la exposición de este componente del retablo a mucha humedad, probablemente incluyendo el contacto directo con escurrimientos de agua. Esto ha acarreado la formación de problemáticas de tipo estructural en el soporte, en combinación con alteraciones de las propiedades adhesivas y cohesivas de las capas superpuestas. Gracias a la representación gráfica de las obras con mayor indicador de riesgo, ha sido posible apreciar de forma general las áreas más problemáticas, correspondientes al lado derecho del retablo.

\subsubsection{Conjunto de pinturas y esculturas}

Para comprender las problemáticas de conservación del conjunto de obras rescatadas tras el sismo, cada elemento ha sido identificado a partir de la documentación fotográfica realizada, y relacionado con la respectiva coordenada alfanumérica (tabla 96).

Tabla 96 - Referencia de muestras y obras.

\begin{tabular}{|l|l|}
\hline \multicolumn{2}{|l|}{ PINTURA DE CABALLETE Y ESCULTURA POLICROMADA - TEMPLO DE SAN MARTÍN DE TOURS } \\
\hline M & IDENTIFICACIÓN DE LA OBRA \\
\hline 1 & Santo. Escultura en madera policromada y dorada. Siglo XVII. \\
\hline 2 & Virgen de Dolores. Escultura en madera policromada y telas encoladas. Siglo XIX. \\
\hline 3 & Virgen de Guadalupe, óleo sobre lienzo. Siglo XVIII. \\
\hline 4 & Nuestra Señora de Velen ${ }^{290}$. Óleo sobre lienzo. Siglo XVIII. \\
\hline 5 & Santa Bárbara. Óleo sobre lienzo. Siglo XVIII. \\
\hline 6 & San Cristobal. Óleo sobre lienzo. Siglo XVIII. \\
\hline 7 & Santo franciscano. Escultura policromada y dorada, con estofados. Siglo XVII. \\
\hline
\end{tabular}

\footnotetext{
${ }^{290}$ Transcripción literal del título de advocación que aparece en la obra.
} 
\begin{tabular}{|l|l}
\hline 8 & Cristo a la columna. Escultura policromada. Siglo XVIII.
\end{tabular}

Tras el estudio de los datos recolectados, ha sido posible determinar:

- fenomenologías de alteración y deterioro activas (tabla 97) junto a su estimación cuantitativa y porcentual (gráfica 24);

- incidencia de las alteraciones y deterioro desglosada según las capas constitutivas del sistema (tabla 98);

- indicador de riesgo del conjunto (tabla 99);

- alteraciones y deterioros presentes en cada obra/área complementada por una estimación de la superficie afectada por cada fenómeno (tablas 100107);

- obra con mayor indicador de riesgo y prioridad (imágenes 83, 84 y 85);

En este caso no ha sido posible realizar un croquis del índice de riesgo y prioridad ya que no se conoce la ubicación originaria de las obras en el interior del tempo. La información obtenida ha sido complementada por una propuesta de interpretación de los datos.

Tabla 97 - Fenomenologías de alteración y deterioro presentes y su incidencia total (B - Barniz, PP _ Película pictórica, $\mathrm{Pr}$ - preparación, L - lienzo/entelado, M - Madera/bastidor).

\begin{tabular}{|l|l|}
\hline FENOMENOLOGÍA DE ALTERACIÓN Y DETERIORO & $\begin{array}{l}\text { TOTAL } \\
\text { INCIDENCIA DE } \\
\text { DETERIORO }\end{array}$ \\
\hline PP - Acumulación de polvo fino & 7 \\
\hline PP - Craquelado & 7 \\
\hline PP - Deformaciones de la superficie: Desprendimientos & 7 \\
\hline PP - Lagunas: Numerosas pequeñas en esquinas cuarteados & 7 \\
\hline PP - Presencia de materiales ajenos & 7 \\
\hline PP - Deformaciones de la superficie: Descamación & 6 \\
\hline PP - Grietas puntuales/intracapas & 6 \\
\hline Pr: Pérdida de adhesión con la película pictórica & 6 \\
\hline M - Acumulación de polvo: Fino & 6 \\
\hline B - Alteración cromática: Manchas & 5 \\
\hline PP - Cuarteados generalizados & 5 \\
\hline PP - Deformaciones de la superficie: Levantamientos & 5 \\
\hline PP - Lagunas: Área inferior & 5 \\
\hline PP - Traumatismos: Rayados & 5 \\
\hline
\end{tabular}




\begin{tabular}{|c|c|}
\hline PP - Cuarteados perimetrales & 4 \\
\hline PP - Cuarteados a contacto con los elementos estructurales del bastidor & 4 \\
\hline PP - Deformaciones de la superficie: Cordilleras & 4 \\
\hline PP - Traumatismos: Rayados & 4 \\
\hline Pr - Deformaciones de la superficie: Levantamientos & 4 \\
\hline L - Deformación de plano: Marcas de los elementos estructurales & 4 \\
\hline L - Deformación de plano: Perímetro & 4 \\
\hline L - Deformación de plano: Deformación del área inferior & 4 \\
\hline L - Deformación de plano: Deformación y rigidez & 4 \\
\hline L - Acumulación de polvo: Fino & 4 \\
\hline M - Desprendimiento & 4 \\
\hline B - Alteración cromática: Oscurecimiento & 3 \\
\hline B- Alteración cromática: Blanqueamiento & 3 \\
\hline B - Alteración cromática: Zonas a diferente brillo & 3 \\
\hline PP- Acumulación de polvo grasoso/adherido & 3 \\
\hline PP - Alteración cromática: Blanqueamiento & 3 \\
\hline PP - Alteración cromática: Tono café-marrón & 3 \\
\hline PP- Alteración cromática: Oscurecimiento & 3 \\
\hline PP - Deformaciones de la superficie: Hundimientos & 3 \\
\hline PP - Lagunas: Grandes áreas & 3 \\
\hline L - Deformación de plano: Arrugas en las esquinas & 3 \\
\hline L - Deformación de plano: Hundimiento y cuarteado película pictórica & 3 \\
\hline L- Rigidez & 3 \\
\hline L - Acumulación de polvo: Generalizado & 3 \\
\hline M - Manchas: Blancas & 3 \\
\hline M - Acumulación de polvo: Zona inferior & 3 \\
\hline M - Acumulación de polvo: Generalizado & 3 \\
\hline B - Cuarteado & 2 \\
\hline B- Daños mecánicos & 2 \\
\hline PP - Cuarteados en forma circular o telaraña & 2 \\
\hline PP - Cuarteados en forma de espina de pez & 2 \\
\hline PP - Deformaciones de la superficie: Solapamientos & 2 \\
\hline Pr - Cuarteado & 2 \\
\hline L- Roturas: Desfibrados & 2 \\
\hline L- Desprendimiento & 2 \\
\hline L- Laguna & 2 \\
\hline L - Intervenciones anteriores: Puntuales & 2 \\
\hline M - Presencia de galerías de xilófagos & 2 \\
\hline M - Manchas: Negras & 2 \\
\hline PP - Cuarteados en los ángulos & 1 \\
\hline
\end{tabular}




\begin{tabular}{|l|l|}
\hline PP - Cuarteados en áreas de color & 1 \\
\hline PP - Deformaciones de la superficie: Cazoletas & 1 \\
\hline Pr: lagunas & 1 \\
\hline Pr: Pulverulencia & 1 \\
\hline Pr: desprendimientos & 1 \\
\hline L - Deformación de plano: Deformación puntual o localizada & 1 \\
\hline L - Roturas: Cortes & 1 \\
\hline L - Roturas: Desgarros & 1 \\
\hline L - Roturas: Multidireccional & 1 \\
\hline L - Roturas: Naturales & 1 \\
\hline L - Roturas: Artificiales & 1 \\
\hline L- Manchas: Colores & 1 \\
\hline L- Manchas: Filamentos & 1 \\
\hline L- Alteración cromática: Oscurecimiento & 1 \\
\hline L - Acumulación de polvo: Zona inferior & 1 \\
\hline M - Grietas: Fendas & 1 \\
\hline M - Acumulación de polvo: Grasoso/adherido & 1 \\
\hline M - Alteración estructural: pérdida/movimiento de nudos & 1 \\
\hline M - Intervenciones anteriores & 1 \\
\hline B - Alteración cromática: Pérdida de transparencia & 1 \\
\hline
\end{tabular}




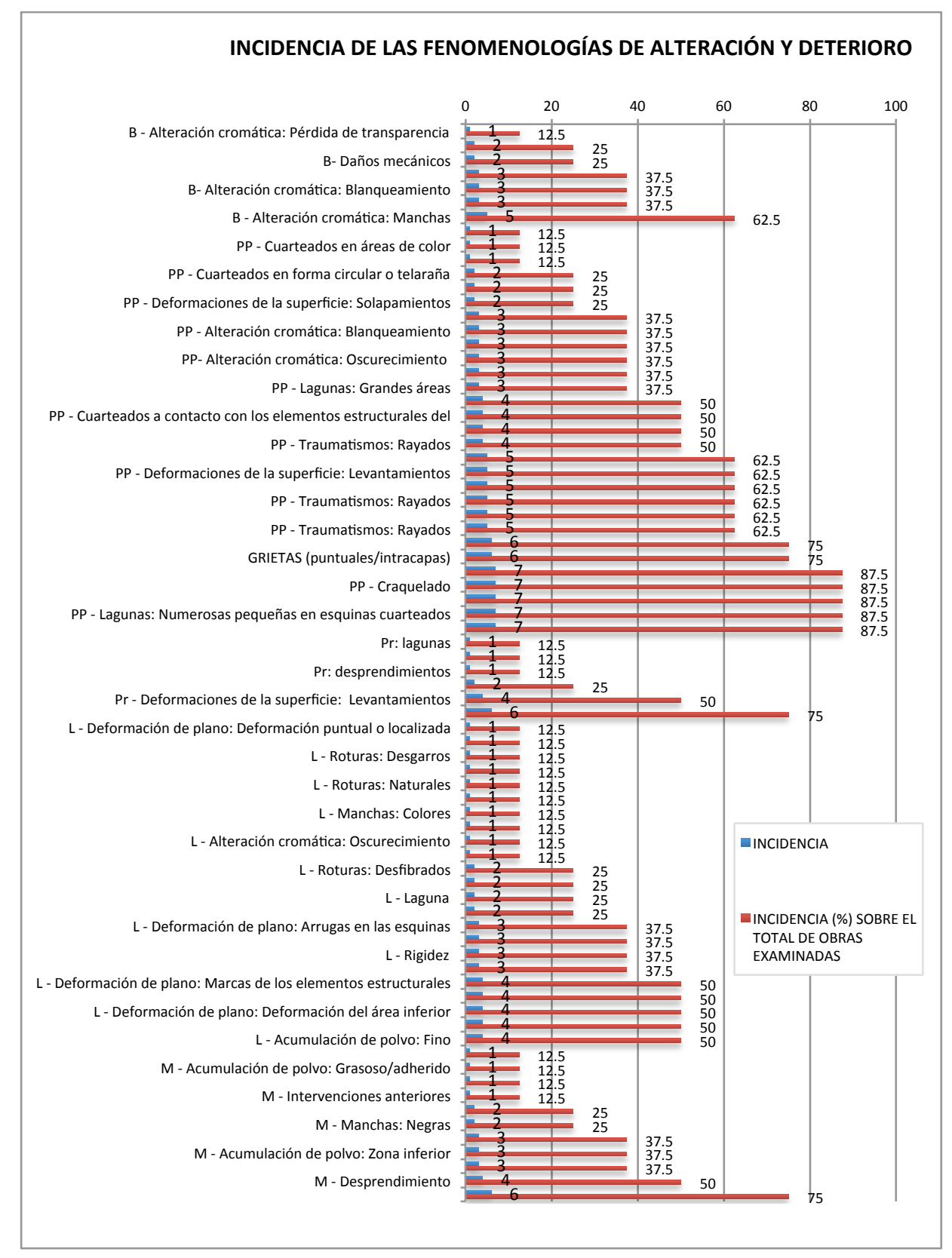

Gráfica 24 - Panorámica de las alteraciones y deterioros presentes en el grupo de obras. 


\begin{tabular}{|l|l|l|l|l|l|l|l|l|l|}
\hline $\begin{array}{l}\text { ESTRATO } \\
\text { PERTENENCIA }\end{array}$ & M1 & M2 & M3 & M4 & M5 & M6 & M7 & M8 & TOTAL \\
\hline B & 2 & 3 & 5 & 2 & 4 & 0 & 2 & 1 & 19 \\
\hline PP & 20 & 22 & 19 & 13 & 8 & 9 & 16 & 13 & 120 \\
\hline $\mathrm{Pr}$ & 3 & 2 & 1 & 3 & 0 & 1 & 3 & 2 & 15 \\
\hline $\mathrm{L}$ & 0 & 2 & 18 & 9 & 12 & 8 & 0 & 1 & 50 \\
\hline M & 4 & 1 & 4 & 3 & 3 & 7 & 5 & 0 & 27 \\
\hline TOTAL & 29 & 30 & 47 & 30 & 27 & 25 & 26 & 17 & 231 \\
\hline
\end{tabular}

Tabla 99 - Escala de riesgo e índice de prioridad.

\begin{tabular}{|l|l|}
\hline \multicolumn{2}{|l|}{ ESCALA DE RIESGO } \\
\hline MUESTRA & TOTAL INCIDENCIA DE DETERIORO \\
\hline 3 & 47 \\
\hline 2 & 30 \\
\hline 4 & 30 \\
\hline 1 & 29 \\
\hline 5 & 27 \\
\hline 7 & 26 \\
\hline 6 & 25 \\
\hline 8 & 17 \\
\hline
\end{tabular}




\begin{tabular}{|c|c|c|}
\hline \multicolumn{3}{|l|}{ M3 (incidencia de deterioros: 47 ) } \\
\hline \multicolumn{3}{|l|}{ BARNIZ } \\
\hline FENOMENOLOGÍA DE ALTERACIÓN Y DETERIORO & $\begin{array}{l}\text { INCIDENCIA } \\
\text { SUPERFICIAL }\end{array}$ & EXTENSIÓN SUPERFICIAL (\%) \\
\hline Barniz - Alteración cromática: Oscurecimiento & 4 & $75-100$ \\
\hline Barniz - Cuarteado & 3 & $50-75$ \\
\hline Barniz - Alteración cromática: Zonas a diferente brillo & 2 & $25-50$ \\
\hline Barniz - Alteración cromática: Manchas & 1 & $0-25$ \\
\hline Barniz - Daños mecánicos & 1 & $0-25$ \\
\hline \multicolumn{3}{|l|}{ PELÍCULA PICTÓRICA } \\
\hline FENOMENOLOGÍA DE ALTERACIÓN Y DETERIORO & $\begin{array}{l}\text { INCIDENCIA } \\
\text { SUPERFICIAL }\end{array}$ & EXTENSIÓN SUPERFICIAL (\%) \\
\hline Película pictórica - Acumulación de polvo fino & 4 & $75-100$ \\
\hline Película pictórica - Cuarteados en los ángulos & 4 & $75-100$ \\
\hline Película pictórica - Cuarteados perimetrales & 4 & $75-100$ \\
\hline $\begin{array}{l}\text { Película pictórica - Cuarteados a contacto con los } \\
\text { elementos estructurales del bastidor }\end{array}$ & 4 & $75-100$ \\
\hline Película pictórica - Cuarteados generalizados & 4 & $75-100$ \\
\hline Película pictórica - Craquelado & 4 & $75-100$ \\
\hline $\begin{array}{l}\text { Película pictórica - Alteración cromática: Tono café- } \\
\text { marrón }\end{array}$ & 3 & $50-75$ \\
\hline $\begin{array}{l}\text { Película pictórica - Lagunas: Numerosas pequeñas en } \\
\text { esquinas cuarteados }\end{array}$ & 3 & $50-75$ \\
\hline $\begin{array}{l}\text { Película pictórica - Deformaciones de la superficie: } \\
\text { Descamación }\end{array}$ & 2 & $25-50$ \\
\hline $\begin{array}{l}\text { Película pictórica - Deformaciones de la superficie: } \\
\text { Desprendimientos }\end{array}$ & 2 & $25-50$ \\
\hline Película pictórica - Lagunas: Área inferior & 2 & $25-50$ \\
\hline Película pictórica - Traumatismos: Abrasión & 2 & $25-50$ \\
\hline Película pictórica - Traumatismos: Desgaste & 2 & $25-50$ \\
\hline $\begin{array}{l}\text { Película pictórica - Deformaciones de la superficie: } \\
\text { Hundimientos }\end{array}$ & 1 & $0-25$ \\
\hline Película pictórcia - Grietas puntuales/intracapas & 1 & $0-25$ \\
\hline Película pictórica - Lagunas: Grandes áreas & 1 & $0-25$ \\
\hline Película pictórica - Traumatismos: Rayados & 1 & $0-25$ \\
\hline Película pictórica - Traumatismos: Arañazos & 1 & $0-25$ \\
\hline Película pictórica - Presencia de materiales ajenos & 1 & $0-25$ \\
\hline
\end{tabular}




\begin{tabular}{|c|c|c|}
\hline FENOMENOLOGÍA DE ALTERACIÓN Y DETERIORO & $\begin{array}{l}\text { INCIDENCIA } \\
\text { SUPERFICIAL }\end{array}$ & EXTENSIÓN SUPERFICIAL (\%) \\
\hline $\begin{array}{l}\text { Preparación: pérdida de adhesión con la película } \\
\text { pictórica }\end{array}$ & 2 & $25-50$ \\
\hline \multicolumn{3}{|l|}{ SOPORTE TEXTIL } \\
\hline FENOMENOLOGÍA DE ALTERACIÓN Y DETERIORO & $\begin{array}{l}\text { INCIDENCIA } \\
\text { SUPERFICIAL }\end{array}$ & EXTENSIÓN SUPERFICIAL (\%) \\
\hline Lienzo - Deformación de plano: Arrugas en las esquinas & 4 & $75-100$ \\
\hline Lienzo - Deformación de plano: Perímetro & 4 & $75-100$ \\
\hline $\begin{array}{l}\text { Lienzo - Deformación de plano: Deformación del área } \\
\text { inferior }\end{array}$ & 4 & $75-100$ \\
\hline Lienzo - Rigidez & 4 & $75-100$ \\
\hline Lienzo - Acumulación de polvo: Fino & 4 & $75-100$ \\
\hline Lienzo - Acumulación de polvo: Zona inferior & 4 & $75-100$ \\
\hline Lienzo - Acumulación de polvo: Generalizado & 4 & $75-100$ \\
\hline Lienzo - Deformación de plano: Deformación y rigidez & 2 & $25-50$ \\
\hline $\begin{array}{l}\text { Lienzo - Deformación de plano: Marcas de los elementos } \\
\text { estructurales }\end{array}$ & 1 & $0-25$ \\
\hline $\begin{array}{l}\text { Lienzo - Deformación de plano: Deformación puntual o } \\
\text { localizada }\end{array}$ & 1 & $0-25$ \\
\hline $\begin{array}{l}\text { Lienzo - Deformación de plano: Hundimiento y } \\
\text { cuarteado película pictórica }\end{array}$ & 1 & $0-25$ \\
\hline Lienzo - Roturas: Cortes & 1 & $0-25$ \\
\hline Lienzo - Roturas: Desgarros & 1 & $0-25$ \\
\hline Lienzo - Roturas: Multidireccional & 1 & $0-25$ \\
\hline Lienzo - Roturas: Desfibrados & 1 & $0-25$ \\
\hline Lienzo - Roturas: Artificiales & 1 & $0-25$ \\
\hline Lienzo - Desprendimiento & 1 & $0-25$ \\
\hline Lienzo - Laguna & 1 & $0-25$ \\
\hline \multicolumn{3}{|l|}{ BASTIDOR } \\
\hline FENOMENOLOGÍA DE ALTERACIÓN Y DETERIORO & $\begin{array}{l}\text { INCIDENCIA } \\
\text { SUPERFICIAL }\end{array}$ & EXTENSIÓN SUPERFICIAL (\%) \\
\hline Madera - Acumulación de polvo: Fino & 4 & $75-100$ \\
\hline Madera - Acumulación de polvo: Zona inferior & 4 & $75-100$ \\
\hline Madera - Acumulación de polvo: Generalizado & 4 & $75-100$ \\
\hline Madera - Presencia de galerías de xilófagos & 1 & $0-25$ \\
\hline
\end{tabular}


Tabla 101 - Extensión superficial (\%) de las fenomenologías de alteración y deterioro registradas. Muestra

\begin{tabular}{|c|c|c|}
\hline \multicolumn{3}{|l|}{ M2 - (total incidencia de deterioro: 30 ) } \\
\hline \multicolumn{3}{|l|}{ BARNIZ } \\
\hline FENOMENOLOGÍA DE ALTERACIÓN Y DETERIORO & $\begin{array}{l}\text { INCIDENCIA } \\
\text { SUPERFICIAL }\end{array}$ & EXTENSIÓN SUPERFICIAL (\%) \\
\hline Barniz - Alteración cromática: Blanqueamiento & 4 & $75-100$ \\
\hline Barniz - Alteración cromática: Manchas & 2 & $25-50$ \\
\hline Barniz - Daños mecánicos & 1 & $0-25$ \\
\hline \multicolumn{3}{|l|}{ PELÍCULA PICTÓRICA } \\
\hline FENOMENOLOGÍA DE ALTERACIÓN Y DETERIORO & $\begin{array}{l}\text { INCIDENCIA } \\
\text { SUPERFICIAL }\end{array}$ & EXTENSIÓN SUPERFICIAL (\%) \\
\hline Película pictórica - Acumulación de polvo fino & 4 & $75-100$ \\
\hline Película pictórica - Alteración cromática: Blanqueamiento & 4 & $75-100$ \\
\hline Película pictórica - Alteración cromática: Oscurecimiento & 4 & $75-100$ \\
\hline Película pictórica - Cuarteados generalizados & 3 & $50-75$ \\
\hline Película pictórica - Craquelado & 3 & $50-75$ \\
\hline $\begin{array}{l}\text { Película pictórica - Deformaciones de la superficie: } \\
\text { Levantamientos }\end{array}$ & 2 & $25-50$ \\
\hline $\begin{array}{l}\text { Película pictórica - Deformaciones de la superficie: } \\
\text { Cordilleras }\end{array}$ & 2 & $25-50$ \\
\hline Película pictórica - Presencia de materiales ajenos & 2 & $25-50$ \\
\hline $\begin{array}{l}\text { Película pictórica }- \text { Acumulación de polvo } \\
\text { grasoso/adherido }\end{array}$ & 1 & $0-25$ \\
\hline Película pictórica - Cuarteados en forma circular o telaraña & 1 & $0-25$ \\
\hline Película pictórica - Cuarteados en forma de espina de pez & 1 & $0-25$ \\
\hline $\begin{array}{l}\text { Película pictórica - Deformaciones de la superficie: } \\
\text { Descamación }\end{array}$ & 1 & $0-25$ \\
\hline $\begin{array}{l}\text { Película pictórica - Deformaciones de la superficie: } \\
\text { Hundimientos }\end{array}$ & 1 & $0-25$ \\
\hline $\begin{array}{l}\text { Película pictórica - Deformaciones de la superficie: } \\
\text { Desprendimientos }\end{array}$ & 1 & $0-25$ \\
\hline $\begin{array}{l}\text { Película pictórica - Deformaciones de la superficie: } \\
\text { Solapamientos }\end{array}$ & 1 & $0-25$ \\
\hline Película pictórcia - Grietas puntuales/intracapas & 1 & $0-25$ \\
\hline Película pictórica - Lagunas: Numerosas pequeñas en & 1 & $0-25$ \\
\hline
\end{tabular}




\begin{tabular}{|l|l|l|}
\hline esquinas cuarteados & & \\
\hline Película pictórica - Lagunas: Área inferior & 1 & $0-25$ \\
\hline Película pictórica - Traumatismos: Rayados & 1 & $0-25$ \\
\hline Película pictórica - Traumatismos: Abrasión & 1 & $0-25$ \\
\hline Película pictórica - Traumatismos: Desgaste & 1 & $0-25$ \\
\hline Película pictórica - Traumatismos: Arañazos & 1 & $0-25$ \\
\hline PREPARACIÓN & $\begin{array}{l}\text { INCIDENCIA } \\
\text { SUPERFICIAL }\end{array}$ & EXTENSIÓN SUPERFICIAL (\%) \\
\hline $\begin{array}{l}\text { FENOMENOLOGÍA DE ALTERACIÓN Y DETERIORO } \\
\text { Preparación: pérdida de adhesión con la película pictórica }\end{array}$ & 1 & $0-25$ \\
\hline $\begin{array}{l}\text { Preparación - de } \\
\text { superficie: Levantamientos }\end{array}$ & 1 & $0-25$ \\
\hline $\begin{array}{l}\text { SOPORTE TEXTIL } \\
\text { FENOMENOLOGÍA DE ALTERACIÓN Y DETERIORO }\end{array}$ & $\begin{array}{l}\text { INCIDENCIA } \\
\text { SUPERFICIAL }\end{array}$ & EXTENSIÓN SUPERFICIAL (\%) \\
\hline $\begin{array}{l}\text { Lienzo - Deformación de plano: Deformación y rigidez } \\
\text { Lienzo - Deformación de plano: Hundimiento y cuarteado } \\
\text { película pictórica }\end{array}$ & 1 & $0-25$ \\
\hline $\begin{array}{l}\text { BASTIDOR } \\
\text { FENOMENOLOGÍA DE ALTERACIÓN Y DETERIORO }\end{array}$ & $\begin{array}{l}\text { INCIDENCIA } \\
\text { SUPERFICIAL }\end{array}$ & EXTENSIÓN SUPERFICIAL (\%) \\
\hline Madera - Desprendimiento & 1 & $0-25$ \\
\hline
\end{tabular}

Tabla 102 - Extensión superficial (\%) de las fenomenologías de alteración y deterioro registradas. Muestra 4.

\begin{tabular}{|l|l|l|}
\hline M4 (total incidencia de deterioro: 30 ) \\
\hline BARNIZ & $\begin{array}{l}\text { INCIDENCIA } \\
\text { SUPERFICIAL }\end{array}$ & EXTENSIÓN SUPERFICIAL (\%) \\
\hline FENOMENOLOGÍA DE ALTERACIÓN Y DETERIORO & 2 & $25-50$ \\
\hline Barniz - Cuarteado & 1 & $0-25$ \\
\hline Barniz - Alteración cromática: Zonas a diferente brillo & & \\
\hline PELÍCULA PICTÓRICA & $\begin{array}{l}\text { INCIDENCIA } \\
\text { SUPERFICIAL }\end{array}$ & EXTENSIÓN SUPERFICIAL (\%) \\
\hline FENOMENOLOGÍA DE ALTERACIÓN Y DETERIORO & 3 & $50-75$ \\
\hline Película pictórica - Cuarteados perimetrales & 3 & $50-75$ \\
\hline $\begin{array}{l}\text { Película pictórica - Cuarteados a contacto con los } \\
\text { elementos estructurales del bastidor }\end{array}$ & 3 & $50-75$ \\
\hline Película pictórica - Lagunas: Área inferior &
\end{tabular}




\begin{tabular}{|c|c|c|}
\hline Película pictórica - Cuarteados en áreas de color & 2 & $25-50$ \\
\hline Película pictórica - Cuarteados generalizados & 2 & $25-50$ \\
\hline $\begin{array}{l}\text { Película pictórica - Deformaciones de la superficie: } \\
\text { Descamación }\end{array}$ & 2 & $25-50$ \\
\hline $\begin{array}{l}\text { Película pictórica - Deformaciones de la superficie: } \\
\text { Levantamientos }\end{array}$ & 2 & $25-50$ \\
\hline $\begin{array}{l}\text { Película pictórica - Deformaciones de la superficie: } \\
\text { Cazoletas }\end{array}$ & 2 & $25-50$ \\
\hline $\begin{array}{l}\text { Película pictórica - Lagunas: Numerosas pequeñas en } \\
\text { esquinas cuarteados }\end{array}$ & 2 & $25-50$ \\
\hline Película pictórica - Craquelado & 1 & $0-25$ \\
\hline $\begin{array}{l}\text { Película pictórica - Deformaciones de la superficie: } \\
\text { Cordilleras }\end{array}$ & 1 & $0-25$ \\
\hline $\begin{array}{l}\text { Película pictórica - Deformaciones de la superficie: } \\
\text { Desprendimientos }\end{array}$ & 1 & $0-25$ \\
\hline Película pictórcia - Grietas puntuales/intracapas & 1 & $0-25$ \\
\hline \multicolumn{3}{|l|}{ PREPARACIÓN } \\
\hline FENOMENOLOGÍA DE ALTERACIÓN Y DETERIORO & $\begin{array}{l}\text { INCIDENCIA } \\
\text { SUPERFICIAL }\end{array}$ & EXTENSIÓN SUPERFICIAL (\%) \\
\hline Preparación: pérdida de adhesión con la película pictórica & 2 & $25-50$ \\
\hline 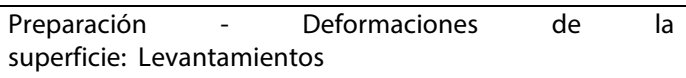 & 1 & $0-25$ \\
\hline Preparación - Cuarteado & 1 & $0-25$ \\
\hline \multicolumn{3}{|l|}{ SOPORTE TEXTIL } \\
\hline FENOMENOLOGÍA DE ALTERACIÓN Y DETERIORO & $\begin{array}{l}\text { INCIDENCIA } \\
\text { SUPERFICIAL }\end{array}$ & EXTENSIÓN SUPERFICIAL (\%) \\
\hline $\begin{array}{l}\text { Lienzo - Deformación de plano: Marcas de los elementos } \\
\text { estructurales }\end{array}$ & 4 & $75-100$ \\
\hline Lienzo - Deformación de plano: Perímetro & 4 & $75-100$ \\
\hline $\begin{array}{l}\text { Lienzo - Deformación de plano: Deformación del área } \\
\text { inferior }\end{array}$ & 4 & $75-100$ \\
\hline Lienzo - Deformación de plano: Deformación y rigidez & 4 & $75-100$ \\
\hline Lienzo - Acumulación de polvo: Fino & 4 & $75-100$ \\
\hline $\begin{array}{l}\text { Lienzo - Deformación de plano: Hundimiento y cuarteado } \\
\text { película pictórica }\end{array}$ & 2 & $25-50$ \\
\hline Lienzo - Manchas: Colores & 2 & $25-50$ \\
\hline Lienzo - Manchas: Filamentos & 1 & $0-25$ \\
\hline Lienzo - Intervenciones anteriores: Puntuales & 1 & $0-25$ \\
\hline \multicolumn{3}{|l|}{ BASTIDOR } \\
\hline FENOMENOLOGÍA DE ALTERACIÓN Y DETERIORO & $\begin{array}{l}\text { INCIDENCIA } \\
\text { SUPERFICIAL }\end{array}$ & EXTENSIÓN SUPERFICIAL (\%) \\
\hline Madera - Acumulación de polvo: Fino & 4 & $75-100$ \\
\hline
\end{tabular}




\begin{tabular}{|l|l|l|}
\hline Madera - Manchas: Blancas & 2 & $25-50$ \\
\hline Madera - Manchas: Negras & 1 & $0-25$ \\
\hline
\end{tabular}

M1 (total incidencia de deterioro: 29$)$

\section{BARNIZ}

\begin{tabular}{|l|l|l|}
\hline FENOMENOLOGÍA DE ALTERACIÓN Y DETERIORO & $\begin{array}{l}\text { INCIDENCIA } \\
\text { SUPERFICIAL }\end{array}$ & EXTENSIÓN SUPERFICIAL (\%) \\
\hline Barniz - Alteración cromática: Blanqueamiento & 4 & $75-100$ \\
\hline Barniz - Alteración cromática: Manchas & 2 & $25-50$ \\
\hline PELÍCULA PICTÓRICA & &
\end{tabular}

PELÍCULA PICTÓRICA

INCIDENCIA SUPERFICIAL

Película pictórica - Acumulación de polvo fino

Película pictórica - Cuarteados generalizados

\begin{tabular}{l|l}
\hline Película pictórica - Craquelado & 3
\end{tabular}

Película pictórica - Alteración cromática: Blanqueamiento

Película pictórica - Alteración cromática: Oscurecimiento

Película pictórica - Deformaciones de la superficie:

Descamación

Levantamientos

Película pictórica - Deformaciones de la superficie:

Desprendimientos

Película pictórcia - Grietas puntuales/intracapas

Película pictórica - Acumulación de polvo

grasoso/adherido Acumulación de polvo

Película pictórica - Cuarteados en forma circular o telaraña

Película pictórica - Cuarteados en forma de espina de pez

Película pictórica - Deformaciones de la superficie: Cordilleras

Película pictórica - Deformaciones de la superficie: Hundimientos

Película pictórica - Deformaciones de la superficie: Solapamientos

Película pictórica - Lagunas: Numerosas pequeñas en

esquinas cuarteados

2

1

1

EXTENSIÓN SUPERFICIAL (\%)

\begin{tabular}{l|l}
4 & $75-100$ \\
\hline
\end{tabular}

\begin{tabular}{l|l}
4 & $50-75$ \\
\hline
\end{tabular}

\begin{tabular}{l|l}
3 & $50-75$ \\
\hline
\end{tabular}

\begin{tabular}{l|l}
3 & $50-75$
\end{tabular}

\begin{tabular}{l|l}
\hline $30-75$ \\
\hline
\end{tabular}

\begin{tabular}{l|l}
$25-50$ &
\end{tabular}

2

25-50

\begin{tabular}{l|l}
$25-50$ \\
\hline 2
\end{tabular}

\begin{tabular}{l|l}
1 & $0-25$
\end{tabular}

\begin{tabular}{l|l}
1 & $0-25$
\end{tabular}

\begin{tabular}{l|l}
$0-25$ \\
\hline 1 & $0-25$
\end{tabular}

\begin{tabular}{l|l}
1 & $0-25$
\end{tabular}

\begin{tabular}{l|l}
1 & $0-25$
\end{tabular}

\begin{tabular}{l|l}
$0-25$ \\
1
\end{tabular}

0-25

\begin{tabular}{l|l}
1 & $0-25$
\end{tabular}

\begin{tabular}{l|l}
\hline 1 & $0-25$
\end{tabular}




\begin{tabular}{|l|l|l|}
\hline Película pictórica - Traumatismos: Rayados & 1 & $0-25$ \\
\hline Película pictórica - Traumatismos: Abrasión & 1 & $0-25$ \\
\hline Película pictórica - Traumatismos: Arañazos & 1 & $0-25$ \\
\hline Película pictórica - Presencia de materiales ajenos & 1 & $0-25$ \\
\hline $\begin{array}{l}\text { PREPARACIÓN } \\
\text { FENOMENOLOGÍA DE ALTERACIÓN Y DETERIORO }\end{array}$ & $\begin{array}{l}\text { INCIDENCIA } \\
\text { SUPERFICIAL }\end{array}$ & EXTENSIÓN SUPERFICIAL (\%) \\
\hline $\begin{array}{l}\text { Preparación: pérdida de adhesión con la película } \\
\text { pictórica }\end{array}$ & 1 & $0-25$ \\
\hline Preparación: Pulverulencia & 1 & $0-25$ \\
\hline $\begin{array}{l}\text { Preparación Deformaciones de la } \\
\text { superficie: Levantamientos }\end{array}$ & 1 & $0-25$ \\
\hline $\begin{array}{l}\text { SOPORTE LÍGNEO } \\
\text { FENOMENOLOGÍA DE ALTERACIÓN Y DETERIORO }\end{array}$ & $\begin{array}{l}\text { INCIDENCIA } \\
\text { SUPERFICIAL }\end{array}$ & EXTENSIÓN SUPERFICIAL (\%) \\
\hline Madera - Acumulación de polvo: Fino & 3 & $50-75$ \\
\hline Madera - Acumulación de polvo: Zona inferior & 3 & $50-75$ \\
\hline Madera - Desprendimiento & 1 & $0-25$ \\
\hline $\begin{array}{l}\text { Madera - Alteración estructural: pérdida/movimiento de } \\
\text { nudos }\end{array}$ & 1 & $0-25$ \\
\hline
\end{tabular}

Tabla 104 - Extensión superficial (\%) de las fenomenologías de alteración y deterioro registradas. Muestra

\begin{tabular}{|c|c|c|}
\hline \multicolumn{3}{|l|}{ M5 (total incidencia de deterioro: 27 ) } \\
\hline \multicolumn{3}{|l|}{ BARNIZ } \\
\hline FENOMENOLOGÍA DE ALTERACIÓN Y DETERIORO & $\begin{array}{l}\text { INCIDENCIA } \\
\text { SUPERFICIAL }\end{array}$ & EXTENSIÓN SUPERFICIAL (\%) \\
\hline Barniz - Alteración cromática: Pérdida de transparencia & 4 & $75-100$ \\
\hline Barniz - Alteración cromática: Blanqueamiento & 4 & $75-100$ \\
\hline Barniz - Alteración cromática: Zonas a diferente brillo & 3 & $50-75$ \\
\hline Barniz - Alteración cromática: Manchas & 2 & $25-50$ \\
\hline \multicolumn{3}{|l|}{ PELÍCULA PICTÓRICA } \\
\hline FENOMENOLOGÍA DE ALTERACIÓN Y DETERIORO & $\begin{array}{l}\text { INCIDENCIA } \\
\text { SUPERFICIAL }\end{array}$ & EXTENSIÓN SUPERFICIAL (\%) \\
\hline Película pictórica - Acumulación de polvo fino & 4 & $75-100$ \\
\hline Película pictórica - Alteración cromática: Blanqueamiento & 4 & $75-100$ \\
\hline Película pictórica - Cuarteados perimetrales & 2 & $25-50$ \\
\hline $\begin{array}{l}\text { Película pictórica - Cuarteados a contacto con los } \\
\text { elementos estructurales del bastidor }\end{array}$ & 2 & $25-50$ \\
\hline
\end{tabular}




\begin{tabular}{|c|c|c|}
\hline Película pictórica - Craquelado & 2 & $25-50$ \\
\hline $\begin{array}{l}\text { Película pictórica - Lagunas: Numerosas pequeñas en } \\
\text { esquinas cuarteados }\end{array}$ & 1 & $0-25$ \\
\hline Película pictórica - Lagunas: Área inferior & 1 & $0-25$ \\
\hline Película pictórica - Presencia de materiales ajenos & 1 & $0-25$ \\
\hline \multicolumn{3}{|l|}{ SOPORTE TEXTIL } \\
\hline FENOMENOLOGÍA DE ALTERACIÓN Y DETERIORO & $\begin{array}{l}\text { INCIDENCIA } \\
\text { SUPERFICIAL }\end{array}$ & EXTENSIÓN SUPERFICIAL (\%) \\
\hline Lienzo - Acumulación de polvo: Fino & 4 & $75-100$ \\
\hline Lienzo - Acumulación de polvo: Generalizado & 4 & $75-100$ \\
\hline $\begin{array}{l}\text { Lienzo - Deformación de plano: Marcas de los elementos } \\
\text { estructurales }\end{array}$ & 2 & $25-50$ \\
\hline Lienzo - Deformación de plano: Perímetro & 2 & $25-50$ \\
\hline Lienzo - Roturas: Desfibrados & 2 & $25-50$ \\
\hline Lienzo - Roturas: Naturales & 2 & $25-50$ \\
\hline Lienzo - Deformación de plano: Arrugas en las esquinas & 1 & $0-25$ \\
\hline $\begin{array}{l}\text { Lienzo - Deformación de plano: Deformación del área } \\
\text { inferior }\end{array}$ & 1 & $0-25$ \\
\hline Lienzo - Deformación de plano: Deformación y rigidez & 1 & $0-25$ \\
\hline Lienzo - Desprendimiento & 1 & $0-25$ \\
\hline Lienzo - Laguna & 1 & $0-25$ \\
\hline Lienzo - Rigidez & 1 & $0-25$ \\
\hline \multicolumn{3}{|l|}{ BASTIDOR } \\
\hline FENOMENOLOGÍA DE ALTERACIÓN Y DETERIORO & $\begin{array}{l}\text { INCIDENCIA } \\
\text { SUPERFICIAL }\end{array}$ & EXTENSIÓN SUPERFICIAL (\%) \\
\hline Madera - Acumulación de polvo: Fino & 4 & $75-100$ \\
\hline Madera - Manchas: Blancas & 1 & $0-25$ \\
\hline Madera - Manchas: Negras & 1 & $0-25$ \\
\hline
\end{tabular}

Tabla 105 - Extensión superficial (\%) de las fenomenologías de alteración y deterioro registradas. Muestra 7.

M7 (total incidencia de deterioro: 26 )

\section{BARNIZ}

\begin{tabular}{|l|l|l|}
\hline FENOMENOLOGÍA DE ALTERACIÓN Y DETERIORO & $\begin{array}{l}\text { INCIDENCIA } \\
\text { SUPERFICIAL }\end{array}$ & EXTENSIÓN SUPERFICIAL (\%) \\
\hline Barniz - Alteración cromática: Oscurecimiento & 4 & $75-100$ \\
\hline Barniz - Alteración cromática: Manchas & 1 & $0-25$ \\
\hline PELÍCULA PICTÓRICA & & \\
\hline
\end{tabular}




\begin{tabular}{|c|c|c|}
\hline FENOMENOLOGÍA DE ALTERACIÓN Y DETERIORO & $\begin{array}{l}\text { INCIDENCIA } \\
\text { SUPERFICIAL }\end{array}$ & EXTENSIÓN SUPERFICIAL (\%) \\
\hline Película pictórica - Acumulación de polvo fino & 4 & $75-100$ \\
\hline $\begin{array}{l}\text { Película pictórica - Alteración cromática: Tono café- } \\
\text { marrón }\end{array}$ & 4 & $75-100$ \\
\hline Película pictórica - Alteración cromática: Oscurecimiento & 4 & $75-100$ \\
\hline Película pictórica - Cuarteados generalizados & 2 & $25-50$ \\
\hline Película pictórica - Craquelado & 2 & $25-50$ \\
\hline Película pictórica - Presencia de materiales ajenos & 2 & $25-50$ \\
\hline $\begin{array}{l}\text { Película pictórica }- \text { Acumulación de polvo } \\
\text { grasoso/adherido }\end{array}$ & 1 & $0-25$ \\
\hline $\begin{array}{l}\text { Película pictórica - Deformaciones de la superficie: } \\
\text { Descamación }\end{array}$ & 1 & $0-25$ \\
\hline $\begin{array}{l}\text { Película pictórica - Deformaciones de la superficie: } \\
\text { Levantamientos }\end{array}$ & 1 & $0-25$ \\
\hline $\begin{array}{l}\text { Película pictórica - Deformaciones de la superficie: } \\
\text { Desprendimientos }\end{array}$ & 1 & $0-25$ \\
\hline Película pictórcia - Grietas puntuales/intracapas & 1 & $0-25$ \\
\hline Película pictórica - Lagunas: Grandes áreas & 1 & $0-25$ \\
\hline Película pictórica - Traumatismos: Rayados & 1 & $0-25$ \\
\hline Película pictórica - Traumatismos: Abrasión & 1 & $0-25$ \\
\hline Película pictórica - Traumatismos: Desgaste & 1 & $0-25$ \\
\hline Película pictórica - Traumatismos: Arañazos & 1 & $0 \leq 25$ \\
\hline \multicolumn{3}{|l|}{ PREPARACIÓN } \\
\hline FENOMENOLOGÍA DE ALTERACIÓN Y DETERIORO & $\begin{array}{l}\text { INCIDENCIA } \\
\text { SUPERFICIAL }\end{array}$ & EXTENSIÓN SUPERFICIAL (\%) \\
\hline Preparación: desprendimientos & 2 & $25-50$ \\
\hline 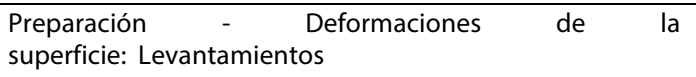 & 2 & $25-50$ \\
\hline Preparación: lagunas & 1 & $0-25$ \\
\hline \multicolumn{3}{|l|}{ SOPORTE EN MADERA } \\
\hline FENOMENOLOGÍA DE ALTERACIÓN Y DETERIORO & $\begin{array}{l}\text { INCIDENCIA } \\
\text { SUPERFICIAL }\end{array}$ & EXTENSIÓN SUPERFICIAL (\%) \\
\hline Madera - Acumulación de polvo: Fino & 4 & $75-100$ \\
\hline Madera - Acumulación de polvo: Generalizado & 4 & $75-100$ \\
\hline Madera - Acumulación de polvo: Grasoso/adherido & 2 & $25-50$ \\
\hline Madera - Grietas: Fendas & 1 & $0-25$ \\
\hline Madera - Desprendimiento & 1 & $0-25$ \\
\hline
\end{tabular}




\begin{tabular}{|c|c|c|}
\hline \multicolumn{3}{|l|}{ M6 (total incidencia de deterioro: 25 ) } \\
\hline \multicolumn{3}{|l|}{ PELÍCULA PICTÓRICA } \\
\hline FENOMENOLOGÍA DE ALTERACIÓN Y DETERIORO & $\begin{array}{l}\text { INCIDENCIA } \\
\text { SUPERFICIAL }\end{array}$ & EXTENSIÓN SUPERFICIAL (\%) \\
\hline Película pictórica - Acumulación de polvo fino & 4 & $75-100$ \\
\hline Película pictórica - Presencia de materiales ajenos & 4 & $75-100$ \\
\hline $\begin{array}{l}\text { Película pictórica - Cuarteados a contacto con los } \\
\text { elementos estructurales del bastidor }\end{array}$ & 3 & $50-75$ \\
\hline Película pictórica - Craquelado & 3 & $50-75$ \\
\hline $\begin{array}{l}\text { Película pictórica - Deformaciones de la superficie: } \\
\text { Desprendimientos }\end{array}$ & 3 & $50-75$ \\
\hline Película pictórica - Cuarteados perimetrales & 2 & $25-50$ \\
\hline $\begin{array}{l}\text { Película pictórica - Lagunas: Numerosas pequeñas en } \\
\text { esquinas cuarteados }\end{array}$ & 2 & $25-50$ \\
\hline Película pictórica - Lagunas: Área inferior & 2 & $25-50$ \\
\hline $\begin{array}{l}\text { Película pictórica - Deformaciones de la superficie: } \\
\text { Cordilleras }\end{array}$ & 1 & $0-25$ \\
\hline \multicolumn{3}{|l|}{ PREPARACIÓN } \\
\hline FENOMENOLOGÍA DE ALTERACIÓN Y DETERIORO & $\begin{array}{l}\text { INCIDENCIA } \\
\text { SUPERFICIAL }\end{array}$ & EXTENSIÓN SUPERFICIAL (\%) \\
\hline $\begin{array}{l}\text { Preparación: pérdida de adhesión con la película } \\
\text { pictórica }\end{array}$ & 2 & $25-50$ \\
\hline \multicolumn{3}{|l|}{ SOPORTE TEXTIL } \\
\hline FENOMENOLOGÍA DE ALTERACIÓN Y DETERIORO & $\begin{array}{l}\text { INCIDENCIA } \\
\text { SUPERFICIAL }\end{array}$ & EXTENSIÓN SUPERFICIAL (\%) \\
\hline Lienzo - Deformación de plano: Arrugas en las esquinas & 4 & $75-100$ \\
\hline $\begin{array}{l}\text { Lienzo - Deformación de plano: Deformación del área } \\
\text { inferior }\end{array}$ & 4 & $75-100$ \\
\hline Lienzo - Acumulación de polvo: Fino & 4 & $75-100$ \\
\hline Lienzo - Acumulación de polvo: Generalizado & 4 & $75-100$ \\
\hline $\begin{array}{l}\text { Lienzo - Deformación de plano: Marcas de los elementos } \\
\text { estructurales }\end{array}$ & 3 & $50-75$ \\
\hline Lienzo - Deformación de plano: Perímetro & 2 & $25-50$ \\
\hline Lienzo - Intervenciones anteriores: Puntuales & 2 & $25-50$ \\
\hline Lienzo - Alteración cromática: Oscurecimiento & 1 & $0-25$ \\
\hline \multicolumn{3}{|l|}{ BASTIDOR } \\
\hline FENOMENOLOGÍA DE ALTERACIÓN Y DETERIORO & $\begin{array}{l}\text { INCIDENCIA } \\
\text { SUPERFICIAL }\end{array}$ & EXTENSIÓN SUPERFICIAL (\%) \\
\hline
\end{tabular}




\begin{tabular}{|l|l|l|}
\hline Madera - Acumulación de polvo: Zona inferior & 4 & $75-100$ \\
\hline Madera - Intervenciones anteriores & 4 & $75-100$ \\
\hline Madera - Acumulación de polvo: Fino & 3 & $50-75$ \\
\hline Madera - Acumulación de polvo: Generalizado & 3 & $50-75$ \\
\hline Madera - Presencia de galerías de xilófagos & 1 & $0-25$ \\
\hline Madera - Desprendimiento & 1 & $0-25$ \\
\hline Madera - Manchas: Blancas & 1 & $0-25$ \\
\hline
\end{tabular}

Tabla 107 - Extensión superficial (\%) de las fenomenologías de alteración y deterioro registradas. Muestra 8.

\begin{tabular}{|c|c|c|}
\hline \multicolumn{3}{|l|}{ M8 (total incidencia de deterioro: 17 ) } \\
\hline \multicolumn{3}{|l|}{ BARNIZ } \\
\hline FENOMENOLOGÍA DE ALTERACIÓN Y DETERIORO & $\begin{array}{l}\text { INCIDENCIA } \\
\text { SUPERFICIAL }\end{array}$ & EXTENSIÓN SUPERFICIAL (\%) \\
\hline Barniz - Alteración cromática: Oscurecimiento & 4 & $75-100$ \\
\hline \multicolumn{3}{|l|}{ SOPORTE TEXTIL } \\
\hline FENOMENOLOGÍA DE ALTERACIÓN Y DETERIORO & $\begin{array}{l}\text { INCIDENCIA } \\
\text { SUPERFICIAL }\end{array}$ & EXTENSIÓN SUPERFICIAL (\%) \\
\hline Película pictórica - Acumulación de polvo fino & 4 & $75-100$ \\
\hline $\begin{array}{l}\text { Película pictórica - Alteración cromática: Tono café- } \\
\text { marrón }\end{array}$ & 4 & $75-100$ \\
\hline $\begin{array}{l}\text { Película pictórica - Deformaciones de la superficie: } \\
\text { Descamación }\end{array}$ & 1 & $0-25$ \\
\hline $\begin{array}{l}\text { Película pictórica - Deformaciones de la superficie: } \\
\text { Levantamientos }\end{array}$ & 1 & $0-25$ \\
\hline $\begin{array}{l}\text { Película pictórica - Deformaciones de la superficie: } \\
\text { Desprendimientos }\end{array}$ & 1 & $0-25$ \\
\hline Película pictórcia - Grietas puntuales/intracapas & 1 & $0-25$ \\
\hline $\begin{array}{l}\text { Película pictórica - Lagunas: Numerosas pequeñas en } \\
\text { esquinas cuarteados }\end{array}$ & 1 & $0-25$ \\
\hline Película pictórica - Lagunas: Grandes áreas & 1 & $0-25$ \\
\hline Película pictórica - Traumatismos: Rayados & 1 & $0-25$ \\
\hline Película pictórica - Traumatismos: Abrasión & 1 & $0-25$ \\
\hline Película pictórica - Traumatismos: Desgaste & 1 & $0-25$ \\
\hline Película pictórica - Traumatismos: Arañazos & 1 & $0-25$ \\
\hline Película pictórica - Presencia de materiales ajenos & 1 & $0-25$ \\
\hline \multicolumn{3}{|l|}{ PREPARACIÓN } \\
\hline FENOMENOLOGÍA DE ALTERACIÓN Y DETERIORO & $\begin{array}{l}\text { INCIDENCIA } \\
\text { SUPERFICIAL }\end{array}$ & EXTENSIÓN SUPERFICIAL (\%) \\
\hline
\end{tabular}




\begin{tabular}{|l|l|l|}
\hline $\begin{array}{l}\text { Preparación: pérdida de adhesión con la película } \\
\text { pictórica }\end{array}$ & 1 & $0-25$ \\
\hline Preparación - Cuarteado & 1 & $0-25$ \\
\hline SOPORTE TEXTIL & $\begin{array}{l}\text { INCIDENCIA } \\
\text { SUPERFICIAL }\end{array}$ & EXTENSIÓN SUPERFICIAL (\%) \\
\hline FENOMENOLOGÍA DE ALTERACIÓN Y DETERIORO & 1 & $0-25$ \\
\hline Lienzo - Rigidez & 1 & \\
\hline
\end{tabular}

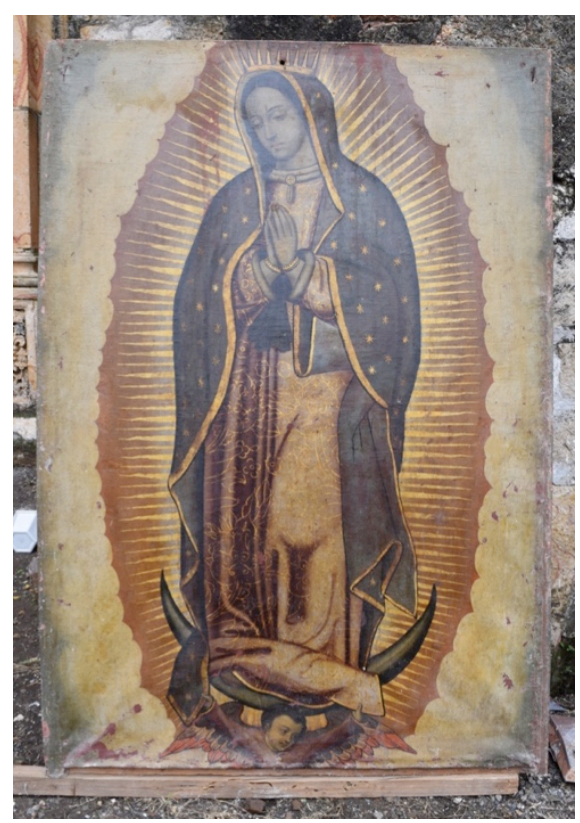

Imagen 83 - Obra con mayor indicador de riesgo (M3). Virgen de Guadalupe, siglo XVIII. Anverso.

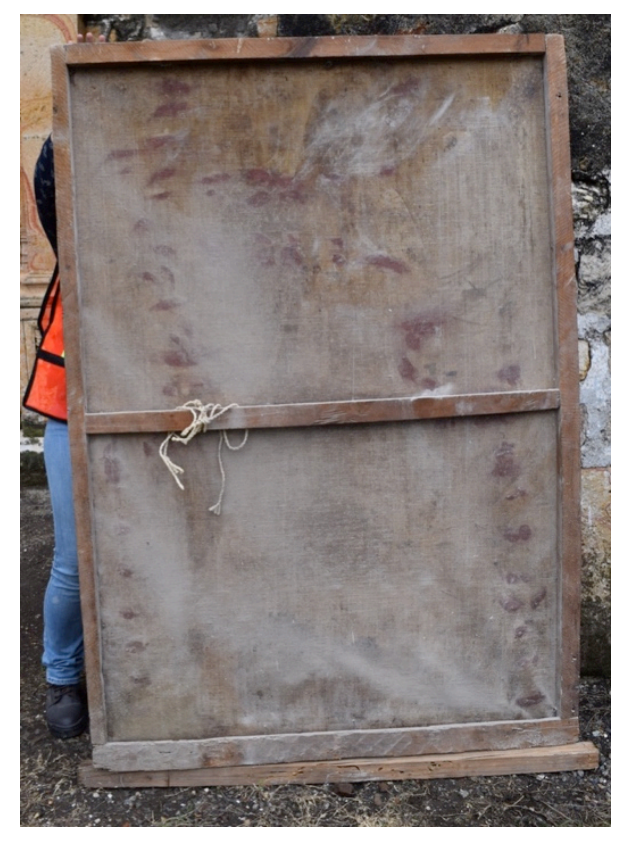

Imagen 84 - Obra con mayor indicador de riesgo (M3). Virgen de Guadalupe, siglo XVIII. Reverso. 


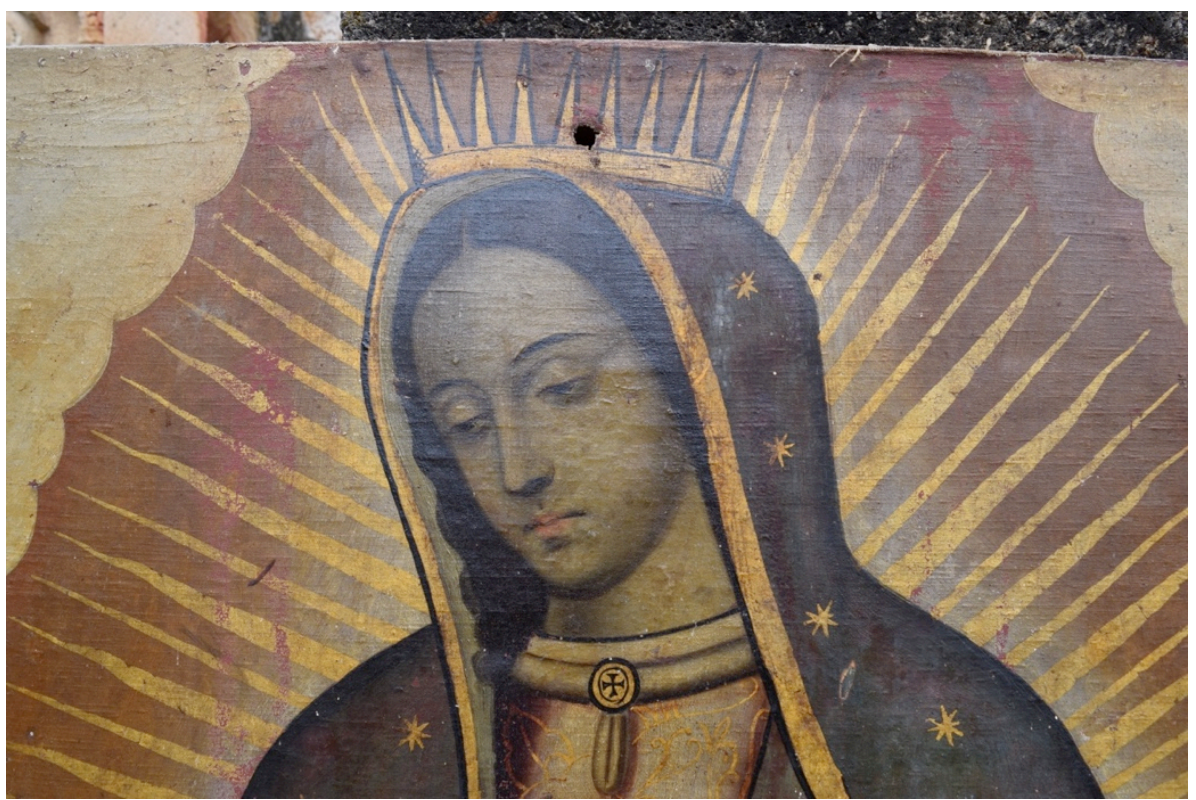

Imagen 85 - Detalle del estado de la pintura (M3).

Tomando como ejemplo la obra con mayor indicador de riesgo (M3), y evaluando los resultados derivados de los fenómenos registrados, se puede afirmar que parte de su historial conservativo ha sido compuesto por las siguientes dinámicas ${ }^{291}$ :

- Envejecimiento natural de los materiales compositivos: oxidación de los aglutinantes oleosos y resinas. Ésto favorece la formación de microfisuras y craquelados debido a una pérdida de elasticidad. La variación en la reflexión de la luz genera un cambio en la apreciación estética de la obra.

- Intervenciones de mantenimiento con aplicación de sustancias de naturaleza oleosa y/o ceras. Esto puede haber favorecido la adhesión de partículas de suciedad y polvo además de la formación de áreas con diferente brillo.

291 Ibídem. El proceso de interpretación de resultados es parte de la aportación del profesional de la conservación y restauración encargado de realizar el diagnóstico. A través del método se propone un acercamiento a sus posibilidades aplicativas y de resolución de las fases preliminares de estudio. El análisis de resultados propuesto es indicativo de los posibles alcances derivados de la información arrojada. 
- Traumatismos superficiales (limpiezas inadecuadas, manipulación de la obra, eventos accidentales) han ocasionado la formación de hundimientos, roturas, abrasiones, desgaste, rayados, cuarteados.

- Uso de cirios y velas en proximidad de la obra con finalidad devocional.

- Acumulación de polvo y sustancias ajenas se relacionan a una falta de mantenimiento y limpieza periódicos, aunque en esta circunstancia ha sido agravado por el evento sísmico extraordinario.

- Exposición de la obra a ciclos de variación termohigrométrica, con probable exposición a contenidos de humedad relativa lo suficientemente elevado como para favorecer la pérdida del poder adhesivo de la cola animal. Esto, junto al método de sujección del lienzo al bastidor, ha generado fallos en el tensado del soporte. La película pictórica presenta craquelados generalizados, más severos en correspondencia de la deformación de la tela (ángulo y perímetro).

- La diferente variación dimensional que sufren los materiales sometidos a las condiciones mencionadas ha ocasionado probemáticas de adhesión y cohesión entre la película pictórica y las capas subyacentes, favoreciendo la formación de descamación, levantamientos, desprendimientos, grietas intracapas, lagunas.

- La oxidación de los materiales aglutinantes tiene como efecto una variación cromática de la superficie pictórica hacia una tonalidad marrón-café. Este fenómeno es favorecido por parámetros conservativos caracterizados por una elevada humedad relativa y escasa iluminación.

- El soporte textil presenta considerables problemáticas relacionadas con una pérdida de tensado y flexibilidad. Este fenómeno se debe a un proceso de oxidación de las fibras del lienzo, favorecido por parámetros termohigrométricos con elevada humedad relativa y por la acción fotoquímica de los rayos UV. Esta problemática debilita la resistencia del lienzo a los impactos mecánicos externos, exponiéndolo a roturas, desfibrados, desprendimientos y lagunas. La oxidación del lienzo está ligada con las variaciones en las características de los materiales que conforman el 
sistema (adhesivos, aglutinantes, resinas) y es más severa cuanto más estén alterados dichos componentes. Es indicativo de un sistema de sujección del soporte al bastidor sin cuñas de tensado.

- La acumulación de polvo entre bastidor y soporte ha incrementado la deformación del plano en el área inferior de la pintura, reflejándose negativamente en las capas superpuestas.

- La presencia de galerías de insectos xilófagos es indicativo de la existencia de condiciones de conservación óptimas para el desarrollo de esta tipología de deterioro biológico.

Gracias al apoyo de las estimaciones de la extensión superficial de los deterioros, podemos concluir que la mayor problemática de la obra es la que se deriva de la alteración en el tensado del soporte textil que, aunado a las condiciones termohigrométricas de conservación, se ha reflejado negativamente sobre la película pictórica. A estos efectos siguen la acumulación de polvo y los fenómenos derivados de traumatismos, relacionados con los acontecimientos a los que se expuso la obra y a su manipulación incorrecta a lo largo del tiempo. Finalmente, la alteración cromática y la rigidez son indicio de una variación en las propiedades de los materiales empleados (originalmente o en sucesivas intervenciones) derivada de procesos de oxidación y envejecimiento. 


\subsection{Templos del centro histórico de San Luis Potosí (S.L.P.)}

El centro histórico de San Luis Potosí presenta varios testigos arquitectónicos del arte barroco que tuvo su auge ${ }^{292}$ en la época virreinal, entre los siglos XVII-XVIII. Los recintos religiosos ubicados en el entramado de calles de esta zona urbana evocan los antiguos vestigios de las órdenes que en él desarrollaron su labor de evangelización, educación y gestión de los recursos del territorio, levantando templos y conventos. De las majestuosas construcciones impulsadas por jesuitas, franciscanos, agustinos y carmelitas entre otros, se seleccionaron las portadas de los edificios que siguen albergando motivos ornamentales y esculturas en sus fachadas (imagen 86).

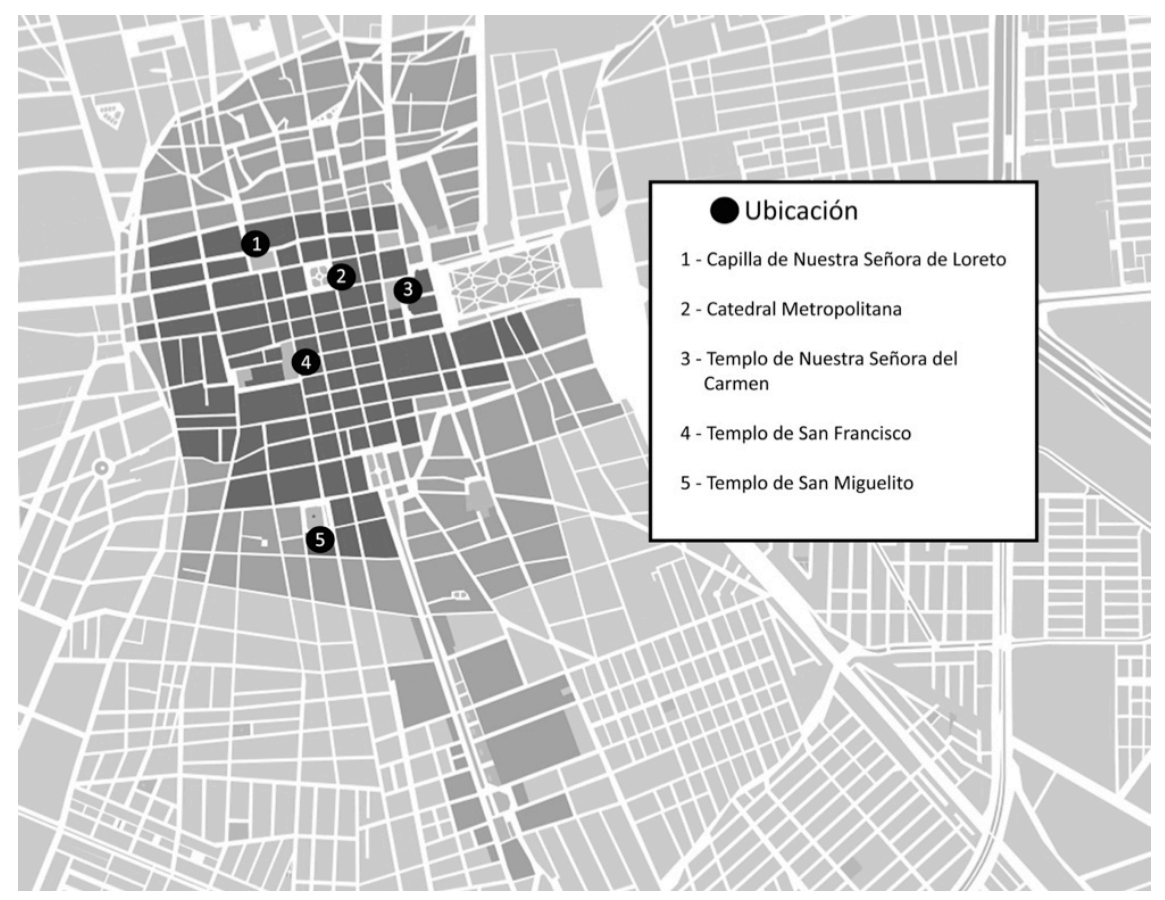

Imagen 86 - Ubicación de los casos de estudio ${ }^{293}$. Centro histórico de San Luis Potosí.

292 Durante los siglos XVI-XVIII el estilo barroco de influencia española permea el territorio mexicano, encontrando, hacia 1690, un apogeo en la exuberancia de las decoraciones y motivos ornamentales. Es en este periodo cuando el estilo barroco mexicano adquiere características y personalidad propias, fruto de la fertilidad social, económica y artística de la época. TOUSSAINT, M. (1990). El arte colonial en México. México: Universidad Nacional Autónoma de México, p. XIII-XIV.

293 Imagen modificada de "Centro histórico de San Luis Potosí". <https://centrohistoricoslp.com/mapa/> [Consulta: 5 de diciembre de 2020]. 
La capilla de Nuestra Señora de Loreto (imagen 87) se ubica en la esquina de plaza Fundadores, comunicando en su interior con el colindante templo de La Compañía de Jesús. Su construcción a aula única está fechada en $1625^{294}$ y destaca en el tejido urbano por su fachada-retablo de estilo barroco salomónico ${ }^{295}$ con ricas decoraciones en cantera rosa. Sus laterales se delimitan por pilastras tablereadas ${ }^{296}$ rematadas por una cornisa semicircular, dominada por una cruz.

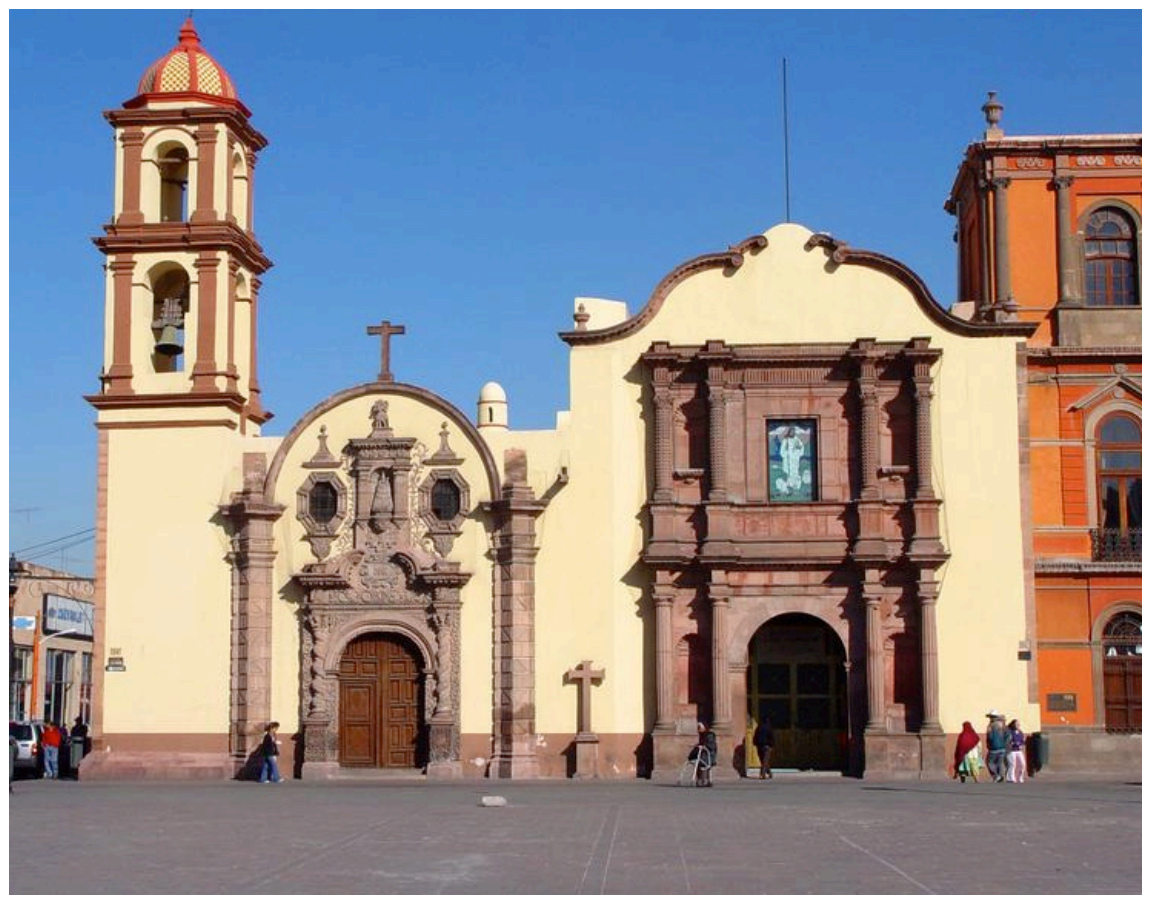

Imagen 87 - Capilla de Nuestra Señora de Loreto (izquierda) y templo de La Compañía de Jesús $(\text { derecha })^{297}$.

${ }^{294}$ KAISER SCHLITTLER, A. (2014). Breve historia de la ciudad de San Luis Potosí. México: Kaiser.

295 El barroco salomónico adquiere su denominación por la presencia de la homónima columna, cuyo fuste se desarrolla de forma helicoidal alrededor de su eje. Florece en los límites de los siglos XVII y XVIII, principalmente al centro y norte de México. GONZÁLEZ GALVÁN, M. (2006). Trazo, proporción y símbolo en el arte virreinal: antología personal. México: Universidad Nacional Autónoma de México, p. 123.

${ }^{296}$ Los fustes tablerados incorporan decoraciones geométricas en la superficie de las pilastras. Se difunden en la primera mitad del siglo XVIII en la zona centro y occidental de México. GONZÁLEZ GALVÁN, M. (2006), op. cit., p. 134.

297 "Parroquia del Sagrario Metropolitano" en México en Fotos.

<https://www.mexicoenfotos.com/MX12182358439373.jpg> [Consulta: 27 de noviembre de 2020]. 
La catedral metropolitana (imagen 88) se ubica en el mismo lugar en donde, en 1593, surgió la primera ermita de la ciudad. Su construcción inició en 1670 y concluyó en $1730^{298}$. Se compone por un edificio de tres naves, con una fachada en estilo barroco estructurada en pisos y calles a manera de biombo y enmarcados por columnas de inspiración salomónica. Los doce nichos albergan, desde 1906, unas esculturas en mármol de Carrara realizadas por el taller de los hermanos Biagi (imagen 89). Éstas, ejecutadas en ocasión de las celebraciones para el centenario de la Independencia, sustituyen las obras en cantera rosa que hoy en día se pueden observar en la orilla de la cornisa lateral del templo. Representan a los doce apóstoles y están inspiradas en las esculturas existentes en San Juan de Letrán en Roma ${ }^{299}$.

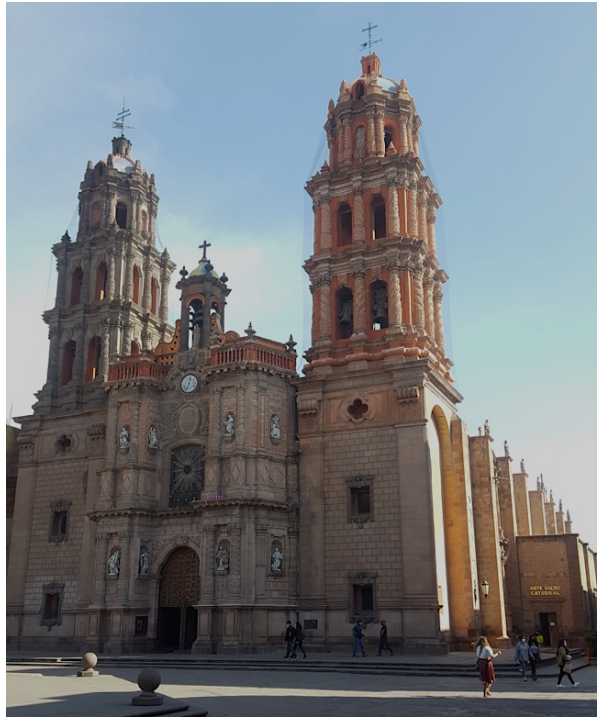

Imagen 88 - Catedral Metropolitana de San Luis Potosí.

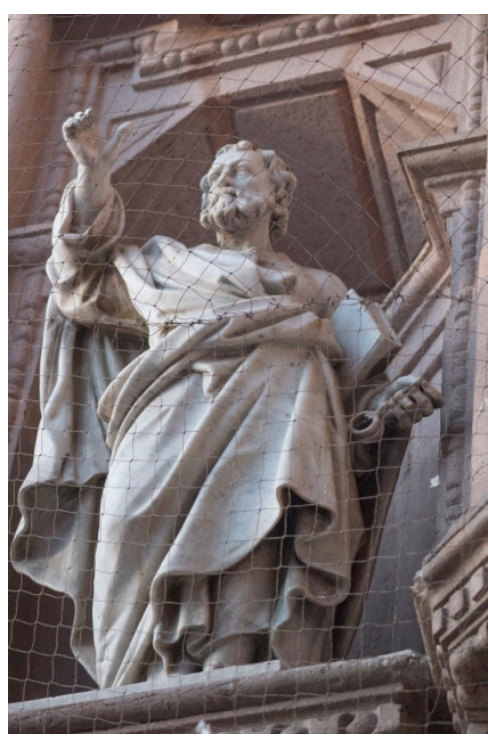

Imagen 89 - Escultura del apóstol Pedro ${ }^{300}$.

El conjunto conventual del que forma parte el templo del Carmen empezó a construirse en $1749^{301}$ y representa un magnífico ejemplo de barroco

\footnotetext{
298 KAISER SCHLITTLER, A. (2014), op.cit., p. 70.

${ }^{299}$ MASTROIACOVO, T., BLASCO PÉREZ, M.V., NIETO VILLENA, A (2017). "Los hermanos Biagi y las esculturas de la catedral Metropolitana" en Universitarios Potosinos, año 14, núm. 211, pp. 12-17.

${ }^{300}$ Foto: Blanca Elena Sánchez Araujo.

${ }^{301}$ KAISER SCHLITTLER, A. (2014), op.cit., p. 73.
} 
churrigueresco. Sus portadas (imagen 90 y 91) se componen por una rica decoración ultrabarroca ${ }^{302}$, estructurada de acuerdo a la modalidad de fachada-retablo con pilastras de tipo estípite ${ }^{303}$. El acceso norte al recinto religioso está enmarcado por la portada Josefina.

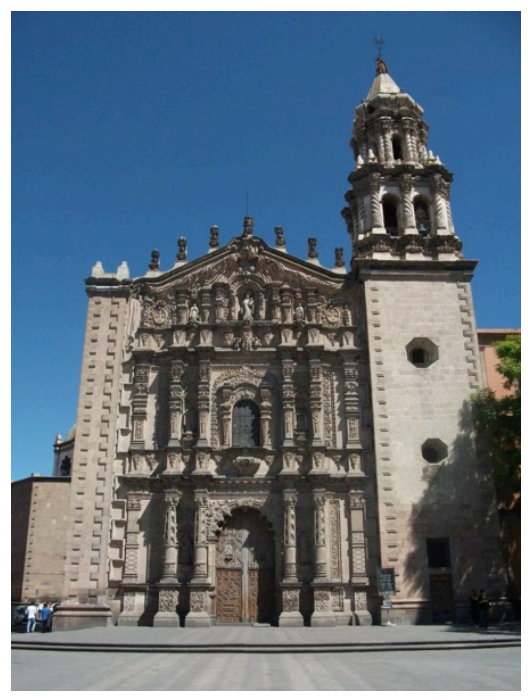

Imagen 90 - Fachada del templo del Carmen ${ }^{304}$, San Luis Potosí.

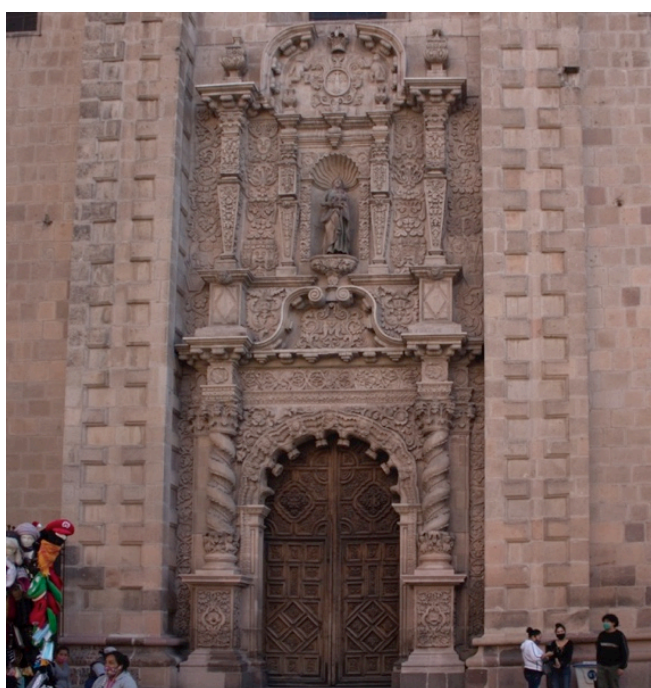

Imagen 91 - Portada Josefina ${ }^{305}$, acceso lateral al templo del Carmen.

La construcción de la fachada del templo de San Francisco data del año $1686^{306}$. Su portada (imagen 92) se compone por una fachada retablo barroca de tipo ecléctico. Sus rasgos puristas, visibles en las columnas y trabeación con medallones

302 El término ultrabarroco fue coniado por el Dr. Atl para describir la abundancia y riqueza de decoraciones propias del barroco mexicano "para indicar que vienen del barroco y que van más allá. DR. ATL (1927). Iglesias de México. Vol. VI. México: Publicaciones de la Secretaría de Hacienda, p. 144.

${ }^{303}$ Las pilastras estípite caracterizan y definen el estilo barroco churrigueresco. La abstracción geométrica de estos elementos se compone por combinaciones decorativas diferentes, enmarcadas en una modulación derivada de la figura humana. Su mayor manifestación se registra a mediados de la segunda mitad del siglo XVIII en todo México, adquiriendo variantes locales. GONZÁLEZ GALVÁN, M. (2006), op. cit., p.135.

304 "Templo del Carmen" en Consejo del Centro Histórico de San Luis Potosí. <https://centrohistoricoslp.com/templo-del-carmen/> [Consulta: 27 de noviembre de 2020].

${ }^{305}$ Foto: Blanca Elena Sánchez Araujo.

${ }^{306}$ KAISER SCHLITTLER, A. (2014), op.cit., p. 64 y 67. 
de evocación clásica, se combinan con los fustes de tipo salomónico y con la modulación curvilínea de la cornisa de remate (imagen 93).

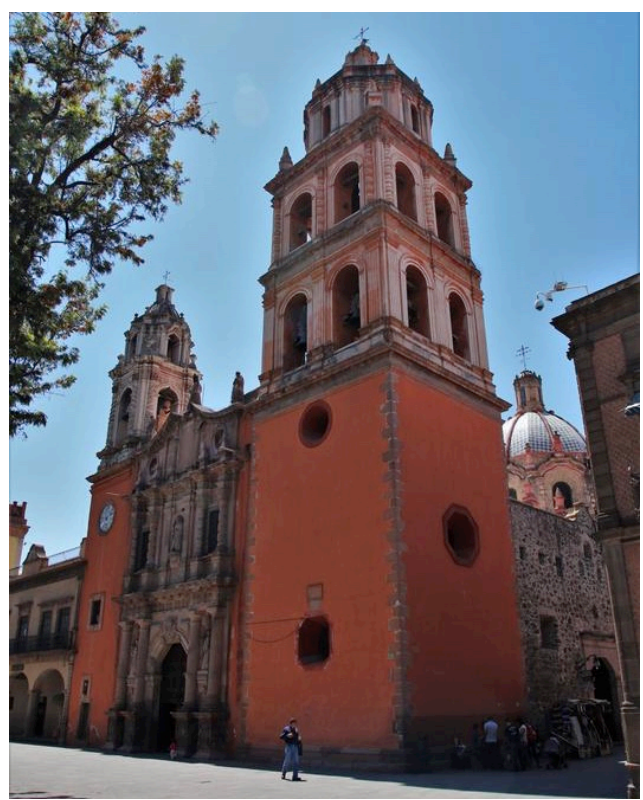

Imagen 92 - Templo de San Franciso, vista general de la fachada ${ }^{307}$.

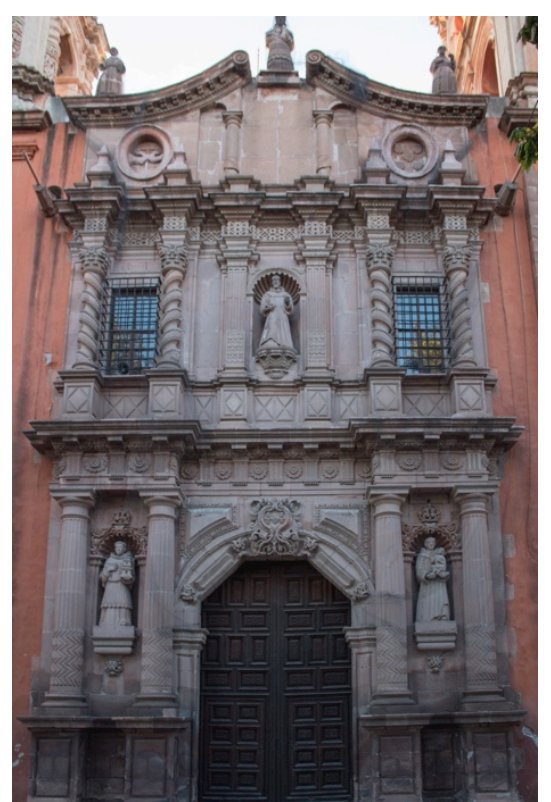

Imagen 93 - Vista frontal del templo ${ }^{308}$.

El templo de San Miguel, construido por los franciscanos en $1733^{309}$, se encuentra en la zona sur del centro de la ciudad. La portada de acceso (imagen 94 y 95) se compone por una fachada-retablo con ornamentaciones barrocas de estilo purista, visible en la ordenación de la superficie por medio de columnas y pilastras de reminiscencia clásica ${ }^{310}$.

307 "Templo de San Franscisco" en México en Fotos.

<https://www.mexicoenfotos.com/MX15472737712554.jpg> [Consulta: 27 de noviembre de 2020].

${ }^{308}$ Foto: Blanca Elena Sánchez Araujo.

${ }^{309}$ KAISER SCHLITTLER, A. (2014), op.cit., p. 78.

${ }^{310}$ Las reminiscencias clásicas se encuentran en las características de forma, modulación y moldura, pero no en términos de proporción. Se difunde a mitad del siglo XVII en el centro del país. GONZÁLEZ GALVÁN, M. (2006), op. cit., p. 133. 


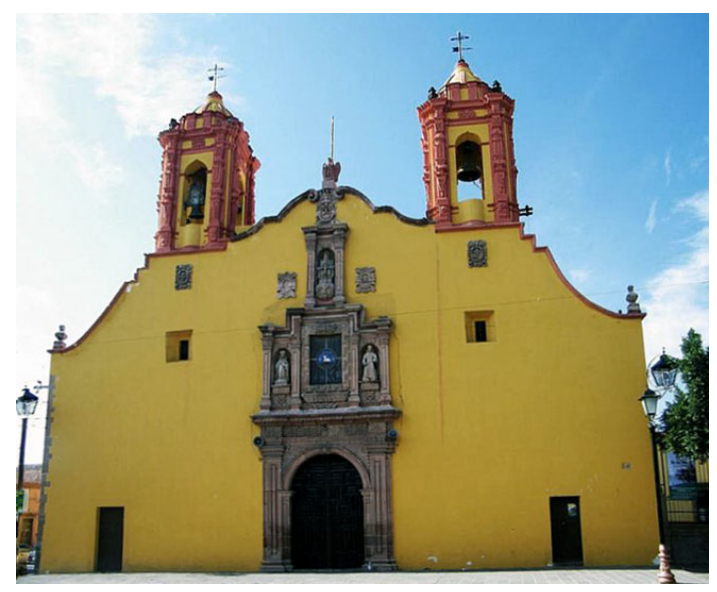

Imagen 94 - Templo de San Miguelito ${ }^{311}$.

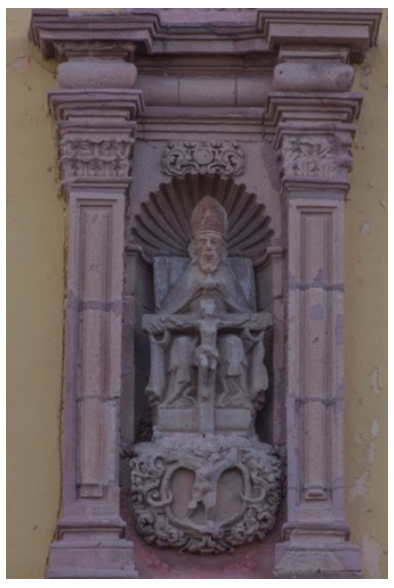

Imagen 95 - Detalle de la fachada ${ }^{312}$.

Estos ejemplos de arquitectura barroca se encuentran en condiciones conservativas diferentes, algunos han sido objeto de acciones de restauración, como se puede apreciar por la presencia de revoques o de elementos sustitutivos de los pétreos originales. Como medida de mantenimiento contra la acción de las aves, muchos cuentan con una protección por medio de mallas.

\subsubsection{Capilla de Nuestra Señora de Loreto}

Para la implementación del método se han analizado, sobre documentación fotográfica, un total de 3 esculturas en cantera rosa (tabla 108), las cuales se han relacionado con coordenadas numéricas (tabla 109) que identifican su número de muestra y su ubicación en la fachada (imagen 96).

\footnotetext{
${ }^{311}$ Foto: Eduardo López.

${ }^{312}$ Foto: Blanca Elena Sánchez Araujo.
} 
Tabla 108 - Datos de las modalidades de registro y análisis.

\begin{tabular}{|l|l|}
\hline \multicolumn{2}{|l|}{ CAPILLA DE NUESTRA SEÑORA DE LORETO } \\
\hline Registro realizado en: & Octubre 2020 \\
\hline Objeto de estudio: & Material pétreo (cantera rosa) \\
\hline Tiempo de registro de datos: & 20 minutos, sobre documentación fotográfica \\
\hline Total de obras analizadas: & 3 esculturas \\
\hline Profesionales empleados: & 1 \\
\hline Tiempo para el análisis de datos & 20 minutos \\
\hline
\end{tabular}

Tabla 109 - Referencia de muestras y esculturas de la fachada.

\begin{tabular}{|l|l|}
\hline \multicolumn{2}{|l|}{ FACHADA DE LA CAPILLA DE NUESTRA SEÑORA DE LORETO } \\
\hline $\mathrm{M}$ & IDENTIFICACIÓN DE LAS OBRAS (imagen XX) \\
\hline 1 & $\begin{array}{l}\text { Cantera rosa. Escultura de bulto redondo, Virgen de Loreto, nicho central. Fachada-retablo, siglo } \\
\text { XVIII. }\end{array}$ \\
\hline 2 & Cantera rosa. Escultura de bulto redondo, San Miguel Arcángel, remate. Fachada-retablo, siglo XVIII. \\
\hline 3 & Cantera rosa. Escultura de bulto redondo, cruz de remate. Fachada, siglo XVIII. \\
\hline
\end{tabular}




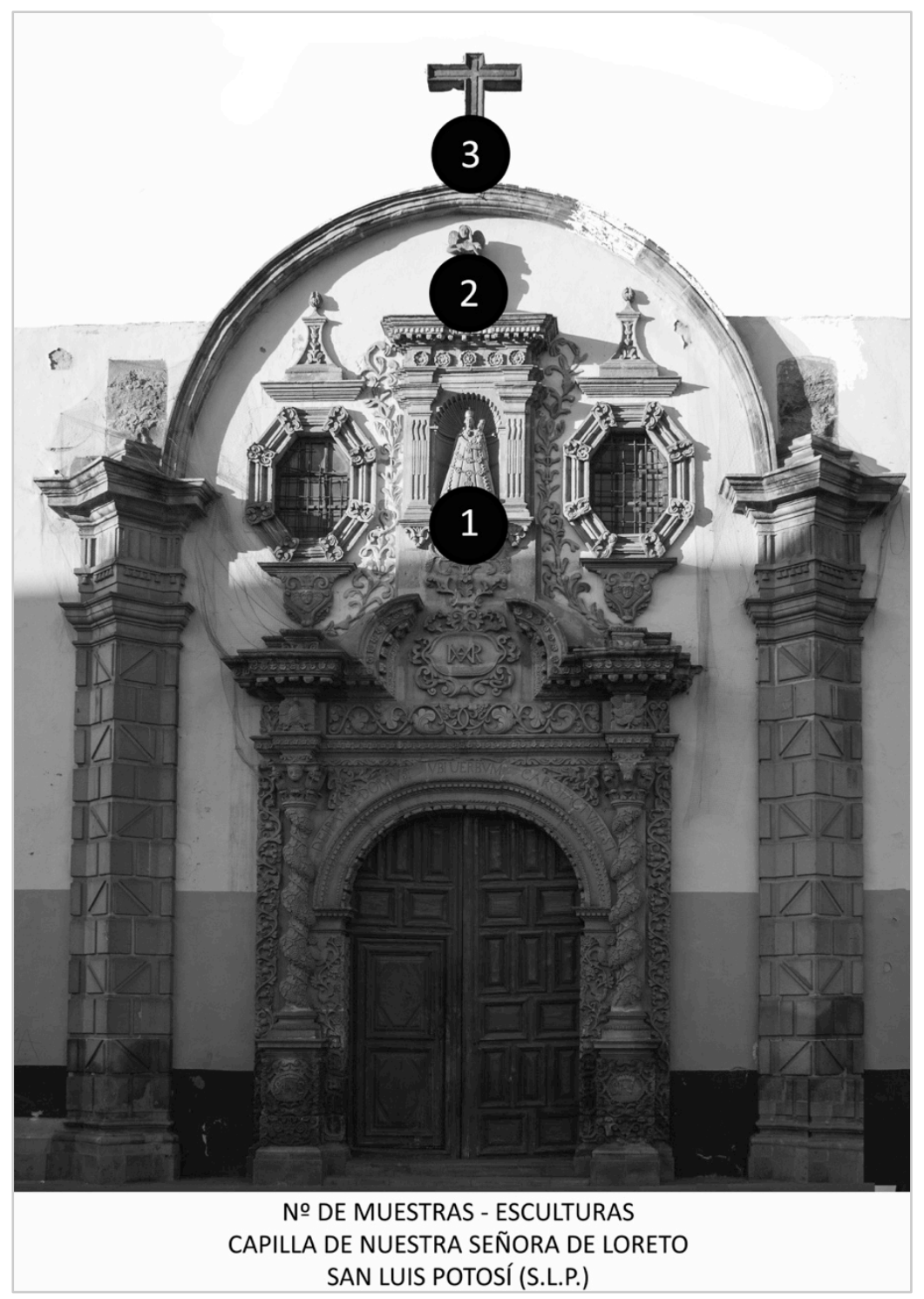

Imagen 96 - Identificación de muestras y ubicación.

Tras el análisis de los datos recolectados, ha sido posible identificar:

- fenomenologías de alteración y deterioro activas (tabla 110) junto a su estimación cuantitativa y porcentual (gráfica 25); 
- indicador de riesgo del conjunto (tabla 111);

- croquis del indicador de riesgo y prioridad (imagen 97);

- obra con mayor indicador de riesgo y prioridad (imágenes 98 y 99);

- alteraciones y deterioros presentes en cada obra/área complementada por una estimación de la superficie afectada por cada fenómeno (tablas 112114);

La información obtenida ha sido complementada por una propuesta de interpretación de los datos, junto a los demás casos de estudio, al final del capítulo.

Tabla 110 - Panorámica de las dinámicas de alteración que están afectando las esculturas de la fachada.

\begin{tabular}{|l|l|}
\hline FENOMENOLOGÍA DE ALTERACIÓN Y DETERIORO & $\begin{array}{l}\text { TOTAL } \\
\text { INCIDENCIA } \\
\text { DETERIORO }\end{array}$ \\
\hline Fisuras y deformaciones - Fisura & 3 \\
\hline Morfologías inducidas por pérdidas - Faltantes: Agujero & 3 \\
\hline Fisuras y deformaciones - Fractura Lineal & 2 \\
\hline Separación - Disgregación: desmenuzamiento & 2 \\
\hline Morfologías inducidas por pérdidas - Aumento de la rugosidad & 2 \\
\hline Morfologías inducidas por pérdidas - Faltantes: Volumétricos & 2 \\
\hline Separación - Ampollas & 1 \\
\hline Separación - Delaminación & 1 \\
\hline Separación - Descamación & 1 \\
\hline Morfologías inducidas por pérdidas - Erosión: Pérdida de matriz & 1 \\
\hline Alteración cromática y depósitos - Suciedad & 1 \\
\hline
\end{tabular}




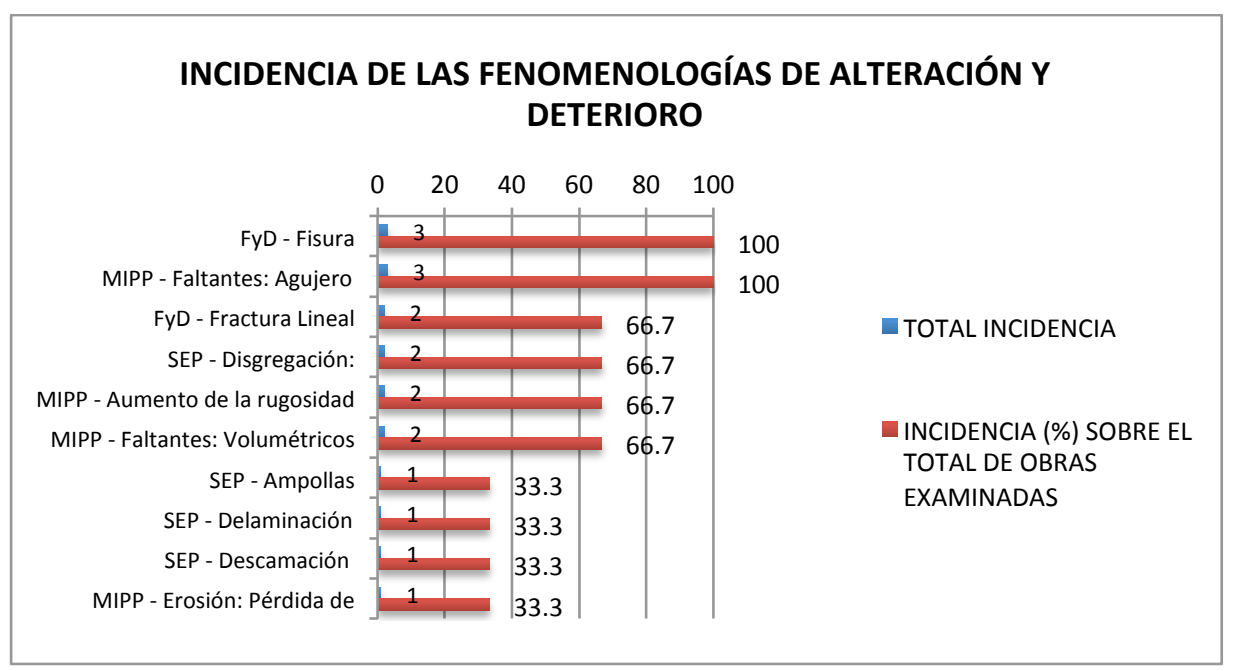

Gráfica 25 - Incidencia de las fenomenologías de alteración y deterioro y presencia (\%) en relación a la totalidad de muestras analizadas (3).

Tabla 111 - Indicador de riesgo obtenido a partir de la incidencia cuantitativa de las fenomenologías de alteración y deterioro registradas.

\begin{tabular}{|l|l|}
\hline \multicolumn{2}{l}{ INDICADOR DE RIESGO } \\
\hline MUESTRA & TOTAL INCIDENCIA DE DETERIORO \\
\hline 1 & 9 \\
\hline 2 & 5 \\
\hline 3 & 4 \\
\hline
\end{tabular}




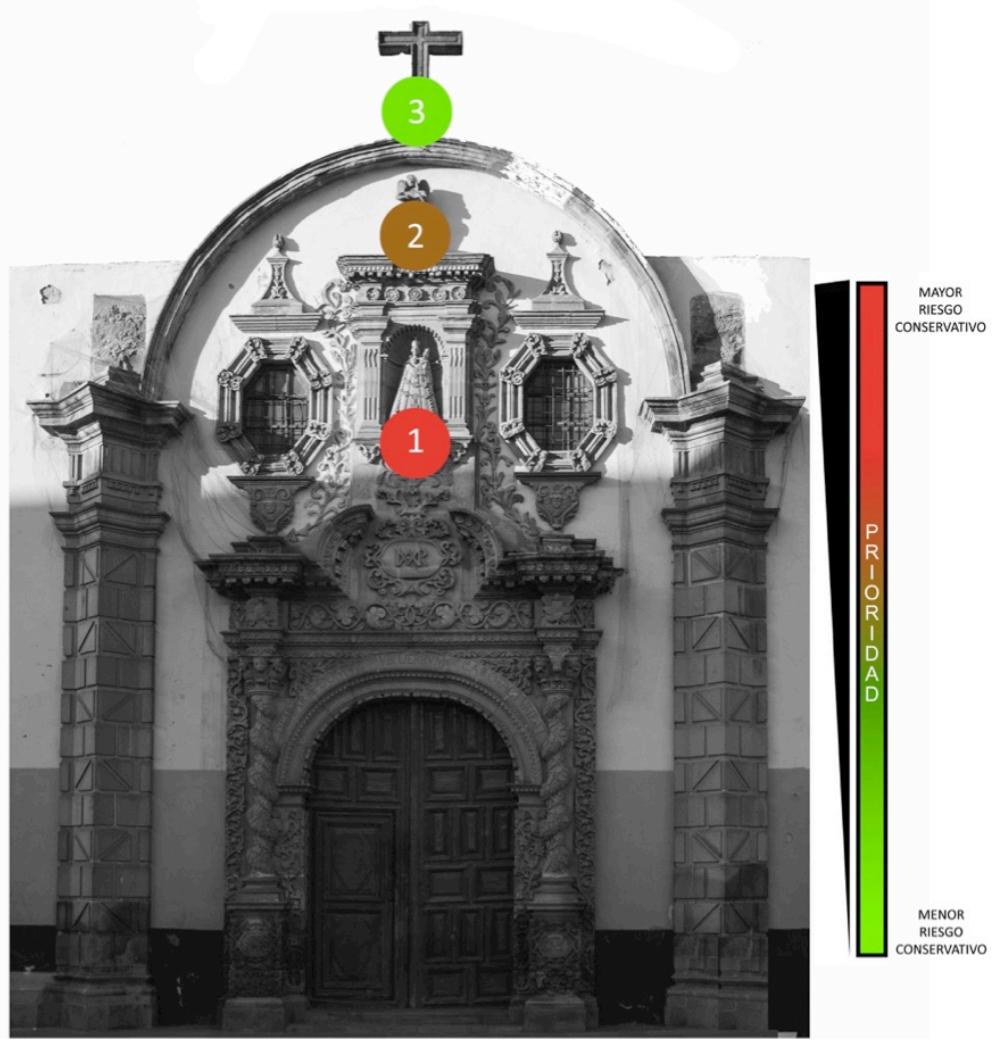

Imagen 97 -Indicador de riesgo. 


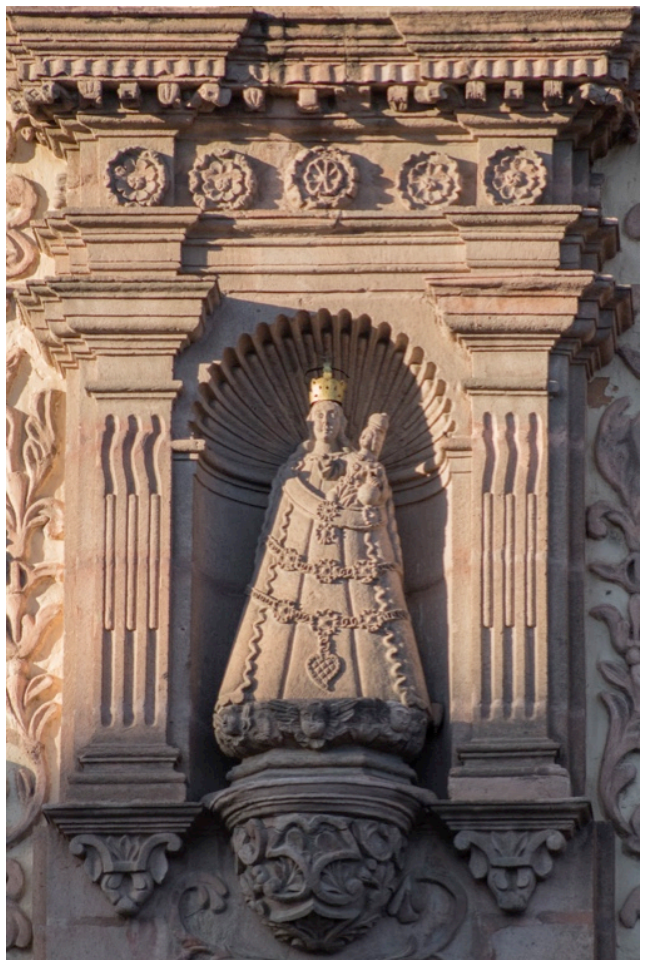

Imagen 98 - Obra (M1) con mayor problemáticas conservativas $s^{313}$

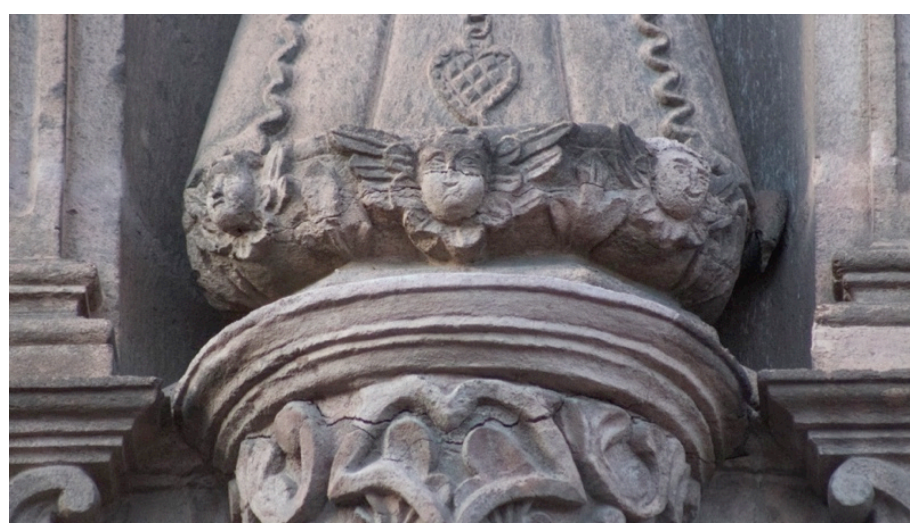

Imagen 99 - Detalle ${ }^{314}$ de algunas de las fenomenologías de alteración y deterioro registradas (M1).

\section{${ }^{313}$ Foto: Blanca Elena Sánchez Saraujo.}


Tabla 112 - Extensión superficial (\%) de las fenomenologías de alteración y deterioro registradas. Muestra 1.

\begin{tabular}{|l|l|l|}
\hline \multicolumn{2}{|l|}{ M1 (total incidencia de deterioro: 9) } \\
\hline FENOMENOLOGÍA DE ALTERACIÓN Y DETERIORO & $\begin{array}{l}\text { INCIDENCIA } \\
\text { SUPERFICIAL }\end{array}$ & $\begin{array}{l}\text { EXTENSIÓN SUPERFICIAL } \\
(\%)\end{array}$ \\
\hline Fisuras y deformaciones - Fisura & 1 & $0-25$ \\
\hline Fisuras y deformaciones - Fractura Lineal & 1 & $0-25$ \\
\hline Separación - Blistering & 1 & $0-25$ \\
\hline Separación - Delaminación & 1 & $0-25$ \\
\hline Separación - Disgregación: desmenuzamiento & 1 & $0-25$ \\
\hline Separación - Descamación & 1 & $0-25$ \\
\hline $\begin{array}{l}\text { Morfologías inducidas por pérdidas - Erosión: Pérdida de } \\
\text { matriz }\end{array}$ & 1 & $0-25$ \\
\hline $\begin{array}{l}\text { Morfologías inducidas por pérdidas - Aumento de la } \\
\text { rugosidad }\end{array}$ & 1 & $0-25$ \\
\hline Morfologías inducidas por pérdidas - Faltantes: Agujero & 1 & $0-25$ \\
\hline
\end{tabular}

Tabla 113 - Extensión superficial (\%) de las fenomenologías de alteración y deterioro registradas. Muestra 2.

\begin{tabular}{|l|l|l|}
\hline M2 (total incidencia de deterioro: 5) & $\begin{array}{l}\text { EXTENSIÓN SUPERFICIAL } \\
(\%)\end{array}$ \\
\hline FENOMENOLOGÍA DE ALTERACIÓN Y DETERIORO & $\begin{array}{l}\text { INCIDENCIA } \\
\text { SUPERICIAL }\end{array}$ & $0-25$ \\
\hline Fisuras y deformaciones - Fisura & 1 & $0-25$ \\
\hline Fisuras y deformaciones - Fractura Lineal & 1 & $0-25$ \\
\hline Separación - Disgregación: desmenuzamiento & 1 & $0-25$ \\
\hline Morfologías inducidas por pérdidas - Faltantes: Agujero & 1 & $0-25$ \\
\hline $\begin{array}{l}\text { Morfologías inducidas por pérdidas - Faltantes: } \\
\text { Volumétricos }\end{array}$ & 1 & \\
\hline
\end{tabular}

${ }^{314}$ Foto: Blanca Elena Sánchez Saraujo. 
Tabla 114 - Extensión superficial (\%) de las fenomenologías de alteración y deterioro registradas. Muestra

\begin{tabular}{|l|l|l|}
\hline M3 (total incidencia de deterioro: 4) & $\begin{array}{l}\text { EXTENSIÓN SUPERFICIAL } \\
\text { (\%) }\end{array}$ \\
\hline FENOMENOLOGÍA DE ALTERACIÓN Y DETERIORO & $\begin{array}{l}\text { INCIDENCIA } \\
\text { SUPERICIAL }\end{array}$ & $0-25$ \\
\hline Fisuras y deformaciones - Fisura & 1 & $0-25$ \\
\hline $\begin{array}{l}\text { Morfologías inducidas por pérdidas - Aumento de la } \\
\text { rugosidad }\end{array}$ & 1 & $0-25$ \\
\hline Morfologías inducidas por pérdidas - Faltantes: Agujero & 1 & $0-25$ \\
\hline $\begin{array}{l}\text { Morfologías inducidas por pérdidas - Faltantes: } \\
\text { Volumétricos }\end{array}$ & 1 & \\
\hline
\end{tabular}

\subsubsection{Catedral Metropolitana}

Para la implementación del método se han analizado, sobre documentación fotográfica, un total de 13 elementos, 12 de ellos en mármol de Carrara y 1 en cantera rosa (tabla 115). A cada uno se le ha conferido un número de identificación (tabla 116) que determina su ubicación en la fachada (imagen 100).

Tabla 115 - Datos de las modalidades de registro y análisis.

\begin{tabular}{|l|l|}
\hline CATEDRAL METROPOLITANA \\
\hline Registro realizado en: & Octubre 2020 \\
\hline Objeto de estudio: & Material pétreo (cantera rosa y mármol de Carrara) \\
\hline Tiempo de registro de datos: & 40 minutos, sobre documentación fotográfica \\
\hline Total de obras analizadas: & 13 esculturas \\
\hline Profesionales empleados: & 1 \\
\hline Tiempo para el análisis de datos & 40 minutos \\
\hline
\end{tabular}


Tabla 116 - Referencia de muestras y esculturas ${ }^{315}$ de la fachada.

\begin{tabular}{|c|c|}
\hline \multicolumn{2}{|c|}{ ESCULTURAS DE LA FACHADA - CATEDRAL METROPOLITANA } \\
\hline M & IDENTIFICACIÓN DE LAS OBRAS (imagen XX) \\
\hline 1 & $\begin{array}{l}\text { Mármol de Carrara, escultura de bulto redondo, Bartolomé, primera calle, segundo piso, fachada, } \\
\text { siglo XX. }\end{array}$ \\
\hline 2 & $\begin{array}{l}\text { Mármol de Carrara, escultura de bulto redondo, Simón el Zelote, primera calle, primer piso, fachada, } \\
\text { siglo XX. }\end{array}$ \\
\hline 3 & $\begin{array}{l}\text { Mármol de Carrara, escultura de bulto redondo, Santiago el Menor, segunda calle, segundo piso, } \\
\text { fachada, siglo XX. }\end{array}$ \\
\hline 4 & Mármol de Carrara, escultura de bulto redondo, Andrés, segunda calle, primer piso, fachada, siglo XX. \\
\hline 5 & $\begin{array}{l}\text { Mármol de Carrara, escultura de bulto redondo, Judas Tadeo, tercera calle, segundo piso, fachada, } \\
\text { siglo XX. }\end{array}$ \\
\hline 6 & Mármol de Carrara, escultura de bulto redondo, Pedro, tercera calle, primer piso, fachada, siglo XX. \\
\hline 7 & $\begin{array}{l}\text { Mármol de Carrara, escultura de bulto redondo, Santiago el Mayor, cuarta calle, segundo piso, } \\
\text { fachada, siglo XX. }\end{array}$ \\
\hline 8 & Mármol de Carrara, escultura de bulto redondo, Pablo, cuarta calle, primer piso, fachada, siglo XX. \\
\hline 9 & Mármol de Carrara, escultura de bulto redondo, Mateo, quinta calle, segundo piso, fachada, siglo XX. \\
\hline 10 & Mármol de Carrara, escultura de bulto redondo, Felipe, quinta calle, primer piso, fachada, siglo XX. \\
\hline 11 & Mármol de Carrara, escultura de bulto redondo, Tomás, sexta calle, segundo piso, fachada, siglo XX. \\
\hline 12 & $\begin{array}{l}\text { Mármol de Carrara, escultura de bulto redondo, Juan Evangelista, sexta calle, primer piso, fachada, } \\
\text { siglo XX. }\end{array}$ \\
\hline 13 & Cantera rosa, escultura de bulto redondo, San Miguel Arcángel, remate de la fachada, siglo XVIII. \\
\hline
\end{tabular}

${ }^{315}$ La identificación de las esculturas se ha relizado por medio de una comparación visual con las imágenes de las originales en San Juan de Letrán (Roma, Italia). "Le statue degli apostoli in San Giovanni in Laterano", 21 febbraio 2019. <https://www.italianways.com/it/le-statue-degli-apostoli-in-san-giovanni-in-laterano/> [Consulta: 10 de diciembre de 2020]. 


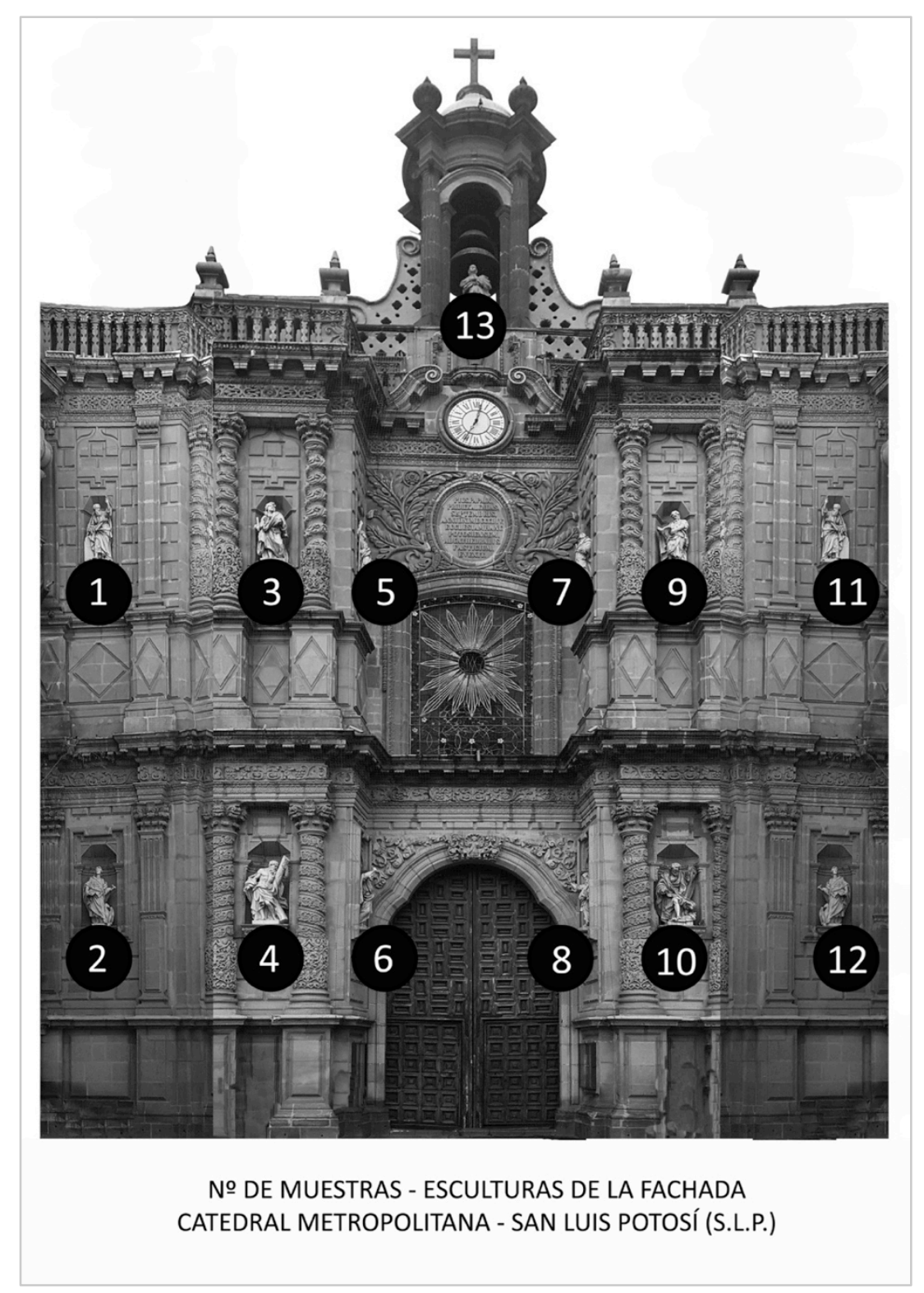

Imagen 100 - Identificación de muestras y ubicación. 
Tras el análisis de los datos recolectados, ha sido posible identificar:

- fenomenologías de alteración y deterioro activas (tabla 117) junto a su estimación cuantitativa y porcentual (gráfica 26);

- indicador de riesgo del conjunto (tabla 118);

- croquis del indicador de riesgo y prioridad (imagen 101);

- obra con mayor indicador de riesgo y prioridad (imágenes 102 y 103);

- alteraciones y deterioros presentes en cada obra/área complementada por una estimación de la superficie afectada por cada fenómeno (tablas 119132);

La información obtenida ha sido complementada por una propuesta de interpretación de los datos, junto a los demás casos de estudio, al final del capítulo.

Tabla 117 - Panorámica de las dinámicas de alteración que están afectando las esculturas de la fachada.

\begin{tabular}{|l|l|}
\hline FENOMENOLOGÍA DE ALTERACIÓN Y DETERIORO & TOTAL \\
\hline Alteración cromática y depósitos - Suciedad & 13 \\
\hline Alteración cromática y depósitos - Costra: Costra negra & 12 \\
\hline Alteración cromática y depósitos - Depósito & 11 \\
\hline Alteración cromática y depósitos - Costra: Concreción & 10 \\
\hline Morfologías inducidas por pérdidas - Faltantes: Volumétricos & 7 \\
\hline Fisuras y deformaciones - Fisura & 6 \\
\hline Alteración cromática y depósitos - Alteración cromática: Tinción & 4 \\
\hline Morfologías inducidas por pérdidas - Aumento de la rugosidad & 3 \\
\hline Fisuras y deformaciones - Craquelado & 2 \\
\hline Alteración cromática y depósitos - Costra: Encrustación & 2 \\
\hline Alteración cromática y depósitos - Eflorescencias & 2 \\
\hline Separación - Estallido & 1 \\
\hline Separación - Disgregación: Granular & 1 \\
\hline Separación - Disgregación sacaroidea & 1 \\
\hline Morfologías inducidas por pérdidas - Erosión: Pérdida de matriz & 1 \\
\hline Morfologías inducidas por pérdidas - Erosión: Redondeamiento & 1 \\
\hline Morfologías inducidas por pérdidas - Faltantes: Agujero & 1 \\
\hline
\end{tabular}




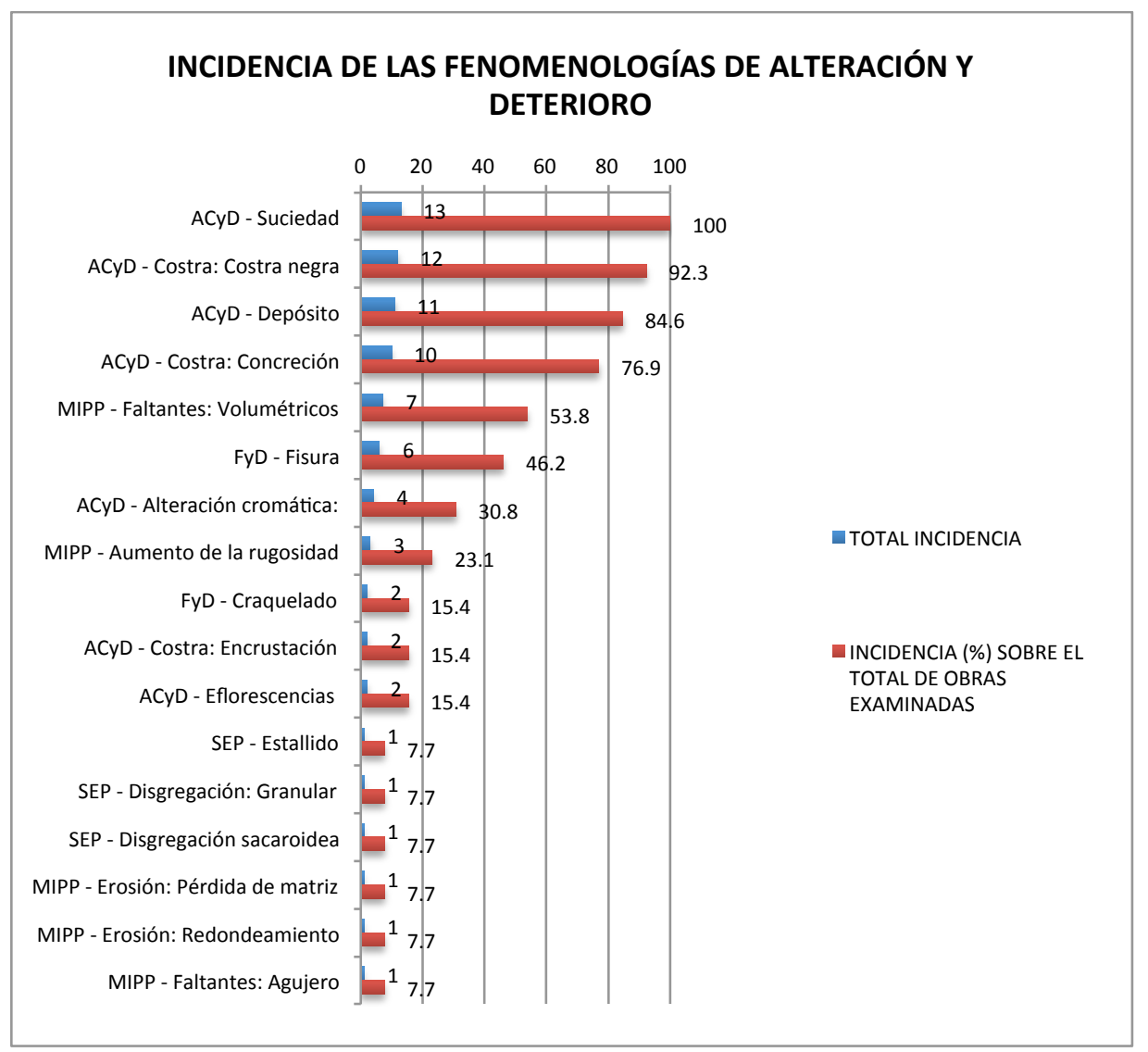

Gráfica 26 - Incidencia de las fenomenologías de alteración y deterioro y presencia (\%) en relación a la totalidad de muestras analizadas (13).

Tabla 118 - Indicador de riesgo obtenido a partir de la incidencia cuantitativa de las fenomenologías de alteración y deterioro registradas.

\begin{tabular}{|l|l|}
\hline \multicolumn{2}{|l|}{ INDICADOR DE RIESGO } \\
\hline MUESTRA & TOTAL INCIDENCIAS DE DETERIORO \\
\hline 10 & 9 \\
\hline 4 & 8 \\
\hline 13 & 8 \\
\hline 5 & 7 \\
\hline 6 & 7 \\
\hline
\end{tabular}




\begin{tabular}{|l|l|}
\hline 8 & 7 \\
\hline 2 & 6 \\
\hline 3 & 6 \\
\hline 9 & 5 \\
\hline 11 & 5 \\
\hline 12 & 5 \\
\hline 7 & 3 \\
\hline 1 & 2 \\
\hline
\end{tabular}

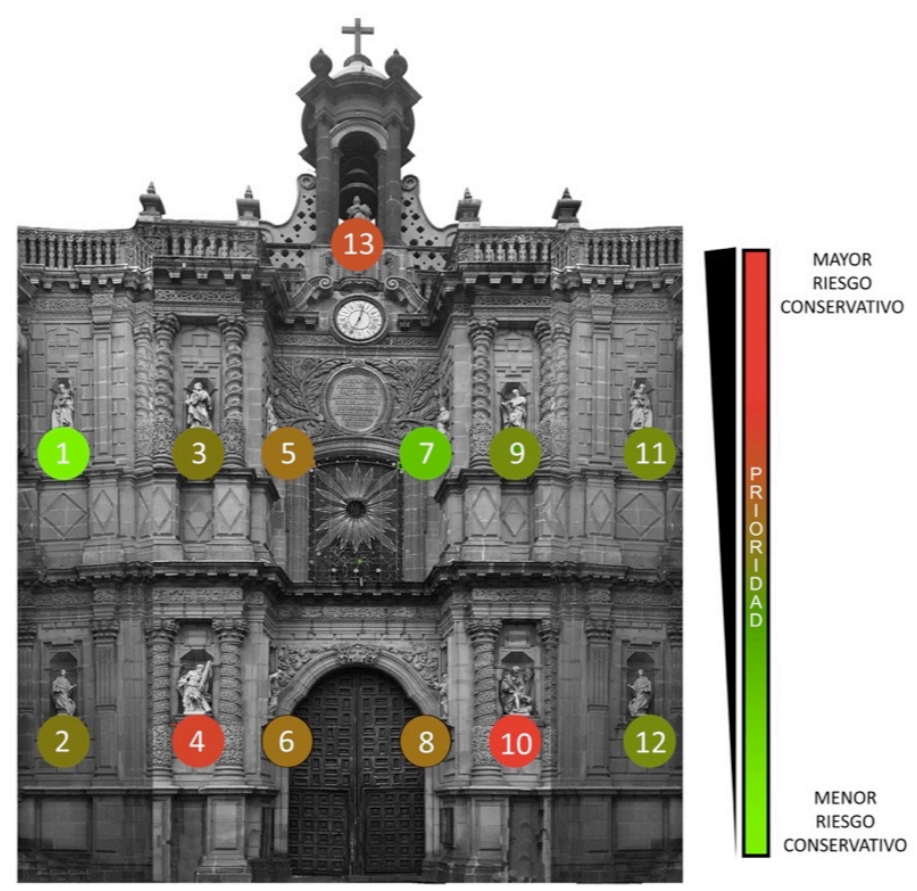

ÍNDICE DE RIESGO - ESCULTURAS

CATEDRAL METROPOLITANA, SAN LUIS POTOSÍ (S.L.P.)

Imagen 101 - Indicador de riesgo de las obras albergadas en la fachada de la Catedral Metropolitana. 


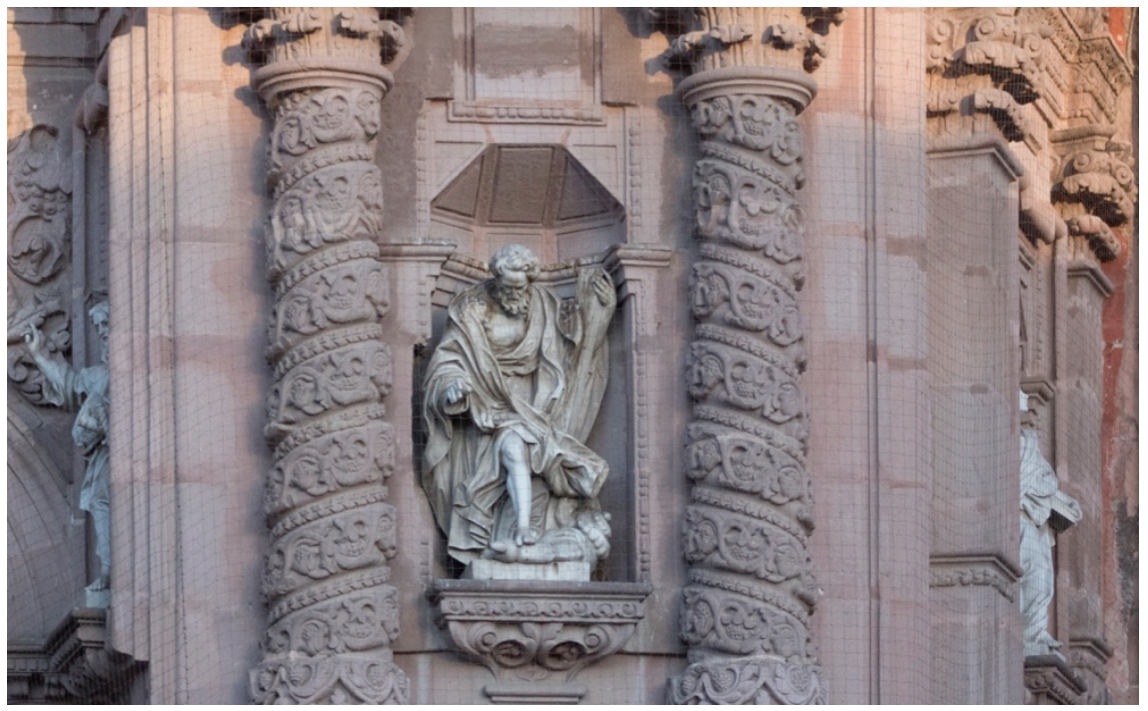

Imagen 102 - Escultura con mayor indicador de riesgo ${ }^{316}$ (M10).

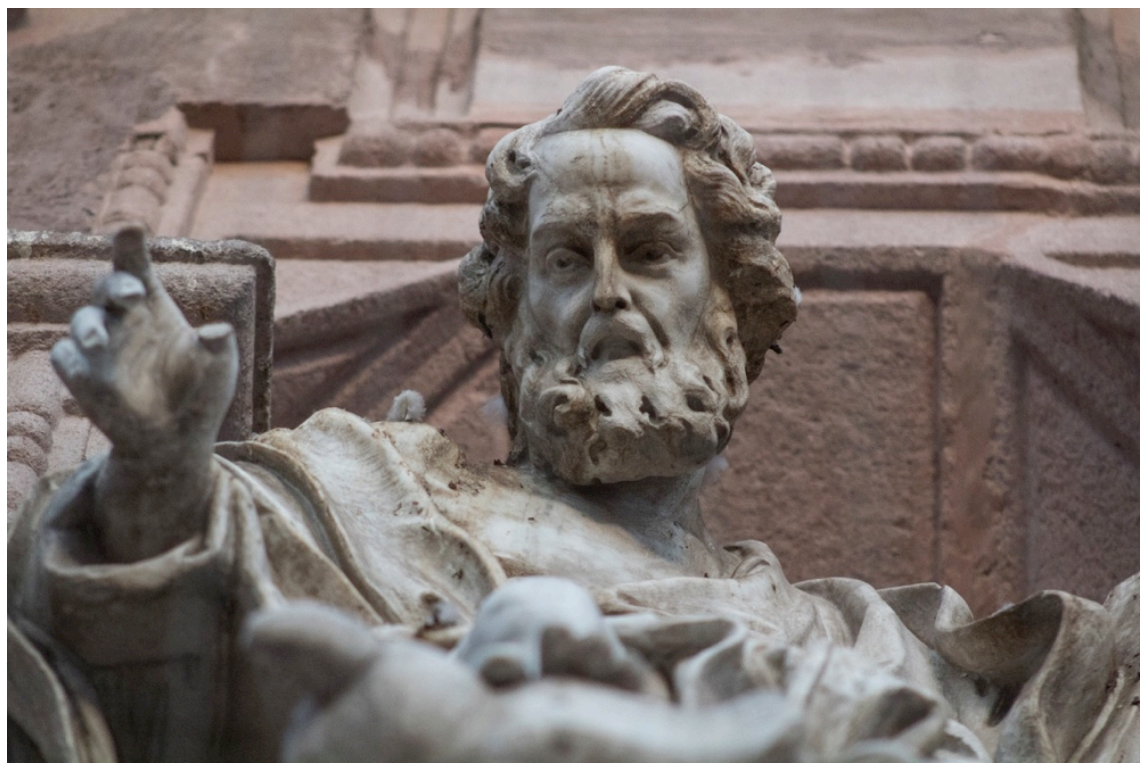

Imagen 103 - Detalle de las fenomenologías de alteración y deterioro ${ }^{317}$ (M10).

\section{${ }^{316}$ Foto: Blanca Elena Sánchez Saraujo.}




\begin{tabular}{|l|l|l|}
\hline \multicolumn{2}{|l|}{ M10 (total incidencia de deterioro: 9) } & $\begin{array}{l}\text { EXTENSIÓN SUPERFICIAL } \\
(\%)\end{array}$ \\
\hline FENOMENOLOGÍA DE ALTERACIÓN Y DETERIORO & $\begin{array}{l}\text { INCIDENCIA } \\
\text { SUPERICIAL }\end{array}$ & $75-100$ \\
\hline Alteración cromática y depósitos - Suciedad & 4 & $50-75$ \\
\hline Alteración cromática y depósitos - Costra: Costra negra & 3 & $25-50$ \\
\hline Alteración cromática y depósitos - Costra: Concreción & 2 & $25-50$ \\
\hline Alteración cromática y depósitos - Costra: Encrustación & 2 & $25-50$ \\
\hline Alteración cromática y depósitos - Depósito & 2 & $0-25$ \\
\hline Separación - Disgregación sacaroidea & 1 & $0-25$ \\
\hline $\begin{array}{l}\text { Morfologías inducidas por pérdidas - Erosión: Pérdida de } \\
\text { matriz }\end{array}$ & 1 & $0-25$ \\
\hline $\begin{array}{l}\text { Morfologías inducidas por pérdidas - Aumento de la } \\
\text { rugosidad }\end{array}$ & 1 & $0-25$ \\
\hline $\begin{array}{l}\text { Morfologías inducidas por pérdidas - Faltantes: } \\
\text { Volumétricos }\end{array}$ & 1 & \\
\hline
\end{tabular}

Tabla 120 - Extensión superficial (\%) de las fenomenologías de alteración y deterioro registradas. Muestra 4.

\begin{tabular}{|l|l|l|}
\hline \multicolumn{2}{|l|}{ M4(total incidencia de deterioro: 8) } \\
\hline FENOMENOLOGÍA DE ALTERACIÓN Y DETERIORO & $\begin{array}{l}\text { INCIDENCIA } \\
\text { SUPERFICIAL }\end{array}$ & EXTENSIÓN SUPERFICIAL (\%) \\
\hline Alteración cromática y depósitos - Suciedad & 3 & $50-75$ \\
\hline Fisuras y deformaciones - Fisura & 1 & $0-25$ \\
\hline Morfologías inducidas por pérdidas - Faltantes: Agujero & 1 & $0-25$ \\
\hline $\begin{array}{l}\text { Morfologías inducidas por pérdidas - Faltantes: } \\
\text { Volumétricos }\end{array}$ & 1 & $0-25$ \\
\hline Alteración cromática y depósitos - Costra: Costra negra & 1 & $0-25$ \\
\hline Alteración cromática y depósitos - Costra: Concreción & 1 & $0-25$ \\
\hline Alteración cromática y depósitos - Depósito & 1 & $0-25$ \\
\hline $\begin{array}{l}\text { Alteración cromática y depósitos - Alteración cromática: } \\
\text { Tinción }\end{array}$ & 1 & $0-25$ \\
\hline
\end{tabular}

${ }^{317}$ Foto: Blanca Elena Sánchez Saraujo. 
Tabla 121 - Extensión superficial (\%) de las fenomenologías de alteración y deterioro registradas. Muestra 13.

\begin{tabular}{|l|l|l|}
\hline M13 (total incidencia de deterioro: 8) & $\begin{array}{l}\text { EXTENSIÓN SUPIDENCIA } \\
\text { SUPERFICIAL }\end{array}$ \\
\hline FENOMENOLOGÍA DE ALTERACIÓN Y DETERIORO & 1 & $0-25$ \\
\hline Fisuras y deformaciones - Fisura & 1 & $0-25$ \\
\hline Separación - Bursting & 1 & $0-25$ \\
\hline Separación - Disgregación: Granular & 1 & $0-25$ \\
\hline $\begin{array}{l}\text { Morfologías inducidas por pérdidas - Erosión: } \\
\text { Redondeamiento }\end{array}$ & 1 & $0-25$ \\
\hline $\begin{array}{l}\text { Morfologías inducidas por pérdidas - Aumento de la } \\
\text { rugosidad }\end{array}$ & 1 & $0-25$ \\
\hline $\begin{array}{l}\text { Morfologías inducidas por pérdidas - Faltantes: } \\
\text { Volumétricos }\end{array}$ & 1 & $0-25$ \\
\hline Alteración cromática y depósitos - Costra: Costra negra & 1 & $0-25$ \\
\hline Alteración cromática y depósitos - Suciedad & 1 & \\
\hline
\end{tabular}

Tabla 122 - Extensión superficial (\%) de las fenomenologías de alteración y deterioro registradas. Muestra

\begin{tabular}{|l|l|l|}
\hline M5 (total incidencia de deterioro: 7) & \multicolumn{2}{l|}{} \\
\hline FENOMENOLOGÍA DE ALTERACIÓN Y DETERIORO & $\begin{array}{l}\text { INCIDENCIA } \\
\text { SUPERFICIAL }\end{array}$ \\
\hline Alteración cromática y depósitos - Suciedad & 4 & $75-100$ \\
\hline Alteración cromática y depósitos - Depósito & 3 & $50-75$ \\
\hline Alteración cromática y depósitos - Costra: Concreción & 2 & $25-50$ \\
\hline Fisuras y deformaciones - Fisura & 1 & $0-25$ \\
\hline Alteración cromática y depósitos - Costra: Costra negra & 1 & $0-25$ \\
\hline $\begin{array}{l}\text { Alteración cromática y depósitos - Alteración cromática: } \\
\text { Tinción }\end{array}$ & 1 & $0-25$ \\
\hline Alteración cromática y depósitos - Eflorescencias & 1 & $0-25$ \\
\hline
\end{tabular}


Tabla 123 - Extensión superficial (\%) de las fenomenologías de alteración y deterioro registradas. Muestra 6.

\begin{tabular}{|l|l|l|}
\hline \multicolumn{2}{|l|}{ M6 (total incidencia de deterioro: 7) } \\
\hline FENOMENOLOGÍA DE ALTERACIÓN Y DETERIORO & $\begin{array}{l}\text { INCIDENCIA } \\
\text { SUPERFICIAL }\end{array}$ & EXTENSIÓN SUPERFICIAL (\%) \\
\hline Alteración cromática y depósitos - Suciedad & 4 & $75-100$ \\
\hline Alteración cromática y depósitos - Costra: Costra negra & 2 & $25-50$ \\
\hline Alteración cromática y depósitos - Costra: Concreción & 2 & $25-50$ \\
\hline Fisuras y deformaciones - Fisura & 1 & $0-25$ \\
\hline Alteración cromática y depósitos - Depósito & 1 & $0-25$ \\
\hline $\begin{array}{l}\text { Alteración cromática y depósitos - Alteración cromática: } \\
\text { Tinción }\end{array}$ & 1 & $0-25$ \\
\hline Alteración cromática y depósitos - Eflorescencias & 1 & $0-25$ \\
\hline
\end{tabular}

Tabla 124 - Extensión superficial (\%) de las fenomenologías de alteración y deterioro registradas. Muestra 8.

\begin{tabular}{|l|l|l|}
\hline \multicolumn{2}{|l|}{ M8 (total incidencia de deterioro: 7) } \\
\hline FENOMENOLOGÍA DE ALTERACIÓN Y DETERIORO & $\begin{array}{l}\text { INCIDENCIA } \\
\text { SUPERFICIAL }\end{array}$ & EXTENSIÓN SUPERFICIAL (\%) \\
\hline Alteración cromática y depósitos - Suciedad & 4 & $75-100$ \\
\hline Alteración cromática y depósitos - Costra: Costra negra & 2 & $25-50$ \\
\hline Fisuras y deformaciones - Fisura & 1 & $0-25$ \\
\hline $\begin{array}{l}\text { Morfologías inducidas por pérdidas - Faltantes: } \\
\text { Volumétricos }\end{array}$ & 1 & $0-25$ \\
\hline Alteración cromática y depósitos - Costra: Concreción & 1 & $0-25$ \\
\hline Alteración cromática y depósitos - Depósito & 1 & $0-25$ \\
\hline $\begin{array}{l}\text { Alteración cromática y depósitos - Alteración cromática: } \\
\text { Tinción }\end{array}$ & 1 & $0-25$ \\
\hline
\end{tabular}


Tabla 125 - Extensión superficial (\%) de las fenomenologías de alteración y deterioro registradas. Muestra

\begin{tabular}{|l|l|l|}
\hline M2 (total incidencia de deterioro: 6) & \multicolumn{2}{l|}{} \\
\hline FENOMENOLOGÍA DE ALTERACIÓN Y DETERIORO & $\begin{array}{l}\text { INCIDENCIA } \\
\text { SUPERFICIAL }\end{array}$ \\
\hline Alteración cromática y depósitos - Suciedad & 4 & $75-100$ \\
\hline Fisuras y deformaciones - Craquelado & 2 & $25-50$ \\
\hline Fisuras y deformaciones - Fisura & 1 & $0-25$ \\
\hline $\begin{array}{l}\text { Morfologías inducidas por pérdidas - Faltantes: } \\
\text { Volumétricos }\end{array}$ & 1 & $0-25$ \\
\hline Alteración cromática y depósitos - Costra: Concreción & 1 & $0-25$ \\
\hline Alteración cromática y depósitos - Depósito & 1 & $0-25$ \\
\hline
\end{tabular}

Tabla 126 - Extensión superficial (\%) de las fenomenologías de alteración y deterioro registradas. Muestra 3

\begin{tabular}{|l|l|l|}
\hline M3 (total incidencia de deterioro: 6) & \multicolumn{2}{l|}{} \\
\hline FENOMENOLOGÍA DE ALTERACIÓN Y DETERIORO & $\begin{array}{l}\text { INCIDENCIA } \\
\text { SUPERFICIAL }\end{array}$ \\
\hline Alteración cromática y depósitos - Suciedad & 4 & $75-100$ \\
\hline Alteración cromática y depósitos - Costra: Costra negra & 3 & $50-75$ \\
\hline Fisuras y deformaciones - Craquelado (\%) & $0-25$ \\
\hline $\begin{array}{l}\text { Morfologías inducidas por pérdidas - Faltantes: } \\
\text { Volumétricos }\end{array}$ & 1 & $0-25$ \\
\hline Alteración cromática y depósitos - Costra: Concreción & 1 & $0-25$ \\
\hline Alteración cromática y depósitos - Depósito & 1 & $0-25$ \\
\hline
\end{tabular}

Tabla 127 - Extensión superficial (\%) de las fenomenologías de alteración y deterioro registradas. Muestra 9.

\begin{tabular}{|l|l|l|}
\hline \multicolumn{2}{|l|}{ M9 (total incidencia de deterioro: 5) } \\
\hline FENOMENOLOGÍA DE ALTERACIÓN Y DETERIORO & $\begin{array}{l}\text { INCIDENCIA } \\
\text { SUPERFICIAL }\end{array}$ & EXTENSIÓN SUPERFICIAL (\%) \\
\hline Alteración cromática y depósitos - Suciedad & 4 & $75-100$ \\
\hline Alteración cromática y depósitos - Costra: Costra negra & 2 & $25-50$ \\
\hline $\begin{array}{l}\text { Morfologías inducidas por pérdidas - Aumento de la } \\
\text { rugosidad }\end{array}$ & 1 & $0-25$ \\
\hline
\end{tabular}




\begin{tabular}{|l|l|l|}
\hline Alteración cromática y depósitos - Costra: Concreción & 1 & $0-25$ \\
\hline Alteración cromática y depósitos - Depósito & 1 & $0-25$ \\
\hline
\end{tabular}

Tabla 128 - Extensión superficial (\%) de las fenomenologías de alteración y deterioro registradas. Muestra 11.

\begin{tabular}{|l|l|l|}
\hline \multicolumn{2}{|l|}{ M11 (total incidencia de deterioro: 5) } \\
\hline FENOMENOLOGÍA DE ALTERACIÓN Y DETERIORO & $\begin{array}{l}\text { INCIDENCIA } \\
\text { SUPERFICIAL }\end{array}$ & EXTENSIÓN SUPERFICIAL (\%) \\
\hline Alteración cromática y depósitos - Suciedad & 4 & $75-100$ \\
\hline $\begin{array}{l}\text { Morfologías inducidas por pérdidas - Faltantes: } \\
\text { Volumétricos }\end{array}$ & 1 & $0-25$ \\
\hline Alteración cromática y depósitos - Costra: Costra negra & 1 & $0-25$ \\
\hline Alteración cromática y depósitos - Costra: Concreción & 1 & $0-25$ \\
\hline Alteración cromática y depósitos - Depósito & 1 & $0-25$ \\
\hline
\end{tabular}

Tabla 129 - Extensión superficial (\%) de las fenomenologías de alteración y deterioro registradas. Muestra 12.

M12 (total incidencia de deterioro: 5)

\begin{tabular}{|l|l|l|}
\hline FENOMENOLOGÍA DE ALTERACIÓN Y DETERIORO & $\begin{array}{l}\text { INCIDENCIA } \\
\text { SUPERFICIAL }\end{array}$ & EXTENSIÓN SUPERFICIAL (\%) \\
\hline Alteración cromática y depósitos - Costra: Costra negra & 3 & $50-75$ \\
\hline Alteración cromática y depósitos - Suciedad & 3 & $50-75$ \\
\hline Alteración cromática y depósitos - Costra: Encrustación & 2 & $25-50$ \\
\hline Alteración cromática y depósitos - Costra: Concreción & 1 & $0-25$ \\
\hline Alteración cromática y depósitos - Depósito & 1 & $0-25$ \\
\hline
\end{tabular}

Tabla 130 - Extensión superficial (\%) de las fenomenologías de alteración y deterioro registradas. Muestra 7.

\begin{tabular}{|l|l|l|}
\hline \multicolumn{2}{|l|}{ M7 (total incidencia de deterioro: 3 ) } \\
\hline FENOMENOLOGÍA DE ALTERACIÓN Y DETERIORO & $\begin{array}{l}\text { INCIDENCIA } \\
\text { SUPERFICIAL }\end{array}$ & EXTENSIÓN SUPERFICIAL (\%) \\
\hline Alteración cromática y depósitos - Suciedad & 3 & $50-75$ \\
\hline
\end{tabular}




\begin{tabular}{|l|l|l|}
\hline Alteración cromática y depósitos - Costra: Costra negra & 2 & $25-50$ \\
\hline Alteración cromática y depósitos - Depósito & 1 & $0-25$ \\
\hline
\end{tabular}

Tabla 131 - Extensión superficial (\%) de las fenomenologías de alteración y deterioro registradas. Muestra 1.

\begin{tabular}{|l|l|l|}
\hline \multicolumn{2}{|l|}{ M1 (total incidencia de deterioro: 2) } \\
\hline FENOMENOLOGÍA DE ALTERACIÓN Y DETERIORO & $\begin{array}{l}\text { INCIDENCIA } \\
\text { SUPERFICIAL }\end{array}$ & $\begin{array}{l}\text { EXTENSIÓN } \\
(\%)\end{array}$ \\
\hline Alteración cromática y depósitos - Suciedad & 3 & $50-75$ \\
\hline Alteración cromática y depósitos - Costra: Costra negra & 1 & $0-25$ \\
\hline
\end{tabular}

\subsubsection{Templo de Nuestra Señora del Carmen}

Para la implementación del método al caso de estudio, se han analizado un total de 12 elementos, compuestos por 8 esculturas y 4 elementos decorativos (tabla 132). Las coordenadas de identificación y ubicación se presentan en la tabla 133 y en la imagen 104.

Tabla 132 - Datos de las modalidades de registro y análisis.

\begin{tabular}{|l|l|}
\hline TEMPLO DE NUESTRA SEÑORA DEL CARMEN \\
\hline Registro realizado en: & Octubre 2020 \\
\hline Objeto de estudio: & Material pétreo (cantera rosa) \\
\hline Tiempo de registro de datos: & 40 minutos, sobre documentación fotográfica \\
\hline Total de obras analizadas: & 8 esculturas y 4 elementos decorativos \\
\hline Profesionales empleados: & 1 \\
\hline Tiempo para el análisis de datos & 40 minutos \\
\hline
\end{tabular}


Tabla 133 - Referencia de muestras y esculturas de la fachada ${ }^{318}$.

\begin{tabular}{|l|l|}
\hline \multicolumn{2}{|l|}{ ESCULTURAS DE LA FACHADA - TEMPLO DE NUESTRA SEÑORA DEL CARMEN } \\
\hline $\mathrm{M}$ & IDENTIFICACIÓN DE LAS OBRAS (imagen XX) \\
\hline 1 & $\begin{array}{l}\text { Cantera rosa, escultura de bulto redondo, Santa Magdalena de Pazzi, calle lateral (izquierda), tercer } \\
\text { piso, siglo XVIII. }\end{array}$ \\
\hline 2 & Cantera rosa, escultura de bulto redondo, Santísima Virgen, calle central, remate, siglo XVIII. \\
\hline 3 & Cantera rosa, escultura de bulto redondo, San Ángelo, calle lateral (derecha), tercer piso, siglo XVIII. \\
\hline 4 & $\begin{array}{l}\text { Cantera rosa, escultura de bulto redondo, Santa Teresa, calle lateral (izquierda), segundo piso, siglo } \\
\text { XVIII. }\end{array}$ \\
\hline 5 & $\begin{array}{l}\text { Cantera rosa, escultura de bulto redondo, Santa Juan de la Cruz, calle lateral (derecha), segundo piso, } \\
\text { siglo XVIII. }\end{array}$ \\
\hline 6 & $\begin{array}{l}\text { Cantera rosa, escultura de bulto redondo, San Elías, calle lateral (izquierda), primer piso, fachada, } \\
\text { siglo XVIII. }\end{array}$ \\
\hline 7 & Cantera rosa, escultura de bulto redondo, San Eliseo, calle lateral (derecha), primer piso, siglo XVIII. \\
\hline 8 & Cantera rosa, escultura de bulto redondo, elemento decorativo, remate fachada, siglo XVIII. \\
\hline 9 & Cantera rosa, escultura de bulto redondo, elemento decorativo, remate fachada, siglo XVIII. \\
\hline 10 & Cantera rosa, escultura de bulto redondo, elemento decorativo, remate fachada, siglo XVIII. \\
\hline 11 & Cantera rosa, escultura de bulto redondo, San Miguel Arcángel, remate fachada, siglo XVIII. \\
\hline 12 & Cantera rosa, escultura de bulto redondo, elemento decorativo, remate fachada, siglo XVIII. \\
\hline
\end{tabular}

${ }^{318}$ La identificación de las esculturas de la fachada deriva de "Templo de Nuestra Señora del Carmen" en Secretaría de Turismo.

<http://www.ciudadsanluis.com/turismo/iglesias_y_templos/templo_de_nuestra_senora_del_carmen/>

[Consulta: 10 de diciembre de 2020]. 


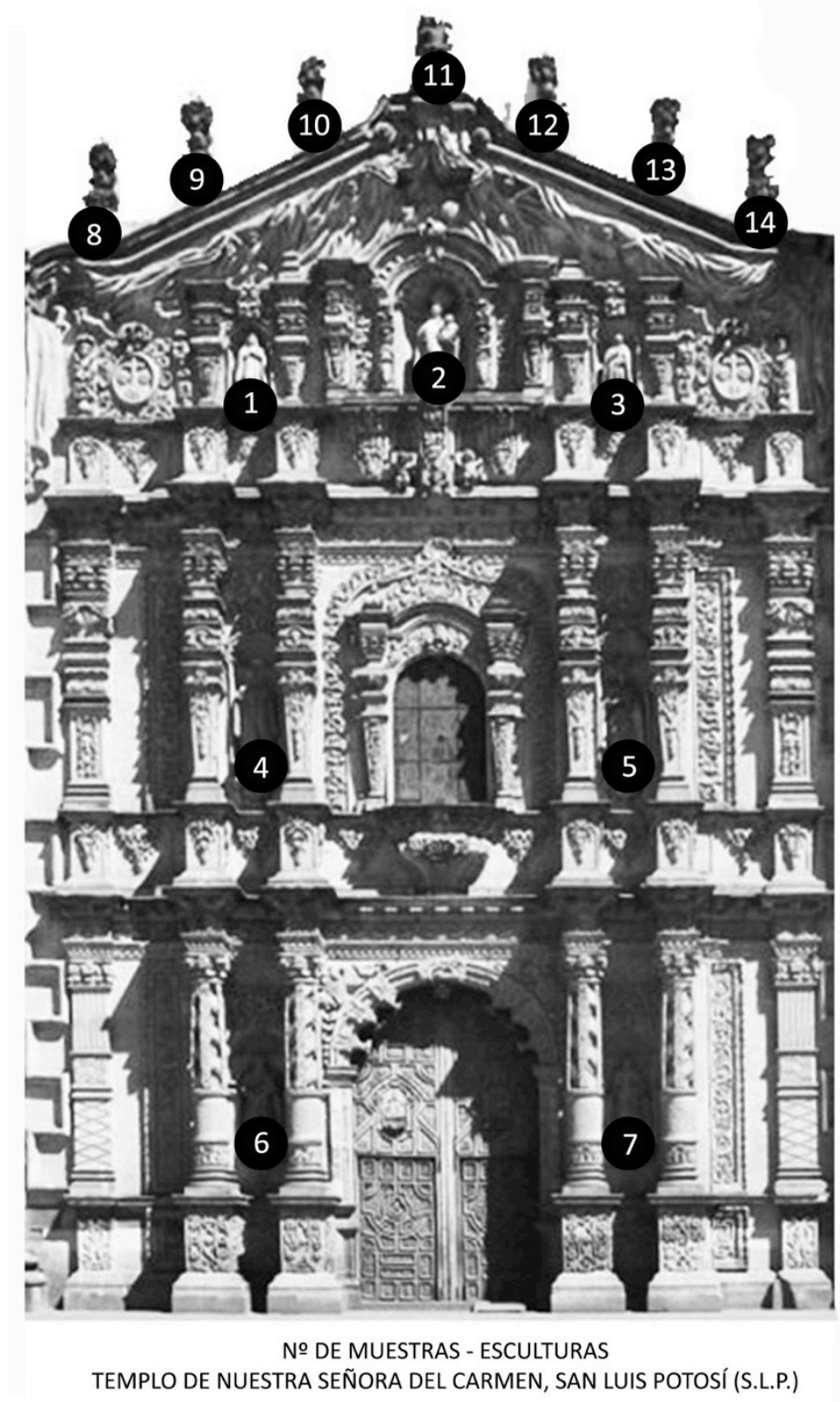

Imagen 104 - Identificación de muestras y ubicación. 
Tras el análisis de los datos recolectados, ha sido posible identificar:

- fenomenologías de alteración y deterioro activas (tabla 134) junto a su estimación cuantitativa y porcentual (gráfica 27);

- indicador de riesgo del conjunto (tabla 135);

- croquis del indicador de riesgo y prioridad (imagen 105);

- obra con mayor indicador de riesgo y prioridad (imagen 106 y 107);

- alteraciones y deterioros presentes en cada obra/área complementada por una estimación de la superficie afectada por cada fenómeno (tablas 136149);

La información obtenida ha sido complementada por una propuesta de interpretación de los datos, junto a los demás casos de estudio, al final del capítulo.

Tabla 134 - Panorámica de las dinámicas de alteración que están afectando las esculturas de la fachada.

\begin{tabular}{|c|c|}
\hline FENOMENOLOGÍA DE ALTERACIÓN Y DETERIORO & $\begin{array}{l}\text { TOTAL } \\
\text { INCIDENCIA DE } \\
\text { DETERIORO }\end{array}$ \\
\hline Alteración cromática y depósitos - Suciedad & 12 \\
\hline Fisuras y deformaciones - Fisura & 10 \\
\hline Morfologías inducidas por pérdidas - Faltantes: Volumétricos & 10 \\
\hline Separación - Disgregación: Granular & 9 \\
\hline Separación - Fragmentación & 9 \\
\hline Morfologías inducidas por pérdidas - Aumento de la rugosidad & 7 \\
\hline Alteración cromática y depósitos - Depósito & 7 \\
\hline Alteración cromática y depósitos - Costra: Costra negra & 6 \\
\hline Alteración cromática y depósitos - Costra: Concreción & 6 \\
\hline Alteración cromática y depósitos - Eflorescencias & 6 \\
\hline Separación - Disgregación: desmenuzamiento & 4 \\
\hline Morfologías inducidas por pérdidas - Faltantes: Agujero & 4 \\
\hline Fisuras y deformaciones - Craquelado & 3 \\
\hline Morfologías inducidas por pérdidas - Erosión: Pérdida de componentes & 3 \\
\hline Morfologías inducidas por pérdidas - Erosión: Pérdida de matriz & 2 \\
\hline Separación - Disgregación: Pulverulencia & 1 \\
\hline Separación - Disyunción en películas & 1 \\
\hline Morfologías inducidas por pérdidas - Alveolización & 1 \\
\hline Morfologías inducidas por pérdidas - Erosión: Erosión diferencial & 1 \\
\hline
\end{tabular}




\begin{tabular}{|l|l|}
\hline Morfologías inducidas por pérdidas - Daño mecánico: Impacto directo & 1 \\
\hline Alteración cromática y depósitos - Costra: Encrustación & 1 \\
\hline Alteración cromática y depósitos - Alteración cromática: Decoloración & 1 \\
\hline
\end{tabular}

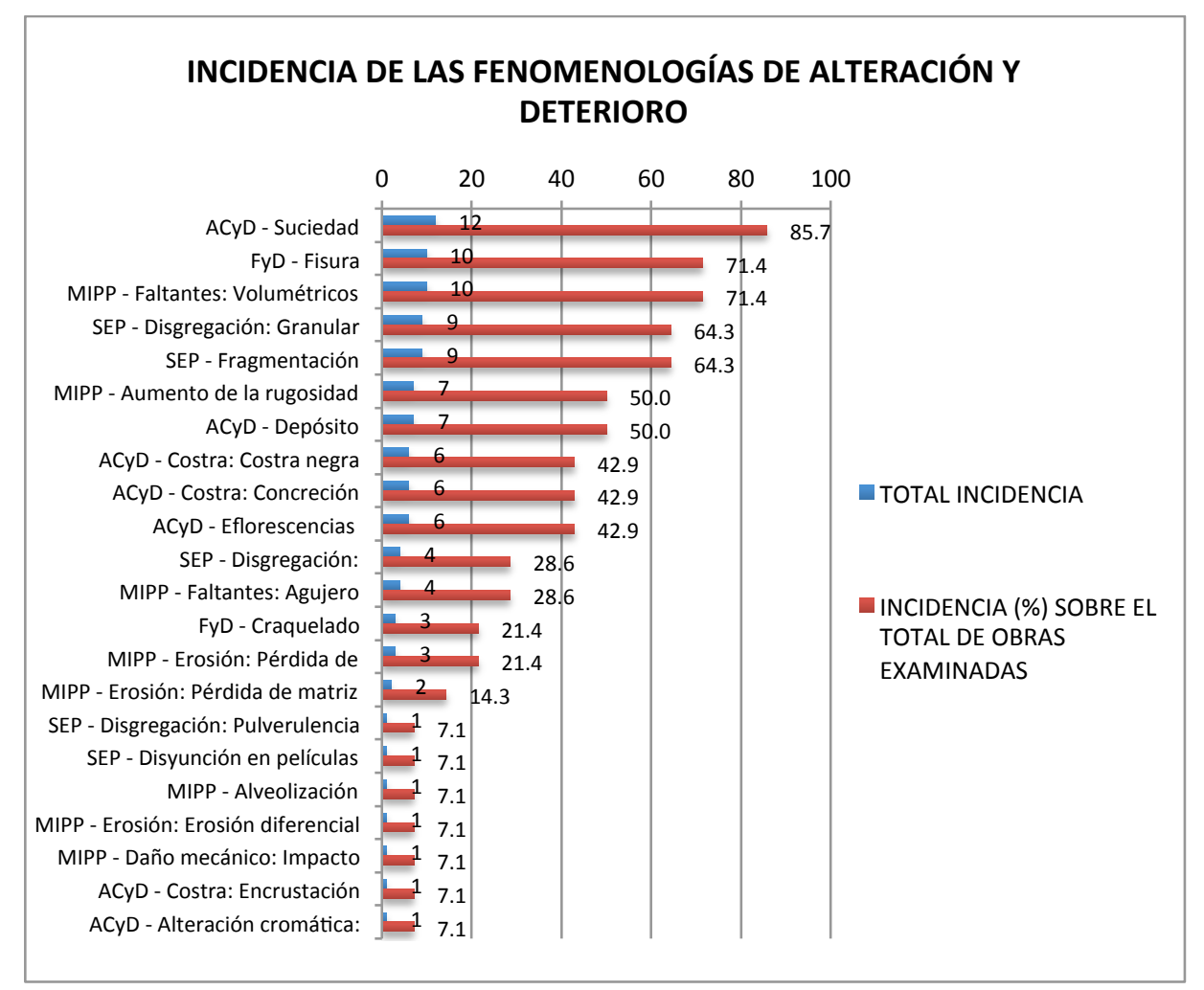

Gráfica 27 - Incidencia de las fenomenologías de alteración y deterioro y presencia (\%) en relación a la totalidad de muestras analizadas (14). 
Tabla 135 - Indicador de riesgo obtenido a partir de la incidencia cuantitativa de las fenomenologías de alteración y deterioro registradas

\section{INDICADOR DE RIESGO}

\section{\begin{tabular}{|l|l|} 
MUESTRA & TOTAL INCIDENCIA DE DETERIORO \\
\hline
\end{tabular}}

5

\begin{tabular}{|l|l|}
\hline 5 & 14 \\
\hline 7 & 12 \\
\hline 11 & 11 \\
\hline 1 & 8 \\
\hline 2 & 8 \\
\hline 4 & 8 \\
\hline 3 & 6 \\
\hline 6 & 6 \\
\hline 9 & 6 \\
\hline 12 & 6 \\
\hline 8 & 5 \\
\hline 10 & 5 \\
\hline 13 & 5 \\
\hline 14 & 5 \\
\hline
\end{tabular}




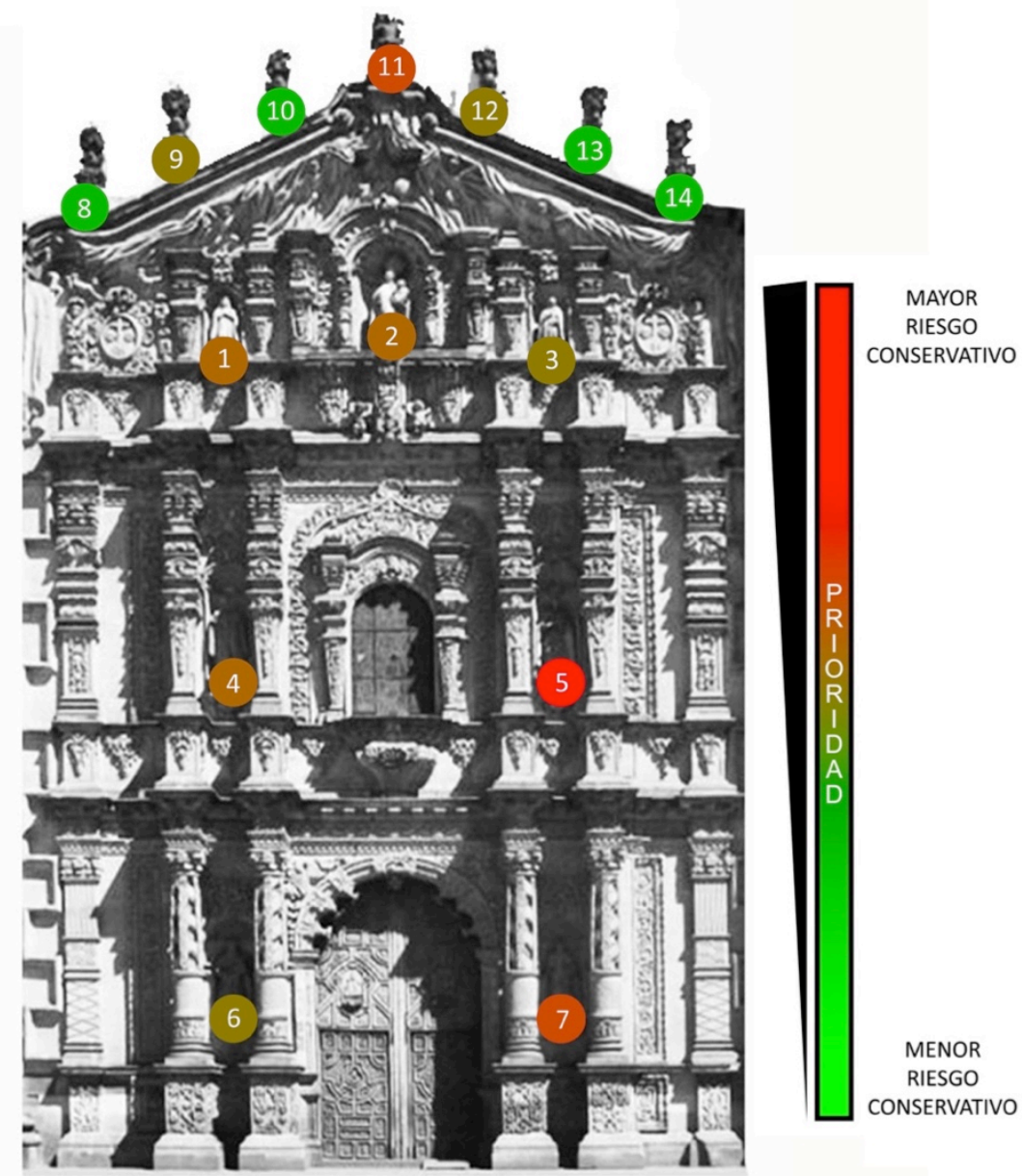

Imagen 105 - Indicador de riesgo de las esculturas y elementos decorativos de la fachada. 


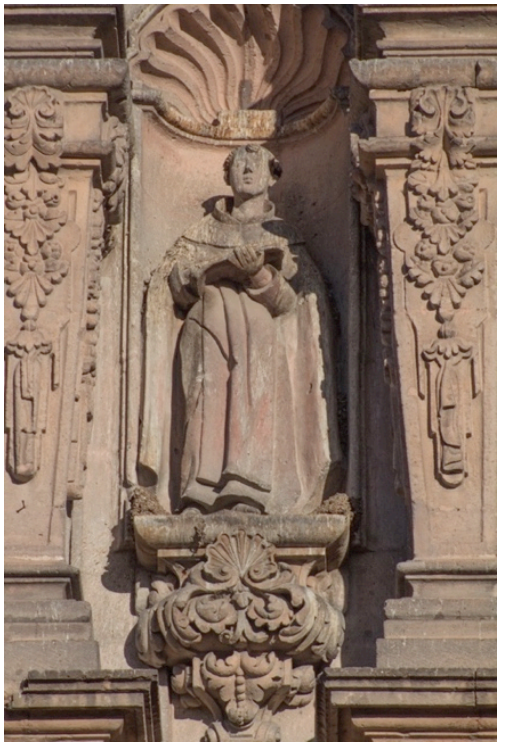

Imagen 106 - Escultura con mayor indicador de riesgo (M5).

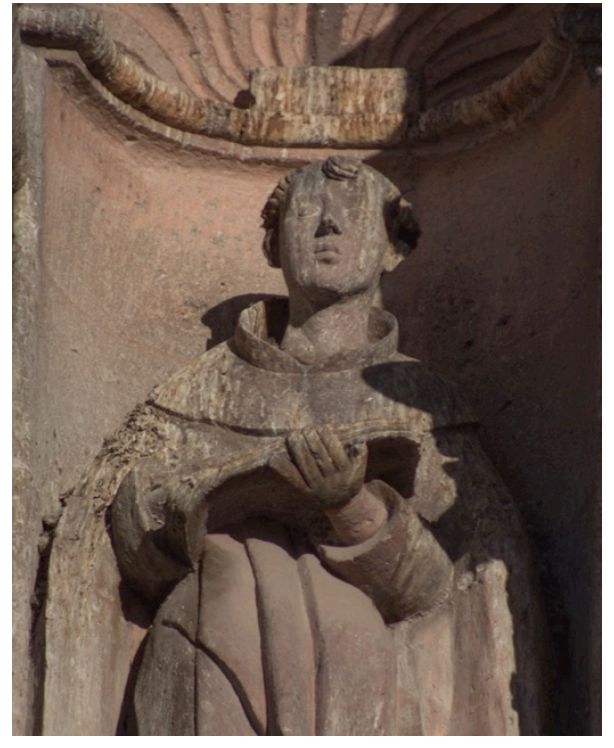

Imagen 107 - Escultura con mayor indicador de riesgo (M5), detalle.

Tabla 136 - Extensión superficial (\%) de las fenomenologías de alteración y deterioro registradas. Muestra 5.

\begin{tabular}{|c|c|c|}
\hline \multicolumn{3}{|l|}{ M5 (total incidencia de deterioro: 14 ) } \\
\hline FENOMENOLOGÍA DE ALTERACIÓN Y DETERIORO & $\begin{array}{l}\text { INCIDENCIA } \\
\text { SUPERFICIAL }\end{array}$ & $\begin{array}{l}\text { EXTENSIÓN SUPERFICIAL } \\
(\%)\end{array}$ \\
\hline Alteración cromática y depósitos - Suciedad & 4 & $75-100$ \\
\hline Alteración cromática y depósitos - Costra: Concreción & 2 & $25-50$ \\
\hline Alteración cromática y depósitos - Costra: Encrustación & 2 & $25-50$ \\
\hline Alteración cromática y depósitos - Depósito & 2 & $25-50$ \\
\hline Fisuras y deformaciones - Fisura & 1 & $0-25$ \\
\hline Fisuras y deformaciones - Craquelado & 1 & $0-25$ \\
\hline Separación - Fragmentación & 1 & $0-25$ \\
\hline Separación - Disyunción en películas & 1 & $0-25$ \\
\hline $\begin{array}{l}\text { Morfologías inducidas por pérdidas - Erosión: Erosión } \\
\text { diferencial }\end{array}$ & 1 & $0-25$ \\
\hline $\begin{array}{l}\text { Morfologías inducidas por pérdidas - Aumento de la } \\
\text { rugosidad }\end{array}$ & 1 & $0-25$ \\
\hline
\end{tabular}




\begin{tabular}{|l|l|l|}
\hline $\begin{array}{l}\text { Morfologías inducidas por pérdidas - Daño mecánico: } \\
\text { Impacto directo }\end{array}$ & 1 & $0-25$ \\
\hline $\begin{array}{l}\text { Morfologías inducidas por pérdidas - Faltantes: } \\
\text { Volumétricos }\end{array}$ & 1 & $0-25$ \\
\hline Alteración cromática y depósitos - Costra: Costra negra & 1 & $0-25$ \\
\hline Alteración cromática y depósitos - Eflorescencias & 1 & $0-25$ \\
\hline
\end{tabular}

Tabla 137 - Extensión superficial (\%) de las fenomenologías de alteración y deterioro registradas. Muestra

\begin{tabular}{|l|l|l|}
\hline \multicolumn{2}{|l|}{ M7 (total incidencia de deterioro: 12) } & EXTENSIÓN SUPERFICIAL (\%) \\
\hline FENOMENOLOGÍA DE ALTERACIÓN Y DETERIORO & $\begin{array}{l}\text { INCIDENCIA } \\
\text { SUPERFICIAL }\end{array}$ & $50-75$ \\
\hline Alteración cromática y depósitos - Suciedad & 3 & $0-25$ \\
\hline Fisuras y deformaciones - Fisura & 1 & $0-25$ \\
\hline Separación - Disgregación: desmenuzamiento & 1 & $0-25$ \\
\hline Separación - Fragmentación & 1 & $0-25$ \\
\hline $\begin{array}{l}\text { Morfologías inducidas por pérdidas - Erosión: Pérdida de } \\
\text { componentes }\end{array}$ & 1 & $0-25$ \\
\hline $\begin{array}{l}\text { Morfologías inducidas por pérdidas - Aumento de la } \\
\text { rugosidad }\end{array}$ & 1 & $0-25$ \\
\hline Morfologías inducidas por pérdidas - Faltantes: Agujero & 1 & $0-25$ \\
\hline $\begin{array}{l}\text { Morfologías inducidas por pérdidas - Faltantes: } \\
\text { Volumétricos }\end{array}$ & 1 & $0-25$ \\
\hline Alteración cromática y depósitos - Costra: Costra negra & 1 & $0-25$ \\
\hline Alteración cromática y depósitos - Costra: Concreción & 1 & $0-25$ \\
\hline Alteración cromática y depósitos - Depósito & 1 & $0-25$ \\
\hline Alteración cromática y depósitos - Eflorescencias & 1 & \\
\hline
\end{tabular}

Tabla 138 - Extensión superficial (\%) de las fenomenologías de alteración y deterioro registradas. Muestra

\begin{tabular}{|l|l|l|}
\hline \multicolumn{2}{|l|}{ M11 (total incidencia de deterioro: 11) } \\
\hline FENOMENOLOGÍA DE ALTERACIÓN Y DETERIORO & $\begin{array}{l}\text { INCIDENCIA } \\
\text { SUPERFICIAL }\end{array}$ & EXTENSIÓN SUPERFICIAL (\%) \\
\hline Fisuras y deformaciones - Fisura & 1 & $0-25$ \\
\hline
\end{tabular}




\begin{tabular}{|l|l|l|}
\hline Separación - Disgregación: desmenuzamiento & 1 & $0-25$ \\
\hline Separación - Disgregación: Granular & 1 & $0-25$ \\
\hline Separación - Disgregación: Pulverulencia & 1 & $0-25$ \\
\hline $\begin{array}{l}\text { Morfologías inducidas por pérdidas - Erosión: Pérdida de } \\
\text { componentes }\end{array}$ & 1 & $0-25$ \\
\hline $\begin{array}{l}\text { Morfologías inducidas por pérdidas - Erosión: Pérdida de } \\
\text { matriz }\end{array}$ & 1 & $0-25$ \\
\hline $\begin{array}{l}\text { Morfologías inducidas por pérdidas - Aumento de la } \\
\text { rugosidad }\end{array}$ & 1 & $0-25$ \\
\hline Morfologías inducidas por pérdidas - Faltantes: Agujero & 1 & $0-25$ \\
\hline $\begin{array}{l}\text { Morfologías inducidas por pérdidas - Faltantes: } \\
\text { Volumétricos }\end{array}$ & 1 & $0-25$ \\
\hline Alteración cromática y depósitos - Costra: Costra negra & 1 & $0-25$ \\
\hline Alteración cromática y depósitos - Suciedad & 1 & $0-25$ \\
\hline
\end{tabular}

Tabla 139 - Extensión superficial (\%) de las fenomenologías de alteración y deterioro registradas. Muestra 1.

\begin{tabular}{|l|l|l|}
\hline \multicolumn{2}{|l|}{ M1 (total incidencia de deterioro: 8) } \\
\hline FENOMENOLOGÍA DE ALTERACIÓN Y DETERIORO & $\begin{array}{l}\text { INCIDENCIA } \\
\text { SUPERFICIAL }\end{array}$ & EXTENSIÓN SUPERFICIAL (\%) \\
\hline Alteración cromática y depósitos - Eflorescencias & 2 & $25-50$ \\
\hline Fisuras y deformaciones - Fisura & 1 & $0-25$ \\
\hline Separación - Disgregación: Granular & 1 & $0-25$ \\
\hline Morfologías inducidas por pérdidas - Alveolización & 1 & $0-25$ \\
\hline $\begin{array}{l}\text { Morfologías inducidas por pérdidas - Aumento de la } \\
\text { rugosidad }\end{array}$ & 1 & $0-25$ \\
\hline Alteración comática y depósitos - Costra: Concreción & 1 & $0-25$ \\
\hline Alteración cromática y depósitos - Depósito & 1 & $0-25$ \\
\hline Alteración cromática y depósitos - Suciedad & 1 & $0-25$ \\
\hline
\end{tabular}


Tabla 140 - Extensión superficial (\%) de las fenomenologías de alteración y deterioro registradas. Muestra

\begin{tabular}{|l|l|l|}
\hline M2 (total incidencia de deterioro: 8) & EXTENSIÓN SUPERFICIAL (\%) \\
\hline FENOMENOLOGÍA DE ALTERACIÓN Y DETERIORO & $\begin{array}{l}\text { INCIDENCIA } \\
\text { SUPERFICIAL }\end{array}$ \\
\hline Separación - Disgregación: Granular & 1 & $0-25$ \\
\hline Separación - Fragmentación & 1 & $0-25$ \\
\hline $\begin{array}{l}\text { Morfologías inducidas por pérdidas - Aumento de la } \\
\text { rugosidad }\end{array}$ & 1 & $0-25$ \\
\hline Morfologías inducidas por pérdidas - Faltantes: Agujero & 1 & $0-25$ \\
\hline Alteración cromática y depósitos - Costra: Concreción & 1 & $0-25$ \\
\hline Alteración cromática y depósitos - Depósito & 1 & $0-25$ \\
\hline Alteración cromática y depósitos - Eflorescencias & 1 & $0-25$ \\
\hline Alteración cromática y depósitos - Suciedad & 1 & $0-25$ \\
\hline
\end{tabular}

Tabla 141 - Extensión superficial (\%) de las fenomenologías de alteración y deterioro registradas. Muestra

\begin{tabular}{|l|l|l|}
\hline M4 (total incidencia de deterioro: 8) & \multicolumn{2}{l|}{} \\
\hline FENOMENOLOGÍA DE ALTERACIÓN Y DETERIORO & $\begin{array}{l}\text { INCIDENCIA } \\
\text { SUPERFICIAL }\end{array}$ \\
\hline Alteración cromática y depósitos - Suciedad & 4 & $75-100$ \\
\hline Alteración cromática y depósitos - Depósito & 2 & $25-50$ \\
\hline Fisuras y deformaciones - Fisura & 1 & $0-25$ \\
\hline Separación - Disgregación: desmenuzamiento & 1 & $0-25$ \\
\hline Separación - Fragmentación & 1 & $0-25$ \\
\hline $\begin{array}{l}\text { Morfologías inducidas por pérdidas - Faltantes: } \\
\text { Volumétricos }\end{array}$ & 1 & $0-25$ \\
\hline Alteración cromática y depósitos - Costra: Costra negra & 1 & $0-25$ \\
\hline Alteración cromática y depósitos - Costra: Concreción & 1 & $0-25$ \\
\hline
\end{tabular}


Tabla 142 - Extensión superficial (\%) de las fenomenologías de alteración y deterioro registradas. Muestra 3.

\begin{tabular}{|l|l|l|}
\hline \multicolumn{2}{|l|}{ M3 (total incidencia de deterioro: 6) } \\
\hline FENOMENOLOGÍA DE ALTERACIÓN Y DETERIORO & $\begin{array}{l}\text { INCIDENCIA } \\
\text { SUPERFICIAL }\end{array}$ & EXTENSIÓN SUPERFICIAL (\%) \\
\hline $\begin{array}{l}\text { Morfologías inducidas por pérdidas - Erosión: Pérdida de } \\
\text { componentes }\end{array}$ & 1 & $0-25$ \\
\hline $\begin{array}{l}\text { Morfologías inducidas por pérdidas - Aumento de la } \\
\text { rugosidad }\end{array}$ & 1 & $0-25$ \\
\hline $\begin{array}{l}\text { Morfologías inducidas por pérdidas - Faltantes: } \\
\text { Volumétricos }\end{array}$ & 1 & $0-25$ \\
\hline Alteración cromática y depósitos - Costra: Concreción & 1 & $0-25$ \\
\hline Alteración cromática y depósitos - Depósito & 1 & $0-25$ \\
\hline Alteración cromática y depósitos - Eflorescencias & 1 & $0-25$ \\
\hline
\end{tabular}

Tabla 143 - Extensión superficial (\%) de las fenomenologías de alteración y deterioro registradas. Muestra 6.

\begin{tabular}{|l|l|l|}
\hline \multicolumn{2}{|l|}{ M6 (total incidencia de deterioro: 6) } \\
\hline FENOMENOLOGÍA DE ALTERACIÓN Y DETERIORO & $\begin{array}{l}\text { INCIDENCIA } \\
\text { SUPERFICIAL }\end{array}$ & EXTENSIÓN SUPERFICIAL (\%) \\
\hline Alteración cromática y depósitos - Suciedad & 3 & $50-75$ \\
\hline Fisuras y deformaciones - Craquelado & 1 & $0-25$ \\
\hline Alteración cromática y depósitos - Costra: Costra negra & 1 & $0-25$ \\
\hline Alteración cromática y depósitos - Depósito & 1 & $0-25$ \\
\hline $\begin{array}{l}\text { Alteración cromática y depósitos - Alteración cromática: } \\
\text { Decoloración }\end{array}$ & 1 & $0-25$ \\
\hline Alteración cromática y depósitos - Eflorescencias & 1 & $0-25$ \\
\hline
\end{tabular}

Tabla 144 - Extensión superficial (\%) de las fenomenologías de alteración y deterioro registradas. Muestra 9.

M9 (total incidencia de deterioro: 6)

\begin{tabular}{|l|l|l|}
\hline FENOMENOLOGÍA DE ALTERACIÓN Y DETERIORO & $\begin{array}{l}\text { INCIDENCIA } \\
\text { SUPERFICIAL }\end{array}$ & EXTENSIÓN SUPERFICIAL (\%) \\
\hline Alteración cromática y depósitos - Suciedad & 4 & $75-100$ \\
\hline Fisuras y deformaciones - Fisura & 1 & $0-25$ \\
\hline
\end{tabular}




\begin{tabular}{|l|l|l|}
\hline Separación - Disgregación: desmenuzamiento & 1 & $0-25$ \\
\hline Separación - Disgregación: Granular & 1 & $0-25$ \\
\hline Separación - Fragmentación & 1 & $0-25$ \\
\hline $\begin{array}{l}\text { Morfologías inducidas por pérdidas - Faltantes: } \\
\text { Volumétricos }\end{array}$ & 1 & $0-25$ \\
\hline
\end{tabular}

Tabla 145 - Extensión superficial (\%) de las fenomenologías de alteración y deterioro registradas. Muestra 12.

\begin{tabular}{|l|l|l|}
\hline \multicolumn{2}{|l|}{ M12 (total incidencia de deterioro: 6) } & \multicolumn{1}{l|}{} \\
\hline FENOMENSIÓN SUPERFICIAL (\%) \\
\hline Fisuras y deformaciones - Craquelado & $\begin{array}{l}\text { INCIDENCIA } \\
\text { SUPERFICIAL }\end{array}$ & $0-25$ \\
\hline Separación - Disgregación: Granular & 1 & $0-25$ \\
\hline $\begin{array}{l}\text { Morfologías inducidas por pérdidas - Erosión: Pérdida de } \\
\text { matriz }\end{array}$ & 1 & $0-25$ \\
\hline $\begin{array}{l}\text { Morfologías inducidas por pérdidas - Aumento de la } \\
\text { rugosidad }\end{array}$ & 1 & $0-25$ \\
\hline Morfologías inducidas por pérdidas - Faltantes: Agujero & 1 & $0-25$ \\
\hline Alteración cromática y depósitos - Costra: Costra negra & 1 & $0-25$ \\
\hline
\end{tabular}

Tabla 146 - Extensión superficial (\%) de las fenomenologías de alteración y deterioro registradas. Muestra 8.

\begin{tabular}{|l|l|l|}
\hline \multicolumn{2}{|l|}{ M8 (total incidencia de deterioro: 5) } \\
\hline FENOMENOLOGÍA DE ALTERACIÓN Y DETERIORO & $\begin{array}{l}\text { INCIDENCIA } \\
\text { SUPERFICIAL }\end{array}$ & EXTENSIÓN SUPERFICIAL (\%) \\
\hline Alteración cromática y depósitos - Suciedad & 4 & $75-100$ \\
\hline Fisuras y deformaciones - Fisura & 1 & $0-25$ \\
\hline Separación - Disgregación: Granular & 1 & $0-25$ \\
\hline Separación - Fragmentación & 1 & $0-25$ \\
\hline $\begin{array}{l}\text { Morfologías inducidas por pérdidas - Faltantes: } \\
\text { Volumétricos }\end{array}$ & 1 & $0-25$ \\
\hline
\end{tabular}


Tabla 147 - Extensión superficial (\%) de las fenomenologías de alteración y deterioro registradas. Muestra 10.

\begin{tabular}{|l|l|l|}
\hline M10 (total incidencia de deterioro: 5) \\
\hline FENOMENOLOGÍA DE ALTERACIÓN Y DETERIORO & $\begin{array}{l}\text { INCIDENCIA } \\
\text { SUPERFICIAL }\end{array}$ & EXTENSIÓN SUPERFICIAL (\%) \\
\hline Alteración cromática y depósitos - Suciedad & 4 & $75-100$ \\
\hline Fisuras y deformaciones - Fisura & 1 & $0-25$ \\
\hline Separación - Disgregación: Granular & 1 & $0-25$ \\
\hline Separación - Fragmentación & 1 & $0-25$ \\
\hline $\begin{array}{l}\text { Morfologías inducidas por pérdidas - Faltantes: } \\
\text { Volumétricos }\end{array}$ & 1 & $0-25$ \\
\hline
\end{tabular}

Tabla 148 - Extensión superficial (\%) de las fenomenologías de alteración y deterioro registradas. Muestra 13.

\begin{tabular}{|l|l|l|}
\hline M13 (total incidencia de deterioro: 5) \\
\hline FENOMENOLOGÍA DE ALTERACIÓN Y DETERIORO & $\begin{array}{l}\text { INCIDENCIA } \\
\text { SUPERFICIAL }\end{array}$ & EXTENSIÓN SUPERFICIAL (\%) \\
\hline Alteración cromática y depósitos - Suciedad & 4 & $75-100$ \\
\hline Fisuras y deformaciones - Fisura & 1 & $0-25$ \\
\hline Separación - Disgregación: Granular & 1 & $0-25$ \\
\hline Separación - Fragmentación & 1 & $0-25$ \\
\hline $\begin{array}{l}\text { Morfologías inducidas por pérdidas - Faltantes: } \\
\text { Volumétricos }\end{array}$ & 1 & $0-25$ \\
\hline
\end{tabular}

Tabla 149 - Extensión superficial (\%) de las fenomenologías de alteración y deterioro registradas. Muestra 14.

M14 (total incidencia de deterioro: 5)

\begin{tabular}{|l|l|l|}
\hline FENOMENOLOGÍA DE ALTERACIÓN Y DETERIORO & $\begin{array}{l}\text { INCIDENCIA } \\
\text { SUPERFICIAL }\end{array}$ & EXTENSIÓN SUPERFICIAL (\%) \\
\hline Alteración cromática y depósitos - Suciedad & 4 & $75-100$ \\
\hline Fisuras y deformaciones - Fisura & 1 & $0-25$ \\
\hline Separación - Disgregación: Granular & 1 & $0-25$ \\
\hline Separación - Fragmentación pórdidas - Faltantes: & 1 & $0-25$ \\
\hline $\begin{array}{l}\text { Morfologías inducidas por } \\
\text { Volumétricos }\end{array}$ & $0-25$ \\
\hline
\end{tabular}




\subsubsection{Templo de San Francisco}

Para la implementación al caso de estudio, se analizaron un total de 6 esculturas en cantera rosa (tabla 150), cuyas coordenadas de identificación y ubicación se especifican en la tabla 151 y en la imagen 108.

Tabla 150 - Datos de las modalidades de registro y análisis.

\begin{tabular}{|l|l|}
\hline TEMPLO DE SAN FRANCISCO \\
\hline Registro realizado en: & Octubre 2020 \\
\hline Objeto de estudio: & Material pétreo (cantera rosa) \\
\hline Tiempo de registro de datos: & 20 minutos, sobre documentación fotográfica \\
\hline Total de obras analizadas: & 6 esculturas \\
\hline Profesionales empleados: & 1 \\
\hline Tiempo para el análisis de datos & 20 minutos \\
\hline
\end{tabular}

Tabla 151 - Referencia de muestras y esculturas ${ }^{319}$ de la fachada.

\begin{tabular}{|l|l|}
\hline \multicolumn{2}{|l|}{ ESCULTURAS DE LA FACHADA - TEMPLO DE SAN FRANCISCO DE ASÍS } \\
\hline M & IDENTIFICACIÓN DE LAS OBRAS (imagen XX) \\
\hline 1 & $\begin{array}{l}\text { Cantera rosa, escultura de bulto redondo, fraile franciscano, escultura izquierda, remate de la } \\
\text { fachada, siglo XVIII. }\end{array}$ \\
\hline 2 & $\begin{array}{l}\text { Cantera rosa, escultura de bulto redondo, San Luis Obispo de Tolosa, escultura central, remate de la } \\
\text { fachada, siglo XVIII. }\end{array}$ \\
\hline 3 & $\begin{array}{l}\text { Cantera rosa, escultura de bulto redondo, fraile franciscano, escultura derecha, remate de la fachada, } \\
\text { siglo XVIII. }\end{array}$ \\
\hline 5 & $\begin{array}{l}\text { Cantera rosa, escultura de bulto redondo, San Francisco de Asís, nicho central, segundo piso, } \\
\text { fachada, siglo XVIII. }\end{array}$ \\
\hline 6 & $\begin{array}{l}\text { Cantera rosa, escultura de bulto redondo, San Bonaventura, calle izquierda, primer piso, fachada, } \\
\text { siglo XVIII. }\end{array}$ \\
\hline
\end{tabular}

\footnotetext{
${ }^{319}$ La identificación de las esculturas de la fachada deriva de "1686 Templo de San Francisco" en Cronologías San Luis. <http://cronologiassanluispotosi.com/1686-templo-de-san-francisco.html> [Consulta: 10 de diciembre de 2020].
} 


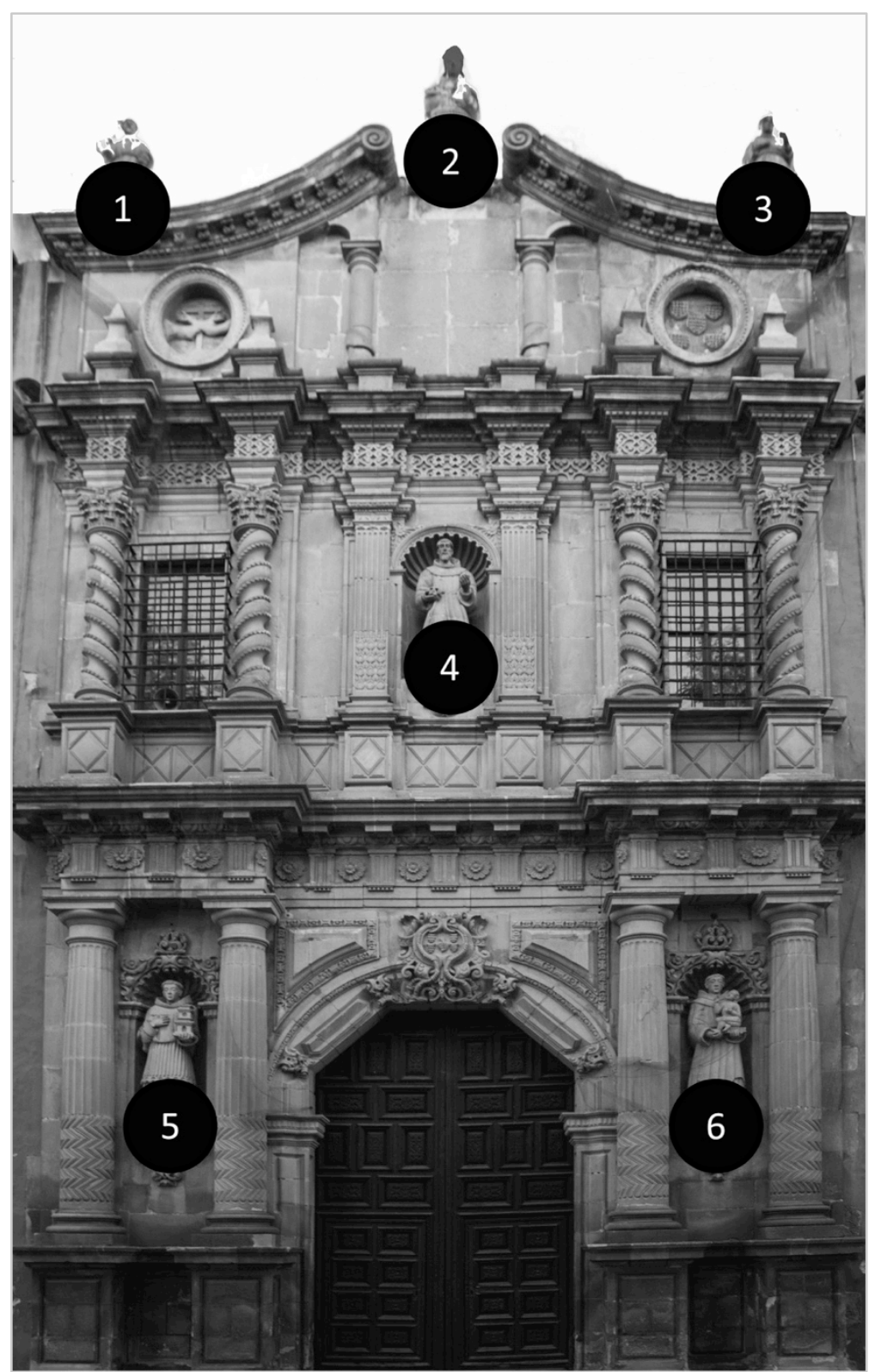

№ DE MUESTRAS - ESCULTURAS

TEMPLO DE SAN FRANCISCO, SAN LUIS POTOSÍ (S.L.P.)

Imagen 108 - Identificación muestras y ubicación. 
Tras el análisis de los datos recolectados, ha sido posible identificar:

- fenomenologías de alteración y deterioro activas (tabla 152) junto a su estimación cuantitativa y porcentual (gráfica 28);

- indicador de riesgo del conjunto (tabla 153);

- croquis del indicador de riesgo y prioridad (imagen 109);

- obra con mayor indicador de riesgo y prioridad (imagen 110 y 111);

- alteraciones y deterioros presentes en cada obra/área complementada por una estimación de la superficie afectada por cada fenómeno (tablas 154159);

La información obtenida ha sido complementada por una propuesta de interpretación de los datos, junto a los demás casos de estudio, al final del capítulo.

Tabla 152 - Panorámica de las dinámicas de alteración que están afectando las esculturas de la fachada.

\begin{tabular}{|c|c|}
\hline FENOMENOLOGÍA DE ALTERACIÓN Y DETERIORO & $\begin{array}{l}\text { TOTAL } \\
\text { INCIDENCIA DE } \\
\text { DETERIORO }\end{array}$ \\
\hline Morfologías inducidas por pérdidas - Aumento de la rugosidad & 4 \\
\hline Morfologías inducidas por pérdidas - Faltantes: Volumétricos & 4 \\
\hline Fisuras y deformaciones - Fisura & 3 \\
\hline Separación - Disgregación: desmenuzamiento & 3 \\
\hline Morfologías inducidas por pérdidas - Erosión: Pérdida de matriz & 3 \\
\hline Alteración cromática y depósitos - Depósito & 3 \\
\hline Fisuras y deformaciones - Craquelado & 2 \\
\hline Separación - Bursting & 2 \\
\hline Separación - Disgregación: Pulverulencia & 2 \\
\hline Alteración cromática y depósitos - Costra: Costra negra & 2 \\
\hline Fisuras y deformaciones - Fractura Lineal & 1 \\
\hline Separación - Delaminación & 1 \\
\hline Separación - Fragmentación & 1 \\
\hline Separación - Descamación & 1 \\
\hline Morfologías inducidas por pérdidas - Daño mecánico: Impacto directo & 1 \\
\hline Morfologías inducidas por pérdidas - Faltantes: Agujero & 1 \\
\hline Alteración cromática y depósitos - Eflorescencias & 1 \\
\hline Alteración cromática y depósitos - Suciedad & 1 \\
\hline
\end{tabular}




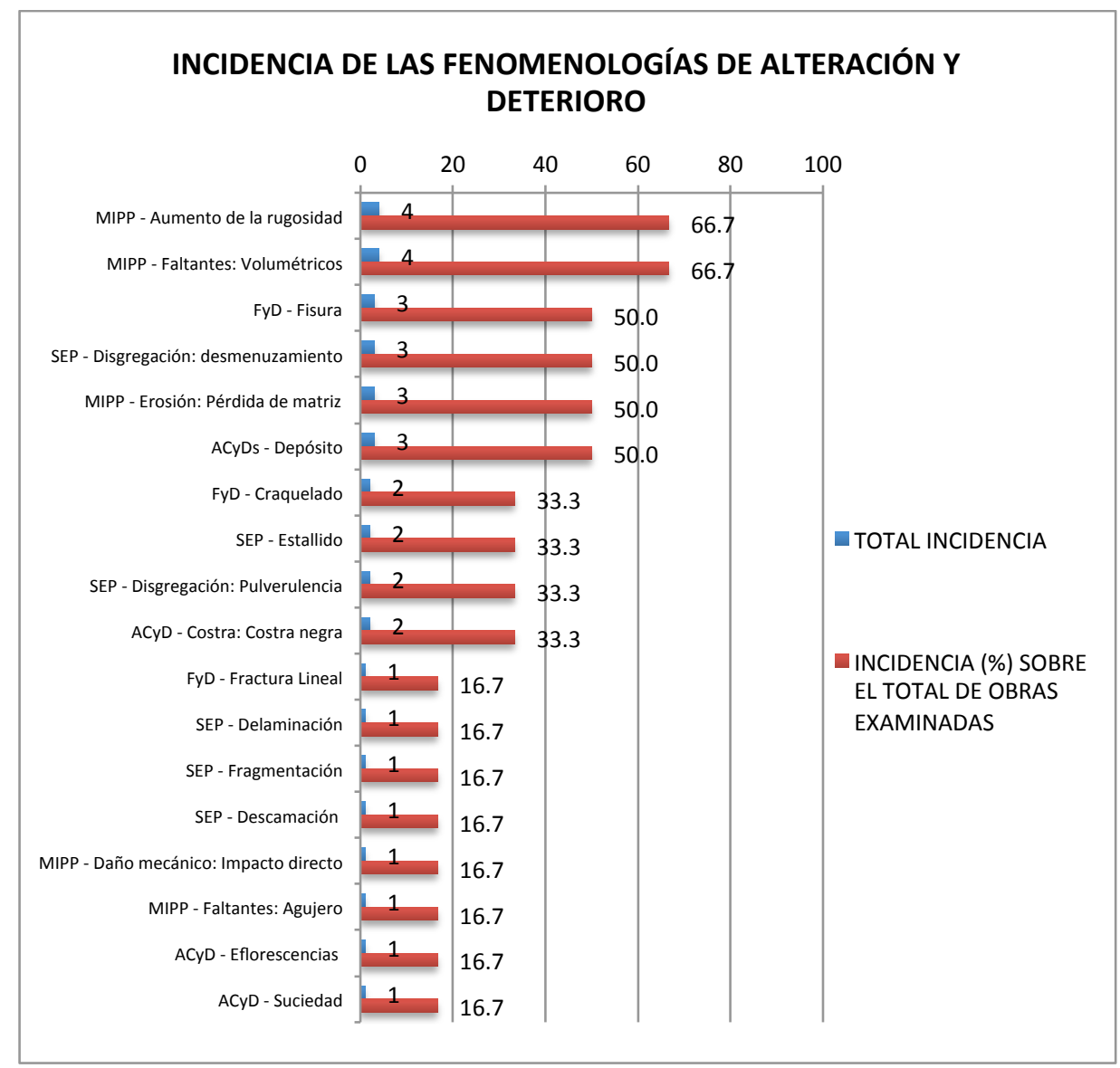

Gráfica 28 - Incidencia de las fenomenologías de alteración y deterioro y presencia (\%) en relación a la totalidad de muestras analizadas (6).

Tabla 153 - Indicador de riesgo obtenido a partir de la incidencia cuantitativa de las fenomenologías de alteración y deterioro registradas.

\begin{tabular}{|l|l|}
\hline \multicolumn{2}{|l|}{ INDICADOR DE RIESGO } \\
\hline MUESTRA & TOTAL INCIDENCIA DE DETERIORO \\
\hline 2 & 11 \\
\hline 1 & 7 \\
\hline 5 & 6 \\
\hline 4 & 5 \\
\hline 6 & 4 \\
\hline 3 & 3 \\
\hline
\end{tabular}




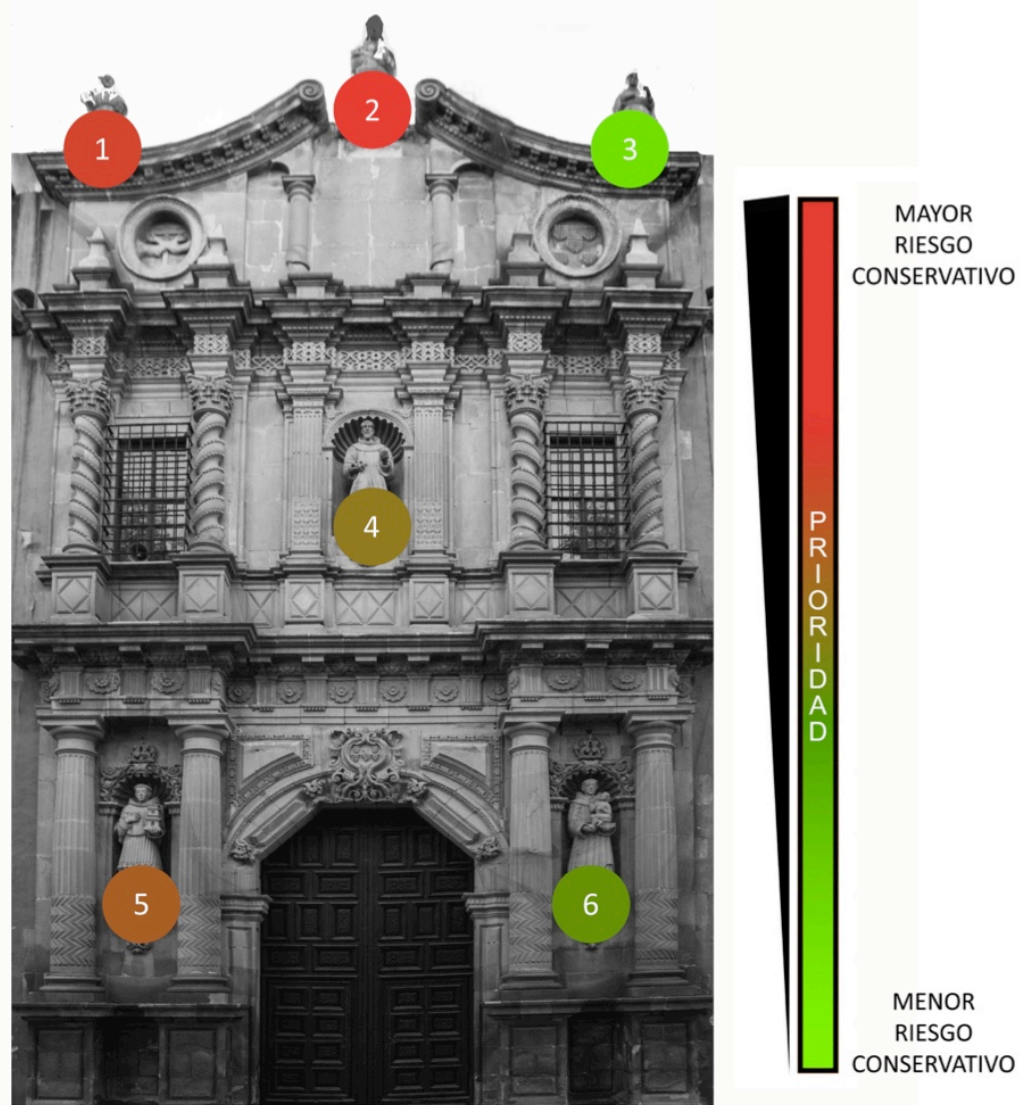

Imagen 109 - Indicador de riesgo, esculturas de la fachada. 


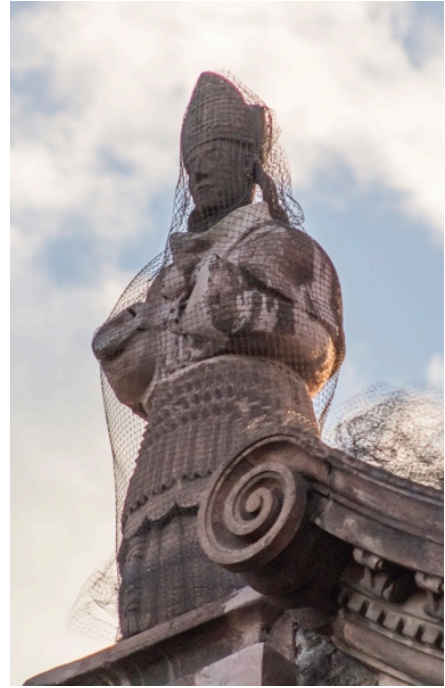

Imagen 110 - Escultura con mayor indicador de riesgo $(\mathrm{M} 2)^{320}$

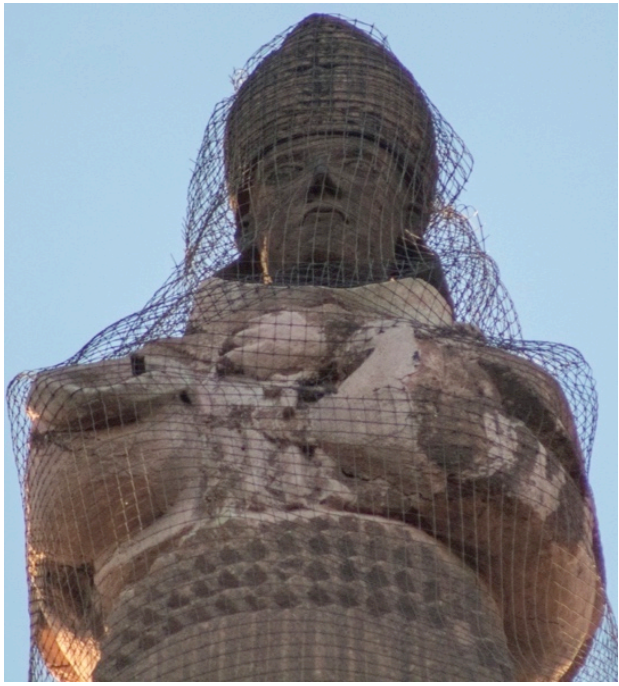

Imagen 111 - Acercamiento a la escultura con mayor indicador de riesgo $\mathrm{o}^{321}$.

Tabla 154 - Extensión superficial (\%) de las fenomenologías de alteración y deterioro registradas. Muestra 2.

\begin{tabular}{|l|l|l|}
\hline \multicolumn{2}{|l|}{ M2 (total incidencia de deterioro: 11) } & \multicolumn{2}{l|}{$\begin{array}{l}\text { EXTENSIÓN SUPERFICIAL (\%) } \\
\text { SUPERFICIAL }\end{array}$} \\
\hline Alteración cromática y depósitos - Costra: Costra negra & 3 & $50-75$ \\
\hline Fisuras y deformaciones - Fisura & 2 & $25-50$ \\
\hline Separación - Disgregación: desmenuzamiento & 2 & $25-50$ \\
\hline $\begin{array}{l}\text { Morfologías inducidas por pérdidas - Erosión: Pérdida de } \\
\text { matriz }\end{array}$ & 2 & $25-50$ \\
\hline $\begin{array}{l}\text { Morfologías inducidas por pérdidas - Aumento de la } \\
\text { rugosidad }\end{array}$ & 2 & $25-50$ \\
\hline Fisuras y deformaciones - Craquelado & 1 & $0-25$ \\
\hline
\end{tabular}

\footnotetext{
${ }^{320}$ Foto: Blanca Elena Sánchez Araujo.
}

${ }^{321}$ Foto: Blanca Elena Sánchez Araujo. 


\begin{tabular}{|l|l|l|}
\hline Separación - Estallido & 1 & $0-25$ \\
\hline Separación - Delaminación & 1 & $0-25$ \\
\hline Separación - Disgregación: Pulverulencia & 1 & $0-25$ \\
\hline Separación - Fragmentación por pérdidas - Faltantes: & 1 & $0-25$ \\
\hline $\begin{array}{l}\text { Morfologías inducidas pótricos } \\
\text { Volumé }\end{array}$ & $0-25$ \\
\hline
\end{tabular}

Tabla 155 - Extensión superficial (\%) de las fenomenologías de alteración y deterioro registradas. Muestra

\begin{tabular}{|l|l|l|}
\hline \multicolumn{2}{|l|}{ M1 (total incidencia de deterioro: 7) } & \multicolumn{1}{l|}{} \\
\hline FENOMENOLOGÍA DE ALTERACIÓN Y DETERIORO & $\begin{array}{l}\text { SUPERFICIAL } \\
\text { SUPIÓN SUPERFICIAL (\%) }\end{array}$ & \multicolumn{2}{l|}{} \\
\hline Separación - Estallido & 1 & $0-25$ \\
\hline Separación - Disgregación: Pulverulencia & 1 & $0-25$ \\
\hline Separación - Descamación & 1 & $0-25$ \\
\hline $\begin{array}{l}\text { Morfologías inducidas por pérdidas - Erosión: Pérdida de } \\
\text { matriz }\end{array}$ & 1 & $0-25$ \\
\hline $\begin{array}{l}\text { Morfologías inducidas por pérdidas - Aumento de la } \\
\text { rugosidad }\end{array}$ & 1 & $0-25$ \\
\hline $\begin{array}{l}\text { Morfologías inducidas por pérdidas - Faltantes: } \\
\text { Volumétricos }\end{array}$ & 1 & $0-25$ \\
\hline \begin{tabular}{l} 
Alteración cromática y depósitos - Suciedad \\
\hline
\end{tabular}
\end{tabular}

Tabla 156 - Extensión superficial (\%) de las fenomenologías de alteración y deterioro registradas. Muestra 5 .

\begin{tabular}{|l|l|l|}
\hline M5 (total incidencia de deterioro: 6) & \multicolumn{1}{l|}{ EXTENSIÓN SUPERFICIAL (\%) } \\
\hline FENOMENOLOGÍA DE ALTERACIÓN Y DETERIORO & $\begin{array}{l}\text { INCIDENCIA } \\
\text { SUPERFICIAL }\end{array}$ \\
\hline Fisuras y deformaciones - Fisura & 1 & $0-25$ \\
\hline Fisuras y deformaciones - Fractura Lineal & 1 & $0-25$ \\
\hline Fisuras y deformaciones - Craquelado & 1 & $0-25$ \\
\hline Separación - Disgregación: desmenuzamiento & 1 & $0-25$ \\
\hline $\begin{array}{l}\text { Morfologías inducidas por pérdidas - Faltantes: } \\
\text { Volumétricos }\end{array}$ & 1 & $0-25$ \\
\hline Alteración cromática y depósitos - Depósito & 1 & $0-25$ \\
\hline
\end{tabular}


Tabla 157 - Extensión superficial (\%) de las fenomenologías de alteración y deterioro registradas. Muestra 4.

\begin{tabular}{|l|l|l|}
\hline \multicolumn{2}{|l|}{ M4 (total incidencia de deterioro: 5) } \\
\hline FENOMENOLOGÍA DE ALTERACIÓN Y DETERIORO & $\begin{array}{l}\text { INCIDENCIA } \\
\text { SUPERFICIAL }\end{array}$ & EXTENSIÓN SUPERFICIAL (\%) \\
\hline $\begin{array}{l}\text { Morfologías inducidas por pérdidas - Aumento de la } \\
\text { rugosidad }\end{array}$ & 1 & $0-25$ \\
\hline Morfologías inducidas por pérdidas - Faltantes: Agujero & 1 & $0-25$ \\
\hline $\begin{array}{l}\text { Morfologías inducidas por pérdidas - Faltantes: } \\
\text { Volumétricos }\end{array}$ & 1 & $0-25$ \\
\hline Alteración cromática y depósitos - Depósito & 1 & $0-25$ \\
\hline Alteración cromática y depósitos - Eflorescencias & 1 & $0-25$ \\
\hline
\end{tabular}

Tabla 158 - Extensión superficial (\%) de las fenomenologías de alteración y deterioro registradas. Muestra 6.

\begin{tabular}{|l|l|l|}
\hline \multicolumn{2}{|l|}{ M6 (total incidencia de deterioro: 4) } \\
\hline FENOMENOLOGÍA DE ALTERACIÓN Y DETERIORO & $\begin{array}{l}\text { INCIDENCIA } \\
\text { SUPERFICIAL }\end{array}$ & EXTENSIÓN SUPERFICIAL (\%) \\
\hline Fisuras y deformaciones - Fisura & 1 & $0-25$ \\
\hline Separación - Disgregación: desmenuzamiento & 1 & $0-25$ \\
\hline $\begin{array}{l}\text { Morfologías inducidas por pérdidas - Aumento de la } \\
\text { rugosidad }\end{array}$ & 1 & $0-25$ \\
\hline Alteración cromática y depósitos - Depósito & 1 & $0-25$ \\
\hline
\end{tabular}

Tabla 159 - Extensión superficial (\%) de las fenomenologías de alteración y deterioro registradas. Muestra 3.

\begin{tabular}{|l|l|l|}
\hline \multicolumn{2}{|l|}{ M3 (total incidencia de deterioro: 3) } \\
\hline FENOMENOLOGÍA DE ALTERACIÓN Y DETERIORO & $\begin{array}{l}\text { INCIDENCIA } \\
\text { SUPERFICIAL }\end{array}$ & EXTENSIÓN SUPERFICIAL (\%) \\
\hline Alteración cromática y depósitos - Costra: Costra negra & 2 & $25-50$ \\
\hline $\begin{array}{l}\text { Morfologías inducidas por pérdidas - Erosión: Pérdida de } \\
\text { matriz }\end{array}$ & 1 & $0-25$ \\
\hline $\begin{array}{l}\text { Morfologías inducidas por pérdidas - Daño mecánico: } \\
\text { Impacto directo }\end{array}$ & 1 & $0-25$ \\
\hline
\end{tabular}




\subsubsection{Templo de San Miguelito}

Para la implementación del método al caso de estudio han sido analizadas 4 esculturas en cantera rosa (tabla 160). El número de muestra relacionado y su ubicación se especifican en la tabla 161 y en la imagen 112.

Tabla 160 - Datos de las modalidades de registro y análisis.

\begin{tabular}{|l|l|}
\hline TEMPLO DE SAN MIGUELITO \\
\hline Registro realizado en: & Octubre 2020 \\
\hline Objeto de estudio: & Material pétreo (cantera rosa) \\
\hline Tiempo de registro de datos: & 15 minutos, sobre documentación fotográfica \\
\hline Total de obras analizadas: & 4 esculturas \\
\hline Profesionales empleados: & 1 \\
\hline Tiempo para el análisis de datos & 15 minutos \\
\hline
\end{tabular}

Tabla 161 - Referencia de muestras y esculturas ${ }^{322}$ de la fachada.

\begin{tabular}{|l|l|}
\hline \multicolumn{2}{|l|}{ ESCULTURAS DE LA FACHADA - TEMPLO DE SAN MIGUEL ARCÁNGEL } \\
\hline $\mathrm{M}$ & IDENTIFICACIÓN DE LAS OBRAS (imagen XX) \\
\hline 1 & $\begin{array}{l}\text { Cantera rosa, escultura de bulto redondo, Santísima Trinidad, tercer cuerpo, nicho central, fachada, } \\
\text { siglo XVIII. }\end{array}$ \\
\hline 2 & $\begin{array}{l}\text { Cantera rosa, escultura de bulto redondo, San Francisco de Asís, calle izquierda, segundo cuerpo, } \\
\text { fachada, siglo XVIII. }\end{array}$ \\
\hline 3 & $\begin{array}{l}\text { Cantera rosa, escultura de bulto redondo, Santo Domingo de Guzmán, calle derecha, segundo } \\
\text { cuerpo, fachada, siglo XVIII. }\end{array}$ \\
\hline 4 & Cantera rosa, escultura de bulto redondo, San Miguel Arcángel, remate de la fachada, siglo XX. \\
\hline
\end{tabular}

\footnotetext{
322 La identificación de las esculturas de la fachada deriva de "1730 Templo de San Miguelito" en Cronologías San Luis. <http://cronologiassanluispotosi.com/1730-tempo-de-san-miguelito.html> [Fecha: 10 de diciembre de 2020].
} 


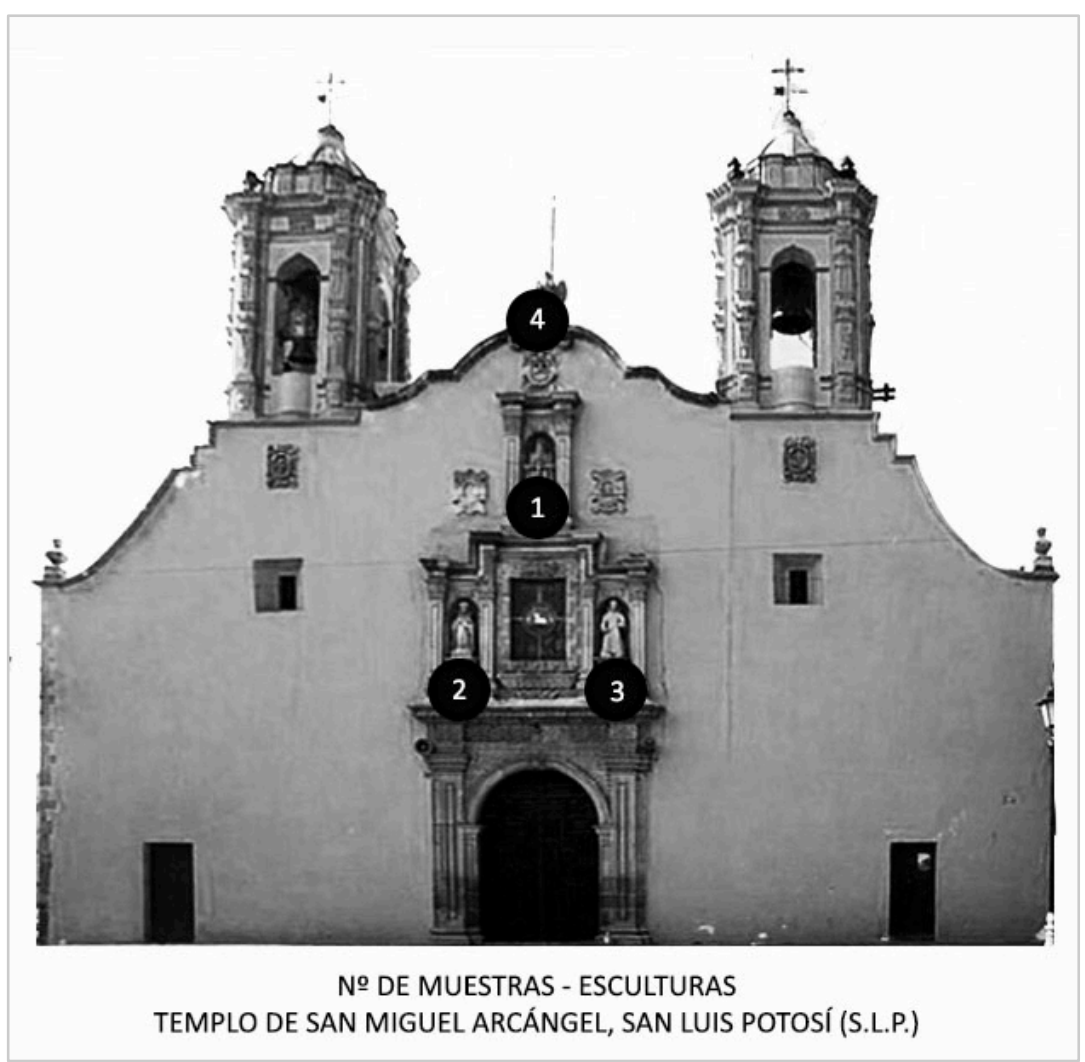

Imagen 112 - Identificación de muestras y ubicación.

Tras el análisis de los datos recolectados, ha sido posible identificar:

- fenomenologías de alteración y deterioro activas (tabla 162) junto a su estimación cuantitativa y porcentual (gráfica 29);

- indicador de riesgo del conjunto (tabla 163);

- croquis del indicador de riesgo y prioridad (imagen 112);

- obra con mayor indicador de riesgo y prioridad (imagen 113 y 114);

- alteraciones y deterioros presentes en cada obra/área complementada por una estimación de la superficie afectada por cada fenómeno (tablas 164167);

La información obtenida ha sido complementada por una propuesta de interpretación de los datos, junto a los demás casos de estudio, al final del capítulo. 
Tabla 162 - Panorámica de las dinámicas de alteración que están afectando las esculturas de la fachada.

\begin{tabular}{|l|l|}
\hline FENOMENOLOGÍA DE ALTERACIÓN Y DETERIORO & $\begin{array}{l}\text { TOTAL } \\
\text { INCIDENCIA DE } \\
\text { DETERIORO }\end{array}$ \\
\hline Fisuras y deformaciones - Fisura & 3 \\
\hline Fisuras y deformaciones - Fractura Lineal & 3 \\
\hline Separación - Disgregación: desmenuzamiento & 3 \\
\hline Morfologías inducidas por pérdidas - Alveolización & 3 \\
\hline Morfologías inducidas por pérdidas - Erosión: Erosión diferencial & 3 \\
\hline Morfologías inducidas por pérdidas - Aumento de la rugosidad & 3 \\
\hline Morfologías inducidas por pérdidas - Faltantes: Agujero & 3 \\
\hline Morfologías inducidas por pérdidas - Faltantes: Volumétricos & 3 \\
\hline Alteración comática y depósitos - Eflorescencias & 3 \\
\hline Morfologías inducidas por pérdidas - Faltantes: Perforación & 2 \\
\hline Fisuras y deformaciones - Craquelado & 1 \\
\hline Separación - Fragmentación & 1 \\
\hline Separación - Fragmentación en esquirlas & 1 \\
\hline Morfologías inducidas por pérdidas - Daño mecánico: Impacto directo & 1 \\
\hline Morfologías inducidas por pérdidas - Faltantes: agujereado & 1 \\
\hline Alteración cromática y depósitos - Costra: Concreción & 1 \\
\hline Alteración cromática y depósitos - Depósito & 1 \\
\hline Alteración cromática y depósitos - Suciedad & 1 \\
\hline Morfologías inducidas por pérdidas - Erosión: Pérdida de componentes & 1 \\
\hline
\end{tabular}




\section{INCIDENCIA DE LAS FENOMENOLOGÍAS DE ALTERACIÓN Y} DETERIORO

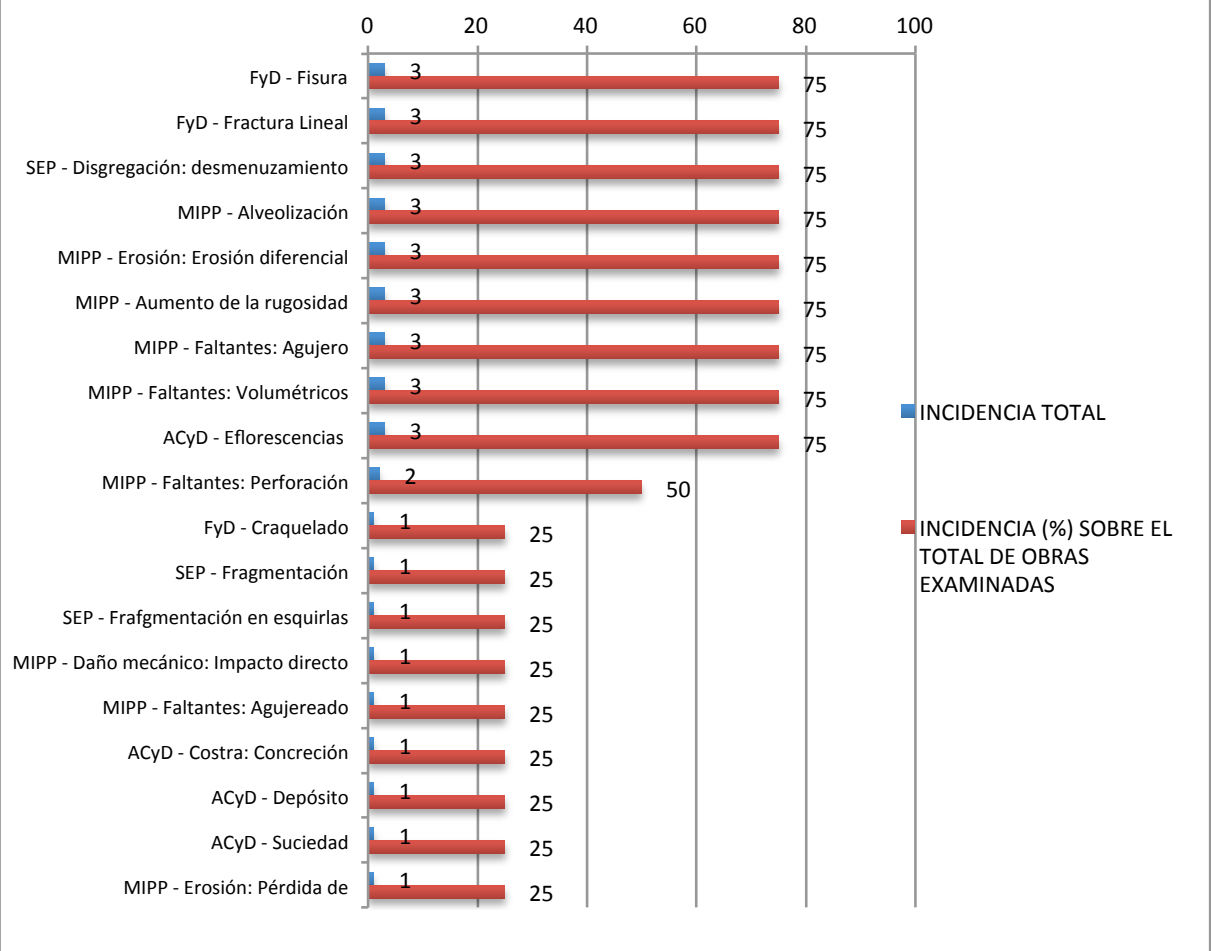

Gráfica 29 - Incidencia de las fenomenologías de alteración y deterioro y presencia (\%) en relación a la totalidad de muestras analizadas (4).

Tabla 163 - Indicador de riesgo obtenido a partir de la incidencia cuantitativa de las fenomenologías de alteración y deterioro registradas.

\begin{tabular}{|l|l|}
\hline \multicolumn{2}{|l|}{ INDICADOR DE RIESGO } \\
\hline MUESTRA & TOTAL INCIDENCIA DE DETERIORO \\
\hline 1 & 16 \\
\hline 3 & 11 \\
\hline 2 & 10 \\
\hline 4 & 1 \\
\hline
\end{tabular}




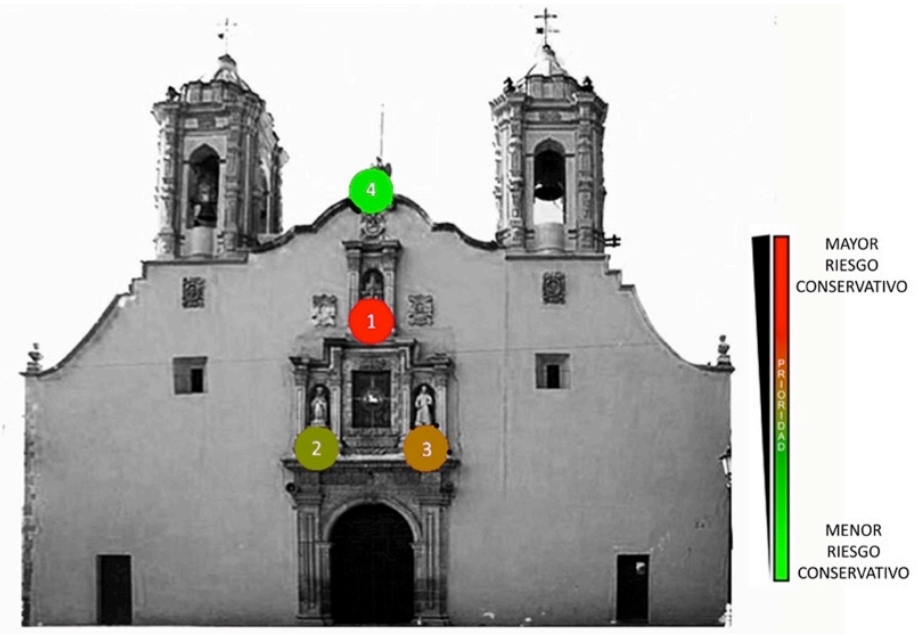

Imagen 112 - Indicador de riesgo de los elementos de la fachada.

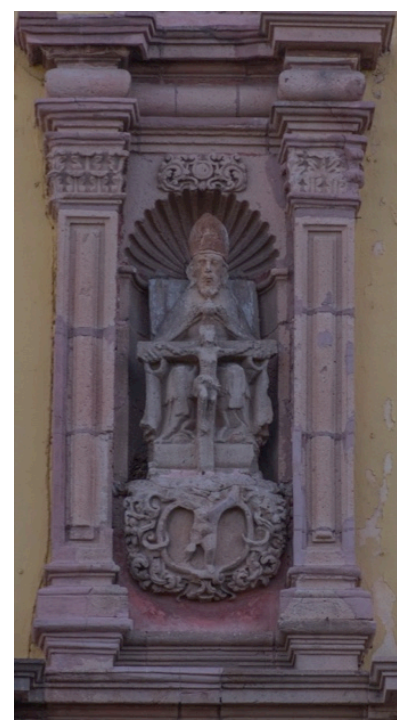

Imagen 113 -Obra con mayor indicador de riesgo (M1), vista general ${ }^{323}$.

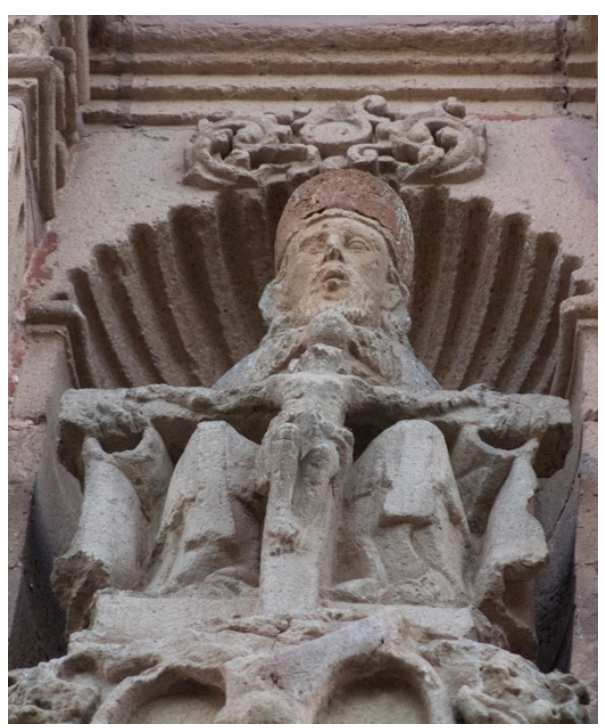

Imagen 114 - Obra con mayor indicador de riesgo, acercamiento ${ }^{324}$.

\footnotetext{
${ }^{323}$ Foto: Blanca Elena Sánchez Saraujo.

${ }^{324}$ Foto: Blanca Elena Sánchez Saraujo.
} 


\begin{tabular}{|l|l|l|}
\hline \multicolumn{2}{|l|}{ M1 (total incidencia de deterioro: 16) } \\
\hline FENOMENOLOGÍA DE ALTERACIÓN Y DETERIORO & $\begin{array}{l}\text { INCIDENCIA } \\
\text { SUPERFICIAL }\end{array}$ & $\begin{array}{l}\text { EXTENSIÓN } \\
(\%)\end{array}$ \\
\hline $\begin{array}{l}\text { Morfologías inducidas por pérdidas - Aumento de la } \\
\text { rugosidad }\end{array}$ & 3 & $50-75$ \\
\hline Morfologías inducidas por pérdidas - Alveolización & 2 & $25-50$ \\
\hline Morfologías inducidas por pérdidas - Faltantes: Agujero & 2 & $25-50$ \\
\hline Alteración comática y depósitos - Eflorescencias & 2 & $25-50$ \\
\hline Fisuras y deformaciones - Fisura & 1 & $0-25$ \\
\hline Fisuras y deformaciones - Fractura Lineal & 1 & $0-25$ \\
\hline Fisuras y deformaciones - Craquelado & 1 & $0-25$ \\
\hline Separación - Disgregación: desmenuzamiento & 1 & $0-25$ \\
\hline Separación - Fragmentación & 1 & $0-25$ \\
\hline $\begin{array}{l}\text { Morfologías inducidas por pérdidas - Erosión: Erosión } \\
\text { diferencial }\end{array}$ & 1 & $0-25$ \\
\hline $\begin{array}{l}\text { Morfologías inducidas por pérdidas - Daño mecánico: } \\
\text { Impacto directo }\end{array}$ & 1 & $0-25$ \\
\hline Morfologías inducidas por pérdidas - Faltantes: Perforación & 1 & $0-25$ \\
\hline Morfologías inducidas por pérdidas - Faltantes: Agujereado & 1 & $0-25$ \\
\hline $\begin{array}{l}\text { Morfologías inducidas por pérdidas - Faltantes: } \\
\text { Volumétricos }\end{array}$ & 1 & $0-25$ \\
\hline Alteración cromática y depósitos - Depósito & 1 & $0-25$ \\
\hline Alteración cromática y depósitos - Suciedad & $0-25$ \\
\hline
\end{tabular}

Tabla 165 - Extensión superficial (\%) de las fenomenologías de alteración y deterioro registradas. Muestra 3.

M3 (total incidencia de deterioro: 11)

\begin{tabular}{|l|l|l|}
\hline FENOMENOLOGÍA DE ALTERACIÓN Y DETERIORO & $\begin{array}{l}\text { INCIDENCIA } \\
\text { SUPERFICIAL }\end{array}$ & $\begin{array}{l}\text { EXTENSIÓN SUPERFICIAL } \\
(\%)\end{array}$ \\
\hline Alteración cromática y depósitos - Eflorescencias & 2 & $25-50$ \\
\hline Fisuras y deformaciones - Fisura & 1 & $0-25$ \\
\hline Fisuras y deformaciones - Fractura Lineal & 1 & $0-25$ \\
\hline Separación - Disgregación: desmenuzamiento & 1 & $0-25$ \\
\hline
\end{tabular}




\begin{tabular}{|l|l|l|}
\hline Morfologías inducidas por pérdidas - Alveolización & 1 & $0-25$ \\
\hline $\begin{array}{l}\text { Morfologías inducidas por pérdidas - Erosión: Erosión } \\
\text { diferencial }\end{array}$ & 1 & $0-25$ \\
\hline $\begin{array}{l}\text { Morfologías inducidas por pérdidas - Aumento de la } \\
\text { rugosidad }\end{array}$ & 1 & $0-25$ \\
\hline Morfologías inducidas por pérdidas - Faltantes: Agujero & 1 & $0-25$ \\
\hline Morfologías inducidas por pérdidas - Faltantes: Perforación & 1 & $0-25$ \\
\hline $\begin{array}{l}\text { Morfologías inducidas por pérdidas - Faltantes: } \\
\text { Volumétricos }\end{array}$ & 1 & $0-25$ \\
\hline Alteración cromática y depósitos - Costra: Concreción & 1 & $0-25$ \\
\hline
\end{tabular}

Tabla 166 - Extensión superficial (\%) de las fenomenologías de alteración y deterioro registradas. Muestra

\begin{tabular}{|l|l|l|}
\hline M2 (total incidencia de deterioro: 10) & $\begin{array}{l}\text { INCIDENCIA } \\
\text { SUPERFICIAL } \\
\text { FENOMENOLOGÍA DE ALTERACIÓN Y DETERIORO }\end{array}$ \\
\hline Alteración cromática y depósitos - Eflorescencias & 2 & $25-50$ \\
\hline Fisuras y deformaciones - Fisura & 1 & $0-25$ \\
\hline Fisuras y deformaciones - Fractura Lineal & 1 & $0-25$ \\
\hline Separación - Disgregación: desmenuzamiento & 1 & $0-25$ \\
\hline $\begin{array}{l}\text { Separación - Splintering } \\
\text { Morfologías inducidas por pérdidas - Alveolización }\end{array}$ & 1 & $0-25$ \\
\hline $\begin{array}{l}\text { Morfologías inducidas por pérdidas - Erosión: Erosión } \\
\text { diferencial }\end{array}$ & 1 & $0-25$ \\
\hline $\begin{array}{l}\text { Morfologías inducidas por pérdidas - Aumento de la } \\
\text { rugosidad }\end{array}$ & 1 & $0-25$ \\
\hline Morfologías inducidas por pérdidas - Faltantes: Agujero & 1 & $0-25$ \\
\hline $\begin{array}{l}\text { Morfologías inducidas por pérdidas - Faltantes: } \\
\text { Volumétricos }\end{array}$ & 1 & $0-25$ \\
\hline
\end{tabular}




\begin{tabular}{|c|c|c|}
\hline M4 (total incidencia de deterioro: 1 ) & & \\
\hline FENOMENOLOGÍA DE ALTERACIÓN Y DETERIORO & $\begin{array}{l}\text { INCIDENCIA } \\
\text { SUPERFICIAL }\end{array}$ & $\begin{array}{l}\text { EXTENSIÓN SUPERFICIAL } \\
(\%)\end{array}$ \\
\hline $\begin{array}{l}\text { Morfologías inducidas por pérdidas - Erosión: Pérdida de } \\
\text { componentes }\end{array}$ & 1 & $0-25$ \\
\hline
\end{tabular}

De acuerdo con la información arrojada por el análisis de datos, se puede afirmar $^{325}$ que:

La escultura M1 (incidencia de deterioro: 9) de la fachada de la Capilla de Nuestra Señora de Loreto presenta fenómenos de alteración y deterioro pertenecientes al grupo de fisuras y deformaciones, separación, y morfologías inducidas por pérdidas. Éstos, afectan a una porción de la superficie de la escultura entre el $0-25 \%$. Las fisuras y fracturas, pueden deberse al intemperismo, defectos en la piedra, problemas estáticos, anclajes de hierro oxidados o rejuntados con morteros demasiado duros. Las grietas también pueden ser causadas por vibraciones debidas a temblores sísmicos, el fuego y las heladas; la presencia de delaminación, desmenuzamiento y descamación, puede conjugarse con la acción de cristalización de las sales. Estos fenómenos, aunados a una pérdida de la matriz por procesos de tipo físico-químico y biológico, favorecieron un aumento de la rugosidad superficial y la presencia de agujeros. Esta pérdida selectiva de pequeñas partículas de piedra puede responder a un proceso progresivo de degradación o repentino como resultado de intervenciones desafortunadas tales como limpiezas agresivas.

La morfología de alteración de los materiales observada en la fachada de la Catedral Metropolitana evidenciaron un mayor indicador de riesgo para la M10 (incidencia de deterioro: 9). En esta escultura, los fenómenos con mayor incidencia pertenecen a los grupos de: alteración cromática y depósitos, separación, y morfologías inducidas por pérdidas. Hay suciedad sobre casi la totalidad de la superficie (75-100\%), seguida por la presencia de costra negra en una amplia área de la obra (50-75\%). Ésta debe su origen en los procesos de disolución de la matriz

${ }^{325}$ ICOMOS-ISCS. Illustrated Glossary on Stone Deterioration Patterns.

$<$ https://www.icomos.org/publications/monuments_and_sites/15/pdf/Monuments_and_Sites_15_ISCS_Gl ossary_Stone.pdf> [Consulta: 3 de marzo de 2016]. 
carbonática del sustrato pétreo. Se desarrollan generalmente en zonas abrigadas por escurrimientos directos, en ambientes urbanos. Las costras negras suelen estar firmemente adheridas al sustrato y se componen, en gran medida, de partículas atmosféricas atrapadas en una matriz de yeso. Las concreciones y encrustaciones, que afectan la escultura a un $25-50 \%$ de la superficie, se relacionan con un proceso de precipitación, seguida de lixiviación de cualquier tipo, asociada por la presencia de material movilizado por percolación del agua y procedente, por lo tanto, del propio edificio. En su composición son frecuentes los carbonatos, sulfatos, óxidos metálicos y sílice. Se registra la presencia, en la misma medida, de depósitos compuestos por una acumulación de material exogénico como polvo y guano de paloma. En menor cantidad (0-25\%) se registra la presencia de disgregación sacaroidea y de pérdida de la matriz, con consiguiente aumento de la rugosidad superficial. En los mármoles cristalinos, la disgregación sacaroidea deriva de los procesos de dilatación térmica, mientras la pérdida de la matriz se debe a procesos de degradación de tipo físico-químico. Hay faltantes volumétricos, derivados de la exposición a traumatismos de tipo físico mecánico de las partes salientes de la escultura.

La M5 (incidencia de deterioro: 14) de la fachada del Templo de Nuestra Señora del Carmen, presenta alteraciones pertenecientes al grupo de: alteración cromática y depósitos, fisuras y deformaciones, separaciones, y morfologías inducidas por pérdidas. Entre el $75-100 \%$ de la superficie presenta acumulación de suciedad, compuesta probablemente por una fina capa de partículas exógenas y contaminantes atmosféricos transportados por el viento. Aunado a esto, se encuentran depósitos, concreciones y encrustaciones en un área superficial estimada entre el $25-50 \%$. Éstos, se deben a la acción de las palomas, a un proceso de precipitación seguida de lixiviación de cualquier tipo y acumulación de material movilizado por percolación del agua y procedente de la propia estructura del edificio. En menor medida (0-25\% de la superficie) la escultura presenta: fisuras y craquelados, relacionados con la acción del intemperismo y a los mismos defectos en la piedra. La fragmentación puede asociarse a tensiones en el material derivadas de sobrecargas, mientras el disyunción en películas se debe a la cristalización de las sales en la superficie. El fenómeno de erosión diferencial, con pérdida de la superficie original y suavizado de las formas, suele ser el resultado de procesos químicos, físicos y/o biológicos en piedras heterogéneas que contienen zonas más duras y/o menos porosas. La degradación selectiva de los componentes de la piedra ha acarreado un aumento de la rugosidad, un efecto que puede responder también a intervenciones desafortunadas tales como limpiezas agresivas. Las huellas de impactos directos y los faltantes volumétricos indican la exposición de la obra a traumatismos físico-mecánicos, por acción antrópica y por la exposición de la escultura a la acción directa de los agentes externos. La existencia de costra negra 
puede ser el resultado de procesos de disolución de los componentes de la piedra, junto a fenómenos de cristalización y englobación de partículas atmosféricas, contaminantes, polvo y suciedad. La presencia de eflorescencias indica la existencia de sales solubles, probablemente derivadas de la composición de la misma piedra y son el resultado de la evaporación del agua cargada de sales alojada en los poros de la piedra o derivarse del historial de contaminación atmosférica del contexto.

En la M2 (incidencia de deterioro: 11) del Templo de San Francisco se registraron alteraciones del grupo de alteraciones cromáticas y depósitos, fisuras y deformaciones, separaciones y morfologías inducidas por pérdidas. Entre el 50$75 \%$ de la superficie presenta costra negra, derivada de procesos de disolución de la matriz del material pétreo, asociada a la englobación de partículas de suciedad, contaminantes atmosféricos y polvo entre otros. Entre el $25-50 \%$ del material está afectado por fisuras, desmenuzamiento, pérdida de la matriz y aumento de la rugosidad. Dichos fenómenos se deben a procesos de alteración de tipo físicoquímico con consiguiente pérdida del cementante, acompañados por la exposición al intemperismo. Estas alteraciones se ven favorecidas por defectos en la piedra, problemas estáticos, presencia de anclajes de hierro oxidados, o rejuntados con morteros demasiado duros. La exposición a vibraciones, heladas o gradientes térmicos extremos, favorecen y aumentan la gravedad de estas alteraciones. En menor medida (entre $0-25 \%$ de la superficie) se encuentran fenómenos derivados de la presencia de sales solubles y su cristalización. A esto se debe la existencia de estallidos y delaminación. El incremento en el volumen de inclusiones minerales (arcillas, minerales de hierro, etc.) que forman parte del contenido original de la piedra y que se encuentran cerca de su superficie, junto a la corrosión de metales de refuerzo, también puede inducir el estallido del material. La disolución del cementante ha favorecido una pérdida de cohesión, apreciable por la pulverulencia de la superficie, y la exposición a los agentes atmosféricos y a los gradientes térmicos han acarreado la formación de craqueladuras. La existencia de fragmentación puede relacionarse con tensiones en el material pétreo por sobrecargas o por el uso de morteros demasiado duros. La pérdida de elementos volumétricos suele ser consecuencia directa de la exposición de los resaltes y salientes de la escultura a traumatismos de tipo físico mecánico.

La M1 (incidencia de deterioro: 16) del Templo de San Miguelito presenta un aumento de la rugosidad en el $50-75 \%$ de la superficie. A esto se asocia, en un 25$50 \%$ del material, la presencia de alveolización, agujeros y eflorescencias derivados de procesos de disgregación causados por meteorización diferencial, debida, posiblemente, a heterogeneidades en las propiedades físicas y químicas de la piedra. Estos fenómenos pueden relacionarse con la presencia de sales en el 
material y los efectos de su cristalización. En menor cantidad (0-25\%) se observa la existencia de fisuras, fracturas, craquelados, desmenuzamiento, fragmentación, que pueden deberse a la acción del intemperismo, a defectos en la piedra, a problemas estáticos, a la presencia de anclajes de hierro oxidados, o rejuntados con morteros demasiado duros y presencia de sobrecargas. La presencia de erosión diferencial es un rasgo que se encuentra en piedras heterogéneas que contienen zonas más duras y/o menos porosas, que presentan una resistencia diferente hacia los procesos de degradación físico-química. Hay traumatismos derivados de impactos directos sobre la superficie de la piedra, probablemente por acciones de tipo antropogénico. El agujereado puede deberse a una degradación parcial o selectiva del material derivado de colonización biológica o limpiezas demasiado agresivas. La presencia de depósitos y suciedad se deben a la acumulación de guano y partículas atmosféricas, propiciadas por la acción de las aves y por la falta de mantenimiento periódico.

A la luz de los datos arrojados, el conjunto patrimonial constituido por las fachadas barrocas del centro histórico, está afectado principalmente por la falta de mantenimiento y por la misma naturaleza instrínseca de los materiales. Éstos, expuestos a intemperismo, además de padecer alteraciones cromáticas considerables, han desarrollado unas fenomenologías de deterioro específicas de su propia constitución mineral, como se puede apreciar por los efectos de alteración derivados de la presencia de sales en la cantera rosa y de la exposición de ésta a los estímulos térmicos propios del clima ${ }^{326}$. Este material pétreo ha desarrollado alteraciones cuales fisuras y deformaciones, separaciones y pérdidas, hasta llegar a un aumento de la rugosidad superficial con pérdida de los matices escultóricos. Los gradientes térmicos, aunados a la presencia de contaminantes y a la acumulación de depósitos de naturaleza variada, han favorecido la pérdida de la continuidad material de los mármoles, induciendo la formación de costras negras y disgregación sacaroidea. La conservación al exterior, aunque protegida por mallas contra la acción de las aves, ha expuesto las obras a traumatismos mecánicos de diversa naturaleza con consiguiente pérdida de elementos volumétricos, además de

\footnotetext{
${ }^{326}$ De acuerdo a la investigación del Dr. Rúbén López Doncel de la Facultad de Geología de la Universidad Autónoma de San Luis Potosí, en colaboración con la Georg-August-Universität de Göttingen (Alemania), sobre las características de la cantera rosa empleada en el patrimonio arquitectónico de San Luis Potosí "la formación de salitre, como se le conoce comúnmente, es dependiente de las condiciones climáticas, donde la precipitación media anual y las horas de sol por año deben conjugarse para favorecer la formación de sales. Este fenómeno está presente en nuestras rocas y es, sin duda, un factor a considerar para la prevención de daños y la toma de medidas apropiadas a la hora de restaurar". LÓPEZ DONCEL, R., CARDONA VELÁZQUEZ, N., WEDEKIND, W. (2015). "El rescate del patrimonio cultural pétreo de San Luis Potosi" en Universitarios Potosinos, año 12, no 194, diciembre, pp. 4-10.
} 
favorecer la acumulación de material exógeno que, de no ser eliminado, podría propiciar el desarrollo de efectos de alteración y deterioro secundarios. 


\section{Referencias bibliográficas}

"1730 Templo de San Miguelito" en Cronologías San Luis. <http://cronologiassanluispotosi.com/1730-tempo-de-san-miguelito.html> [Consulta: 10 de diciembre de 2020].

"1686 Templo de San Francisco" en Cronologías San Luis. $<$ http://cronologiassanluispotosi.com/1686-templo-de-san-francisco.html> [Consulta: 10 de diciembre de 2020].

CALVO, A. (2002). Conservación y restauración de pintura sobre lienzo. Barcelona: El Serbal.

"Centro histórico de San Luis Potosí". <https://centrohistoricoslp.com/mapa/> [Consulta: 5 de diciembre de 2020].

DR. ATL (1927). Iglesias de México. Vol. VI. México: Publicaciones de la Secretaría de Hacienda.

GONZÁLEZ GALVÁN, M. (2006). Trazo, proporción y símbolo en el arte virreinal: antología personal. México: Universidad Nacional Autónoma de México.

Haciendas de México: ex hacienda de Peotillos. <https://www.haciendasmexico.mx/ex-hacienda-de-peotillos/> [Consulta: 20 de noviembre de 2020].

HORNEMANN INSTITUT (2015). European Illustrated Glossary for Conservation Terms of Wall Painting and Architectonic Surfaces. <https://www.hornemanninstitut.de/doi/2016ewa2.pdf> [Consulta: 19 de mayo 2017].

Huaquechula. <https://www.corazondepuebla.com.mx/descubre/huaquechula/> [Consulta: 27 de noviembre de 2020].

"Huaquechula: la vida después del sismo", 26 de septiembre de 2017.<https://manati.mx/2017/09/26/el-renacer-del-convento-dehuaquechula/> [Consulta: 20 de noviembre de 2020].

ICOMOS-ISCS (2008). Illustrated Glossary on Stone Deterioration Patterns. $<$ https://www.icomos.org/publications/monuments_and_sites/15/pdf/Monume nts_and_Sites_15_ISCS_Glossary_Stone.pdf> [Consulta: 3 de marzo de 2016].

INAH-CONACULTA (2010). Haciendas del Altiplano Potosino. México: EME ediciones.

INAH-GOBIERNO DE MÉXICO. "Restaura INAH retablo centenario de Puebla", en Boletín de Noticias, 1 de marzo de 2012. <https://inah.gob.mx/boletines/1596restaura-inah-retablo-centenario-de-puebla> [Consulta: 27 de noviembre de 2020]. 
"INAH restaura retablo con pinturas de Villalpando", en Boletín de Noticias, 8 de noviembre de 2012. <https://inah.gob.mx/boletines/2140-inah-restaura-retablocon-pinturas-de-villalpando> [Consulta: 27 de noviembre de 2020].

INAH, GOBIERNO DE MÉXICO. "Secretaría de Cultura, INAH y Embajada de Estados Unidos recuperan conjunto conventual de Huaquechula, Puebla" en Boletín de Noticias, 18 de septiembre de 2018. < https://inah.gob.mx/boletines/7560secretaria-de-cultura-inah-y-embajada-de-estados-unidos-recuperan-conjuntoconventual-de-huaquechula-puebla> [Consulta: 27 de noviembre de 2020].

INAH, GOBIERNO DE MÉXICO. "Alistan diagnóstico para restauración integral del conjunto conventual de Huaquechula, Puebla", en Boletín de Noticias, 7 de agosto de 2019. <https://inah.gob.mx/boletines/8367-alistan-diagnostico-pararestauracion-integral-del-conjunto-conventual-de-huaquechula-puebla> [Consulta: 27 de noviembre de 2020].

INEGI, Marco Geoestadístico, diciembre 2018. <www.cuentame.inegi.org.mx> [Consulta 15 de noviembre de 2020].

KAISER SCHLITTLER, A. (2014). Breve historia de la ciudad de San Luis Potosí. México: Kaiser.

"Le statue degli apostoli in San Giovanni in Laterano", 21 febbraio 2019. $<$ https://www.italianways.com/it/le-statue-degli-apostoli-in-san-giovanni-inlaterano/> [Consulta: 10 de diciembre de 2020].

LÓPEZ DONCEL, R., CARDONA VELÁZQUEZ, N., WEDEKIND, W. (2015). “El rescate del patrimonio cultural pétreo de San Luis Potosi" en Universitarios Potosinos, año 12, núm. 194, diciembre, pp. 4-10.

MASTROIACOVO, T., et al. (2016-2017). "Estudio termográfico y diagnóstico de las pinturas decorativas del patio interior de la hacienda de Peotillos (Villa Hidalgo, San Luis Potosí, México)" en Archè, Revista del Instituto de Restauración del Patrimonio, núm. 11 y 12, 2016-2017, pp. 163-168.

MASTROIACOVO, T., BLASCO PÉREZ, M.V., NIETO VILLENA, A (2017). “Los hermanos Biagi y las esculturas de la catedral Metropolitana" en Universitarios Potosinos, año 14, núm. 211, pp. 12-17.

MEDIANERO HERNÁNDEZ, J.M. (1992). "Un ejemplo de capilla abierta en la Universidad de Mareantes de Triana" en Laboratorio de Arte, 5-1992, pp. 223-239.

"Parroquia del Sagrario Metropolitano" en México en Fotos. <https://www.mexicoenfotos.com/MX12182358439373.jpg> [Consulta: 27 de noviembre de 2020]. 
"Templo del Carmen" en Consejo del Centro Histórico de San Luis Potosí. <https://centrohistoricoslp.com/templo-del-carmen/> [Consulta: 27 de noviembre de 2020].

"Templo del Carmen" en Secretaría de Turismo. <http://www.ciudadsanluis.com/turismo/iglesias_y_templos/templo_de_nuestr a_senora_del_carmen/> [Consulta: 10 de diciembre de 2020].

"Templo de San Franscisco" en México en Fotos. <https://www.mexicoenfotos.com/MX15472737712554.jpg> [Consulta: 27 de noviembre de 2020].

TOUSSAINT, M. (1990). El arte colonial en México. México: Universidad Nacional Autónoma de México, p. XIII-XIV.

VIVANCOS RAMÓN, V. (2007). La conservación y restauración de la pintura de caballete. Pintura sobre tabla. Madrid: Tecnos. 


\section{Capítulo 4 Resultados y discusión}

A continuación, se presentan los resultados obtenidos en las fases de diseño, mejora e implementación de las tablas de registro unificadas presentadas en esta investigación. Éstas, creadas para enfrentar las fases preliminares de diagnóstico y generar una estimación del indicador de riesgo del patrimonio cultural con una mínima inversión de recursos, han sido desarrolladas a partir del estudio de conjuntos patrimoniales compuestos por las siguientes categorías:

- pinturas murales y recubrimientos arquitectónicos;

- esculturas en material pétreo;

- pintura de caballete y escultura en madera policromada;

Entre las metas establecidas, destacó la de hallar una forma efectiva de identificar y gestionar la información sobre las exigencias conservativas de los grupos mencionados, diseñando por ello una metodología operativa que permitiera solventar algunas problemáticas operativas propias de las fases de evaluación preliminar del estado de conservación del patrimonio cultural, cuales:

- disponibilidad de recursos técnicos, humanos, temporales y económicos limitados;

- gran cantidad de variables de estudio compuestas por técnicas, tipología, número;

- amplia extensión territorial del contexto geográfico en el que surgió el estudio; 
- falta de implementación de modelos de fichas unificados para la recolección de los datos conservativos generales;

Con la finalidad de ofrecer una herramienta que pudiera suplir a estas limitaciones, parte de los esfuerzos llevados a cabo en esta investigación han sido dirigidos al diseño de un procedimiento de recolección y análisis de los datos focalizado en el registro de las fenomenologías de alteración y deterioro del Patrimonio Cultural.

El diseño del método tuvo en cuenta los siguientes parámetros:

- contemplar el uso de recursos básicos, apto para ser empleado en la mayoría de situaciones y contextos;

- encontrar un método de registro y análisis sencillo y efectivo, que pudiera brindar informaciones representativas sobre el contexto de estudio;

- estructurar los conceptos inherentes a las fenomenologías de alteración y deterioro de forma unificada para favorecer su entendimiento y comparación;

- determinar unos parámetros de medida y registro de la información que fueran sencillos y rápidos.

\subsection{Diseño de matrices de datos}

Los aspectos relevantes tomados en cuenta a la hora de estructurar la propuesta metodológica han sido relacionados con las fases operativas preliminares de diagnóstico, en donde las principales acciones realizadas por parte del profesional de la conservación pueden ser clasificadas en:

- observar

- registrar

- ordenar

- estimar/cuantificar

- analizar

- interpretar

La fase inicial de observación y reconocimiento de las fenomenologías de alteración y deterioro está íntimamente ligada a la metodología de registro. Juntas, constituyen la base de un correcto entendimiento de las exigencias conservativas del patrimonio cultural. Por ello, ha sido indispensable llevar a cabo una selección de los criterios a registrar en las fases de inspección, determinando hacia qué 
fenómenos dirigir la atención del profesional y, tomando en cuenta la finalidad de poder lograr un medio de análisis y generación de resultados sencillo y representativo, determinar el medio idóneo de registro de la información.

Estos aspectos se solucionaron gracias a los alcances en el campo de las ciencias estadísticas, de donde ha sido posible extraer el medio de ordenación de los conceptos y el modelo de ficha de registro útiles al registro y análisis de los datos. Ésta, inspirada en las matrices de datos empleadas en el campo de la ecología para gestionar, analizar y comprender un amplio espectro de información, se estructuró a partir de los datos específicos de las fenomenologías de alteración y deterioro que afectan al patrimonio cultural, generando unos prototipos de fichas cuyos criterios han sido organizados en dos ejes en donde (tabla 168):

- el eje vertical: reúne las especies de alteración y deterioro;

- el eje horizontal: desglosa los casos de estudio;

Tabla 168 - Ejemplo de la estructura de matriz para la recolección de datos empleada en la investigación.

\begin{tabular}{|l|c|c|c|}
\hline ESPECIES & \multicolumn{3}{|c|}{ MUESTRAS } \\
\hline $\begin{array}{l}\text { FENOMENOLOGÍA DE ALTERACIÓN } \\
\text { Y DETERIORO }\end{array}$ & MUESTRA 1 & MUESTRA 2 & MUESTRA 3 \\
\hline Fenomenología de deterioro A & 0 & 0 & 0 \\
\hline Fenomenología de deterioro B & 0 & 0 & 0 \\
\hline Fenomenología de deterioro C & 0 & 0 & 0 \\
\hline
\end{tabular}

La terminología reunida para cada grupo de obras de arte ha sido el resultado de las aportaciones realizadas para el sector de la conservación del patrimonio cultural por parte de las instituciones involucradas en la generación de glosarios con vocablos unificados. Dichos documentos, elaborados por comités de científicos y profesionales de esta rama del conocimiento, brindaron un óptimo punto de partida para la estructuración de los datos a recolectar en las fichas de registro, proveyendo el sistema de un abanico de terminologías reconocidas a nivel internacional ${ }^{127}$.

327 Gracias a los glosarios oficiales, es posible profundizar en cada concepto, encontrándose su respectiva definición, traducción y representación. 
Las publicaciones empleadas para tal propósito fueron:

- HORNEMANN INSTITUT (2015). European Illustrated Glossary for Conservation Terms of Wall Painting and Architectonic Surfaces ${ }^{328}$.

- ICOMOS-ISCS (2008). Illustrated Glossary on Stone Deterioration Patterns ${ }^{329}$.

Para el estudio de pinturas de caballete y escultura policromada, se generó un listado de fenomenologías de alteración y deterioro a partir de publicaciones de habla hispana del sector:

- CALVO, A. (2002). Conservación y restauración de pintura sobre lienzo ${ }^{330}$.

- CALVO, A., GARCÍA FERNÁNDEZ-VILLA, S., BAILÃO, A. (2018). Terminología básica de conservación y restauración del patrimonio cultura ${ }^{331}$.

- VIVANCOS RAMÓN, V. (2007). La conservación y restauración de la pintura de caballete. Pintura sobre tabla ${ }^{332}$.

- VIVANCOS RAMÓN, V. y CASTELL AGUSTí, M. (2010). Problemas y tratamientos del soporte de pintura de caballete ${ }^{333}$.

Para esta última clase de obras, los conceptos reunidos se estructuraron de acuerdo a la conformación del sistema tecnológico más representativo (imagen 115),

compuesto por:

- Capa de protección.

- Película pictórica y/o policromía.

- Capa de preparación y/o imprimación.

- Soporte textil y/o entelado.

- Soporte en madera y/o bastidor.

328 HORNEMANN INSTITUT (2015). European Illustrated Glossary for Conservation Terms of Wall Painting and Architectonic Surfaces. <https://www.hornemann-institut.de/doi/2016ewa2.pdf> [Consulta: 19 de mayo 2017].

${ }^{329}$ ICOMOS-ISCS (2008). Illustrated Glossary on Stone Deterioration Patterns. $<$ https://www.icomos.org/publications/monuments_and_sites/15/pdf/Monuments_and_Sites_15_ISCS_Gl ossary_Stone.pdf> [Consulta: 3 de marzo de 2016].

${ }^{330}$ CALVO, A. (2002). Conservación y restauración de pintura sobre lienzo. Barcelona: El Serbal.

${ }^{331}$ CALVO, A., GARCÍA FERNÁNDEZ-VILLA, S., BAILÃO, A. (2018). Terminología básica de conservación y restauración del patrimonio cultural. Madrid: Universidad Complutense de Madrid. $<$ https://www.researchgate.net/publication/323613615_Terminologia_basica_de_conservacion_y_restaura cion_del_Patrimonio_Cultural> [Consulta: 12 marzo de 2019].

332 VIVANCOS RAMÓN, V. (2007). La conservación y restauración de la pintura de caballete. Pintura sobre tabla. Madrid: Tecnos.

333 VIVANCOS RAMÓN, V. y CASTELL AGUSTÍ, M. (2010). Problemas y tratamientos del soporte de pintura de caballete. Valencia: Universidad Politécnica de Valencia. 
TECNOLOGÍA DE LAS OBRAS PICTÓRICAS Y ESCULTÓRICAS: SISTEMA-TIPO DE LAS CAPAS CONSTITUTIVAS

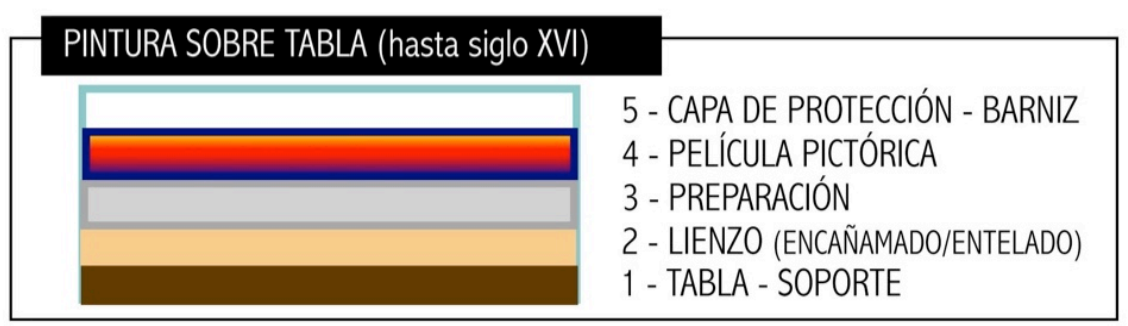

\section{PINTURA SOBRE LIENZO (desde siglo XVI)}

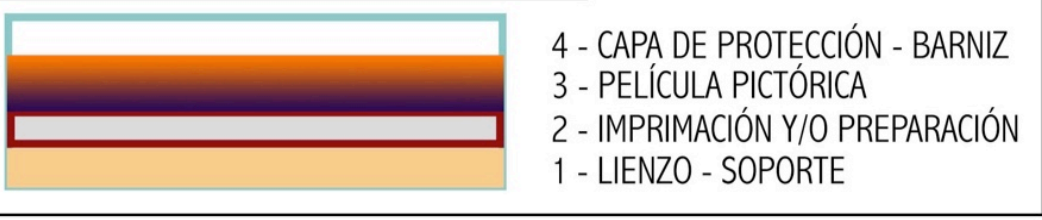

\section{ESCULTURA POLICROMADA (desde siglo XI)}

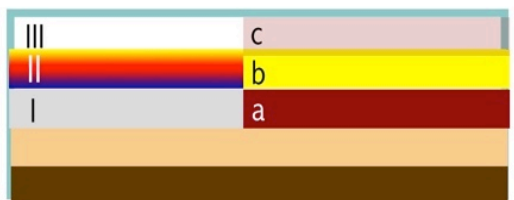

5 - BARNIZ(III)/CORLA(C)

4 - POLICROMÍA(II)/DORADO(b)

3 - PREPARACIÓN(I)/BOL(a)

2 - ENTELADO

1 - MADERA - SOPORTE

Imagen 115 - Representación del sistema constitutivo de las tipologías de obras examinadas en este estudio.

Un ejemplo de las variables consideradas para el diseño de las tablas de registro para los diferentes conjuntos se aprecia en la tabla 169. 
Tabla 169 - Comparativa entre la artículación y número de niveles y criterios que componen las tablas de registro propuestas para las diferentes clases de obras en examen.

\begin{tabular}{|l|c|c|}
\hline TIPOLOGÍA DE OBRAS & $\begin{array}{c}\text { CANTIDAD DE NIVELES EN LA } \\
\text { QUE SE DESGLOSA LA TABLA } \\
\text { DE REGISTRO }\end{array}$ & $\begin{array}{c}\text { TOTAL DE FENOMENOLOGÍAS DE } \\
\text { ALTERACIÓN Y DETERIORO DE } \\
\text { LA TABLA }\end{array}$ \\
\hline $\begin{array}{l}\text { PINTURA MURAL } \\
\text { RECUBRIMIENTOS } \\
\text { ARQUITECTÓNICOS }\end{array}$ & 2 & 29 \\
\hline $\begin{array}{l}\text { ESCULTURAS EN MATERIAL } \\
\text { PÉTREO }\end{array}$ & 3 & 56 \\
\hline $\begin{array}{l}\text { PINTURA DE CABALLETE } \\
\text { ESCULTURA EN MADERA } \\
\text { POLICROMADA }\end{array}$ & 3 & 115 \\
\hline
\end{tabular}

Esta comparativa ha puesto en evidencia el gran valor de las acciones canalizadas hacia la unificación de la terminología específica para las diferentes clases de patrimonio cuya existencia, para los fines de este estudio, ha constituido un válido instrumento organizativo en las fases de diseño del método. Lo anterior representó una herramienta de simplificación de la ficha y de su estructura.

Sin embargo, en búsqueda de una mayor facilidad en la fase de observación y recolección de la información, el diseño de la matriz de datos para pinturas de caballete y esculturas policromadas generó una tabla caracterizada por una gran articulación de criterios y complejidad. La voluntad de abarcar la pluralidad de fenómenos que pueden afectar a esta clase de obras influyó en la cantidad de información seleccionada para la construcción de la ficha de registro y la información arrojada tras el análisis.

Es importante destacar que, análogamente a los ejemplos citados, las pinturas murales se constituyen por un sistema de estratos. Dichos elementos pueden presentar diferente naturaleza y grosor, con la peculiaridad de estar vinculados a un soporte fijo de tipo arquitectónico. Esta conformación, determinó la organización y clasificación de los parámetros propuestos por Mora y Philippot en su "Ficha técnica para la relación de los análisis y de las operaciones de una pintura mural" ${ }^{\prime 334}$. En ella, los criterios a evaluar durante las fases de inspección están estructurados en tres niveles, componiéndose por una totalidad de 85 aspectos a clasificar ordenados en siete grupos, incluyendo datos históricos, técnicos y propuestas de tratamientos. Las

334 MORA, P., MORA, L. y PHILIPPOT, P (1999). La conservazione delle pitture murali. Milano: Compositori, pp. 361-363. 
informaciones estructuradas de acuerdo a estos puntos, están dirigidas a profundizar de forma exhaustiva el estado de una obra y a diferencia del método propuesto en este estudio contemplan un despliegue de recursos mayor (tabla 170).

Tabla 170 - Datos comparativos de la ficha propuesta por Mora y Philippot y la tabla de criterios unificados propuesta en esta investigación. Se aprecian las diferencias de articulación, criterios a considerar, costes y precisión de la información arrojada.

\begin{tabular}{|c|c|c|c|c|}
\hline TIPOLOGÍA DE FICHA & $\begin{array}{l}\text { No DE NIVELES EN } \\
\text { LA QUE SE } \\
\text { ESTRUCTURA }\end{array}$ & $\begin{array}{l}\text { No DE CRITERIOS A } \\
\text { CONSIDERAR }\end{array}$ & COSTES $^{335}$ & PRECISIÓN ${ }^{336}$ \\
\hline $\begin{array}{l}\text { FICHA TÉCNICA PARA LA } \\
\text { RELACIÓN DE LOS ANÁLISIS } \\
\text { Y DE LAS OPERACIONES DE } \\
\text { UNA PINTURA MURAL }\end{array}$ & 3 & 85 & $\begin{array}{l}\text { MEDIANOS } \\
\text { ELEVADOS }\end{array}$ & $\begin{array}{l}\text { MEDIANA } \\
\text { ELEVADA }\end{array}$ \\
\hline $\begin{array}{l}\text { TABLA DE REGISTRO } \\
\text { UNIFICADA PARA PINTURA } \\
\text { MURALY } \\
\text { RECUBRIMIENTOS } \\
\text { ARQUITECTÓNICOS }\end{array}$ & 2 & 29 & BAJOS & MEDIANA \\
\hline
\end{tabular}

De acuerdo a lo expuesto, cabe destacar que la creación de una ficha simplificada de la pluralidad de criterios reunidos en los puntos propuestos por Mora y Philippot ha respondido a las exigencias de simplificación y rapidez de las fases de estudio preliminares establecidas como propósito de esta investigación. Esto justifica el diferente despliegue de medios técnicos y profesionales necesarios a su implementación lo cual, indudablemente, influye en la precisión y profundización de los estudios.

\subsection{Aplicación del método y análisis de datos}

Las tablas de registro unificadas ${ }^{337}$ se aplicaron a unas experiencias piloto con la finalidad de evaluar ventajas, limitaciones y posibles mejoras en su implementación. La conformación de los sistemas de obras de arte escogidos y el contexto en el que se conservan, ofrecieron un medio útil para analizar los procesos de toma de datos

\footnotetext{
335 Clasificación de costes propuesta por GETTY CONSERVATION INSTITUTE (2007). Guiding Principles Recording, Documentation and Information Management for Conservation of Heritage Places.

336 Ibídem. Clasificación del nivel de precisión de la información propuesta por Getty Conservation Institute (2007).

${ }^{337}$ Para las fichas empleadas en las experiencias-piloto véase el homónimo apartado.
} 
en términos de inversión de recursos y evaluar la calidad de la información arrojada. De acuerdo a la meta propuesta por el método, se buscó brindar un enfoque general del estado de las diferentes colecciones, a partir del registro de la incidencia de los efectos de los procesos de alteración y deterioro en los materiales.

Como casos de estudio se seleccionaron unos conjuntos patrimoniales del estado de San Luis Potosí (México) pertenecientes a las categorías que se exponen a continuación:

- Pinturas murales y recubrimientos arquitectónicos: murales del siglo XX del estado.

- Pinturas de caballete y escultura policromada: colección del Museo de Arte Sacro de Real de Guadalcázar.

- Esculturas en materiales pétreos: monumentos funerarios del Panteón Municipal del Saucito.

En estas experiencias, se llevaron a cabo las siguientes actividades:

- registro de las fenomenologías de alteración y deterioro;

- registro fotográfico;

- análisis de los datos;

- generación de informes de diagnóstico e indicadores de riesgo.

Tras la implementación de la herramienta de acercamiento a las problemáticas conservativas propuestas, se delimitaron las ventajas y limitaciones encontradas. Éstas se analizaron de acuerdo a los criterios propuestos en el planteamiento de la investigación:

- Viabilidad de uso de acuerdo a los recursos necesarios para su aplicación (temporales, humanos, económicos y técnicos);

- Practicidad del método en función de la accesibilidad y claridad de las informaciones requeridas para su uso;

- Efectividad y representatividad de la información obtenida, evaluando la calidad de los resultados en relación a los medios necesarios a su implementación.

Entre las modalidades de cumplimentación de las fichas propuestas, se contemplaron:

- Modalidad de cumplimentación in situ; 
- Modalidad de cumplimentación virtual, sobre documentación fotográfica.

Además de la forma de registro de la información presencial, se exploró la posibilidad de llevar a cabo la actividad sobre documentación fotográfica. Esta forma de recolección de datos se reveló una opción interesante, respondiendo a las casuísticas de posibilidades presentes en el cumplimiento de las tareas de conservación y monitoreo de las obras en el territorio. Dicho aspecto toma en consideración circunstancias extraordinarias, como acontece en ocasión de los seísmos, en donde el personal no puede extender el tiempo dedicado a las tareas de documentación inherentes al estado de conservación del patrimonio en el sitio, sea por falta de seguridad del inmueble, sea por la limitación de los medios disponibles. En este caso, tener la posibilidad de documentar fotográficamente las obras, mientras se procede a su resguardo físico, ejecutando el diagnóstico en un segundo momento, podría representar un recurso de gran valía ${ }^{338}$. Este aspecto, que supone una ventaja en las circunstancias mencionadas, se pone en evidencia tomando en cuenta que las condiciones óptimas para el registro y observación de las condiciones conservativas de una obra de arte, requieren del contacto visual directo.

La posibilidad de acoplar el método de registro ofrecido en este estudio con sistemas virtuales de documentación fotográfica podría representar una vertiente útil para la gestión del patrimonio cultural en situaciones que contemplan el uso de sistemas remotos de monitoreo, inspección y registro tal como el uso de drones.

\subsection{Análisis de ventajas y limitaciones}

El registro de las condiciones conservativas de los grupos de obras examinados se realizó en primera instancia empleando la modalidad de cumplimentación de datos de presencia/ausencia (1/0), en donde se registraban solamente los fenómenos presentes en las obras (tabla 171) con la inversión de tiempo indicada en la tabla 172.

\footnotetext{
${ }^{338}$ Esta reflexión surgió gracias a las experiencias maduradas en ocasión de los terremotos de L'Aquila (2009 Italia) y Puebla (2017, México).
} 
Tabla 171 - Ejemplo del llenado de la matriz de datos por medio de la estimación de presencia (1) o ausencia (0) propuesto en la primera versión del método.

\begin{tabular}{|l|c|c|c|}
\hline ESPECIES & \multicolumn{3}{|c|}{ MUESTRAS } \\
\hline $\begin{array}{l}\text { FENOMENOLOGÍA DE ALTERACIÓN } \\
\text { Y DETERIORO }\end{array}$ & MUESTRA 1 & MUESTRA 2 & $1 / 0$ \\
\hline Fenomenología de deterioro A & $1 / 0$ & $1 / 0$ & $1 / 0$ \\
\hline Fenomenología de deterioro B & $1 / 0$ & $1 / 0$ & $1 / 0$ \\
\hline
\end{tabular}

Tabla 172 - Modalidades de registro y análisis. Experiencias-piloto.

\begin{tabular}{|c|c|c|c|c|}
\hline $\begin{array}{l}\text { CASOS } \\
\text { ESTUDIO }\end{array}$ & $\begin{array}{l}\text { No DE OBRAS } \\
\text { REGISTRADAS }\end{array}$ & $\begin{array}{l}\text { RECOLECCIÓN DE DATOS } \\
\text { (TIEMPO/MODALIDAD) }\end{array}$ & $\begin{array}{l}\text { ANÁLISIS DE LA } \\
\text { INFORMACIÓN } \\
\text { (TIEMPO) }\end{array}$ & $\begin{array}{l}\text { PROFESIONALES } \\
\text { EMPLEADOS } \\
\text { (REGISTRO) }\end{array}$ \\
\hline $\begin{array}{l}\text { Murales del } \\
\text { siglo XX }\end{array}$ & 21 & $\begin{array}{l}2 \mathrm{~h} / \text { sobre documentación } \\
\text { fotográfica }\end{array}$ & $1 \mathrm{~h}$ & 1 \\
\hline $\begin{array}{l}\text { Panteón } \\
\text { Municipal }\end{array}$ & 63 & $2 \mathrm{~h} /$ presencial & $1 \mathrm{~h}$ & 2 \\
\hline $\begin{array}{l}\text { Museo de Arte } \\
\text { Sacro }\end{array}$ & 34 & $2 \mathrm{~h} /$ presencial & $1 \mathrm{~h}$ & 2 \\
\hline TOTAL & 118 & $6 \mathrm{~h}$ & $3 \mathrm{~h}$ & 5 \\
\hline
\end{tabular}

Para cada caso de estudio se obtuvo la información inherente a:

- panorámicas de las alteraciones y deterioros presentes;

- gráficas representativas de los fenómenos registrados;

- indicador de riesgo y prioridad estimado sobre la base de la incidencia cuantitativa de las fenomenologías de alteración y deterioro, calculada a partir de su presencia o ausencia (1/0); 
- croquis con la representación de las áreas/obras según su índice de riesgo;

- identificación de la obra con mayor índice de riesgo y prioridad;

- determinación de las problemáticas específicas activas de cada elemento del conjunto.

De la primera implementación del método sobre la producción muralista del siglo $X X$, se pudo obtener un análisis de datos según dos niveles de información: fuentes de deterioro (1) y fenomenologías (2), sin poder abarcar una correlación entre estos factores, aunque las informaciones pudieron brindar los supuestos básicos para generar una escala de riesgo sustentada en las incidencias de las presencias de los fenómenos.

En la aplicación de la ficha de registro diseñada para la colección del Museo de Arte Sacro, se corroboró que la estructuración teórica del método y el orden de registro de los datos, que procedía del soporte hacia las capas superficiales, generaron un retraso en el reconocimiento de los mismos. Lo anterior se justificó por la influencia ejercida por la dinámica de la visión, que permite observar con mayor claridad las capas exteriores.

En el estudio sobre los monumentos fúnebres del Panteón municipal del Saucito, este aspecto ha sido tomado en cuenta, ordenando los fenómenos a registrar según su tamaño, entendido como su facilidad de apreciación visual, y logrando una mayor efectividad en conducir la observación empezando por los datos macroscópicos y generales, como un primer acercamiento a la obra, y luego registrando los datos que requieren una visión más detallada.

Un ejemplo útil al entendimiento de la ordenación mencionada se aprecia en la tabla 173.

Tabla 173 - Porción de tabla unificada perteneciente a los materiales pétreos. En ella se aprecia la voluntad de ordenación de los conceptos de lo general a lo específico (de izquierda hacia derecha) y de mayor visibilidad hacia el detalle (de arriba hacia abajo).

\begin{tabular}{|l|l|l|}
\hline ESPECIE & SUBESPECIE & CARACTERÍSTICAS \\
\hline \multirow{4}{*}{ Separación } & \multirow{4}{*}{ Disgregación } & Desmoronamiento \\
& & Granular \\
& & Pulverulencia \\
& & Arenización \\
& & Sugaring \\
\hline
\end{tabular}


Estos aspectos se incluyeron en las mejoras del método, cuyo propósito fue ofrecer un perfeccionamiento en la dinámica de observación y registro de los fenómenos, junto a un apoyo en la identificación de los factores responsables de la pérdida paulatina del patrimonio cultural. Ya que cada fenómeno es indicativo de determinados parámetros conservativos del lugar de resguardo, lo que podemos definir como su historial microclimático ${ }^{339}$, su presencia determina la existencia de los factores responsables del desarrollo de reacciones y cambios en los materiales, en donde los efectos visibles responden a pautas específicas, e identificativas de sus causas.

Tras cada experiencia, en pos de un perfeccionamiento del método, se determinaron las ventajas y limitaciones encontradas de acuerdo a los criterios mencionados anteriormente: viabilidad, practicidad, efectividad de uso y representatividad de las informaciones.

Entre las ventajas:

- La existencia de glosarios ilustrados con terminología unificada para pintura mural, recubrimientos arquitectónicos y materiales pétreos ha facilitado la estructuración de la matriz de datos así como la interpretación de resultados.

- Los tiempos y recursos necesarios para el registro se han revelado idóneos a los parámetros de efectividad, velocidad y personal necesario propuestos en los objetivos del estudio, siendo posible abarcar el diagnóstico de un total de 118 obras. Esto se realizó dedicando 6 horas totales a la recolección de los datos, con el empleo de 5 profesionales de la conservación. El análisis de la información se realizó en 3 horas (tabla 172).

- Los recursos técnicos necesarios a la aplicación del método han sido mínimos; para el registro: cámara fotográfica, fichas de registro (en físico o digital). Para el análisis de la información: ordenador con hojas de cálculo Excel $^{\oplus}$.

- Los resultados arrojados se consideran representativos de las reales condiciones conservativas a las que se exponen las obras, ya que de acuerdo a la interpretación de resultados propuesta, coinciden con el estado y parámetros del contexto en el que se custodian.

339 En este contexto se entiende como historial microclimático el conjunto histórico de condiciones conservativas a las que el bien cultural, o colección, ha sido expuestos. Éste se caracteriza por las peculiaridades propias del entorno medioambiental, resultante de la interacción combinada entre clima y condiciones del inmueble, incidencia de los factores externos, exposición a la intemperie y acciones de origen antrópica. 
Las limitaciones encontradas en esta primera versión del método se debieron principalmente a la organización de la información en la tabla de registro, de acuerdo a los criterios que se exponen a continuación:

- Para la tabla de pinturas murales y recubrimientos arquitectónicos, la estructuración de los conceptos, con la presencia de fuentes (causas) y fenomenologías de deterioro (efectos) en la misma matriz de datos, se reveló poco funcional al análisis, ocasionando una reiteración de conceptos en los resultados del estudio sobre la incidencia de los fenómenos.

- La falta de glosarios unificados con terminologías específicas de las alteraciones y deterioros para pintura de caballete y escultura policromada ha representado un reto para la selección de términos y su estructuración en las tablas de datos.

- En el caso de las fichas para pinturas de caballete y escultura en madera policromada, la ordenación de los conceptos en la matriz de datos se reveló limitativo en términos de observación y registro. Lo anterior debido a que la tabla se estructuró desde el soporte hacia las capas superficiales, poniendo de manifiesto cómo el orden de observación influye en los tiempos requeridos para el reconocimiento de los fenómenos.

- En la calidad de la información arrojada, destacó la necesidad de acompañar los resultados con una estimación de la gravedad de las alteraciones registradas.

Conforme a estas reflexiones, se establecieron los siguientes márgenes de mejora:

- Eliminación del registro y observación de las voces correspondientes a las fuentes de alteración y deterioro; éstas generaban una interferencia, ejercida por el proceso cognitivo de la observación, en donde el reconocimiento de los fenómenos se relacionaba con la voluntad de interpretación de los mismos ${ }^{340}$.

- Implementación de una ficha de registro focalizada únicamente en la morfología específica de alteración y deterioro.

\footnotetext{
340 Eliminar las voces y terminologías relacionadas con la interpretación de los fenómenos encuentra su fundamento en la capacidad que estos poseen de generar una interferencia derivada de la experiencia y formación del profesional. La voluntad de registrar las causas de las fenomenologías presentes acarreaba una mayor inversión de tiempo para la resolución de la inspección visual y, finalmente, del registro de las condiciones de la colección.
} 
- Diseño de un método complementario para la estimación aproximada de la extensión superficial de los fenómenos de alteración y deterioro presentes.

- Estructuración de los conceptos en la tabla acordes a su accesibilidad visual: desde las capas más externas hasta el soporte.

\subsection{Mejora del método}

De acuerdo a los resultados arrojados por la primera versión del método, se implementaron las mejoras citadas, diseñando unas fichas acordes a los nuevos criterios $^{341}$.

En primera instancia se modificó el modelo de datos a registrar, empleando la modalidad de cumplimentación de datos en términos de abundancia con el uso de referentes numéricos entre 1-4 correspondientes a una evaluación general de la extensión de los fenómenos (tabla 174).

Tabla 174 - Ejemplo del llenado de la matriz de datos por medio de la estimación de abundancia (1-4) propuesto en la versión mejorada del método.

\begin{tabular}{|l|c|c|c|}
\hline \multicolumn{1}{|l|}{ ESPECIES } & \multicolumn{3}{|c|}{ MUESTRAS } \\
\hline $\begin{array}{l}\text { FENOMENOLOGÍA DE } \\
\text { ALTERACIÓN Y DETERIORO }\end{array}$ & MUESTRA 1 & MUESTRA 2 & MUESTRA 3 \\
\hline Fenomenología de deterioro A & $1-4$ & $1-4$ & $1-4$ \\
\hline Fenomenología de deterioro B & $1-4$ & $1-4$ & $1-4$ \\
\hline Fenomenología de deterioro C & $1-4$ & $1-4$ & $1-4$ \\
\hline
\end{tabular}

Lo anterior, se impulsó en vista de la creación de una herramienta cuyo uso fuera sencillo y rápido, brindando el mayor alcance posible en términos de deducciones sobre el estado de conservación de las obras. Por ello, los referentes paramétricos escogidos para delimitar la gravedad de un deterioro se establecieron de acuerdo a evaluaciones aproximadas de su amplitud, proponiendo el uso de una escala numérica de 1 a 4, en dónde:

- 1, corresponde a una difusión del deterioro entre el 0-25\% de la superficie;

\footnotetext{
${ }^{341}$ Para las fichas definitivas véase el apartado "Mejora del método".
} 
- 2 , corresponde a una difusión del deterioro entre el 25-50\% de la superficie;

- 3, corresponde a una difusión del deterioro entre el 50-75\% de la superficie;

- 4, corresponde a una difusión del deterioro entre el $75-100 \%$ de la superficie;

De acuerdo al uso de los parámetros sugeridos para la evaluación de la gravedad de las alteraciones y deterioros presentes, es importante precisar que ésta se ha estimado a lo largo de la investigación según dos vertientes, las cuales corresponden a la tipología de matriz de datos empleada para el registro:

a. gravedad según la incidencia cuantitativa de los fenómenos (matriz de presencia/ausencia).

b. Gravedad según la extensión superficial visible de los fenómenos (matriz de abundancia).

Por lo tanto, el índice de gravedad es indicativo respectivamente de la presencia (a) o de la extensión del área afectada nivel estético-visual (b) por determinados fenómenos. Lo que corresponde a las evaluaciones de tipo estructural del estado de un bien cultural se reserva para consideraciones específicas posteriores al uso de la herramienta propuesta en este estudio.

Éstas se utilizaron con nuevos conjuntos de estudio, con la finalidad de examinar su viabilidad aplicativa y la calidad de la información obtenida ${ }^{342}$. Las modalidades de registro de las condiciones conservativas, junto a los recursos y tiempos necesarios, relacionados con el tamaño de muestra abarcado, se exponen en la tabla 175.

\footnotetext{
${ }^{342}$ En esta fase, se presentan los resultados derivados de las experiencias llevadas a cabo de forma directa. Se involucraron otros profesionales del sector, con el objetivo de brindar la posibilidad de aplicar la herramienta a otros contextos y realidades de estudio. Gracias a esta colaboración, se obtuvo una evaluación y retroalimentación sobre uso del método que se especifican a continuación.
} 
Tabla 175 - Modalidades de registro y análisis. Implementación del método.

\begin{tabular}{|c|c|c|c|c|}
\hline CASOS DE ESTUDIO & $\begin{array}{l}\text { № DE OBRAS } \\
\text { REGISTRADAS }\end{array}$ & $\begin{array}{l}\text { RECOLECCIÓN DE DATOS } \\
\text { (TIEMPO/MODALIDAD) }\end{array}$ & $\begin{array}{l}\text { ANÁLISIS DE LA } \\
\text { INFORMACIÓN } \\
\text { (TIEMPO) }\end{array}$ & $\begin{array}{l}\text { PROFESIONALES } \\
\text { EMPLEADOS } \\
\text { (REGISTRO) }\end{array}$ \\
\hline $\begin{array}{ll}\text { Pinturas } & \\
\text { decorativas } & \text { ex } \\
\text { hacienda } & \text { de } \\
\text { Peotillos } & \end{array}$ & 14 áreas $^{343}$ & $\begin{array}{c}2 \mathrm{~h} / \text { sobre } \\
\text { documentación } \\
\text { fotográfica }\end{array}$ & $1 \mathrm{~h}$ & 1 \\
\hline $\begin{array}{l}\text { Conjunto de } \\
\text { obras del Templo } \\
\text { de San Martín de } \\
\text { Tours }\end{array}$ & $27^{344}$ & $\begin{array}{l}2 \mathrm{~h} / \text { sobre } \\
\text { documentación } \\
\text { fotográfica }\end{array}$ & $2 \mathrm{~h}$ & 1 \\
\hline $\begin{array}{l}\text { Elementos } \\
\text { escultóricos y } \\
\text { decorativos de las } \\
\text { fachadas barrocas }\end{array}$ & $38^{345}$ & $\begin{array}{l}2.25 \mathrm{~h} / \text { sobre } \\
\text { documentación } \\
\text { fotográfica }\end{array}$ & $2.25 \mathrm{~h}$ & 1 \\
\hline TOTAL & 79 & $6.25 \mathrm{~h}$ & $5.25 \mathrm{~h}$ & 3 \\
\hline
\end{tabular}

Tras el análisis de la información, ha sido posible identificar:

- fenomenologías de alteración y deterioro activas junto a su estimación cuantitativa (cantidad de deterioros presentes) y porcentual (relación de los deterioros con la totalidad de obras examinadas);

- incidencia de las alteraciones y deterioro desglosada según las capas constitutivas del sistema, para pintura de caballete y escultura policromada;

- indicador de riesgo de los conjuntos patrimoniales;

343 Las áreas mencionadas se estructuran a lo largo de un perímetro compuesto por cuatro paredes principales. Éstas, constituyen el marco del patio central en el que se ubican las decoraciones y poseen una extensión superficial aproximada de $40 \mathrm{~m} \times 5 \mathrm{~m}^{2}$ cada una, vanos incluidos.

${ }^{344}$ De las cuales, 19 componentes del Retablo de la Virgen de la Luz, 4 esculturas en madera policromada y 4 pinturas al óleo sobre lienzo. Para sus características véase el apartado dedicado al Templo de San Martín de Tours (Huaquechula, Puebla)

345 De las cuales, 3 esculturas de la Capilla de Nuestra Señora de Loreto, 13 esculturas de la Catedral Metropolitana, 12 esculturas del templo de Nuestra Señora del Carmen, 6 esculturas del Templo de San Francisco y 4 esculturas del templo de San Miguelito, todas ubicadas en las fachadas del centro histórico de San Luis Potosí. Para sus características véase el apartado dedicado a las fachadas de los Templos del centro histórico de San Luis Potosí". 
- croquis del indicador de riesgo y prioridad;

- obra con mayor indicador de riesgo y prioridad;

- alteraciones y deterioros presentes en cada obra/área complementadas por una estimación porcentual de la superficie afectada por cada fenómeno;

En la versión mejorada del sistema, la fase de recolección de la información se estructuró conforme a una evaluación de la extensión de los fenómenos de alteración y deterioro, permitiendo profundizar la información obtenida tras el análisis, sin por ello modificar de forma significativa los tiempos necesarios para la recolección y análisis de los datos (tablas 176 y 177).

Tabla 176 - Estimación de tiempos para la recolección de datos.

\begin{tabular}{|l|l|l|}
\hline TIEMPO & MÉTODO-PILOTO & MÉTODO MEJORADO \\
\hline Recolección de datos & 6 horas/118 & 6.25 horas/79 obras \\
\hline Promedio/obra & 3.1 minutos/obra & 4.7 minutos/obra \\
\hline
\end{tabular}

Tabla 177 - Estimación de tiempos para el análisis de datos.

\begin{tabular}{|l|l|l|}
\hline TIEMPO & MÉTODO-PILOTO & MÉTODO MEJORADO \\
\hline Análisis de datos & 3 horas/118 & 5.25 horas/79 obras \\
\hline Promedio/obra & 1.5 minutos/obra & 4 minutos/obra \\
\hline
\end{tabular}

\subsection{Análisis de la información}

El análisis de la información recaudada se llevó a cabo por medio de unas hojas de cálculo Excel $^{\oplus}$ dotadas de las fórmulas matemáticas necesarias para la rápida elaboración de los valores numéricos. Éstos, inherentes a los datos recolectados en términos de presencia/ausencia (1/0) y abundancia (1-4) (tablas 178 y 179), una vez analizados generarán los indicadores necesarios para la estimación de los indicadores de riesgo y prioridad de la colección.

Los resultados arrojados indicaron, de acuerdo al eje consultado, las informaciones que se presentan a continuación:

- el resultado de la suma de valores del eje horizontal arrojó la puntuación específica de la incidencia (matriz de presencia/ausencia) o de extensión (matriz de abundancia) de una determinada fenomenología de alteración y 
deterioro; a mayor puntuación correspondió una mayor presencia y/o extensión del fenómeno.

- el resultado de la suma de valores de los ejes verticales proporcionan indicadores específicos de cada muestra de estudio. A mayor puntuación correspondió una mayor inestabilidad de la obra en términos de conservación e integridad de sus materiales constitutivos.

La información obtenida puede ser leída según diferentes niveles, globales y específicos. La estructura de la matriz de recolección de datos y la sucesiva elaboración de los valores, permitieron generar indicadores de:

- estado general de la colección;

- evaluación específica de las problemáticas presentes en cada elemento del grupo de obras.

Tabla 178 - Matriz de datos adaptada a la hoja de cálculo Excel ${ }^{\oplus}$ y dotada de las fórmulas matemáticas útiles a una rápida elaboración de los datos insertados. Caso de estudio de las pinturas murales de la ex-hacienda de Peotillos (Villa Hidalgo, San Luis Potosí), matriz de presencia/ausencia (1/0).

\begin{tabular}{|c|c|c|c|c|c|c|c|c|c|c|c|c|c|c|c|}
\hline ESPECIFICACIONES & м1 & M2 & мз & M4 & M5 & M6 & M7 & м8 & м9 & M10 & M11 & M12 & M13 & M14 & Ттт. \\
\hline Morfologías inducidas por pérdidas - Laguna & 1 & 1 & 1 & 1 & 1 & 1 & 1 & 1 & 1 & 1 & 1 & 1 & 1 & 1 & 14 \\
\hline Morfologías inducidas por pérdidas - Oquedad & 1 & & & & & & & & & & 1 & & & & 2 \\
\hline Morfologías inducidas por pérdidas - Disgregación & 1 & 1 & 1 & 1 & 1 & 1 & 1 & 1 & 1 & 1 & 1 & 1 & 1 & 1 & 14 \\
\hline Morfologías inducidas por pérdidas - Abrasión & 1 & 1 & 1 & 1 & 1 & 1 & 1 & 1 & 1 & 1 & 1 & 1 & 1 & 1 & 14 \\
\hline Morfologías inducidas por pérdidas - Corrosión & & & & & & & & & & & & & & & 0 \\
\hline Morfologías inducidas por pérdidas - Delaminación & & & & & & & & & & & & & & & \\
\hline Morfologías inducidas por pérdidas - Exfoliación & & & & & & & & & & & & & & & \\
\hline Morfologías inducidas por pérdidas - Descamación & & & & & & & & & & & & & & & \\
\hline Morfologías inducidas por pérdidas - Pulverización & & & & & & & & & & & & & & & \\
\hline Morfologías inducidas por pérdidas - Erosión eólica & & & & & & & & & & & & & & & 0 \\
\hline Fisuras y deformación - Craquelado & & & & & & & & & & & & & & & 0 \\
\hline Fisuras y deformación - Microfisura & & & & & & & & & & & & & & & 0 \\
\hline Fisuras y deformación - Grietas & 1 & 1 & 1 & 1 & & & 1 & & & & & & & & 5 \\
\hline Fisuras y deformación - Grietas estructurales & & 1 & 1 & & & & & & & & & & & & 2 \\
\hline Fisuras y deformación - Deformación & 1 & 1 & 1 & 1 & 1 & 1 & 1 & 1 & 1 & 1 & 1 & 1 & 1 & 1 & 14 \\
\hline
\end{tabular}




\begin{tabular}{|c|c|c|c|c|c|c|c|c|c|c|c|c|c|c|c|}
\hline Fisuras y deformación-Abolsamiento & 1 & 1 & 1 & 1 & 1 & 1 & 1 & 1 & 1 & 1 & 1 & 1 & 1 & 1 & 14 \\
\hline Alteración cromática y depósitos - Pátina & & & & & & & & & & & & & & & 0 \\
\hline Alteración cromática y depósitos - Velo blanquecino & & & 1 & 1 & & & & & & & & & & & 2 \\
\hline Alteración cromática y depósitos - Amarilleamiento & & & & & & 1 & 1 & 1 & & 1 & 1 & & & & 5 \\
\hline Alteración cromática y depósitos - Oscurecimiento & & 2 & & & & 1 & 1 & & & & & & & & 4 \\
\hline Alteración cromática y depósitos - Saturación de color & & & & & & & & & & & & & & & 0 \\
\hline Alteración cromática y depósitos - Blanqueamiento & & & & & & & 1 & & & & & & & & 1 \\
\hline Alteración cromática y depósitos - Decoloración & 1 & 1 & 1 & 1 & 1 & 1 & 1 & 1 & 1 & 1 & 1 & 1 & 1 & 1 & 14 \\
\hline Alteración cromática y depósitos - Alteración de pigmentos & & & & & & & & & & & & & & & \\
\hline Alteración cromática y depósitos - Eflorescencia salina & & & 1 & 1 & & & & & & & & & & & 2 \\
\hline Alteración cromática y depósitos - Repintes & & & 1 & & 1 & & & & & & & & & 1 & 3 \\
\hline Alteración cromática y depósitos - Depósitos & 1 & 1 & & & & & & & & & & & & & 2 \\
\hline Intervenciones externas - Intervenciones estructurales & 1 & 1 & 1 & 1 & 1 & & 1 & & & & & 1 & 1 & 1 & 9 \\
\hline Intervenciones externas - Modificaciones & & & 1 & & & & & & & & & & 1 & 1 & 3 \\
\hline TOTAL & 10 & 12 & 13 & 10 & 8 & 8 & 11 & 7 & 6 & 7 & 8 & 7 & 8 & 9 & 18 \\
\hline
\end{tabular}

Tabla 179 - Matriz de datos adaptada a la hoja de cálculo Excel ${ }^{\circledR}$ y dotada de las fórmulas matemáticas útiles a una rápida elaboración de los datos insertados. Caso de estudio de las pinturas murales de la ex-hacienda de Peotillos (Villa Hidalgo, San Luis Potosí), matriz de abundancia (1-4).

\begin{tabular}{|l|c|c|c|c|c|c|c|c|c|c|c|c|c|c|c|}
\hline ESPECIFICACIONES & M1 & M2 & M3 & M4 & M5 & M6 & M7 & M8 & M9 & M10 & M11 & M12 & M13 & M14 & тот. \\
\hline Morfologías inducidas por pérdidas - Laguna & $\mathbf{2}$ & $\mathbf{2}$ & $\mathbf{1}$ & $\mathbf{2}$ & $\mathbf{2}$ & $\mathbf{1}$ & $\mathbf{1}$ & $\mathbf{1}$ & $\mathbf{1}$ & $\mathbf{1}$ & $\mathbf{1}$ & $\mathbf{1}$ & $\mathbf{1}$ & $\mathbf{1}$ & 18 \\
\hline Morfologías inducidas por pérdidas - Oquedad & $\mathbf{1}$ & & & & & & & & & & $\mathbf{1}$ & & & & 2 \\
\hline Morfologías inducidas por pérdidas - Disgregación & $\mathbf{2}$ & $\mathbf{2}$ & $\mathbf{1}$ & $\mathbf{2}$ & $\mathbf{2}$ & $\mathbf{1}$ & $\mathbf{2}$ & $\mathbf{2}$ & $\mathbf{2}$ & $\mathbf{1}$ & $\mathbf{1}$ & $\mathbf{1}$ & $\mathbf{1}$ & $\mathbf{1}$ & $\mathbf{2 1}$ \\
\hline Morfologías inducidas por pérdidas - Abrasión & $\mathbf{2}$ & $\mathbf{2}$ & $\mathbf{1}$ & $\mathbf{1}$ & $\mathbf{1}$ & $\mathbf{1}$ & $\mathbf{1}$ & $\mathbf{1}$ & $\mathbf{1}$ & $\mathbf{1}$ & $\mathbf{1}$ & $\mathbf{1}$ & $\mathbf{1}$ & $\mathbf{1}$ & 16 \\
\hline Morfologías inducidas por pérdidas - Corrosión & & & & & & & & & & & & & & & 0 \\
\hline Morfologías inducidas por pérdidas - Delaminación & & & & & & & & & & & & & & & \\
\hline Morfologías inducidas por pérdidas - Exfoliación & & & & & & & & & & & & & & & \\
\hline Morfologías inducidas por pérdidas - Descamación & & & & & & & & & & & & & \\
\hline Morfologías inducidas por pérdidas - Pulverización & & & & & & & & & & & & & & & \\
\hline Morfologías inducidas por pérdidas - Erosión eólica & & & & & & & & & & & & & & 0 \\
\hline
\end{tabular}




\begin{tabular}{|c|c|c|c|c|c|c|c|c|c|c|c|c|c|c|c|}
\hline Fisuras y deformación - Craquelado & & & & & & & & & & & & & & & 0 \\
\hline Fisuras y deformación - Microfisura & & & & & & & & & & & & & & & 0 \\
\hline Fisuras y deformación - Grietas & 1 & 1 & 1 & 1 & & & 1 & & & & & & & & 5 \\
\hline Fisuras y deformación - Grietas estructurales & & 1 & 1 & & & & & & & & & & & & 2 \\
\hline Fisuras y deformación - Deformación & 2 & 2 & 2 & 2 & 2 & 1 & 1 & 1 & 1 & 1 & 1 & 1 & 1 & 1 & 19 \\
\hline Fisuras y deformación-Abolsamiento & 2 & 2 & 2 & 2 & 2 & 1 & 1 & 1 & 1 & 1 & 1 & 1 & 1 & 1 & 19 \\
\hline Alteración cromática y depósitos - Pátina & & & & & & & & & & & & & & & 0 \\
\hline Alteración cromática y depósitos - Velo blanquecino & & & 1 & 1 & & & & & & & & & & & 2 \\
\hline Alteración cromática y depósitos - Amarilleamiento & & & & & & 1 & 1 & 2 & & 1 & 1 & & & & 6 \\
\hline Alteración cromática y depósitos - Oscurecimiento & & 2 & & & & 1 & 1 & & & & & & & & 4 \\
\hline Alteración cromática y depósitos - Saturación de color & & & & & & & & & & & & & & & 0 \\
\hline Alteración cromática y depósitos - Blanqueamiento & & & & & & & 1 & & & & & & & & 1 \\
\hline Alteración cromática y depósitos - Decoloración & 1 & 1 & 1 & 3 & 2 & 1 & 1 & 1 & 1 & 1 & 1 & 1 & 1 & 1 & 17 \\
\hline Alteración cromática y depósitos - Alteración de pigmentos & & & & & & & & & & & & & & & 0 \\
\hline Alteración cromática y depósitos - Eflorescencia salina & & & 1 & 1 & & & & & & & & & & & 2 \\
\hline Alteración cromática y depósitos - Repintes & & & 4 & & 1 & & & & & & & & & 3 & 8 \\
\hline Alteración cromática y depósitos - Depósitos & 1 & 1 & & & & & & & & & & & & & 2 \\
\hline Intervenciones externas - Intervenciones estructurales & 1 & 1 & 4 & 1 & 1 & & 1 & & & & & 1 & 1 & 1 & 12 \\
\hline Intervenciones externas - Modificaciones & & & 4 & & & & & & & & & & 4 & 3 & 11 \\
\hline TOTAL & 15 & 17 & 24 & 16 & 13 & 8 & 12 & 9 & 7 & 7 & 8 & 7 & 11 & 13 & 18 \\
\hline
\end{tabular}

Llevando a cabo una comparativa entre los datos obtenidos tras el análisis y útiles para la generación de unos indicadores de deterioro, se puede observar ligeras variaciones entre la modalidad de presencia/ausencia (1/0) y de abundancia (1-4). Esto se debe a que las metodologías de registro de los datos iniciales aportan informaciones de diferente naturaleza.

En el primer caso (tabla 180), se asiste a la generación de un indicador de deterioro sustentado en la variedad de fenomenologías presentes. En el segundo (tabla 181), el elemento ordenador deriva de la extensión de las mismas. 
Tabla 180 - Escala de riesgo y prioridades derivada de la matriz de presencia/ausencia. Caso de estudio: ex hacienda de Peotillos (Villa Hidalgo, San Luis Potosí).

\begin{tabular}{|c|c|}
\hline MUESTRA & INCIDENCIA DE LAS FENOMENOLOGÍAS DE ALTERACIÓN Y DETERIORO \\
\hline M3 & 12 \\
\hline M2 & 11 \\
\hline M7 & 10 \\
\hline M1 & 10 \\
\hline M4 & 9 \\
\hline M14 & 8 \\
\hline M5 & 8 \\
\hline M6 & 8 \\
\hline M11 & 8 \\
\hline M13 & 7 \\
\hline M8 & 7 \\
\hline M10 & 7 \\
\hline M12 & 6 \\
\hline M9 & \\
\hline & \\
\hline
\end{tabular}

Tabla 181 - Escala de riesgo y prioridades derivada de la matriz de abundancia. Caso de estudio: ex hacienda de Peotillos (Villa Hidalgo, San Luis Potosí).

\begin{tabular}{|c|c|}
\hline MUESTRA & EXTENSIÓN DE LAS FENOMENOLOGÍAS DE ALTERACIÓN Y DETERIORO \\
\hline M3 & 24 \\
\hline M2 & 17 \\
\hline M4 & 16 \\
\hline M1 & 15 \\
\hline M5 & 13 \\
\hline M7 & 12 \\
\hline M13 & 11 \\
\hline M14 & 11 \\
\hline M8 & 9 \\
\hline M6 & 8 \\
\hline M11 & 8 \\
\hline M9 & 7 \\
\hline M10 & 7 \\
\hline M12 & 7 \\
\hline
\end{tabular}

Tras la elaboración de los datos, el método ofrece diferentes niveles de información. Por ejemplo, es posible generar un índice de los fenómenos presentes, 
cuya ordenación, varía en función de la cumplimentación de la matriz de recolección de datos empleado. En el caso de la modalidad de presencia/ausencia, se obtiene una ordenación de los fenómenos presentes en el caso de estudio analizado según su incidencia (tabla 182), mientras para el modelo de cumplimentación en términos de abundancia, se obtiene un indicador que indica el orden de las alteraciones y deterioros en términos de extensión superficial (tabla 183).

Tabla 182 - Indicador de presencia de alteraciones y deterioros derivada de la matriz de presencia/ausencia. Caso de estudio: ex hacienda de Peotillos (Villa Hidalgo, San Luis Potosí).

\begin{tabular}{|l|c|}
\hline PRESENCIA DE DETERIOROS & NÚMERO \\
\hline Morfologías inducidas por pérdidas - Laguna & 14 \\
\hline Morfologías inducidas por pérdidas - Disgregación & 14 \\
\hline Morfologías inducidas por pérdidas - Abrasión & 14 \\
\hline Fisuras y deformación - Deformación & 14 \\
\hline Fisuras y deformación - Abolsamiento & 14 \\
\hline Alteración cromática y depósitos - Decoloración & 14 \\
\hline Intervenciones externas - Intervenciones estructurales & 9 \\
\hline Alteración cromática y depósitos - Amarilleamiento & 6 \\
\hline Fisuras y deformación - Grietas & 5 \\
\hline Alteración cromática y depósitos - Oscurecimiento & 4 \\
\hline Alteración cromática y depósitos - Repintes & 3 \\
\hline Intervenciones externas - Modificaciones & 3 \\
\hline Morfologías inducidas por pérdidas - Oquedad & 2 \\
\hline Fisuras y deformación - Grietas estructurales & 2 \\
\hline Alteración cromática y depósitos - Velo blanquecino & 2 \\
\hline Alteración cromática y depósitos - Eflorescencia salina & 2 \\
\hline Alteración cromática y depósitos - Depósitos & 2 \\
\hline Alteración cromática y depósitos - Blanqueamiento & 1 \\
\hline
\end{tabular}

Tabla 183 - Indicador de extensión de las alteraciones y deterioros derivada de la matriz de abundancia. Caso de estudio: ex hacienda de Peotillos (Villa Hidalgo, San Luis Potosí).

\begin{tabular}{|l|c|}
\hline EXTENSIÓN DE DETERIOROS & NÚMERO \\
\hline Morfologías inducidas por pérdidas - Disgregación & 21 \\
\hline Fisuras y deformación - Deformación & 19 \\
\hline Fisuras y deformación - Abolsamiento & 19 \\
\hline
\end{tabular}




\begin{tabular}{|l|l|}
\hline Morfologías inducidas por pérdidas - Laguna & 18 \\
\hline Alteración cromática y depósitos - Decoloración & 17 \\
\hline Morfologías inducidas por pérdidas - Abrasión & 16 \\
\hline Intervenciones externas - Intervenciones estructurales & 12 \\
\hline Intervenciones externas - Modificaciones & 11 \\
\hline Alteración cromática y depósitos - Repintes & 8 \\
\hline Alteración cromática y depósitos - Amarilleamiento & 6 \\
\hline Fisuras y deformación - Grietas & 5 \\
\hline Alteración cromática y depósitos - Oscurecimiento & 4 \\
\hline Morfologías inducidas por pérdidas - Oquedad & 2 \\
\hline Fisuras y deformación - Grietas estructurales & 2 \\
\hline Alteración cromática y depósitos - Velo blanquecino & 2 \\
\hline Alteración cromática y depósitos - Eflorescencia salina & 2 \\
\hline Alteración cromática y depósitos - Depósitos & 2 \\
\hline Alteración cromática y depósitos - Blanqueamiento & 1 \\
\hline
\end{tabular}

Analizando los datos presentados en las tablas anteriores, es posible determinar que el conjunto de pinturas murales decorativas a las que se refiere el estudio presentan lagunas, disgregación, abrasión, deformación, abolsamientos y decoloración en 14/14 casos, es decir en el 100\% de las muestras estudiadas (tabla 182 y sucesivamente gráfica 30). En términos de extensión superficial, la fenomenología de alteración y deterioro más extendida corresponde a la disgregación (21), seguida por la deformación y abolsamientos (19), lagunas (17) etc. (tabla 183).

En esta comparativa, se logran apreciar las diferentes tipologías de información obtenidas por medio del método, en donde:

- La matriz de presencia/ausencia genera una panorámica sobre la variedad de fenómenos presentes en el conjunto de muestras;

- La matriz de abundancia permite identificar cuales de estos fenómenos han alcanzado una mayor extensión superficial.

Estos datos, sometidos al ojo experto de un conservador, ofrecen la oportunidad de llevar a cabo un barrido general del estado de la colección o del caso de estudio, además de permitir un acercamiento específico a cada obra/muestra de estudio. 
Las gráficas de barras con las estimaciones cuantitativas de las fenomenologías presentes han sido complementadas por la valoración porcentual de los efectos de alteración activos en las colecciones. Esto, con el propósito de ofrecer una valoración gráfica porcentual que permitiera acceder a los resultados globales de forma más inmediata y sencilla, abarcando una panorámica de la distribución de los problemas presentes en el conjunto (gráfica 30).

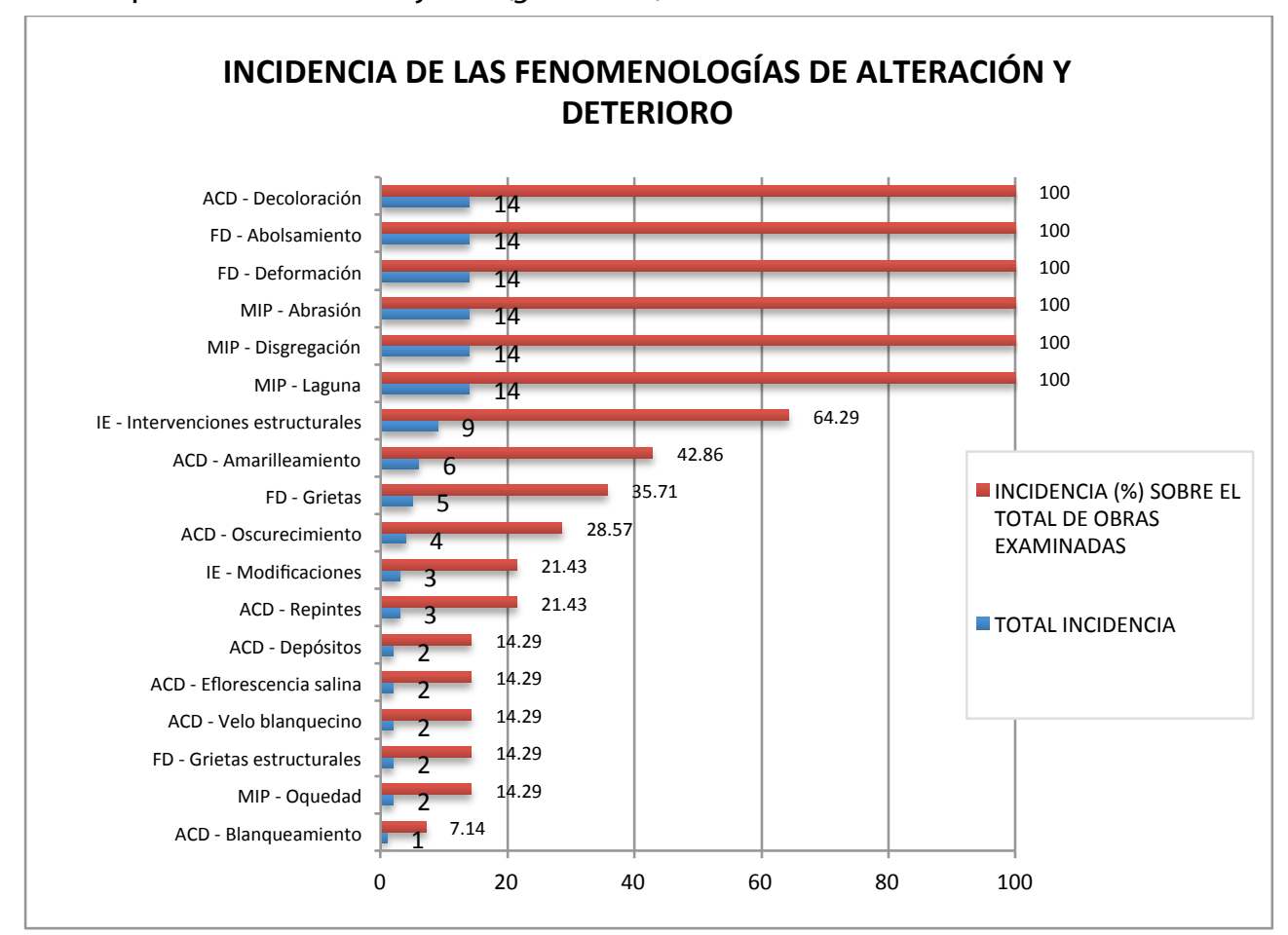

Gráfica 30 - Ejemplo de estimación cuantitativa y porcentual de las fenomenologías de alteración y deterioro. Pinturas decorativas de la ex hacienda de Peotillos (Villa Hidalgo, San Luis Potosí).

Las gráficas generadas tras el análisis de datos para pintura de caballete y escultura policromada aportan informaciones análogas a las presentadas anteriormente (gráfica 30), con la ventaja de poder apreciar una panorámica de las problemáticas desglosada por capas (gráfica 31).

Por medio de este soporte gráfico se logró representar el estado global del Retablo de la Virgen de la Luz (Huaquechula, Puebla) en donde, analizando los resultados arrojados, se logra apreciar parte de las limitaciones encontradas en las fichas creada para este tipo de obras. De acuerdo a lo que se expone a continuación: 
- El $84,5 \%(16 / 19)$ de los elementos presentan manchas en la película de protección. Paralelamente, sólo el 15.8\% presenta daños de tipo mecánico.

- El $100 \%$ (19/19) de los elementos presentan acumulación de polvo fino, levantamientos, desprendimientos y rayados a nivel de la película pictórica. Mientras tan sólo el 5.3\% (1/19) presenta solapamiento de la capa de policromía.

A nivel visual es objetivamente muy complicado poder separar e identificar la materialidad de la capa de protección y la de la película pictórica. Esto influyó en la precisión alcanzada por los resultados de la tabla de registro, cuya información está desvirtuada por la organización de los criterios de observación. Este aspecto ofrece un medio de reflexión interesante a partir del cual considerar modificaciones y mejoras futuras de la estructura profundizada en estas experiencias. 


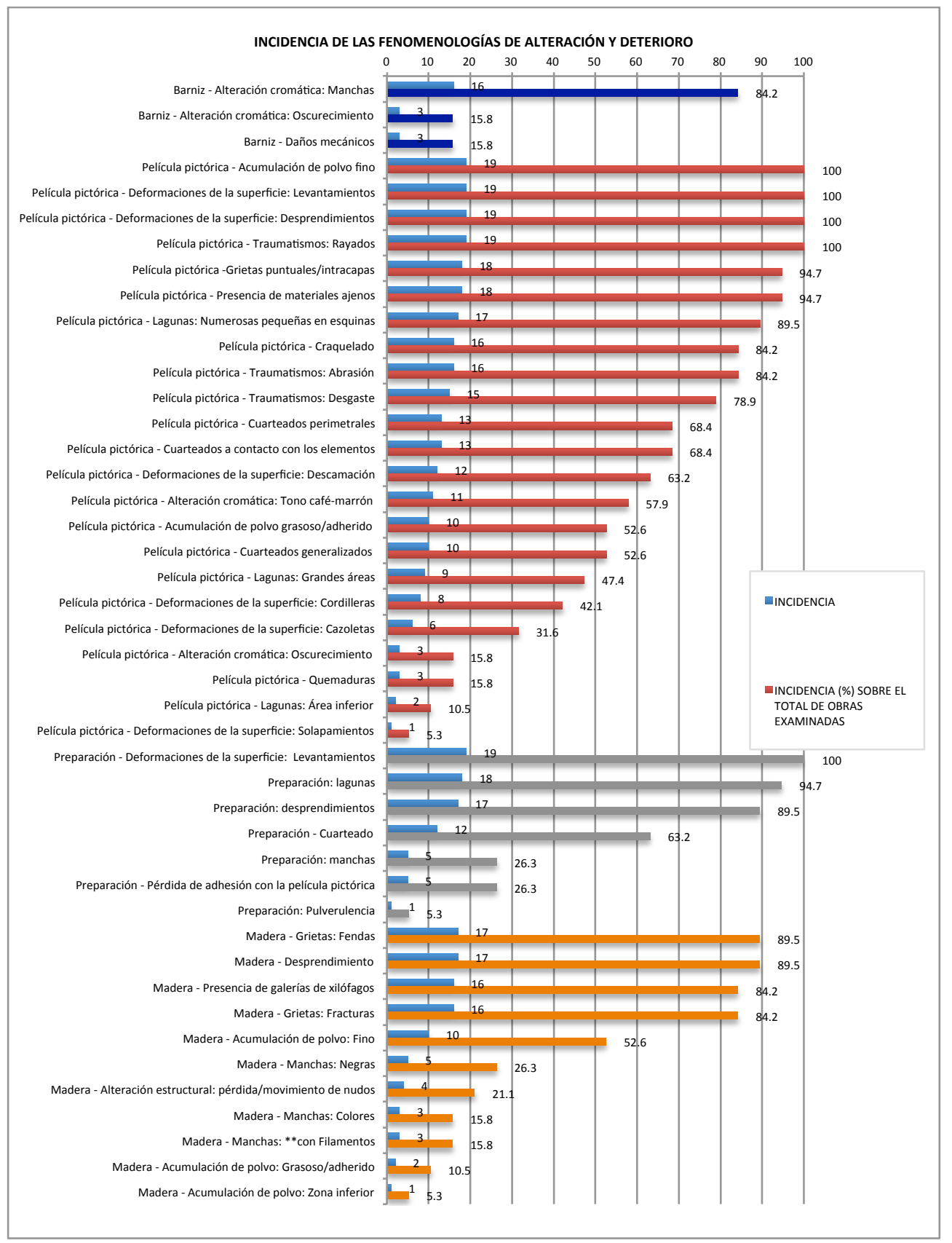

Gráfica 31 - Ejemplo de estimación cuantitativa y porcentual de las fenomenologías de alteración y deterioro. Retablo de la Virgen de la Luz (Huaquechula, Puebla). 
De acuerdo al análisis crítico de la estructura de la ficha de registro para pinturas y esculturas policromadas, cabe destacar que la organización acorde a las capas constitutivas de los sistemas tecnológicos más difusos permitió generar resultados específicos para cada estrato. Gracias a esta ordenación, fue posible obtener el desglose de la incidencia de las alteraciones y deterioro de forma específica para cada capa constitutiva del sistema (tabla 184), aunque los valores indicados no pueden ser comparados entre sí debido a que no hay una uniformidad inicial en el número de fenómenos a observar para cada capa.

Tabla 184 - Ejemplo de los resultados obtenidos gracias a la estructuración de la ficha de registro para pintura de caballete y escultura policromada. Conjunto de bienes rescatados del Templo de Huaquechula (Puebla).

\begin{tabular}{|c|c|c|c|c|c|c|c|c|c|}
\hline $\begin{array}{c}\text { ESTRATO DE } \\
\text { PERTENENCIA }\end{array}$ & M1 & M2 & M3 & M4 & M5 & M6 & M7 & M8 & TOTAL \\
\hline B & 2 & 3 & 5 & 2 & 4 & 0 & 2 & 1 & $\mathbf{1 9}$ \\
\hline PP & 20 & 22 & 19 & 13 & 8 & 9 & 16 & 13 & $\mathbf{1 2 0}$ \\
\hline Pr & 3 & 2 & 1 & 3 & 0 & 1 & 3 & 2 & $\mathbf{1 5}$ \\
\hline $\mathbf{L}$ & 0 & 2 & 18 & 9 & 12 & 8 & 0 & 1 & $\mathbf{5 0}$ \\
\hline $\mathbf{M}$ & 4 & 1 & 4 & 3 & 3 & 7 & 5 & 0 & $\mathbf{2 7}$ \\
\hline TOTAL & $\mathbf{2 9}$ & $\mathbf{3 0}$ & $\mathbf{4 7}$ & $\mathbf{3 0}$ & $\mathbf{2 7}$ & $\mathbf{2 5}$ & $\mathbf{2 6}$ & $\mathbf{1 7}$ & $\mathbf{2 3 1}$ \\
\hline
\end{tabular}

La mayor cantidad de información o valores inherentes un estrato específico de la obra es en parte el resultado de la pluralidad de criterios que fueron considerados para la construcción de las fichas. Este aspecto tiene que ser tomado en cuenta a la hora de interpretar los resultados del análisis y no puede considerarse indicativo de la mayor gravedad de afectación de un estrato frente a otro.

Es fundamental recordar que la organización de la ficha de registro por capas es una propuesta desarrollada a partir de una proyección ideal del sistema que compone una pintura o escultura. La naturaleza de una obra de este tipo está condicionada por muchas variables no solo tecnológicas, también históricas, como modificaciones o intervenciones anteriores. Éstas, caracterizan cada elemento por una singular combinación de capas, imprimaciones, veladuras, barnices, corlas que están íntimamente ligadas entre sí, a nivel técnico y visual. Lo anterior puede acarrear complicaciones a la hora de identificar, registrar e interpretar los datos, por lo cual es necesario someter la información obtenida a la atenta y escrupulosa evaluación por parte del profesional del sector. Dichos datos no pueden ser considerados absolutos, ya que representan un indicador del estado de conservación de las obras, a partir del cual generar acciones específicas de profundización y evaluación. 


\subsection{Generación de los indicadores de riesgo}

De acuerdo a la RAE, la definición de "indicador de riesgo" corresponde a un valor cuyo resultado es obtenido con un método de cálculo cuyo uso posee la finalidad de evaluar los riesgos de determinados elementos, factores 0 circunstancias. En este estudio, gracias a los diferentes modelos de matriz empleados, la información relativa a la determinación de los indicadores de riesgo obtenida respondió a dos modalidades.

La primera, resultante de la incidencia cuantitativa de los fenómenos, fue el producto del uso de la matriz de presencia o ausencia (1/0) y generó un indicador basado en la pluralidad de alteraciones y deterioros presentes en las obras analizadas. Este valor ha sido tomado en cuenta para estructurar los datos de la primera implementación del método y en la versión mejorada del mismo. Dicho aspecto ha sido considerado como criterio de clasificación de los resultados, estableciendo como parámetro ordenador la riqueza derivada de la variedad de deterioros existentes.

En esta perspectiva, se han puesto en relación la pluralidad de alteraciones y deterioros con una mayor complejidad de fenómenos activos. Paralelamente, para generar un acercamiento a la extensión superficial de cada problemática específica, se ofreció una estimación aproximada de la superficie afectada por los mismos. Ofrecer por medio de la tabla mostrada a continuación la información mencionada tuvo la finalidad de favorecer la comprensión y discernimiento de los datos por parte del conservador (tabla 185).

Tabla 185 - Ejemplo de la representación de datos específicos sobre el estado de conservación con referencias a la incidencia cuantitativa y a la extensión superficial (\%) de las fenomenologías de alteración y deterioro registradas. Muestra 10, Catedral Metropolitana.

\begin{tabular}{|l|c|c|}
\hline \multicolumn{2}{|c|}{ M10 (total incidencia de deterioro: 9) } \\
\hline FENOMENOLOGÍA DE ALTERACIÓN Y DETERIORO & $\begin{array}{c}\text { INCIDENCIA } \\
\text { SUPERFICIAL }\end{array}$ & $\begin{array}{c}\text { EXTENSIÓN } \\
\text { SUPERFICIAL (\%) }\end{array}$ \\
\hline Alteración cromática y depósitos - Suciedad & 4 & $75-100$ \\
\hline Alteración cromática y depósitos - Costra: Costra negra & 3 & $50-75$ \\
\hline Alteración cromática y depósitos - Costra: Concreción & 2 & $25-50$ \\
\hline Alteración cromática y depósitos - Costra: Encrustación & 2 & $25-50$ \\
\hline Alteración cromática y depósitos - Depósito & 2 & $25-50$ \\
\hline Separación - Disgregación: Sugaring & 1 & $0-25$ \\
\hline Morfologías inducidas por pérdidas - Erosión: Pérdida de matriz & 1 & $0-25$ \\
\hline Morfologías inducidas por pérdidas - Aumento de la rugosidad & 1 & $0-25$ \\
\hline Morfologías inducidas por pérdidas - Faltantes: Volumétricos & 1 & $0-25$ \\
\hline
\end{tabular}


Tomando como ejemplo el caso de estudio presentado en la tabla 185, es posible identificar una separación entre los datos arrojados por las diferentes tipologías de matrices. En este caso de estudio, correspondiente a la Muestra 10 de la catedral Metropolitana, se pueden observar las informaciones inherentes a los aspectos que se exponen a continuación:

- incidencia de las fenomenologías de alteración y deterioro, derivada de la matriz de presencia/ausencia (1/0); en el caso de estudio propuesto se expresa en un valor igual a 9.

- extensión superficial (\%) de cada fenómeno de alteración y deterioro, resultado de la matriz de abundancia (1-4); en el caso de estudio propuesto se reproponen los valores 1-4 empleados en la matriz de registro y su referencia en términos de extensión superficial (\%).

En búsqueda de una unificación de los resultados, que permitiera generar un indicador global, dirigido a un mayor nivel de representatividad de la información. Por ello, se propone la generación de un valor de referencia cuyo resultado derive de la sumatoria entre los datos numéricos mencionados, en donde el índice de prioridad responderá al indicador de riesgo cuya estimación será el resultado de:

- valor numérico de la incidencia de deterioros (matriz de presencia/ausencia) sumado al valor numérico de su extensión superficial (matriz de abundancia).

Para ejemplificar con mayor efectividad el concepto, es útil presentar una elaboración de los datos mencionados. Tomando la información obtenida tras el análisis de las esculturas de la fachada de la Catedral Metropolitana de la ciudad de San Luis Potosí, se obtienen dos tipologías de indicadores de riesgo y prioridad:

- Resultado de la indicencia de las fenomenologías de alteración y deterioro (tabla 186).

- Resultado de la extensión de las fenomenologías de alteración y deterioro (tabla 187). 
Tabla 186 - Indicador de riesgo derivado de la pluralidad de fenomenologías de alteración y deterioro registradas. Caso de estudio: esculturas de la fachada de la Catedral Metropolitana.

\begin{tabular}{|c|c|}
\hline MUESTRA & INCIDENCIA DE LAS FENOMENOLOGÍAS DE ALTERACIÓN Y DETERIORO \\
\hline M10 & 8 \\
\hline M4 & 8 \\
\hline M13 & 7 \\
\hline M5 & 7 \\
\hline M6 & 7 \\
\hline M8 & 6 \\
\hline M2 & 6 \\
\hline M3 & 5 \\
\hline M9 & 5 \\
\hline M11 & 5 \\
\hline M12 & 3 \\
\hline M7 & 2 \\
\hline M1 & \\
\hline & \\
\hline
\end{tabular}

Tabla 187 - Indicador de riesgo derivado de la extensión superficial de las fenomenologías de alteración y deterioro registradas. Caso de estudio: esculturas de la fachada de la Catedral Metropolitana.

\begin{tabular}{|c|c|}
\hline MUESTRA & EXTENSIÓN DE LAS FENOMENOLOGÍAS DE ALTERACIÓN Y DETERIORO \\
\hline M10 & 17 \\
\hline M5 & 12 \\
\hline M6 & 11 \\
\hline M3 & 11 \\
\hline M8 & 10 \\
\hline M2 & 10 \\
\hline M4 & 10 \\
\hline M12 & 9 \\
\hline M9 & 8 \\
\hline M11 & 8 \\
\hline M13 & 6 \\
\hline M7 & 4 \\
\hline M1 & \\
\hline
\end{tabular}

A través de la sumatoria de los resultados obtenidos es posible generar el indicador de riesgo global, es decir, el resultado de la sumatoria de valores que 
incluye la incidencia de las fenomenologías de alteración y deterioro aunadas a la extensión superficial estimada (tabla 188).

Tabla 188 - Indicador de riesgo y prioridades elaborado tras la sumatoria de valores obtenidos de las matrices de datos.

\begin{tabular}{|c|c|}
\hline MUESTRA & INDICADOR GLOBAL DE RIESGO Y PRIORIDADES \\
\hline M10 & 26 \\
\hline M5 & 20 \\
\hline M6 & 19 \\
\hline M4 & 18 \\
\hline M8 & 18 \\
\hline M3 & 17 \\
\hline M2 & 16 \\
\hline M13 & 16 \\
\hline M12 & 15 \\
\hline M9 & 14 \\
\hline M11 & 13 \\
\hline M7 & 9 \\
\hline M1 & 6 \\
\hline
\end{tabular}

A la luz de estas reflexiones es necesario destacar que las tablas propuestas varían el orden de los indicadores de riesgo y prioridades debido a que presentan los mismos resultados abarcándolos desde enfoques diferentes. Por lo tanto la información ofrecida por las tablas 186, 187 y 188 puede considerarse complementaria entre sí (diagrama 27). 


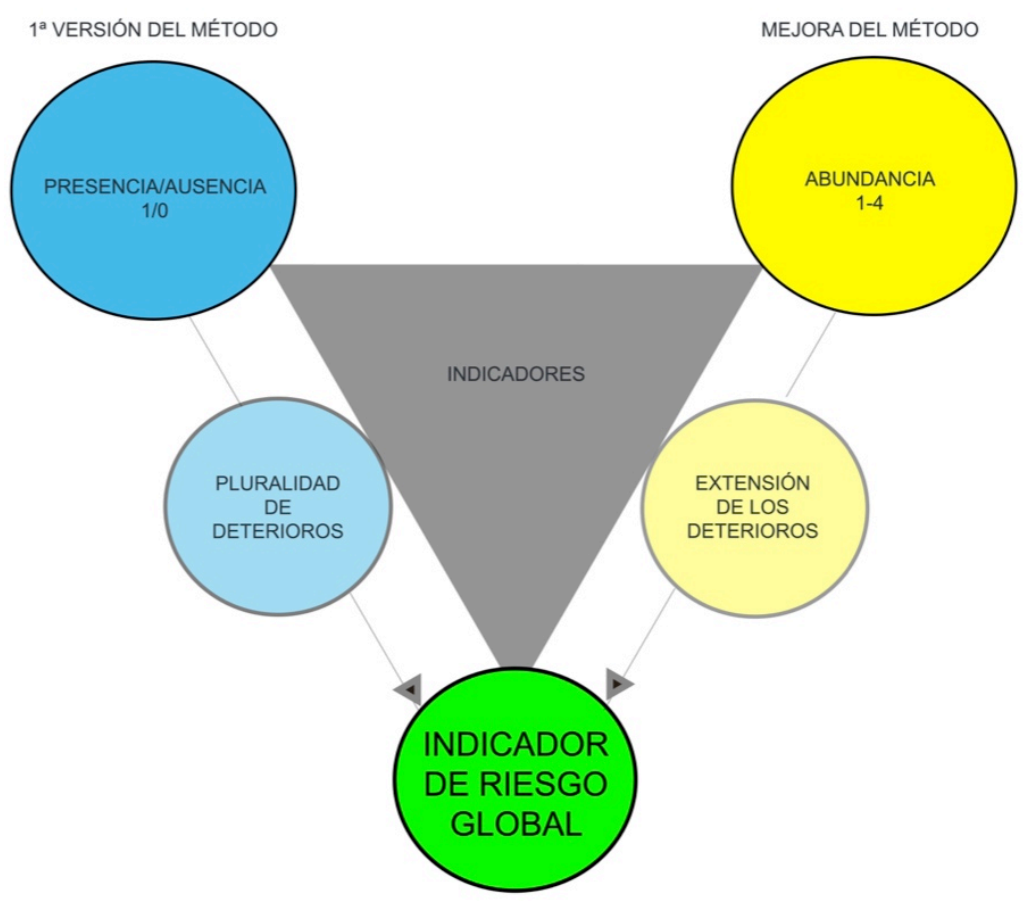

Diagrama 27 - Esquema de las diferentes modalidades de registro y análisis de datos abarcadas en esta investigación.

A continuación se resumen los enfoques brindados por las diferentes estrategias de cálculo y análisis de los datos:

- Indicador de riesgo basado en la pluralidad de alteraciones y deterioros registrados (tabla 186).

- Indicador de riesgo basado en la extensión superficial de las fenomenologías de alteración y deterioro observadas (tabla 187).

- Indicador global de riesgo y prioridades como resultado de los valores expresados en las modalidades de cálculo anteriores (tabla 188).

Puede ser viable la posibilidad de generar un interfaz de cálculo y elaboración de los resultados que permita extraer los indicadores de riesgo según las exigencias del caso. 


\subsection{Representación gráfica de los resultados}

La representación gráfica de las obras con mayor indicador de riesgo permitió una apreciación inmediata e intuitiva de las áreas con más problemáticas. Este aspecto posee la doble ventaja de brindar un acercamiento a los elementos menos estables pudiéndolos ubicar en relación al contexto o estructura del que forman parte.

Tomando como ejemplo las elaboraciones visuales de los datos para el Museo de Arte Sacro de Guadalcázar, el retablo de la Virgen de la Luz de Puebla y la ex hacienda de Peotillos, se pudo observar cómo la representación de los elementos con mayor riesgo indica también dinámicas y problemas implícitos al lugar de conservación. Éstas, constituyen un valor añadido en la información arrojada, ya que influyen en la conservación de las obras. Un ejemplo de ello puede ser la incidencia de un mayor riesgo en correspondencia con una determinada posición en el recinto museal (imagen 116 y 117) o en la estructura del conjunto (imagen 118 y 119).

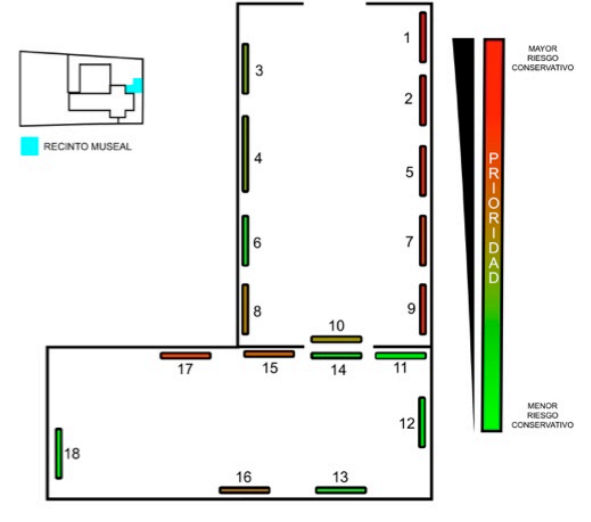

PINTURAS - MUSEO DE ARTE SACRO

Imagen 116 - Representación de la escala de riesgo para la colección de pintura de caballete, Museo de Arte Sacro de Guadalcázar (San Luis Potosí).

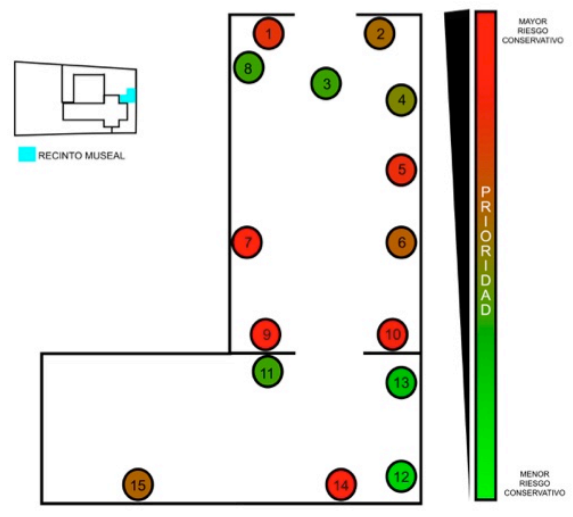

ESCULTURAS - MUSEO DE ARTE SACRO

Imagen 117 - Representación de la escala de riesgo para la colección de escultura policromada, Museo de Arte Sacro de Guadalcázar (San Luis Potosí). 


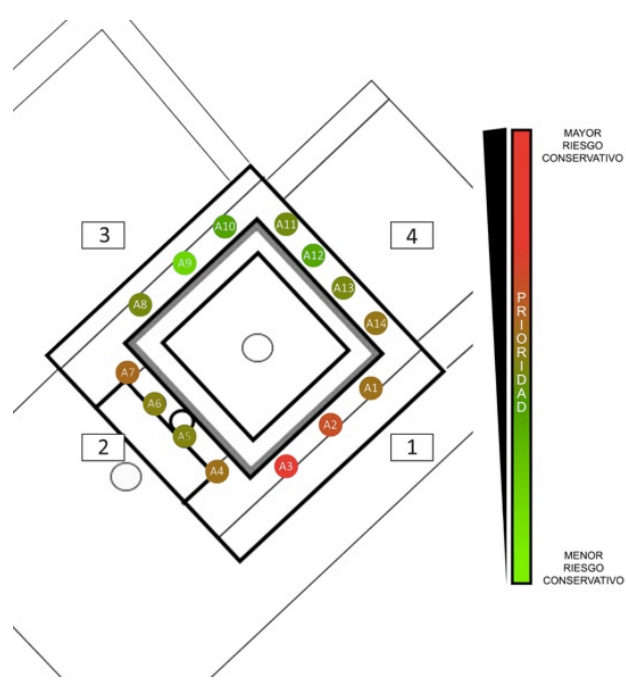

Imagen 118 - Representación de la escala de riesgo para las pinturas murales decorativas de la ex hacienda de Peotillos (Villa Hidalgo, San Luis Potosí).

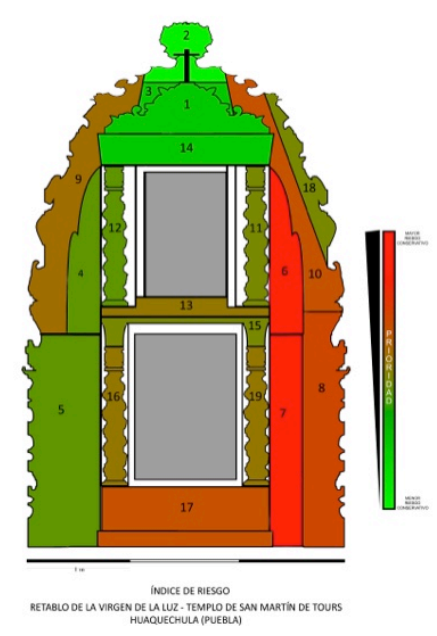

Imagen 119 -Representación de la escala de riesgo para el retablo de la Virgen de la Luz de Huaquechula (Puebla).

En la fase final de la implementación del método a los casos de estudio propuestos, se ha formulado un análisis de causa-efecto del elemento con mayor riesgo sustentada en las fuentes bibliográficas consultadas para el diseño de las fichas de registro. Esto representó una propuesta de interpretación, que permitió relacionar la información con el contexto e historial conservativo conocido. La lectura de resultados será una tarea del profesional de la conservación y restauración de bienes culturales ${ }^{346}$; al igual que los análisis de tipo químico, la información se compone por elementos cualitativos y cuantitativos que el ojo experto del operador deberá de descifrar en pos de una comprensión óptima de las necesidades de la colección.

Paralelamente a las experiencias presentadas en este documento, se involucraron otros profesionales del sector, con el objetivo de brindar la posibilidad de aplicar el método a diferentes contextos y realidades de estudio. Gracias a esta colaboración, se obtuvo una evaluación y retroalimentación sobre el procedimiento propuesto. A través de una encuesta ${ }^{347}$, realizada tras el registro de datos y de la

${ }^{346}$ Como afirmado por Férnandez Martínez (2007) en el campo de la Arqueoestadística, "Ios resultados nunca hablan por sí mismos, sino que han de ser forzosament interpretados, y aquí interviene de forma decisiva la libertad y la posición teórica de cada investigador/a", op. cit., p. 27.

${ }^{347}$ La evaluación de los parámetros se formuló en base 10, en donde 1 correspondió a muy negativo y 10 a excelente. 
recepción de los resultados, se logró una valoración de los parámetros que se especifican a continuación:

- sencillez del método;

- claridad de las informaciones presentadas en la matriz de datos;

- practicidad del uso del método;

- nivel de conocimientos necesarios para su implementación;

- rapidez en el registro de la información;

- utilidad del método;

- representatividad de los resultados;

- eficacia de la información y recolección de datos;

- viabilidad de su probable implementación;

- viabilidad de uso en situaciones de emergencia y/o escasez recursos;

En búsqueda de una evaluación externa del método, dirigida a generar una valoración por parte de profesionales del sector de la conservación del patrimonio cultural, se analizaron un total de 21 obras $^{348}$, constituidas por pinturas de caballete (4), esculturas en material pétreo (13), recubrimientos arquitectónicos (2) y esculturas en madera policromada y dorada (2), se obtuvo un promedio de tiempos de recolección de datos/obra de 10.71 minutos, con una evaluación general del método de 8.65/10 (tabla 189).

\footnotetext{
${ }^{348}$ Tras la propuesta de colaboración para determinar una evaluación del método, se obtuvieron respuestas de 3 restauradores, por lo tanto los resultados presentados no se pueden considerar e no es representativos de un colectivo más numeroso.
} 
Tabla 189 - Evaluación (1/10) del método por parte de profesionales de la conservación.

\begin{tabular}{|c|c|c|c|c|}
\hline CRITERIOS EVALUADOS & CASO $1^{349}$ & CASO $2^{350}$ & CASO $3^{351}$ & PROMEDIO \\
\hline Sencillez & 10 & 10 & 7 & 9 \\
\hline Claridad de las informaciones & 9 & 9 & 7 & 8.33 \\
\hline Practicidad del método & 10 & 10 & 8 & 9.33 \\
\hline Conocimientos necesarios & 8 & 9 & 7 & 8 \\
\hline $\begin{array}{l}\text { Rapidez de recolección de } \\
\text { datos }\end{array}$ & 9 & 9 & 8 & 8.66 \\
\hline Tiempo requerido & $\begin{array}{l}20 \mathrm{~min} . \\
(3.33 \mathrm{~min} . / \mathrm{obra})\end{array}$ & $\begin{array}{l}2 \text { h y } 30 \text { min. } \\
\text { (13 min./obra) }\end{array}$ & $\begin{array}{l}45 \mathrm{~min} . \\
\text { (7.5 min./obra) }\end{array}$ & $\begin{array}{l}10.71 \\
\text { min./obra }\end{array}$ \\
\hline $\begin{array}{l}\text { TOTAL DE } \\
\text { EXAMINADAS }\end{array}$ & 6 & 10 & 5 & 7 \\
\hline
\end{tabular}

Análogamente a la interpretación de resultados ofrecidas en los casos de estudio de esta investigación, se generaron informes de diagnóstico sobre las problemáticas específicas de cada conjunto analizado. Éstos, se sometieron a una valoración por parte de los responsables de la recolección de datos, obteniendo una evaluación promedio de la utilidad del método igual a 9/10 mientras la calidad de la información arrojada tras el análisis se estimó en $8.33 / 10$, con la consideración de una viabilidad de uso igual a 9.33/10, quedando una nota promedio de la experiencia en 8.84/10 (tabla 190).

${ }^{349}$ Caso 1, conjunto de obras de la Parroquia de San Pedro, Real de Guadalcázar, San Luis Potosí. Gracias a la colaboración de la restauradora S.J.R.

350 Caso 2, conjunto de esculturas en piedra de Vicenza, colección privada, Vicenza, Italia. Gracias a la colaboración de la restauradora E.C.

351 Caso 3, conjunto de recubrimientos arquitectónicos y elementos en material pétreo de Jaén, España. Gracias a la colaboración de la restauradora I.M.C.S. 


\begin{tabular}{|l|c|c|c|c|}
\hline CRITERIOS EVALUADOS & CASO 1 & CASO 2 & CASO 3 & PROMEDIO \\
\hline Utilidad del método & 10 & 9 & 8 & 9 \\
\hline $\begin{array}{l}\text { Representatividad de los } \\
\text { resultados }\end{array}$ & 9 & 9 & 8 & 8.66 \\
\hline $\begin{array}{l}\text { Eficacia de la información y } \\
\text { recolección de datos }\end{array}$ & 9 & 8 & 7 & 8 \\
\hline $\begin{array}{l}\text { Viabilidad de su probable } \\
\text { implementación }\end{array}$ & 10 & 10 & 8 & 9.33 \\
\hline $\begin{array}{l}\text { Viabilidad de uso en } \\
\text { situaciones de emergencia o } \\
\text { escasez de recursos }\end{array}$ & 10 & 10 & 8 & \\
\hline
\end{tabular}

Los profesionales con los que se llevó a cabo la colaboración, destacaron las ventajas que se relatan a continuación:

- El formato del método, junto a los datos e información brindados en los resultados, es útil para una mejora en la gestión de la planeación de las fases de acercamiento e intervención de conservación y restauración de la colección.

- El procedimiento ofrece una panorámica exhaustiva del estado de la colección y de sus exigencias conservativas. La información brindada, de acuerdo a los tiempos y medios empleados para su recolección, es pertinente y representativa de las condiciones en las que se encuentran las obras.

Como márgenes de mejora, propusieron:

- Agregar informaciones sobre el historial conservativo de las obras como: intervenciones anteriores, traslados, exposiciones, préstamos, etc.

- Agregar documentación fotográfica específica y de detalle de las piezas.

Comparando los resultados obtenidos de la investigación, en términos de posibilidades aplicativas y recursos necesarios para la investigación de las casuísticas 
enfrentadas, este método se ubica en el nivel A de los propuestos en 2007 por el Getty Conservation Institute ${ }^{352}$, en relación a costos, siendo posible su aplicación con una inversión de medios temporales, humanos y técnicos bajos.

Para su empleo, serán necesarios uno o pocos días en el sitio, con el personal encargado del registro dotado de herramientas básicas como cámaras fotográficas y fichas para las fases de registro, y ordenador con hojas de trabajo Excel ${ }^{\circledR}$ para el análisis de la información. No obstante, la calidad de la información arrojada, permite obtener datos del nivel $B$, de mediana precisión, inherentes a la determinación de las condiciones iniciales del bien cultural con una descripción de las problemáticas que lo están afectando. Todo lo anterior, acompañado por una documentación fotográfica general y por datos de referencia de tipo cualitativo y cuantitativo sobre las fenomenologías de alteración y deterioro presentes. De acuerdo a esta clasificación, los alcances de la herramienta propuesta en esta investigación, abarcan el nivel C, gracias a la posibilidad de incorporarla en las rutinas de mantenimiento y monitoreo de los conjuntos patrimoniales sometidos a intervenciones de conservación y restauración (tabla 191).

${ }^{352}$ GETTY CONSERVATION INSTITUTE (2007). Recording, Documentation, and Information Management for the Conservation of Heritage Places. Illustrated Examples.

<https://www.getty.edu/conservation/publications_resources/pdf_publications/recordim_vol2.html> [Consulta: 15 de mayo de 2020]. 
Tabla 191 - Niveles de registro del Patrimonio Cultural. Traducido de GETTY CONSERVATION INSTITUTE (2007). Guiding Principles - Recording, Documentation and Information Management for Conservation of Heritage Places.

\begin{tabular}{|c|c|c|c|}
\hline & $\begin{array}{c}\text { A } \\
\text { REGISTROS DE } \\
\text { RECONOCIMIENTO }\end{array}$ & $\begin{array}{c}\text { B } \\
\text { REGISTROS } \\
\text { PRELIMINARES }\end{array}$ & $\begin{array}{c}\text { C } \\
\text { REGISTROS } \\
\text { DETALLADOS }\end{array}$ \\
\hline PRECISIÓN & BAJA & MEDIANA & ELEVADA \\
\hline $\begin{array}{l}\text { OBJETIVO } \\
\text { DEL } \\
\text { REGISTRO }\end{array}$ & $\begin{array}{l}1 \text { - RECONOCIMIENTO } \\
2 \text { - INVENTARIO INICIAL } \\
3 \text { - PLANEACIÓN INICIAL } \\
4 \text { - DATOS DE REFERENCIA }\end{array}$ & $\begin{array}{l}1 \text { - PLANEACIÓN } \\
2 \text { - CONDICIONES INICIALES } \\
3 \text { - INVESTIGACIÓN } \\
4 \text { - ESTABILIZACIÓN } \\
5 \text { - DISEÑO PRELIMINAR } \\
6 \text { - DATOS DE REFERENCIA }\end{array}$ & $\begin{array}{l}1 \text { - CONDICIÓN INICIAL } \\
2 \text { - DISEÑO } \\
3 \text { - CONSTRUCCIÓN } \\
4 \text { - REGISTROS DE CONSTRUCCIÓN } \\
5 \text { - MONITOREO/MANTENIMIENTO } \\
6 \text { - POSTERIDAD }\end{array}$ \\
\hline $\begin{array}{l}\text { PRECISIÓN } \\
\text { DE LOS } \\
\text { DIBUJOS }\end{array}$ & NO A ESCALA & $\begin{array}{l}\text { PLANOS Y ALZADOS } \\
\pm 5.0 \text { in. }( \pm 10 \mathrm{~cm}) \\
\text { DETALLES } \\
\pm 1.0 \mathrm{in} .( \pm 2 \mathrm{~cm})\end{array}$ & $\begin{array}{l}\text { PLANOS Y ALZADOS } \\
\pm 0.5 \text { in. }( \pm 1 \mathrm{~cm}) \\
\text { DETALLES } \\
\pm 0.1 \text { in. }( \pm 2 \mathrm{~mm})\end{array}$ \\
\hline RESULTADOS & $\begin{array}{l}1 \text { - Documentación fotográfica } \\
2 \text { - Planeación fotográfica } \\
3 \text { - Condiciones iniciales } \\
4 \text { - Dibujos descriptivos }\end{array}$ & $\begin{array}{l}1 \text { - Dibujos a escala } \\
2 \text { - Descripción/Condición del BC } \\
3 \text { - Observaciones } \\
4 \text { - Reporte fotográfico }\end{array}$ & $\begin{array}{l}1 \text { - Dibujos a escala } \\
2 \text { - Descripción/Condición del BC } \\
3 \text { - Observaciones } \\
4 \text { - Reporte fotográfico }\end{array}$ \\
\hline $\begin{array}{c}\text { COSTOS } \\
\text { (TIEMPOS, RECURSOS } \\
\text { HUMANOS) }\end{array}$ & $\begin{array}{c}\text { BAJO } \\
\text { (pocos días en el sitio } \\
\text { con el grupo de registro) }\end{array}$ & $\begin{array}{l}\text { MODERADO } \\
\text { (varias semanas o más en el sitio } \\
\text { con el equipo de registro y } \\
\text { participación de los conservadores } \\
\text { profesionales) }\end{array}$ & $\begin{array}{c}\text { MODERADO/ELEVADO } \\
\text { (tiempos extensos y actividades } \\
\text { prolongadas en el sitio con el } \\
\text { equipo de registro e incremento en la } \\
\text { participación de los conservadores } \\
\text { profesionales) }\end{array}$ \\
\hline
\end{tabular}

Considerando el abanico de problemáticas analizadas, junto a la cantidad de información recaudada y a los medios empleados para su implementación, se puede afirmar que el uso de tablas unificadas para la resolución de las fases preliminares de diagnóstico del patrimonio cultural ha resultado ser una herramienta útil y viable, para ser empleada en circunstancias o contextos caracterizados por limitaciones económicas, temporales, técnicas y humanas, capaz de poner el foco de atención sobre las dinámicas que están afectando al patrimonio y permitiendo establecer rutas de acción efectivas y sostenibles, basadas en exigencias estimadas de forma cuantitativa y cualitativa, que otorgan un medio de exploración asequible al estado de conservación de las colecciones. 
La decisión de generar unos modelos de fichas con parámetros unificados, respondió eficazmente a la problemática original de este estudio, en donde la dispersión y falta de criterios comunes en el momento de recibir e integrar la información, destacaban por ser las principales limitaciones para la creación de un sistema común de datos, de acuerdo a lo mencionado en el documento de Diagnóstico de trabajo ${ }^{353}$ del cuadrienio 2014-2018 del Instituto Nacional de Antropología e Historia de México ${ }^{354}$. La falta de centralidad en el manejo de los datos inherentes a las obras localizadas en el territorio junto a la carencia de medios y procesos unificados para el análisis de la considerable cantidad de patrimonio cultural bajo su jurisdicción ${ }^{355}$, habían sido analizados críticamente por la institución, evidenciando las problemáticas derivadas de la gestión y de la toma de decisiones relacionadas con la conservación de este importante acervo socio-cultural.

De acuerdo a los resultados obtenidos, el método planteado en este estudio podría brindar la oportunidad de construir indicadores eficaces, permitiendo, por las características del sistema, una futura centralización y estandarización de las informaciones. Gracias a la unificación de criterios propuesta en el método de recolección de datos presentado, inspirada en la metodología de estudio estadístico, es posible considerar la generación de datos cuya ventaja reside en su posible comparación, supliendo al inconveniente determinado por la falta de coordinación entre las metodologías de monitoreo oficiales y el registro de las condiciones conservativas del patrimonio en las realidades locales ${ }^{356}$. En las tablas de registro diseñadas, los indicadores, responsables de cumplir la función de comparar, informar, señalar y medir el estado actual de áreas específicas ${ }^{357}$,

${ }_{33}^{33}$ INAH, GOBIERNO DE MÉXICO. Diagnóstico del plan de trabajo 2014-2018.

$<$ https://inah.gob.mx/images/stories/Transparencia/programa_trabajo/diagnostico.pdf $>$ [Consulta: 7 de marzo de 2019].

${ }^{354}$ Para los detalles, el apartado "Estado de la Cuestión".

${ }^{355}$ CÁMARA DE DIPUTADOS. Nota №. 1510 (2019). INAH, INBA y Secretaría de Cultura, sin diagnósticos sobre estado del patrimonio cultural material e inmaterial que determinen necesidades de conservación y protección: ASF <http://www5.diputados.gob.mx/index.php/esl/Comunicacion/Agencia-de-

Noticias/2019/Febrero/23/1510-INAH-INBA-y-Secretaria-de-Cultura-sin-diagnosticos-sobre-estado-delpatrimonio-cultural-material-e-inmaterial-que-determinen-necesidades-de-conservacion-y-proteccionASF> [Consulta: 20 de abril de 2020].

${ }^{356}$ RAND, E. y GARCÍA GRINDA, J.L. (2015). "Management documentation indicators \& good practice at cultural heritage places" en The International Archives of the Photogrammetry, Remote Sensing and Spatial Information Sciences, Volume XL-5/W7, 25th International CIPA Symposium. Taiwan: Taipei.

357 Un ejemplo de indicadores empleados para establecer el impacto de la cultura en el desarrollo de un determinado país: económico, educativo, gubernamental, participación social, equidad de género, comunicación y patrimonio. UNESCO. Diversidad de las expresiones culturales. $<$ https://es.unesco.org/creativity/indicadores-de-desarrollo/caja-de-herramientas> [Consulta: 10 de junio de 2020]. Para mayores detalles véase "Estado de la cuestión". 
corresponden a las fenomenologías de alteración y deterioro y a los parámetros propuestos para su estimación cuantitativa.

Un ejemplo de las posibilidades mencionadas se expone en la tabla 192, presentada a continuación, en donde se muestra la comparación de los resultados obtenidos tras el análisis de los conjuntos escultóricos y ornamentales de las fachadas del centro histórico de la capital potosina. En ella, es posible apreciar como la escultura correspondiente a la muestra 1 del Templo de San Miguel Arcángel es la más afectada por pluralidad de deterioros (16), seguida por la muestra 5 del templo de Nuestra Señora del Carmen (14), y la muestra 7 del mismo conjunto (12). La utilidad de esta tipología de comparativa reside en la posibilidad de abarcar una panorámica general a partir de la cual será posible cotejar las dinámicas conservativas específicas de cada conjunto y, sucesivamente, de cada obra analizada. Lo anterior será posible gracias a la disponibilidad de resultados generales y concretos de los universos de estudio que, abarcando una estimación porcentual de la superficie afectada, en los casos de las obras de caballete y escultura policromada, permite ahondar hasta las problemáticas propias de cada estrato constitutivo del sistema.

Tabla 192 - Comparación de los resultados de la incidencia cuantitativa de las fenomenologías de alteración y deterioro.

INCIDENCIA DE LAS FENOMENOLOGÍAS DE ALTERACIÓN Y DETERIORO ELEMENTOS ESCULTÓRICOS Y ORNAMENTALES CENTRO HISTÓRICO DE SAN LUIS POTOSÍ

\begin{tabular}{|c|c|c|c|c|c|c|c|c|c|}
\hline \multicolumn{2}{|c|}{$\begin{array}{c}\text { Capilla de } \\
\text { Nuestra Señora } \\
\text { de Loreto }\end{array}$} & \multicolumn{2}{|c|}{$\begin{array}{c}\text { Catedral } \\
\text { Metropolitana }\end{array}$} & \multicolumn{2}{|c|}{$\begin{array}{l}\text { Templo de Nuestra } \\
\text { Señora del Carmen }\end{array}$} & \multicolumn{2}{|c|}{$\begin{array}{l}\text { Templo de San } \\
\text { Francisco }\end{array}$} & \multicolumn{2}{|c|}{$\begin{array}{l}\text { Templo de San } \\
\text { Miguel Arcángel }\end{array}$} \\
\hline$M$ & TOTAL & $M$ & TOTAL & M & TOTAL & M & TOTAL & M & TOTAL \\
\hline 1 & 9 & 10 & 9 & 5 & 14 & 2 & 11 & 1 & 16 \\
\hline 2 & 5 & 4 & 8 & 7 & 12 & 1 & 7 & 3 & 11 \\
\hline 3 & 4 & 13 & 8 & 11 & 11 & 5 & 6 & 2 & 10 \\
\hline- & - & 5 & 7 & 1 & 8 & 4 & 5 & 4 & 1 \\
\hline- & - & 6 & 7 & 2 & 8 & 6 & 4 & - & - \\
\hline- & - & 8 & 7 & 4 & 8 & 3 & 3 & - & - \\
\hline- & - & 2 & 6 & 3 & 6 & - & - & - & - \\
\hline- & - & 3 & 6 & 6 & 6 & - & - & - & - \\
\hline- & - & 9 & 5 & 9 & 6 & - & - & - & - \\
\hline- & - & 11 & 5 & 12 & 6 & - & - & - & - \\
\hline
\end{tabular}




\begin{tabular}{|c|c|c|c|c|c|c|c|c|c|}
\hline- & - & 12 & 5 & 8 & 5 & - & - & - & - \\
\hline- & - & 7 & 3 & 10 & 5 & - & - & - & - \\
\hline- & - & 1 & 2 & 13 & 5 & - & - & - & - \\
\hline- & - & - & - & 14 & 5 & - & - & - & - \\
\hline
\end{tabular}

Para un correcto aprovechamiento de las ventajas brindadas por el uso de los números en relación a las actividades de medición y comparación de las características conservativas de un contexto, es importante mencionar que la fase más compleja y fundamental del estudio presentado ha sido la estructuración de las informaciones y el diseño de las tablas de registro, ya que de ellas deriva la calidad original de los datos de partida. A través de lo que se define como matriz de datos y muestra, se obtendrán resultados de mayor o menor calidad de acuerdo a lo experimentado en las diferencias registradas entre la primera y segunda implementación del método ${ }^{358}$.

Comparando las experiencias en la aplicación del sistema, el diseño de una matriz de datos inspirada en los modelos de tablas de frecuencia de contingencia y estructurada alrededor de dos ejes, ha permitido el hallazgo de resultados representativos, extrayendo hipótesis y conclusiones útiles para la comprensión del contexto de estudio. En la versión-piloto del método se optó por el empleo de un modelo dicotómico, basado en el registro de la presencia o ausencia (1/0) de los fenómenos. En la mejora del procedimiento de recolección de la información, se decidió emplear un sistema de recogida de datos sustentado en la abundancia, expresando la cantidad de deterioro presente en términos de extensión superficial por medio de una escala numérica de 1 a 4 . A la luz de la información extraída del proceso, el perfeccionamiento del sistema ha permitido mejorar la calidad de la información.

Cabe destacar que, aunque se haya perseguido la objetividad en la recolección de criterios y en la ordenación de las informaciones, los datos seleccionados constituyen siempre un producto de la interpretación del profesional y de su experiencia, pudiendo variar según las condiciones y formación del mismo. Conforme a lo expresado anteriormente, destaca el valor añadido del procedimiento, que permite fomentar una alfabetidad visual en el profesional. La existencia de un material visual de soporte en los glosarios consultados satisface una necesidad de tipo práctico, favoreciendo el proceso de identificación de determinados preceptos que pueden ser así registrados y analizados a través del método propuesto. De acuerdo a estos conceptos, cada aplicación del método

358 FERNÁNDEZ MARTíNEZ, V.M. (2015). Arqueo estadística, métodos cuantitativos en arqueología. Madrid: Alianza, p. 23. 
podrá favorecer el desarrollo de la experiencia formativa del conservador, participando en la ampliación de los recursos inteligibles propios de las dinámicas de alteración y deterioro de los materiales constitutivos de las obras de arte.

De acuerdo a las reflexiones desarrolladas sobre las exigencias de estandarización e individualización de la documentación del patrimonio cultural, es importante recordar lo mencionado por Mora y Philippot ${ }^{359}$ al respecto. Las fases de estudio preliminar, de las que depende la organización y efectividad de las acciones de conservación, se definen en relación a aspectos complementarios y contradictorios, que oscilan entre la necesidad de estudiar de forma pormenorizada cada caso, abriéndose a la comprensión de sus peculiaridades conservativas, técnicas e históricas y la voluntad de impulsar el uso de criterios que favorezcan la comparación entre las diferentes realidades investigadas. Tras las experiencias realizadas a lo largo de la presente investigación, es útil remarcar la aportación de la misma en relación a la profundización científica de las exigencias conservativas del patrimonio cultural destacando los aspectos útiles para la mejora de las fases de gestión de las acciones de conservación.

El uso de tablas con criterios unificados permite el futuro desarrollo de técnicas de análisis de tipo estadístico, posibles gracias al diseño de los parámetros básicos usados para las fases de recolección de datos. Éstos permitirán fomentar un sistema centralizado de monitoreo de las condiciones del patrimonio cultural, que, adoptado a escala nacional, abriría el camino hacia la generación de estadísticas y comparativas entre contextos y realidades diferentes, tal como en los estudios desarrollados en el marco de los indicadores socio-económicos por la UNESCO-FSC, pero específicas del estado de conservación de las obras de arte que constituyen la herencia cultural de un territorio ${ }^{360}$. Esta posibilidad, podría favorecer la generación de informaciones útiles para extraer consideraciones sobre el estado de salud del patrimonio.

La generación de datos unificados sobre el estado de conservación de los bienes culturales participa en la generación de información eficaz para la comparación nacional e internacional de las condiciones y exigencias del legado históricoartístico de los países, favoreciendo el intercambio de estrategias y recursos útiles para su salvaguarda, además de proporcionar un acercamiento a las realidades que necesitan una investigación de tipo científico urgente.

\footnotetext{
${ }^{359}$ MORA, P., MORA, L. y PHILIPPOT, P (1999). Op. cit. p. 40.

360 Para los detalles de este estudio, véase "Estado de la cuestión".
} 
Queda abierto el camino hacia la posible extensión y revisión de los criterios propuestos en las tablas unificadas diseñadas para esta investigación, ya que éstos influyen en la calidad de la información recolectada y de los resultados obtenidos, junto al posible desarrollo de éstos en función de los enfoques propios de la cultura estadística. Lo anterior, en pos de la creación de un sistema de monitoreo más eficaz y representativo, que podría extenderse también a las demás clases de patrimonio cultural.

A la luz de los resultados obtenidos en esta investigación, se puede afirmar que el diseño e implementación de tablas de registro unificadas para la resolución de las fases preliminares de estudio y diagnóstico del patrimonio cultural, representa una herramienta útil, cuyo alcance puede llegar a profundizar en el estado de conservación de un amplio espectro de bienes culturales, gracias a su facilidad de uso y a los recursos mínimos necesarios para su empleo. La posible incorporación del sistema a la rutina de monitoreo y diagnóstico a escala local, gracias a la asequibilidad de las herramientas necesarias para su uso, representa una propuesta real y viable para ser implementada, participando en la actualización de las exigencias conservativas del patrimonio cultural de forma sencilla, rápida y económica. 


\section{Referencias bibliográficas}

CALVO, A. (2002). Conservación y restauración de pintura sobre lienzo. Barcelona: El Serbal.

CALVO, A., GARCÍA FERNÁNDEZ-VILLA, S., BAILÃO, A. (2018). Terminología básica de conservación y restauración del patrimonio cultural. Madrid: Universidad Complutense de Madrid.

$<$ https://www.researchgate.net/publication/323613615_Terminologia_basica_d e_conservacion_y_restauracion_del_Patrimonio_Cultural> [Consulta: 12 marzo de 2019].

GETTY CONSERVATION INSTITUTE (2007). Recording, Documentation, and Information Management for the Conservation of Heritage Places. Illustrated Examples. $<$ https://www.getty.edu/conservation/publications_resources/pdf_publications/ recordim_vol2.html> [Consulta: 15 de mayo de 2020].

HORNEMANN INSTITUT (2015). European Illustrated Glossary for Conservation Terms of Wall Painting and Architectonic Surfaces. <https://www.hornemanninstitut.de/doi/2016ewa2.pdf> [Consulta: 19 de mayo 2017].

ICOMOS-ISCS (2008). Illustrated Glossary on Stone Deterioration Patterns. $<$ https://www.icomos.org/publications/monuments_and_sites/15/pdf/Monume nts_and_Sites_15_ISCS_Glossary_Stone.pdf> [Consulta: 3 de marzo de 2016].

INAH, GOBIERNO DE MÉXICO. Diagnóstico del plan de trabajo 2014-2018. $<$ https://inah.gob.mx/images/stories/Transparencia/programa_trabajo/diagnosti co.pdf> [Consulta: 7 de marzo de 2019].

CONACULTA, GOBIERNO DE MÉXICO, INAH. Programa institucional de mediano plazo 2014-2018 del Instituto Nacional de Antropología e Historia. <https://www.inah.gob.mx/images/stories/Transparencia/2014/pimp_2014_201 8_institucional.pdf> [Consulta: 7 de marzo de 2019].

FERNÁNDEZ MARTíNEZ, V.M. (2015). Arqueo estadística, métodos cuantitativos en arqueología. Madrid: Alianza.

MORA, P., MORA, L. y PHILIPPOT, P (1999). La conservazione delle pitture murali. Milano: Compositori.

RAND, E. y GARCÍA GRINDA, J.L. (2015). "Management documentation indicators \& good practice at cultural heritage places" en The International Archives of the Photogrammetry, Remote Sensing and Spatial Information Sciences, Volume XL5/W7, 25th International CIPA Symposium. Taiwan: Taipei. 
UNESCO. Diversidad de las expresiones culturales. $<$ https://es.unesco.org/creativity/indicadores-de-desarrollo/caja-deherramientas> [Consulta: 10 de junio de 2020].

VIVANCOS RAMÓN, V. (2007). La conservación y restauración de la pintura de caballete. Pintura sobre tabla. Madrid: Tecnos.

VIVANCOS RAMÓN, V. y CASTELL AGUSTÍ, M. (2010). Problemas y tratamientos del soporte de pintura de caballete. Valencia: Universidad Politécnica de Valencia. 


\section{Conclusiones}

La oportunidad de entrar en contacto con el rico y complejo contexto cultural de la República Mexicana, ha representado un medio de exploración de vertientes de gran interés, en donde, a la abundancia de testigos de carácter histórico artístico de sumo valor, se asociaron las dificultades derivadas del enfrentamiento de cuestiones de tipo práctico. Entre ellas, la necesidad de determinar rutas y criterios dirigidos a la selección de casos de estudio, en el planteamiento de diseños experimentales, o la toma de decisiones para establecer acciones de tipo conservativo en conjuntos de obras complejas y variadas.

Uno de los aspectos fundamentales, a la hora de implementar estrategias de conservación para los bienes de interés cultural, está representado por la disponibilidad de recursos, sean ellos de tipo económico, técnico o humano. Éstos influyen en los alcances brindados por las actividades preliminares de estudio y diagnóstico de las obras, de las cuales dependen las tomas de decisiones inherentes a las actividades de conservación a emprender. Los sistemas de registro comúnmente empleados carecían de parámetros útiles para la recolección y análisis de grandes cantidades de datos, dificultando la comparación de resultados para el establecimiento de prioridades y riesgos.

Gracias al desarrollo de esta investigación ha sido posible diseñar e implementar una metodología unificada de registro y análisis de las fenomenologías de alteración y deterioro del patrimonio cultural sustentada en la necesidad de hallar 
respuestas a las problemáticas observadas en México y comunes a la mayoría de los contextos culturales existentes. Entre las inquietudes que alimentaron el nacimiento de este proyecto, destacó la voluntad de generar una herramienta de estudio acorde a los recursos y medios existentes en las áreas de investigación involucradas, buscando mejorar las estrategias de conservación de esta extraordinaria herencia histórico-artística, de las que depende no sólo el mantenimiento de los testigos materiales, sino también el desarrollo económico, social y cultural de la colectividad.

Una de las peculiaridades que se tomó en consideración para la realización de esta investigación, fue la extensión geográfica de México y la riqueza de obras que conforman su patrimonio cultural. La imposibilidad de alcanzar un monitoreo de todos los bienes ubicados en el territorio en márgenes de tiempo factibles, representó desde siempre una limitación para el cotejo de las necesidades conservativas de los diferentes tipos de obras, llegando a impulsar la creación del procedimiento ofrecido en este estudio.

De acuerdo a lo mencionado en los apartados introductorios, la gestión de los sitios de carácter histórico-artístico de México involucra a diferentes instituciones. Este aspecto representa un factor común en las realidades de muchos países, que acarrea una mayor complejidad de gestión del patrimonio cultural. Por ello, en el establecimiento de los criterios para el planteamiento del método propuesto, se persiguió la generación de un sistema de evaluación y priorización de las fases preliminares de diagnóstico dirigido a la detección de las necesidades del patrimonio cultural cuyos requisitos deseables fueran la asequibilidad de medios necesarios para su implementación, junto a la tempestividad, medición efectiva y sencillez en la elaboración de la información. Una herramienta operativa a través de la cual examinar y evaluar el estado de conservación del patrimonio cultural para sucesivamente dedicar recursos y proyectos específicos, permitiendo una canalización efectiva de los medios necesarios.

Por lo que parte de los esfuerzos puestos como base del diseño del sistema propuesto, se dirigieron hacia la creación de unos recursos adecuados para las características de este contexto sociocultural tan complejo y único, ofreciendo mejorar las fases de gestión de las problemáticas derivadas del estudio de conjuntos de obras extensos por número y tipología, con una inversión mínima de medios. Conforme a lo anterior, se buscó la creación de una herramienta capaz de facilitar la resolución de las fases preliminares de estudio del patrimonio cultural, considerando, para su implementación, una inversión mínima de recursos técnicos, económicos y profesionales, sin detrimento de la calidad de la información recogida y analizada. Esto respondió a la falta de planteamientos unificados para el análisis 
del estado de salud del patrimonio manifestado por el mismo Instituto Nacional de Antropología e Historia en su informe del cuadrienio 2014-2018 ${ }^{361}$.

El haber enfrentado el estudio de la producción muralista del estado de San Luis Potosí, puso las bases para reflexionar sobre las modalidades idóneas para hacer frente al diagnóstico de un abanico de obras ubicadas en diferentes contextos geográficos. En relación a las exigencias de formular un planteamiento experimental sustentado en las características técnico-materiales de la pintura mural arqueológica mexicana, el acercamiento a los potenciales ofrecidos por el análisis de datos estadísticos permitió generar un primer modelo de recolección y estudio de datos, que fue perfeccionado gracias a las experiencias llevadas a cabo sobre la colección del Museo de Arte Sacro de Guadalcázar (San Luis Potosí) y de los monumentos funerarios del panteón Municipal del Saucito de la capital del estado.

Procurando optimizar la inversión de recursos humanos y temporales necesarios para la toma de información y su posterior análisis, se optó por la creación de un medio de exploración del estado del patrimonio cultural que permitiera abarcar un amplio espectro de datos en limitados márgenes de tiempo. Lo anterior, además de buscar agilizar las operaciones de registro y elaboración de las alteraciones que afectan paulatinamente al patrimonio, tomó en consideración la posibilidad de generar resultados representativos de la situación y comparables a diferente escala. Este conjunto de inquietudes llevó a concebir y diseñar unas fichas de recolección de datos con parámetros unificados, formuladas a partir de las empleadas para el análisis de tipo estadístico de la información. La estrategia seleccionada, inspirada en los modelos de tablas de contingencia comúnmente empleados para el análisis exploratorio de datos, ha resultado ser un apoyo metodológico valioso para el registro y análisis de las dinámicas de alteración y deterioro del patrimonio cultural, acordes a las premisas establecidas como fundamento de la investigación.

Ha sido esencial, para la selección y organización de la terminología técnica propuesta en las tablas de registro, alcanzar un conocimiento exhaustivo de los vocablos empleados, aproximándose a los mismos con una mirada crítica y constructiva. Gracias a la experiencia madurada en la formación LATAM-ICCROM en $2016^{362}$ ha sido posible comprender el valor de la metodología de acercamiento al contexto cultural de estudio, tomando consciencia de las limitaciones que aun coexisten en el momento de enfrentarse al trabajo interdisciplinario en el campo de la conservación del patrimonio en donde, conforme a las experiencias formativas y a

\footnotetext{
${ }^{361}$ Véase "Estado de la cuestión".

362 Ibídem.
} 
la especialización de los profesionales, se suelen interpretar semánticamente los fenómenos, influenciando las fases de registro de las alteraciones.

Gracias a esta experiencia ha sido posible reconsiderar la importancia de la observación y de la comprensión de los fenómenos. Éstos se perciben con los sentidos en donde la vista juega un papel fundamental. A la luz de los datos expuestos, es posible afirmar que por medio de los ojos se logran asimilar informaciones y conceptos con una elevada efectividad, cuya eficacia necesita ser impulsada por medio de referencias fotográficas. Paralelamente, gracias al ordenamiento ejercido por medio de los números, ha sido posible determinar las características conservativas de los bienes objeto de estudio, ofreciendo una estimación de las fenomenologías de alteración y deterioro responsables de la pérdida paulatina del patrimonio cultural.

La tipología de datos e informaciones arrojados por el método ha abarcado términos cualitativos y cuantitativos, llegando a generar indicadores de riesgo de conservación útiles a la priorización de las tareas específicas de estudio, análisis y diagnóstico. Éstos, han favorecido la identificación de las áreas o elementos de mayor riesgo conservativo ${ }^{363}$. De acuerdo con los resultados presentados en la investigación, a mayor indicador de riesgo corresponde una mayor afectación del bien cultural en términos de presencia y extensión superficial de las alteraciones y deterioros. Los indicadores, necesitarán de la interpretación por parte del profesional de la conservación del patrimonio cultural. Esta figura, será la encargada de discernir de manera crítica las informaciones desglosadas en las tablas.

La posibilidad de representar gráficamente los datos obtenidos constituye un medio de apoyo para la comunicación de las informaciones inherentes a las áreas o elementos con mayor riesgo claro y directo ${ }^{364}$. Por medio de las gráficas es posible ver desglosados los datos cualitativos (fenomenologías de alteración y deterioro) y los datos cuantitativos derivados de la matriz de presencia/ausencia (1/0). Lo anterior permite comprender la incidencia de un determinado fenómeno y su presencia en relación al conjunto de estudio (\%) ${ }^{365}$.

Gracias a la matriz de abundancia (1-4) ${ }^{366}$, es posible generar datos que, junto a los criterios anteriormente descritos, poseen el valor añadido de permitir evaluar la extensión superficial (\%) aproximada de una determinada alteración o deterioro ${ }^{367}$.

${ }^{363}$ Un ejemplo de ello se puede apreciar en el capítulo 4 Resultado y discusiones, véase pp. 402-403.

${ }^{364}$ Ibídem.

${ }^{365}$ Capítulo 4 Resultados y discusiones, gráfica 31, véase, p. 387.

${ }^{366}$ Véase pp. 386-395. 
La posibilidad de conocer la metodología de Observación Visual Organizada ${ }^{368}$, estructurada a partir de la lógica de la percepción y de la psicología cognitiva, ha generado una concienciación del beneficio derivado de la creación de una táctica de acercamiento a las problemáticas conservativas, exenta lo más posible de desvirtuaciones subjetivas. Lo anterior, reiterando el poder de las imágenes como medios de comunicación libre de distorsión, destacó una vez más el gran valor de los glosarios ilustrados generados por iniciativas de ICOMOS-ISCS Illustrated Glossary on Stone Deterioration Patterns y el grupo de trabajo EWAGLOS ${ }^{369}$ European Illustrated Glossary for Conservation Terms of Wall Painting and Architectonic Surfaces, como medio de apoyo y acercamiento a los contextos de estudio. Éstos, concebidos como soporte visual a emplearse por medio de comparación de las imágenes en la fase de identificación, han representado una herramienta muy valiosa para ejecutar las tareas de registro. Paralelamente, se ha demostrado que su uso participa activamente al fomento del conocimiento y profundización de las dinámicas propias de las alteraciones y deterioros de los materiales constitutivos de las obras de arte.

Ya que a mayor cantidad de referentes visuales corresponde una mayor capacidad de reconocimiento y observación de los fenómenos, es posible afirmar que la familiarización con el método propuesto y con los criterios presentes en las tablas de registro ayudará a fomentar la alfabetidad visual del operador en relación con las fenomenologías de alteración y deterioro que afectan el patrimonio históricoartístico.

La decisión de emplear como punto de partida para la estructuración del método los glosarios citados, ha sido sustentada en la voluntad de generar unas tablas con criterios unificados. El uso de terminologías oficiales y estandarizadas a nivel internacional posee la ventaja de poder ser comprendida a nivel intercultural, facilitando el uso de la herramienta metodológica propuesta y la comparación de las informaciones obtenidas entre contextos diferentes. Tras la evaluación de los resultados derivados de los casos de estudio constituidos por pintura de caballete y escultura en madera policromada, la falta de una terminología unificada de referencia ha influido en los criterios de sencillez, recolección de datos y representatividad de las informaciones, aportando una mayor complejidad en el uso y en la interpretación de los datos obtenidos.

\footnotetext{
${ }^{367}$ Véase tabla 185, p. 397.

368 Ibídem.

${ }^{369}$ Ibídem.
} 
Para los universos de estudio pertenecientes a pintura de caballete y escultura policromada, cabe destacar que la estructuración de las fichas de registro propuestas ha respondido a las peculiaridades tecnológicas y estratigráficas más difusas, indicadas en esta investigación bajo la definición de sistema-tipo. Esto, en busca de una ordenación de los criterios correspondientes a las fenomenologías de alteración y deterioro lo más representativa posible de las características de esta clase de bienes culturales. La determinación del sistema-tipo ${ }^{370}$ que compone la clase de obras mencionada ha resultado útil para la organización y ordenación de las informaciones en las tablas de registro. No obstante, es importante evidenciar que es necesario pulir ulteriormente la terminología y la estructura de las fichas, ya que las mismas presentan amplios márgenes de mejoras debido a la extensión y pluralidad de criterios que incluyen en comparación con las creadas para los demás conjuntos de estudio.

Debido a que el grado de profundización y conocimiento de un bien cultural suele ser directamente proporcional a la inversión de los recursos profesionales, humanos, técnicos y económicos necesarios, las acciones de conservación dependen con frecuencia de escalas de prioridades basadas en el valor monetario del patrimonio, dejando excluidos testigos considerados secundarios a favor de otros. Por ello, las acciones de tutela se pueden ver influenciadas por criterios dictados por retorno de imagen e inversión económica, más que por la gravedad o inestabilidad de las condiciones de conservación de un bien. Estos aspectos, aunados a la falta de un sistema centralizado para el establecimiento de un diagnóstico unificado del patrimonio que requiera recursos mínimos para ser aplicado, explican porqué los organismos comprometidos con la conservación del legado cultural, se enfrentan con frecuencia a la imposibilidad de activar políticas de protección efectivas.

En pos de favorecer una toma de decisiones adecuada, capaz de priorizar las acciones de conservación y la asignación de recursos de acuerdo a las exigencias conservativas de los bienes culturales, el estudio se ha dirigido hacia la formulación de una respuesta metodológica compatible con la realidad de estudio, tomando en cuenta los recursos disponibles en el medio socio-cultural analizado. Cabe destacar que las premisas en las que se ha enmarcado la situación del patrimonio cultural mexicano, han representado un punto de partida para la formulación de este método, y son tan valiosas para su comprensión cuanto representativas de la situación de las demás realidades culturales.

\footnotetext{
${ }^{370}$ Véase pp. 133-134.
} 
Las experiencias recaudadas en diferentes realidades y contextos, entre las cuales cabe recordar el sismo que sacudió el centro de México en 2017, reiteraron la importancia de hallar un medio de acercamiento preliminar a las fases de diagnóstico de los bienes culturales que respondiera a las exigencias de tiempo, economicidad y representatividad. En esta circunstancia, se puso de manifiesto el valor representado por la posibilidad de ejercer acciones precisas para la salvaguarda, en tiempos reducidos y con el auxilio de medios técnicos y profesionales mínimos.

La elaboración de esta herramienta de registro, ha generado un apoyo metodológico que, por los alcances presentados en los resultados, podría revelarse útil para los profesionales del sector: conservadores, gestores de museos, restauradores e instituciones públicas y privadas responsables de su resguardo y tutela. Las informaciones obtenidas constituyen un valioso punto de comienzo para la interpretación de los fenómenos a nivel específico, proponiéndose como un método de acercamiento global en donde la relación entre medios necesarios y calidad de resultados arrojados ha resultado ser ventajosa. Esto cumplió con el objetivo de implementar un modelo operativo que permitiera el registro de las alteraciones y deterioros presentes, junto a la evaluación de su extensión superficial, a través de una recolección rápida y representativa de los datos. Lo anterior se fundamenta en la cantidad de patrimonio analizada, relacionándola con los recursos utilizados y la calidad de información arrojada. Por medio de las experiencias maduradas en esta investigación, ha sido posible examinar un total de 197 elementos ${ }^{371}$, compuestos a su vez por 38 esculturas y 63 monumentos en material pétreo, $23^{372}$ pinturas murales, 22 pinturas sobre lienzo, 20 esculturas en madera policromada, y 19 componentes de un retablo en madera policromada y dorada, con una mínima inversión de recursos temporales para el registro ( 12 horas y 25 minutos) y análisis de los datos (8 horas y 25 minutos) ${ }^{373}$. Como recurso técnico

\footnotetext{
${ }^{371}$ En este contexto los elementos corresponden a las muestras de estudio; éstas se constituyen por obras síngolas, áreas, elementos constitutivos de bienes culturales. Un ejemplo de ello, son las áreas según las cuales se ha desglosado el caso de estudio de las pinturas murales decorativas de la ex hacienda de Peotillos (Villa Hidalgo, S.L.P.) y los componentes del retablo en madera policromada del retablo de la Virgen de la Luz (Huaquechula, Puebla).

372 De estas 23 pinturas murales, una corresponde a las pinturas murales decorativas de la ex hacienda de Peotillos que ha sido a su vez desglosada en 14 áreas de estudio distribuidas en 4 superficies de aproximadamente $40 \times 5 \mathrm{~m}$ (vanos incluidos). Véase pp. 234-235.

${ }^{373}$ Tiempos totales de registro y análisis de datos para el total de las obras examinadas, desde la fase de diseño del método hasta su implementación. Para detalles sobre los recursos temporales empleados en la aplicación definitiva del método véase el apartado correspondiente del capítulo 4 Resultados y discusión tabla 189, p. 405.
} 
necesario para su implementación, el método ha respondido positivamente a las metas propuestas al comienzo del estudio. Para su aplicación se han empleado únicamente una cámara fotográfica y una laptop para el procesamiento de los datos por medio de una hoja de cálculo de Excel ${ }^{\circledR}$. En términos de recursos humanos, el conjunto de obras ha sido analizado por tres profesionales de la conservación y restauración del patrimonio cultural.

Los datos presentados ponen en evidencia la viabilidad del método en términos de velocidad y efectividad del registro con una mínima inversión de recursos. Tomando en consideración los niveles de registro del patrimonio cultural propuesto por GETTY CONSERVATION INSTITUTE (2007), gracias a una inversión de bajo costo ha sido posible lograr un nivel de información de mediana precisión, inherentes a la determinación de las condiciones iniciales del bien cultural junto a una descripción de las problemáticas que lo están afectando ${ }^{374}$. De acuerdo a los alcances de la herramienta propuesta en esta investigación y considerando la posibilidad de incorporarla en las rutinas de mantenimiento y monitoreo de los conjuntos patrimoniales sometidos a intervenciones de conservación y restauración, es posible considerar la posibilidad de un nivel de datos elevado ${ }^{375}$. La meta de lograr un medio operativo necesitado de medios básicos para su implementación y puesta en acción ha sido ampliamente satisfecha, debido a que para la aplicación del método han sido empleadas herramientas de trabajo de fácil alcance hoy en día en la mayoría de los contextos.

Lo anterior pone en evidencia otro aspecto fundamental del estudio, la versatilidad del método, que se revela apto para ser aplicado en la mayoría de medios y situaciones, además de ser aplicable a medios de exploración y documentación complementarios, como el telediagnóstico por medio de drones hoy en día en fuerte desarrollo, o en casos en donde la documentación no puede ser realizada de forma presencial. A ejemplo de ello, se cita el valor adquirido por los medios digitales y de trabajo a distancia en este último año, debido a la contingencia sanitaria del Covid-19. De la misma forma, puede acontecer que por situaciones de emergencia o catástrofes naturales, el profesional del sector pueda verse limitado en su posibilidad de desplazarse en físico hacia el lugar objeto de estudio. La posibilidad de trabajar sobre archivos fotográficos y video en remoto representa una posibilidad aplicativa de gran valor.

\footnotetext{
${ }^{374}$ Véase capítulo 4 Resultados y discusión, tabla 191 y pp. 407-408.

375 Ibídem.
} 
Conscientes de las limitaciones y de los amplios márgenes de mejora que podrán incorporarse a las experiencias recaudadas a lo largo de la ideación del método propuesto, es posible afirmar que todos estos factores concurrirán a conservar el legado social, histórico, artístico y material del patrimonio cultural de forma funcional y exitosa. Un método que podría complementar, según las exigencias del caso, las demás herramientas desarrolladas en años de investigación por parte de los profesionales de la conservación y particularmente adecuado a situaciones de escasez en términos de tiempo, personal y medios técnicos.

Es importante recordar que el tejido cultural mexicano, caracterizado por una extensa pluralidad de grupos culturales, es parte de las acciones de cuidado y transmisión de su patrimonio cultural ya que, alrededor de ello, se rige el establecimiento y vigencia de su identidad actual, cuyos rasgos se definen a través de un sincretismo exclusivo. En este contexto tan heterogéneo, no se puede prescindir del valor insoslayable aportado por la participación activa de la comunidad.

Conforme a lo expuesto, reiterando la gran extensión y complejidad de este legado histórico-artístico, puede ocurrir que parte de las actividades de monitoreo sea delegada parcialmente a los propietarios o detentores legales de los objetos de interés cultural. Estas figuras, de las cuales forman parte sujetos de formación y cultura variadas, se encargan de su cuidado y de contactar, a cadencia temporal, con las autoridades correspondientes para revisar el estado de las colecciones y dictaminar en relación a las actividades de conservación, difusión y restauración. Esto representa sin duda una fortaleza en la cual apoyarse para delegar parte de las actividades de monitoreo del estado de conservación del patrimonio.

Las actividades de revisión, inspección y conservación del patrimonio cultural del estado potosino, de acuerdo con las especificaciones legislativas vigentes, corresponden al INAH y al INBAL, instituciones que trabajan en conjunto con entes privados, comúnmente representados por las instituciones religiosas y los patronatos adscritos a diferentes iniciativas como las emprendidas por las comunidades o las propuestas por emprendedores y público en general.

Considerar invertir en la formación de los agentes delegados a la tutela del patrimonio cumpliría con el objetivo de optimizar los esfuerzos por parte de la sociedad entera, instituciones, iniciativas privadas y ciudadanos. Para este efecto, en vista de futuros desarrollos de este estudio, se propone el diseño de una matriz de datos simplificada, a emplearse por los responsables del monitoreo de las obras artísticas que carecen de formación específica. Por ello, se plantea el diseño de una ficha con un conjunto de términos limitado y acompañados por imágenes 
interactivas, con la finalidad de ofrecer una herramienta de uso intuitivo y de fácil aplicación.

Esta futura línea de investigación está dirigida a involucrar a las comunidades y al público en general en la responsabilidad social que supone la conservación del patrimonio cultural, no sólo como reto comunitario y local, sino como objetivo de alcance trascendental para el bien común de todos, ya que permite mantener una identidad colectiva de la que toda persona forma parte. Contemplar la posible incorporación de estos agentes a las tareas de diagnóstico no sustituye el trabajo especializado de los profesionales del sector, sino que lo acompaña en las fases preliminares y menos especializadas, aligerando parte de la carga de trabajo de monitoreo.

A la luz de los resultados propuestos, se puede afirmar que el conjunto de experiencias que han hecho posible el diseño e implementación de las tablas de registro unificadas propuestas en esta investigación, ha permitido generar un medio complementario y sencillo para enfrentar las fases preliminares de diagnóstico. Este procedimiento, puede ser útil para ser empleado en realidades locales, con potencial para ser desarrollado a escala nacional y en contingencias extraordinarias como las vividas durante el seísmo, representando un medio de trabajo y acercamiento a las problemáticas del patrimonio cultural, capaz de implementarse con mínimos recursos.

Este trabajo, fruto de las observaciones recaudadas en la República Mexicana, se ofrece como estrategia útil al diagnóstico de contextos necesitados de un medio de exploración sencillo y económico, poniéndose al servicio de la conservación del legado histórico y artístico que, desde México, podrá aplicarse a todas las diferentes realidades cuya meta sea la protección de su herencia cultural a través de acciones sustentadas en exigencias concretas, con una mínima inversión de recursos. 


\section{Bibliografía general}

ACROYD, P., YOUNG, CH. (1999). "The preparation of artists' canvases: factors that affect adhesión between ground and canvas" en 12th Triennal Meeting, ICOMCC, Lyon, p. 265-270.

ALCALÁ DONEGONI, L.E. (1999). “La obra del pintor novohispano Francisco Martínez" en Anales del Museo de América, n 7, UAM, Departamento de Historia y Teoría del Arte, Ministerio de Educación Cultura y Deporte, Subdirección General de Documentación y Publicaciones, Gobierno de España, pp. 175-187.

<https://repositorio.uam.es/bitstream/handle/10486/671800/obra_alcala_ama_199 9.pdf? sequence $=1$ \&isAllowed $=y>$ [Consulta: 10 de enero de 2021].

ARMESTO DÍAZ, J.A., ARILLA AGÓRRIZ, E. (1999). La cal. Valencia: UPV.

ARNHEIM, R. (2006). Arte y percepción visual. Madrid: Alianza Formas.

BADIA, F. (2012). "Monitoraggio e controllo della gestione dei siti UNESCO. II piano di gestione come opportunità mancata?" en Tafter Journal, Esperienze e strumenti per cultura e territorio, núm. 52. $<$ http://www.tafterjournal.it/2012/10/01/monitoraggio-e-controllo-della-gestionedei-siti-unesco-il-piano-di-gestione-come-opportunita-mancata/> [Consulta: 10 de junio de 2020].

BAECKER, D. (2017). "Teorías sistémicas de la comunicación" en REVISTA MAD, Magíster en Análisis Sistémico Aplicado a la Sociedad, N37, p. 1-20.

BASELGA, A. y GÓMEZ RODRÍGUEZ, C. (2019). "Diversidad alfa, beta y gamma: ¿cómo medimos diferencias entre comunidades biológicas?" en Nova Acta Científica $\begin{array}{llll}\text { Compostelana (Bioloxía), 26, 39-45. } & \text { p. }\end{array}$ $<$ http://webspersoais.usc.es/export9/sites/persoais/persoais/carola.gomez/pdfs/Bas elga_y_Gomez-Rodriguez2019.pdf> [Consulta: 19 de julio de 2020.

BERGER, G.A., RUSSEL, W.H. (1988). "An evaluation of the preparation of canvas painting using stress measurements" en Studies in Conservation, n०33, IIC London, p. 187-204.

BEVILACQUA, N., BORGIOLI, L. y ADROVER GARCÍA, I. (2010). I pigmenti nell'arte dalla preistoria alla rivoluzione industriale. Collana I Talenti. Padova: II Prato.

BLASCO PÉREZ, M.V. (2015). Nace, crece y envejece. La imaginería novohispana de caña de maíz. Una aproximación al comportamiento del material. Tesis doctoral. Valencia: Universitat Politècnica de València.

<https://riunet.upv.es/handle/10251/59418> [Consulta: 5 de junio de 2020].

BLASCO PÉREZ, M.V., MASTROIACOVO, T., SOLBES GARCÍA, Á. (2017). "Tecnologías aplicadas al análisis de bienes culturales: el Retablo Mayor del Colegio San Ignacio de Loyola" en Seminario Internacional de Desarrollo de Nuevos Productos 
SIDNP de la Facultad del Hábitat, Universidad Autónoma de San Luis Potosí, S.L.P. México.

Calculadora de Área. Google Maps <https://www.calcmaps.com/es/map-area/> [Consulta: 27 de febrero de 2021].

CALVO, A. (2002). Conservación y restauración de pintura sobre lienzo. Barcelona: El Serbal.

CALVO, A., GARCÍA FERNÁNDEZ-VILLA, S., BAILÃO, A. (2018). Terminología básica de conservación y restauración del patrimonio cultural. Madrid: Universidad Complutense de Madrid.

$<$ https://www.researchgate.net/publication/323613615_Terminologia_basica_de_c onservacion_y_restauracion_del_Patrimonio_Cultural> [Consulta: 12 marzo de 2019].

CÁMARA DE DIPUTADOS. Nota №. 1510 (2019). INAH, INBA y Secretaría de Cultura, sin diagnósticos sobre estado del patrimonio cultural material e inmaterial que determinen necesidades de conservación y protección: ASF.

$<$ http://www5.diputados.gob.mx/index.php/esl/Comunicacion/Agencia-deNoticias/2019/Febrero/23/1510-INAH-INBA-y-Secretaria-de-Cultura-sindiagnosticos-sobre-estado-del-patrimonio-cultural-material-e-inmaterial-quedeterminen-necesidades-de-conservacion-y-proteccion-ASF> [Consulta: 20 de abril de 2020].

"Centro histórico de San Luis Potosi". <https://centrohistoricoslp.com/mapa/> [Consulta: 5 de diciembre de 2020].

CIENCIA Y TÉCNICA ADMINISTRATIVA CyTA. Herramientas para el Análisis, Cuantitativo y Cualitativo, Aplicables a sistemas de gestión de la calidad <http://www.cyta.com.ar/biblioteca/bddoc/bdlibros/herramientas_calidad/causaef ecto.htm> [Consulta: 20 de abril de 2020].

CLAUDIA E. MORENO, (2001). Métodos para medir la biodiversidad. M\&TManuales y Tesis SEA, vol. 1. Zaragoza: CYTED, ORCYT/UNESCO \& SEA.

Colegio de San Ignacio de Loyola Vizcaínas.

$<$ https://colegiovizcainas.edu.mx/historia-del-colegio\#1543601725966-583d5dbdd76b> [Consulta: 20 de noviembre de 2020].

CONACULTA, GOBIERNO DE MÉXICO, INAH. "Programa institucional de mediano plazo 2014-2018 del Instituto Nacional de Antropología e Historia". <https://www.inah.gob.mx/images/stories/Transparencia/2014/pimp_2014_2018_i nstitucional.pdf $>$ [Consulta: 7 de marzo de 2019].

CONSEJO DEL CENTRO HISTÓRICO DE SAN LUIS POTOSÍ. "La ciudad de San Luis en la actualidad" en La fundación de San Luis Potosí. <https://centrohistoricoslp.com/planos-historicos/> [Consulta: 15 de agosto de 2018]. 
Crónica, Cultura. "El Saucito, cementerio de San Luis, tendrá su museo a partir de agosto" en Crónica, Cultura, 26 de abril de 2015.

$<$ https://www.cronica.com.mx/notas/2015/895571.html> [Consulta: 16 de junio de 2020].

DE LA FUENTE, B., coord. (1996). La pintura mural prehispánica en México. México: UNAM-IIE.

"Francisco Martínez, activo 1718-1758" en Colección Blaisten. $<$ https://museoblaisten.com/artista.php?id=286\&url=Francisco-Martinez> [Consulta: 10 de enero 2021].

DÍAZ MARTOS, A. (1975). Restauración y conservación del arte pictórico. Madrid: Arte restauro.

DONDIS, D.A., (2008). La sintaxis de la imagen, Introducción al alfabeto visual. Barcelona: Gustavo Gili.

DR. ATL (1927). Iglesias de México. Vol. VI. México: Publicaciones de la Secretaría de Hacienda.

ESTADOS UNIDOS MEXICANOS. "Constitución Política de los Estados Unidos Mexicanos". Diario Oficial de la Federación, 5 de febrero de 1917, p. 319. <http://www.diputados.gob.mx/LeyesBiblio/pdf/1_060320.pdf> [Consulta: 20 de abril de 2020].

FERNÁNDEZ MARTÍNEZ, V.M. (2015). Arqueo estadística, métodos cuantitativos en arqueología. Madrid: Alianza.

FITZNER, B., HEINRICHS, K. (2002). "Damage diagnosis on stone monuments weathering forms, damage categories and damage indices" en Natural stones and weathering, Geological Institute. Aachen: University of Technology. $<$ http://citeseerx.ist.psu.edu/viewdoc/download?doi=10.1.1.610.6890\&rep=rep1\&ty pe $=$ pdf $>$ [Consulta: 13 de mayo de 2019].

FUNDACIÓN PARA LA CULTURA Y EL DESARROLLO, ASOCIACIÓN DE AMIGOS DEL PAÍS (2004). Diccionario histórico biográfico de Guatemala . Guatemala: Asociación de Amigos del País y Fundación para la Cultura y el Desarrollo.

GARCÍA SANJUÁN, L. (2005). Introducción al reconocimiento y análisis arqueológico del territorio. Barcelona: Ariel.

GETTY CONSERVATION INSTITUTE (2007). Guiding Principles - Recording, Documentation and Information Management for Conservation of Heritage Places. $<$ https://www.getty.edu/conservation/publications_resources/pdf_publications/rec ordim.html $>$ [Consulta: 15 de mayo de 2020].

GETTY CONSERVATION INSTITUTE (2007). Recording, Documentation, and Information Management for the Conservation of Heritage Places. Illustrated Examples. 
$<$ https://www.getty.edu/conservation/publications_resources/pdf_publications/rec ordim_vol2.html> [Consulta: 15 de mayo de 2020].

GOBIERNO DEL ESTADO DE SAN LUIS POTOSÍ, INEGI (2017). Anuario estadístico y geográfico de San Luis Potosí 2017. México: INEGI.

$<$ https://datatur.sectur.gob.mx/ITxEF_Docs/SLP_ANUARIO_PDF.pdf $>$ [Consultado el: 20 de noviembre de 2020].

GOBIERNO DE MÉXICO (2010). Camino Real de Tierra Adentro. $<$ https://patrimonioculturalyturismo.cultura.gob.mx/patrimonio_mundial/cultural/ti erra_adentro/> [Consulta: 20 de febrero de 2020].

GOBIERNO DE MÉXICO. "Secretaría de Educación Pública" en Diario Oficial de la Federación, TOMO CDXXIII (4), 7 de diciembre de 1988, pp. 11- 14. $<$ http://dof.gob.mx/nota_to_imagen_fs.php?cod_diario=206408\&pagina=11\&secci on $=0>$ [Consulta: 10 de diciembre de 2020].

GOBIERNO DE MÉXICO. "Secretaría de Educación Pública" en Diario Oficial de la Federación, 17 de diciembre 2015. <http://www.dof.gob.mx/nota_detalle.php?codigo=5420363\&fecha $=17 / 12 / 2015>$ [Consulta: 10 de diciembre de 2020].

GOBIERNO DE MÉXICO. "Manual de Organización General de la Secretaría de Cultura" en Diario Oficial de la Federación, 12 de diciembre de 2017. $<$ https://www.dof.gob.mx/nota_detalle.php?codigo $=5501065 \&$ fecha $=12 / 10 / 2017>$ [Consulta: 10 de diciembre de 2020].

GOBIERNO DE MÉXICO, INAH. "Quienes somos?". $<$ https://www.inah.gob.mx/quienes-somos> [Consulta: 2 de mayo de 2021].

GOBIERNO DE MÉXICO, SECRETARÍA DE CULTURA, INBAL. <https://inba.gob.mx/patrimonio> [Consulta: 2 de mayo de 2021].

GOBIERNO MUNICIPAL SAN LUIS POTOSÍ, H. AYUNTAMIENTO DE SAN LUIS POTOSÍ 2018-2021. Ayuntamiento da mantenimiento al Panteón del Saucito con motivo del día de las madres. <https://sanluis.gob.mx/ayuntamiento-damantenimiento-al-panteon-del-saucito-con-motivo-del-dia-de-las-madres/> [Consulta: 16 de junio de 2020].

GOMBRICH, E.H., HOCHBERG, J. y BLACK, M. (1996). Arte, percepción y realidad. Barcelona: Paidós estética.

GONZÁLEZ GALVÁN, M. (2006). Trazo, proporción y símbolo en el arte virreinal: antología personal. México: Universidad Nacional Autónoma de México.

Google Maps vista satelital online. Panteón del Saucito. <https://www.google.com/maps/@22.18112,-100.9997383,280m/data=!3m1!1e3> [Consulta: 17 de junio de 2020]. 
GUERRERO URBINA, M.F., MASTROIACOVO, T. (2015). "Investigación, estudio y diagnóstico de las pinturas murales del Internado Damián Carmona en San Luis Potosí (S.L.P.)" en Inducción a la Ciencia, la Tecnología y la Innovación en la UASLP, Vol. III, n 4, pp. 817-823.

GUYE, L. (1976). Reseña de "Cinco haciendas mexicanas" de Jan Bazant en Nueva Antropología, I (4), pp. 121-124.

<https://www.redalyc.org/articulo.oa?id=159/15900408> [Consulta: 26 de Noviembre de 2020].

HAAG, S., DE MARIA Y CAMPOS, A., RIVERO WEBER, L., FEEST, C., coord. (2012). EI penacho del México antiguo. Viena: ZKF Publishers, Museum für Völkerkünde, CONACULTA-INAH.

HAMMER, Ø., HARPER, D. A. T., RYAN, P. D. (2001). “PAST: Paleontological Statistics Software Package for Education and Data Analysis" en Paleontología Electrónica, №4, 1. p. 9.

Haciendas de México: ex hacienda de Peotillos.

$<$ https://www.haciendasmexico.mx/ex-hacienda-de-peotillos/> [Consulta: 20 de noviembre de 2020].

HODDER, I. y ORTON, C. (1990). Análisis espacial en arqueología. Barcelona: Crítica.

HORNEMANN INSTITUT (2015). European Illustrated Glossary for Conservation Terms of Wall Painting and Architectonic Surfaces. <https://www.hornemanninstitut.de/doi/2016ewa2.pdf> [Consulta: 19 de mayo 2017].

Huaquechula.

<https://www.corazondepuebla.com.mx/descubre/huaquechula/> [Consulta: 27 de noviembre de 2020].

"Huaquechula: la vida después del sismo", 26 de septiembre de 2017.<https://manati.mx/2017/09/26/el-renacer-del-convento-de-huaquechula/> [Consulta: 20 de noviembre de 2020].

ICH, UNESCO (2019). Patrimonio Cultural Inmaterial.

$<$ https://ich.unesco.org/es/busqueda-

00795? $q=$ mexico\&criteriaSearch $=$ element $\& p=1>$ [Consulta: 10 de junio de 2020].

ICOM (2017). Código de Deontología de ICOM para Museos. París: Consejo Internacional de Museos, UNESCO.

ICOMOS-ISCS (2008). Illustrated Glossary on Stone Deterioration Patterns. $<$ https://www.icomos.org/publications/monuments_and_sites/15/pdf/Monuments _and_Sites_15_ISCS_Glossary_Stone.pdf> [Consulta: 3 de marzo de 2016]. 
ICCROM. Enfoque regional América Latina y Caribe.

$<$ https://www.iccrom.org/es/regions/america-latina-y-el-caribe> [Consulta: 15 abril 2020].

ICCROM, ICOMOS, IUCN, UNESCO, (2010). Managing disaster risks for World Heritage. <https://whc.unesco.org/en/documents/115730> [Consulta: 15 de febrero 2019].

ICCROM, INAH-CNCPC. Programa del Curso de observación, documentación y diagnóstico LATAM. Zona Arqueológica de Chicanná, Campeche, México. <https://www.iccrom.org/wp-content/uploads/Curso-Piedra-LATAM.pdf> [Consulta: 8 marzo 2020].

ICOMOS-ISCS (2008). Illustrated Glossary on Stone Deterioration Patterns. $<$ https://www.icomos.org/publications/monuments_and_sites/15/pdf/Monuments _and_Sites_15_ISCS_Glossary_Stone.pdf> [Consulta: 3 de marzo de 2016].

INAFED, GOBIERNO DE MÉXICO. "Estado de San Luis Potosi" en Enciclopedia de los Municipios $y$ Delegaciones de México. $<$ http://siglo.inafed.gob.mx/enciclopedia/EMM24sanluispotosi/municipios/24017a. html> [Consulta: 10 de junio de 2020].

INAH, Código de Deontología del ICOM para los Museos, p. 4. $<$ https://conservacion.inah.gob.mx/normativa/wpcontent/uploads/Documento59.pdf> [Consulta: 10 de febrero de 2021].

INAH-CONACULTA (2010). Haciendas del Altiplano Potosino. México: EME ediciones.

INAH, GOBIERNO DE MÉXICO. "Ley Federal sobre Monumentos y Zonas Arqueológicas, Artísticas e Históricas" en Diario Oficial de la Federación del 6 de mayo de 1972, p. 20. $<$ https://www.ucol.mx/content/cms/13/file/federal/LEY_FED_SOBRE_MONUMENTO S.pdf> [Consulta: 10 junio de 2020].

INAH, GOBIERNO DE MÉXICO (2019). "80 años de proteger, investigar, conservar y difundir nuestro patrimonio cultural" en Boletín del Instituto Nacional de Antropología e Historia. <https://www.inah.gob.mx/boletines/7921-inah-80-anos-deproteger-investigar-conservar-y-difundir-nuestro-patrimonio-cultural> [Consulta: 25 de febrero de 2019].

INAH, GOBIERNO DE MÉXICO. "Ley orgánica del Instituto Nacional de Antropología e Historia" en Diario Oficial de la Federación, 3 de febrero de 1939, p. 9. <http://www.diputados.gob.mx/LeyesBiblio/pdf/170_171215.pdf> [Consulta: 20 abril de 2020].

INAH-GOBIERNO DE MÉXICO. "Restaura INAH retablo centenario de Puebla", en Boletín de Noticias, 1 de marzo de 2012. <https://inah.gob.mx/boletines/1596restaura-inah-retablo-centenario-de-puebla> [Consulta: 27 de noviembre de 2020]. 
"INAH restaura retablo con pinturas de Villalpando", en Boletín de Noticias, 8 de noviembre de 2012. <https://inah.gob.mx/boletines/2140-inah-restaura-retablocon-pinturas-de-villalpando $>$ [Consulta: 27 de noviembre de 2020].

INAH. "Centro Histórico de San Luis Potosí recibe certificación de Patrimonio Mundial por parte del INAH y de la UNESCO" en Boletines, 7 de marzo de 2018. $<$ https://www.inah.gob.mx/boletines/7003-centro-historico-de-san-luis-potosirecibe-certificacion-de-patrimonio-mundial-por-parte-del-inah-y-de-la-unesco> [Consulta: 15 de abril de 2018].

INAH, GOBIERNO DE MÉXICO. "Secretaría de Cultura, INAH y Embajada de Estados Unidos recuperan conjunto conventual de Huaquechula, Puebla" en Boletín de Noticias, 18 de septiembre de 2018. < https://inah.gob.mx/boletines/7560secretaria-de-cultura-inah-y-embajada-de-estados-unidos-recuperan-conjuntoconventual-de-huaquechula-puebla> [Consulta: 27 de noviembre de 2020].

INAH, GOBIERNO DE MÉXICO. Diagnóstico del plan de trabajo 2014-2018. $<$ https://inah.gob.mx/images/stories/Transparencia/programa_trabajo/diagnostico. pdf $>$ [Consulta: 7 de marzo de 2019].

INAH, GOBIERNO DE MÉXICO. "Alistan diagnóstico para restauración integral del conjunto conventual de Huaquechula, Puebla", en Boletín de Noticias, 7 de agosto de 2019. <https://inah.gob.mx/boletines/8367-alistan-diagnostico-para-restauracionintegral-del-conjunto-conventual-de-huaquechula-puebla> [Consulta: 27 de noviembre de 2020].

INAH, GOBIERNO DE MÉXICO. Zona Arqueológica Chicanná. $<$ https://www.inah.gob.mx/zonas/63-zona-arqueologica-chicanna> [Consulta: 22 de abril de 2020].

INAH, GOBIERNO DE MÉXICO. "Surge el Patronato del INAH A.C., puente entre la sociedad civil y el cuidado del patrimonio cultural de México" en Boletín de Noticias, 25 de octubre 2019. <https://www.inah.gob.mx/boletines/8613-surge-el-patronatodel-inah-a-c-puente-entre-la-sociedad-civil-y-el-cuidado-del-patrimonio-cultural-demexico $>$ [Consulta: 10 de diciembre de 2020].

INAH, GOBIERNO DE MÉXICO. Acciones de restauración. $<$ https://www.inah.gob.mx/sismos> [Consulta: 28 de noviembre de 2020].

"INBA cambia a INBAL... y desata polémica" en Capital Mexico, 11 de enero de 2019. <https://www.capitalmexico.com.mx/nacional/inba-cambia-a-inbal-escorrecto/> [Consulta: 10 de junio de 2020].

INBAL, GOBIERNO DE MÉXICO <https://inba.gob.mx/transparencia/obra> [Consulta:10 de junio de 2020].

INEGI (2002). Síntesis de Información geográfica del estado de San Luis Potosí. $<$ https://www.inegi.org.mx/contenidos/productos/prod_serv/contenidos/espanol/b 
vinegi/productos/historicos/2104/702825224240/702825224240_5.pdf> [Consulta: 27 de febrero de 2021].

INEGI: Continuo Nacional del Conjunto de Datos Geográficos de la Carta de Climas, serie I, en Clima del estado de San Luis Potosí del 15 de marzo de 2019. $<$ https://www.paratodomexico.com/estados-de-mexico/estado-san-luispotosi/clima-san-luis-potosi.html> [Consulta: 27 de febrero de 2021].

INEGI, GOBIERNO DE MÉXICO (s.f.). Referencias geográficas y extensión territorial de México. <https://www.inegi.org.mx/inegi/spc/doc/internet/1-

geografiademexico/man_refgeog_extterr_vs_enero_30_2088.pdf > [Consulta: 25 de febrero de 2019].

INEGI, GOBIERNO DE MÉXICO (2005). "Información de Climas (escala 1: 1000 000)" en Guía para la Interpretación de Cartografía Climatológica.<http://internet.contenidos.inegi.org.mx/contenidos/productos/prod _serv/contenidos/espanol/bvinegi/productos/geografia/publicaciones/guiascarto/clima/CLIMATIII.pdf> [Consulta: 25 de febrero de 2019].

INEGI, Marco Geoestadístico, diciembre 2018. <www.cuentame.inegi.org.mx> [Consulta 15 de noviembre de 2020].

INSTITUTO DE INVESTIGACIÓN DE RECURSOS BIOLÓGICOS ALEXANDER VON HUMBOLDT (2014). Métodos para el análisis de datos: una aplicación para resultados provenientes de caracterizaciones de biodiversidad. [http://www.bionica.info/biblioteca/HumboldtAnalisisDatos.pdf] <Consulta: 20 de marzo de 2019>.

IPICYT, CIENCIAS AMBIENTALES (2017). Diplomado en técnicas estadísticas para el análisis de biodiversidad. <https://ipicyt.edu.mx/storage-sipicyt/difusion/04TecEstAnalisisbiodiversidad.pdf > [Consulta: 7 de marzo de 2020].

KAISER SCHLITTLER, A. (2014). Breve historia de la ciudad de San Luis Potosí. México: Kaiser.

KECK, S. (1969). "Mechanical alteration of he Paint Film", en Studies en Conservation, 14, IIC, London, p. 9.

KRICKEBERG, W. (1961). Las antiguas culturas mexicanas. México: FCE.

KUKA, J. (2012). Monitoring cultural indicators, ICCPR, Barcelona. pp. 2-5.

LITTMANN, E.R. (1960). "Ancient Mesoamerican Mortars, Plasters and Stuccos: The Use of Bark Extracts in Lime Plasters" en American Antiquity, vol. 25, núm. 4., pp. 593-597. <https://doi.org/10.2307/276642> [Consulta: 5 de junio de 2020].

LEG Eurostat (2000). "Cultural statistics in the EU" en Eurostat Working Paper, Population and Social Conditions Series, 3/2000/E/No1. Final report of the LEG. Luxembourg: Eurostat.

LEONARDO OVIEDO, G. (2004). "La Definición del Concepto de Percepción en Psicología con Base en la Teoría Gestalt" en Revista de Estudios Sociales UNIANDES. 
<https://www.ufrgs.br/psicoeduc/gestalt/percepcion-en-la-teoria-gestalt/> [Consulta: 25 de abril de 2020].

LEONOR MERINO, B. y GARCÍA COOK, Á., coord. (2007). La producción alfarera en el México Antiguo vol. V, La alfarería en el Posclásico (1200-1521 d.C.) y el intercambio cultural y las permanencias. México: Instituto Nacional de Antropología e Historia.

"Le statue degli apostoli in San Giovanni in Laterano", 21 febbraio 2019. $<$ https://www.italianways.com/it/le-statue-degli-apostoli-in-san-giovanni-inlaterano/> [Consulta: 10 de diciembre de 2020].

"Llama INAH a preservar identidad de haciendas y casonas" en Informador.Mx del 4 de agosto de 2014. <https://www.informador.mx/Cultura/Llama-INAH-apreservar-identidad-de-haciendas-y-casonas-20140804-0067.html> [Consulta: 26 de noviembre de 2020].

LÓPEZ DONCEL, R., CARDONA VELÁZQUEZ, N., WEDEKIND, W. (2015). "El rescate del patrimonio cultural pétreo de San Luis Potosí" en Universitarios Potosinos, año 12, núm. 194, diciembre, pp. 4-10.

MAGALONI KERPEL, D.I. (1995). “Técnicas de la pintura mural en Mesoamérica” en Arqueología Mexicana, vol. III, núm. 16, pp. 16-23. México: Raíces.

MAGALONI KERPEL, D.I. (1996). Materiales y técnicas de la pintura mural Maya. De la Fuente, B., directora. Tesis de maestría en Historia del Arte, México, Facultad de Filosofía y letras, UNAM. México: UNAM-IIE.

MAGALONI KERPEL, D.I. (2008). "Los colores de la selva" en Arqueología Mexicana, vol. XVI, núm. 93, pp.46-50 México: Raíces.

MAGALONI KERPEL, D.I., (2016). Albores de la Conquista. La historia pintada del Códice Florentino. México: Artes de México y del Mundo, Secretaría de Cultura.

MAGAR, V. y PEDELİ, C. (2008). "Training on Archaeological Conservation in Southeast Europe: an Approach to the Preliminary Condition Assessment" en ICCROM Newsletter, Diciembre 2008, n³4, p. 10-11.

MAGURRAN, A. E. (1988). Ecological diversity and its measurement. New Jersey: Princeton University Press.

MARIJNISSEN, R. (1985). Tableaux. Authentiques. Maquillés. Faux. L'expertise des tableaux et les methodes de laboratoire. Bruxelles: Elsevier.

MARTÍNEZ CABETAS, C. y RICO MARTíNEZ, L. et al. (2003). Diccionario técnico Akal de conservación y restauración de bienes culturales. Español-Alemán-Inglés-ItalianoFrancés. Madrid: Akal.

MASTROIACOVO, T., et al. (2016-2017). “Estudio termográfico y diagnóstico de las pinturas decorativas del patio interior de la hacienda de Peotillos (Villa Hidalgo, San Luis Potosí, México)" en Archè, Revista del Instituto de Restauración del Patrimonio, núm. 11 y 12, 2016-2017, pp. 163-168. 
MASTROIACOVO, T., SORIANO SANCHO, M.P., REGIDOR ROS, J.L. (2017). "Índice de riesgo relacionado con factores de alteración y deterioro en las pinturas murales del siglo XX de San Luis Potosí (S.L.P., México)" en Archè, Instituto Universitario de Restauración del Patrimonio de la UPV - No 11 y 12, pp.157-162.

MASTROIACOVO, T., BLASCO PÉREZ, M.V., NIETO VILLENA, A. (2017). "LoS hermanos Biagi y las esculturas de la Catedral Metropolitana Potosina" en Universitarios Potosinos, año 14, núm. 211, pp. 13-17. San Luis Potosí: UASLP.

MASTROIACOVO, T., BLASCO PÉREZ, M.V., NIETO VILLENA, A. (2017). “El valor de la colaboración interinstitucional como medio de investigación y didáctica: experiencias entre el Museo Colegio de las Vizcaínas y UASLP" en Seminario Internacional de Desarrollo de Nuevos Productos SIDNP de la Facultad del Hábitat, Universidad Autónoma de San Luis Potosí, S.L.P. México.

MECD (2014). Manual de seguimiento y análisis de condiciones ambientales. Madrid: Secretaría General Técnica, Subdirección General de Documentación y Publicaciones. <http://www.culturaydeporte.gob.es/planesnacionales/dam/jcr:3312b805-4c20-46b6-a897-71cead432bf7/manual-condicionesamb-2018.pdf> [Consulta: 10 de febrero de 2021].

MEDIANERO HERNÁNDEZ, J.M. (1992). "Un ejemplo de capilla abierta en la Universidad de Mareantes de Triana" en Laboratorio de Arte, 5-1992, pp. 223-239.

MILLER, M.E. (2009). Arte y arquitectura maya. México: FCE.

MORA, P., MORA, L. y PHILIPPOT, P (1999). La conservazione delle pitture murali. Milano: Compositori.

MORALES BOCARDO, R. (s.f.), Museo de Arte Sacro, Parroquia de San Pedro de Guadalcázar, Diócesis de Matehuala, S.L.P.

NACIONES UNIDAS, MÉXICO (2016), "Descubre los 34 sitios de México inscritos en la Lista de Patrimonio" en Sitios Patrimonio Mundial de la humanidad en México. $<$ http://www.onu.org.mx/descubre-los-34-sitios-de-mexico-inscritos-en-la-lista-depatrimonio/> [Consulta: 15 de febrero de 2019].

NICOLAS MEDINA, C. (2008). "La ciencia cognitiva y el estudio de la mente" en Revista IIPSI, Facultad de Psicología, UNMSM, Vol. 11, № 1. P. 183 - 198.

NOGUERA AUZA, E. (1967). "La cerámica funeraria y ritual en Mesoamérica" en Anales de Antropología, Revista del Instituto de Investigaciones Antropológicas UNAM, vol.1, núm.4, pp. 127-140 $<$ http://www.revistas.unam.mx/index.php/antropologia/article/view/17459/pdf_36 2> [Consulta: 10 de junio de 2020].

"Panteón del Saucito, 127 años de historia" en Plano informativo, 02 de noviembre de 2016 <http://planoinformativo.com/488447/panteon-del-saucito127-anos-de-historia-slp> [Consulta: 15 de agosto de 2018]. 
"Panteón de El Saucito cumple 127 años" en Código San Luis, 2 de noviembre de 2016. <https://archivo.codigosanluis.com/panteon-de-el-saucito-cumple-127anos/> [Consulta: 27 de febrero de 2021].

"Parroquia del Sagrario Metropolitano" en México en Fotos. <https://www.mexicoenfotos.com/MX12182358439373.jpg> [Consulta: 27 de noviembre de 2020].

Patronato de Restauración y Conservación del Patrimonio Artístico del Centro Histórico. <https://centrohistoricoslp.com/patronato-restauracion-conservacion/> [Consulta: 10 de diciembre d 2020].

PEDELÍ, C. (2013). "An interdisciplinary conservation module for condition survey on cultural heritages with a 3d information system" en International Archives of the Photogrammetry, Remote Sensing and Spatial Information Sciences, Volume XL-5/W2, XXIV International CIPA Symposium. Strasbourg: P. Grussenmeyer. 483-487 Disponible en <https://doi.org/10.5194/isprsarchives-XL-5-W2-483-2013> [Consulta: 11 de mayo 2020].

PEDELÍ, C. (2014). "A methodology for an organised visual examination on condition assessment of cultural heritage" en e-dialogos, Annual digital journal on research in Conservation and Cultural Heritage, $\mathrm{n}^{\circ}$ 4, december, pp. 22-29. <http://www.diadrasis.org/public/files/edialogos_004-PEDELI.pdf> [Consulta: $11 \mathrm{de}$ mayo de 2020].

PÉREZ GALINDO, Raúl (2013). Estadística aplicada para ciencias económicas, administrativas y sociales. México, D.F.: Trillas.

PINGARRÓN, L.B. (2013). "El uso de la cal en el mundo prehispánico mesoamericano" en La cal. Historia, propiedades y usos. México: UNAM.

POLICÍA FEDERAL DEL GOBIERNO DE MÉXICO (2018). "La Comisión Nacional de Seguridad y la Secretaría de Cultura firman convenio de colaboración para proteger el patrimonio cultural" en Nota de prensa, 28 de marzo de 2018. $<$ https://www.gob.mx/policiafederal/prensa/la-comision-nacional-de-seguridad-yla-secretaria-de-cultura-firman-convenio-de-colaboracion-para-proteger-elpatrimonio-cultural> [Consulta: 14 de febrero de 2019].

POOLE, N. (2015). Collections Management Performance Indicators. London: The Collections Trust.

RAND, E. y GARCÍA GRINDA, J.L. (2015). “Management documentation indicators \& good practice at cultural heritage places" en The International Archives of the Photogrammetry, Remote Sensing and Spatial Information Sciences, Volume XL-5/W7, 25th International CIPA Symposium. Taiwan: Taipei.

RIVERA PÉREZ, M.E. (2015). "OVO un mortero fluido", en Conservación y Restauración, Boletín de la CNCPC, No 7, diciembre. P. 84-89.

RUDOLF, A. (2006). Arte y percepción visual. Madrid: Alianza Forma. 
SALAZAR GONZÁLEZ, G. (2000). Las haciendas en el siglo XVI, en la región minera de San Luis Potosí. Su espacio, forma, función, material, significado y la estructuración regional. San Luis Potosí: Universidad Autónoma de San Luis Potosí, Facultad del Hábitat.

SHANNON, C. \& WEAVER, W. (1948). The Mathematical Theory of Communication. Illinois: Urbana.

SECRETARÍA DE CULTURA, CNCPC, INAH. "Nosotros somos". $<$ https://conservacion.inah.gob.mx/index.php/2018-nosotros/> [Consulta: 2 de mayo de 2021].

SIC, GOBIERNO DE MÉXICO (2019). "Museo de Arte Sacro de San Pedro de Guadalcázar" en Museos, San Luis Potosí. $<$ https://sic.cultura.gob.mx/ficha.php?table=museo\&table_id $=1110>$ [Consulta: 20 de febrero de 2019].

SIBILIO PARRI, B. (2011). "Uno strumento di gestione del patrimonio culturale: il caso dei siti UNESCO" en Economia e diritto del terziario, Vol. 23, núm. 2, pp. 307-333.

SPELLERBERG, I. F. (1991). Monitoring ecological change. Cambridge: University Press.

STRESSER-PÉAN, C. (2012). De la vestimenta y los hombres. Una perspectiva histórica de la indumentaria indígena en México. La indumentaria precortesiana. México: FCE, CEMCA, Fundación Alfredo Harp Helú, Museo Textil de Oaxaca.

SUÁREZ, O. S. (1968). Inventario del muralismo mexicano, siglo VII-1968. México D.F.: Universidad nacional Autónoma de México UNAM.

TAMAYO, J. L., (1993). Geografía moderna de México. México: Trillas.

"Templo del Carmen" en Consejo del Centro Histórico de San Luis Potosí. $<$ https://centrohistoricoslp.com/templo-del-carmen/> [Consulta: 27 de noviembre de 2020].

"Templo del Carmen" en Secretaría de Turismo.

$<$ http://www.ciudadsanluis.com/turismo/iglesias_y_templos/templo_de_nuestra_s enora_del_carmen/> [Consulta: 10 de diciembre de 2020].

"Templo de San Franscisco" en México en Fotos. $<$ https://www.mexicoenfotos.com/MX15472737712554.jpg> [Consulta: 27 de noviembre de 2020].

TOUSSAINT, M. (1990). El arte colonial en México. México: Universidad Nacional Autónoma de México, p. XIII-XIV.

UNESCO (2014). Indicadores UNESCO de cultura para el desarrollo. Indicadores centrales de sostenibilidad. $<$ https://es.unesco.org/creativity/sites/creativity/files/digitallibrary/cdis/Patrimonio.pdf> [Consulta: 14 de marzo de 2019]. 
UNESCO. State of Conservation System (SOC). < https://whc.unesco.org/en/soc/> [Consulta: 10 de mayo de 2020].

UNESCO (1986). "The UNESCO Framework for Cultural Statistics. Statistical Commission and Economic Commission for Europe" en UNESCO, Conference of European Statisticians. Third Joint meeting on Cultural Statistics, 17-20 March 1986. CES/AC/44/11. 13 February 1986.

UNESCO (2009). Framework For Cultural Statistics.

$<$ http://uis.unesco.org/sites/default/files/documents/unesco-framework-forcultural-statistics-2009-en_0.pdf> [Consulta: 15 de marzo de 2019].

UNESCO (2007). Campus Central de la Ciudad Universitaria de la Universidad Nacional Autónoma de México. <https://whc.unesco.org/es/list/1250> [Fecha de consulta: 21 de febrero de 2021].

UNESCO. Diversidad de las expresiones culturales.

$<$ https://es.unesco.org/creativity/indicadores-de-desarrollo/caja-de-herramientas> [Consulta: 10 de junio de 2020].

UNESCO, (2018). "Mexico, Properties inscribed in World Heritage List" en About World Heritage, The States Parties. <https://whc.unesco.org/en/statesparties/mx> [Consulta: 14 de febrero de 2019].

UNESCO (2010). "Camino Real de Tierra Adentro" en World Heritage List. <https://whc.unesco.org/en/list/1351> [Consulta: 14 de febrero de 2020].

VARGAS SABADÍAS, A. (1995). Estadística descriptiva e inferencial. Cuenca: Universidad de Castilla-La Mancha.

VÁZQUEZ DE ÁGREDOS y HORCAJADA CAMPOS (2017). "La doble piel de la arquitectura Maya: el estuco y el color" en RA monográfico, pp. 84-97. $<$ https://core.ac.uk/download/pdf/228598681.pdf> [Consulta: 2 de marzo de 2019].

VÁZQUEZ SALGUERO, D. y CORRAL BUSTOS, A., (2004). Monumentos funerarios del Saucito, San Luis Potosí, 1889-1916. San Luis Potosí: El Colegio de San Luis COLSAN.

VIVANCOS RAMÓN, V. (2007). La conservación y restauración de la pintura de caballete. Pintura sobre tabla. Madrid: Tecnos.

VIVANCOS RAMÓN, V. y CASTELL AGUSTÍ, M. (2010). Problemas y tratamientos del soporte de pintura de caballete. Valencia: Universidad Politécnica de Valencia.

WHITTAKER, R.H. (1960). "Vegetation of the Siskiyou Mountains, Oregon and California" en Ecological Monographs, Vol. 30-3, p. 279-338.

WHC, UNESCO (2019). "World heritage List Statistics". $<$ https://whc.unesco.org/en/list/stat\#d1 > [Consulta: 05 de junio de 2020].

Word reference <https://www.wordreference.com/definition/karst> [Consulta: 10 de febrero de 2021]. 
XARRIÉ, M. (2007). Diccionario de conservación y restauración de obras de arte 1 (AZ). Barcelona: Balaam.

"1730 Templo de San Miguelito" en Cronologías San Luis. <http://cronologiassanluispotosi.com/1730-tempo-de-san-miguelito.html> [Consulta: 10 de diciembre de 2020].

"1686 Templo de San Francisco" en Cronologías San Luis. $<$ http://cronologiassanluispotosi.com/1686-templo-de-san-francisco.html> [Consulta: 10 de diciembre de 2020]. 